(3.) 


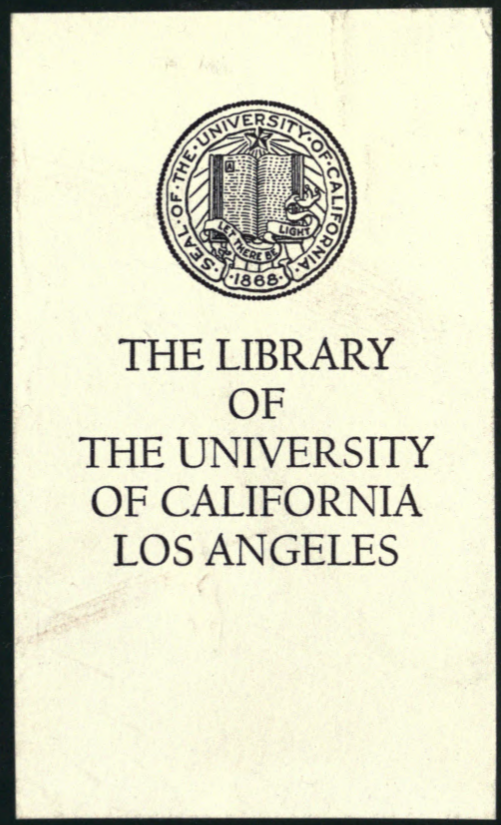





\section{CONTRIBUTION TO OUR KNOWLEDGE}

$\mathrm{OF}$

\section{S E E D L I N G S}

BY THE RIGHT HON.

SIR JOHN LUBBOCK, BART.

M.P., F.R.S., D.C.L., LL.D.

WITI 68:4 FIGURES IN TEXT

IN TWO VOLUMES

VOL. I.

LONDON

KEGAN PAUL, TRENCH, TRÜBNER, \& CO. Ltd.

PATERNOSTER HOUSE, CHARING CROSS ROAD 
(The rights of translation and of reproduction are reserved) 



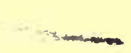

\section{PREFACE}

Tre germination of plants is certainly not the least interesting portion of their life-history, but it has not as yet attracted the attention it deserves. The forms of cotyledons, and the fact that they differ so much from the subsequent leaves, had of course been alluded to more or less fully in botanical works, but no explanation had been offered, and KLEBs ${ }^{1}$ in a recent memoir expressly states that the problem is still an enigma.

Under these circumstances it seemed to me that the subject was very promising, and it was evident that Kew would afford unrivalled opportunities for such an investigation. I applied, therefore, to Sir Joseph Hooken, and I cannot too cordially thank him, as well as his successor, Mr. Thiselton Dyer, and indeed the whole of the staff, for the facilities they have offered me, and for their valuable assistance in many ways.

I have also to thank Mr. Carruthers and the Trustees of the British Museum, Mr. Lisch and the authorities of the Cambridge Botanic Gardens, and other friends, especially Mr. Hanbury, for the gift or loan of many rare or interesting

1 Beitr. zur Morphologic u. Biologie der Keimung: 'Im Allgemeinen sind uns diese Verschiedenheiten in den Blattformen hinsichtlich ihrer biologischen Bedeutung für die Pflanze ein Räthsel.'-Untersuch. Bot. Instit. zu Tübingen 184. 
specimens. By degrees a large store of material accumulated, which I made use of for several papers which the Linnean Society has done me the honour of publishing in their Journal. I thought, however, that it would be well to publish descriptions and figures of the more interesting species, especially as many of them are not often grown from seed, and are therefore not easily procurable.

The seedlings were drawn in most cases either by $\mathrm{Mr}$. Henry, or by my assistant, Mr. Fraser, to whose skill and ability I am greatly indebted. In the classification, etc., I have followed Benthay and Hooker's great work, the 'Genera Plantarum.' My time has latterly been so much occupied with other matters that Mr. Rende has been good enough to see the book through the press. Sir Joseph Hooker has also most kindly looked through the proofs, and made many valuable suggestions, for which I beg to offer him my very warm thanks. 


\section{A CONTRIBUTION}

TO OUR

\section{KNOWLEDGE OF SEEDLINGS}

\section{N T R O D U C TIO N. ${ }^{1}$}

Forms of Leaves.

I have elsewhere ${ }^{2}$ called attention to the forms of leaves, and discussed the causes to which we may ascribe the endless differences which they present. Vertical leaves, for instance, are generally long and narrow, horizontal ones have a tendency towards width, which brings the centre of gravity nearer to the point of support. Wide leaves, again, are sometimes heart-shaped, sometimes palmate. The former shape is obviously that which would arise if a linear leaf were gradually widened at the base; and I have pointed out that in many species with palmate leaves-for instance, species of Passiflora, Cephalandra, Hibiscus, \&c.- - the first, or few first, leaves are entire and more or less cordate. The cordate form, then, appears to be the early, the palmate a later form. But how has the palmate form arisen?

The origin is perhaps connected with the manner in which the leaves are folded up, more or less like a fan, into the bud, so as to save space.

Another advantage perhaps is that in cordate leaves with

1 This Introduction is taken from the Journal of the Linnean Society (Botany), vol. xxii. and vol. xxiv.

${ }^{2}$ Flowers, Fruits, and Leaves (Nature Series), Macmillan \& Co. See also various papers in the Journal of the Linnean Society. 
veins following the curvature of the leaf-as, for instance, in Tamus (fig. 1) - the vascular bundles pursue necessarily a curved course; while in palmate leaves, as in Acer (fig. 2), the veins are straight; and it is clearly an advantage that the main channels which convey the nutritive fluid should hold a direct course. In such cases the leaf naturally assumes the lobed form with a vein running to the point of each lobe. There has indeed been some question whether the path of the sap lies mainly in the cell-walls or in the cell-cavities; but the evidence seems to point strongly to the latter view. ${ }^{1}$ The tracheids of, say, the Yew 'are at least seventy or eighty times as long as they are broad, so that in travelling trans-

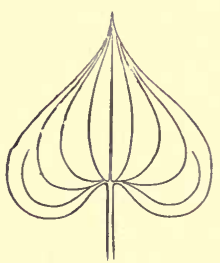

Fig. 1.-Leaf of Tamus, to show the curved course of the veins.

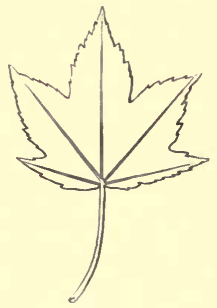

Fra. 2.-Leaf of Sycamore, to show the straight course of the veins.

versely the length of a single tracheid the water-current has to traverse seventy cell-walls instead of one.' ${ }^{2}$

In reply, then, to the question why some plants should have cordate leaves with curved veins, while others have palmate leaves with straight ones, I suggested that the first retains the old form of leaf, while the latter has assumed one which presents certain advantages.

In my book on Flowers, Fruits, and Leaves, I have also given some account of the causes which have determined the form and structure of seeds and fruits.

These considerations naturally led me to the study of cotyledons.

1 See for instance Darwin and Phillips, ' On the Transpiration Stream in Cut Branches,' Proc. Cambridge Phil. Soc. vol. v.

2 Loc. cit. p. 364. 
No one who has ever looked at seedlings can fail to have been struck by the contrast which the cotyledons afford, not only to the final leaves, but even to those by which they are immediately followed.

Let us then take certain plants (especially, as far as possible, the commonest and most familiar), and see what light ean be thrown on the varied forms which their seedlings present. Look, for instance, at the familiar Mustard and Cress ; the first (fig. 3 ) has kidney-shaped cotyledons, one of

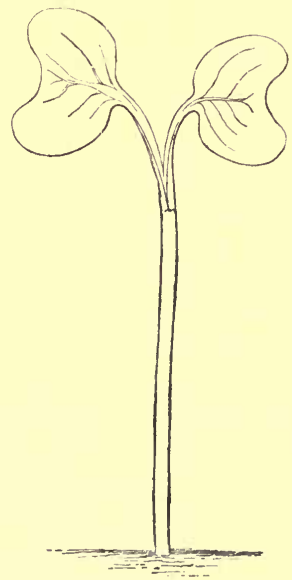

Fig. 3.-Seedling of Mustard (Brassica nigra), $\times \mathbf{3}$.

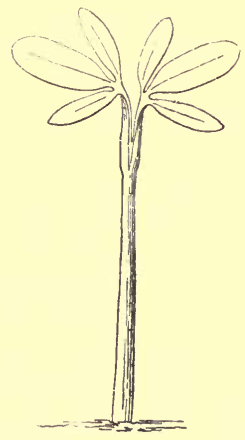

Fig. 4.-Seedling of Cress (Lepidium sativum), $\times 3$.

them rather larger than the other : while the Cress (Lepidium sativum) (fig. 4), on the other hand, has the cotyledons divided into three lobes. The Pink (Dianthus) (fig. 22) has broad cotyledons, the Chickweed (Cerastium) (fig. 23) narrow ones; those of the Beech (fig. 13) are fan-shaped in outline; those of the Sycamore (fig. 9) shaped almost like a knife-blade; those of Eschscholtzia (fig. 40) divided like a hay-fork; those of the Bean or Acorn thick and fleshy.

Mustard and Cress were the delight and wonder of our childhood; but at that time it never occurred, to me at least, 
to ask why they were formed as they are, and why they differed so much. So they grew, and beyond that it did not occur to me, nor I think to most, that it was possible to inquire.

I now propose, however, to suggest reasons which may account for some, at any rate, of these differences.

In previous memoirs I have discussed the causes which regulate the forms of seeds, and will not now therefore enter into them. I may, however, observe that the shape of the cotyledons seems to have little, if any, influence on that of the seed.

\section{Ovule and Seed.}

The seed of a flowering-plant contains a more or less highly developed embryo, which, after a certain time, will, under favourable conditions, resume growth, emerging from the seed-coat to produce the young plant or seedling. In the section of flowering-plants known as Gymnosperms, and including the Conifers and Cycads, the seeds are borne naked on an open scale, while in the far larger section of the Angiosperms they are protected till ready for dispersion in the closed cavity of the Fruit.

The seed is the result of the fertilisation of the ovule by the pollen. The effect of fertilisation, however, extends beyond the ovules to the ovary in which they are contained, causing often immense increase in size, as well as important structural changes. The ovary thus becomes the fruit as the ovule has become the seed.

Sometimes the effect extends still further to other parts of the flower, which thus persist, usually with increased size or change of structure, and form part of what is then termed a pseudocarp or false fruit. In the apple, for instance, the edible portion consists of the greatly developed floral-receptacle, which includes the ovary as its core. The ovules are borne usually on some definite part of the ovary wall or walls known as the placenta. They consist of an internal portion, the nucellus, one cell of which grows at the expense of the rest to form an embryo-sac, which again contains the egg-cell or oosphere, and one or two integuments entirely surrounding 
it except at the apex, where a small aperture, known as the micropyle, is left. In the process of fertilisation the pollentube passes down the micropyle to the oosphere which, enclosed in the embryo-sac, approaches very close to the outer wall of the ovule at this point. After fertilisation the oosphere develops into the embryo, the rest of the embryo-sac becoming filled with a cellular tissue, the endosperm, containing a store of food for the young plant. This is, however, sometimes re-absorbed before germination, so that the embryo occupies the whole interior of the mature seed. The original substance of the ovule, the nucellus, is often completely displaced by the embryo-sac, and the subsequent development of endosperm in its interior. One or two layers, however, may persist and share with the integuments in the formation of the seed-coats. Occasionally, as occurs in the Nymphæaceæ, Piperaceæ, and some of the Scitamineæ, a considerable portion of the nucellus remains in the mature seed, sharing with the endosperm the function of storing reserve material, or it may quite take the place of the endosperm.

There is considerable variety in the position and arrangement of parts of the ovule and subsequently of the seed. They are attached to the placenta by a stalk or funicle, the point of connection with the funicle being called the hilum. Vascular tissue supplying nutriment runs up the funicle into the integuments, and the point reached before the nutritive vessels ramify is the chalaza.

In some cases usually where there is only one ovule in the ovary or ovary-cell, as e.g. in Buckwheat or Nettle, the ovule stands erect, and the micropyle is opposite the hilum, which in this case coincides with the chalaza. The ovule is then said to be orthotropous ${ }^{1}$ or straight. But this, though the simplest, is the least common form of seed. More often, as in the Bean, Chickweed, and many others, the ovule during its growth is curved on itself, so that the apex and the micropyle are brought down very near to the base. Such ovules are known as cam. pylotropous or curved.

1 Figures of the various positions of the ovule are given in various textbooks ; see, for instance, Prantl and Vines' Text-book on Botany, ed. 4, p. 173 fig. 130 ; or Asa Gray's Structural Botany, p. 278. 
In a third category the ovule itself is straight, but it stands as it were at right angles to the base of attachment. These are called half-anatropous or half-reversed.

Lastly, in a very large number-in fact the largestthe ovule is quite inverted on its base; the funicle, or stalk, growing with its curvature, and forming a sort of ridge or raphe, which is very conspicuous in the ovule, but gradually becomes less and less apparent, finally becoming merged in the seed-coat. The chalaza is thus carried right away from the hilum to the opposite end, and the whole ovule or seed is reversed, so that the true base is removed from, and the true apex brought close to, the point of union with the ovary. Such are called anatropous or reversed.

Now this seems a very curious and roundabout arrangement. It is described in all works on general Botany, but those which I have seen do not give any explanation of its object or purpose. I will for the moment omit any consideration of campylotropous and half-anatropous seeds, and confine myself to orthotropous and anatropous forms.

In most orthotropous species, as for instance in the Buckwheat, the ovule is straight, upright, and attached by its base to the funicle and base of the ovary. At the free end is the micropyle, and immediately below it the egg-cell, which, when fertilised by the pollen, becomes the rudiment or embryo of the future plant. When the pollen falls on the stigma it soon pushes out a little tube, which rapidly elongates, passes into the cavity of the ovary, and entering the micropyle of the ovule fertilises it.

But ovules thus constituted are, as I have already mentioned, exceptional. In a great many plants the ovule, instead of being upright and attached to the base of the ovary, is, on the contrary, attached to the summit and pendent. Now in a pendent orthotropous ovule the micropyle is turned away from the pollen-tube, and the object and effect of the ovule being reversed or anatropous is to bring it back into a convenient position for fertilisation. So also, when there are many ovules, the result of the anatropous arrangement is again to bring the micropyle into a suitable position.

The structure and arrangement of the ovule have been the 
subject of various important memoirs, which, however, have been almost exclusively descriptive. Dalmer ${ }^{1}$ indeed quotes Schleiden, who, speaking of Berberis, pointed out that among the normal anatropous ovules here and there one occurs which is orthotropous, and that these never develop into seeds ("Die Befruchtung der Ovule scheint mir aber in ganz bestimmter Beziehung zu dem vorgeschriebenen Lauf der Pollenschläuche zu stehen, denn stets beobachtete ich, dass diese regelwidrige atropen Eichen unbefruchtet blieben'). The pollen-tubes, however, would naturally follow the regular course; and we could not, I think, deduce a general conclusion from such rare and abnormal cases. Dalmer himself does not seem to have done so; for, after referring to the different forms of ovules, he observes that 'sometimes the form of the ovule appears to be adapted so as to facilitate the entrance of the pollen-tube' ('scheint zuweilen die Gestalt des Ovulums dem Eintritt des Pollenschlauches angepasst zu sein '). Even here, then, the explanation I venture to suggest seems referred to rather as an exceptional occurrence than as a general explanation of this remarkable arrangement. It must be admitted that there are some cases in which the anatropy of the ovule appears at first sight rather disadvantageous than otherwise. Most of these can, I believe, be explained, while in some it is possible that the plants retain, eren perhaps to their present disadvantage, an arrangement inherited from an ancestral condition in which it was beneficial. I hope, howerer, to enter into this question more fully on a future occasion.

The mature seed contains the more or less differentiated embryo, in some cases, as in Larkspur (Delphinium) (fig. 104), very small, consisting only of a small basal portion the radicle, which on germination gives rise to the primary root, and one (Monocotyledons), two (Dicotyledons), or several (Conifers) seed-leaves or cotyledons, sheathing a microscopic plumulefrom which the future stem is developed. The rest of the space is occupied by the mealy, oily, fleshy, or horny endosperm. In other cases, as in the Ash (Fraxinus) (fig. 46) or Castor Oil (Ricinus) (fig. 52), the embryo is much larger, and

1 'Ueber die Leitung der Pollenschläuche bei den Angiospermen,' Jenaisch Zeits. 1880, p. 530 . 
we find a little miniature plant, generally white, sometimes green, but still embedded in endosperm. In others, again, the endosperm is reduced almost to a film, as in Hippophaë (fig. 53), and finally, as in the Bean (fig. 51), the embryo occupies the whole seed, and the nourishment intended for the young plant is stored up in the cotyledons themselves. Similarly, in a Walnut, the.two halves of the seed are filled by the two cotyledons, and attached to them may be found the little plantlet with a delicate white radicle, and a little plumule bearing five or six minute rudiments of leaves, often just tipped with green.

The Bean and Walnut are instances of exalbuminous or non-endospermic seeds, while those containing endosperm (or perisperm) are termed albuminous. The seed-coat is double in cases where the ovule was provided with two integuments, the outer coat, or testa, developed from the outer integument, being the stronger and often crustaceous in texture. The inner coat or tegmen is thin or soft and delicate, conforming closely to the surface of the endosperm or embryo. It is developed chiefly from the inner integument of the ovule, and is therefore wanting in ovules with only one coat.

The testa is often provided with appendages or outgrowths of very diverse form and nature, but generally having reference to dissemination of the seed, as in the case of wings or tufts of hair. A more or less incomplete accessory seed-coat is sometimes formed between the time of fertilisation and ripening of the seed. This is known as an aril. Good instances are seen in the Water Lily (Nymphae) and the Yew. Crest-like or wart-shaped appendages developed during the same period are known as strophioles or caruncles. The Castor Oil (Ricinus) supplies a good instance of the latter.

\section{Forms of Cotyledons.}

I will now pass from seeds to seedlings. No one who has ever looked at young plants can have failed to be struck by the contrast they afford to the older specimens belonging to the same species. This arises partly from differences in the leaves, partly from the contrast which the cotyledons, or seed- 
leaves, afford, not only to the final leaves, but even to those by which they are immediately followed.

This contrast between the cotyledons and true leaves is so great that one might almost be pardoned for asking whether they can be brought into actual correlation.

So far, indeed, are the cotyledons from agreeing with the forms of the leaves, that the difficulty is to find any which have been clearly influenced by them. One species of Ipomœa (I. Pes-capre) has both cotyledons and leaves, as the name denotes, somewhat like the foot of a goat; but the leaves vary considerably, and it is probable that the resemblance may be accidental. A clear case is, however, afforded by the Onagrariex, where in Enothera and some allied genera the form of the mature cotyledons is evidently related to the leaves. Even here, however, the resemblance is confined to a basal portion of the cotyledon which makes its appearance subsequent to germination, and no trace of it is shown in the cotyledons themselves when they first appear.

The forms of the cotyledons in many species have been the subject of special memoirs by Tittmann, Irmisch, Wichura, Winkler, Tscherning, and other botanists; but they have not given any reasons for the various forms assumed.

Klebs, indeed, one of the most recent writers on the subject, in his interesting Memoir on Germination, ${ }^{1}$ refers to this diversity of form, and expressly says that these differences are an enigma ("Sind gewiss diese Verschiedenheiten in den Blattformen hinsichtlich ihrer biologisehen Bedeutung für die Pflanze ein Räthsel'). He observes, however, that on the whole the forms of cotyledons are much simpler than those of leaves, and he suggests that while in some cases perhaps, like the first leaves, they retain the form which characterised the species in bygone ages, we may rather, as a more generally applicable explanation, apply to them the suggestion of Goebel with reference to stipules, and regard them as simplified by arrest." Another suggestion has been that cotyledons are ' $a$ survival of the universal foliage of deciduous trees in olden geological days, ere time had differentiated them into their

1 'Beiträge zur Morphologie und Biologie der Keimung,' Untcrsuch. Botan. Inst. $v$. Tubingen, 1884 (Band i. p. 536).

${ }^{2}$ Loc. cit. p. 613. 
present varied forms.' Even, however, if this suggestion were the real explanation of the comparative simplicity, it would throw no light on the differences between the cotyledons of different species.

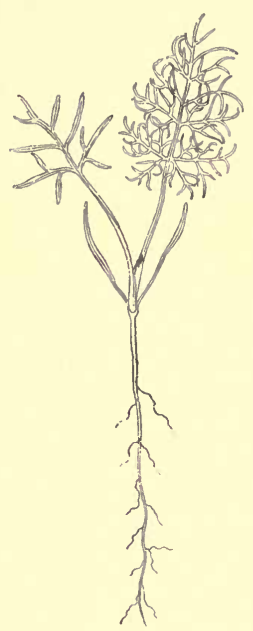

FIg. 5.-Seedling of Foniculum vulgare. $₫$ Half nat. size.

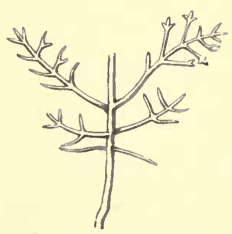

Fig. 6.-Seedling of Coreopsis filifolia. Half nat. size.

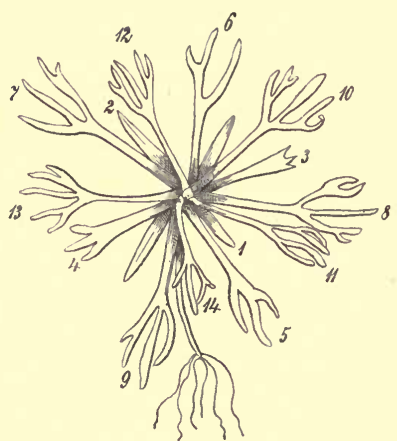

FIG. 7.-Seedling of Ceratocephalus falcatus. Nat. size. The numerals indicate the successive leaves.

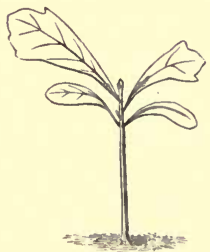

FIG. 8.-Seedling of Platanus. Nat. size.

Though cotyledons do not present nearly such extensive variations as leaves, still they do differ considerably from one another.

Some are narrow, in illustration of which I may refer to 
Fœniculum (fig. 5), Coreopsis (fig. 6), Ceratocephalus (fig. 7), and Ferula (in the hollow stalk, or ferule, of which Prometheus brought down fire from heaven), \&c., where the ultimate leaves are much divided; Platanus (fig. 8) and Acer (fig. 9),

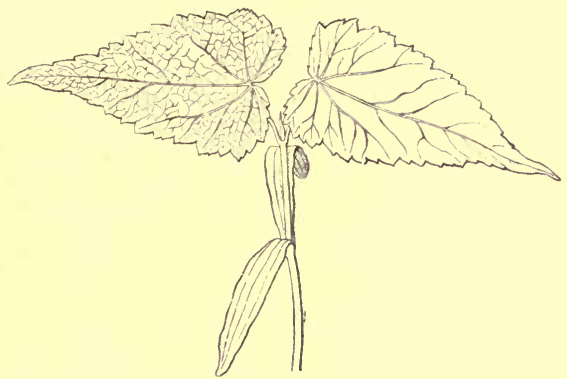

FIG. 9.-Seedling of Acer Pseudo-Platanus. Half nat. size.

(In this and some other figures, one (or more) of the leaves is given in outline only.)

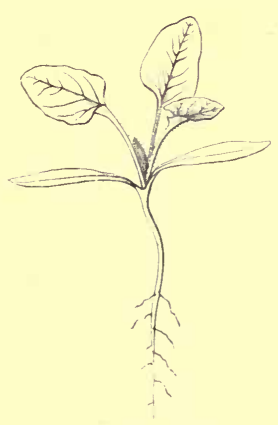

Fig. 10.-Seedling of Chenopodium Bonus-Henricus. Nat. size.

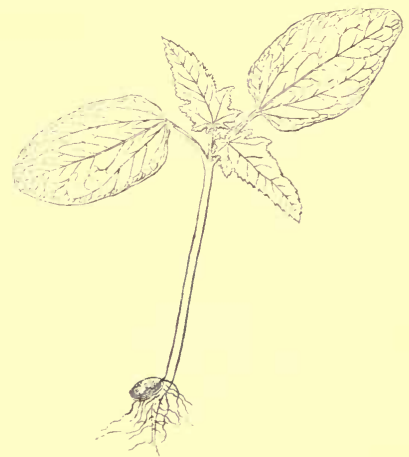

FIc. 11.-Seedling of Rrcinus sanguineus One fourth nat. size.

where the ultimate leaves are palmate; and Chenopodium (fig. 10), where they are more or less triangular.

Some cotyledons are broad, in illustration of which I give figures of Ricinus (fig. 11), Impatiens (fig. 12), Beech (Fagus) (fig. 13), Brassica (fig. 3), Hippophaë (fig. 14), Rivina (fig. 15), 


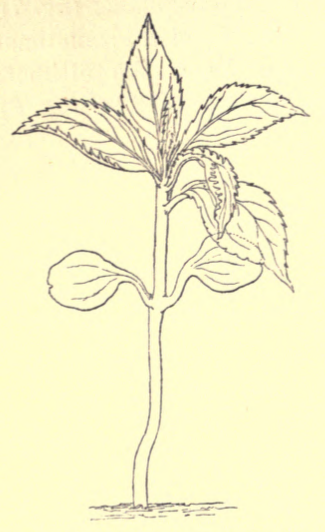

F1G. 12.-Seedling of Impatiens balsamina. Half nat. size.

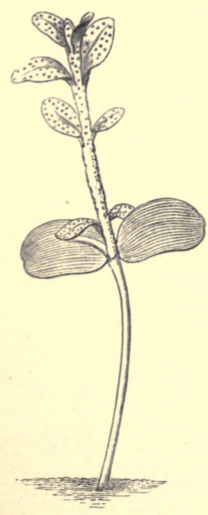

Frg. 14.-Seedling of Hippophaë rhamnordes. Half nat. size.

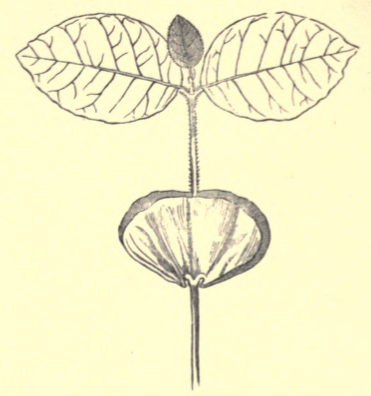

Fig. 13.-Seedling of Beech (Fagus sylvatica). Half nat. size.

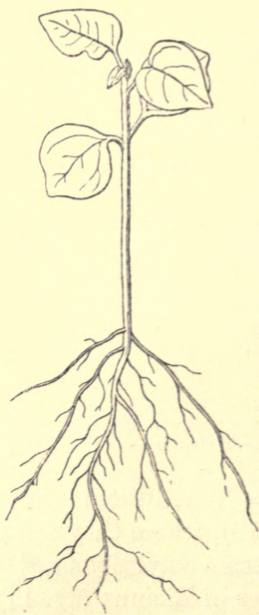

Frg. 15.-Seedling of Rivina lavis. Nat. size. 


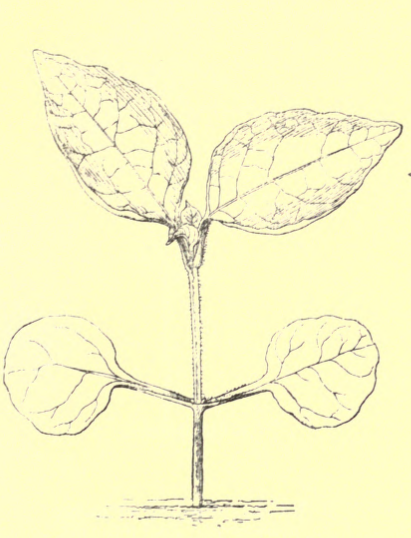

FIG. 16.-Seedling of Asystasia coromandeliana. Half nat. size.

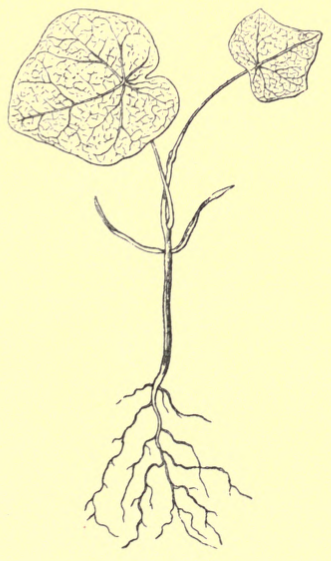

Fig. 18.-Seedling of Menispermum canadense. Half nat. size.

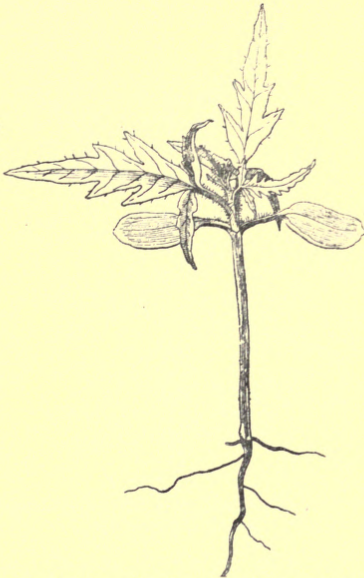

Fig. 17.-Seedling of Rhus typhina. Half nat. size.

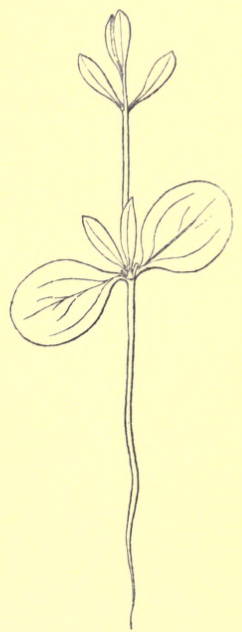

FIG. 19.-Seedling of Linum monogynum. Nat. size. 


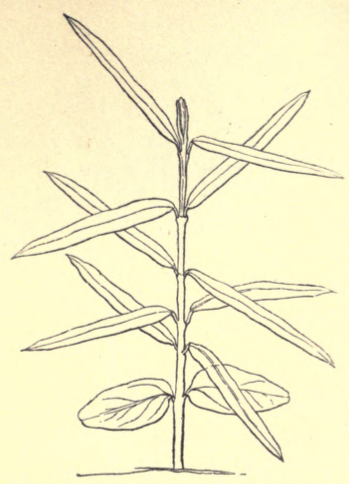

Frg. 20.-Seedling of Olea cuspidata. Two-thirds nat. size.

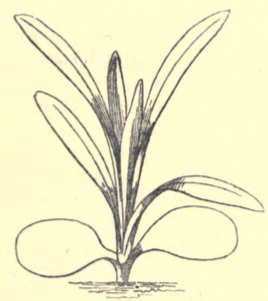

Fig. 22.-Seedling of Pink (Dianthus Caryophyllus). Nat. size.

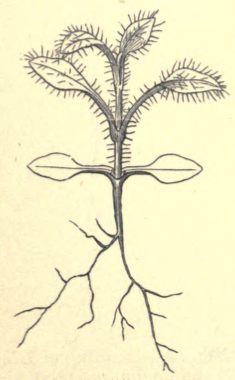

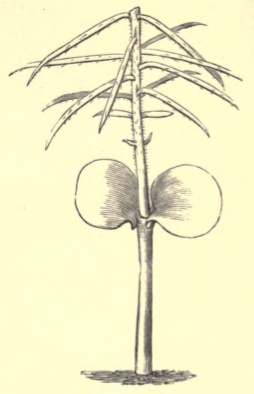

FIg. 21,-Seedling of Hakea acicularis. Half nat. size.

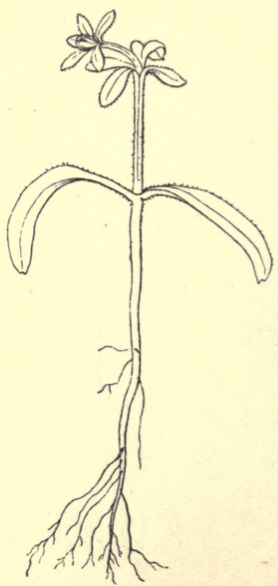

FIG. 24.-Seedling of Galium saccharatum. Nat. size.

Frg. 23.-Seedling of Cerastium arvense. Half nat. size. 


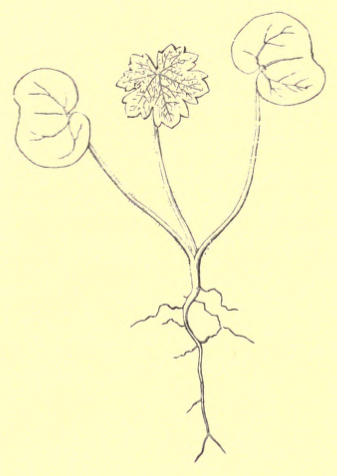

FIG. 25.-Seedling of Geranium sanguineum. Nat. size.

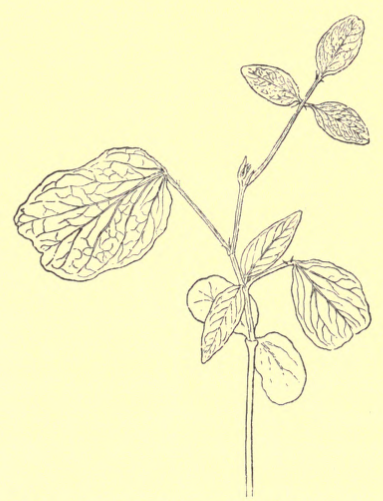

FIG. 27.--Seedling of Clitoria Ternatea. Half nat. size.

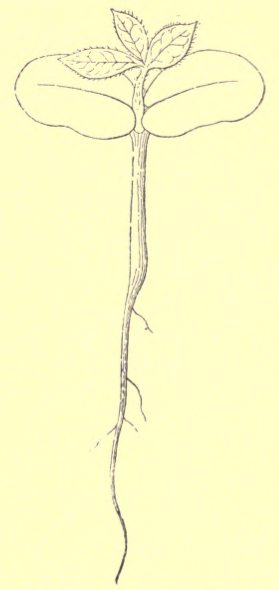

Fig. 26.-Seedling of Laburnum (Laburnum vulgare). Nat. size.

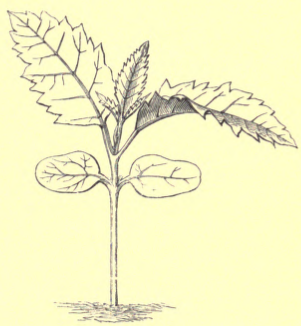

FIG. 28.-Seedling of Schinus terebinthifolia. Two-thirds nat. size. 


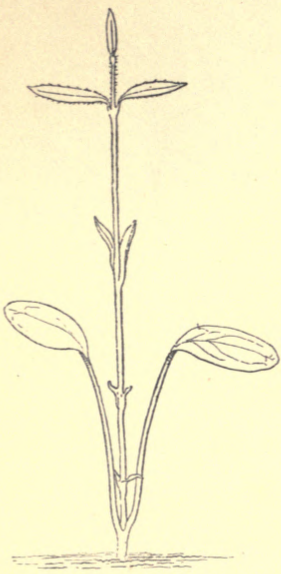

Fig. 29.-Seedling of Microloma, $\times 1 \frac{1}{2}$.

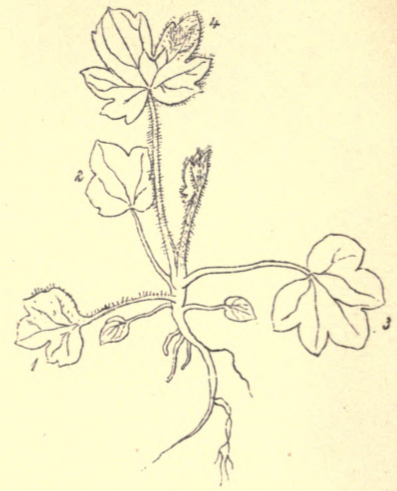

Fig. 30.-Seedling of Delphinium elatum. Two-thirds nat. size.

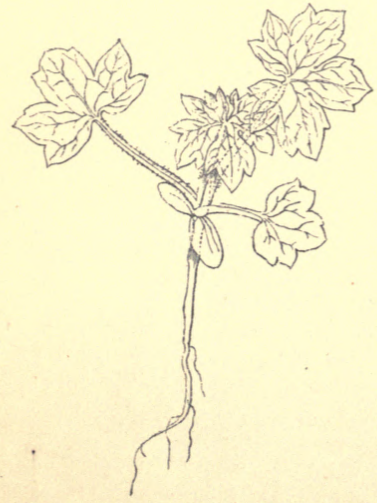

Frg: 31.-Seedling of Delphinium Staphysagria. Half nat. size.

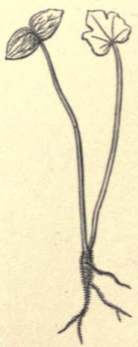

Frg. 32.- Seedling of Delphinium nudicaule. Half nat. size. 
Asystasia ${ }^{1}$ (fig. 16), Rhus typhina (fig. 17), and Flax (Linum) (fig. 19). We find some species with narrow cotyledons and broad leaves, as Menispermum (fig. 18), while in others the cotyledons are broad and the leaves narrow, as in an Australian Flax (Linum monogynum) (fig. 19), Hakea (fig. 21), and the Pink (Dianthus) (fig. 22), \&c.

In some cases we find instances of broad and narrow cotyledons in the same family, as in Chickweed (fig. 23) and Pink (fig. 22), belonging to the Caryophyllaceæ; sometimes even in the same genus, as Gallium saccharatum (fig. 24) and Galium Aparine (figs. 91 and 92).

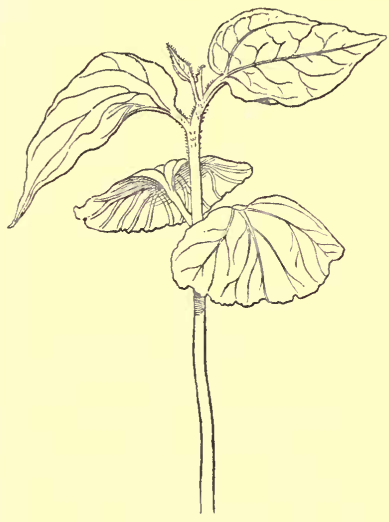

Fig. 33.-Seedling of Cordia subcordata. Half nat. size.

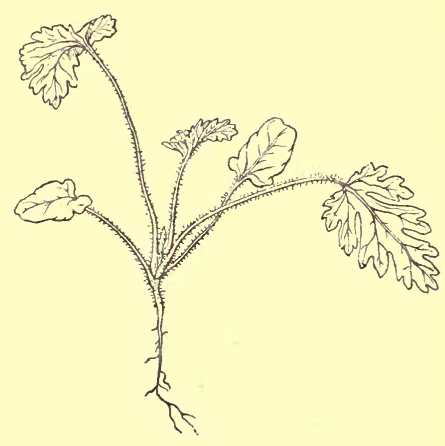

FIG. 34.-Seedling of Pelargonium australe. Half nat. size.

In some cases the two cotyledons are unequal, as in the Mustard (fig. 3), Cabbage, Radish, Cereus (fig. 63), Pachira, ${ }^{2}$ \&c.: in some the two halves of each cotyledon are unequal, as in the Geranium (fig. 25) ; or they are otherwise unsymmetrical, as in the Lupine, Laburnum (fig. 26), Clitoria (fig. 27), Schinus (fig. 28). Sometimes they are sessile, as Acer (fig. 9), Hakea (fig. 21), Laburnum (fig. 26), \&c. ; sometimes

1 In Asystasia coromandeliana there is an interesting peculiarity. The first pair of leaves of each branch, or at any rate of the lower branches, approximate to the form of the cotyledons.

${ }^{2}$ As described by Mr. Lynch (Journ. Linn. Soc. vol. xvii. p. 147). 


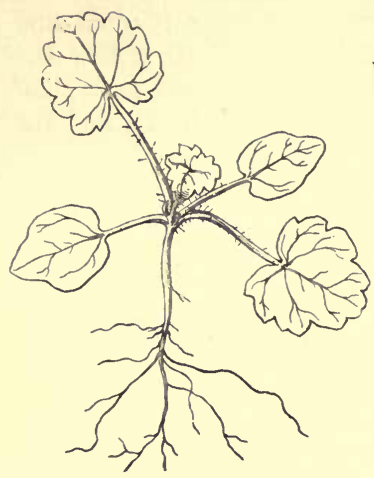

Fra. 35.-Seedling of Malva moschata. Nat, size.

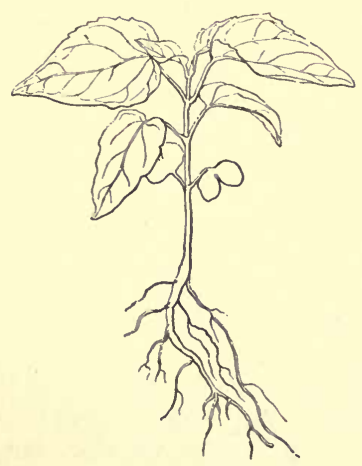

Fig. 37.-Seedling of Catalpa Kampferi. Half nat. size.

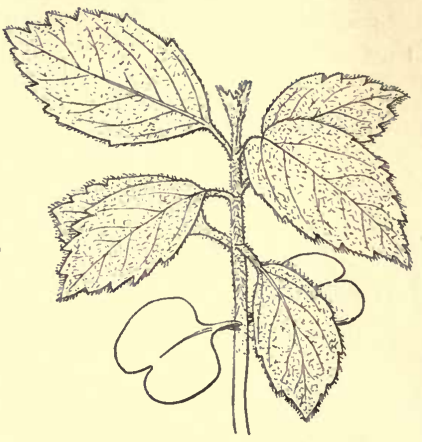

Fra. 36.-Seedling of Spathodea campanulata. Nat. size.

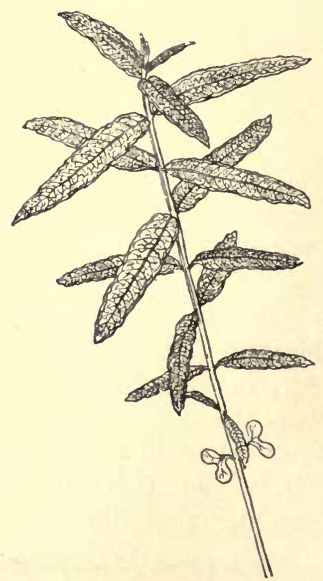

Frg. 38.-Seedling of Eucalyptus sp. Half nat. size. 


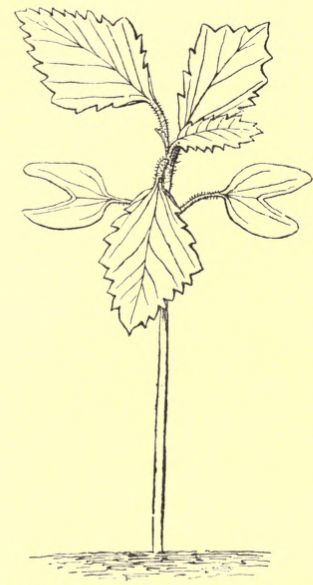

FIg. 39.-Seedling of Pentapetes phonicea. Nat. size.

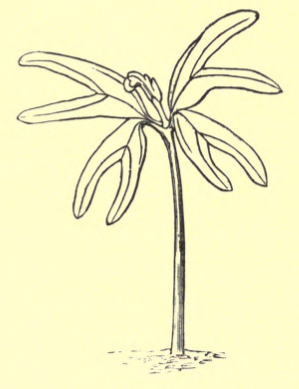

FIg. 41.-Seedling of Pterocarya caucasica. Nat. size.

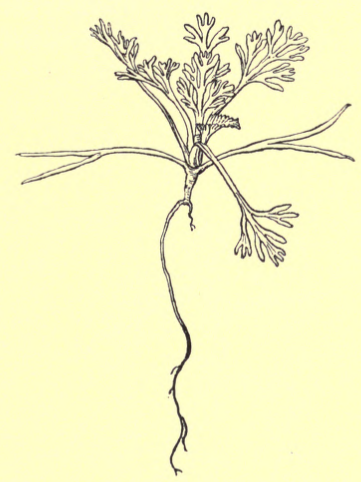

FIG. 40.-Seedling of Eschscholtzia californica. Nat. size.

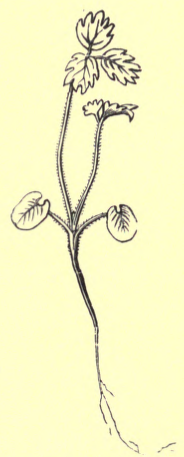

Fig. 42.-Seedling of Poterium Sanguisorba. Twice nat. size. 
they are supported on petioles, as in Microloma (fig. 29), which again are occasionally connate. These differences may occur in very closely allied species; for instance, in Delphinium Staphysagria (fig. 31 ) the cotyledons are sessile, while in D. elatum (fig. 30 ) they are petioled, and in D. nudicaule (fig. 32) the petioles are connate.

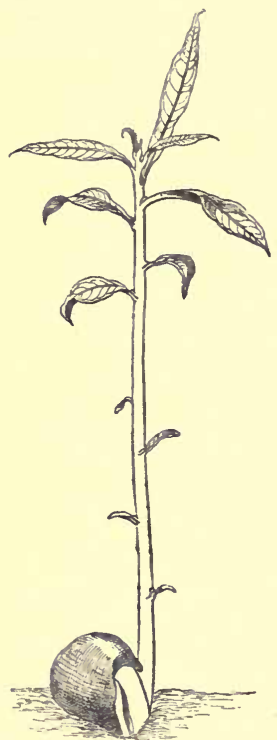

Fig. 43.-Seedling of Sapindus incequalis. Half nat. size.

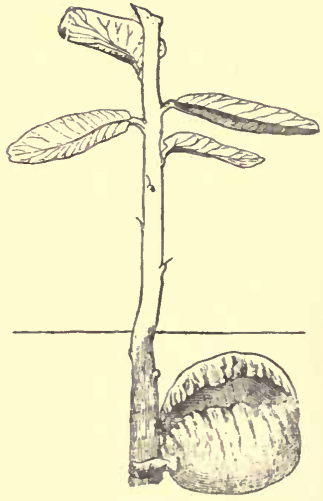

FIg. 44.-Seedling of Rhus Thunbergii. Half nat. size.

Generally the cotyledons are entire; but sometimes crenate, as in Cordia (fig. 33), or lobed, as in Pelargonium (fig. 34) and Malva (fig. 35). Often they are emarginate, as in Impatiens (fig. 12), Mustard (fig. 3), and Cabbage, Ipomœea (fig. 88), Convolvulus, Galium (fig. 92), Eucalyptus (fig. 38), Pentapetes (fig. 39), \&c. They are sometimes even bifid, as in Eschscholtzia (fig. 40) and Ipomœa dasysperma (fig. 89); trifid, as in the Cress (Lepidium) (fig. 4); or in four long lobes, as in Pterocarya (fig. 41). Sometimes auricled at the 
base, as in Poterium (fig. 42) and Cuphea. Sometimes they are large; sometimes small. Generally they are leaf-like; but sometimes, as in Rhus Thunbergii (fig. 44), Sapindus (fig. 43), and among English plants in the Oak, Nut, Pea, Bean, Mercurialis perennis, ${ }^{1}$ Melittis Melissophyllum, ${ }^{2}$ Nymphæa, Nuphar, Rhamnus Frangula, Trientalis, Daphne, \&c., they are thick and fleshy.

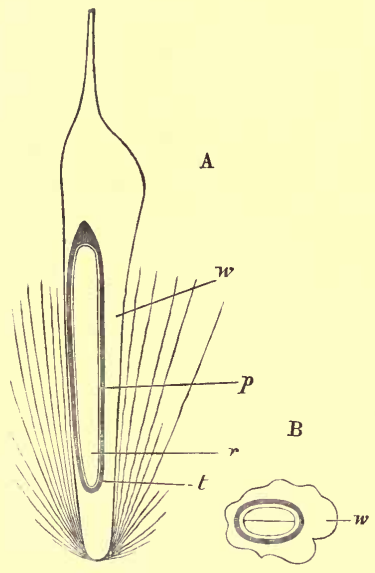

Fig. 45.-A, Fruit of Platanus, longitudinal section, $\times 6: w$, woody part. $\mathrm{B}$, transverse section, $\times 12$.

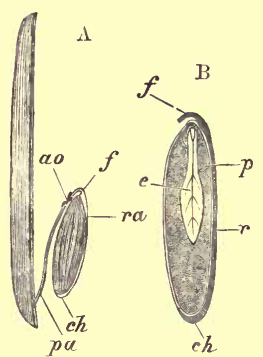

Fig. 46.-A, samara of Fraxinus excelsior, nat. size, with one half removed and the seed pulled out: $p a$, placental axis; $a o$, abortive ovule; $f$, funicle. $\mathrm{B}$, longitudinal section of seed. In germination the embryo grows to the whole length of the seed.

Except where otherwise stated, $c$ stands for cotyledon; oc, outer cotyledon; $i c$, inner cotyledon; $c h$, chalaza ; $e$, embryo; $f$, funiculus; $h$, hilum; $m$, micropyle $p$, endosperm ; $r$, radicle; $t$, testa.

\section{Narrow Cotyledons.}

Let us now begin with such species as have narrow cotyledons, and see if we can throw any light on this characteristic. The problem is simple enough in such eases as Platanus, where we have on the one hand narrow cotyledons (fig. 8) and on the other hand a long narrow seed (fig. 45, $p$ )

1 Winkler, 'Ueber die Keimpflanze des Mercurialis perennis,' Flora, 1880.

${ }^{2}$ Irmisch. 'Zur Naturg. v. Melittis,' Bot. Zeit. 1858, p. 233. 
fully occupied by a straight embryo. Again, in the Ash (Fraxinus) (fig. 46), Ursinia (fig. 47), \&c., the cotyledons lie parallel to the longer axis of the seed, which is narrow and elongated. Such cases, however, are comparatively few; and there are a large number of species in which the seeds are

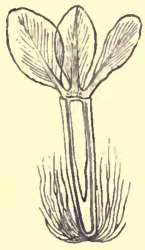

FIG. 47.-Achene of Ursinia speciosa. Longitudinal section, $\times 2 \frac{1}{s}$. Transverse section, $\times 10$.
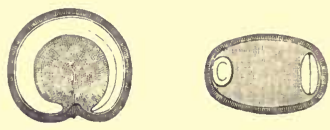

Fig. 48.-Chenopodium Bonus-Henricus, vertical and transverse sections of seed.

broad and even orbicular, while yet the cotyledons are narrow, as for instance in Chenopodium (fig. 48) and Menispermum (fig. 49).

A

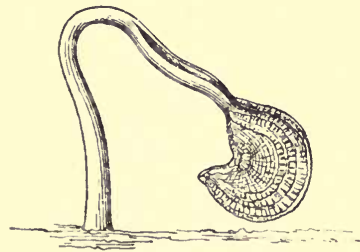

B

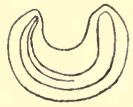

C

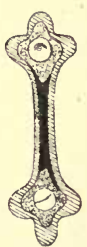

FIo. 49.-Menispermum canadense.

A, germinating, seedling, $\times 2$. B, vertical section of seed, $\times 4$. $\mathrm{C}$, transverse section of seed, $\times 2$.

In these it will generally be found that the cotyledons lie transversely to the seed. In Menispermum (fig. 18) the fruit (fig. 49) is laterally compressed and horseshoe-shaped, with a crest along the edge ; the seed (fig. $49, \mathrm{~B}$ ) conforms to the shape of the fruit, and the embryo is curved and linear, the cotyledons being applied to one another face to face, and at right angles to the plane of the seed, so that the edges of the cotyledons touch the walls of the seed at each side. 
The Syeamore (Acer Pseudo-Platanus) (fig. 9) has also narrow cotyledons; but the arrangement is very different. The fruit (fig. 50) is winged, the seed somewhat obovoid and exalbuminous - that is to say, the embryo, instead of lying embedded in food-material, occupies the whole cavity of the seed. Now if we wished to pack a leaf into a cavity of this form, it would be found convenient to choose one of a long strap-like shape, and then roll it up into a sort of ball. This is, I believe, the reason why this form of cotyledon is most suitable in the case of the Sycamore. The mode of folding, however, as shown in fig. 50, A and B, is not always the same. I shall suggest a reason for the difference further on.

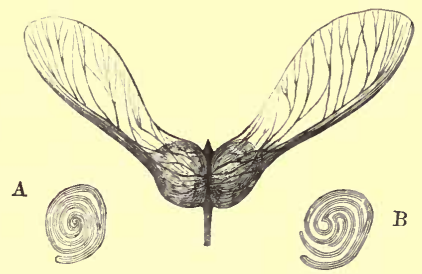

FIG. 50.-Acer Pseudo-Platanus. Fruit, nat. size. A, B, embryo, showing two modes of arrangement of cotyledons.

In other species the narrowness of the cotyledons is perhaps an advantage in facilitating the exit from the seed. See, for instance, the cases of Galium (p. 28) and Symplocos.

\section{Broad Cotyledons.}

I now pass to species with broad cotyledons. The Acorn Nut, Bean (Phaseolus) (fig. 51), and Pea afford familiar cases, in which the two broad, fleshy, thickened cotyledons conform to and occupy the whole seed. In the Castor-oil plant (Ricinus) (fig. 11) the seed (fig. 52) is ovoid-oblong, somewhat compressed dorso-ventrally, and beautifully mottled, while the projecting knob at the hilum gives it very much the appearance of a beetle or large tick. The endosperm is abundant, fleshy, white, and surrounds the embryo. The embryo is straight, flat, large, central, and white; the cotyledons broad, 
obtuse-oblong, and approximately following the general outline of the seed. In Hippophaë (fig. 14) we have a somewhat similar case ; but the cotyledons are fleshy and occupy almost the whole of the seed (fig. 53). In Euonymus, again, the seed is obovoid, slightly compressed laterally. The endosperm is
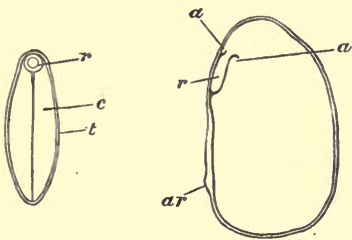

Fig. 51.-Phaseolus multiflorus. Section of seed parallel and vertical to cotyledons, three-fourths nat. size: $a, a$, auricles; $a r$, arillode.
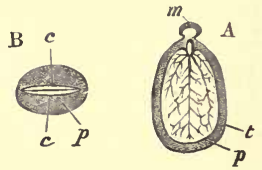

Fig. 52.-Ricinus sanguineus. A, longitudinal section of seed, nat. size. B, transverse section of seed, nat. size.

abundant, fleshy, firm, and white, entirely surrounding the embryo. The embryo is straight, flat, central, pale green, extending very nearly from one end of the seed to the other. In the Flax the seed is ovate, obliquely pointed, glabrous, plano-convex, laterally much compressed, placed edgeways on
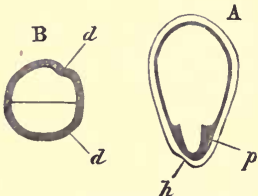

Frg. 53-Hippophaé rhamnoides. A, longitudinal section of seed, $\times 4$. B, transverse section of seed, $\times 4: d d$, depressed line.

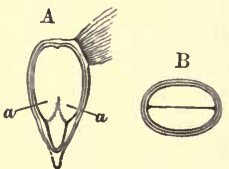

Fig. 54.-Moscharia pinnatifida. A, longitudinal section of seed, $\times 8$. B, transverse section of seed, $\times 8: a$, auricles.

the placenta, and the cotyledons lie parallel to the flattened axis of the seed. In other cases the seeds are still more flattened, as in Ailanthus, Passiflora, Cobæa, Stephanotis, \&c.

The Compositæ generally have narrow cotyledons. In Moscharia, however, they are somewhat broader, the seed (fig. 54) heing obovoid, with the cotyledons lying the broad way. 
In many cases, seeds of the same shape produce cotyledons of very different form.

Compare together, for instance, Ruellia (fig. 55) and Cerastium (fig. 23 seedling, and fig. 56 seed). Both have A

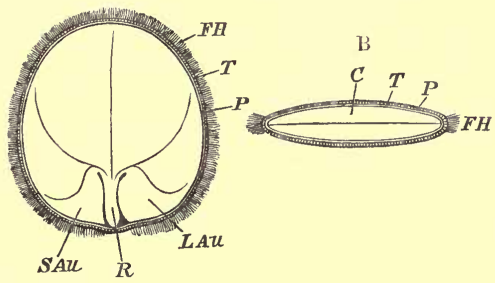

FIG. 55.-Ruellia longifolia. A, longitudinal section of seed, $\times 10$. B, transverse section of seed, $\times 10$ : $\mathrm{FH}$, fringe of hairs; LAu, larger, and SAu, smaller auricle.

compressed, nearly orbicular seeds, but in Ruellia the cotyledons are broad, in the Chickweed they are narrow. If, however, we make sections of the seeds, the cause of this difference becomes obvious, because in one (fig. 55) the cotyledons lie parallel, in the other (fig. 56) transverse, to the seed.
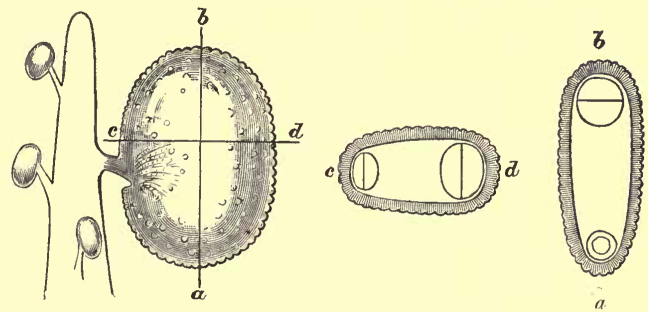

FIG. 56.-Cerastium arvense, $\times \mathbf{1 5}$.

The form of the cotyledons often differs greatly even in the same family.

The Caryophyllacee, for instance, afford us an interesting illustration. The cotyledons in this family are placed with their backs to the placenta, and in most species are narrow, 
as in Cerastium (figs. 23 and 56). In some of them, however, such as the Pink itseif (Dianthus) (fig. 22) and Tunica, they are wide.

Now in most genera, as in Stellaria, Spergularia, Cerastium, \&c., the seeds are laterally compressed; the cotyledons consequently lie transversely to the seed, and their width therefore is limited by the thickness of the seed, as in fig. 56. The case is, however, somewhat complicated by the fact that the seed and embryo are both curved.

On the other hand, in the Pink (fig. 57) the seeds are not laterally but dorsally compressed, attached to the columnar
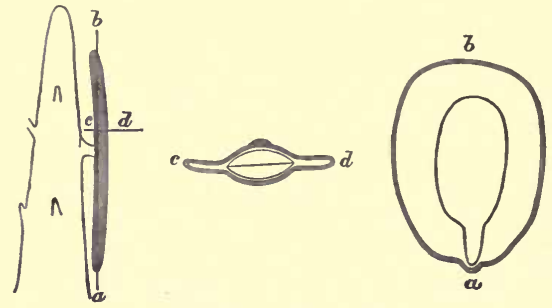

Frg. 57.-Dianthus Caryophyllus, $\times 15$.

(In figs. 56 and 57 the letters $a, b$, and $c, d$ indicate the directions of the sections.)

placenta by the middle of the interior face, so that the cotyledons are straight, parallel to the seeds, and have in consequence plenty of room to widen out.

In Solanum the fruit is roundish, glabrous, indehiscent, and many-seeded. The seeds are kidney-shaped, much compressed laterally, and placed with their narrow edge to the placenta, surrounded by a paler margin, glabrous and white; the hilum is small, and on the middle of the ventral edge. The embryo is, in the mature seed, much curved, embedded in, but lying near the outer edge of, the endosperm. The radicle occupies the lower and narrow part of the seed. The cotyledons are linear, not broader than the radicle, curved, with their tips close to the hilum, and their back to the placental axis, and at right angles to the plane of the seed, the whole width of which accordingly they occupy, 
so that they cannot grow any wider. On the other hand, while the fruit of Cestrum is not very unlike that of Solanum, the seeds are very different in shape, being peltate, more or less obovate, with the broad end towards the apex of the seed, so that the cotyledons hare room to widen themselres.

Sometimes we meet with species having both narrow and broad cotyledons, eren in the same genus. For instance, Coreopsis filifolia (fig. 6) has narrow, Coreopsis auriculata broad, cotyledons. If, however, we examine the seeds we find that those of C. filifolia are narrow or subcylindrical (fig. 58),

A

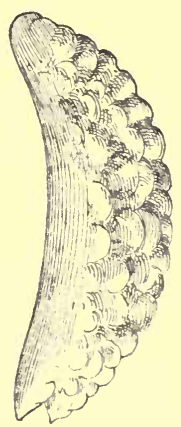

B

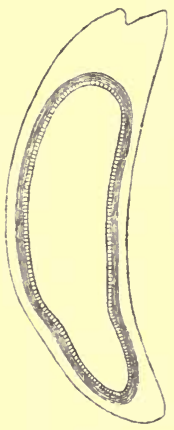

C

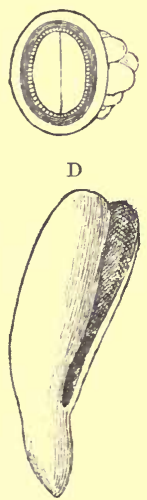

FIg. 58.-Coreopsis filifolia. A, achene, $\times 14$. B, longitudinal section, $\times 14$. $\mathrm{C}$, transverse section, $\times 14$. D, embryo, $\times 14$.

while those of C. auriculata (fig. 59) are broadly obovate; and as in both cases the embryo fills the seed, this difference sufficiently accounts for the dissimilarity in the cotyledons.

The genus Galium is an interesting case. Here also we find some species with narrow, some with broad, cotyledons; but the contrast seems to be due to a very different cause. G. Aparine (fig. 91) has broad, G. saccharatum (fig. 24) narrow, cotyledons. In G. saccharatum the fruit (fig. 60) deeply lobed, two-celled, two-seeded, indehiscent, and densely covered with tubercles. The seed is globose, deeply hollowed 
on the ventral surface. The embryo (fig. $60, r, c$ ) is curved, following the concavity of the hollow, with the larger part of the endosperm lying towards the periphery. The cotyledons are linear and obtuse. Fig. 60 shows that, so far as the form of the seed is concerned, there is no reason why the cotyledons should not be much broader than they are. The explanation
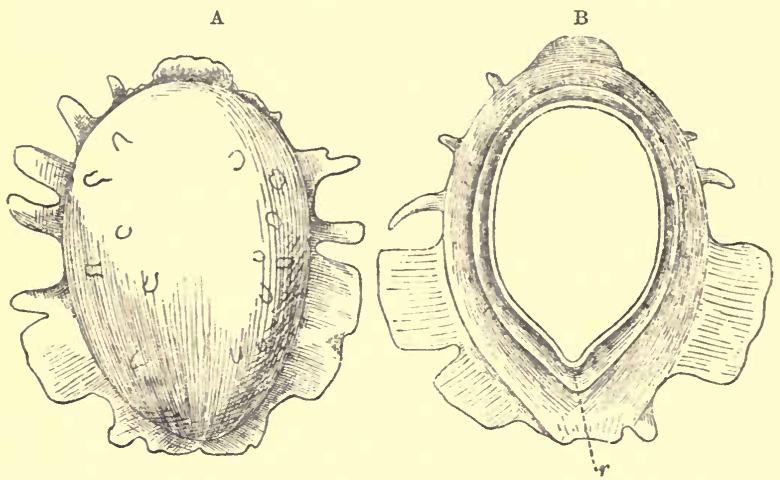

$\mathrm{D}$
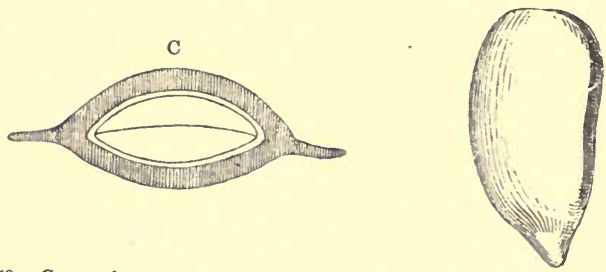

F1G. 59.-Coreopsis auriculata. A, achene, $\times 14$. B, longitudinal section, $\times 14$ $\mathrm{C}$, transverse section, $\times 14$. D, embryo, $\times 14$

may perhaps be found in the structure of the pericarp (fig. 60, $p . c)$, which is thick, tough, and corky. It is rery impervious to water, and may be advantageous to the embryo by resisting the attacks of drought and of insects, and perhaps if the seed be swallowed by a bird, by protecting it from being digested. On the other hand it does not split open, and is too tough to be torn by the embryo. The cotyledons, therefore, if they 
had widened, as they might otherwise have done, would have found it impossible to emerge from the seed. They evade the difficulty, however, by remaining narrow (fig. $60, \mathrm{C}$ ). On the

A

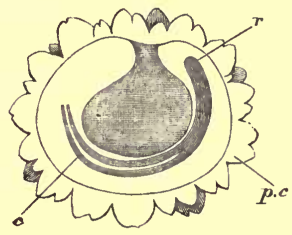

B

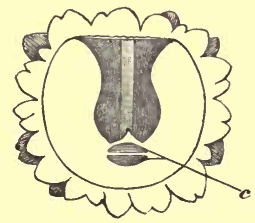

C

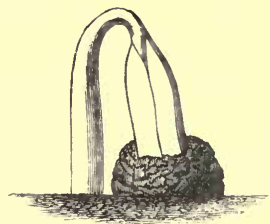

FIG. 60.-Galium saccharatum. A, longitudinal section of seed, $\times 8$. B, transverse section of seed, $\times 8$. C, germinating seedling, $\times 4$.
A

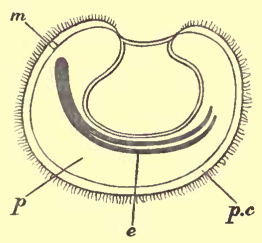

B

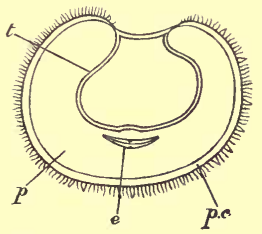

C

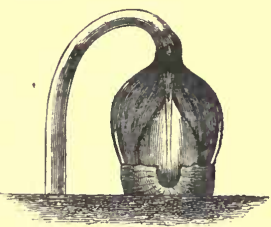

Fig. 61.-Galium Aparine. A, longitudinal section of seed, $\times 8$. B, transverse section of seed, $\times 8$. C, germinating seedling, $\times 4$.

other hand, in G. Aparine the pericarp is much thinner (fig. 61), and the embryo is able to tear it open (fig. 61, C). In this case, therefore, the cotyledons can safely widen without endangering their exit from the seed. 
The thick corky covering of G. saccharatum is doubtless much more impervious to water than the comparatively thin testa of G. Aparine. The latter species is a native of our own isles, while G. saccharatum inhabits Algiers,' the hotter parts of France, \&e. May not, then, perhaps the thick corky envelope be adapted to enable it to withstand the heat and drought?

In all these species the cotyledons are flat or nearly so, but a large number are enabled to widen themselves by being more or less folded. One form of this is afforded by the Radish (Raphanus) and Brassica (fig. 3). Fig. 62, A, shows a seed of Raphanus sativus, and, as shown in fig. $62, \mathrm{~B}-\mathrm{E}$, the latter of which represents a young seedling, the cotyledons are applied to one another face to face, and then folded along the middle.

\section{Unequal Cotyledons.}

I now turn to those species in which the two cotyledons are unequal in size.

Several of these cases have been discussed by Darwin, ${ }^{1}$ who attributed the inequality to the fact of ' a store of nutriment being laid up in some other part, as in the hypocotyl, or one of the two cotyledons, or one of the secondary radicles.' I differ with the greatest hesitation from so high an authority; but do not see the connection between the store of food being partly laid up in some other part of the plant and the inequality between the cotyledons. Why should it affect one more than the other? I venture to suggest that the difference is due rather to the position of the embryo in the seed, which in some cases favours one cotyledon more than the other. For instance, in many cases the cotyledons are what is called ' incumbent,' that is to say the radicle is folded upon one of the cotyledons, and in such species the outer cotyledon is often rather larger than the other, as for instance in Hesperis matronalis.

The Hemp (Cannabis) and Caylusea present us with cases more or less resembling that of Hesperis. 
In the Mustard (fig. 3), Cabbage, Radish (Raphanus), and some other Crucifers, the difference is more marked, and is
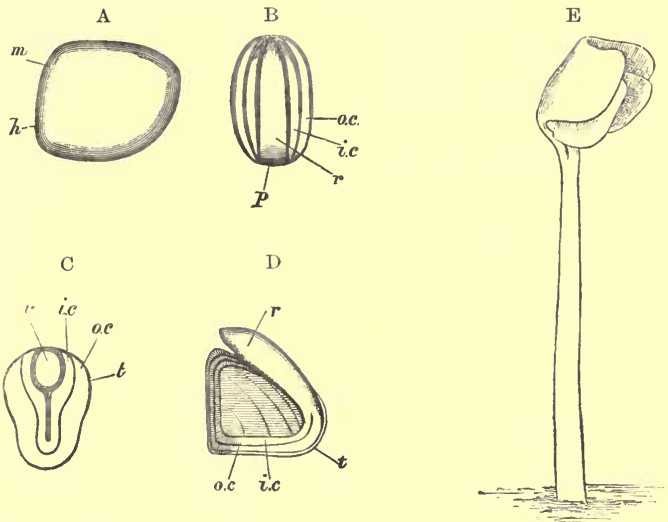

Fig. 62.-Raphunus sativus. A, outline of seed, $\times 4: m$, micropyle; $h$, hilum. B, embryo extracted from seed, $\times 4$. C, embryo, $\times 4$; vertical section. $\mathrm{D}$, embryo, seen from the side, $\times 4$ : o.c, outer cotyledon; i.c, inner cotyledon; $r$, radicle; $t$, testa. $\mathrm{E}$, germinating seedling, $\times 2$, showing the cotyledons still folded.

due to a different cause. The cotyledons, as just mentioned, are applied to one another face to face (fig. 62, B-D), and

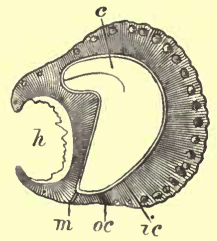

F1G. 63-Cereus Napoleonis. Section of seed: oc, outer coat of testa; $i c$ inner coat of testa
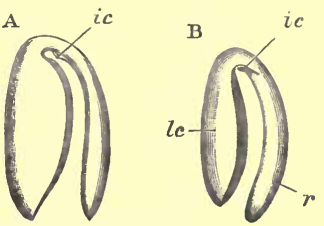

FIG. 64.-A, embryo of Abronia arenaria, $\times 6: i c$, smaller cotyledon. $\mathrm{B}$, embryo of $A$. umbellata, $\times 6: i c$, right and inner cotyledon; $l c$, left cotyledon

then doubled longitudinally one inside the other. The outer one, therefore, having more space, becomes larger and the petiole is longer. In Cereus (fig. 63) the embryo is much 
curved, and the cotyledons being thick and fleshy, the inner one is naturally smaller than the outer.

In Abronia umbellata (fig. 64, B) the embryo is large, much curved or doubled on itself, and lies outside the endosperm, the two edges of the cotyledon reaching almost to the radicle. The second cotyledon (ic) is minute, generally not more than one-seventh the length of the outer one, though in one seed it attained nearly half the length of the other. In another species of the same genus, A. arenaria, the smaller cotyledon is reduced to a mere knob (fig. $64, \mathrm{~A}, i c$ ).
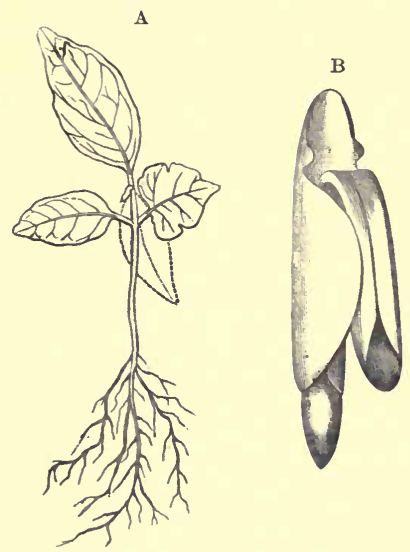

C

D

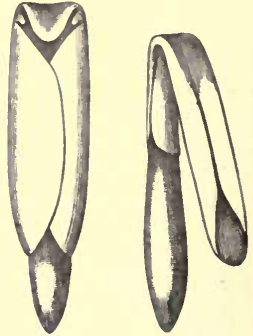

Fic. 65.-Petiveria octandra. A, seedling, half nat. size. B, embryo partly unfolded $\times 6$. C, outer and shorter cotyledon. D, inner and longer cotyledon.

Cases in which one of the cotyledons is rudimentary also occur in the genera Ranunculus, ${ }^{1}$ Carum, ${ }^{2}$ Cyclamen, \&c.

In Petiveria octandra (fig. $65, \mathrm{~A}$ ) the cotyledons are very interesting. The one is about $3 \mathrm{~cm}$. long, $1 \frac{1}{4}$ broad, oblong, tapering at both ends, and entire. The other is shorter and broader, $2 \mathrm{~cm}$. long by $1 \frac{3}{4}$ broad, subcordate, with a large terminal lobe, and one, more or less pronounced, on each side. At first I thought this curious want of symmetry must

1 See Irmisch, Beit. aur vergl. Morphol. der Pflanzen (Halle, 1854).

${ }^{2}$ Hegelmaier, Vergl. Untersuchungen (Stuttgart, 1878). 
be accidental. It is, however, normal, and is explained by the peculiar form and arrangement of the embryo (fig. 65, B-D) in the seed. The fruit is an achene of peculiar form; it is oblong-linear, subcuneate, and laterally compressed, bifid at the apex, and crowned with 2-6 unequal, closely reflexed,

$A$

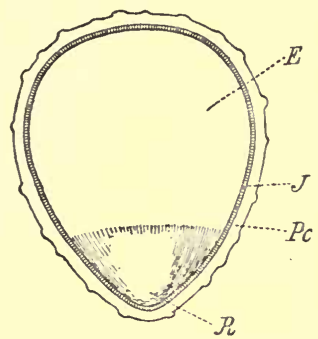

C

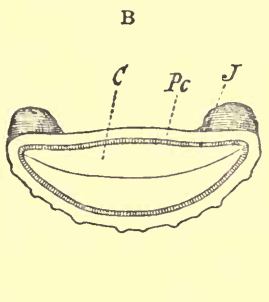

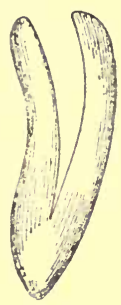

Fig. 66.-Coreopsis Atkinsoniana. A, longitudinal section of echene, $\times 10$. $\mathrm{B}$, transverse section of achene, $\times 10$. C, embryo, $\times 10$.

acute bristles, more or less hairy, one-celled, one-seeded, and indehiscent. The seed is oblong-linear, and tapers somewhat, conforming to the interior of the fruit. The embryo is large; the inner cotyledon is doubled on itself; the outer one is also turned over at the end, and wraps round the narrower one, ${ }^{1}$ not reaching, however, to the narrow end of the seed: the terminal lobe of the shorter and broader cotyledon is the part which is folded over, and the lateral lobes, which are much smaller in the embryo, are also due to the fold, as shown in fig. 65, B-D.

In Coreopsis Atkinsoniana the

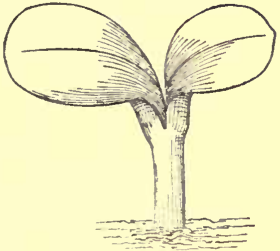

Fig. 67.-Coreopsis Atkinsoniana. Seedling, $\times 10$.

seeds are obovate, curved longitudinally, and compressed dorso-ventrally, conforming to the interior of the fruit. The embryo again is slightly bent, following the direction of the seed. Consequently the one cotyledon occupies the inner,

1 The narrow cotyledon is sometimes absent. 
the other the outer side of the curve; and, as shown in fig. 67, the outer one is distinctly larger than the other.

In Thunbergia reticulata the cotyledons are unequal, ovate, obtuse, slightly emarginate, and cordate at the base. The larger one is slightly denticulated, and has a curious embossed area in the centre; the smaller one is, on the contrary, smooth and entire, or nearly so. The seed is orbicular or oblong; exalbuminous, 3-4 mm. in diameter, compressed, with a cavity on the inner side. The embryo is slightly curved; and the cotyledons lie with their faces towards the hilum, which is very prominent; the inner cotyledon is turned up at the edges, and wraps, to a certain extent, round the outer one. The raised or embossed patch in the centre of this cotyledon is due to the inward curvature of the testa.

\section{Unsymetrical Cotyledons.}

In other cases, as in the Geraniums (fig. 25), Schinus (the False Pepper) (fig. 28), Clitoria (fig. 27), Laburnum (fig. $26)$, Lupines, \&c., there is inequality, not between the two

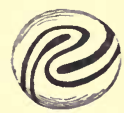

Fig. 68.-Section through embryo of Geranium, showing the mode of folding of the cotyledons.

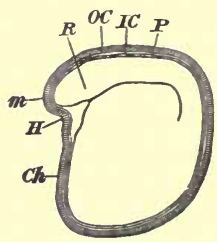

Fig. 69.-Seed of Laburnum vulgare, $\times 6$ : $O C$, outer coat; IC, inner coat.

cotyledons, but between the two halves of each cotyledon. In the Geraniums this is due to the manner in which the cotyledons are folded. In the Cabbage and Mustard we have seen that one cotyledon is folded inside the other; in the Geranium they are convolute (fig. 68), one half of each being folded inside one half of the other-the two inner halves being the smaller, the two outer the larger ones.

In the Laburnum (fig. 26) and in Clitoria (fig. 27), on the 
other hand, the inequality in the two sides of the cotyledon is due to the inequality between the two sides of the seed (fig. 69).

In Heritiera macrophylla the cotyledons fill the seed, which conforms to the shape of the carpels, and the fact that these are somewhat unequal-sided renders the seed and consequently the cotyledons so likewise.

In the Lupines the seeds are obliquely oblong, compressed laterally, and without endosperm, the embryo being large, fleshy, yellowish, and occupying the whole seed. It is doubled on itself, and the cotyledons are folded along the radicle, which nearly equals them in length, with the smaller halves turned towards the radicle, and in such a manner that they and the radicle together occupy one half of the seed, and about equal the larger halves of the cotyledons, which fill the other.

In Triphasia the inequality is due, partly at any rate, to a different cause. The seeds are oval, somewhat flattened, especially on the ventral aspect. The embryo is large, and occupies the whole seed. The cotyledons are very unequal in size, and the smaller one is more or less enclosed in the larger. But, in addition to this, there are often, indeed generally, two and sometimes three embryos in each seed; these differ in size, and the smaller ones often intrude more or less on one of the cotyledons belonging to the larger ones.

\section{Crenate Cotyledons.}

The vast majority of plants have the edges of the cotyledons entire. There are some few, however, in which they are more or less crenate, as for instance in Cordia subcordata (fig. 33).

In this species the embryo occupies the whole of the ovoid-conical seed. There is no FIG. 70.-Embryo of endosperm, and the cotyledons, in order to occupy the whole space, are longitudinally

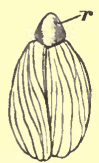
folded (fig. 70), thus giving rise to the crenations on the margin. 
Accumbent and Incumbent Cotylemons.

There are two ways in which the radicle may be bent over the cotyledons.

Sometimes it is turned up over the back of one of the cotyledons, as in figs. 71 and 72 , and is said to be incumbent;

Fig. 71.
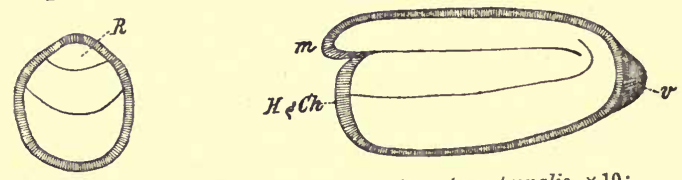

FIGS. 71 and 72.-Sections of seed of Hesperis matronalis, $\times 10$ :

Fig. 72.

$v$, hollow in testa.

while sometimes it is turned along the edge of the cotyledons, as in figs. 73 and 74 , which are then termed accumbent. The divisions of the Cruciferæ are based to some extent on this character, some groups being accumbent and some incumbent. I puzzled for some time over the reasons which could account for this difference, though the explanation

Fig. 74.
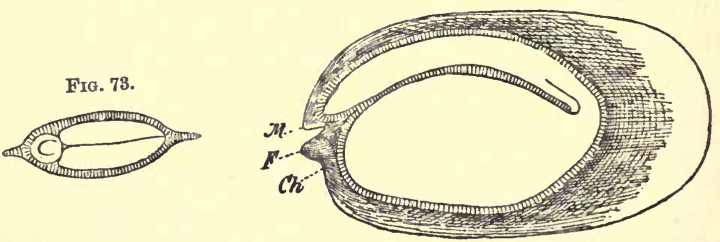

Figs. 73 and 74.-Section of seed of Cheiranthus Cheiri, $\times 10$.

which I would suggest is very simple when once stated. I scarcely feel justified however in doing more than throwing it out as a suggestion.

Seen in section the two forms would be as shown in figs. 71 and 73. Now if from the form of the pods, or for any other reâson, it is an advantage that the seed should be compressed, as in fig. 73, then, the thickness of the cotyledons 
remaining the same, it is better that the radicle should be accumbent; while, on the other hand, in a thicker or globular seed, as in fig. 71, the incumbent arrangement is most convenient. In fact we find that in groups, such as the Arabideæ, where the seeds are as a rule compressed, the radicle is almost always accumbent; while in incumbent groups, such as the Sisymbrieæ, they are, on the contrary, more or less turgid.

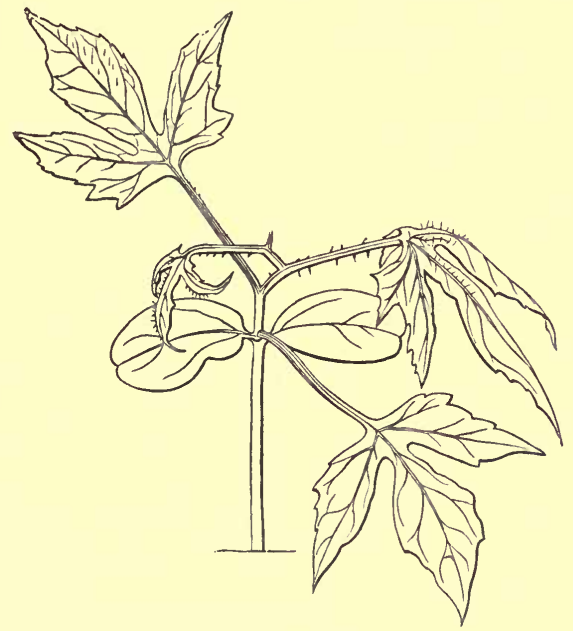

Fig. 75.-Seedling of Bryonia laciniosa. Half nat. size.

As an actual example of an incumbent form I give Hesperis matronalis (figs. 71 and 72), and of an accumbent, Cheiranthus Cheiri (figs. 73 and 74).

\section{Petioles.}

The cotyledons are sometimes sessile, as in Acer (fig. 9), Hippophaë (fig. 14), Hakea (fig. 21), Clitoria (fig. 27); sometimes supported on petioles, which in many cases, as in Microloma (fig. 29), attain a considerable length.

Occasionally we meet with both sessile and petioled coty- 
ledons even within the limits of the same genus. For instance, Delphinium Staphysagria (fig. 31) has the cotyledons sessile, while those of D. elatum (fig. 30) have petioles. In Bryonia laciniosa (fig. 75) the cotyledons are nearly sessile, while those of B. dioica (fig. 76) have petioles.

There is nothing, so far as I know, in the structure of the seed to account for this difference. It is observable, however, that while the cotyledons of Bryonia laciniosa (fig. 75) and those of D. Staphysagria (fig. 31) are raised by the hypocotyl somewhat above the level of the ground, those of Bryonia dioica (fig. 76) and of D. elatum (fig. 30) are attached close to the ground. In fact the cotyledons are carried up in both cases,

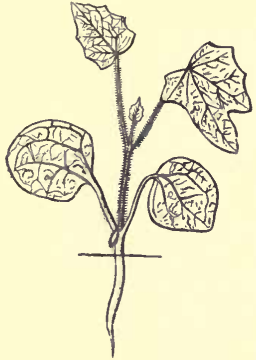

Fig. 76.-Seedling of Bryonia dioica. Nat. size. but in B. laciniosa and D. Staphysagria by the hypocotyledonary portion of the axis or stalk of the plant, in B. dioica and in D. elatum, on the other hand, by their own petioles.

I may also refer to Vitis hypoglauca and V. cebennensis, the former with a short hypocotyl and long petioles, the latter with a long hypocotyl and short petioles.

In short, we may say that the cotyledons are, as a general rule, sessile when they are raised by the growth of the hypocotyl, while they are petiolate when they take their origin close to the ground. There are, no doubt, some exceptions; for instance, in some species of Hedysarum the cotyledons are radical and yet sessile. I have, however, often in Algeria seen seedlings of this group in hot exposed situations, where they 'held the field' alone, and being sure of ample heat and light did not require to be raised above the surface.

The opposite exception is perhaps more common-i.e. when the cotyledons, though raised, are still petiolate. Here, however, the cotyledons are probably petiolate for the same reason as the leaves-viz., when the foliage is large, leaf-stalks are an advantage in carrying the lower leaves out of the shadow of those immediately above them. 
In another species of Delphinium (D. nudicaule) (fig. 32) the cotyledons are raised well above the surface of the ground on a stem consisting of their own two stalks or petioles, which are connate, though readily separable from one another. Connate cotyledons also occur in Phlomis tuberosa, Smyrnium perfoliatum (fig. 77), Polygonum Bistorta, ${ }^{1}$ \&c. Gray ${ }^{2}$ observes that the economy of this arrangement is not apparent. Assuming, however, that the elevation of the cotyledons is an advantage, perhaps, as I have suggested, from carrying

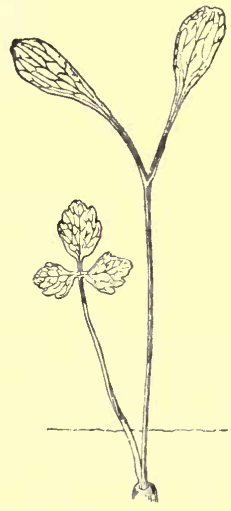

Frg. 77.-Seedling of Smyrnium perfoliatum. Half nat. size

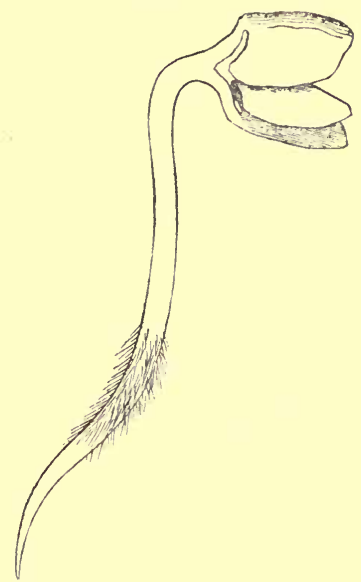

FIG. 78.-Germinating seedling of Geranium bohemicum, $\times 6$.

them above the surrounding herbage, the combination of the two petioles-reversing the old fable of the bundle of stickswould, with the same amount of material, give a considerable addition of strength.

For instance, in Smyrnium perfoliatum (fig. 77) the hypocotyl is undeveloped, the cotyledons are oblong-elliptic, emarginate, obtuse, generally unequal-sided or subfalcate, with long petioles, 3-nerved from the base, and finely reticulate,

1 Winkler, 'Ueber die Keimblätter der deutschen Dicotylen,' Bot. Verh. Brandenburg, 1874.

2 Structural Botany, p. 21. 
connate into one terete piece for $55-75 \mathrm{~mm}$. of their length, split a little way at the base to allow the plumule to emerge, free in the upper part, semiterete and slightly channelled above.

In this case it is obvious that if the petioles had been separate, they would have been far too weak to stand upright, and their length therefore would have been comparatively useless.

In Polygonum polystachyum, again, the petioles are connate and form a hollow tube through which the leaves pass ; so that the seedling has the appearance of possessing an erect hypocotyl with nearly sessile cotyledons.

In other cases, however, the existence of petioles apparently has reference to the arrangement of the embryo in the seed.

In the Geraniums, for instance, as has been already mentioned, the cotyledons are folded on themselves, one half of each lying within the other. Fig. 78 represents an embryo partially unfolded, and it will be seen that in the position assumed by the cotyledons the petioles are necessarily as long as half their breadth. In Eucalyptus Globulus, again (fig. 90), the mode of folding of the cotyledons would be impossible but for the petioles.

Lastly, in cases where the cotyledons do not leave the seed, the petioles leave room for the free growth of the plumule, as in Sapindus (fig. 43).

\section{Lobed Cotyledons.}

The great majority of cotyledons are entire, but some are more or less lobed. For instance, those of the Mallow (fig. 35) are broadly ovate, minutely emarginate, cordate at the base, and three-lobed or -angled towards the apex, with three veins, each running into one of the lobes.

Those of Lavatera and Althæa are similar. The embryo is green, curved, and occupies a great part of the seed. The cotyledons are applied face to face; then, as growth continues, the tip becomes curved, and depressed into a median longitudinal furrow, the fold of the one lying in that of the other. 
The embryo is of the form shown in fig. 79 : the horn or process $r$ is the radicle; the rest is the cotyledon, of which the free end $f$ is folded on itself and turned downwards. In this way the embryo fills the seed, leaving a small space between the cotyledons and also between $f$ and $r$ which is occupied by endosperm. Perhaps it may make the arrangement clearer to take a piece of note-paper, cut it into the form of an egg (fig. 80), turn the broad portion $a b$ downwards, so that the parts $a$ and $b$ have their under faces turned to one another, and then press down the line $e f$, and bring the points $c$ and $d$ together, so that $c e f$ and $d e f$ have their

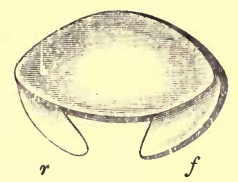

Fig. 79.-Embryo of Mallow. Enlarged.

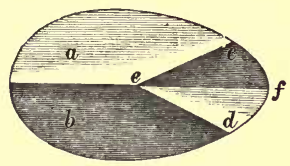

Fig. 80.

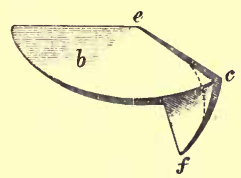

Fic. 81.

Figs. 80 and 81.-Piece of paper prepared to show the mode and effect of the folding of the embryo.

upper surfaces together, and the apex $f$ pointing downwards. We shall then have an object shaped as in fig. 81, with a sharp point at $c$, which would not conform to the rounded shape of the seed. If, now, to make it do so, we cut off the point $c$ along the dotted line and then unfold the paper, we shall find that it has the form of the cotyledon of Malva (fig. 35) with a bay or notch on each side. In Erodium the arrangement is somewhat similar, and it seems clear that the lobes are due to the manner in which the embryo is folded.

In Enothera and some allied species the cotyledons also present a terminal lobe. This, however, is not due to folding. 
The terminal lobe is the original cotyledon, and the basal portion is altogether subsequent growth, which, moreover, to some extent, assumes the character of the true leaf. I shall presently refer to this interesting group in more detail.

The case of Petiveria octandra (fig. 66) has been already described.

\section{Emarginate Cotyledons.}

In a great many species the cotyledons are emarginate, and even in some more or less deeply bifid. No explanation of this has, so far as I know, yet been offered. It is, in fact, as I shall hope to show, by no means always due to the same cause.
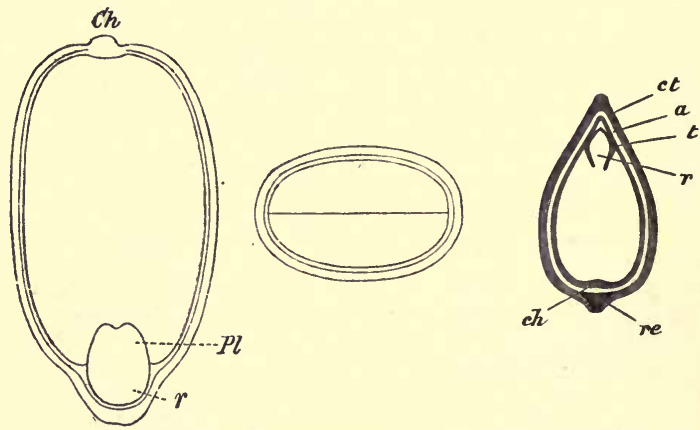

Frg. 82.-Longitudinal and transverse sections Frg. 88.-Longitudinal section of seed of Impatiens parviflora $\times 10: P l$, plumule.

of Poterium Sanguisorba, $\times 9$ : $c t$, calyx-tube; $a$, achene; $r e$, receptacle.

One of the simplest cases is that of the Oak, where the thick fleshy embryo occupies the whole of the seed. The chalaza is situated at the centre of one end, at the extremity of the cotyledons, and the walls of the seed being at that point somewhat thickened, the cotyledons are slightly pressed in. The same explanation applies to various other species, as, for instance, to the Impatiens (figs. 12 and 82), Poterium (figs. 42 and 83), Cuphea (fig. 84), and Nettle (Urtica) (fig. 85).

In Helianthus Cucumis the seed itself is slightly notched 
at the point where it articulates with the receptacle; and the cotyledons, which, with the rest of the embryo, eventually occupy the whole interior of the seed, conform to this notch.

In such cases as the Mustard (fig. 3), Cabbage, and Radish, the emargination is due to a totally different cause. The seed (fig. 62, A) is oblong, thick, and slightly narrower at one end than the other. There is no endosperm, so that the embryo occupies the whole seed, and as this is somewhat deep, the cotyledons, in order to occupy the whole space, are folded and arranged one over the other, like two sheets of note-paper, as shown in fig. $62, \mathrm{~B}-\mathrm{E}$, the radicle being folded along the edge.
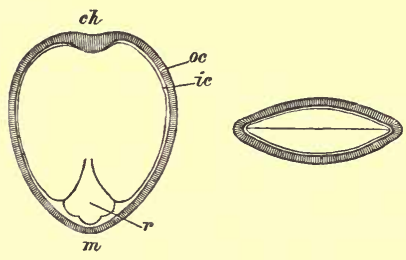

FIG. 84.-Longitudinal and transverse sections of seed of Cuphea silenoides, $\times 10: o c$, outer coat; $i c$, inner coat.

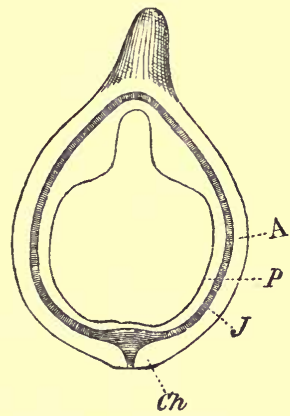

FIG. 85.-Achene of Nettle

(Urtica dioica), $\times 30$ : $J$, testa.

Fig. 62, D, represents the embryo a little opened out; and fig. $62, \mathrm{C}$, a section showing the radicle and the outer and inner cotyledons. To this folding the emargination is due. If a piece of paper be taken, folded on itself, cut into the form shown in fig. 62, A, with the fold along the edge from $m$ to $h$, and then unfolded, the reason for the form of the cotyledon becomes clear at once. Zilla myagroides affords a similar case.

But it may be said that in the Wallflower the seed has a similar outline, and yet (fig. 86) the cotyledons are not emarginate. The reason of this is that in the Wallflower (Cheiranthus) (figs. 73, 74) the seed is more compressed than in the Mustard and Radish (fig. 62, B, C), and the cotyledons 
are not folded; so that the whole, not the half, of each cotyledon corresponds to the form of the seed.

In the Bignoniaceæ, again, a large number of species have emarginate cotyledons; and this would appear also, as for instance in Pithecoctenium Aubletii, to

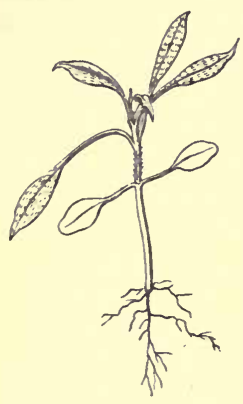

Fro. 86.-Seedling of Cheiranthus Cheiri. Two-thirds nat. size. be due to the chalaza, though in a different manner. The seeds themselves are transversely oblong, much compressed dorsally, surrounded on all sides except the base by an extremely thin, transparent, membranous wing, which is traversed by nerves radiating from the central part of the testa, and is uneven at the margin. The raphe is ventral, extending from the hilum to the centre of the embryo. The chalaza is attached to the embryosac a little above the middle of the embryo. The radicle is very small, distant from, but pointing to, the hilum. The embryo is straight and flat; the cotyledons grow until they come to the point of attachment of the chalaza, when they extend forwards on each side, forming two lobes.

In Oroxylum indicum the general structure of the seed is very similar, but the growth of the two lobes of the cotyledons is even more luxuriant, so that they actually overlap. A structure more or less similar occurs in other genera of this family.

The emargination is very much deeper in other groups, and due to other conditions, for instance in the Convolvulaceæ. In Convolvulus Soldanella (fig. 87) the embryo, which is eventually very large, lies at first straight in the seed embedded in a clear jelly-like endosperm, and rests on a solid ovate, grooved, white ridge (fig. $87, \mathrm{~B}$ and $\mathrm{C}, a$ ), which rises from close to the micropyle. This tongue-like ridge grows with the embryo. At the opposite end of the seed the raphe and chalaza form a somewhat prominent ridge (b) projecting into the endosperm. The cotyledons in this stage are planoconvex, applied face to face, orbicular, entire, green, with 
distinct petioles, 5-nerved, with two lateral, subopposite branches from the midrib some distance below the apex. The plumule and radicle are small. The cotyledons gradually increase in size and grow over the process in which the radicle $(a)$ lies, extending to the apex of the seed, doubling over and abutting against the ridge formed by the raphe and

A

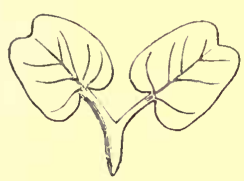

B

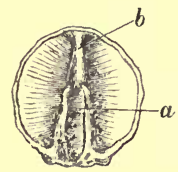

C

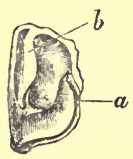

Fig. 87.-Convolvulus Soldanella. A, embryo, $\times 2$. B, section of seed after removul of the dorsal surface, embryo, and endosperm, $\times 2 . \mathrm{C}$, side view of ditto, $\times 2$.

chalaza $(b)$, and thus becoming more and more emarginate at the apex. The notch is therefore due to their continuing to grow at the sides after their apex has reached this ridge.

In Ipomœa purpurea (fig. 88, A-C), where the seed is constructed generally on the same model as in Convolvulus

A

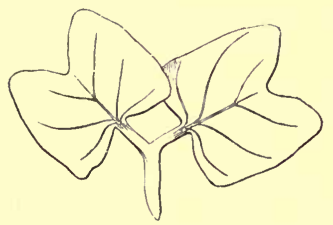

B

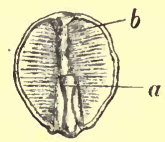

C

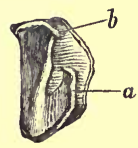

FIG. 88.-Ipomcea purpurea. A, embryo, $\times 2 . \quad$ B, section of seed after removal of dorsal surface, embryo, and endosperm, $\times 2$. C, side view of ditto, $\times \mathbf{2}$.

Soldanella, the ridge formed by the raphe and chalaza (fig. $88, \mathrm{~B}$ and $\mathrm{C}, b$ ), is more prominent, and consequently the notch of the cotyledon is deeper. Lastly, in Ipomœa dasysperma (fig. 89, A-C) the projecting ridge of the chalaza is still more developed and reaches nearly to the process which supports the radicle; the cotyledons are thus precluded from 
growing in length, and in consequence send out two long wings, so that they are divided almost to the base (fig. 89, A).

In Shorea, again, the division of the cotyledons is perhaps due to an internal process of the seed. I have not, however, had an opportunity of examining a specimen.

In Eucalyptus (fig. 38) we have a different case. The

B

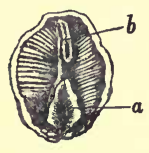

C

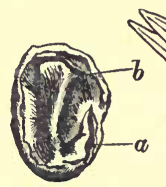

A

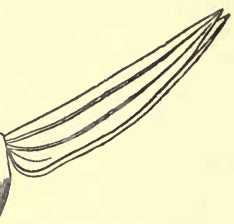

FIG. 89.-Ipomaea dasysperma. A, embryo, $\times 2 . \quad$ B, section of seed after removal of dorsal surface, embryo, and endosperm, $\times 2$. C, side view of ditto, $\times 2$.

embryo is (with the exception of the petioles) straight or nearly so, fleshy, white, occupying the whole of the seed, and conforming to it in general outline; the cotyledons are deflexed and convolute round the radicle, which the lobes equal in length, while half of one cotyledon lies over half the other; one half of each consequently lying against the testa.

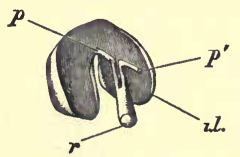

Fic. 90.-Embryo of Eucalyptus Globulus, one cotyledon being cut away : $p$, petiole; $p^{\prime}$, cut end of petiole; i.l, inner lobe of cotyledon. $\times 4$.

The radicle is stout, fleshy, truncate at the end where it lies against the testa, but otherwise entirely enclosed by the folded cotyledons. The true length of the cotyledon is determined by the distance between the end of the petiole and the opposite pole of the seed. The side of the cotyledons, however, being folded back, that part which lies beyond the petioles is enabled by folding round the radicle to widen, and this consequently gives the cotyledons their more or less pronounced hour-glass shape.

Moreover, in speaking of emarginate cotyledons, we must distinguish between two very opposite cases, of which I may take Galium Aparine and Enothera Lindleyana as illustre- 
In Senecio, again, the majority of species have entire cotyledons. In some, however, as in S. erucæfolius, they are emarginate. Even here, however, they are at first entire (fig. 93), and the emargination does not make its appearance until after germination, when the cotyledons gradually become much widened (fig. 94). In fact, S. squalidus, S. viscosus, S. vulgaris, \&c. have the cotyledons narrow and entire; while in S. erucæfolius and S. cruentus, where they grow more in width than in length, they become emarginate. Among other cases where the cotyledons are at first entire, but after germination become emarginate, may be mentioned some species of Lithospermum.

Bryonia laciniosa (fig. 75) also has the cotyledons emarginate, while in B. dioica (fig. 76) they are entire. They are, however, originally entire in botb cases, and the emargination in B. laciniosa is due to the fact that in that species

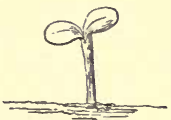

Fig. 93.-Young seedling of Senecio erucafolius.

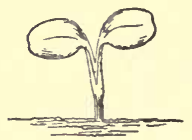

Frg. 94.-Ditto, a few days older.

the cotyledons grow much more than in B. dioica. There is no great difference in size between the seeds, those of $B$. laciniosa being perhaps one-tenth larger. On the other hand, the cotyledons of $B$. laciniosa attain a length three times greater than those of B. dioica, as shown in the figures (figs. 75 and 76 ). In the genus Tacsonia, again, the cotyledons are entire in T. Van-Volxemi and T. Leschenaultii, and emarginate in T. ignea. Here also, however, they are at first entire, and only become emarginate after leaving the seed.

\section{Divided Cotyledons.}

The genus Pterocarya has very curious cotyledons (fig. 41), due to a cause entirely different from any of those we have considered hitherto.

They are bipartite, each primary division narrowing to a 
cuneate base, and being again deeply divided, so as to make in all four ultimate, linear, oblong, obtuse, entire segments. In this case the endocarp is thickened, bony, and its cavity is divided at the base into four cells (fig. 95, A, $c$ c $c$ c ) by the thickening and consequent intrusion of the dorsal and ventral walls.

The seed (fig. 95, B) is conical above, deeply four-lobed below (fig. 95, B, $l l l l$ ), one lobe $(l)$ passing into each of these cells (c). The embryo again follows suit, and each cotyledon sends a lobe into each of the four cells, thus assuming the peculiar form characteristic of the species.

In Eschscholtzia (fig. 40) the cotyledons are deeply bifid, resembling a hay-fork with two long prongs. In this case we find no such structure of the fruit or seed to account for the

A

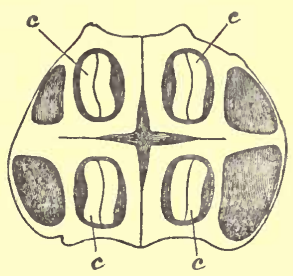

Fig. 95.-Ptcrocarya caucasica. A, transverse section of nut, $\times 6$; showing the four hollows $c, c, c, c$, which are occupied by the four prolongations of the seed. $\mathrm{B}$, seed, $\times 6$.

peculiarity. My first idea was that such cases might possibly be due to some difference in the endosperm, as occurs in certain Umbellifers, Delphinium, \&c., and which might have permitted growth more readily in certain directions than in others. Thin sections, however, showed no such differences. Moreover, Schizopetalon Walkeri (one of the Cruciferæ) (fig. 97, A-D) has the cotyledons as deeply divided as in Eschscholtzia; and as there is no endosperm, but the embryo occupies the whole seed, within which the long lobes of the cotyledons wind about more or less irregularly, the division cannot be due to differences in the endosperm. There are, moreover, other plants, such as the Sycamore (fig. 50) and Hop, where the cotyledons are also narrow, winding, and occupy the whole seed, but are not divided. We must there- 
fore seek some other explanation, and I will suggest the following.

In most of the species which I have examined, when the cotyledons remain in the seed they do not leave the ground.

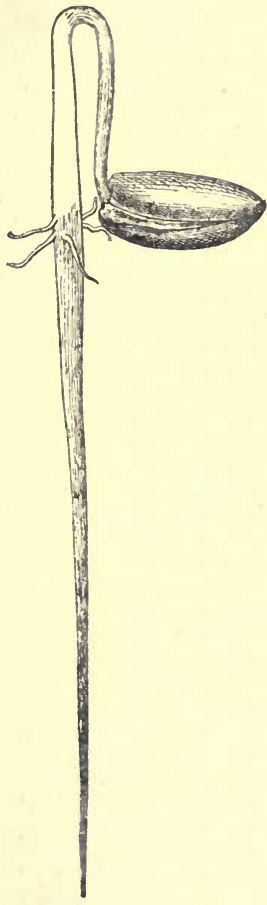

FIG. 96.-Germinating seedling of Anona.

In some cases, however, as in Anona (fig.96), the hypocotyl is long, stout, and rises in the form of a loop during germination, while the cotyledons, which at first are very small, gradually increase almost to the length and breadth of the seed, throw themselves into undulations, and, it being perhaps on this account impossible to withdraw themselves from the seed, are eventually torn from the hypocotyl. In Bignonia insignis, again, the cotyledons, though flat and leaf-like, are unable to emerge from, or at any rate do not emerge from, the seed. This may possibly give us a clue to such cases as Eschscholtzia and Schizopetalon, which, I would venture to suggest, may have reference to the manner in which the cotyledons free themselves from the seed. If this is delayed, the young plant suffers considerably, and indeed often perishes. That the process is not, however, so simple as might be imagined, may be seen from the interesting case afforded by the Cucurbitaceæ, where, in Mr. Darwin's words, ${ }^{1}$ 'the seed-coats are ruptured by a curious contrivance, described by $\mathbf{M}$. Flahaut. A keel or peg is developed on one side of the summit of the radicle or base of the hypocotyl; and this holds down the lower half of the seed-coats (the radicle being fixed into

1 Movements of Plants, p. 102. Bower has pointed out in Welwitschia that a corresponding process serves to absorb the endosperm, acting in fact as a feeder to the young plant (Quart. Journ. Micr. Sci. vol. xxi.). 
the ground), whilst the continued growth of the arched hypocotyl forces upwards the upper half, and tears asunder the seed-coats at one end, and the cotyledons are then easily withdrawn.'

May not the narrowness of the cotyledons in Eschscholtzia and their deep fission be due to a similar cause? The seed is slightly pyriform, and the radicle emerges from the narrower end. It bursts through the soil in an arch, and instead of

A
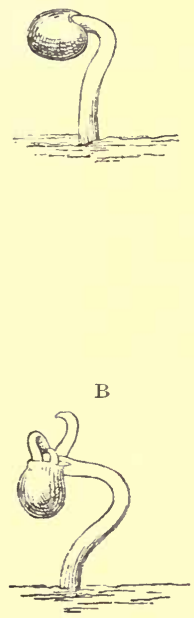

D

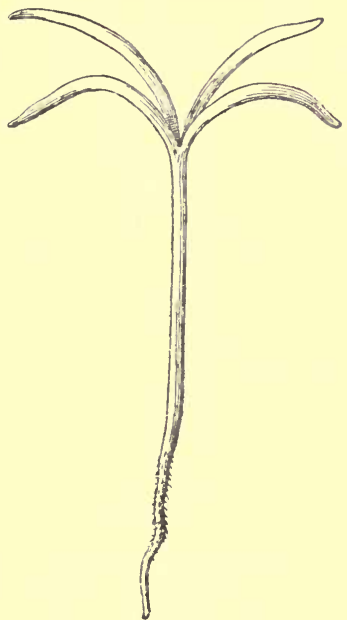

Fig. 97.-Stages in the growth of seedling of Schizopetalon Walkeri, $\times 2 \frac{1}{2}$ -

leaving the seed-coats in the earth as usual, carries them up with it. Then the two arms of the cotyledons separate, widen the orifice, and draw themselves out.

This suggestion seems to be confirmed by the evidence of Schizopetalon (fig. 97, A-D), one of the other few cases where the cotyledons are bipartite. Here, also, the radicle emerges through a comparatively small orifice, and the seed-coats, from which the cotyledons seem to have some difficulty in freeing themselves, are carried up by the hypocotyl, while eventually 
the lobes of the cotyledons draw themselves out one by one. In Opuntia basilaris, again, which differs from O. Labourtiana in having narrow cotyledons, the seed-coats are similarly carried up, and the cotyledons free themselves by divergence. In this species, also, it is interesting that one or both cotyledons are often bifid. Is it possible that the multiplicity of the cotyledons in Conifers (fig. 98) can be due to the same cause?

In Ephedra there is a special membrane, which remains attached to the root, and thus prevents the testa from being carried up on the tips of the cotyledons.

The common Cress (Lepidium sativum) (fig. 4), to which I have already referred, is a very interesting case, for while in

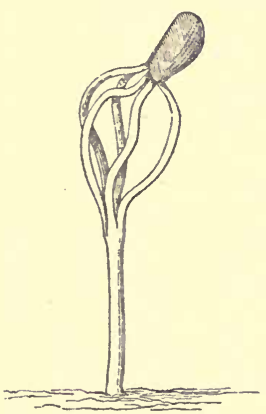

Fra. 98.-Seedling of Pinus rigida, $\times \mathbf{2}$.

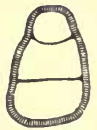

FIG. 99.-Section of seed of Lepidium graminifolium, $\times 15$.

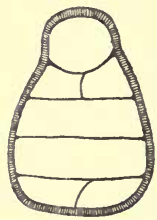

Frg. 100.-Section of seed of L. sativum, $\times 15$.

the other species, at any rate in the other English species, of the genus the cotyledons are entire, in Lepidium sativum, on the contrary, each possesses two long, narrow lateral lobes.

Fig. 99 represents a section through the seed of L. graminifolium, which may be taken as representing the ordinary arrangement in the genus. The seeds, conforming to the shape of the capsule, are somewhat triangular, with the radicle in the narrow end. The embryo occupies the whole of the seed, there being no endosperm. In L. sativum (fig. 100) the seed is of the same form, but nearly twice as large, and if, therefore, the cotyledons were to occupy the whole additional 
space, they would become extremely thick. In endospermic seeds this would present no difficulty, as the additional space would be simply filled by endosperm. In Lepidium, however, this device cannot be resorted to; but the two lobes just fill up the vacancy.

In the Lime (Tilia) (fig. 101) we have another very interesting case.

The cotyledons are broad, foliaceous, rhomboid-subtriangular, and 5-lobed, 5-nerved at the base, with the outer and lower pair of nerves slender, alternately nerved upwards, reticulate, shining and thinly pubescent on both surfaces, deep green above, paler beneath, petiolate; lobes oblong-obtuse, with a strong nerve running into each, the outer ones always largest and sometimes ovate; middle pair of lobes always the smallest, and oblong or subulate; lamina 15-21 mm. long, 17-25 mm. from tip to tip of the basal pair of lobes; petiole semiterete, shallowly channelled above, pubescent, 6-8 $\mathrm{mm}$. long.

The fruit is an ovoid

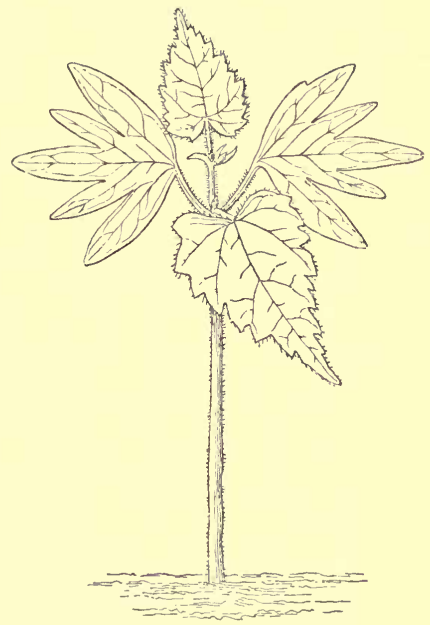

Fra. 101.-Tilia vulgaris. Seedling. Nat. size.

or subglobose nut, with five obtuse angles, tomentose with somewhat rufous hairs, one-celled by the rupture of the septa, one-seeded, indehiscent, tipped with the persistent base of the style, woody, and attached to a large deciduous bract which serves to disseminate it by the aid of the wind.

The seed is ascending or erect, obovoid or subglobose, deep brown, smooth, with a firm or crustaceous testa of two distinct layers; hilum oval, comparatively large on the ventral aspect 
a little above the base, and longitudinal ; raphe ventral, proceeding from the hilum to the apex of the seed; chalaza apical, prominent externally as well as internally in the mature state by a deeper brown blotch; radicle inferior.

The endosperm in the mature seed is copious, firm, pale yellow, and homogeneous. There is therefore so far nothing in any way analogous to the causes which have led to the existence of the lobes in the species previously described.

The embryo is at first straight; the radicle is stout and obtuse; the cotyledons ovate, obtuse, plano-convex, fleshy, pale green, and applied face to face. They grow, however, considerably; and when (fig. 102, A) they meet the wall of the

A

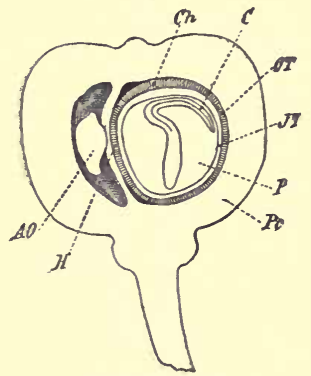

Fra. 102.-Tilia.
B

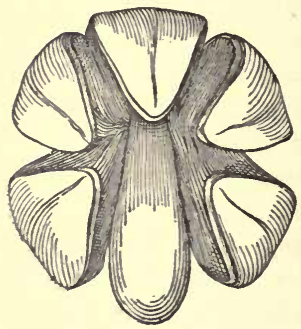

A, section of seed, $\times 4$. B, embryo, $\times 8$.

seed they bend back on themselves, and then curve round, following the general outline of the seed (fig. 102, B). If any one will take a eommon tea-cup and try to place in it a sheet of paper, the paper will of course be thrown into ridges. If these ridges be removed and so much left as will lie smoothly inside the cup, it will be found that the paper has been cut into lobes more or less resembling those of the cotyledons of Tilia. Or if, conversely, a pieee of paper be eut out into lobes resembling those of the cotyledons, it will be found that the paper will fit the concarity of the cup. The case is almost like that of our own hand, which can be opened and closed conveniently owing to the division of the five fingers.

It may be said that the seed of the Sycamore (Acer) is not 
very dissimilar in form to that of the Lime (Tilia); and yet the cotyledons are long, narrow, and strap-shaped, while those of the Lime are rhomboid and five-lobed; but it must be remembered that in the Sycamore the embryo occupies the whole seed, while in the Lime it is embedded in endosperm.

The peculiar lobed form of the cotyledons of Tilia thus enables them, I would suggest, to lie conveniently in the globose seed.

\section{Auricled Cotyledons.}

Some cotyledons are markedly auricled. As illustrations I give Poterium (fig. 42) and Hakea (fig. 21). This form is, I am disposed to suggest, a provision to fill up vacant space in the seed. In the seed of Hippophaë (fig. 53) the form of the cotyledon leaves at each side of its base two spaces $(d)$, which are occupied by endosperm. In Cuphea (fig. 84), Ruellia (fig. 55), and Poterium (fig. 83), on the other hand, there is no endosperm, and it is consequently an advantage that the cotyledon should develop auricles in order to fill up the space.

If this is the explanation of the auricles, we should expect to find them developed principally in families where the endosperm is deficient. Now in the species I have examined, auricled cotyledons occur in 35 genera, belonging to 22 families, of which 13 have no endosperm, while in 6 of the 9 others it is reduced almost to a film.

The argument in the case of Cuphea is further strengthened by the pecu-

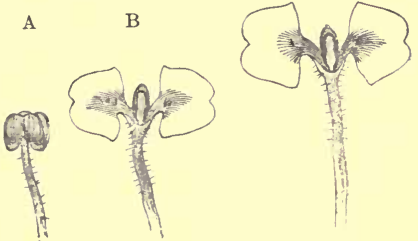

Fig. 103.-Three stages in the growth of the seedling of Cuphea silenoides. liar conformation of the radicle (fig. 84), which is threelobed, the reason being, I would suggest, that the radicle cooperates with the cotyledons in the endeavour to fill up the vacant spaces.

In support of this view I also would observe that the 
auricles seem to be of little use to the young plant. For instance, the embryo of Cuphea, while in the seed (fig. 84) has very large auricles, which in the seedling (fig. 103, A-C) soon disappear. In Ruellia, again (fig. 55), we have a similar case.

\section{Size of Seeds.}

As regards the size of seeds, if we could imagine a state of things in which every seed grew and attained maturity, then to keep up the number of any given species existing at any time, it would be sufficient if each plant produced but one or two seeds during its whole life. There is, however, an enormous destruction of seeds. The great majority are eaten by animals, or fail to secure a suitable site for germination ; of those which do germinate, again, many are crowded out by their fellows. Darwin observed that out of 357 seedlings which came up in a space of 3 feet by 2 , no less than 295 were destroyed by slugs and insects. Now the greater the chance against any given seed reaching a suitable locality and attaining maturity, the larger number of seeds must the plant produce in order to maintain its numbers, and, as a general rule, the smaller will the individual seeds be. On the contrary, the greater the chance that each seed enjoys of arriving at maturity, the smaller the number of seeds that is necessary, and in such cases it is an advantage that the seeds should be large.

Hence parasitic plants generally produce a large number of very small seeds, though there are exceptions due to other considerations, as, for instance, in the Mistletoe ( $\mathrm{I}$ believe, indeed, in all the Loranthaceæ), where the seeds are carried by birds.

An interesting illustration is afforded by certain species which produce two kinds of pods, as, for instance, Cardamine chenopodifolia of Brazil. Besides ordinary pods, which resemble those of any other Cardamine, and contain several seeds, this plant produces a second sort of pod underground. Now in the ordinary pods the number of seeds increases, of course, the chance that some one will find a suitable place. On the other hand, the subterranean pods are sown, as it were, 
by the plant itself. In this case, if there were a number of seeds they would only get in one another's way, and hence, perhaps, the fact that the subterranean pods only produce one or two seeds.

In most species the seeds vary somewhat in size; but in such cases it would not be conclusive to contrast the produce of large seeds with that of smaller ones, because it might fairly be said that the former were better nourished, and inherently, perhaps, more vigorous. In Cardamine chenopodifolia of Brazil, however, the seeds from the underground pods are larger than the others, and Grisebach found that they produced more vigorous seedlings. ${ }^{1}$

There are, on the contrary, other considerations which may make it an advantage that the number of seeds produced by a flower should be reduced, as, for instance, in the case of the Compositæ, where the agglomeration of a number of flowers into a single head, as in the Daisy, and their consequent diminution in size, renders it an advantage that each floret should produce but one seed.

The species with large seeds may, as already mentioned, be divided into two groups-first, those in which the embryo is surrounded by endosperm ; and, secondly, those in which it occupies the whole seed.

In the former the arrangement of the embryo presents no special difficulties, as the endosperm simply fills up all vacant spaces. In the latter, on the contrary, Nature has to exercise much ingenuity, and adopts various devices to fill up the whole space.

One plan is to arrange the cotyledons face to face, and then roll them up in a ball. This is adopted, amongst other eases, in the Sycamore (fig. 50), and hence the long strap-like form of the cotyledons. Another is to arrange the cotyledons face to face, and then double them up, as in the Cabbage, Mustard, Radish (fig. 62, B-D), \&c.

In a third the cotyledons are convolute edgeways, as in Calycanthus.

In Lepidium sativum the cotyledons are trifid (figs. 4 and

1 'Der Dimorphismus der Fortpfl. v. Cardamine chenopodifolia,' Göttinger Nachrichtungen, 1878. 
100); in Cordia they are thrown into plaits (fig. 70). In. others we have still more complex folds, as in the Beech.

In such cases as the Lupine the cotyledons become so fleshy and thickened that they almost lose the appearance of leaves; in this instance they are set free by the splitting of the testa. When, however, the testa does not readily split, and where in large seeds there is no endosperm, the difficulty of unfolding the cotyledons and extricating them from the seed becomes greater, and we arrive at cases where Nature seems to have abandoned the attempt, and, as in the Oak and Horse Chestnut, the cotyledons never quit the seed. Thus, among the Juglandeæ, Pterocarya has leaf-like cotyledons, while those of the Walnut never quit the shell. Every one, however, must have observed the elaborate folds into which the two cotyledons are thrown-folds which seem to have no significance or importance now, and which carry us back to a time when the Walnut, like the Pterocarya, had foliaceous cotyledons.

If these suggestions be correct, we should expect that species with non-emerging cotyledons would generally have large seeds and be exalbuminous. This certainly appears to be the rule; among the species with reference to which I have notes, there are 37 genera in which the cotyledons are subterranean or remain in the seed. The seeds themselves are notably large, and all but three are exalbuminous. Occasionally we meet with subterranean and foliaceous cotyledons in the same genus, as, for instance, in Rhus, Rhamnus, Mercurialis, ${ }^{1}$ Phaseolus, \&c.

Phaseolus vulgaris presents us with an intermediate stage, the cotyledons being aerial and green, but fleshy and by no means true leaves. In Melittis melissophyllum, again, according to Irmisch, ${ }^{2}$ the fleshy cotyledons generally remain in the seed, and are held together by the testa : but they sometimes burst the shell, and stand out from one another. Like true subterranean cotyledons, they have no stomata.

When the cotyledons are large, thick, and fleshy they often contain sufficient nourishment to render the plants for

1 Winkler, F'lora, 1880, p. 339.

2 'Zur Naturgeschichte von Melittis Melissophyllum,' Bot. Zeit. 1858, p. 233. 
some time independent of any fresh supply. In such cases the seedlings sometimes push up for awhile without any fullydeveloped leaves, the first few being reduced to very small size or almost obsolete, as in Rhus (fig. 44), Sapindus (fig. 43), Tropæolum, Bertholletia, Camellia, Xanthochymus, Calophyllum, Calodendron, Ochna, Citrus, Corylus, \&c.

\section{Size of Embryo.}

As already mentioned, there are many cases, in fact many whole orders, in which the ripe seed is entirely occupied by the embryo ; in other cases, again, as in Delphinium (fig. 104), the embryo is very small, and examples of every intermediate stage might be given.
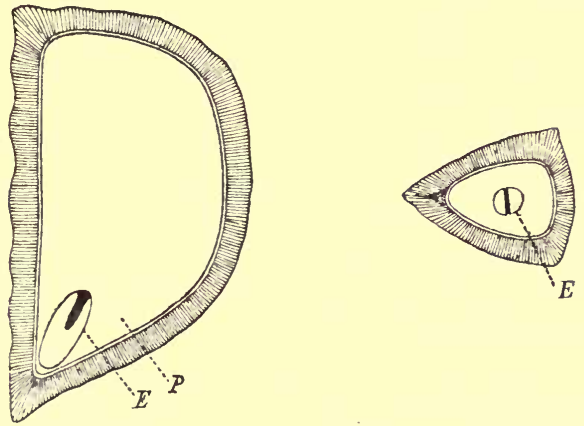

FIg. 104.-Longitudinal and transverse sections of seed of Delphinium Staphysagria, $\times 12$.

Where it is an advantage to the plant that germination should be rapid, this of course can be more readily secured if the embryo is large. In fact, we find that species with large embryos, such, for instance, as Cabbage, Pea, \&c., germinate much more rapidly than those, such as Umbellifers, Ranunculaceæ, \&c., in which the embryos are small.

On the other hand, in some cases, time is less important, and here other considerations come into play. The protection of the embryo is mainly effected by the outer coverings; but 
the endosperm itself contributes also, ${ }^{1}$ and hence a small embryo is less liable to injury.

\section{Size of Cotyledons.}

It is hardly necessary to say that the size of the plant does not determine that of the cotyledons. Winkler has pointed out that the largest of our Nettles has the smallest cotyledons. ${ }^{2}$ It is, on the other hand, natural that large seeds, as a general rule, produce large cotyledons. This is, however, by no means a complete explanation. There are many cases in which the cotyledons grow considerably after quitting the seed. In the wonderful genus Welwitschia it was at one time supposed that the two great leaves were persistent cotyledons. This view is now abandoned. In many of the Monocotyledons, however, the cotyledons acquire a considerable length. I have already had occasion to allude to cases among the Dicotyledons in which the cotyledon continues to grow for some time after quitting the seed.

Streptocarpus Rexii affords, perhaps, the most remarkable case. The cotyledons are at first small, rotund, and shortly petiolate. Soon, however, one of them begins to grow, and becomes an at first ovate, then oblong, and finally panduri-

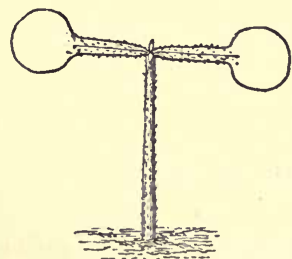

Fig. 105,-Seedling of Enothera bistorta, $\times 3$. form, obtuse, entire, persistent leaf, attaining a length of more than 18 inches. The other cotyledon retains the original form, and soon drops off. In some specimens, however, both cotyledons retain their original form, and it is the first true leaf which develops.

In the cultivated form of the Mango, the cotyledons are divided into more or less irregular lobes; and in a specimen kindly given me by Mr. Ridley, one of the lobes developed into an independent plant.

I See Marloth, 'Ueber Mech. Schutzmittel der Samen gegen schädliche Einflüsse von Aussen,' Engler's Bot. Jahrb. 1883, p. 225.

2 'Ueber die Keimblätter der deutschen Dicotylen,' Verh. Bot. Ver. Brandenburg, 1874, p. 11. 
Some of the Onagrarieæ have seedlings with very curious cotyledons. For instance, I was greatly puzzled by the seedling of Enothera bistorta, in which (fig. 105) the cotyledons were long and linear, suddenly widening at the end into a large orbicular expansion, which gives them a very peculiar appearance.

In Eucharidium grandiflorum (fig. 108) the form of the cotyledon might not unnaturally be supposed to be a case similar to that of Malva. In reality, however, the explanation is very different. In Eucharidium the lobes have nothing to

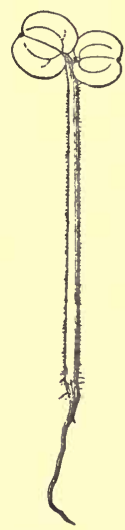

FIG. 106.-Seedling of Eucharidium grandiflorum, $\times 3$.

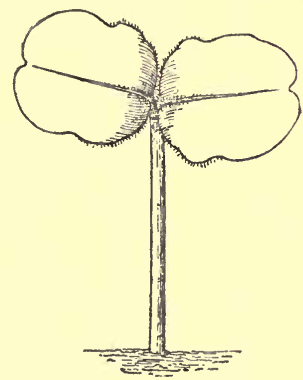

FIG. 107.-Eucharidium grandiflorum: ten days after germination, $\times 3$.

do with the arrangement of the embryo in the seed. The young plant, indeed, immediately after germination, presents no trace of them. The cotyledons, when they first emerge from the seed (fig. 106), are oblong-orbicular, sessile, cordate or auricled at the base, and emarginate at the apex, with a small purple tooth in the notch: they grow rather rapidly, become shortly petioled, and develop one or two lateral, incurved nerves on each side of the midrib.

In the next stage, about eight days after germination, they exhibit a very slight constriction near the base of the cotyledons, with a small obtuse tooth. This basal portion increases 
much more rapidly, while the growth of the terminal portion (which is, in fact, the original cotyledon) becomes gradually

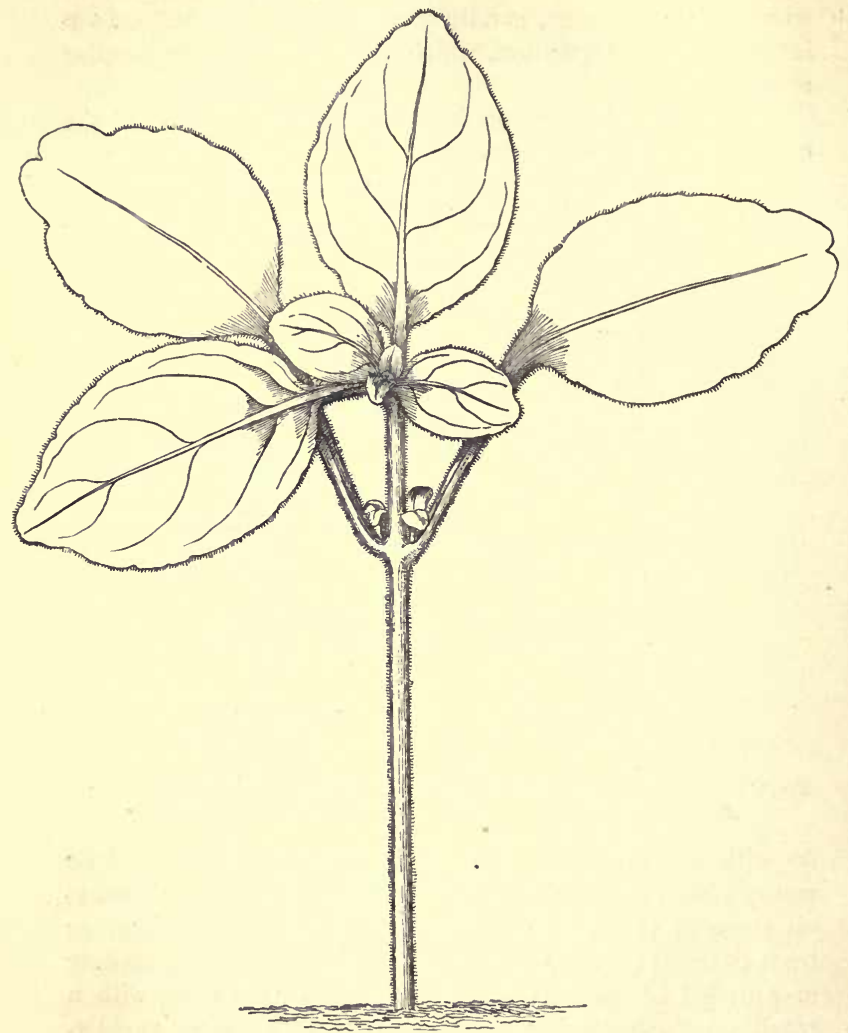

FIg. 108.-Eucharidium grandiflorum: showing final form of cotyledons. Nat. size.

arrested. The tooth becomes more marked (fig. 107), and by the tenth day the new portion is obtusely bidentate or crenate, and nearly equals the original cotyledon in size. 
In its final form (fig. 108) the new portion is both broader and longer than the true cotyledon, and differs from it not only in the crenations, but in the possession of a more conspicuous midrib and rather stiff hairs. Not only is this basal portion interesting in its mode of development, but also from its similarity to the subsequent leaves. In fact, as fig. 108 shows, it may be said that we have a compound structure formed of a leaf at the base, terminated by the cotyledon.

If, indeed, this species stood alone, we might regard the resemblance as accidental; but we find a very similar growth in other allied species.

In Clarkia pulchella (fig. 109) the cotyledons immediately after germination closely resemble those of Eucharidium grandiflorum (fig. 106). In a short time they become broadly ovate, emarginate, suddenly nar- Fig. 109.-Clarkia pulchella. Two-thirds nat. size. rowed, and rounded

at the base. In this case there is no great change of form; but while the margin of the original cotyledon is glabrous, that of the new growth and of the true leaves (fig. 109) is finely ciliate.

In Enothera stricta the cotyledons immediately after germination are oblong, obtuse, slightly auricled at the base, otherwise entire, sessile, thinly glandular-pubescent on the upper surface, and ciliate. By continued intercalary growth at the base they eventually become (fig. 110) spathulate, obovate or oblong-obovate, obtuse, with a tooth on each side, indicating the point of union of the original cotyledon and the new growth; the lower part with a distinct midrib 
and tapering much at the base, glabrous, with puberulouspubescent petioles, connate at the base.

The first leaves are alternate, lanceolate, obtuse, tapering to the petiole, obsoletely and distantly toothed at the margins, and, like the cotyledons, are glabrous with pubescent petioles.

Similar instances have been observed in many species of Clarkia and Enothera, and will be fully described in the chapter on Onagrarieæ.

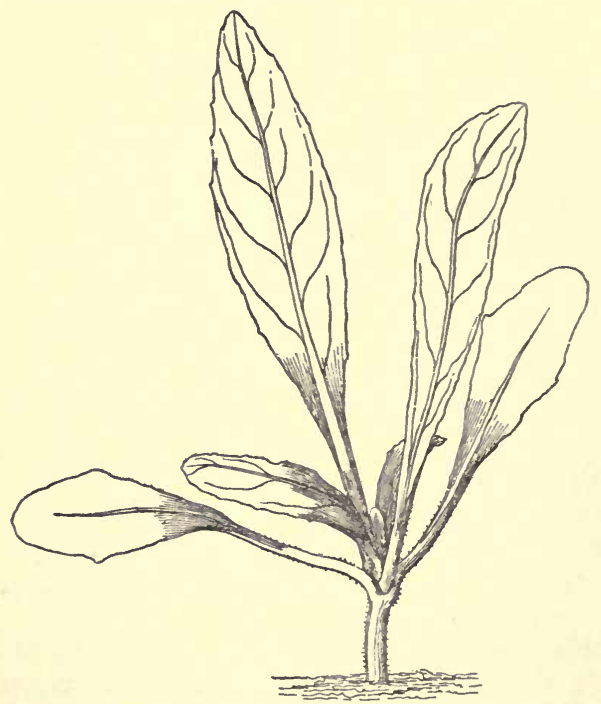

Fra. 110.-Enothera stricta, thirty days after germination. Nat. size.

Here, therefore, we have an interesting group in which at first the cotyledons are very similar, but by subsequent growth at the base develop into several distinct types, in each case closely resembling the leaf characteristic of the species. We can therefore have little, if any, doubt that this growth is influenced by the form of the leaf.

The species in which a connection may perhaps be traced between the characteristics of the leaves and those of the 
cotyledons are so few, that I may mention here that of Embelia Ribes (fig. 111). The leaves are simple, alternate, exstipulate, petiolate, alternately incurvinerved, rather thick and indistinctly reticulate, shining on both surfaces, bright green above, paler beneath, and punctate with dark green sunken glands eventually becoming black, thinly glandular-pubescent on both surfaces; petioles semiterete, channelled above, closely glandular-pubescent, tapering downwards. The first leaf is broadly ovate, or short-elliptic, acute, and serrate except towards the base. The second is similar, but less broad; the third, fourth, and fifth lanceolate, each rather narrower than the preceding.

The cotyledons are ovate, obtuse or subacute, indistinctly alternately incurvinerved, and reticulate, distantly serrate in the upper half, petiolate and tapering into the petiole, glabrous, bright green and shining above, paler beneath, thinly glandular on both surfaces, and dotted with sunken black glands; petioles semiterete, slightly furrowed above, finely glandular-pubescent. Here

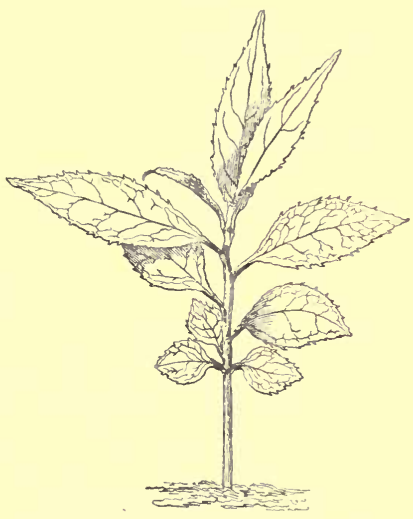

Fig. 111.-Seedling of Embelia Ribes. Half nat. size.

it will be observed that the cotyledons are strikingly like the first leaves; and, moreover, that there is a regular gradation from the broad ovate cotyledon to the final leaves, which are narrow lanceolate. The serration of the cotyledons is a very rare character, which makes the resemblance in this respect all the more significant.

In this connection also I may perhaps mention Eschscholtzia tenuifolia. I have already described ${ }^{1}$ and figured (fig. 40) the germination of E. californica, in which the cotyledons are long, narrow, and deeply bifid, and suggested that this form

1 Vide supra, p. 49. 
enabled them more easily to make their exit from the seed. In that species, where the cotyledons are deeply bifid, the leaves also are much cut up. In E. tenuifolia, on the contrary, both the leaves and cotyledons are long and linear. Here also the form probably facilitates the exit; and one may perhaps suggest that E. californica exhibits a form of which E. tenuifolia represents an earlier and simpler condition.

\section{Position of the Embryo in the Seed.}

As a general rule, the arrangement and position of the embryo in the seed is approximately the same within the limits of any one genus. There are, however, many exceptions.

In the genus Plantago, for instance, the cotyledons sometimes have their faces and sometimes their edges to the placenta. This difference is not indeed mentioned either by

Barnéoud or Decaisne in their

A

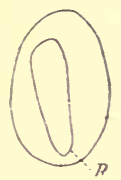

Fig. 112.-Plantago media. A, longitudinal section of seed, $\times 8$. B, transverse section of seed, $\times 8$. respective monographs of the family. Bentham and Hooker, however, say ('Genera Plantarum,' vol. iii. p. 1223) :'Embryo rectus v. rarius hippocrepicus, hilo parallelus $\mathrm{v}$. in fructu monospermo erectus v. transversus.'

In $\mathrm{P}$. media the fruit is capsular, dry, membranous, 2-celled and 2-4-seeded. The seeds (fig. 112, A and B) are plano-convex or subconcavo-convex, peltate, small, with equal obtuse ends; or with the basal end slightly the broader; the testa is thin, pale brown; the hilum a little below the middle on the ventral aspect, round, and deeper brown than the rest of the testa; the raphe tapers from the hilum obliquely towards the upper end of the testa. The endosperm is copious, fleshy, and white. The embryo is straight, narrow, white, a little shorter than the endosperm, and embedded in it, a little nearer the dorsal aspect of the seed and somewhat oblique to the median axis; the cotyledons are linear-spathulate, taper- 
ing towards the base, obtuse, entire, and with their faces towards the placenta; the radicle is inferior, obtuse, and shorter than the cotyledons.

In P. lanceolata (fig. 113) the capsule is also 2-celled, with one seed in each cell. The seed is concave on the ventral side, at first pale green, at length becoming yellow. The hilum is oval, forming a white or pale spot about or a little below the middle on the ventral aspect. The endosperm is abundant, fleshy, or almost horny when dry, and semitransparent. The embryo is straight, white, embedded in the endosperm, and a little shorter than the seed. The cotyledons are narrowly oblong or linear, obtuse, plano-convex, closely applied face to face, and with their edges to the placenta. The radicle is narrower than the cotyledons, inferior, and tapering downwards.

In P. Coronopus the capsule is many-seeded. The seeds are oblongoval, suddenly tapering to an obtuse point at the lower end, small, in transverse section somewhat dia-

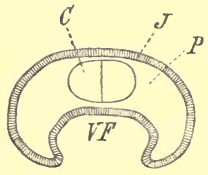

Fig. 113.-Plantago lanceolata. Transverse section of seed, $\times 12$. mond-shaped, with the angles rounded off, and attached to the placenta considerably below the middle. They are much smaller than those of P. media, and differ much among themselres. The embryo is comparatively large, straight, central, nearly equalling the endosperm in length; the cotyledons are linear obtuse, entire, plano-convex, thick, closely applied face to face, and with their edges to the placenta.

In P. maritima the fruit is narrowly ovoid, 2-celled, 2 -seeded. The seed is oblong-lanceolate, biconvex or flattened on the ventral side. The embryo is straight, large, and nearly fills the seed; the cotyledons have their edges to the placenta.

In P. Cynops the fruit is green, with a pale line where the two carpels come together, and a darker one along the middle of the carpel, giving it in a young state the appearance of consisting of four carpels, 2-celled, 2-seeded. The seed is ovate, obtuse, peltate, compressed dorsally, concare on the ventral side, smooth, shining, deep green when young, and sufficiently transparent to show the embryo by transmitted 
light. The embryo is straight; the cotyledons linear, obtuse, entire, closely applied face to face, with their edges to the placenta.

In $\mathrm{P}$. arenaria and $\mathrm{P}$. major the cotyledons are also placed with their edges to the placenta.

I was for some time much puzzled as to why the cotyledons in P. media should be placed differently from those of the other species examined; though the reason seems in reality very simple. At first $I$ thought it might have reference to the mode in which the embryo emerges from the seed; but this does not seem to have any bearing on it. In P. lanceolata, however, and its allies the cotyledons are narrow and thick; and the seed being somewhat compressed, it will be seen from fig. 113 that if the embryo had been placed with the faces of the cotyledons to the placenta, it would not have had room to develop.

On the other hand, in P. media (fig. 112) the reverse is the case: the cotyledons are thin and comparatively wide; their width, in fact, is greater than their thickness. It follows that, if they had been arranged as in the other species, they would not have had room to develop. The difference of position is therefore explained by the fact that in P. media the width of the cotyledons is greater than the thickness; while in P. lanceolata \&c., on the contrary, the thickness of the two cotyledons, taken together, is greater than their breadth.

The normal arrangement of an embryo in the seed is to have the faces of the cotyledons turned to the placenta. There are, however, not a few cases in which, as in these species of Plantago, the cotyledons have their edges to the placenta. When this is the case, it may be suggested as possible that the position is due to the fact of the seeds being more or less, in some cases very much, flattened; and that the embryo is twisted round at right angles to its normal position, so that the cotyledons may lie in the broad way of the seed, as in Ailanthus, Euonymus, Passiflora, Linum, Fraxinus, Diospyros, Heliotropium, and many Crucifers, Leguminosæ, and Rosaceæ.

On the other hand, in the case of Claytonia (fig. 114) this explanation will not apply. There would appear no reason, so 
far as the seed is concerned, why the cotyledons should not lie in the usual position.

It has occurred to me that perhaps the arrangement of the cotyledons may have reference to their exit from the seed. If we examine a germinating seedling of Claytonia, we shall see that the testa splits vertically from the micropyle, and the

A

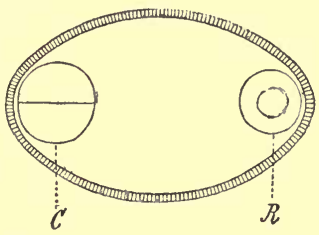

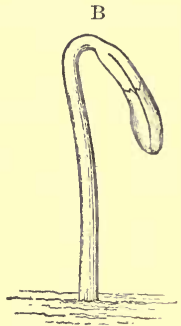

FIG. 114.-Claytonia perfoliata. A, transverse section of seed, $\times 15$. $\mathrm{B}$, seedling, $\times 6$.

cotyledons from their position, when they separate, act with greater advantage in enlarging the orifice, and thus securing their exit, than they would if they occupied the more usual position. This, however, I only throw out as a suggestion which requires further investigation.

When the seed is flattened laterally, the embryo must either be narrow or lie with the edges of its cotyledons to the placenta.

For instance, in Heliophila pilosa var. incisa the seeds (fig. 115, A and B) agree closely in form with those of Cheiranthus $(C$. Cheiri) (figs. 73 and 74); they are oblong-obtuse at each end, compressed dor-
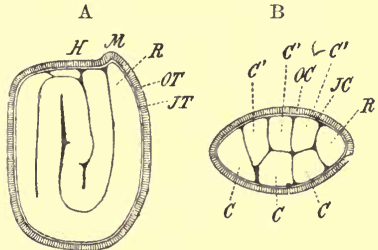

Frg. 115.-Heliophila pilosa. A, longitudinal section of seed, $\times 12$. B transverse section of seed, $\times 12$. sally, with a notch at one end, and in section are narrow elliptic ; but while the cotyledons of Cheiranthus are broad, in Heliophila they are long and linear. The reason of this may be that while 
in Cheiranthus and other Arabideæ the pods are flattened dorsally and the cotyledons are accumbent in the broad way of the seed (figs. 73 and 74), those of the Sisymbrieæ, to which Heliophila belongs, have (fig. 115, A and B) the cotyledons incumbent, so that they lie across the seed, and it is consequently an advantage that they should be linear.

Similar cases occur in other Orders, as for instance in Caryophyllaceæ and Solanaceæ.

\section{Concluding Remarks.}

The conditions under which the seedlings are grown naturally exercise some influence on the form of the leaves. For instance, in Mimulus luteus, if the seedlings have sufficient room the first leaves are shortly stalked and deltoid, while the primary nodes are but little developed; on the contrary, if they are more crowded, the internodes and petioles are longer and the leaves are oval.

In the Primrose we find an arrangement which almost seems as if it were intended to give the seedling some power of locomotion. The hypocotyl is sometimes horizontal, and throws out strong adventitious roots, the upper part, how ever, becoming vertical as usual.

As a general rule, the first buds produced by the seedlings are in the axils of the leaves, or more rarely of the cotyledons. In some species of Linaria, however, the hypocotyl itself throws out one or more buds which develop into branches. The advantage of this may be that, if the main shoot is cropped or broken even down to the root, the plant is capable of throwing up another stalk.

We thus find an almost inexhaustible series of beautiful adaptations to purpose. On the other hand, there are not wanting cases in which it would seem that the adaptation is not complete, or that a certain change, which has been of superior importance, has involved a minor evil.

The Oak, Beech, Nut, \&c. afford us a very interesting series of species. Fig. 117 represents a diagram of a Nut with the parts somewhat separated from one another, so as to show the relations more clearly. The mycropyle $(m)$ is at the 
apex of the seed. The ovule, however, is not straight and orthotropous, which would be, or at any rate seem to be, the simplest arrangement. Quite the contrary, for we find a long placental axis $(p l)$ which extends to the apex of the nut, and from which starts a raphe $(r)$, which returns about half way back again to the place where the true attachment or chalaza $(c h)$ is situated. I have in vain endeavoured to discover or imagine any circumstances which would render this complex arrangement specially adapted to present conditions. It would seem as if it would be simpler and give Nature less trouble if the ovule sat directly with its base on the stalk, thus doing away with both the placental axis $(p l)$ and the raphe $(r)$.

This view is strengthened by the fact that such an arrangement has been in fact nearly attained by the Oak. The ovule

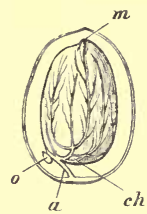

FIc. 116.-Seed of Oak (Quercus pedunculata). Nat. size. o, abortive ovule.

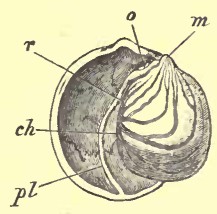

Fra. 117.--Seed of Nut (Corylus avellana). Nat. size, o, abortive ovule.

in this genus is theoretically anatropous, but the placental axis and the raphe are both greatly shortened (fig. 116), so that the distance which the nourishment has to traverse is much less, though the actual place of attachment remains the same. The Oak in fact seems to have appreciated the difficulties of the situation, and to have in great measure neutralised them. Is it fanciful to imagine that some ages hence the Oak may be practically orthotropous?

But why should these species be anatropous if it is an advantage to be orthotropous? On this question some light is thrown by the fact that while one seed only eomes to maturity, the ovary contains originally several cells each with one or two ovules, though none of the others come to anything. They can, however, easily be seen, either at the apex of the 
seed, as in the Nut (fig. 117, o), Beech (Fagus), \&c., or, as in the Oak (fig. 116,o), near the base. Their presence appears to indicate that these species are descended from ancestors the fruit of which was composed of several cells, each with more than one seed-a state of things therefore very unlike the present, and when the anatropous condition would be an advantage. If this view be correct, the structure of the fruit in the Nut, Beech, \&c. becomes peculiarly interesting, because it represents a case in which the present arrangements are not those in all respects most convenient to the plant, and renders it probable that the same explanation may apply to other cases of difficulty.

We meet indeed with a great many cases in which a larger or smaller number of the ovules, often all but one, fail to hecome developed. In some of them we may perhaps see a provision to increase the chances of fertilisation. There are others, however, in which this explanation will not hold good. In Ptelea, for instance, the ovary contains 2-3 cells, each containing two ovules, one inserted rather above the other, and the inferior ovule constantly fails to develop. In this and other similar cases we can hardly doubt that the existence of this second, and now functionless, ovule carries us back to a time when the ancestors of our present Ptelea habitually produced two seeds.

In Paliurus the fruit normally contains three, but sometimes only two, loculi, each with a single seed. Again, in Myagrum the ovary is spuriously 3-celled, but the two outer cells produce no seed. In Hæmanthus there are three cells, each containing a seed, only one of which, however, comes to maturity. In Convallaria there are three cells, each with two ovules, but only one of the six is generally developed. In Phillyrea and Canarium there are two ovules, only one of which is developed; and we meet with similar cases in Gyrinopsis, Jasminum, Esculus, Cordia, and many others.

From the point of view as to the origin of these differences, the variations in seedlings offer great interest. For example, out of 135 seedlings of Lepidium sativum (which, as already mentioned, differs from the rest of the genus in having tripartite cotyledons), no less than 25 , or as much as $18 \frac{1}{2}$ per 
cent., differed from the type, and had this character more or less imperfectly developed. Under cultivation the seedlings of Primula sinensis often have one of the cotyledons deeply bifid; in one lot of seedlings this was the case with, for instance, over 20 per cent. of the plants.

In Poterium Sanguisorba the calyx-tube generally contains one, but sometimes two or even three achenes. In Ranunculus, occasionally, the petioles of the cotyledons are connate.

In Enothera the cotyledons are either straight, or with one or both involute. Irmisch states that the cotyledons of Clematis recta, which are usually aerial, sometimes remain below ground; while the reverse is the case in Melittis, and, according to Winkler, in Dentaria and Mercurialis, for the cotyledons, which are generally fleshy and subterranean, sometimes rise above ground and form small green leaves.

Many species occasionally have one or both cotyledons divided. ${ }^{1}$

In Rheum the cotyledons are generally parallel, but in some cases one of them is placed more or less obliquely with reference to the other.

In Fagopyrum the position and arrangement of the cotyledons in the seed vary greatly. The cotyledons are turned about after striking into an angle of the seed, and then, following the testa, assume very various positions. In Carum Carui the cotyledons sometimes have their backs to the axis of the fruit, and sometimes their edges, while at others they are oblique.

In Cheiranthus pygmæus the cotyledons are said to be sometimes accumbent, sometimes incumbent, and straight or convolute, even in the same pod.

It would be easy to multiply such cases, but I will only mention one more, in which I will venture to suggest a reason for the variation. In Acer (fig. 118, 1), the embryo originates in a short tubular cavity opposite the micropyle, and is at first straight, with an extremely short turlinate radicle, and ovate, obtuse, closely adpressed cotyledons. As growth continues the embryo extends itself along the lower side of the seed, and curves with it, becoming gradually lanceolate, or

1 See Goebel, Grundzilge Syst. Spec. Pflanzen-Morphologie, p. 505; or Eng. trans., Outlines of Classification \&c. p. 446. 
oblong-lanceolate (fig. 118, 2). When the cotyledons have reached the upper, narrow end of the seed, the curvature of the wall turns them down again on themselves (fig. 118, 3). This growth is continued until the tips reach the radicle again, and the ultimate arrangement of the embryo differs according to whether they then curve inwards or outwards. This, again, seems to depend on the exact direction of the growth of the cotyledons. If they strike (fig. 118,5 ) against the process which encloses the radicle, then their general direction naturally carries them outwards, until the wall of the seed again turns them upwards, so that they become plicate; if, on the contrary, the tips of the cotyledons pass just within the

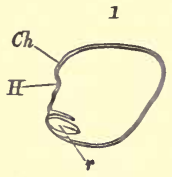

4

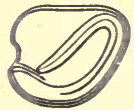

2

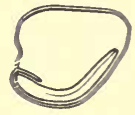

5

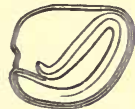

3

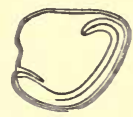

6
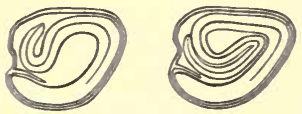

Sections of seed in seven successive stages, showing growth of embryo, $\times 3$.

micropylar process and touch the radicle, then they are compelled to grow in the opposite direction, and they become spirally coiled. In the specimens examined the latter arrangement was exceptional.

\section{Forms of the First Leaves.}

Some particulars with reference to the first leaves and the transition between them and those of the final form will be found in the following pages. I will only here observe that the first leaves are generally simple, or at any rate simpler than those which follow.

In species with trifoliate leaves, the first leaf is generally 
simple, as in the Clovers. When the mature leaves are pinnate, the first ones are generally trifoliate; and when the final leaves are bipinnate, the first ones are generally pinnate. I have already observed that species with lobed or palmate leaves often commence with one or more which are entire and heart-shaped.

In most cases, therefore, the first leaves are simpler than those which follow. In species from very dry localities, however, the reverse is often the case. For instance, in Lasiopetalum ferrugineum (fig. 119), from

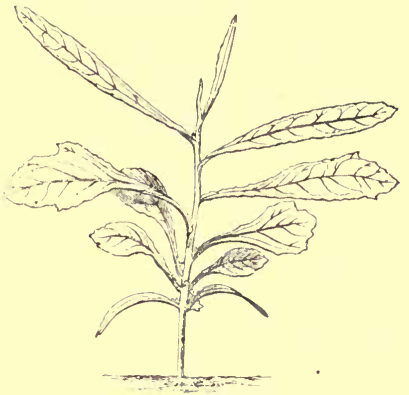

FIG. 119.-Seedling of Lasiopetalum ferrugineum. Half nat. size.

Adelaide, the first few leaves are spathulate and more or less lobed, the final ones linear. Again, in Dodonæa viscosa, also from Adelaide, the first leaves are lobed, the subsequent ones simple. Heterospermum is another interesting case.

\section{Relation of the Seeduing to the Seed.}

To return for a moment to the case of seedlings. The question of course arises whether the embryo conforms to the seed, or whether the shape of the seed is determined with reference to the form of the cotyledons. The seeds, however, are evidently constructed with reference to the habits, conditions, \&c. of the plant. I have elsewhere dealt with the structure of the seed, and must content myself here with the simple statement that we have no reason to suppose that it is influenced by the form of the embryo. On the other hand, it seems equally clear that the form of the embryo, and especially of the cotyledons, is essentially influenced by that of the seed.

The Tea (Thea), for instance, presents us with a very interesting case, in which the cotyledons vary greatly in shape, following that of the seed, and depending on the number of 
ovules which develop; they are contained in a wooden capsule, and are variously compressed. In Citrus also the cotyledons are unequal and irregular, several embryos being contained in each seed, and sometimes squeezed together in the utmost confusion.

In several other cases among those which have been already referred to, we can hardly doubt, I think, that the form of the cotyledon has been affected by the seed and not vice versa.

Let me in conclusion take one other illustration. The cotyledons of the Sycamore (fig. 9) are long, narrow, and strap-like; those of the Beech (fig. 13) are short, very broad, and fan-like. Both species are exalbuminous, the embryo occupying the whole interior of the seed.

Now in the Sycamore the seed is more or less an oblate spheroid, and the long ribbon-like cotyledons, being rolled up into a ball, fit it closely, the inner cotyledon being often somewhat shorter than the other. On the other hand, the nuts of the Beech are more or less triangular: an arrangement like that of the Sycamore would therefore be utterly unsuitable, as it would necessarily leave great gaps. The cotyledons, however, are folded up like a fan, but with more complication, and in such a manner that they fit beautifully into the triangular nut.

Can we, however, carry the argument one stage further? Why should the seed of the Sycamore be globular, and that of the Beech triangular? Is it clear that the cotyledons are constituted so as to suit the seed? May it not be that it is the seed which is adapted to the cotyledons? In answer to this we must examine the fruit, and we shall find that in both cases the cavity of the fruit is approximately spherical. That of the Sycamore, however, is comparatively small, say $\frac{1}{5}$ inch in diameter, and contains one seed, which exactly conforms to the cavity in which it lies. In the Beech, on the contrary, the involucre is at least twice the diameter, and contains from two to four fruits, which consequently, in order to occupy the space, are compelled (to give a familiar illustration, like the segments of an orange) to take a more or less triangular form. 
Thus, then, in these cases, starting with the form of the fruit, we see that it governs that of the seed, and that of the seed again determines that of the cotyledons. But though the cotyledons often follow the form of the seed, this is not invariably the case: other factors must also be taken into consideration; but when this is done, we can, I venture to think, throw much light on the varied forms which seedlings assume. 


\section{RANUNCULACEAE.}

\section{Bentham et Hooker, Genera Plantarum, i. 1.}

Fruit and Seed.-The fruits of Ranunculaceæ are either achenes often more or less pointed, sometimes feathery (Clematis, some species of Anemone), or follicles, sometimes united into a capsule (Nigella), or one- to few-seeded berries (Actæa).

The seeds are erect, pendulous, or horizontal ; ${ }^{1}$ the embryo is minute except in Trautvetteria.

The shape of the seed varies with that of the carpels and the number of ovules. There are four principal typas : rounded and smooth, granular, angular, and winged.

When the fruit is an achene (Ranunculus, Clematis, Anemone) the shape of the seed conforms to the interior of the achene.

In Thalictrum the achenes are ribbed, in Ranunculus they are nrinkled (water forms), or smooth, in some slightly hairy, in others (R. arvensis, R. parviflorus) covered with tubercles, or spines which are often more or less hooked, and probably serve to promote the dispersion of the seeds. In some (R. scapigerus, R. multiscapus, \&c.) the style itself is hooked. In other cases dispersion is aided by the presence of wings, or by a long feathery process consisting of the persistent style. This also serves a useful purpose by fixing the seed to the ground and thus enabling the seedling to emerge from the testa; as, for instance, in Clematis graveolens.

1 The ovules are anatropous, either solitary, erect, and with a ventral raphe (Ranunculeæ), or pendulous with a dorsal raphe (Clematideæ, Anemoneæ). The result of this is that in both the pollen-trbe has direct access to the micropyle, which would not otherwise be the case. 
In Clematis foetida the hairs are very long, but are confined to the lower part of the style; while in others, as for instance in C. Viticella, the style is quite short.

So also in Anemone, some species, as for instance A. virginiana, have the achenes hairy, terminating in a short, more or less curved, horn; while in others the achene bears a long feathery tail.

In the Helleboree the fruit is follicular, with numerous horizontal ovules; and the seeds are winged (Nigella orientalis), rounded (some species of Nigella), smooth (Aquilegia), or angular (some Delphiniums). This latter difference is perhaps due to the fact that in Aquilegia many of the ovules become aborted, so that the seeds have plenty of room to expand, while in Delphinium they are generally crowded together.

In Aquilegia the plants, when agitated by the wind, scatter the seeds in all directions, and their smoothness under these circumstances perhaps facilitates their dispersal.

Nigella orientalis differs from most of its congeners in the possession of winged seeds. The testa is loose and reticulated.

Actæa has baccate fruits, with numerous angled seeds. The testa is very thick.

Cotyledons.- The prevalent type of the cotyledons is broad, and bluntly ovate. They are typically three- to five-veined, though the variation is not easily seen in fresh specimens. They are larger, as a general rule, in the annual than in the perennial species. In some of the marsh species they are narrow and somewhat elongated, as is also the case with the leaves.

The cotyledons generally have a petiole, but sometimes they are sessile, as for instance in Delphinium Staphysagria (fig. 135). This, as I have suggested in my introductory chapter, is perhaps because, while those of Delphinium elatum, for instance (fig. 136), are attached close to the ground, those of D. Staphysagria are carried up by the hypocotyl, and do not therefore require stalks of their own.

The greatest amount of modification occurring in any one genus is perhaps found in Anemone. In A. nemorosa the 
cotyledons are connate by their edges, forming a tube obliquely split at the top. The petioles of the cotyledons are more or less connate in most species at the base ; they are united for half their length in A. Coronaria, nearly to the top in A. rupicola, and quite so in A. polyantha. In Anemone nemo-

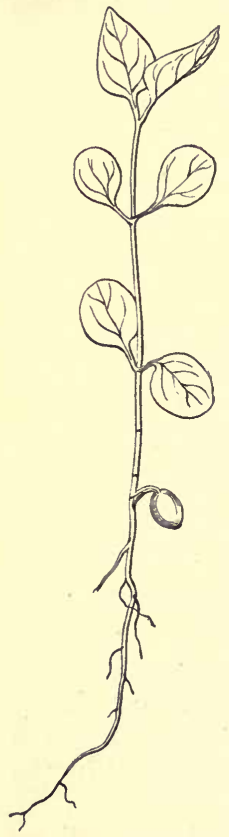

FIG. 120.-Clematis recta, var. lathyrifolia. Nat. size. rosa the petioles are completely suppressed.

Connate petioles also occur in Trollius, Delphinium nudicaule (fig. 137), D. trollifolium, and in some other species to the same extent as in Anemone polyantha.

In Clematis recta the cotyledons are fleshy and do not leave the seed. As usual in such cases the first few leaves are reduced to scales. 120).

Clematis recta, L., var. lathyrifolia (fig.

Primary root yellowish, with short lateral rootlets.

Hypocotyl short and tapering into the primary root.

Cotyledons petiolate, subterranean, and not leaving the seed.

Stem erect, terete, but becoming angular above, glabrous; 1st internode (in sketched specimen) short and hidden by remains or sheaths of cotyledons; 2nd $2 \mathrm{~mm}$. long; 3rd $6 \mathrm{~mm}$.; 4 th $7 \mathrm{~mm}$; 5th $18 \mathrm{~mm}$.; 6th $11.5 \mathrm{~mm}$.

Leaves compound in the adult plant, simple in seedling stage, cauline, opposite, exstipulate, petiolate, glabrous, green above, subglaucous beneath.

The leaves of Nos. 1-3 pair inclusive had fallen off; as above mentioned they are, as usual in such cases, quite small.

No. 4 pair, rotund-ovate, obtuse, entire.

No. 5 pair, rotund, obtuse, entire, sub-trinerved.

No. 6 pair, ovate, acute, entire, trinerved at the base.

Ultimate leaves (in this variety) bipinnate, leaflets lanceolate, 
entire, acute, three- or five-nerved; terminal one larger, trifid, or tripartite, or divided to the rachis.

\section{Clematis recta, $L$.}

Fruit an achene very shortly stipitate, broadly oval, much compressed laterally, deep brown, nearly or quite glabrous, terminated by a long, feathery, persistent style; walls of achene very much thickened at the sutures by a mass of cortex on each side, making in all four pieces; considerably thinner at the sides.

Seed suborbicular and conforming to the interior of the achene, with rounded or obtuse edges; outer seed-coat (testa) thicker, deep brown; inner (tegmen) very thin, membranous, pale brown; hilum and micropyle at the upper, basal end of the seed; funicle short.

Endosperm copious, fleshy, white.

Embryo minute, straight, colourless, lying in the endosperm, close to its upper end and towards the dorsal edge of the seed.

Cotyledons sessile, obtuse, entire, plano-convex, lying closely applied face to face in the narrow plane of the seed; radicle very short, and blunt, shorter than the cotyledons, close to the upper end of the endosperm.

\section{Clematis graveolens, Lindl., var. orientalis (fig. 121).}

Achene narrowly ellipsoid, laterally compressed, densely covered with silky ascending hairs, and ending in a long, feathery style; pericarp comparatively thin.

Seed conforming to the interior of the achene, suspended from near the apex of the cell, anatropous; seed-coats thin.

Endosperm as in C. recta.

Embryo differs from that of C. recta in being larger, and in the ovate, or suboval cotyledons lying in the broader plane of the seed, i.e. with their backs to the sides of the seed and their edges to the sutures; radicle oblong, obtuse, stout, about equal in length to the cotyledons, but less in diameter than their breadth.

The radicle in germination pushes out at the apex of the achene, which splits rather deeply into two valves, thus allowing the embryo free exit. The primary root develops numerous root-hairs at an early stage, which fix the seedling firmly in the soil.

The achene is rarely if ever carried up by the cotyledons, but is securely fixed in the soil by the long, feathery, persistent style. 


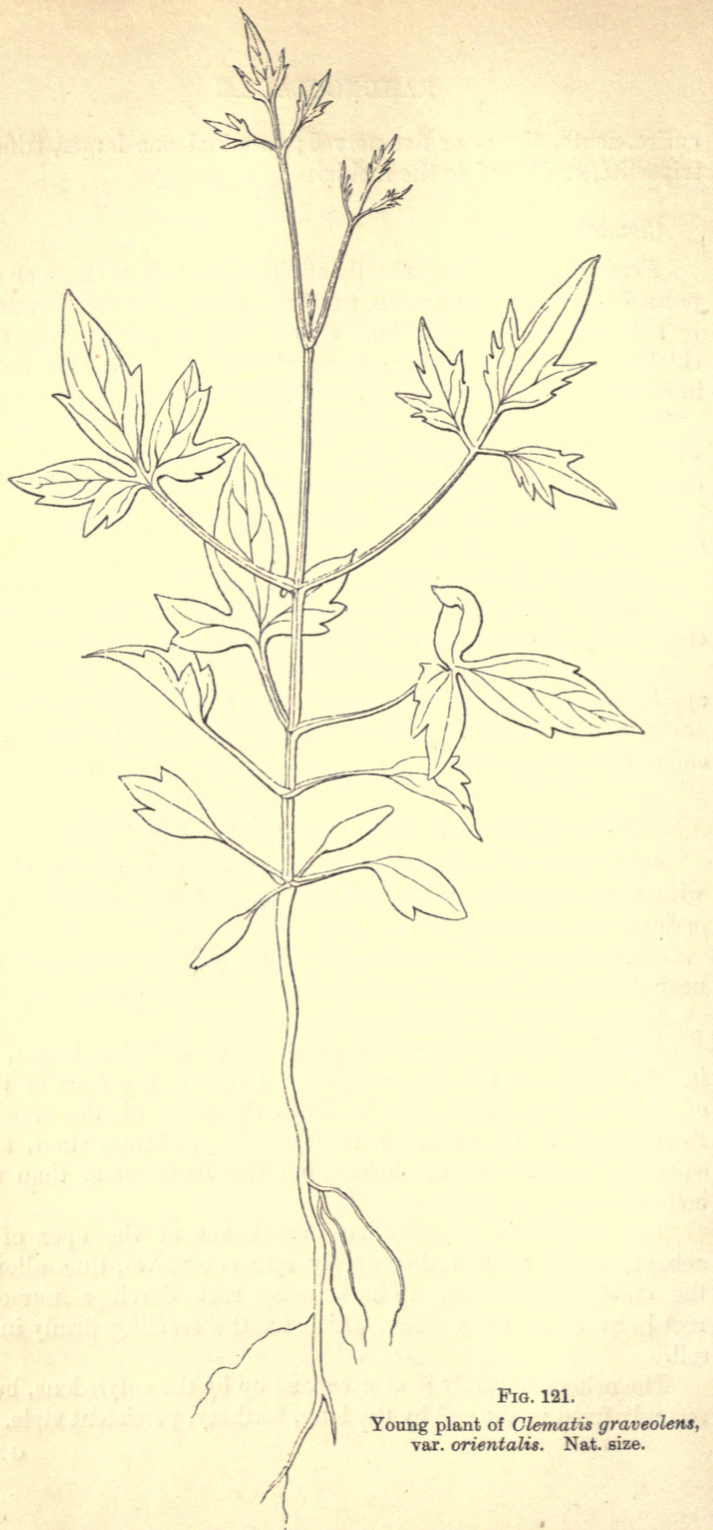


The cotyledons (fig. 121) are lanceolate, obtuse, narrowed at the base into a short petiole, obscurely trinerved, glabrous, pale greenish-yellow, but not yet properly coloured, or full-sized. Hypocotyl rather long, slender, almost colourless or tinged with purple at the apex, glabrous.

Atragene alpina, L. (fig. 122).

Hypocotyl terete, pale green, emerging $4 \mathrm{~mm}$. above the soil.

Cotyledons slightly pubescent, dark green, petiolate; lamina ovate, obtuse, $8 \mathrm{~mm}$. long, $6 \mathrm{~mm}$. broad; petiole flattened above, $6 \mathrm{~mm}$. long.

Stem undeveloped in seedling stage.

Leaves of seedling simple, radical (ultimately cauline), apparently alternate or the pairs very unequally developed, subdistichous, exstipulate, pubescent, deep green, petiolate, petioles channelled above, dilated and clasping at the base, pubescent.

No. 1. Small, transversely oblong or oval.

No. 2. Broader than long.

No. 3. Transversely oval, obscurely tridentate.

No. 4. Trilobed with obtuse or emarginate lobes.

No. 5. Trifid; middle

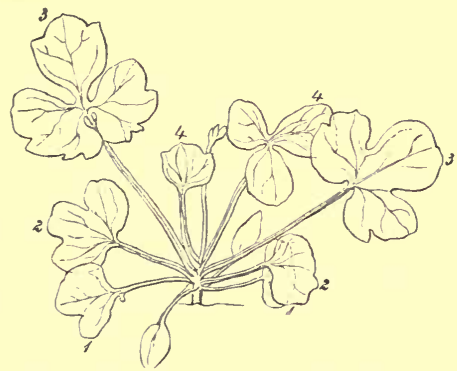

FIG. 122.-Atragene alpina, var. genuina. Nat. size. The numbers indicate the order of development of the leaves.

lobe broadly obovate, emarginate, lateral lobes bidentate.

No. 6. Tripartite; middle lobe rotund-cuneate, tridentate; lateral lobes transversely broadest, unequally dentate along the apex.

No. 7. Tripartite; lobes broadly obovate, emarginate.

No. 8. Subreniform, shortly trifid.

Anemone rivularis, Buchan. (fig. 123).

Primary root stout, tapering downwards, dark-coloured or brown with lateral rootlets of same colour.

Hypocotyl short, stout, white or suffused with red, 3-4 mm. long. 
Cotyledons foliaceous, glabrous, petiolate; petiole semiterete, channelled above, dilated and connate at the base, bright reddish purple, $12 \mathrm{~mm}$. long; lamina oval, obtuse,

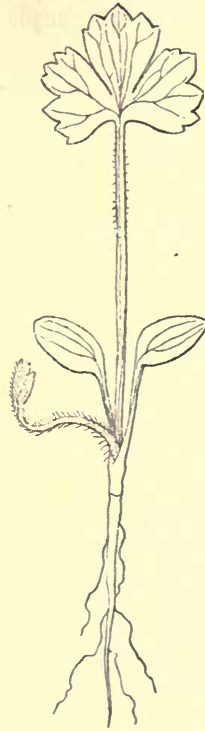

Fra. 123.-Anemone rivularis. Nat. size. mucronate, obscurely trinerved, $1 \mathrm{~cm}$. long, $6 \mathrm{~mm}$. broad.

Stem herbaceous.

Leaves radical (ultimately cauline), simple, alternate, exstipulate, petiolate, hairy all over; petioles semiterete, channelled above, dilated towards the base.

No. 1. Reniform, deeply tripartite, fivenerved; middle segment cuneate, three- to fivetoothed above; teeth triangular, mucronate, frequently aristate; lateral segments bifid and toothed above; teeth similar to those of the middle segment.

\section{Anemone fulgens, Gay.}

Primary root slender, flexuous, brown, densely covered with root-hairs.

Hypocotyl subterranean, shortly fusiform, deep brown and covered with longitudinal corky ridges, 3-5 $\mathrm{mm}$. long, fleshy or tuberous.

Cotyledons roundly ovate, oblique, varying greatly in shape and size, smaller, but otherwise very similar to those of A. rivularis.

Stem subsequently forming an underground fleshy rhizome, and not developed in the seedling.

Leaves simple, radical, alternate, exstipulate, petiolate, with the petiole sheathing at the base, ultimately much divided.

Nos. 1-2. Leaf small, reniform, three- to five-nerved, with three to five cuspidate teeth; finely ciliate.

\section{Anemone Coronaria, $L .^{1}$}

Hypocotyl suppressed or very short and subterranean.

Cotyledons with petioles connate for two-thirds of their length, and appearing to spring from one side; free part of petioles terete, channelled on the upper side; limb oval or oblong, emarginate, glabrous, $5 \mathrm{~mm}$. long, $3.5 \mathrm{~mm}$. broad.

Stem a subterranean fleshy rhizome, perennial. 
Leaves radical, ternately cut, alternate, exstipulate, petiolate; petioles subterete, channelled above, sheathing at the base.

No. 1. Tri-fid or -partite, glabrous, springing from the bud, which is situated some distance beneath the soil, deep green above, red or purple beneath; middle lobe trifid, cuneate at the base, and the middle segment often tridentate; lateral lobes unilateral and bifid or toothed along the posterior side.

\section{Anemone polyantha, Don.}

Cotyledons connate by their petioles to the very top, and the laminæ also sometimes connate at the base, appearing perfoliate.

Leaves. No. 1. Reniform, trifid, trinerved, terminal lobe tridentate; lateral lobes bidentate. The plumule emerges at the base of the cotyledon.

Ultimate leaves orbicular, five- to nine-lobed and -nerved; lobes obtuse, frequently trifid, cut, toothed-basal ones much overlapping.

\section{Anemone rupicola, Camb.}

Cotyledons connate by their petioles nearly to the top.

Leaves. No. 1. Cuneate, trinerved, shortly trifid; middle lobe tridentate ; lateral lobes bi- to tri-dentate. This leaf is sometimes absent.

No. 2. Reniform-triangular, deeply trifid, three- to five-nerved; middle lobe cuneate, tridentate; lateral lobes bifid or sub-bifid and slightly toothed.

Anemone nemorosa, A. Pulsatilla, and A. Hepatica have been described and figured by Irmisch. ${ }^{1}$

Thalictrum minus, $L$. (fig. 124).

Hypocotyl terete, glabrous, succulent, reddish, 2-4 mm. long.

Cotyledons broadly ovate, obtuse, subcordate at the base, deep glaucous green, petiolate; petiole $3-5 \mathrm{~mm}$. long, glaucous purple, subterete, flattened above, glabrous ; lamina 4-6 mm. long, 3-4.5 $\mathrm{mm}$. broad.

Stem leafy.

Leaves compound, alternate, exstipulate, petiolate, radical (and cauline ultimately) deep green, minutely pubescent; petioles

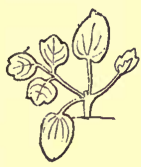

Fig. 124.-Thalictrum minus. Nat. size. terete, dilated and sheathing at the base, minutely pubescent.

No. 1. Ternate, leaflets rotund, trifid, reticulate-the lateral ones being oblique on the posterior side. 
Ranunculus Cymbalaria, Pursh. (fig. 125).

Primary root elongated, slender, furnished with a dense tuft of hairs at the base, and scattered ones, gradually becoming shorter towards the apex.

A

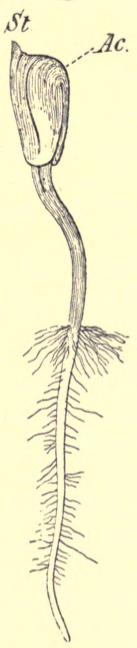

B

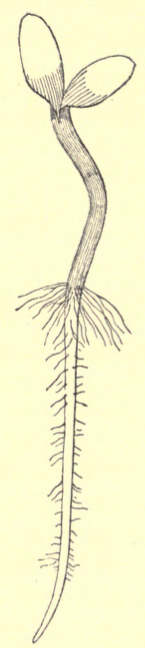

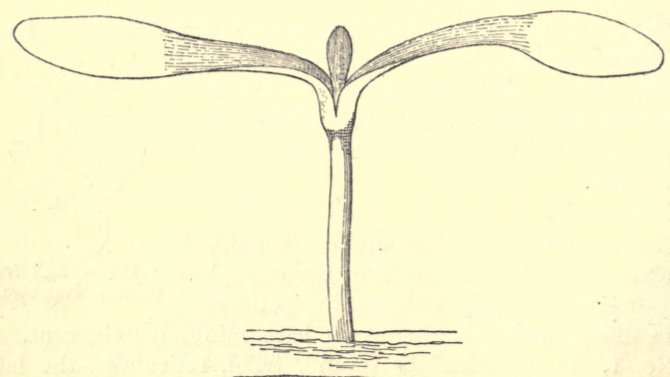

Fig. 125.-Ranunculus Cymbalaria, $\times$ 8. A, seedling, with the cotyledons still in the achene, $A c ; S t$, stigma. $\mathrm{B}$, seedling three days old. $\mathrm{C}$, seedling thirty-nine days old. 
Hypocotyl glabrous. Petioles of cotyledons just visible, but the cotyledons have not yet escaped from the achene.

Three days after germination: Cotyledons now free, oblong, obtuse, entire, shortly petiolate.

Thirty-nine days after germination: Cotyledons spathulate, entire, petiolate, glabrous, pale green, $3 \cdot 5-5 \mathrm{~mm}$. long, including the petioles, which are connate at the base. Plumule developing and first leaf appearing.

Sixty days after germination: The cotyledons have longer petioles than at the last stage, but are otherwise similar. Two first leaves oval, obtuse, entire, glabrous, with long petioles dilated and sheathing at the base.

Ranunculus acris, $L$. (fig. 126).

Primary root a tap-root with numerous colourless lateral rootlets.

Hypocotyl short, $\cdot 5 \mathrm{~mm}$. long, $1 \mathrm{~mm}$. thick, cylindrical, colourless near the base, greyishbrown near the cotyledons, where it also develops root-hairs.

Cotyledons petiolate, the petioles connate and sheathing at the base; lamina about $1 \mathrm{~cm}$. long, nearly $5 \mathrm{~cm}$. broad, ovate-lanceolate, obtuse, entire, with sunk midrib, glabrous, light green; petiole as long as lamina, nearly $1 \mathrm{~mm}$. broad, slightly channelled and glabrous.

Leaves simple, radical and cauline, alternate, exstipulate, palmati-nerved and -lobed, slightly pubescent on both surfaces, deep green above, paler beneath ; petiolate, petiole semiterete, channelled above, sheathing

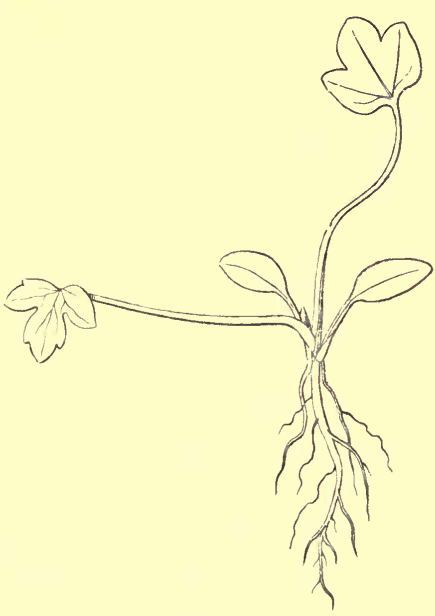

Fig. 126.-Ranunculus acris. Nat. size. at the base.

No. 1. Subrotund from a flattened base, five-nerved, trifid, lobes obtuse.

No. 2. Trilobed, lobes ovate, obtuse, often showing a small tooth on each side. 
R. millefoliatus, which hasbeen described and figured by Irmisch, ${ }^{1}$ belongs to this type.

Ranunculus arvensis, $L .^{2}$ (fig. 127).

Primary root tapering downwards, rather stout, with very few lateral rootlets ; a number of adventitious roots spring from the base of the hypocotyl and are soon equal to, or stronger than, the primary one ; adventitious roots are also given off from the cotyledonary node.

Hypocotyl stout, succulent, colourless, $7 \mathrm{~mm}$. to $1 \cdot 7 \mathrm{~cm}$. long, glabrous.

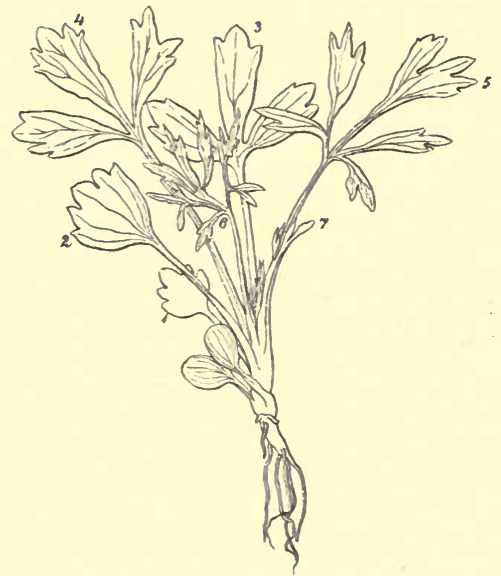

Fis. 127.-Ranunculus arvensis. Half nat. size.

Cotyledons opposite, glabrous, pale green; petioles channelled above, convex beneath, much dilated at the base, and connate; lamina oblong, oval, $12 \mathrm{~mm}$. long, $8 \mathrm{~mm}$. broad.

Stem erect, terete, glabrous, pale green, annual ; 1st-4th internode undeveloped, 5th more or less lengthened and sheathed by the bases of the petioles.

Leaves simple, radical and cauline, alternate, exstipulate, ciliate, light green, ultimately glabrous, petiolate; petioles semiterete, channelled above, slightly pubescent when young, much dilated and sheathing at the base, with somewhat ciliate sheaths.

No. 1. Rotund-cuneate, five-toothed.

' Bot. Zeit. 1865.

2 Irmisch, Bot. Zeit. 1857, taf. ii. 
No. 2. Broadly obovate-cuneate, obscurely five-nerved with five large teeth above.

No. 3. Tripartite; divisions cuneate, tridentate above, basal ones not opposite.

No. 4. Tripartite, with the basal divisions nearly opposite, teeth more numerous above.

No. 5. Trisected; middle segment acutely cuneate, unequally trifid, lobes slightly toothed at the apex; lateral segments bipartite with their anterior lobes trifid, narrowly cuneate, and their posterior lobes bifid above.

No. 6. Trisected; middle segment tripartite, divisions linear, entire or slightly toothed; lateral segments bipartite, divisions divaricate, more or less cut up into linear pieces.

\section{Ranunculus hederaceus (fig. 128).}

Primary root as in $\mathrm{R}$. acris, but few lateral rootlets.

Hypocotyl suppressed.

Cotyledons opposite, nearly equal ; base of petioles sheathing, petioles about $10 \mathrm{~mm}$. long, $\cdot 75 \mathrm{~mm}$. broad, blade $7.5 \mathrm{~mm}$. long and nearly as broad, suborbicular, rounded at both ends, slightly emarginate, distinctly penninerved, reticulate, glabrous, membranous, bright green.

Leaves radical and cauline, alternate, exstipulate, petiolate.

No. 1. Petiole glabrous, channelled, sheathing at base, $20 \mathrm{~mm}$. long, $1 \mathrm{~mm}$. broad; lamina broadly cordate, trifid, palmatinerved, reticulate, glabrous, bright green, 10-15 mm. long, and as broad.

No. 2. Similar but five-fid.

Note.-The cotyledons of R. tuberosus, R. caucasicus, R. Flammula, R. Boræanus, R. macrophyllus, R. Brutius,

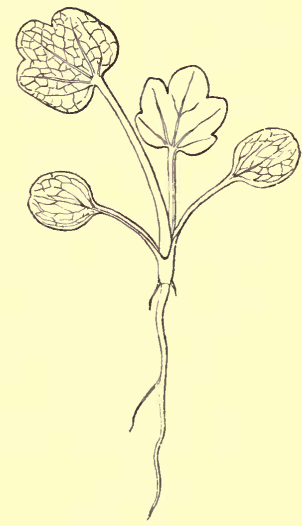

FIG. 128.

Ranunculus hederaceus. Nat. size.

R. Stevensi, R. cortusæfolius, and possibly many others, have their cotyledons slightly emarginate when fully developed.

Ranunculus repens, $L$. (fig. 129).

Hypocotyl erect, terete, short, mostly subterranean, colourless, glabrous. 
Cotyledons rotund-ovate, obtuse, entire, deep green, opaque, glabrous, obscurely three- to five-nerved from the base; lamina

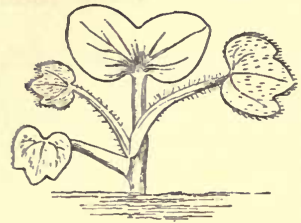

Fig. 129.

Ranunculus repens, $\times 2$. Abnormal specimen. 5-6 mm. long, 4.5-5 mm. broad; petiole semiterete, slightly channelled above, slightly dilated at the base, 6-7 $\mathrm{mm}$. long.

In the accompanying sketch is a seedling with the petioles and basal part of lamina united along one edge so as to appear like one large bifid cotyledon.

Stem. Several of the first internodes undeveloped.

Ceratocephalus falcatus, Pers. (fig. 130).

Primary root suddenly breaking up into a number of equally strong rootlets.

Hypocotyl fleshy, terete, tapering into the root, reddish beneath the cotyledons.

Cotyledons linear, obtuse, with revolute margin, fleshy, deep green above, paler beneath, $1 \mathrm{~cm}$. long, $2 \mathrm{~mm}$. broad.

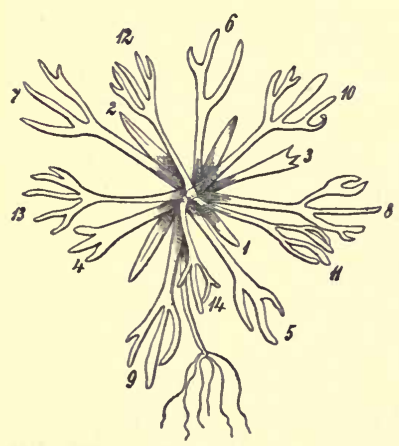

Fig. 130.

Ceratocephalus falcatus. Nat. size.

Stem annual, very short; internodes undeveloped.

Leaves simple, radical in a rosette, alternate, exstipulate, rather succulent, bright green above, paler beneath, woolly when young, glabrescent, petiolate; petioles flattened on both surfaces, dilated at the base.

Nos. 1 and 2. Linear, entire, similar to the cotyledons.

No. 3. Spathulate; apex tridentate.

No. 4. Spathulate, trifid.

Nos. 5 and 6. Cuneate, unequally trilobed.

Nos. 7 and 8 . Cuneate, tripartite ; segments linear, lateral ones bifid at apex.

No. 9. Tripartite, with linear segments.

No. 10. Tripartite; lateral segments unequally lobed.

No. 11. Doubly bipartite.

No. 12. Tripartite; lateral segments bifid. 
No. 13. Similar.

No. 14. Cuneate, tripartite; lateral segments unequal.

Trollius Ledebouri, Rchb., var. polycephalus, Rgl. (fig. 131).

Primary root slender, normal, soon superseded by strong adventitious roots from the base of the leaves and cotyledons.

Hypocotyl not developed.

Cotyledons ovate, obtuse, entire, alternately penninerved; nerves indistinct and seen only by transmitted light, glabrous, bright green above, much paler beneath, petiolate; petioles semiterete, channelled above, connate for about one-third of their length, much dilated and sheathing at the base, split on one side to allow the egress of the plumule, light shining green, glabrous, 8-11 $\mathrm{mm}$. long; lamina, $6.5-8 \mathrm{~mm}$. long, $5-5.5 \mathrm{~mm}$. broad.

Stem herbaceous, forming a perennial rhizome which sends up annual flowering stems; primary internodes undeveloped.

Leaves simple, radical and cau. line, alternate, exstipulate, petiolate, palmati-nerved, and -lobed, reticulate; reticulations best seen in young leaves;

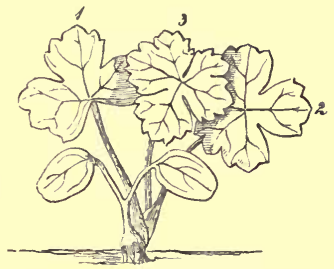

FIG. 131.-Trollius Ledebouri, v. polycephalus. Nat. size. light green above, paler or almost glaucous beneath, shining on both surfaces; petioles terete in the seedling, tapering upwards, light green, often tinged with red below, much dilated and clasping at the base.

No. 1. Rotund-cordate, palmately five-nerved, and three-lobed or five-lobulate; middle lobe cuneate, slightly trifid, with obtuse glandular cuspidate teeth; lateral lobes bifid and slightly toothed with glandular, cuspidate teeth.

No. 2. Similar.

No. 3. Tripartite; middle lobe broadly cuneate with numerous glandular cuspidate teeth; lateral lobes broader at the base than the middle lobe, slightly bifid with similar teeth.

Nigella sativa, $L$. (fig. 132).

Primary root slender, tapering, flexuose.

Hypocotyl erect, terete, glabrous, pale green, $13 \mathrm{~mm}$. long, $1 \mathrm{~mm}$. thick. 
Cotyledons petiolate, glabrous ; lamina oblong, obtuse, tapering into the petiole, $13 \mathrm{~mm}$. long, $6 \mathrm{~mm}$. broad; petiole channelled above, $8.5 \mathrm{~mm}$.

Stem annual, erect, terete, pubescent, pale green ; 1st internode undeveloped; 2nd and 3rd $3 \mathrm{~mm}$. long; 4 th $1 \mathrm{~mm}$. long.

Leaves simple, cau-

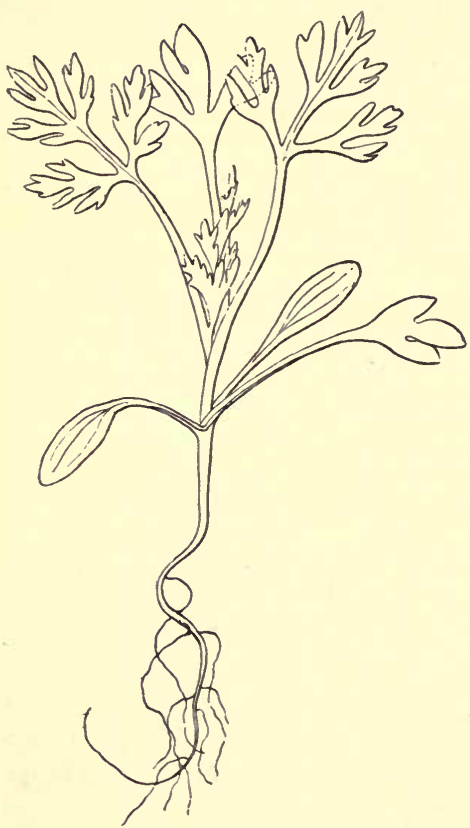

Fro. 182.-Nigella sativa. Nat. size. line, alternate, exstipulate, bright green and shining on both sides, sparsely pubescent, petiolate; petioles channelled above, slightly ridged beneath, dilated and sheathing at the base, pale green, pubescent.

No. 1. Cuneate, deeply trifid with oblong, obtuse segments.

No. 2. Cuneate, tripartite, divisions bifid.

No. 3. Tri-pinnatisect; basal lobes 1-2pinnatifid; terminallobe tripartite.

No. 4. Similar to the last but rather more cut up.

The cotyledons of $\mathrm{N}$. integrifolia closely resemble those of $\mathrm{N}$. sativa; as also do those of $\mathrm{N}$. damascena, which, however, are somewhat broader in the middle.

Aquilegia chrysantha, Gray, var. truncata (fig. 133).

Hypocotyl 3-7 mm. long, $1 \mathrm{~mm}$. thick, glabrous, purple.

Cotyledons petiolate; petioles terete or flattened above, connate at the base, $7 \mathrm{~mm}$. long, purple, glabrous; lamina ovate, obtuse, - entire, glabrous, faintly trinerved, glaucous blue or often tinged with purple, $7 \mathrm{~mm}$. long, $5 \mathrm{~mm}$. broad.

Leaves radical, alternate, ternately compound, glabrous, petiolate; 
petiole dilated and sheathing at the base, stipuliform as in the Umbelliferæ.

No. 1. Lamina ternate; leaflets trifid or the lateral ones bifid, petiolulate; lobes obtuse, rounded; petiolules $1 \mathrm{~mm}$. long, the middle one longer ; petiole terete, $8-15 \mathrm{~mm}$. long, purplish.

The seedlings of Aquilegia flavescens closely resemble those of $\mathrm{A}$. chrysantha, and the same may be said of A. cærulea.

The cotyledons of Aquilegia atropurpurea, A. Wittmanniana, A. dichroa, and probably others, have a slight emargination when fully developed.

Isopyrum grandiflorum, Fisch.

Primary root slender, tapering, with lateral rootlets.

Hypocotyl short, glabrous, tapering indistinguishably into the root, and mostly subterranean.

Cotyledons small, glaucous, glabrous, petiolate, orbicular or rotund-ovate; lamina $3 \mathrm{~mm}$. long, $2.5 \mathrm{~mm}$. broad; petiole slender, $5 \mathrm{~mm}$.long.

Stem herbaceous or shrubby, with very short scarcely developed internodes, densely covered with the withered petioles of old leaves.

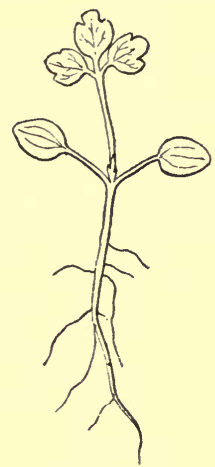

FIg. 133.-Aquilegia chrysantha, var. truncata. Nat. size.

Leaves biternate on the adult plant (primary ones simply ternate), radical and ultimately cauline, alternate, exstipulate, glabrous, glaucous, purplish beneath, petiolate; petioles slender, terete, or slightly flattened above, dilated and sheathing at the base, glaucous, glabrous.

Nos. 1-3. Ternate; leaflets suborbicular, entire.

No. 4. Ternate; terminal leaflet unequally bifid; lateral leaflets bifid or bipartite.

No. 5. Ternate; terminal leaflet trifid; lateral leaflets unequally bifid, with the smaller lobe on the posterior side.

No. 6. Ternate; terminal leaflet tripartite with sub-obovate segments; lateral leaflets bipartite with the posterior segment oval, the much larger anterior one rotund-obovate.

No. 7. Ternate; terminal leaflet tripartite, with the middle segment obovate, the lateral ones narrower; lateral leaflets bipartite with the posterior segments small and oval, the anterior one elliptic, obtuse.

No. 8. Almost biternate, with obovate leaflets. 
Ultimate leaves biternate with the secondary segments tripartite, varying greatly in size from $\frac{1}{2}-2$ inches in diameter; primary divisions triangular; secondary cuneate; ultimate segments obovate or cuneate, entire.

In Isopyrum fumarioides the cotyledons are somewhat more elongated.

Delphinium Staphysagria, L. (fig. 134).

Fruit of one to five follicles, each containing many seeds and dehiscing along the ventral suture.

Seeds obovoid, rather acutely trigonous, or variously ridged and angled; testa thick and corky, deeply reticulated, black externally; tegmen thin and membranous, pale brown; chalaza apical and as well as the raphe rather obscure; micropyle and hilum basal.

A
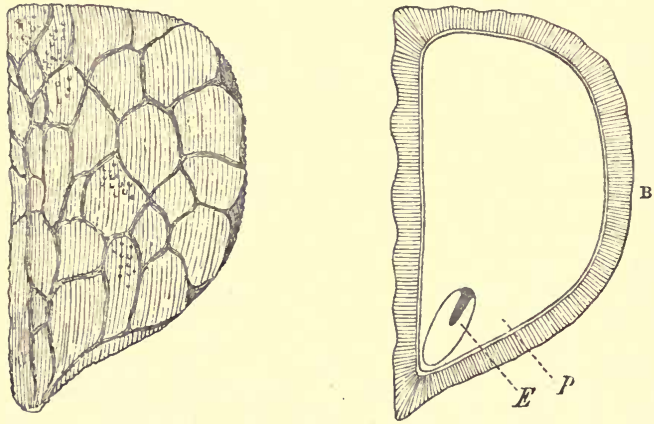

Fro. 134.-Delphinium Staphysagria. A, seed $\times 18$. B, longitudinal section of seed: $E$, embryo; $P$, endosperm.

Endosperm copious in the mature seed, white with a small subtransparent mass separating the cotyledons.

Embryo straight, minute, embedded in the endosperm at the base of the seed; cotyledons ovate, obtuse, entire, sessile, diverging; radicle short, obtuse.

Seedling (fig. 135).

Primary root tapering downwards with numerous fleshy lateral rootlets, dark-coloured.

Hypocotyl erect, terete, succulent, glabrous, colourless below ground, pale green above, $3 \mathrm{~cm}$. long, $3 \mathrm{~mm}$. thick.

Cotyledons ovate-oblong, obtuse, glabrous, fleshy; upper surface 
deep green, with three milk-white veins, shortly petiolate; petiole $3 \mathrm{~mm}$. long; lamina $13.5 \mathrm{~mm}$. long, $7.5 \mathrm{~mm}$. broad.

Stem herbaceous, biennial, elongated before flowering.

Leaves simple, radical, ultimately cauline, alternate, exstipulate, petiolate; both petiole and lamina pubescent when young, ultimately becoming glabrous, deep green and shining above, with anastomosing milkwhite veins, paler green and shining beneath; petioles channelled above, dilated and sheath. ing at the base, rather thick.

No. 1. Palmately tri-nerved and -fid: middle lobe minutely tridentate; lateral lobes bidentate; teeth triangular, tipped with a mucro.

No. 2. Palmately five-nerved and three-lobed; middle lobe unequally tridentate; lateral lobes unequally bifid.

No. 3. Palmately five-nerved

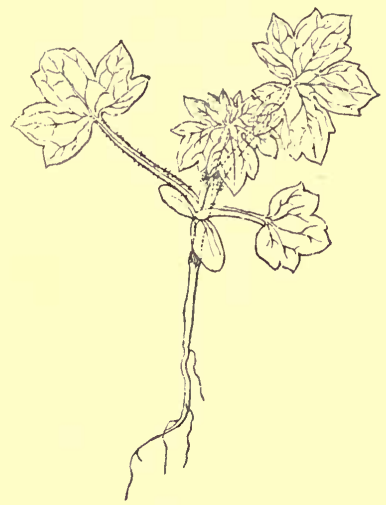

FIG. 135.-Delphinium Staphysagria Half nat. size. and five-lobed; terminal and middle lobes unequally tridentate; basal lobes unequally bifid.

No. 4. Palmatipartite; nerves and divisions five; terminal and middle lobes unequally trifid (middle much the largest), subrhomboid; lateral or basal lobes overlapping, dentate or sublobulate along the posterior or basal side.

Ultimate leaves palmately five- to seven-nerved and -lobed, or -partite, reticulated with white or green nerves; one to three of the terminal or central lobes subcuneate and trifid; the two to four basal lobes unequally bifid with the smaller lobe on the posterior or basal side. Uppermost leaves tripartite, trifid, or entire.

\section{Delphinium elatum, $L$.}

Seed obovoid, triangular or variously compressed, pale or deep brown; testa membranous, shrivelled or wrinkled; tegmen paler and thinner; hilum \&c. as in D. Staphysagria.

Endosperm as in D. Staphysagria, copious, fleshy, white, except a small quantity between the cotyledons and at their apex, which is transparent. 
Embryo larger than in D. Staphysagria, while the cotyledons have short petioles; otherwise similar.

Seedling (fig. 136).

Primary root perennial, fleshy, with a few rootlets, which are fleshy near its base and fibrous towards its apex.

Hypocotyl merging with and scarcely distinguishable from the root, stout, fleshy.

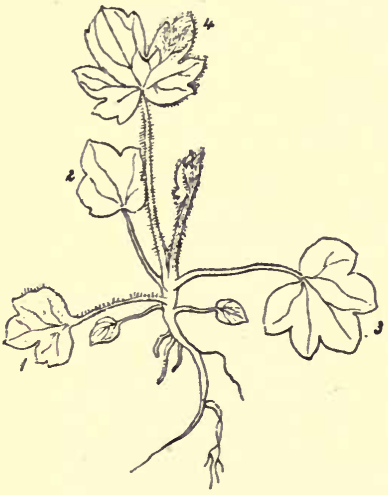

Frg. 136.-Delphinium elatum, var.

Two-thirds nat. size.

Cotyledons oval, foliaceous, often unequal in size, slightly pubescent, petiolate; petiole subterete, flattened above, about $1 \mathrm{~cm}$. to $1.5 \mathrm{~cm}$. long; lamina ovate, subacute, $8 \mathrm{~mm}$. long, $6 \mathrm{~mm}$. broad.

Stem undeveloped in seedling stage.

Leaves simple, radical and cauline, alternate, exstipulate, coarsely hairy on both surfaces, almost villous on the under surface and the petioles; petiole dilated and sheathing at the base, subterete, channelled above.

No. 1. Palmately trifid, trinerved, lobes frequently unequal.

No. 2. Similar but larger and foreshadowing further subdivision on the posterior or basal side.

No. 3. Palmately five-fid, five-nerved, with rounded, obtuse lobes.

No. 4. Palmately tripartite, five-nerved, with the lateral segments bifid and showing evidence of further subdivision on the posterior side, cordate at the base; ultimate lobes and teeth mucronate.

Ultimate leaves palmately five- to nine-lobed; middle lobe cuneate, trifid, and cut or incise-serrate; lateral lobes generally oblong, bi- to tri-fid, incise-serrate, or cut.

The seedlings of $\mathrm{D}$. hybridum resemble those of $\mathrm{D}$. elatum. In D. cardinale the petioles are connate at the base.

Delphinium nudicaule, Torr. et Gray (fig. 137).

Primary root tapering downwards, with a few lateral rootlets and abundantly covered with rusty-brown hairs. 
Hypocotyl very short or suppressed, or indistinguishable from the root or together with the latter becoming fleshy, tapering downwards and forming the persistent rootstock of the plant.

Cotyledons ovate, acute, mucronate, fiveto seven-nerved longitudinally, glabrous, pale green, connate by their bases and forming a little cup; petioles terete, erect, slender at the base and split on one side to allow the escape of the plumule, glabrous, pale green, $2-8 \mathrm{~cm}$. long, connate through their whole length; lamina 6-12 mm. long, 3.5-9.5 broad.

Stem herbaceous, erect, twelve to eighteen inches long, elongating when about to flower; primary internodes undeveloped.

Leaves simple, palmately lobed, radical and cauline, alternate, exstipulate, palmati-nerved, bright green above, paler beneath, shining on both surfaces, petiolate; petiole terete, slightly flattened on the upper side, or channelled to-

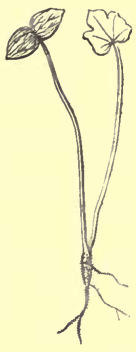

FIG. 137.-Delphinium nudicaule. Half nat. size. wards the apex, somewhat dilated at the base and sheathing, pale green, glabrous.

No. 1. Palmately three- to five-fid, five- to seven-nerved, lobes generally cuspidate, teeth tipped with a glandular mucro.

Delphinium trollifolium has the petioles of the cotyledons united in the same way as D. nudicaule.

\section{Delphinium Consolida, $L$.}

Primary root similar to D. Stapliysagria.

Hypocotyl erect, terete, glabrous, pale greenish-white or stained with red, tapering insensibly into the root, protruding 8-12 $\mathrm{mm}$. above the soil.

Cotyledons broadly oblong-ovate, obtuse, entire, tipped with a pale-coloured mucro, glabrous, obscurely trinerved with the lateral nerves much branched, anastomosing, incurved and uniting with the midrib close to the apex, petiolate; petioles grooved above, convex on the back, dilated and connate at the base, 9.5-12 $\mathrm{mm}$. long; lamina 12-13.5 mm. long, 7-9 mm. wide.

Stem herbaceous, annual, elongating when about to flower; primary internodes undeveloped.

Leaves simple, radical and cauline, alternate, exstipulate, tri-par. tite or -sect, with the venation ramifying accordingly, and obscurely reticulate, pubescent on both surfaces when young, glabrescent, light green and opaque above, paler beneath and somewhat shining, 
petiolate; petioles semiterete, channelled above, dilated and amplexicaul at the base, tapering apwards.

No. 1. Palmately tripartite with nerves running into the primary and secondary segments; middle segment cuneate, trifid with obtuse mucronate secondary segments; lateral segments obliquely cuneate, twice bifid, with oblong obtuse mncronate secondary segments.

No. 2. Palmately tri-partite or -sect; middle lobe rhomboidcuneate, trifid with its middle segment again trifid, and its lateral ones unequally bifid; lateral lobes obliquely cuneate bipartite with the anterior segment unequally trifid and the posterior segment unequally bifid.

No. 3. Trisect; middle lobe broadly palmately-cuneate and divided almost like the first leaf; lateral lobes similar in outline, smaller and somewhat less cut.

No. 4. Multisect.

\section{Delphinium Ajacis, $L$.}

Primary root as in D. Staphysagria.

Hypocotyl as in D. Consolida.

Cotyledons elliptic-oblong, obtuse, terminated by a glandular mucro, very similar to those of $\mathrm{D}$. Consolida, but with a longer petiole, of 10-17 mm.

Stem as in D. Consolida.

Leaves as in D. Consolida.

No. 1. Tripartite; segments elliptic or oblong-elliptic, entire, tipped with a pale-coloured glandular mucro, the terminal one broadest, and the lateral one sometimes bifid.

No. 2. Similar, larger, generally with the lateral, sometimes with all the segments bifid.

No. 3. Palmately trisect; middle segment rhomboid-cuneate, deeply trifid; lateral segments obliquely cuneate, obliquely or unequally bi- or tri-partite.

Nos. 4 and 5. Trisect; middle segment cuneate, palmately trisect and sparingly lobed-lateral lobes or segments obliquely bisected with their anterior halves deeply trifid, and their posterior halves deeply bifid.

NotE.- One or both of the cotyledons are sometimes bifid or parted to the very base, simulating three or four cotyledons in the latter cases.

Aconitum cernuum, Koell.

Hypocotyl short and subterranean.

Cotyledons oval-oblong, acute, entire. glabrous, light green, 
trinerved, petiolate; petioles very long, channelled on the upper side, $3-3.5 \mathrm{~cm}$. long.

Stem with primary internodes undeveloped.

Leaves simple, palmatifid, radical, alternate, exstipulate, petiolate, glabrous, light green, cordate at the base, trinerved; lobes acute, usually divided into two to three secondary lobes or trifid.

\section{DILLENIACE E.}

Benth. et Hook. Gen. Pl. i. 10.

The ovules are one or many, anatropous and ascending. The raphe is ventral as in the Ranunculaceæ, and probably for the same reason. The seeds are single or few, and generally provided with an aril. The embryo is minute with the radicle inferior, near the hilum.

The members of this order being chiefly natives of the southern hemisphere, and but few of them popular hothouse plants, are seldom raised from seeds in this country; consequently but little opportunity is afforded for observations on the cotyledons. Those of Hibbertia dentata are linearlanceolate, sessile, narrowed to the base, where they are shortly connate and sheathe the young stem, persistent, somewhat coriaceous, $20 \mathrm{~mm}$. long, and $5 \mathrm{~mm}$. broad. The persistent nature and subcoriaceous texture are characteristic of genera and species of arboreal or shrubby habit with evergreen leaves. The Dilleniaceæ are either trees or shrubs, sometimes twiners, rarely suffruticose or herbs.

\section{Hibbertia dentata, $R . B r$.}

Hypocotyl succulent, 1-2 $\mathrm{cm}$. long, $2 \mathrm{~mm}$. thick, terete, glabrous, pink near the base, green above.

Cotyledons sessile and forming a short sheath round the base of the first internode of the stem, $2 \mathrm{~cm}$. long, $5 \mathrm{~mm}$. broad, linearlanceolate, mucronate, with sunk midrib, glabrous, rather firm and persistent, dark green above, paler below.

Stem terete, $2 \mathrm{~mm}$. thick at the first internode, which is about $1.5 \mathrm{~cm}$. long; the successive internodes gradually increase in length and thickness, hirsute, reddish, but green under the sheathing petioles and seed-leaves. 
Leaves simple, cauline, alternate, exstipulate, alternately penninerved, nervation reticulate, glabrous except at the margin and on the principal nerves beneath, deep green above, paler beneath, often stained red in the adult plant; petiolate, petioles short, deeply channelled above and partly sheathing the stem.

No. 1. Small, oblong, obtuse, nearly entire.

Nos. 2-4. Oblong, acute, margin shallowly dentate with the teeth slightly recurved, somewhat oblique at the base.

\section{CALYCANTHACEE.}

Benth. et Hook. Gen. Pl. i. 15.

Fruit and Seed.-The fruit is an achene containing an oblong or obovoid seed. Several fruits, or few by abortion, are surrounded by the deeply cup-shaped thalamus or receptacle, which increases in size and persists till the seeds are ripe. The seeds are exalbuminous, being wholly occupied with the large embryo, the cotyledons of which are corvolute, of very unusual outline. The short radicle is close to the hilum of the anatropous seed.

Cotyledons.-Two genera, including in the aggregate only four well-marked species, constitute the whole of this small Order. They differ widely in the characters of the embryo from all the allied Orders, but show a certain amount of affinity with Magnoliaceæ through Illicium. The cotyledons are longitudinally convolute, like a roll of manuscript, in both genera, and together with the radicle and embryo occupy the whole of the seed. Those of Calycanthus macrophyllus are apparently unsymmetrical, almost transversely oblong, with a broad, shallow apical sinus, a narrower and deeper sinus at the base, and a notch above a small lobe at the base of the smaller half of each cotyledon.

Leaves.-Typically these are opposite, but occasionally they are slightly alternate by the development of the internode. Being simple and entire, with the principal nerves ascending and incurved, they present no very striking features. The two first pairs of Chimonanthus fragrans are very small, 
almost rudimentary, and recall what may be seen in many species belonging to widely separated Orders, which have subterranean cotyledons. Instances occur in Clematis recta (fig. 120), Rhus Thunbergiana (fig. 255), Lecythis Sapucajo, Quercus pedunculata, the Walnut, and many others, the congeneric species of some of which have aerial cotyledons.

The explanation is probably that when a large store of reserve food-material is laid up in fleshy cotyledons, the plant is able to form a considerable length of stem independently of well-developed leaves. In Chimonanthus the cotyledons are fleshy, but they are aerial, and well exposed to light by being elevated on a hypocotyl $3-4.5 \mathrm{~cm}$. above the ground.

\section{Chimonanthus fragrans, Lindl.}

Fruit an achene, oblong, deep brown, almost black, $17 \mathrm{~mm}$.long, 8-9 mm. broad.

Hypacotyl woody, erect, terete, glabrous, greenish-yellow, $3-4.5 \mathrm{~cm}$. above soil.

Cotyledons large, foliaceous, convolute in the seed, after germination broader than long, petiolate, deeply auricled at the base, auricles incurved, obscurely trinerved and reticulate-veined, glabrous, fleshy and very brittle, bright green above, paler or yellowishgreen beneath, $2 \cdot 6 \mathrm{~cm}$. long, $3 \cdot 8 \mathrm{~cm}$. broad. They persist for more than a year.

Stem woody, erect, terete, glabrous, thinly dotted with lenticels, pale green; 1st internode 1.65 mm. long; 2nd $2.4 \mathrm{~cm}$.; 3rd $2 \cdot 2 \mathrm{~cm}$. ; 4 th $3 \cdot 25 \mathrm{~cm}$. ; 5 th $4 \cdot 25 \mathrm{~cm}$.

Leaves simple, entire, cauline, opposite (sometimes alternate), exstipulate, petiolate, hairy on the margin and beneath the midrib, ultimately becoming glabrous but very rough and scabrous, alternately and irregularly penninerved, pale green above, paler beneath, shining; petioles short, slightly channelled above, convex beneath, slightly hairy or scabrous on the upper margins, otherwise smooth.

First pair small, scale-like and perishing early.

Second pair similar or sometimes foliaceous and subdimidiate, or very unequally developed on each side of the midrib, deeply and obliquely emarginate, with rounded points.

Third pair foliaceous, subobovate, obliquely and deeply emarginate, with rounded lobes.

Fourth pair lanceolate, acuminate, $12 \cdot 65 \mathrm{~cm}$. long, including the petiole. 
Fifth pair oblong-lanceolate, acuminate, shorter than the last because on the tip of the shoot, which has finished growth for a season.

Ultimate leaves ovate, acuminate, entire, scabrous.

\section{MAGNOLIACEE.}

Benth. et Hook. Gen. Pl. i. 16.

The Magnoliaceæ are trees or shrubs. The leaves are simple and entire or dentate, with an ascending, incurved, penninerved, and reticulate venation. They are leathery and evergreen, or membranous and deciduous, and often have aromatic oil glands. The seeds of Drimys and Illicium have a shining black testa. In Magnolia they

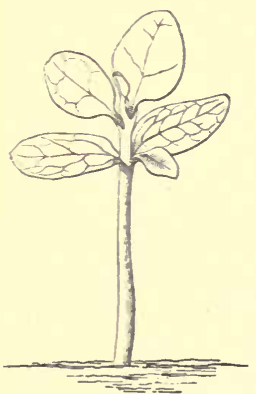

Fic. 138.-Drimys Winteri, $\times 2$ are drupe-like, with the outer coat fleshy and the inner one crustaceous. When the follicles containing them dehisce, they do so along the dorsal suture in Magnolia, Manglietia, and Michelia, allowing the seeds to drop out, suspended by a long, filiform funicle. The seeds are generally fairly large, and contain a copious, oily endosperm. The embryo is small or minute with diverging cotyledons. In the Tuliptree (Liriodendron) the seed is contained in a persistent samaroid carpel.

The cotyledons of Drimys Winteri (fig. 138) are oblong, ovate, obtuse, obscurely trinerved and reticulate, punctate with pellucid glands, and rather persistent. The seedlings are of slow growth. The first leaf is several times smaller than the cotyledons; and the succeeding two are ronndish or ovate, and nearly the size of the latter.

Drimys Winteri, Forst. (fig. 138).

Hypocotyl erect, terete, glabrous, pale green, 11-14 mm. long.

Cotyledons oblong-ovate, obtuse, entire, shortly petiolate, glabrous, bright green above, glaucous beneath, with pellucid glandular 
dots; obscurely trinerved and reticulate ; petiole flattened above, convex beneath, $\cdot 5$ to $1 \mathrm{~mm}$.long; lamina $7-9 \mathrm{~mm}$. long, $3.45 \mathrm{~mm}$. wide.

Stem erect, terete, glabrous, pale green, ultimately woody ; 1 st internode undeveloped or $\cdot 25-1 \mathrm{~mm}$. long ; 2 nd and $3 \mathrm{rd}$ each 1-1.5 mm.

Leaves simple, entire, cauline, alternate, exstipulate, petiolate, alternately penninerved, with the nerves incurved and uniting some distance within the margin, and anastomosing beyond, glabrous, deep green above, glaucous beneath; petiole flattened above or shallowly grooved, convex or rounded on the back, very short.

No. 1. Broadly ovate or oval, obtuse, very small.

Nos. 2-4. Similar and gradually larger, sometimes rotund.

Ultimate leaves oblanceolate-oblong, acuminate, obtuse, alternately and ascendingly penninerved, obscurely reticulate, light or deep green above, glaucous beneath; coriaceous, evergreen, 5-8

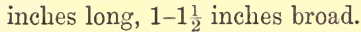

\section{ANONACEA.}

Benth. et Hook. Gen. Pl. i. 20.

Frit and Seed.-The carpels are generally numerous. The ripe fruit is either dry and dehisces like a follicle with two valves as in Anaxagorea ; baccate, one-celled and one-seeded as in Polyalthia; woody and one-celled with the seeds embedded in pulp as in Monodora; or fleshy and united into a large multilocular indehiscent fruit as in Anona. The fruit is rarely dehiscent in the Order, and the seeds are generally of large size, sometimes arillate. There are one or two erect, anatropous ovules in each cell with the raphe ventral, or the ovules are numerous and arranged in one or two rows along the ventral suture. In the species of Anona the ovules are solitary in each cell, and the seed attains a large size, is broadly oblong and more or less compressed laterally. The outer coat is thick and corky or subwoody, while the inner one is invaginated, i.e. dips deeply into the fleshy and copious endosperm, making it ruminated. The embryo in the mature seed is small and situated close to the hilum, embedded in endosperm. The ruminated character of the endosperm is common to the Order.

The seeds differ greatly even in nearly allied species. Thus 
in Oxymitra patens they are globular with numerous blunt processes; in 0 . Grayana they have two, in other species four wings, while others again are round and smooth.

Cotyledons.- The seedlings of Anona arestrong and vigorous but present a singular anomaly, inasmuch as the cotyledons

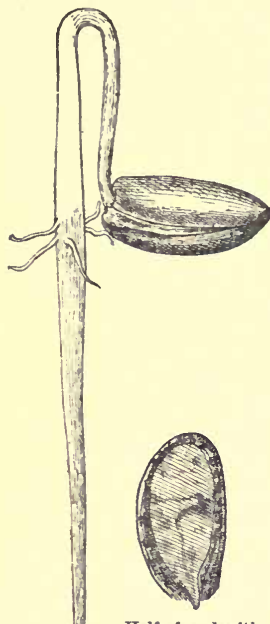

Half of seed with cotyledon.

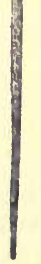

Fro. 139.-Anona, ? laurifolia. Nat. size.

are in some species torn from the axis during germination. The seeds of A. laurifolia split longitudinally, the strong radicle strikes straight downwards fixing the seedling firmly in the soil, and the hypocotyl forms an ascending or elongating loop. The large seed remains underground, while the hypocotyl at length pulls out the plumule, and straightens, leaving the cotyledons behind. If a seed is eut open at this point the cotyledons are seen to be oblong or oval, obtuse, petiolate, almost equalling the length and breadth of the seed, and much undulated or wrinkled in order to accommodate themselves to the inequalities of the much ruminated endosperm. They exhibit an ascending, incurved, feathernerved venation very similar to that of the leaves, and at this stage are surrounded or included between two equal halves of the endosperm with a small quantity of the same between them. A. Cherimolia behaves in exactly the same way, and the cotyledons are invariably torn from the axis and left in the subterranean seed.

A. palustris is an exception to the other species examined, inasmuch as the cotyledons become aerial. They are oval, or oblongelliptic, obtuse, petiolate, foliaceous, with a penninerved, incurved venation, and in every respect similar to that of a true leaf with the exception that the leaves are acuminate. 
Anona, ? laurifolia, Dunal (fig. 139).

Primary root very long, fleshy, thick, colourless, penetrating the soil perpendicularly to a great depth, furnished with short stout horizontal lateral rootlets at the base of the hypocotyl, and immediately beneath the soil or at the depth the seed was buried before germination.

Hypocotyl long, stout, tapering upwards, glabrous, mottled and streaked with red on a pale or colourless ground, giving the whole a pale brown or brownish-red appearance, 8-9.5 $\mathrm{cm}$. long, rising in the form of a loop during germination.

Cotyledons oblong, obtuse, petiolate, glabrous, very small in the seed, but during germination increasing almost to the length and breadth of the seed, and becoming much wrinkled and undulated to conform to the inequalities of the much ruminated ends, finally becoming separated from the axis when the hypocotyl has attained a considerable size, and remaining embedded in the subterranean seed between two equal halves of the endosperm, with a thin layer of endosperm between them; lamina $1.5 \mathrm{~cm}$. long, $8 \mathrm{~mm}$. broad; petiole 5-6 mm. long.

Stem woody, erect, terete, hairy, with ascending adpressed hairs.

Leaves simple, entire, cauline, alternate, distichous, exstipulate, petiolate.

Anona Cherimolia, Mill.

Hypocotyl erect, terete, tapering upwards, stout, slightly glabrous, pale green, $5 \cdot 5-7 \mathrm{~cm}$. long.

Cotyledons retained in the seed, which is subterranean, while the hypocotyl straightens without them.

Stem as in preceding species; 1 st internode $5.5 \mathrm{~mm}$. long.

Leaves simple, entire, cauline, alternate (first two sometimes opposite), exstipulate, petiolate, alternately or almost oppositely penninerved and reticulate, with the nerves incurved towards their ends and uniting with those next above them, glabrous or nearly so above, ciliate and more or less hairy beneath; petioles semiterete, channelled above, hairy, with adpressed hairs.

Nos. 1 and 2. Alternate or subopposite, oblong-ovate, obtuse, revolute at the margin, light green slightly glaucous above, glaucous beneath.

\section{Anona palustris, $L$.}

Hypocotyl as in A. Cherimolia, but reddish-green ; $9 \mathrm{~cm}$. long.

Cotyledons aerial, oval or oblong-elliptic, obtuse, entire, shortly 
petiolate, glabrous, dark shining green above, paler beneath, slightly reflexed, about $25 \mathrm{~mm}$. long, 6-12 $\mathrm{mm}$. wide, with a distinct midrib and numerous veinlets, united at their tips, giving the appearance of two lateral veins. In other species of this genus the cotyledons usually remain within the seed.

Stem herbaceous, erect, terete, glabrous, light green ; 1st and 2nd internode 5-10 mm. long.

Leaves lanceolate, acuminate, otherwise as in A. Cherimolia.

\section{MENISPERMACE E.}

Benth. et Hook. Gen. Pl. i. 30.

Fruit and Seed.-The carpels are free and ripen into baccate or drupaceous fruits. The placental or ventral suture of the endocarp enlarges or thickens into a hemispherical process projecting into the eavity of the ovary and determines the shape of the seed. The endocarp is also considerably flattened laterally and forms a strong submarginal moon-shaped ridge on both surfaces close to the outer or dorsal suture. This ridge lodges the correspondingly thickened part of the seed containing the embryo.

The ovule is amphitropous almost throughout the Order and is peltately affixed to the enlarged or hemispherical placenta. In a very few cases it is anatropous. The seed is generally crescent-shaped. The endosperm is fleshy and moderately copious in the Tinosporeæ and Cocculeæ, but scanty in the Cissampelideæ, and absent in Pachygoneæ.

In the first tribe above mentioned there is considerable range of variety in the shape of the embryo. The cotyledons of Aspidocarya are flat, spreading at the base, and parallel above; those of Parabæna and Tinospora are ovate and diverging laterally, those of Anamirta are narrow, very slender and diverging, while Coscinium has a fleshy, much ruminated endosperm, a short, nearly straight embryo, with slender, diverging, deeply sinuately-laciniate cotyledons.

The embryo in the tribes Cocculeæ and Cissampelideæ is cylindrical with adpressed cotyledons, and resembles that of Menispermum (fig. 140) with the exception that it is straight 
in some instances as in Anomospermum. The seeds of the Pachygoneæ are exalbuminous, while the embryo differs chiefly from that of Menispermum in being thick, fleshy, and occupying the whole cavity of the seed.

Cotyledons.--There is a great amount of variety in the cotyledons of the different genera belonging to this Order, but few of them come under observation in a living state from the fact that most of the species are members of tropical regions and are of little or no horticultural value.

A large number of species conform however to Menispermum. It is probable that the cotyledons of some members of the Order would prove subterranean on germination, as for instance in the case of Tiliacora, the embryo of which nearly equals the seed in length, and has fleshy adpressed cotyledons. They are also fleshy and thick in Hyperbæna, cortical and fleshy in Fibraurea, as well as in some others belonging to the tribe Pachygoneæ.
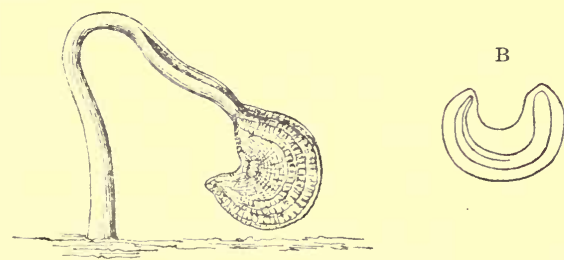

FIg. 140.-Menispermum canadense: A, germinating seedling, $\times 2$; $\mathrm{B}$, vertical section of seed, $\times 2 ; \mathrm{C}$, transverse section of seed, $\times 4$.

Menispermum canadense, $L$. (fig. 140).

Fruit drupaceous, one-seeded, black or bluish black when mature, laterally compressed; endocarp bony, laterally compressed, reniform or horseshoe-shaped, crested along the dorsal edge.

Seed attached to the ventral indented process of the endocarp and conforming to it in shape; testa thin; hilum on the middle of the ventral edge.

Endosperm fleshy, copious, surrounding the embryo, creamy white or yellow.

Embryo linear, much curved in conformity with the seed, fleshy, colourless or yellow; cotyledons linear or semiterete, obtuse, applied 
to each other, face to face, with their backs to the ventral suture of the fruit and their edges in consequence at right angles to the plane of the seed, a little longer than the radicle; radicle cylindrical, obtuse, superior, and close to the base of the style.

Seedling (fig. 141).

Hypocotyl sub-erect, rather firm, about $2.5 \mathrm{~cm}$. long, $1.5 \mathrm{~mm}$. thick, terete, glabrous.

Cotyledons sessile, semi-erect, about $3 \mathrm{~cm}$. long, 1-2 mm. broad, semiterete, entire, obsourely nerved, twisted, glabrous, pale green,

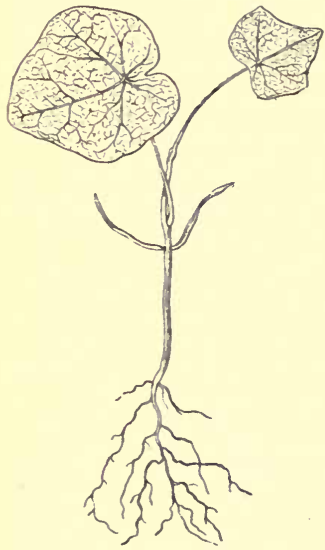

FIc. 141.-Menispermum canadense. Half nat. size. caducous.

Stem slender, twining, the first few internodes $5-7 \cdot 5 \mathrm{~mm}$. long, 1 $\mathrm{mm}$. thick, terete, glabrous, light brown.

Leaves simple, cauline, alternate, exstipulate, petiolate, more or less lobed or angled, peltate, palmatinerved and reticulate, glabrous, membranous, more or less glaucous above, paler beneath with a glaucous bloom ; petiole terete, slightly tapering upwards, glabrous.

No. 1. Peltate, cordate at the base, more or less obtusely fiveangled, radiately five- to sevennerved and closely reticulated.

No. 2. Similar, but often smaller, three- to five-angled, shallowly cordate at the base.

\section{BERBERIDEÆ.}

Benth. et Hook. Gen. Pl. i. 40.

Fruit and Seed.-The fruit of the Berberideæ is a berry or capsule. The ovules are two to indefinite, very rarely solitary, generally anatropous and erect, with the raphe ventral, sometimes orthotropous. The seeds contain a copious, fleshy or somewhat hard endosperm; and the embryo is frequently 
small as in Lardizabala, Caulophyllum, and Nandina, but is occasionally of medium size as in Berberis (fig. 142). In the latter the embryo is nearly three-quarters as long as the seed, and has a terete radicle with broadly ovate, obtuse, emarginate cotyledons. The notch is exceptionally large in this instance, and I could see nothing in the structure of the seed to account for it. It is moreover often altogether absent; but, when present, is apparently due to the slower growth of the organic apex. The seed itself is bluntly triangular in transverse section, and shows the cotyledons lying in the broader plane of the seed, but not always strictly in apposition, a circumstance possibly due to the squeezing produced by the endosperm, while the cavity is a little wider than the embryo it contains. The shape of the seed is due to the mutual pressure of several seeds in a berry or fruit. Either the dorsal aspect of the seed, or the sides, may be the broadest according to the position of the same on the placenta. The general shape of seeds in the order is obovoid, oblong, or globose, and they are generally immersed in pulp without being subject to much pressure when mature.

Cotyledons.-The cotyledons are generally oblong, obtuse, shortly petiolate or subsessile, deep green, glabrous, subcoriaceous, with a few slender, ascending, and generally slightly emarginate veins.

A remarkable type is found in Podophyllum Emodi, a low, creeping or rhizomatous herb from the Himalayas. The blades of the cotyledons are roundly oval, entire or minutely emarginate, with a small tooth in the notch, five- to sevennerved and faintly reticulated and spring horizontally from the apex of a common, terete, rather slender petiole, about 2 inches in length, formed by cohesion of the original two. The petiole splits by a lateral fissure close to the base to allow the exit of the plumule. Instances of this have already been given in Ranunculaceæ. ${ }^{1}$

Berberis Aquifolium, Pursh. (fig. 142).

Frnit baccate, ovoid or ellipsoid, glabrous, deep purple, black when mature and covered with a glaucous bloom tipped with the 
short stout style and annular stigma, one-celled; seeds four to six or fewer, seldom more ; mesocarp juicy, deep vinous purple; endocarp thin, membranous.
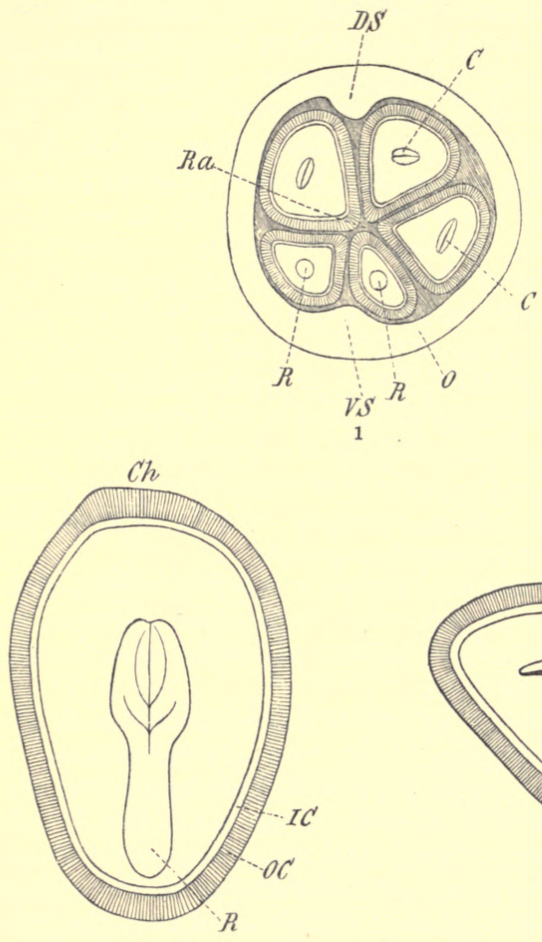

1

2

Fig. 142.-Berberis Aquifolium.

1, Transverse section of fruit, $\times 5: D S$, dorsal suture; $R a$, raphe; $R R$, radicles ; $C, C$, cotyledons ; $V S$, ventral suture; $O$, ovary wall or pericarp.

2 , Longitudinal section of seed, $\times 10: C h$, chalaza; $R$, radicle; $O C$, outer coat (testa); IC, inner coat (tegmen).

3, Transverse section of seed, $\times 10: C$, cotyledon; $O C$, testa; $I C$, tegmen; $R a$, raphe.

Seed oblong-obovoid, obtusely trigonous, or sometimes variously angled by mutual pressure, broadest on the dorsal aspect or the sides according to position (the latter generally characterises those 
seeds towards the upper end of the placenta), pale brown, glabrous, shining; testa thick, coriaceous; tegmen thin, membranous; hilum and micropyle contiguous, basal, the hilum forming a round or oval depressed cavity with a thickened dark margin; raphe ventral, forming a thickening on the ventral angle; chalaza apical, conspicuous.

Endosperm in the mature seed copious, fleshy, white.

Embryo considerably shorter than the endosperm, straight, colourless ; cotyledons oral, obtuse, minutely emarginate, otherwise entire, sessile, trinerved at the base, then again from below the middle to the apex, where the lateral nerves unite with the midrib, and are themselves slightly branched; nearly or quite flat, and applied to one another face to face, or frequently pushed apart with the edges overlapping, lying in the broad way of the seed with their backs to the placenta; radicle cylindrical, obtuse, or thickest near the point, about as long as the cotyledons, embedded in the endosperm close to the micropyle.

There are sometimes three cotyledons ; and in other cases, by proliferation, a second and smaller embryo is produced, closely applied to the larger and perfect one.

Seedling (fig. 143).

Hypocotyl woody, erect, terete, about $3.6 \mathrm{~cm}$. long.

Cotyledons oblong, obtusely pointed, narrowed into the petiole, glabrous, $1.5 \mathrm{~cm}$. long, $5 \mathrm{~mm}$. broad.

Stem woody, erect, lower internodes undeveloped.

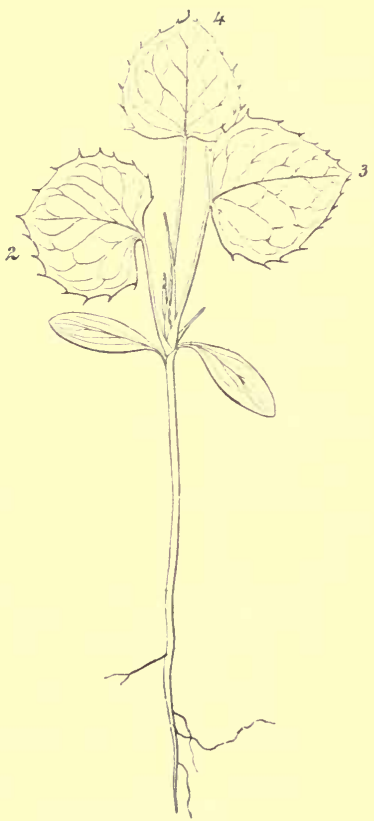

Frg. 143.-Berberis Aquifolium. Nat. size.

Leaves simple in the seedling stage, ultimately imparipinnate, cauline, alternate, stipulate, petiolate, glabrous, coriaceous, reticulately nerved, deep green above, glaucous beneath; petioles filiform, wiry, dilated and sheathing at the base, articulated with the 
lamina; joint swollen; stipules adnate to the petioles with a small, subulate, acute, free point.

No. 1. Reniform, cuspidate, minutely spinous-serrulate.

No. 2. Reniform, cuspidate, finely spinous-serrate, five-nerved at the base.

Nos. 3 and 4. Cordate, finely spinous-serrate, five-nerved at the base.

No. 5. (In a second specimen) unequally bi-foliolate; terminal leaflet obliquely ovate, spinous-serrate; lateral leaflet obliquely oblong-ovate, obtuse, cut away from the base of the terminal one.

No. 6. Trifoliolate ; terminal leaflet oval, spinous-serrate ; lateral leaflets obliquely ovate, spinous-serrate.

Subsequent forms are three- to five-foliolate; lateral leaflets oblong, ovate, actute, spinous-serrate; terminal leaflet oblong-cordate, or simply ovate, acute, spinous-serrate.

Ultimate leaves three- to nine-foliolate ; lateral leaflets obliquely ovate, cut away on the upper side at the base ; terminal one ovate; all spinous-serrate with slightly repand teeth.

Berberis erecta, Auct.?

Hypocotyl similar to that of B. Aquifolium.

Cotyledons subsessile, $1 \cdot 25-1 \cdot 5 \mathrm{~cm}$. long, 4-5 mm. broad, linearoblong, obtuse and emarginate, alternately and ascendingly nerved, glabrous, thin, coriaceous, dull dark green on the upper side, lighter and shining beneath.

Stem firm, terete, glabrous, brownish green, internodes very short.

Leaves, Nos. 1-10. Alike, simple, cauline, alternate, petiolate, alternately nerved and reticulate, glabrous, coriaceous, deep green above, paler beneath; margin spinous-serrate; petioles slender, wiry, more or less sheathing at the base or stipulate.

Berberis vulgaris, L., var. sulcata.

Hypocotyl as in B. Aquifolium, $1 \mathrm{~cm}$. to $2.5 \mathrm{~cm}$. above the soil.

Cotyledons oblong, obtuse, coriaceous, shortly petiolate, $1 \cdot 25 \mathrm{~cm}$. long, $6 \mathrm{~mm}$. broad ; petiole $1.5 \mathrm{~mm}$. long.

Stem woody, erect, terete, glabrous, thickened at the nodes, pale green suffused with red; internodes very irregularly developed; first three to nine undeveloped: in specimen described first three undeveloped; 4 th internode $5.5 \mathrm{~mm}$. long; 5th $1 \mathrm{~cm}$.; 6 th 4.5 mm. ; 7th-10th undeveloped. 
Leaves simple, cauline, alternate, stipulate, petiolate, glabrous, spinous-serrate with the spines directed alternately upwards and downwards forming two rows; petioles filiform, slender, reddish, glabrous, dilated and amplexicaul at the base; stipules minute, nearly wholly adnate to the sheath of the petiole.

No. 1. Ovate, cordate, obtuse.

No. 2. Reniform.

No. 3. Broadly cordate, obtuse.

Nos. 4-6. Cordate, obtuse.

No. 7. Small, rotund-cordate.

Berberis concinua, Hook. $f$.

Hypocotyl erect, terete, glabrous, $3 \cdot 5-4 \mathrm{~mm}$. long, yellowishgreen.

Cotyledons oval or oblong, slightly emarginate, fleshy, petiolate, with short broadish petioles, glabrous, dull green; midribwith numerous ascending branched veinlets, similar to the venation in the leaves.

First leaves opposite, ovate, or subrotund, spiny, shining green above, glaucous-green below, otherwise as in the preceding species.

Berberis sibirica, Pall.

Hypocotyl very similar to that of B. Aquifolium.

Cotyledons very similar to those of B. concinna. The emarginate character is at first very slight or altogether wanting.

Stem erect, terete, herbaceous, ultimately woody ; 1st and 2nd internodes but slightly developed; 3rd 3-4 $\mathrm{mm}$. in length; 4 th exceedingly short.

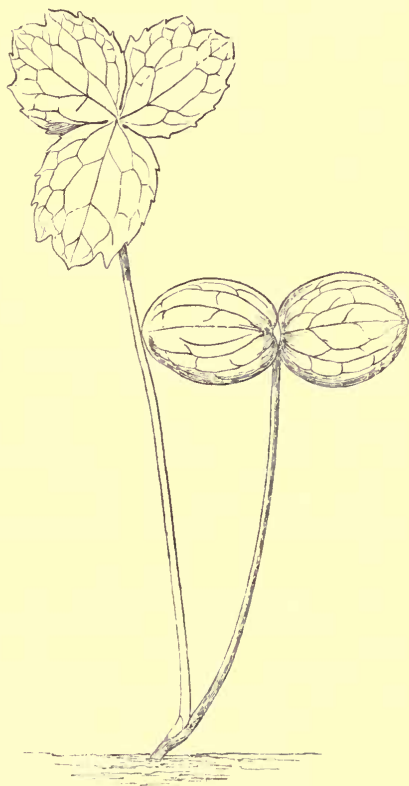

FIG. 144.-Podophyllum Emodi. Nat. size.

First leaves very similar to those of B. vulgaris. 
Podophyllum Emodi, Wall. (fig. 144).

Hypocotyl undeveloped.

Cotyledons broadly oval or rotund-oval, entire or minutely emarginate, with a small tooth in the notch, five- to seven-nerved and faintly reticulate, glabrous, convex above, margin revolute, light green above, pale beneath, shining on both surfaces ; lamina $17 \mathrm{~mm}$. long, $14.5 \mathrm{~mm}$. wide; petioles connate into one terete stalk, thinly and minutely pubescent, pale green, shining, split on one side at the base to allow the plumule to escape, $4 \cdot 9 \mathrm{~cm}$. long.

Stem herbaceous, forming an underground rhizome; 1 st and following internodes undeveloped.

Leaves simple, peltate, radiately or palmately-nerved and partite, radical, alternate, exstipulate, petiolate, glabrous or thinly ciliate, with the lobes one-nerved and strongly reticulate; petiole terete (at least in the seedling stage), glabrous, pale green, erect.

No. 1. Tripartite, with the segments radiating equally in form of a triangle; lobes oval, obtuse, mucronate, irregularly, acutely, and mucronately serrate, the terminal one slightly the largest.

\section{NYMPH EACEE.}

Benth. et Hook. Gen. Pl. i. 45.

Fruit and Seed.-Carpels three to many, free or more or less immersed in the torus, indehiscent when mature and distinct or united to form a fleshy and spongy or pulpy fruit. Ovules one to many, anatropous, pendulous. The embryo in Nelumbo occupies the whole seed, while in the rest of the Order it is very small and there is both endosperm and perisperm. Such cases are very rare; they occur also in the Piperaceæ and in the Zingibereæ, a tribe of the Order Scitamineæ. In the Nymphæaceæ, however, the seed is almost entirely occupied with perisperm, the endosperm being reduced to a thin layer forming a more or less fleshy amniotic sac enclosing the em. bryo at the apex of the perisperm. The seeds are usually anatropous, but in a fruit of Nuphar some may frequently be found that are orthotropous. The seeds are very numerous in Nymphæa, Victoria, and others, and are scattered all over the walls or septa of the ovary. They are few in Cabomba, 
Brasenia, Euryale, and one to two in each carpel or nut of Nelumbium. The ripe seeds are often covered with a pulpy or fleshy aril, which in Euryale is large and fleshy, and serves to float the seeds after liberation from the spongy, baccate fruit, until it bursts or gets broken, when the seeds immediately sink.

The embryo of Cabomba differs from that of Nuphar or Victoria in being shortened, flattened, and rhomboid in vertical section with a scarcely discernible caulicle connecting the cotyledons.

The seeds of Nelumbium differ from all others of the Order in being exalbuminous. The seed contains an embryo consisting of two large, hemispherical, fleshy cotyledons connected by the caulicle or primary axis. Between these is a strongly developed plumule, the leaves of which are closely longitudinally involute at the margins. The petiole is also bent backwards in the direction of the radicle. Germination is very rapid after access of water to the embryo and takes place in a very few days if a small hole is artificially made in the woody pericarp.

Cotyledons.-The typical cotyledons of this Order as far as observed are subterranean-that is, remain in the seed even after germination. Nymphæa, Victoria, and Euryale may be given as examples. Another type is seen in Nelumbium, which, alone in the Order, has exalbuminous seeds. These are larger than any other of the Nymphæaceæ, and contained in a thick and lignified pericarp, while the embryo occupies the whole of the interior, to which it conforms. The cotyledons are hemispherical and lodge between them the greatly enlarged or advanced plumule. They are also subterranean during germination, serving merely as a storehouse of reserve-material.

Leaves. - The leaves of most species of the Order are floating and exhibit but a few types. Seedlings are generally heterophyllous, a circumstance of frequent occurrence amongst aquatic plants whether phanerogams or cryptogams. In the adult state of the plants, all of which are aquatic or marshloving herbs, four distinct types may be given, namely, those which are oblong, orbicular, seutiform, or subsagittate, represented by Nymphæa and Nuphar; secondly, peltate and floating leaves, as seen in Brasenia, Victoria, and Euryale; thirdly, 
peltate and aerial leaves, exhibited by Nelumbium ; and lastly, the finely-divided submerged leaves of Cabomba, which are palmately cut up into slender thread-like segments, resembling those of some forms of Ranunculus aquatilis. The floating leaves of Cabomba are peltate and orbicular.

The stages of the advancing seedling from the juvenile to the adult state, with regard to the leaves, may be readily examined in Nymphæa, Victoria, or Euryale. The seedling of Nymphæa Lotus, var. thermalis, in germination throws down a long root (primary root) into the soil or mud, while the first internode of the plumule grows a little and gives off the first leaf, which is short, slender, and filiform. The first leaf in other species is often longer than in this case. The second, third, and fourth leaves are oblong, lanceolate, obtuse, and all submerged in the water where the seedlings germinated. The ultimate leaves are peltate, orbicular, wavy at the margin, but the basal sinus is open, or at least not connate.

The primary leaves of Victoria and Euryale are even more varied, and, like those of Nymphæa, are produced in a rosette. The first internode in both these genera is more elongated than in the Nymphæa described, while the succeeding ones are undeveloped. From the base of this rosette, strong, adrentitious roots are developed, which soon supplant the primary root. The first leaf of Victoria is filiform and slender, without a spreading blade; the second is narrowly oblong and petiolate; the third is hastate, petiolate, with a long, slender point; and the fourth is oval in outline, peltate, with the basal sinus partly connate, and furnished with a petiole capable of elongating to 18 or 24 inches or even more,' according to the depth of the water in which the seedlings have germinated.

The seedling of Euryale ferox behaves in exactly the same way as that of Victoria, but the second and third leaves are rather stronger and broader. The whole seedling is larger, due no doubt to the larger seed and greater amount of reserve food-material at its command. The fourth leaf in both cases is a floating one and marks a great advance in the development of the plant. The three primary ones are always submerged, at least when the water is deep enough, and probably indicate the ancestral forms through which the 
leaves have passed to their present condition in the adult plant. After the fourth, which is regularly the first floating leaf in both Victoria and Euryale, the succeeding ones become connate along the whole of their basal edges, attaining a perfectly orbicular form by rapid stages. Those of Victoria become turned up at the edges after the plant has reached a considerable size, while those of Euryale always remain flat, merely increasing in diameter. The largest leaves of Victoria are from 6 to 7 feet across, with a circumference of 18 to 21 feet, perfectly orbicular, with the edges turned up to a depth . of from 3 to 6 inches.

The peltate and aerial type of leaf is exhibited by Nelumbium speciosum, whose strong terete petioles vary from 3 to 6 feet in height, bearing at the top a nearly horizontal, peltate, orbicular, umbilicate, glaucous-green lamina, 12, 18, or more inches in diameter.

Finely-cut leaves oceur only in the genus Cabomba, the greater number of which are submerged even in the adult state of the plant. Aerial, peltate, orbicular, and entire leaves seem to be developed chiefly from the apex of the stem when flowering, as the blooms are aerial. The leaves of Barclaya are linear, oblong, or orbicular, recalling in a measure the early stages of Nymphæa. The stem of Cabomba and Brasenia is slender and terete, with elongated internodes, whereas the stem of the other Nymphæaceæ forms a stout, fleshy rhizome or is shortened to a tuber.

\section{Nymphæa Lotus, L., var. thermalis.}

Primary root very long, slender, with numerous root-hairs on the older part, which is brown, but with very few, and at first no, lateral rootlets. Strong adventitious roots are ultimately given off from the second node, below the leaves, and these finally supersede the primary root.

Hypocotyl tapering downwards and indistinguishable from the root proper, subterranean.

Cotyledons very small, remaining in the testa and attaching the young plant to the seed. Seed small, black, globose; testa reticulate.

Stem fleshy, forming a small black ovoid tuber or bulb-like rhizome.

Leaves simple, radical, alternate, exstipulate, petiolate, glabrous, coriaceous or subfleshy, deep green and shining above, pale beneath, 
midrib strongly protruding on the lower surface with many nerves radiating from its base, and given off alternately or suboppositely throughout its length; nerves ascending, forking, reticulate; petiole long, terete, glabrous, pale green, containing two large, central, semi-cylindrical cavities surrounded by eight small ones.

No. 1. Filiform, tapering to the tip and without a lamina, submerged, about $1 \mathrm{~cm}$. long.

Nos. 2-4. Lanceolate-oblong, obtuse, rounded at the base, with a distinct midrib, brownish-green, finely mottled with purple on both surfaces, thin or membranous, submerged.

Ultimate leaves oval or orbicular, floating, slightly peltate by the union of their basal edges for about $1.4 \mathrm{~cm}$.; with slightly diverging auricles, shallowly and acutely repand-dentate, with three nerves converging and entering each tooth, deep green and lucid above, paler beneath and marked with a few irregular discoloured blotches.

The germination of $\mathbf{N}$. alba has been described by Tittmann, 'Denkschrift. der K. Baier. Bot. Ges.' Bd. ii. 1822, p. 101.

Nuphar lutea has also been described by Tittmann in the same memoir.

\section{SARRACENIACEÆ.}

Benth. et Hook. Gen. Pl. i. 48.

Fruit and Seed.-The pistil is superior, syncarpous, with a three- to five-celled ovary made up of as many carpels. The placentation is axile, the numerous ovules are horizon tal, anatropous, and arranged in many series. The fruit is capsular. The seeds are small, numerous, filled with a copious endosperm surrounding a minute embryo near the hilum. The testa is crustaceous, loosely reticulate, or bristly.

The seeds of Sarracenia are short, oblong, nearly or quite sessile, or with a finely reticulated testa, and a very stout raphe forming a deep ridge running along the whole of one side. The very minute embryo lies in the endosperm close to the hilum, and the cotyledons equal the radicle in length. The seeds of Darlingtonia californica ${ }^{1}$ resemble long stalked clublike processes, provided especially at the apex with barb-like bristles. These are longest and strongest at the apical end.

1 See the figure, Le Maout and Decaisne, System of Botany (English translation), p. 213. 
The seed itself is oval in outline, and the funicle terete or cylindrical. The embryo is also cylindrical and nearly as long as the endosperm. The cotyledons are plano-convex, and many times shorter than the radicle.

Seedling.-After germination the cotyledons increase greatly in length proportionately to their width. The hypocotyl is terete, slender, of considerable length, surmounted by the linear, acute, slender, one-nerved cotyledons, which are dilated and connate at the base, forming a little cup surrounding the plumule.

The first leaf of Darlingtonia californica ${ }^{1}$ is narrowly linear, acute, and resembles the cotyledons; but is smaller and shorter. The second and third leaves are clavate, tubular, sheathing at the base, and ending in subulate, hooked, or incurved points.

The adult leaves vary from 12 to 18 inches in length, and are all radical, with the petiole tubular, twisted half round on its axis, furnished with a narrow wing on one side, on the edge of which are glands, vaulted, saccate, and recurved at the apex with the orbicular mouth on the lower side of the hood and facing downwards, striate longitudinally with parallel nerves and smaller ones between them; lamina at the lower and outer edge of the hood, narrowed at the base, with two oblong or lanceolate widely diverging lobes of some considerable length. The interior of the pitcher is furnished with hairs pointing downwards; near the upper end they are short and conical, those below are longer. They are of a glandular nature and serve to decompose insects, which are caught in large numbers.

\section{PAPAVERACEE.}

Benth. et Hook. Gen. Pl. i. 49.

Fruit and Seed.-In this Order the carpels are generally connate into an ovoid or oblong one-celled ovary eventually forming a capsule or pod; they are however distinct in Platystemon, and form a two-celled ovary in Glaucium ; the ovules are anatropous, ascending or horizontal; the micropyle is inferior ;

${ }^{1}$ Le Maout and Decaisne, p. 213. 
and the raphe superior or lateral. The embryo is minute The seeds are globose or reniform, smooth (Sanguinaria, Chelidonium, Hypecoum, Adlumia, \&c.) or alveolate (Papaver, Meconopsis, Glaucium, Rœmeria, \&c.).

One species of Corydalis presents us with an interesting ease of what I have proposed to eall Heterocarpism. ${ }^{1}$ That is to say, the plant produces two kinds of fruit, one somewhat flattened, short and broad, with rounded angles, the other elongated, hooked, and shaped like a shepherd's crook with a thickened staff. The hook perhaps serves for dispersion. It is possible that the alveolate surface of the seed may serve the same purpose-the depressions imprisoning, as it were, a certain quantity of air, and thus lowering the specific gravity.

In the Poppies the seeds are so situated that they can only leave the capsule if it be swung or jerked by the wind. In the case of trees, even seeds with no special adaptation for dispersion must be often carried by the wind to some distance, and to a certain, though less extent this must hold good even with herbaceous plants. It throws light on the, at first sight, eurious fact that in so many plants with small heary seeds the capsules open not at the bottom, as one might perhaps have been disposed to expect, but at the top. A good illustration is afforded by the well-known case of the common Poppy, in which the upper part of the eapsule presents a series of little doors through which, when the plant is swung by the wind, the seeds come out one by one. The little doors are protected from rain by overhanging eaves, and are even said to shut of themselves in wet weather. ${ }^{2}$

Cotyledons.-There are at least four distinct types of cotyledons in the Order, namely, linear, broadly oblong, bifid, and ovate. The first is the most prevalent and characteristic, and may be seen in Platystemon, Papaver, Argemone, Meconopsis, Glaucium, Rœemeria, Hypecoum, and Fumaria. In Papaver villosum var. Heldreichii (fig. 145) they are oblong-linear, obtuse, entire, sessile, one-nerved, and glabrous. Others vary from this in being more slender, and more distinctly linear, and some are narrowed to a petiole as in P. spicatum and occasionally in Meconopsis cambrica. The midrib is not always discernible 
in fresh specimens. A slight modification oceurs in Platystemon californicus (fig. 146), Rœmeria refracta, and Argemone mexicana (fig. 147), where the cotyledons are connate at the base, forming a cup around the plumule. Those of the latter are 16 to $20 \mathrm{~mm}$. long. while in Hypecoum procumbens (fig. 153) they are from 28 to $32 \mathrm{~mm}$., and a similar length in Fumaria.

The second type is seen in Bocconia frutescens (fig. 150), a shrubby species in which the carpel contains only one ovule developing into a very large seed for the Order. The cotyledons are oblong, obtuse, tapering to a short, broad petiole, slenderly five-nerved, faintly reticulate, 28 to $36.5 \mathrm{~mm}$. long, and 6.5 to $11 \mathrm{~mm}$. wide.

The bifid cotyledons of Eschscholtzia californica (fig. 152) may be described as an aberrant type, seeing that they are quite entire in E. tenuifolia. Those of the former are linear, slender, 28-30 mm. long, bifid for $18 \mathrm{~mm}$. of their upper portion, with acute segments, slightly dilated and connate at the very base. When full grown they are only about $1 \mathrm{~mm}$. broad below the fissure, and the segments diverge like the prongs of a hay-fork.

A fourth and rather remarkable type is exhibited by Adlumia cirrhosa (fig. 154), Corydalis lutea (fig. 155), and Cysticapnos africana. In Adlumia they are broadly ovate, acute, three- to five-nerved; in Corydalis lutea ovate or lanceolate-elliptic, with the lamina usually sharply deflexed ; and oblong-ovate, and three- to five-nerved in Cysticapnos africana, a Cape species with a bladder-like fruit otherwise similar to the British Corydalis claviculata, but sometimes separated as a distinct genus. All the three plants mentioned have thin membranous delicately-nerved cotyledons with long petioles, thus differing from the species of most other genera in the Order and recalling in their shape that of typical Ranunculaceæ. The peculiar cotyledons of Eschscholtzia californica have already been referred to. If the seed be moderately well buried in the earth, the bent and elongating hypocotyl pulls the cotyledons out of the testa and they soon unfcld to the light. Should the seed, however, be lightly buried, it is carried up on the tips of the cotyledons, and the latter soon bulge out- 
wards, balloon-fashion, in their efforts to unfold to the light. As they elongate they becorne twisted, turning their upper side to the light, until they finally escape from the dried-up testa, and the membranous, skin-like, used-up endosperm ; they often remain twisted for a short time after they are quite free, but finally assume a spreading or ascending position, with the segments about as long as the undivided portion and diverging like the prongs of a hay-fork. The lobes by narrowing the cotyledons would seem to facilitate twisting in order to escape from the seed. E. tenuifolia, with a smaller embryo and narrower but undivided cotyledons, is otherwise similar to E. californica, and germinates in a similar way.

Papaver villosum, Sil., var. Heldreichii (fig. 145).

Hypocotyl subterranean or 1-2 mm. exposed.

Cotyledons oblong-linear, obtuse, glabrous.

Leaves simple, radical, alternate, exstipulate, petiolate.

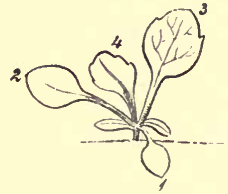

Frg. 145.-Papaver villosum, var. Heldreichii. Nat. size.

No. 1. Lamina rotund-ovate, obtuse, entire, glabrous ; petiole flattened or slightly channelled above, glabrous, subglaucous.

No. 2. Similar, but larger.

No. 3. Lamina rotund-elliptic, obtuse, with a shallow tooth on each side near the apex, obscurely penninerved and reticulate, glabrous or sparsely pilose.

No. 4. Lamina ovate, obtuse, crenate, cuneate at the base.

The cotyledons in $\mathrm{P}$. caucasicum and $\mathrm{P}$. orientale resemble those of $\mathrm{P}$. villosum. In $\mathrm{P}$. spicatum they are slightly broader in the middle.

Papaver orientale, L., var. major.

Primary root nearly perpendicular, unbranched, colourless.

Hypocotyl terete, glabrous, slender, light greyish-green, $1 \mathrm{~cm}$. long, $\cdot 75 \mathrm{~mm}$. thick.

Cotyledons sessile, linear-lanceolate, obtuse at apex, entire with distinct midrib, thin, glabrous, light greyish-green, $1 \mathrm{~cm}$. long, 2-2.5 mm. broad.

Stem elongated when about to flower.

Leaves as in preceding, but petiolate or sessile, alternately penninerved, more or less coarsely hairy in the adult state, with 
a strong midrib, and a yellow or milky-white juice; petioles when present more or less sheathing at the base.

No. 1. Spathulate, obtuse, entire, or with a tooth on one or both sides near the apex, petiolate, glabrous, thin, glaucous.

No. 2. Similar, larger.

No. 3. Subovate, obtuse, with one obtuse serrature on each side.

Papaver spicatum, Boiss. et Bal.

Hypocotyl extremely short or subterranean.

Cotyledons linear, tapering to the base, 3-4 mm. long, not very persistent.

Leaves glaucous, petiolate; petioles channelled above, dilated and sheathing at the base; juice milky.

Nos. 1, 2, and sometimes 3. Entire, with an oblong to rotund or ovate-obtuse lamina, and ascending or incurved nerves, glabrous.

No. 4. Rotund, obtuse, crenate-serrate, glabrous.

No. 5. Ovate, obtuse, coarsely and distantly crenate-serrate, sparsely pilose on the upper surface; nerves ascending and incurved.

No. 6. Ovate-oblong, obtuse, coarsely and distantly crenate-serrate, pilose on the upper surface.

Platystemon californicus, Benth. (fig. 146).

Primary root tapering downwards with numerous lateral rootlets.

Hypocotyl short, hardly appearing above the soil, stout, obconical.

Cotyledons linear, acute, entire, sessile, glabrous, green, indistinctly oneveined as in the leaves.

Stem with primary internodes undeveloped.

First leaves simple,

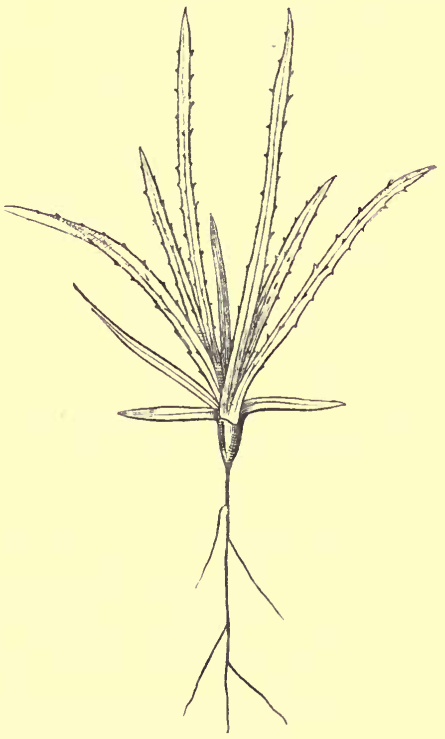

Fig. 146.- Platystemon californicus. Nat. size.

entire, cauline, alternate, exstipulate, sessile, linear, acute, with 
scattered coarse hairs on the upper side, and with a spiny margin, except the first one or two, glabrous on the under side, light green, slightly fleshy, one-veined.

The mode of germination closely resembles that of Eschscholtzia tenuifolia.

Argemone mexicana, $L$. (fig. 147).

Primary root tapering, with numerous branching rootlets.

Hypocotyl undeveloped or subterranean and indistinguishable

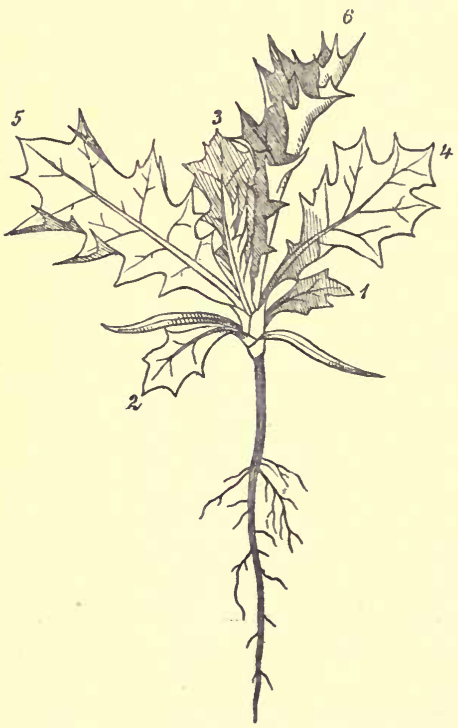

Fig. 147.-Argemone mexicana. Nat. size. from the root.

Cotyledons linear, entire, acute, dilated and connate at the base, forming a cup round the plumule, glabrous, glaucous on both surfaces, without any discernible venation in the fresh state, 16-20 $\mathrm{mm}$. long.

Stem herbaceous, annual, erect, developed when about to flower; primary internodes undeveloped.

Leaves simple, radical and cauline, alternate, exstipulate, sessile, alternately and ascendingly penninerved, pinnatifid, spiny, with thin prickles on both surfaces, otherwise glabrous, deep glaucous - green above with the midrib and principal nerves splashed with white, much paler and uniformly glaucous beneath, dilated and amplexicaul at the base.

Nos. 1-2. Spathulate-cuneate, acutely dentate-serrate near the apex.

No. 3. Spathulate-cuneate, much larger than the first two, spinyserrate.

Nos. 4-6. Obovate, pinnatifid or lobulate, undulate at the margin, with the lobes and teeth tipped with spiny bristles. 
Meconopsis cambrica, Vig. (fig. 148).

Fruit an oblong capsule, tipped with the short, stout, persistent style, one-celled, many-seeded, dehiscing by pores or short valves.

Seed obovoid-reniform, slightly curved, closely reticulated or alveolate, glabrous, dark brown or nearly black; hilum and micropyle contiguous, basal; raphe ventral; chalaza ventral, a little below the apex of the seed and forming a small thickening or crest externally.

Endosperm copious, granular-oily, white.

Embryo small, straight, situated close to the base of the seed, colourless ; cotyledons rotund or rotund-ovate, obtuse, entire, planoconvex, ringent, very short, usually two but sometimes three;

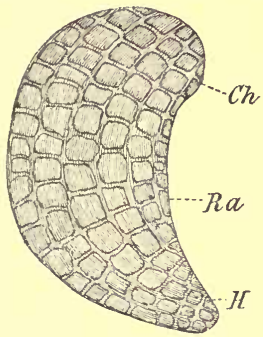

1

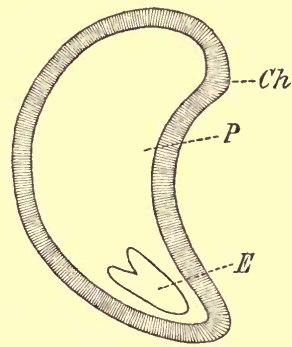

2
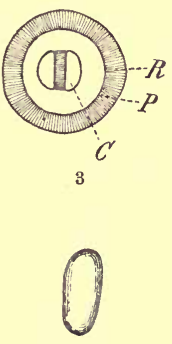

4

FIG. 148.-Meconopsis cambrica.

1, Seed, $\times 30: C h$, chalaza; $R a$, raphe; $H$, hilum.

2, Longitudinal section of seed, $\times 30: E$, embryo; $P$, endosperm ; $C h$, chalaza. 3 , Transverse section of seed, $\times 30: R$, raphe; $P$, endosperm; $C$, cotyledon. 4, Dorsal aspect of embryo, $\times 30$.

radicle short, stout, subturbinate, obtuse, about twice as long as the cotyledons and as broad, lying within the endosperm close to the base of the seed.

\section{Seedling (fig. 149).}

Primary root tapering, colourless, with lateral rootlets.

Hypocotyl fleshy, colourless, 1-4 mm. long.

Cotyledons linear, obtuse, sessile, or frequently narrowed at the base and lengthening into a petiole $5 \mathrm{~mm}$. to $1 \mathrm{~cm}$. long, 1 to $1.5 \mathrm{~mm}$. broad.

Leaves simple, radical and cauline, alternate, exsipulate, petiolate, glabrous, with milky juice; petiole subterete, channelled above, pale green, succulent.

No. 1. Entire, with an ovate, oval, or elliptic lamina. 
No. 2. Similar or sometimes slightly trifid.

No. 3. Deeply trifid; lateral lobes oblique; terminal lobe somewhat obovate, obtuse.

No. 4. Tripartite; lateral lobes oblique or subauricled ; terminal lobe subelliptic or cuneate, subtrifid.
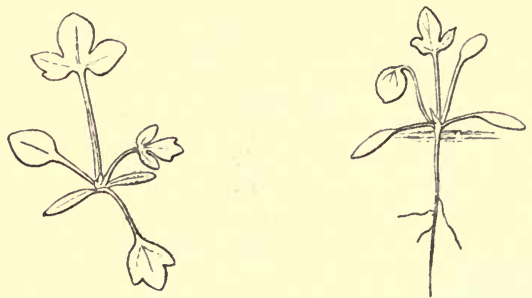

Fra. 149.-Meconopsis cambrica. Nat. size.

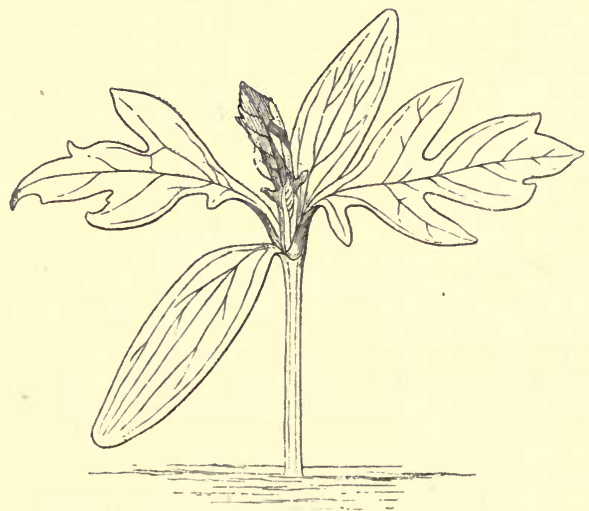

Fia. 150.-Bocconia frutescens. Nat. size.

Bocconia frutescens, $L$. (fig. 150).

Hypocotyl erect, terete, tapering upwards from a stout base, glabrous, pale reddish or slightly striate, $2-3 \mathrm{~cm}$. above the soil.

Cotyledons foliaceous, oblong, obtuse, entire, tapered at the base into a short broad petiole, with many slender, longitudinal nerves, best seen by transmitted light, light glaucous-green above, paler 
beneath with a yellowish hue, slightly reticulate; lamina 26-32 $\mathrm{mm}$. long, $6 \cdot 5-11 \mathrm{~mm}$. wide; petiole broad, flattened above, convex on the back, $2 \cdot 25-4.5 \mathrm{~mm}$. long.

Stem erect, terete, ultimately shrubby; primary internodes undeveloped.

Leaves simple, cauline, alternate, exstipulate, petiolate, alternately and ascendingly penninerved, light glaucous-green above, and obscurely reticulate, paler beneath and distinctly reticulate, glabrous; petiole (in the seedling) semiterete, flattened on the upper side, very slightly winged at the edges, tapering upwards from a broad stout base, rather succulent, with orange-coloured juice.

No. 1. Rhomboid, subacute, tapering to both ends, pinnatifid, with one lobe and a few coarse irregular teeth on each side; lobes or teeth often traversed by two or more longitudinal nerves, and tipped with a glandular mucro.

No. 2. Similar, but larger, and generally more deeply cut.

Glaucium corniculatum, Curt., var. rubrum (fig. 151).

Primary root slender, tapering, colourless, almost devoid of lateral rootlets in the early stage, annual or biennial.

Hypocotyl scarcely distinguishable from the root.

Cotyledons linear, slender, soon perishing.

Stem herbaceous and developed only when about to flower.

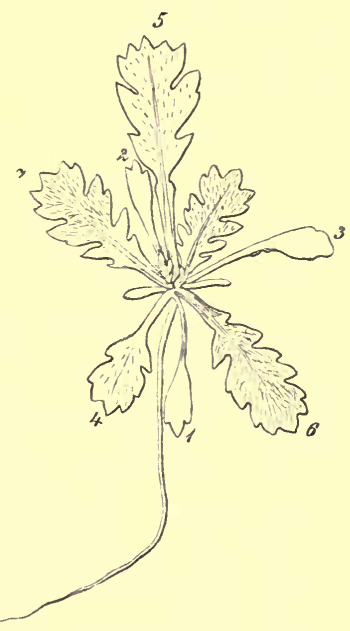

FIG. 151.

Glaucium corniculatum, var. rubrum. Nat. size.

Leaves simple, radical and cauline, alternate, exstipulate, petiolate, more or less pinnatifid or pinnatisect and lobed, pilose on both surfaces, especially when young, deeply glaucous above, paler beneath; petioles flattened above, convex below, pilose or woolly at the margins, dilated and amplexicaul at the base.

Nos. 1-2. Spathulate and entire, or tridentate at the apex.

No. 3. Larger, oblong.

No. 4. Oblong, rather coarsely and acutely serrate. 
No. 5. Cuneate-oblong, somewhat lobed, retuse and dentate at the apex.

No. 6. Somewhat similar but with more numerous lobes.

No. 7. Oblong-cuneate, retuse and tridentate at apex, pinnatifid and tapering very much to the base; lobes and teeth acute, generally tipped with a bristle.

Glancium Serpieri, Heldr.

Cotyledons lanceolate to oblong, obtuse, entire, petiolate, glabrous, pale glaucous-green, pinnatinerved as in the leaves.

Stem with primary internodes undeveloped.

First leaves as in preceding, cauline and cuneate, tridentate above, serrated, with a few long scattered hairs, glaucous-green, pinnatinerved.

\section{Rœmeria refracta, $D C$.}

Hypocotyl terete, its epidermis soon becoming split and completely torn off, 8-13 $\mathrm{mm}$. long.

Cotyledons linear, obtuse, or subacute, entire, connate at the base, glabrous, biconvex, spreading horizontally, 9-11 mm. long.

Stem with its internodes undereloped in the seedling stage.

Leaves simple, radical and cauline, alternate, exstipulate, petiolate, with scattered hairs at least in the young state, brittle, bright green; petiole channelled above, with a prominent ridge beneath, sheathing at the base, narrowly winged as if the leaf were decurrent upon it.

Nos. 1-2. Narrowly spathulate, obtuse, slightly mucronate, tapering gradually into the petiole, entire.

No. 3. Bi- to tri-fid with alternate segments.

Nos. 4-5. Trifid, or 4th to 6th irregularly pinnatifid.

Nos. 6-7. Pinnatifid with alternate segments which are again slightly cut.

Eschscholtzia californica, Cham. (fig. 152).

- Primary root long, tapering, with short lateral rootlets, yellowish, annual.

Hypocotyl short, tapering downwards, pale and stained with red, glabrous, mostly subterranean, about $4 \mathrm{~mm}$. long.

Cotyledons linear, deeply bifid, segments acute, biconvex, glabrous, glaucous, dilated at the base and perfoliate, 2.8 to $3 \mathrm{~cm}$. long (segments about $1.8 \mathrm{~cm}$. long), $1 \mathrm{~mm}$. broad below the fissure.

Stem herbaceous, annual, developed when about to flower.

Leaves simple, radical and cauline, alternate, exstipulate, 
petiolate, glabrous, glaucous on both surfaces; petioles shallowly grooved above, slightly carinate on the back, dilated and clasping at the base. .

No. 1. Cuneate, tripartite ; lateral lobes bifid, terminal trifid; ultimate segments subulate or narrowly oblong, obtuse.

No. 2. Tripartite; lateral lobes cuneate, trifid; terminal one again trilobed with its middle lobe trifid, the others entire.

No. 3. Bi-ternatisect; ultimate segments lanceolate, obtuse, or subacute.

Nos. 4-6. Bi- to tri-ternatisect; ultimate segments as in No. 3.

Ultimate leaves radical, deltoid in outline, tri-ternatisect, with oblanceolate or linear-oblanceolate, subacute segments, tipped with orange-red, petiolate; cauline ex-

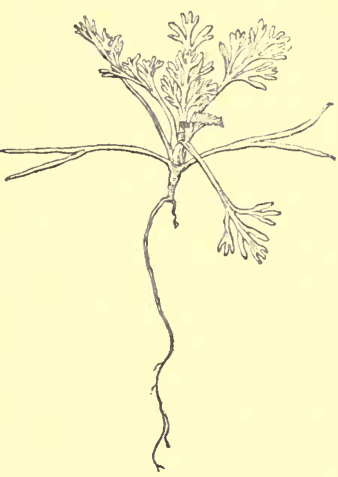

FIG. 152.-Eschscholtzia californica. Nat. size. actly similar or smaller and with shorter petioles.

\section{Eschscholtzia tenuifolia, Benth.}

Primary root as in preceding, but slender, colourless.

Hypocotyl slender, erect, terete, glabrous, pale glaucous-green, or colourless towards the base, $6 \cdot 5-18 \mathrm{~mm}$. long.

Cotyledons slender, linear, attenuated, obtuse, shallowly grooved above, convex on the back, glabrous, glaucous, slightly broader above the middle representing a lamina, ascending or arching outwards above the middle, $14-30 \mathrm{~mm}$. long, $\cdot 5-1 \mathrm{~mm}$. wide.

Stem short, erect, developed when about to flower, leafy ; primary internodes undereloped.

Leaves cauline, entire at first, ultimately pinnatisect, with a vein running through each segment, but not discernible in the fresh state, shallowly grooved above; petioles rounded on the back or subcarinate, grooved above; otherwise as in preceding species.

No. 1. Linear, obtuse, slender, entire, or rarely (? accidental) showing a lateral segment, similar to itself but shorter.

No. 2. Linear, slender, entire, similar to the first.

Hypecoum procumbens, $L$.

Fruit a dry, indehiscent, linear, straight or curved horn-like pod, 
segmented and forming a more or less conspicuous transverse ridge between each seed, each of the latter being contained in a separate lccellus by a transverse development of cellular tissue. During germination the pod or its segments separate slightly along both sutures to allow the seedling to get out.

Seed lenticular, somewhat flattened laterally but convex, rounded on all the edges except the ventral, which is straight, deep brown or almost black, very minutely and inconspicuously glandular or reticuläte.

Germination. When the seeds swell, the pod bursts along both sutures and the radicle protrudes, fixes itself deeply in the soil, and together with the lengthening and straightening hypocotyl assists the cotyledons in making their exit from the seed and pod.

The cotyledons are linear, acute, tapering upwards, and very slender, semiterete at the base, and more or less completely terete upwards, 14-20 mm. long. By their growth in length during

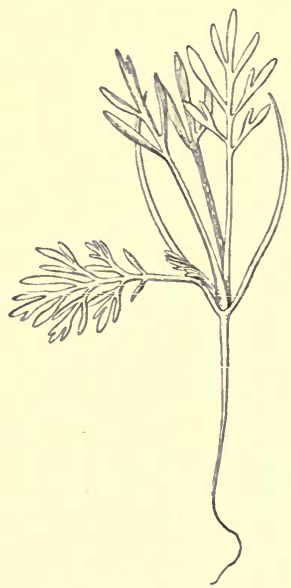

Fig. 153.-Hypecoum procumbens. Nat. size. germination their exit from the seed and pod is materially assisted.

\section{Seedling (fig. 153).}

Primary root slender, tapering, with a few lateral rootlets, annual.

Hypocotyl terete, tapering indistinguishably into the primary root, glabrous, pale green, 3-5 mm. above the soil.

Cotyledons subulate,muchattenuated, slender, tapering upwards from a dilated connate base, sessile, grooved from the base for some distance upwards, pale glaucous-green, fading to a yellowish green when old, glabrous, entire, 2·8-3·2 $\mathrm{cm}$. long, about $1 \mathrm{~mm}$. wide near the base.

Stem annual, developing when about to flower; primary internodes undeveloped.

Leaves simple, radical and cauline, alternate, exstipulate, petiolate, pinnately multisect, with the venation ramifying accordingly, and sending a nerve into every branch or segment, glabrous, glaucous, with slender segments, covered with minute glands; petioles semiterete, flattened or convex above but channelled towards the 
dilated and amplexicaul base, glaucous at first, then a pale green.

No. 1. Pinnatisect, with three oblanceolate-linear, obtuse segments.

No. 2. Similar or with four to five segments, that is, one or two on each side of the leaf.

No. 3. Pinnatisect or slightly bi-pinnatisect, with the secondary divisions on the anterior side of the primary ones ; segments slender, lanceolate-linear.

No. 4. Bi-pinnatisect, with lanceolate-linear, obtuse or rather acute segments.

Adlumia cirrhosa, Raf. (fig. 154).

Primary root tapering, brittle, succulent, yellowish, with a few lateral rootlets.

Hypocotyl erect, terete, succulent, glabrous, reddish, 7-16 mm. long.

Cotyledons petiolate, glabrous, pale green; petioles horizontal, slender, slightly channelled on the upper side, subdilated and connate at the base, $16 \mathrm{~mm}$. long; lamina ovate, acute, faintly five-nerved, pendent, recurved, $6 \mathrm{~mm}$. long, $4 \cdot 25$ $\mathrm{mm}$. broad.

Stem developed the second year to 12 feet or more, slender, climbing by means of tendrils.

Leaves simple, ternatisect, radical and cauline (the second year), alternate, exstipulate, petiolate, glabrous, pale green above, nearly glaucous beneath, thin and delicate, marked

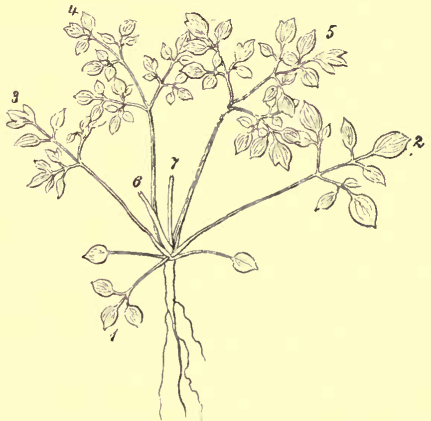

Fı. 154.-Adlumia cirrhosa. Half nat. size. with fine, more or less forking, ascending or suberect veins; petioles succulent, brittle, channelled on the upper side, much dilated at the base and obtusely subcarinate.

Nos. 1 and 2. Ternate; lateral segments ovate, cuspidate; terminal one elliptic, cuspidate. No. 2 in robust specimens biternate.

No. 3. Biternate or in robust seedlings triternate.

No. 4. Triternate. 
No. 5. Triternate, with the terminal lobe of the primary divisions bi- or trifid.

No. 6. Triternate with many of the larger lobes more or less cut.

No. 7. Triternate, and much cut. (Nos. 6 and 7 in fig. 154 have been cut off.)

Ultimate leaves large, triternately multisect; ultimate segments ovate, cuspidate; terminal ones obovate, cuspidate.

Corydalis lutea, DC. (fig. 155).

Hypocotyl erect, terete, glabrous, reddish, about $1 \mathrm{~cm}$. long.

Cotyledons ovate or lanceolate-elliptic, acute, petiolate, glabrous, pale green, often mottled with red; lamina sharply decurved, $6.5 \mathrm{~mm}$. long, $3 \mathrm{~mm}$. broad; petiole terete, glabrous, subdilated at the base, $7 \cdot 5 \mathrm{~mm}$. long.

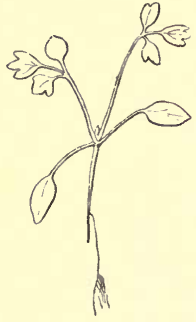

Fig. 155.-Corydalis lutea. Nat. size

Stem herbaceous, short, stout, producing flowering branches.

Leaves simple, ultimately bi-ternatisect, radical and cauline, alternate, exstipulate, petiolate, glabrous, pale glaucous-green; petioles obtusely trigonous, or flattened above and subcarinate beneath, especially towards the base, dilated and semi-amplexicaul at the base, glabrous.

No. 1. Ternatisect; terminal segment rotund, trinerved, trifid; lateral segments rotund, entire or tridentate.

No. 2. Similar.

Ultimate leaves bi- to tri-ternatisect; terminal segment of each primary division cuneate, trifid, with obtuse, mucronate teeth; other segments oval or elliptic, entire or bi- to tri-dentate or -fid, obtuse and mucronate at the tips.

In C. nobilis the cotyledons are oval, oblong, obtuse, and minutely emarginate.

\section{Fumaria Vaillantii, Lois.}

Hypocotyl erect, striated, glabruus, $10 \mathrm{~mm}$. long, reddish.

Cotyledons linear, acute, tapering to the base, entire, light green, glabrous, indistinctly one-veined.

Stem with primary internodes scarcely developed.

Leaves multisect, petiolate, glabrous; 1 st leaf less divided than succeeding leaves, cauline, alternate; segments mostly trilobed, the lobes being again bi- to tri-lobed; lobes linear-lanceolate or linear-oblong, acute. 


\section{Cysticapnos africana, Gaertn.}

Hypocotyl filiform, 3 or $4 \mathrm{~cm}$. long, $\cdot 75 \mathrm{~mm}$. thick, green, with reddish striæ.

Cotyledons petiolate, glabrous, blade $1 \mathrm{~cm}$. long, $4 \mathrm{~mm}$. broad, ovate-lanceolate, trinerved, the lateral nerves sending branches towards the margin only, entire. thin, glaucous; petiole 5 or $6 \mathrm{~mm}$. long, $\cdot 5 \mathrm{~mm}$. thick.

Leaves.-No. 1. Including slender petiole, $1.5 \mathrm{~cm}$. long, 6-8 mm. broad, trifid, glabrous, thin, glaucous.

No. 2. Trisect, basal lobes or sections bifid.

Ultimate leaves simple, multisect, radical and cauline, alternate, exstipulate, petiolate, glabrous, glaucous, membranous; petioles more or less dilated and sheathing at the base.

\section{CRLCIFERT.}

Benth. et Hook. Gen. Pl. i. 57.

Fruit and Seed.-In this great Order the ovary is composed of two connate carpels, very rarely of threeto four, as in 'Tetrapoma, Holargidium (a monotypic Siberian genus now merged in Draba), and sometimes Brassica and Nasturtium ; the ovules are numerous, or few or solitary, pendulous or horizontal, very rarely basilar (Clypeola) or apical (Isatis), campylotropous or half-anatropous, with the raphe ventral and the micropyle superior. The fruit (a pod) is short or elongated, usually twocelled.

The seeds are oblong, subglobose, or flattened and margined, or winged, and exalbuminous (except in some species of Isatis), the embryo occupying the whole seed.

The embryo is rarely straight (Leavenworthia), generally more or less curved. The cotyledons are sometimes linear and coiled on themselves or folded transversely (Diplocolobeæ), but generally broad, sometimes folded in two along their length and embracing the radicle, sometimes incumbent to the radicle (fig. 162), sometimes accumbent (fig. 158).

Diptychocarpus has two kinds of pods, the upper ones, like those of a Matthiola, compressed, with winged seeds, the 
lower ones rounded, indehiscent, and transversely multilocular.

Geococcus buries its pods in the ground.

The Order presents a vast amount of variation in the form of the fruit, seed, and embryo. For purposes of classification of the genera, it is above all things necessary to consider the form and characters of the fruit; though these do not invariably indicate the true lines of natural affinity, as for instance in the case of Raphanus and others amongst the Raphaneæ, and Crambe, Rapistrum, and others amongst the Cakilineæ, which are obviously closely allied to the Brassiceæ.

The Order may be conveniently divided into five groups according to the form and folding of the embryo, excluding some aberrant species which may be dealt with separately. It must be admitted, however, that the form of the embryo alone will not in all cases indicate the true lines of natural affinity, although it offers a convenient means of grouping the seeds. The latter are exceedingly variable in mere outline, being flat, compressed, ovoid, oblong, linear, globular, or winged; but none of these characters are so constant as are the various forms of the embryo. The latter may be briefly described as having the cotyledons accumbent, incumbent, conduplicate, transversely biplicate, and circinately convolute, while in the aberrant forms the cotyledons are sometimes deeply divided.

Taking the Wallflower (Cheiranthus Cheiri) (fig. 158) to represent embryos having accumbent cotyledons, we find that the seed is oblong-oval, much compressed laterally, with the edges produced all round into a thin membranous wing. The embryo is flat with ovate, obtuse, entire cotyledons, and the terete, slightly curved radicle is laid against the edges of the closely adpressed seed-leaves. If the double seed-coat is removed from one side of the seed, the edges of the petioles are seen, in some cases at least, as if the embryo had originated with the cotyledons in the narrow plane of the seed and the seed-leaves had afterwards become twisted round to accommodate them selves in the broader plane during the process of growth.

Embryos with accumbent cotyledons prevail throughout the Arabideæ, Alyssineæ, Thlaspideæ, and in five genera at 
least of the Isatideæ, in Cakile amongst the Cakilineæ, and in Chorispora amongst the Raphaneæ.

Other genera agreeing with Cheiranthus in the flattened and winged characters of the seeds are Matthiola, Diptychocarpus. Cithareloma, Arabis, Farsetia, Vesicaria, Lunaria, and others. Seeds in several other genera have a broad or narrow margin as in Streptanthus and Lonchophora, but can hardly be called winged, while some of the species of Parrya have broadly winged and others entirely wingless seeds.

Cheiranthus pygmæus has accumbent or incumbent, straight or convolute cotyledons even in the same pod.

Wingless seeds whose embryos have accumbent cotyledons are represented by Nasturtium, Cardamine, Aubrietia, Barbarea, Alyssum, Draba, Cochlearia, Biscutella, Thlaspi, Iberis, Cakile, and Chorispora. The seeds of the genera just mentioned further differ amongst themselves in being ovoid or turgid as in Nasturtium and Cochlearia, somewhat compressed in Barbarea, and very much so, or almost flat, in Draba, Alyssum, Biscutella, and Iberis.

Besides Cheiranthus pygmæus above mentioned, there are several other cases where the embryo is slightly but only occasionally modified so that the normally accumbent cotyledons become obliquely so or slightly incumbent in species of Barbarea, Draba bruniæfolia, D. boreale, D. frigida, Cochlearia arctica, C. glauciphylla, Cakile maritima, and possibly some others where the character may be even more marked. Lepidium virginicum also belongs to the group with accumbent cotyledons. It differs markedly from the rest of its congeners, all of which have incumbent cotyledons. Decaptera, consisting of a single species from Chili, has also accumbent cotyledons, although it belongs to the Lepidineæ like the last.

Incumbent cotyledons are characteristic of Sisymbrieæ, Camelineæ, and Lepidineæ, three tribes of considerable size, while many instances also occur in the Isatidex. The cotyledons are likewise incumbent in the Brassiceæ primarily as well as in genera of the Isatideæ, Cakilineæ, and Raphaneæ, with longitudinally plicate or conduplicate cotyledons; but it is convenient to group these types by themselves on account of the distinctly more complicated character of the embryo. The 
seeds in this group are oblong, oval, ovoid, or variously angled ; and there is a general absence of the flattened or winged character typical of the first group. In many instances there is a distinct ridge along one side of the seed, generally, if not always, on the dorsal aspect, and in this the radicle is accommodated, the ridge itself finding room in a corresponding concave or grooved line along the middle of the two valves of the siliqua. Should the seeds be comparatively large, they are arranged in one line along the middle of the two cavities of the ovary. The various species of Erysimum and Sisymbrium show this well. The carpels of Lepidium are laterally flattened and keeled on the back; each cavity contains one, rarely two seeds ; and these are suspended from the apex of the plaeenta, and trigonous with the thinnest edge lying in the cavity of the keel as in L. sativum and L. graminifolium (fig. 171) ; in other cases they are laterally flattened but not trigonous. The seeds of Ethionema heterocarpum are covered with mucilaginous tubercles, and the testa of Lepidium is also mucilaginous when moist, which may assist in retaining it in the soil, while the embryo escapes during germination.

Several curious modifications oceur in this group. The oblong seeds of Isatis tinctoria (fig. 174) are solitary in each fruit, which is indehiscent, and furnished with a curious corky wing along the back of each carpel. The cotyledons are concave longitudinally and slightly embrace the stout radicle. Hesperis matronalis (fig. 162) is unsymmetrical, one of the cotyledons being considerably smaller than the other. The seeds of Sisymbrium officinale are variously shaped and angled, while the radicle in most cases lies obliquely across the back of the cotyledons. The same may be said of Ochthodium ægyptiacum (fig. 175), which has a woody, curiously tuberculated, indehiscent fruit. Tetrapoma, a Siberian genus, containing only one species, has a one- or four-celled ovary, according as the partitions are developed to the centre or not, while there are four split or double placentas with the seeds arranged in eight rows.

Conduplicate cotyledons are typically characteristic of all the eleven genera classed in the tribe Brassiceæ; but they also 
occur in Tetrapterygium, Calepina, Boleum, and Zilla amongst the Isatideæ, and several other genera in this tribe show an approach to the same arrangement by the cotyledons being longitudinally coneave, slightly folded or longitudinally plicate, as in Myagrum, Schimpera, and Texiera. All the seven genera of the Isatideæ just mentioned have short one- to two-celled fruits with as many seeds, thick and lignified pericarps, the thicker parts of which become corky while the fruit is indehiscent. As far as the fruit is concerned they seem reduced forms of Cruciferæ adapted for countries with a dry climate, or for dry, rocky, or chalky places. They may also be allied to the Bras. siceæ, just as Crambe, Muricaria, Rapistrum, Enarthrocarpus, Hemicrambe, Erucaria, Guiraoa, Fortuynia, Physorhynchus, and Morisia amongst the Cakilineæ, undoubtedly are. Raphanus and Raffenaldia amongst the Raphaneæ also approximate to Brassica in the form of the embryo, but differ in having fruits which break up into lomenta or indehiscent pieces each containing one seed. The cotyledons of Anchonium and Sterigma, also belonging to the Raphaneæ, have incumbent and flat or concave cotyledons, showing a tendency to become conduplicate. The shape of seeds having conduplicate cotyledons varies considerably, but taking Brassica, Diplotaxis, Eruca, Succovia, Crambe, and Raphanus as types, the seeds are globose or ovoid. This may be seen by reference to Brassica oleracea or B. nigra. The relation of the seed to the peculiar form of the cotyledon has been already described (ante, p. 43).

Raphanus sativus (fig. 62) and R. maritimus agree in most essential particulars with Brassica, except that the seeds are generally larger, and enclosed singly in indehiscent segments of the pod. A rather differently shaped seed occurs in Zilla myagroides. The fruit is globular, indehiscent, thick, lignified, and surrounded with another thick, 'suberous' or corky layer--the exocarp. Two oval and slightly compressed or lenticular seeds occupy a central position, side by side but in separate cells. The corky exocarp and woody endocarp would indicate adaptation to a dry climate, and we find that the four known species are natives of North Africa, Arabia, and Persia. 
Another modification occurs in Orychophragmus, which has an oblong, subtriquetrous seed. A third and more remarkable type is presented by Euzomodendron, Savignya, Moricandia and Henophyton, the seeds of which are compressed, the testa forming a line round the margin, or a narrow or even broad wing similar to what occurs in Cheiranthus, Matthiola, Lunaria, or Vesicaria with accumbent cotyledons.

Transversely biplicate cotyledons occur in a few genera, of which the principal is Heliophila, containing about fifty or sixty species of annual or perennial herbs with a few shrubs. The fruits vary considerably in being oblong, oval, linearlanceolate or linear and moniliform, and on this account the genus has been split up into some half-a-dozen by different authors. The seeds also vary in being oblong, oval, or almost perfectly orbicular, much compressed or quite flattened laterally, and wingless as in Heliophila pilosa, var. incisa (fig. 166), or broadly winged in $\mathrm{H}$. crithmifolia, $\mathrm{H}$. callosa, and others. There is a more or less deep notch at the hilum in winged seeds. The cotyledons are incumbent, transversely biplicate, and placed in the narrow plane of the seeds with their backs to the placenta. They are consequently very narrow, their width being dependent on the width or size of the seed and the mutual pressure of the folds on the edges of one another. Their thickness depends upon the thickness of the seed, as they are adpressed face to face with their edges to the flattened sides of the latter. Heliophila belongs to the tribe Sisymbrieæ. Chamira, belonging to the same group, agrees with Heliophila in its seeds and embryo. Palmstruckia and Cycloptychis amongst the Isatideæ have also transversely biplicate cotyledons, and Carponema, classed under the Raphaneæ, is remarkable in having oblong, terete seeds and cotyledons like those of Heliophila, to which it is closely allied. See Sond. 'Revis. Helioph.' 3, t. xvii. Senebiera may be included in this group.

Spirally convolute cotyledons occur in the four known species of Bunias. The fruit is short, ovoid, tetragonous, lignified, one- to two-celled with a somewhat compressed seed in each cell, the appearance being due to the shrinking of the 
testa to accommodate itself to the spirally coiled embryo. The cotyledons are incumbent with their edges to the sides of the seed, oblong, obtuse, entire, forming $1 \frac{1}{2}-2$ complete coils with their tips in the centre of the helix. The stout cylindrical radicle extends beyond the cotyledons, occupying the upper and pointed end of the seed, beneath and close to the persistent base of the style.

Only two strikingly aberrant forms in the Order have come under my observation. These are Schizopetalon belonging to the Sisymbriex, and Lepidium sativum amongst the Lepidineæ. Five species of Schizopetalon are recorded, all from Chili. The cotyledons are straight and entire in some of them, but S. Walkeri (fig. 160) has incumbent, deeply bifid, or more often bipartite, spirally convolute, and contorted cotyledons; the slender, linear segments being regularly coiled, but generally more or less interlacing with one another. The species might be grouped with Bunias, but for the deeply divided and contorted cotyledons. Some botanical authorities have described it as having four cotyledons, but they are mostly united in pairs at the base, and sometimes for a considerable part of their length. The embryo by becoming spirally convolute adapts itself to the interior of the small globular seed, which it completely occupies. The radicle is comparatively large and longer than the cotyledons. Lepidium sativum (fig. 171) is another aberrant form. It has been already described (ante, p. 52).

Cotyledons.-Notwithstanding the diversity of the seeds and fruits in this Order, the cotyledons may be roughly grouped into a few leading types, viz., broad and entire, broad and emarginate, linear, oblong or spathulate, and divided.

The first type is represented by Matthiola incana (fig. 156) and Cheiranthus Cheiri (fig. 159), but is not confined to seeds having accumbent cotyledons. Instances of broad, rotund, ovate, oval or elliptic, and entire cotyledons may be found in nearly all the tribes into which the Order is divided. In the case of accumbent cotyledons they are situated in the broader plane of the seed, so that their shape and size is easily accounted for, especially in flattened seeds; but in many cases breadth is attained by a vigorous growth of the cotyle- 
dons subsequent to germination. The following are instances of broad cotyledons oceurring in species scattered throughout the order, namely: Matthiola incana, Alyssum maritimum, Hesperis nivea, Conringia perfoliata, Camelina sativa, Biscutella didyma, Lepidium graminifolium, L. spinosum, Iberis corifolia, and Chorispora tenella. A slight modification is met with in Ethionema gracile and Iberis Lagascana, which have unsymmetrical cotyledons, slightly oblique at the base, and very much so in I. pectinata. It is probable that other instances of the kind occur in Iberis and indeed in other genera. The inequality at the base is due to the fact that part of the space in the seed is occupied by the radicle and petioles, which lie along one edge of the accumbent cotyledons.

Emarginate cotyledons are almost as widely distributed throughout the Order as those that are entire. The notch or sinus is due to two totally different causes. The first type is not owing to any peculiar conformation or structure of the seed, the cotyledons being, as far as could be seen before germination, entire. The notch in the seed-leaves is therefore due to the subsequent greater growth of the sides as compared with the organic apex. Emarginate cotyledons occur in Nasturtium sylvestre, Arabis Turczaninowii, Cardamine hirsuta, C. græca, Lunaria biennis, Cochlearia glastifolia, Sisymbrium officinale, Bivonæa Saviana, and others. The entire and emarginate state is shown in the figure of Sisymbrium officinale (fig. 163).

The second type of emarginate cotyledons occurs among the Brassiceæ and others, in which the cotyledons are conduplicate, as has been already mentioned in the Introduction (see ante, p. 31). Brassica oleracea (fig. 169) may be taken as a type. The cotyledons are emarginate with a broad and moderately deep sinus, broader than long, unequal in size, trinerved at the base with alternate veins upward, and the midrib forking below the apex; the side lobes are rounded and ascending. The inequality is due to the arrangement in the seed, one cotyledon folding over and completely embracing the other, which is necessarily smaller, being in the centre of the sphere. The petiole 
of the larger, occupying the outside of the curve, must also be the longer. The base of the sinus is really the organic apex of the cotyledons, and the ascending lobes are due to lateral development. When the cotyledons are folded longitudinally the two ascending edges of the lateral lobes are pressed against and conform to the interior of the globular seed, while the organic apex is also pressed against the testa and its further development consequently stopped. Growth then proceeds in a lateral direction as long as there is any unoccupied space, thus determining the peculiar form of the cotyledons as seen in germination.

All the species of Brassica observed conform closely to the above type, as do also Noricandia hesperidifolia, Carrichtera Vellæ, Succovia balearica, Raphanus sativus, R. maritimus \&c. Zilla myagroides (fig. 177) seems to differ slightly, but the seeds from which the seedlings were raised were museum specimens, probably old, and the cotyledons, which were slightly eroded in the sinus, might have been deformed. More decided departures from the type are exhibited in several other genera. Diplotaxis erucoides has broadly oblong, obtuse, emarginate cotyledons; in Moricandia arvensis they are obovate or cuneate, and slightly emarginate; while in Orychophragmus sonchifolius they are broadly oblong-ovate and emarginate, the smaller one being more evidently cuneate at the base than the other. All have the cotyledons unequal in size like those of Brassica, and, what is more unusual, they are indistinctly veined in Diplotaxis erucoides, Moricandia arvensis, and Orychophragmus sonchifolius.

In the case of Hesperis matronalis the cotyledons are not only unequal in length, but vary also in size and shape. By reference to the illustration (fig. 162) it will be seen that the unsymmetrical condition already prevails in the seed before germination. The seed is oblong and terete with the incumbent cotyledons slightly concave longitudinally, and the thin radicle lies in the groove. One cotyledon is nearly as thick as the other plus the radicle. After germination the cotyledons of most seedlings belonging to this species are 
obovate, emarginate, the two measuring 25 and $27.5 \mathrm{~mm}$. in length respectively, while cases occur in which they are rotund, emarginate, broader and shorter, measuring $17 \cdot 5$ and $15 \mathrm{~mm}$. respectively, the latter being about $1 \mathrm{~mm}$. wider than those of the first mentioned.

In several of the Sisymbrieæ and Lepidineæ the cotyledons are minute; this seems to be due partly to the small size of the seeds, partly to a limited range of growth. The latter case might arise from the embryo in the seed containing a relatively small amount of reserve-material, or more probably from the plumule developing early and diverting the energies of the plant away from the cotyledons. The latter are shortly oblong, obtuse, with a long petiole in Sisymbrium runcinatum (fig. 164), and S. Sophia, and linearspathulate with rather long petioles in Capsella Bursapastoris (fig. 170) and Senebiera didyma. The cotyledons of all the four species, but especially of Senebiera, recall those of Papaver in their small size and narrowness.

Linear cotyledons occur in Heliophila amplexicanlis (fig. 167), H. crithmifolia, and probably in all the rest of the genus. This type however is quite unusual in the Cruciferæ. The former of the two species has linear, obtuse, entire, one-nerved cotyledons, tapering insensibly or gradually into a short petiole and measuring from $20-25 \mathrm{~mm}$. in length. Those of $\mathrm{H}$. crithmifolia are linear, acute, entire, subterete, distinctly channelled all along the upper surface, sessile, slightly narrowed to the base, thinly pilose, or pubescent, 20-38 mm. long, and becoming disarticulated from the stem at an early age.

It is probable that the seedlings of Palmstruckia, Cycloptychis, Carponema, and Chamira have also linear cotyledons. Spirorhynchus has narrowly linear, incumbent cotyledons. Those of Menonvillea trifida are incumbent, long, narrowly linear, acute, sessile, and glabrous; in the early stages they are circinately coiled.

In all these cases the narrowness of the cotyledons is due to the shape of the seed, the position of the embryo with relation to the broad and narrow planes of the seed, and the peculiar folding of the embryo. 
The spathulate type of cotyledons seems to be largely due to growth subsequent to germination, as we meet with it in a few more or less widely distinct genera having differently shaped seeds and fruits, and widely diverse embryos. Bunias orientalis (fig. 176) may be given as an instance of this type. The cotyledons are spirally coiled in the seed, with their apices in the centre of the coil, where they are distinctly narrowed, but after attaining their full size they are spathulate, obtuse, entire or slightly emarginate, unequal in length, tapering to a short, petiole-like, shortly connate base, and showing a few alternate, ascending veins on each side of a strong midrib. The average length of three of the longer cotyledons measured was $42 \mathrm{~mm}$., and of three of the shorter ones $33 \mathrm{~mm}$. The seed-leares of Cakile maritima are linearspathulate, obtuse, entire, unequal, sessile, tapering to the base, one-nerved, subfleshy. The inclination to assume this shape no doubt originates in the seed, which is oblong, slightly notched at the base, and $3-3.5 \mathrm{~mm}$. in length. The upper division of the two-seeded fruit is the longer and contains the larger seed, which is laterally compressed. The cotyledons are accumbent, sometimes oblique, and lying on the edge of one cotyledon only, which would tend to make one of them narrower than the other, but the inequality in length is more difficult to account for. The cotyledons of C. americana both before and after germination are proportionally broader than those of C. maritima. The seeds of the former are however longer, measuring 5-6 mm., and the cotyledons after germination are spathulate, obtuse, sessile, but tapering to the base, and much more unequal than those of C. maritima.

The divided cotyledons of Schizopetalon Walkeri and Lepidium sativum have been already described. One advantage of this form is perhaps that it enables each of the four segments to emerge from the testa independently of the others. The cotyledons of Schizopetalon Walkeri (fig. 160) are generally divided almost to the base, although there are cases where they are merely forked like those of Eschscholtzia californica in the closely allied Order Papaveracex. The cotyledons become curved and then coiled at a very early age of 
the embryo, which develops very rapidly, and they are ultimately not merely coiled, but frequently interlaced. The whole embryo is extremely delicate or fragile in its earliest stages, and the extreme slenderness of the cotyledons compared with the stout radicle facilitates their being coiled in order to accommodate themselves closely to the interior of the small round seed without waste of space. After germination and when fully grown the cotyledons of Lepidium sativum are so deeply tripartite, each segment being narrowed to the base, that they appear as if digitately compound. The probable origin of their present form has already been suggested, ante p. 52 .

The dispersal of the seeds is in many cases aided by the presence of wings; in some by the agency of animals; in others they are thrown to a greater or less distance by the plant itself.

In the latter cases the walls, when the pod is ripe, are in a state of tension. The seeds are loosely attached to the central piece by short stalks. When the proper moment has arrived, the outer walls are kept in place by a delicate membrane, only just strong enough to resist the tension. The least touch, for instance, a puff of wind blowing the plant against a neighbour, detaches the outer wall, which suddenly rolls itself up, generally with such force as to fly from the plant, thus jerking the seeds to a distance of several feet.

\section{Matthiola incana, $R . B r$. (fig. 156).}

Primary root long, tapering downwards, with a few short lateral rootlets.

Hypocotyl short, erect, terete, tapering insensibly into the root, glabrous, pale green, covered with small crystalline elevations, 8-12 mm. long.

Cotyledons broadly oblong-oval, obtuse and rounded at the end, entire, petiolate, glabrous, light opaque green, with a scarcely visible midrib, but no other discernible venation in the fresh state; lamina 9-11 mm. long, 7-9 mm. wide; petiole grooved above, convex on the back, glabrous with a line of small crystalline elevations on the under side, dilated and slightly connate at the base, 7-9 mm. long.

Stem erect, terete, herbaceous, biennial, densely covered with much branched and radiating stellate hairs; 1st internode 1$1.5 \mathrm{~mm}$. long; 2nd undeveloped; 3rd 1.5-2.5 mm. long. 
Leaves simple, entire, cauline, alternate (first two opposite), exstipulate, petiolate, with a hardly discernible venation, except in very young leaves, where the nerves are alternate, ascending and incurved, uniting with one another within the margin; densely

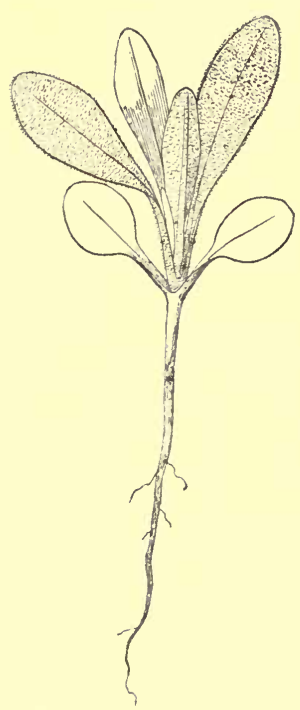

Fig. 156.-Matthiola incana. Nat. size. covered on both surfaces with a muchbranched stellate pubescence or tomentum and becoming hoary, especially in dry places; petioles tapering upwards, from a stout, broadish, semiamplexicaul base, semiterete, slightly convex or flattened on the upper side, hoary with a stellate tomentum like the leaves.

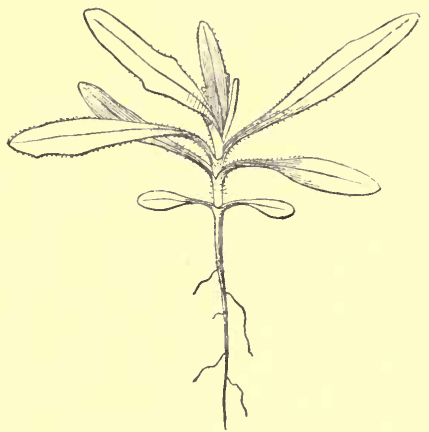

FIg. 157.-Matthiola bicornis.

Nat. size.

Nos. 1 and 2. Oblanceolate, tapering to the petiole, obtuse at the apex and rounded.

Nos. 3 and 4. Similar or somewhat narrower.

Matthiola bicornis, $D C$. (fig. 157).

Primary root as in M. incana.

Hypocotyl very short, tapering into the primary root, colourless, slightly glandular-pubescent, $1 \cdot 5-3 \mathrm{~mm}$. long.

Cotyledons narrowly oblong-spathulate, tapering into the petiole, or slightly glandular-pubescent at the margins, otherwise as in $\mathbf{M}$. incana; lamina 5-6 $\mathrm{mm}$. long, 2-2.25 $\mathrm{mm}$. wide ; petiole flattened above, convex on the back. glabrous or slightly glandular-pubescent, slightly connate at the base, $3 \cdot 5-5 \mathrm{~mm}$. long. 
Stem herbaceous, annual, terete, erect, more or less glandularhairy and densely stellato-tomentose; 1st internode $3-4 \cdot 5 \mathrm{~mm}$. long; 2nd undeveloped; 3rd 1.5-2 mm. long.

Leaves narrower than in $\mathrm{M}$. incana.

Nos. 1 and 2. Opposite, oblong, obtuse, entire.

No. 3. Linear-oblong, obtuse, entire or with one or two very short obtuse teeth.

Nos. 4-6. Linear, obtuse, with one or two blunt deltoid or subtriangular teeth on each side.

\section{Nasturtium sylvestre, $R$. Br.}

Primary root tapering downwards, provided with lateral rootlets. Hypocotyl short, erect, hardly appearing above the surface of the soil, obconical.

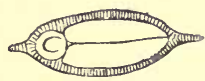

1

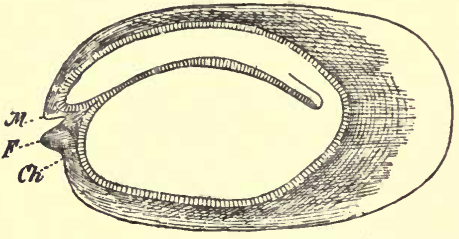

2

Fig, 158,-Cheiranthus Cheiri.

1, Transverse section through middle of seed, $\times 11$.

2, Vertical section of seed, $\times 11: M$, micropyle; $F$, funiculus; $C h$, chalaz\&.

Cotyledons subrotund or oblong, obtuse, emarginate, subfleshy, glabrous, green, indistinctly one-veined, petiolate; petiole rather long, channelled on the upper side.

Stem with primary internodes undeveloped.

First leaves simple, coarsely crenate, radical, alternate, oblong, obtuse, petiolate, exstipulate, hairy, especially on the upper side, green, distinctly pinnatinerved; petioles rather long, deeply channelled on the upper surface.

Cheiranthus Cheiri, L. (fig. 158).

Fruit a siliqua, linear, compressed dorsally, two-edged or subtetragonal, two-celled, dehiscing by two valves from base to apex; placentas many-seeded, parietal ; septum thin, membranous, formed by extension of the placentas.

Seed oblong-oval, much compressed laterally, with the edges produced all round into a thin membranous wing; seed-coat 
double, outer (testa) membranous, pale yellow, glabrous ; inner (tegmen) paler and thinner; hilum basal, at one end of the seed; raphe none; micropyle basal, close to the hilum and superior to it.

\section{Endosperm absent.}

Embryo large, curved, occupying the whole interior of the seed, pale yellow ; cotyledons oblong-oval, obtuse, entire, flat, closely adpressed face to face, petiolate ; radicle slender, cylindrical, suddenly tapered to a subacute point, curved, nearly or quite as long as the accumbent cotyledons; petioles short, slightly twisted to allow the edges of the cotyledons to be applied to the radicle. If it were not for the petioles the cotyledons would evidently be incumbent, as happens in some species of Cheiranthus, with their backs instead of their edges to the placenta ; under existing conditions the backs of the petioles are to the placenta.

\section{Seedling (fig. 159).}

Hypocotyl herbaceous, erect, terete, glabrous, or hairy towards the top; hairs adpressed, forked at right angles and thus appearing as if fixed by the middle; $12-27 \mathrm{~mm}$. long.

Cotyledons broadly ovate, retuse, entire or very minutely or slightly emarginate, suddenly tapering into the petiole, glabrous or slightly hairy here and there on the upper surface ; petiole with forked hairs as described above; lamina 10-13 $\mathrm{mm}$. long, $6 \cdot 2-10 \mathrm{~mm}$. wide ; petiole $8 \cdot 5-$ $11.5 \mathrm{~mm}$. long.

Stem herbaceous, erect, terete, covered with hairs as described above, ultimately shrubby below; internodes short but variable; 1st 3-7 mm. long; 2nd often very short or scarcely developed, bringing the first two leaves nearly opposite; 3rd more elongated.

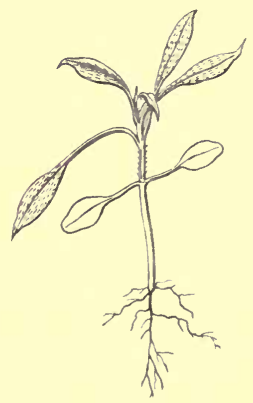

FIg. 159.-Cheiranthus Cheiri (wild specimen). Two-thirds nat. size.

Leaves simple, cauline, alternate, exstipulate, petiolate, covered on both sides, especially in a young state, with forked, peltate hairs rarely branching stellately, and closely adpressed, with the branches lying in the same plane; petioles convex on the back, grooved on the upper face and pubescent like the leaves.

Nos. 1-6. Lanceolate-elliptic, acute, petiolate, obscurely reticulate, often minutely and sparingly denticulate. 
Ultimate leaves narrowly lanceolate, cuspidately acute, narrowed to a rather broad petiole, subcarinate on the back, with a prominent midrib and alternate lateral nerves ascending along the leaf for some considerable distance and uniting, each with the one next above it; white or hoary, especially beneath, with a closely adpressed pubescence of the characteristic forked hairs.

\section{Arabis Turczaninowii, Ledeb.}

Primary root tapering downwards with fibrous lateral rootlets.

Hypocotyl erect, terete, glabrous, almost colourless, 5-10 mm. long.

Cotyledons oval-oblong, emarginate, petiolate, fleshy, green, glabrous; no venation apparent.

Stem : primary internodes undeveloped.

Leaves simple, entire, cauline, alternate, lanceolate, acute, exstipulate, petiolate, finely pubescent, ciliate, pinnatinerved.

\section{Cardamine Impatiens, $L$.}

Fruit a siliqua, linear, compressed dorsally, many-seeded, with the seeds in one row, dehiscing elastically with some force from the base upwards by two valves and scattering the seeds ; septum thin, membranous.

Seed oblong, obtuse at each end, much compressed dorsally, pale yellow, smooth; testa thin, subtransparent; hilum basal, brown; micropyle close to the hilum.

Endosperm absent.

Embryo much curved or doubled upon itself, occupying the whole seed, colourless or pale yellow ; cotyledons oblong, obtuse, entire, plano-convex, accumbent, very shortly petiolate; radicle slender, terete, suddenly tapered to an obtuse point which is slightly curved round the apical ends of the cotyledons, equal to or slightly longer than these.

\section{Cardamine græca, $L$.}

Primary root tapering downwards, colourless, with numerous lateral rootlets.

Hypocotyl terete, rather succulent, flexuose, glabrous, purplish, $2.3 \mathrm{~cm}$. long, $1.5 \mathrm{~mm}$. thick.

Cotyledons foliaceous, glabrous, petiolate; petiole subterete, channelled above, purplish, $1.45 \mathrm{~cm}$. long; lamina rotund-oblong, emarginate, dull green, rather fleshy, $1 \cdot 2 \mathrm{~cm}$. long, $1 \mathrm{~cm}$. broad.

Stem herbaceous. 
Leaves radical, simple, pinnatisect, alternate, exstipulate, petiolate, minutely ciliate at the margins of the lobes when young, glabrescent, dull green above, paler beneath; petioles subterete, channelled above, dilated at the base, dull purplish-green, dotted with pale markings, glabrous.

No. 1. Ternately pinnatisect; lobes rotund-subcuneate, shortly trifid or crenate; lobes most frequently emarginate and mucronate,

No. 2. Pinnatisect; lobes 5, similar to No. 1.

Nos. 3 and 4. Pinnatisect; lobes 7, in three opposite pairs and an odd terminal one.

\section{Cardamine hirsuta, $L$.}

Hypocotyl short, terete, glabrous, passing indistinguishably into the root.

Cotyledons differing from those of $\mathrm{C}$. græca in being rotund, about $3.5 \mathrm{~mm}$. in diameter; petiole $4 \mathrm{~mm}$. long.

Stem herbaceous, annual, developed when about to flower, angled, glabrous or slightly hairy; basal internodes undeveloped.

Leaves simple, radical and cauline, alternate, exstipulate, petiolate, more or less hairy on both sides, bright green above, paler beneath ; petioles subterete, channelled on the upper side.

Nos. 1 and 2. Reniform, subemarginate, obscurely crenate.

No. 3. Reniform with one small lateral lobe, obscurely crenate.

No. 4. Deeply trilobed; lateral lobes obovate; terminal lobe much larger, rounded.

No. 5. Similar, larger.

No. 6. Lyrate-pinnatisect with a terminal, large, rotund lobe and two pairs of much smaller lateral ones.

No. 7. Lyrate-pinnatisect; terminal lobe rotund, minutely emarginate, trinerved; lateral lobes rotund-obovate, minutely emarginate.

No. 8. Pinnatisect; three terminal segments obovate, minutely emarginate, otherwise like No. 7.

Cauline leaves on robust plants lyrate, pinnatisect; segments broad, reniform, or subrotund, angled with excurrent teeth.

On small starved specimens, the lower or all the cauline leaves are lyrate, pinnatisect, with obovate or spathulate segments; the upper ones have linear-oblong segments.

Lunaria biennis, Monch.

Hypocotyl erect, terete, glabrous, 5-6 $\mathrm{cm}$. long, stained with red.

Cotyledons large, broadly oblong, obtuse, slightly emarginate, 
petiolate, glabrous, green, rather distinctly pinnatinerved; petioles from $2.5 \mathrm{~cm}$. long, reddish, channelled on the upper side.

Stem erect, quadrangular, rather flattened, pubescent, herbaceous; 1st internode $3-4 \mathrm{~mm}$. long.

Ricotia Lunaria, $D C$.

Hypocotyl terete, striate, rather slender, 5-7 cm. long.

Cotyledons suborbicular, broad, emarginate or bifid, rather coarsely reticulate, unequal, especially as regards the length of the petioles; lamina of two good-sized specimens 2.5 and $2.7 \mathrm{~cm}$. long, $2 \cdot 6$ and $2 \cdot 7 \mathrm{~cm}$. wide respectively; petioles shallowly grooved above, 2.9 and $3.5 \mathrm{~cm}$. long.

Stem finely pubescent with the first internode shortly elongated or not.

Leaves simple, mostly cauline, alternate, exstipulate, petiolate, usually much cut.

Nos. 1 and 2. Pinnatisect, with five more or less toothed segments.

Nos. 3-6. Pinnatisect or (mostly) bi-pinnatisect.

\section{Alyssum maritimum, Lam.}

Hypocotyl erect, terete, glabrous, 8-9 mm. long, purplish.

Cotyledons oval, obtuse, entire, petiolate, glabrous, green, subfleshy, indistinctly one-veined; petioles rather short, shallowly channelle 2 on the upper face.

Stem erect, terete, herbaceous; primary internodes but slightly developed.

First leaves simple, entire, cauline, alternate (first pair opposite), linear-oblong or lanceolate, obtuse, exstipulate, petiolate, covered with minute silky hairs, green, pinnatinerved.

Cochlearia glastifolia, $L$.

Primary root forming a long tap-root, with numerous lateral rootlets.

Hypocotyl very short, terete, glabrous, purple, 2-3 mm. long.

Cotyledons suborbicular, emarginate, glandular in the notch, slightly oblique at the apex, glabrous, petiolate, opaque above, obscurely trinerved beneath; lamina 5-9 $\mathrm{mm}$. long, 6.5-9 mm. wide ; petiole semiterete, flattened above, widened and slightly connate at the base, $4 \cdot 5-6 \cdot 5 \mathrm{~mm}$. long, purple.

Stem with the internodes undeveloped.

Leaves simple, radical, alternate, exstipulate, petiolate, glabrous, 
with the petiole, midrib, and ascending, incurved, and reticulate venation, purple beneath; petiole semiterete, channelled above, winged in the younger leaves of the seedling from the blade being decurrent upon them.

Nos. 1 and 2. Suborbicular or obovate, slightly emarginate, with a gland in the notch.

Nos. 3 and 4. Obovate, emarginate, glandular in the notch.

Nos. 5 and 6 . Larger and obovate, or tending to be spathulate, and decurrent upon the petiole.
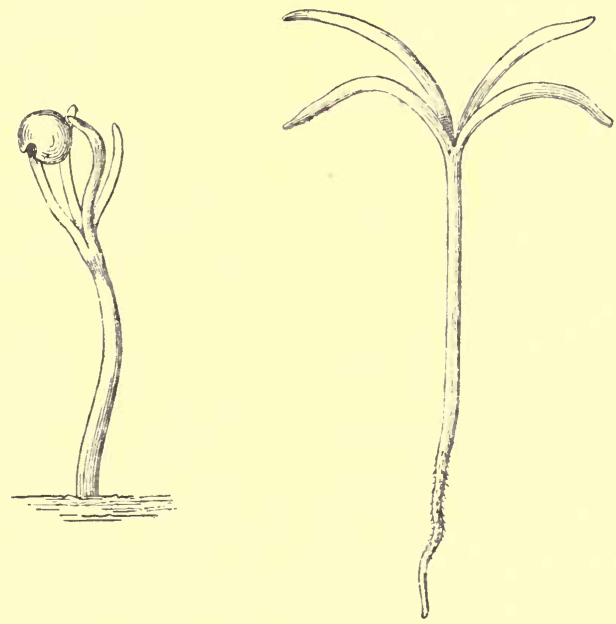

FIG. 160.-Schizopetalon Walkeri, $\times 2 \frac{1}{2}$.

(Early stages in growth of seedling.)

\section{Cochlearia arctica, Schlecht.}

Hypocotyl erect, terete, glabrous, 1-2 $\mathrm{cm}$. long, light green or colourless.

Cotyledons obovate or subrotund, fleshy, unequal, emarginate, with very long petioles, glabrous, bright green, very indistinctly trinerved.

Stem as in the preceding species.

First leaves with long petioles, subrotund, emarginate, obtuse, cordate at the base, bright green, glabrous, distinctly pinnatinerved. 
Schizopetalon Walkeri, Sims.

Fruit a silicula, narrowly linear, subcompressed, two-celled, many-seeded, dehiscent.

Seeds parietal, in one row, globose, very small, pale yellow, often with a bluish tinge; micropyle and hilum punctiform, ventral, contiguous; raphe ventral.

Endosperm absent.

Embryo comparatively large, spirally convolute, and conforming to the interior of the seed; cotyledons bipartite with narrowly linear or acicular segments, sometimes exhibiting regular spiral coils, but often irregular and more or less irregularly twisted amongst
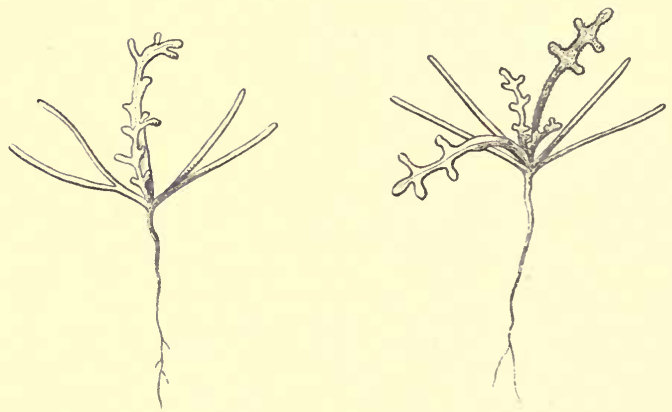

Fra. 161.-Schizopetalon Walkeri. Nat. size.

each other, one or two lobes inside the others ; radicle comparatively large, and rather longer than the incumbent cotyledons, which have their backs to the placenta.

Seedling (figs. 160, 161).

Primary root slender, tapering, with very few lateral rootlets in the young state.

Hypocotyl tapering indistinguishably into the root.

Cotyledons split almost to the very base, but sometimes, although rarely, united (as in accompanying sketch) for $4.75 \mathrm{~mm}$. at the base; segments filiform, blunt, glabrous, deep green, rather fleshy, $2 \mathrm{~cm}$. long.

Stem annual, developed when about to flower.

Leaves simple, pinnatifid, radical and cauline, alternate, exstipulate, petiolate, stellately pubescent, rather fleshy, opaque green; petioles semiterete, flattened above or shallowly grooved, stellately pubescent. 
Nos. 1 and 2. Oblong in outline, pinnatifid; segments five or six, short, oblong, obtuse, or the terminal one spathulate.

No. 3. Oblong in outline, pinnatifid with about seven segments.

Hesperis matronalis, Lam. (fig. 162).

Siliqua linear, tetragonous, subtorulose, glabrous, dehiscing throughout its length by two valves, many-seeded with the seeds in one row, and partly separated by a contraction of the fruit; valves trinerved, with the middle nerve strongest.

Seed oblong, subterete in transverse section, tapering slightly to the apex, where the testa is drawn out into a short margin, glabrous, brown; hilum and micropyle basal, contiguous at the upper end of the seed; chalaza thickened, deep brown, immediately beneath the hilum ; raphe none.

Endosperm absent.

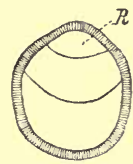

1

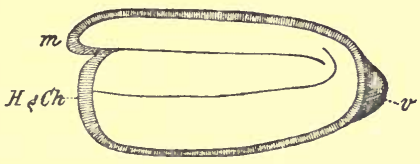

2

FIG. 162.-Hesperis matronalis, $\times 10$.

1, Transverse section of seed: $R$, radicle.

2, Longitudinal section of seed: $m$, micropyle; $H \& C h$, hilum and chalaza; $v$, vacant space in testa.

Embryo doubled upon itself, comparatively large, and occupying the whole interior of the seed, pale yellow; cotyledons incumbent, linear-oblong, obtuse, entire, somewhat grooved or concave longitudinally, shortly petiolate, about equal in length to the interior of the seed, the two frequently of unequal thickness; petioles apparently facilitating the necessary curvature of the embryo; radicle dorsal, obtusely trigonous, about equal in length to the seed, partly accommodated by the concavity of the cotyledons, and partly by extension of the testa along the dorsal aspect.

\section{Seedling.}

Hypocotyl erect, terete, glabrous, tinged with purple, $3-5 \mathrm{~mm}$. above the soil.

Cotyledons very variable in shape and size, often unequal, rotund, emarginate, suddenly tapering to the base, or obovate, emarginate, and gradually tapering to the base, glabrous, light green, alternately and ascendingly penninerved and reticulate, thick and opaque, 
showing the venation only by transmitted light, petiolate; lamina 10-15 $\mathrm{mm}$. long, 10-12 $\mathrm{mm}$. wide (the rotund forms being the wider) ; petiole flattened above, convex beneath, dilated and connate at the base.

Inequality of cotyledons.-In plant No. $1,2.5$ and $2.75 \mathrm{~cm}$; in plant No. 2, 1.75 and $1.5 \mathrm{~cm}$. long.

Stem herbaceous, developed when about to flower; primary internodes undeveloped.

Leaves simple, radical and cauline, alternate, exstipulate, petiolate, alternately, ascendingly incurvinerved, the reticulate venation seen best by transmitted light, rather coarsely hairy all over, deep or light green; petioles channelled above, convex beneath, hairy, stout, tapering upwards from a broad, slightly clasping base ; hairs hyaline, simple or forked, or with a small lateral branch.

Nos. 1-3. Varying from oblong to oval, or broadly ovate, rounded and obtuse at the apex, suddenly tapered at the base, slightly dentate, with the teeth tipped with a yellowish glandular mucro; the nerves incurved and uniting with one another within the margin, forming a series of large reticulations.

\section{Hesperis nivea, Baumg.}

Primary root tapering downwards, with many lateral rootlets.

Hypocotyl terete or tapering downwards, $5-6 \mathrm{~mm}$. long, greenish above, colourless below the soil.

Cotyledons oval-oblong, obtuse, entire, indistinctly one-veined; petioles broad, channelled on the upper surface.

Stem as in H. matronalis.

First leaves entire or slightly serrate; first two broadly subrotund, obtuse, the rest broadly oblong, all covered with rather stiff hairs, indistinctly pinnatinerved; petioles broad, much longer than the leaves, hairy, rather deeply channelled on the upper surface.

\section{Hesperis bituminosa, Savi.}

Hypocotyl 2-3 mm. above the soil.

Cotyledons roundly obovate, more or less unequal, measuring 11 and $13.5 \mathrm{~mm}$. respectively, and in another case 12 and $13 \mathrm{~mm}$., glabrous except the slightly channelled petioles, blunt or very shallowly emarginate.

First leaves ovate, obtuse, slightly dentate, but sometimes more elongated and spathulate, hairy.

Sisymbrium officinale, $L$.

Siliqua linear or subterete, somewhat compressed, short, erect, and closely adpressed to the stem; the numerous seeds mostly in one row. 
Seed oblong, short, blunt at each end, where it is very frequently obliquely compressed or truncate, smooth and minutely reticulated with small superficial areas that swell up in water, yellow ; hilum basal, overlying the chalaza and contiguous to the micropyle; raphe none.

Endosperm absent.

Embryo doubled upon itself, comparatively large, and occupying the whole interior of the seed, pale yellow; cotyledons ovaloblong, obtuse, entire, shortly petiolate, showing a midrib and a few short, alternate, ascending lateral nerves, obliquely incumbent, nearly as long as the interior of the seed ; radicle terete or more or less obtusely angled, traversing one edge of the dorsal aspect of the seed, and then suddenly bent towards the micropyle at one corner of the oblique, rhombusshaped dorsal aspect, longer than the seed by its traversing one end as well as the dorsal face of the embryo.

Seedling (fig. 163).

Primary root long, tapering, fibrous, annual.

Hypocotyl erect, terete, pale green, or sometimes stained with red, becoming

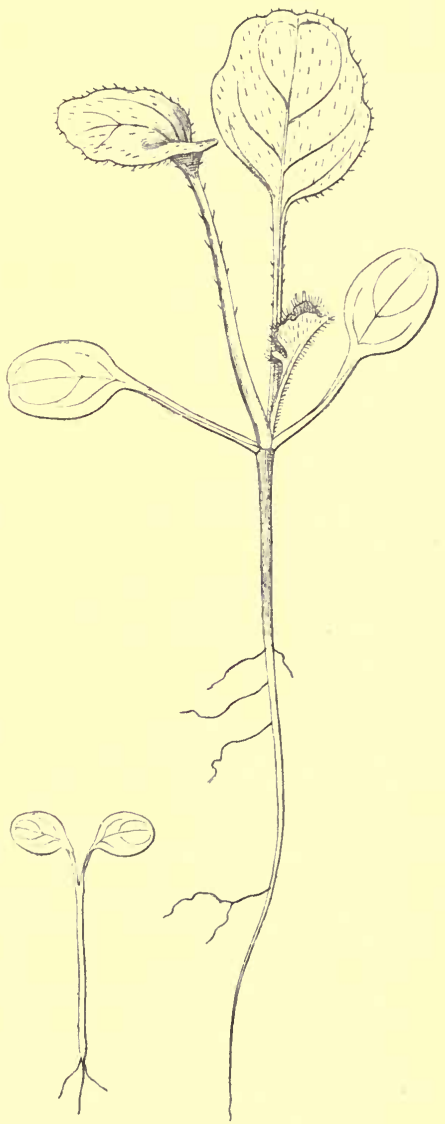

FIG. 163.-Sisymbrium officinale, $\times \mathbf{2}$.

thicker upwards, with a few scattered adpressed hairs; 8-18 mm.long. Cotyledons oval, obtuse and rounded at the apex after germina- 
tion, but becoming emarginate and more elongated at the base by subsequent growth, petiolate, glabrous, with the exception of a few scattered hairs on the petiole, light green above, paler beneath, trinerved at the base, with two other lateral nerves arising from the midrib below the middle of the lamina, describing a curve round an oval space and again uniting with the midrib close to the apical notch; lamina 6-8 $\mathrm{mm}$. long, 4-5.5 $\mathrm{mm}$. wide; petiole slightly channelled above, convex on the back, $7 \cdot 5-9 \mathrm{~mm}$. long.

A few terminal pores or water-stomata are found at the apex of the midrib.

Stem annual, and developed when about to flower; primary internodes undeveloped.

Leaves simple, radical (ultimately cauline), exstipulate, petiolate, coarsely hairy, alternately and ascendingly penninerved, ultimately runcinately pinnatifid and pinnatisect; petioles semiterete, channelled above, dilated and clasping at the base, more or less hairy.

No. 1. Rotund, obtuse, obscurely dentate or crenate, slightly cuneate at the base.

No. 2. Similar but more deeply dentate-crenate and often lobulate at the base.

No. 3. Runcinately pinnatisect with three to five lobes; lateral lobes small, oblong, obtuse, entire or dentate; terminal lobe much the largest, rotund, coarsely and deeply dentate with glandular mucronate teeth.

Sisymbrium runcinatum, Lag. (fig. 164).

Root and hypocotyl as in preceding species.

Cotyledons small, glabrous ; lamina oblong, obtuse, $4 \mathrm{~mm}$. long, $2 \mathrm{~mm}$. broad; petiole $3.5 \mathrm{~mm}$. long.

Stem as in Hesperis matronalis.

Leaves hairy, especially when young and on the petioles, ultimately glabrescent; petioles flattened above, convex beneath, slightly dilated at the base.

No. 1. Small, broadly ovate, obtuse, almost or quite entire.

No. 2. Oblong, sublobulate; lobes rounded.

Nos. 3 and 4. Similar but larger.

No. 5. Oblong, pinnatifid; terminal lobe triangular-hastate, with a very obtuse apex and side lobes. obtuse.

No. 6. Pinnatifid with obtuse lobes; terminal one triangular

Nos. 7-10. Runcinate, pinnatifid; lateral lobes broadly ovate, or triangular obtuse, or rounded at the end, alternate, spreading at 
right angles to the rachis or slightly decurved, frequently tipped with a bristle when young; terminal lobe much the largest, triangular, obtuse.

Sisymbrium Sophia, L. (fig. 165).

Root and hypocotyl as in preceding species.

Cotyledons oblong, obtuse; petiole flattened above, and more or less covered with stellate, stalked hairs, convex beneath.

Leaves more or less lobed or pinnatisect, covered on all parts with stalked and stellately branching hairs; petiole flattened above, convex beneath.

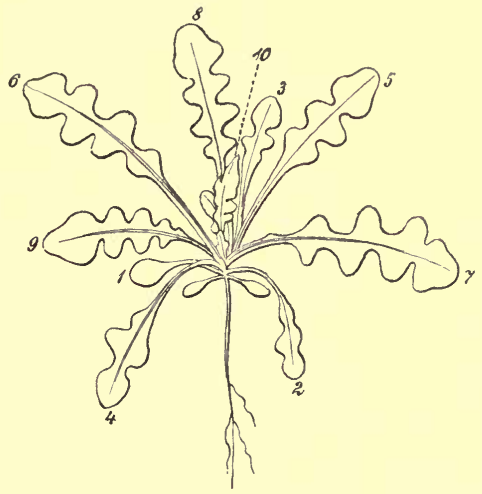

FIG. 164.-Sisymbrium runcinatum. Nat. size.

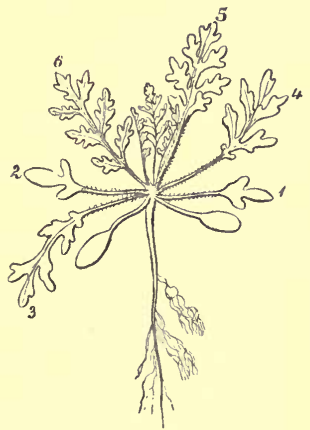

FIG. 165.-Sisymbrium Sophia, Nat. size.

No. 1. Lamina ovate, obtuse, trilobed, cuneate at the base; middle lobe longest.

No. 2. Similar; middle lobe of the lamina a little longer.

No. 3. Lamina oblong, pinnatipartite; lobes slightly toothed, alternate.

No. 4. Lamina oblong, pinnatisect; lobes toothed.

Nos. 5 and 6 . Lamina oblong, pinnatisect; lobes pinnatifid, alternate.

Conringia perfoliata, Link.

Hypocotyl tapering downwards, glabrous, green or colourless, 3-4 $\mathrm{mm}$. long.

Cotyledons rotund-ovate, obtuse, entire, rather fleshy, petiolate, 
glabrous, green, indistinctly one-veined; petioles broad, flat, not quite as long as the lamina.

Stem with primary internodes undeveloped.

First leaves simple, entire, radical, alternate, broadly obovate. oblong, obtuse, glaucous-green, glabrous, pinnatinerved, exstipulate, petiolate; petiole short, broad, slightly channelled on the upper surface.

Heliophila pilosa, Lam., var. $\gamma$, incisa $D C$. (fig. 166).

Siliqua linear, many-seeded.

Seed variable in outline, oblong, or more or less perfectly orbicular, much compressed laterally, with a small notch at the base, and a narrow marginal wing or altogether wingless, pale or deep

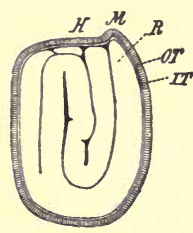

1

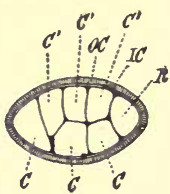

2
FIG. 166.-Heliophila pilosa incisa, $\times 12$.

1, Longitudinal section of seed: $H$, hilum; $M$, micropyle; $R$, radicle; $O T$, testa; $I T$, tegmen.

2, Transverse section of another seed: $C C C$, parts of one cotyledon; $C^{\prime} C^{\prime} C^{\prime}$, parts of the other cotyledon; $K$, radicle; $O C$, testa; $I C$, tegmen. brown, glabrous; both testa and tegmen membranous; hilum, micropyle, and chalaza contiguous, basal ; raphe none.

Embryo filling the entire seed, pale yellow or colourless, much curved and folded; cotyledons incumbent, biplicate, each traversing the length of the seed about three times, that is, first lying towards the base of the seed, then folded back towards its apex, and finally folded again towards the base, and each occupying half the thickness of the seed collaterally, linear, obtuse, entire, square or variously angled; the several folds and the radicle occupy the width of the seed; radicle terete, obtuse, occupying the length of the seed and one end, lying against the back of the third and apical fold of the cotyledons.

The 'Flor Capensis' does not say whether the siliquas of the genus Heliophila are dorsally or laterally compressed, but a figure of Heliophila trifida, Thunbg., in the 'Botanical Register,' 64 , shows a dehiscing siliqua which is dorsally compressed.

\section{Heliophila crithmifolia, Willd.}

Seed orbicular, flattened or much compressed laterally, testa brown, shrunk when dry so as to show the form of the embryo; hilum forming a rather deep notch. 
Cotyledons and radicle arranged as in $\mathrm{H}$. pilosa.

Primary root annual, tapering, but little branched.

Hypocotyl erect, terete, pubescent, 2-2.5 $\mathrm{cm}$. long.

Cotyledons linear, acute, subterete, distinctly channelled along the whole upper surface, very thinly pilose or pubescent, sessile, slightly narrowed to the base, $2-3.8 \mathrm{~cm}$. long, deciduous, becoming disarticulated from the stem.

Stem annual, erect, terete, pubescent; 1st internode $9-10 \mathrm{~mm}$. long.

Leaves simple, cauline, alternate (1st pair almost opposite), exstipulate, petiolate, thinly pubescent, finely divided or cut, with linear subterete acute segments, all channelled on the upper surface; petiole semiterete, channelled above, articulated with the stem.

Nos. 1 and 2. Almost opposite, pinnatisect, with one or two alternate segments on each side.

Succeeding leaves with more numerous, opposite or alternate segments.

Plant running to seed very rapidly, even in the seedling pots before being planted out.

Heliophila amplexicaulis, L. (fig. 167).

Primary root long, tapering downwards, with short lateral rootlets.

Hypocotyl glabrous, purple, dotted with green, 8-10 mm. long.

Cotyledons linear obtuse, entire, tapering insensibly into the petiole, glabrous, erect or ascending, green or more or less tinged with purple; a midrib is present, but no other venation is discernible; $2-2.5 \mathrm{~cm}$. long, 1-1.5 mm. wide.

Stem erect, terete, glabrous, green or

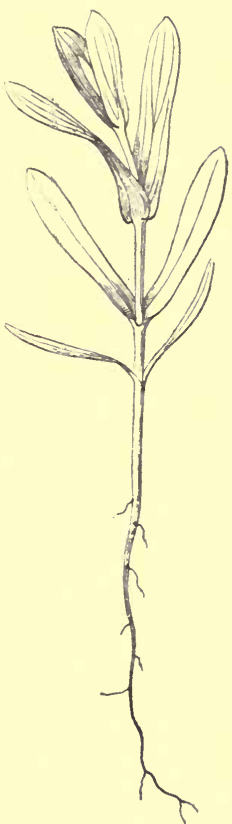

Frg. 167.-Heliophila amplexicaulis. Nat. size. becoming purple and dotted with green, annual; 1st internode 5-10 mm. long, 2nd 6-13 mm.

Leaves opposite (at least on the lower part of the plant up to and including the fifth pair), sessile, with numerous, alternate, ascending, slender nerves, proceeding from the midrib at a very acute angle, incurved, and uniting with one another at their apices, while a number run close to the apex of the leaf, and curving inwards unite 
with the midrib ; glabrous, glaucous-green on both surfaces, amplexicaul at the base.

1st and 2nd pairs linear oblong, cuspidate, somewhat constricted above a broad, amplexicaul base, and again dilated above the middle, entire.

3rd pair oblong, cuspidate, amplexicaul, less conspicuously constricted above the base or not at all, entire.

Camelina sativa, Crantz.

Hypocotyl short, erect, terete, glabrous, 3-5 mm. long, light green or colourless.

Cotyledons oval-oblong, obtuse, entire, glabrous, rather fleshy, shortly petiolate, light green, with no apparent venation.

Stem with primary internodes undeveloped.

First leaves simple, radical, alternate, obovate-oblong, obtuse, crenate, exstipulate, petiolate, hairy, green, pinnatinerved ; the first leaf is often entire; petioles rather long, hairy, channelled on the upper side.

Diplotaxis erucoides, $D C$.

Hypocotyl short, terete, hardly appearing above the surface of the soil.

Cotyledons oblong, obtuse, emarginate, petiolate, rather fleshy, glabrous, green, indistinctly one-veined.

Stem with primary internodes undeveloped.

First leaves simple, radical, alternate, obovate-oblong, obtuse, exstipulate, petiolate, hairy, green, pinnatinerved; the first leaf is entire, the second leaf crenate or almost lobed.

\section{Brassica nigra, Boiss.}

Siliqua sessile, terete, or subtetragonal, beaked, many-seeded; beak often one-seeded and indehiscent.

Seed globose or oblong-globose, often appearing angled from the unequal shrinking of embryo and testa in malformed or immature seeds, small ; testa deep brown or almost black when the seed is perfectly matured; hilum small, occupying one end of the seed when the latter is oblong-globose; chalaza contiguous to the hilum, and forming a dark-coloured spot; raphe none; micropyle close to the hilum.

Embryo large and filling the whole interior of the seed, doubled upon itself twice, pale yellow or in immature seeds deep green; the incumbent cotyledons conduplicate, that is folded upon themselves 
longitudinally, and grasping but not surrounding the radicle with their edges; radicle oblong, suddenly tapering to an obtuse point, shorter than the cotyledons.

\section{Seedling (fig. 168).}

Hypocotyl erect, terete, glabrous, pale green, $1 \cdot 5-3 \cdot 8 \mathrm{~cm}$. long.

Cotyledons broadly cuneate, bifid, broader than long, unequal in size, with two strong, alternate nerves, and one or two short ones, entering each lobe, glabrous, light green, paler beneath, petiolate; average of three larger laminæ $12.8 \mathrm{~mm}$. long, 14.9 $\mathrm{mm}$. wide; of three smaller laminæ 11.75 $\mathrm{mm}$. long, $13.8 \mathrm{~mm}$. wide; petiole shallowly channelled above, convex on the back, slightly connate at the base, glabrous, pale green, unequal in length, the longer one bearing the larger lamina; average length of three of the longer ones $13.75 \mathrm{~mm}$., of three of the shorter ones $12.58 \mathrm{~mm}$.

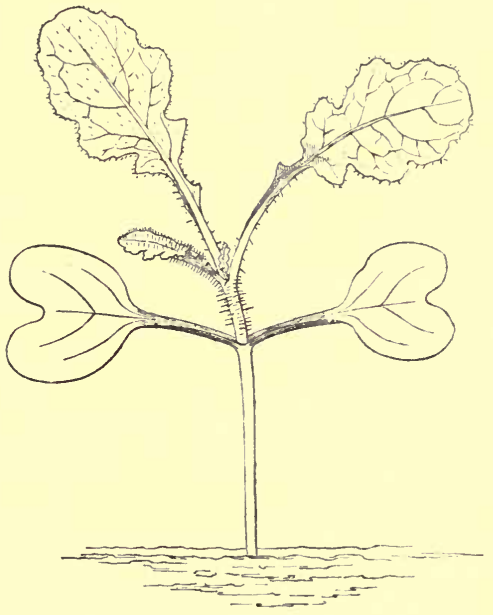

FIG. 168.-Brassica nigra. Nat. size.

The reason for this peculiar form has been suggested above, pages 31 and 43.

Stem erect, terete, coarsely hairy with bulbous-rooted hairs; striated longitudinally or shallowly ridged and furrowed, herbaceous, annual, pale green; 1 st internode $3.5-12.5 \mathrm{~mm}$. long; 2nd to 4 th or more undeveloped.

Leaves simple, radical and cauline, alternate, exstipulate, petiolate, alternately penninerved, with zigzag nerves more or less incurved, and entering straight into the marginal teeth or lobes or giving off branches into them, hairy on both surfaces, reticulate, light green above with sunk nerves, paler beneath with prominent nerves, more or less decurrent on the petiole; petiole semiterete, 
channelled above, with rather acute edges, coarsely hairy, somewhat dilated at the base.

Nos. 1 and 2. Opposite, or slightly alternate by the development of the second internode, oblong-obovate, with a broad, obtuse point, more or less lobulate and dentate, lobes deltoid, obtuse, decurrent on the petiole.

No. 3. Oblong, more or less distinctly lyrate-pinnatifid.

B
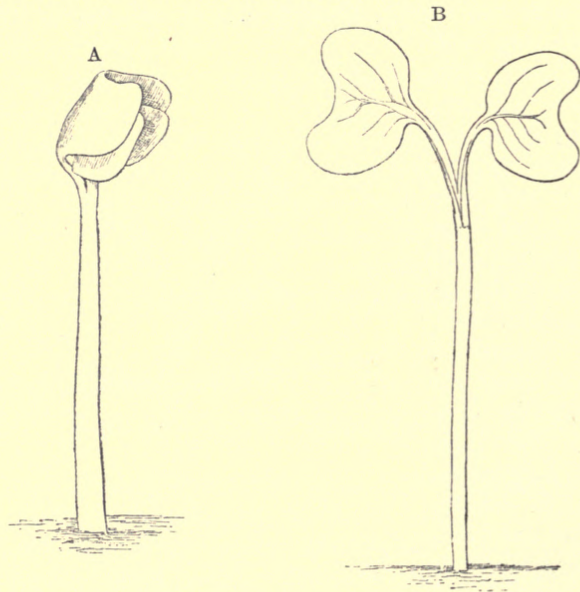

Fig. 169.-Brassica oleracea.

$\mathrm{A} \times 4, \mathrm{~B} \times 3$.

Brassica campestris, L., var. Rapa. White Globe Turnip.

Cotyledons transversely oblong, otherwise as in B. nigra. Individuals vary greatly in size, and length of petioles.

Brassica oleracea, L. (fig. 169).

Cotyledons broader than long, bifid with a broad sinus, lobes ascending, rounded.

Average size of three larger laminæ $6.5 \mathrm{~mm}$. long, $10.08 \mathrm{~mm}$. wide.

Average size of three smaller laminæ $6 \mathrm{~mm}$. long, $8.8 \mathrm{~mm}$. wide.

Average length of three longer petioles $8.58 \mathrm{~mm}$.

Measured seven days after germination. 
In the accompanying sketch, $\mathrm{A}$ and $\mathrm{B}$ represent stages of the germinating seedling.

\section{Brassica elata, Ball.}

Hypocotyl undeveloped or indistinguishable from the primary root, subterranean.

Cotyledons small, transversely oblong, broadly and shallowly emarginate, slightly unequal, glabrous, rather fleshy or succulent, with a faint midrib, but no other venation apparent in the fresh state; lamina in an average of three larger ones $3 \cdot \dot{6} \mathrm{~mm}$. long, $5 \cdot 75 \mathrm{~mm}$. wide; of three smaller ones $3.5 \mathrm{~mm}$. long, $5 \mathrm{~mm}$. wide; petioles flattened above, slightly connate at the base, unequal; average of three longer ones $4 \cdot 3 \mathrm{~mm}$. long; of three shorter ones $3 \cdot 5 \mathrm{~mm}$. long.

Leaves densely pubescent or hairy on both surfaces, petiolate.

Nos. 1 and 2. Rotund-obovate, obtusely dentate.

No. 3 . Obovate, slightly lobate at the base, and obtusely dentate.

Nos. 4 and 5. Lyrate pinnatifid, with the terminal segment much the largest, rotund or oblong, dentate.

\section{Brassica rugosa, Roxb.}

Primary root stout, with lateral rootlets, annual.

Hypocotyl very short and tapering indistinguishably into the primary root, pale green or colourless, with its original epidermis soon splitting.

Cotyledons cuneate, bifid, with rounded obtuse lobes, petiolate, with one or at most two alternate, ascending nerves running into each lobe, glabrous, succulent, deep green above, paler beneath; lamina in an average of three larger ones $9 \cdot 75 \mathrm{~mm}$. long, $11 \mathrm{~mm}$. wide; of three smaller ones $8.58 \mathrm{~mm}$. long, $10.08 \mathrm{~mm}$. wide; petioles flattened above or shallowly grooved, convex on the back, glabrous, unequal; average of three longer ones $10.08 \mathrm{~mm}$. long, of three shorter ones $9 \cdot \dot{6}$.

Stem erect, terete, slightly angular, annual, glabrous, light green; two primary internodes generally undereloped.

Leaves glabrous or slightly hairy and glabrescent when old, alternately and ascendingly penninerved, reticulate; petioles semiterete, grooved above, stout.

Nos. 1 and 2. Spathulate, obtuse, serrato-dentate.

No. 3. Oblong, obtuse, coarsely serrato-dentate.

Nos. 4 and 5. Obovate, obtuse, coarsely, irregularly and somewhat doubly dentate-serrate, with glandular-mucronate serratures. 


\section{Brassica balearica, Rich.}

Primary root biennial.

Hypocotyl erect, terete, glabrous, soon becoming glaucouspurple, 12-18 mm. long.

Cotyledons cuneate-obcordate, with rounded obtuse lobes on each side of the sinus, and about three alternate ascending nerves on each side, passing into the lobes, or the upper pair short and apparently formed by the forking of the midrib; deep glaucous-green above, paler and glaucous beneath, petiolate, glabrous, unequal ; lamina of the longer cotyledon 8-10 mm. long, 11-13 mm. wide; of the smaller one 7-8-10 mm. long, 9-11 mm. wide; longer petiole on the larger cotyledon about 10-13 $\mathrm{mm}$. long; shorter petiole 8-10 $\mathrm{mm}$.

Stem erect, terete, glaucous-purple, glabrous; 1st internode 1-2.25 mm. long, 2nd 4-7 mm.

Leaves glabrous, glaucous, with the midrib and principal nerves purple, alternately penninerved, reticulate.

No. 1. Obovate, slightly crenate.

No. 2. Oval, coarsely crenate.

Nos. 3 and 4. Suborbicular or oblong-orbicular, coarsely and irregularly crenate, slightly decurrent on the petiole in small lobules.

No. 5. Oblong, obtuse, lobulate and crenate, decurrent on the petiole forming small lobules.

\section{Brassica Aristidis, Coss.}

Hypocotyl erect or procumbent, terete, green or purple, glabrous or nearly so, slightly striate, soon losing its epidermis by splitting, 8-15 mm. long.

Cotyledons very similar to those of $\mathrm{B}$. balearica, fleshy, light green above, paler or glaucous beneath ; average of the three larger laminæ $13 . \hat{\mathrm{mm}}$. long, $15.4 \mathrm{~mm}$. wide; of three longer petioles $15.83 \mathrm{~mm}$. long, of the shorter $14 \cdot 6 \mathrm{~mm}$.

Stem developed when about to flower; primary internodes undeveloped.

Leaves radical and cauline, alternately penninerved, pubescent on both surfaces with adpressed hairs.

No 1. Small, obovate, shallowly crenate.

No. 2. Deltoid, obtuse, coarsely crenate.

Nos. 3 and 4. Deltoid, obtuse, coarsely crenate, somewhat decurrent and slightly lobulate on the petiole.

Nos. 5 and 6. Lyrate, pinnatifid, lobulate and coarsely crenate; terminal lobe much the largest, deltoid, lobulate, and coarsely crenate. 


\section{Orychophragmus sonchifolius, Bunge.}

Hypocotyl erect, striated, covered with very minute almost globular hairs, $10.12 \mathrm{~mm}$. long, colourless with a slight purplish tinge towards the upper part.

Cotyledons broadly ovate-oblong, obtuse, minutely emarginate, petiolate, glabrous, green above, stained with dark purple beneath, indistinctly one-veined; petioles rather long, covered with very minute hairs, channelled on the upper side.

Stem with primary internodes undeveloped.

First leaves simple, radical, alternate, exstipulate, petiolate, sub. rotund or oblong, serrate, acute, hairy, light green, pinnatinerved.

\section{Moricandia hesperidiflora, $D C$.}

Primary root tapering downwards with numerous lateral rootlets.

Hypocotyl erect, terete, glabrous, $4-4 \cdot 5 \mathrm{~cm}$. long, light green or colourless.

Cotyledons transversely oblong, emarginate, petiolate, glabrous, unequally divided by the midrib; midrib with a few ascending veinlets ; petioles $1 \cdot 5-2 \mathrm{~cm}$. long.

Stem with the primary internodes undeveloped.

First leaves simple, cauline, alternate, lanceolate, bluntly serrate, petiolate, glabrous, light green; midrib with numerous ascending veinlets.

\section{Moricandia arvensis, $D C$.}

Primary root as in the preceding species.

Hypocotyl as in the preceding species but $8-10 \mathrm{~mm}$. long.

Cotyledons unequal, obovate, slightly emarginate, fleshy, with a long flat petiole, glabrous, green, indistinctly one-veined.

Stem erect, herbaceous, terete, glabrous, pale green ; first internode 1-2 mm. long.

First leaves obovate, notched at the apex, obtuse, tapering to the flat petiole.

\section{Carrichtera Vellæ, $D C$.}

Hypocotyl erect, terete, hairy or villous, 2-3.5 $\mathrm{cm}$. long.

Cotyledons bifid, broader than long, nearly or quite glabrous, petiolate ; lamina 4-5 mm. long, 5-6 $\mathrm{mm}$. wide, subtruncate or distinctly cuneate at the base; petiole thinly pilose, semiterete, channelled above, 7-8 $\mathrm{mm}$. long. The internodes between the cotyledons are sometimes elongated, making the latter alternate. 
Stem herbaceous, erect, annual, hairy with deflexed hairs ; internodes elongated.

Leaves simple, cauline, alternate, exstipulate, petiolate, almost glabrous above, thinly hairy beneath ; petiole semiterete, channelled above.

No. 1. Pinnatifid or pinnatisect with linear segments.

No. 2. Similar.

Nos. 3 and 4. Pinnatisect, with slender segments.

Nos. 5 and following. Bipinnatisect with slender segments.

Succovia balearica, Medik.

Hypocotyl erect, terete, but with a distinct rather deep furrow along its whole length, from the edges of the cotyledons to the base, glabrous.

Cotyledons petiolate, with a bipartite lamina, unequal; lamina transverse with two orbicular or obovate, often unequal lobes, consisting of lateral developments, growth in length being very limited and represented by the undivided portion, the midrib terminating at the base of the sinus. The rounded form of the lobes is due to their shape in the globular seed as each lobe occupies about half the area of the cavity. Each is traversed by two lateral nerves from the midrib, which curve and unite with one another within the margin. The base of the lobes is somewhat auricled, passing into the narrow cuneate leaf-base. Petioles of unequal length, rather deeply channelled above.

Stem erect, herbaceous, slightly pubescent, with shallow ridges from the bases of the leaves.

Leaves, the first two opposite or alternate, five-lobed, with the terminal lobe trifid, and the lateral ones oblong or ovate and slightly toothed, a small basal lobe being sometimes present, glabrous. The other leaves are alternate.

Capsella Bursa-pastoris, Moench (fig. 170).

Primary root long, tapering, colourless, with lateral rootlets, annual.

Hypocotyl subterranean.

Cotyledons small, spathulate, obtuse, petiolate, glabrous.

Stem undeveloped till the time of flowering.

Leaves radical (ultimately cauline), alternate, exstipulate, petiolate, coarsely hairy on both surfaces; petioles convex beneath, much flattened above, broad.

Nos. 1 and 2. Entire with a rotund limb. After these an 
uncertain number are spathulate and entire or oblong and variously dentate.

Ultimate leaves lyrate, pinnatifid or pinnatipartite; terminal lobe ovate, obtuse, irregularly dentate; middle lobes ovate, obtuse, very unequal on the anterior side, with an extra longitudinal vein and irregularly toothed or lobed; basal lobes small.

Cauline leaves ovate, lanceolate and linear, deeply auricled at the base, amplexicaul, sessile, serrate.

Lepidium sativum, L. (figs. 171-2).

Fruit a silicula; septum narrow, laterally compressed, each carpel boat-shaped and falling away from the placenta, containing one, rarely two seeds.
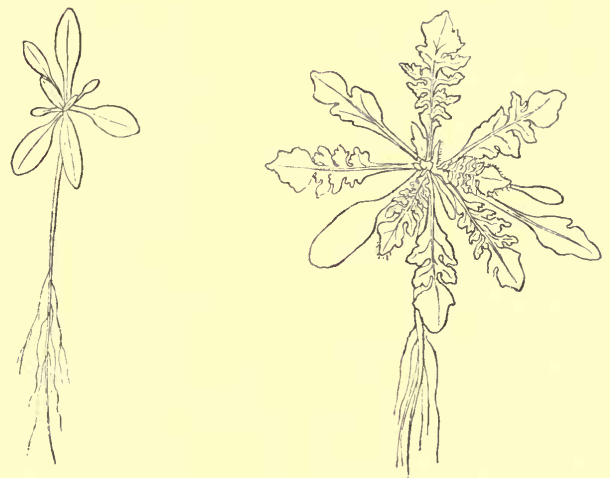

FIG. 170.-Capsella Bursa-pastoris. Nat. size.

Seed oblong, trigonous, pale brownish-yellow, with the narrow or dorsal aspect (containing the radicle) lying in the keel of the carpel, to which it conforms roughly in shape, with the broader ventral aspect to the septum, curved upon itself so that the basal part of the radicle lies in a separate cavity from that of the cotyledons; hilum at the upper end of the seed ; micropyle superior on the dorsal aspect.

Embryo large, curved upon itself, conforming in shape to the seed, yellowish; cotyledons tripartite ( $v$. ante, p. 52), shortly petiolate; middle segment oblong, obtuse, longer than the other two, which are similar but shorter and packed on the back of the middle one, all placed with their backs to the placenta; radicle nearly as long as the incumbent cotyledons, cylindrical, pointed. 
Lepidium graminifolium, $L$.

Seed (fig. 171) v. ante, p. 52.

Seedling (fig. 173).

Primary root slender, tapering downwards, with fibrous lateral rootlets.

Hypocotyl very short, tapering indistinguishably into the primary root.

Cotyledons unequal, oblong, obtuse, entire or minutely emarginate, petiolate, with short ascending or irregular lateral nerves anastomosing with one another and discernible only by transmitted light, glabrous, light green; lamina of the smaller one $5 \cdot 5-7 \cdot 5 \mathrm{~mm}$. long, $3 \cdot 5-4.5 \mathrm{~mm}$. wide; of the larger one $7-10.5 \mathrm{~mm}$.

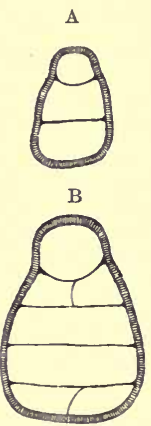

FIG. 171.-Transverse section of seed of Lepidium spp., $\times 15$.

A, L. graminifolium.

B, L. sativum.

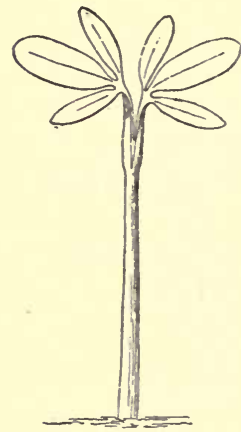

Fig. 172.

Lepidium sativum, $\times \mathbf{8}$.

long, 4-5 $\mathrm{mm}$. wide; petiole flattened above, convex beneath, connate at the base, glabrous; shorter one $4-5 \mathrm{~mm}$., longer $5 \cdot 5-$ $7 \mathrm{~mm}$. long.

Stem herbaceous, forming a persistent rootstock and sending up flowering stems; primary internodes undeveloped.

Leaves simple, radical and cauline, alternate, exstipulate, petiolate, alternately penninerved with the nerves running directly into the teeth or more often incurved, uniting with one another, sending branches into the marginal teeth and more or less distinctly reticulate, ciliate at the margins when young, glabrescent, green above, paler beneath; petioles semiterete, channelled above, dilated and clasping with a usually ciliate margin at the base. 
Nos. 1 and 2. Elliptic or oval, obtuse, somewhat tapered towards the base, obtusely and distantly serrate-crenate.

Nos. 3 and 4 . Elliptic, obtuse, tapered to the base, more deeply serrate-crenate.

Lepidium spinosum, $L$.

Hypocotyl erect, terete, glabrous, 1-2 cm. long, light green or colourless.

Cotyledons oval-oblong, fleshy, entire, petiolate, glabrous, dull green, indistinctly oneveined.

Stem short ; primary internodes undeveloped.

First leaves simple, cauline, obovate or oblong, subacute, coarsely serrate or even crenate, petiolate, glabrous, light green, indistinctly pinnatinerved.

Senebiera didyma, $P$.

Primary root long, tapering and normal, annual.

Hypocotyl subterranean, tapering downwards into the root.

Cotyledons opposite, linear - spathulate, obtuse, tapering to the petiole, 6-8 $\mathrm{mm}$. long including the petiole, glabrous.

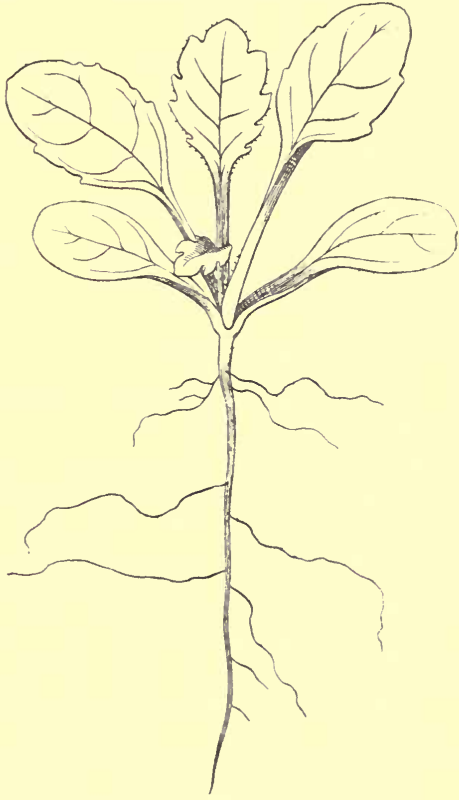

FIg. 173.-Lepidium graminifolium, $\times \mathbf{2}$.

Stem developing later, decumbent, leafy.

Leaves simple, radical and cauline, alternate, exstipulate, petiolate, glabrous, glandular; glands sessile, with a disagreeable smell.

No. 1, and frequently Nos. 2 and 3. Entire with an oblongobtuse or spathulate lamina. Further stages of leaves are oblong, pinnatifid, with elliptic, bristle-tipped segments; terminal lobe largest, entire or trifid. 
Ultimate leaves linear, pinnatisect; terminal lobe deeply trifid with generally entire segments; lateral lobes half-ovate, obtuse, again pinnatifid, but lobes usually all on the anterior side, or with one tooth only on the posterior side; segments all tipped with a bristle.

\section{死thionema gracile, $D C$.}

Hypocotyl 2-6 mm. long.

Cotyledons suborbicular, more or less unequal at the base, entire or sometimes emarginate, fleshy, with a few short, simple or slightly branched hairs on the upper surface, shortly petiolate; lamina 4-5.5 $\mathrm{mm}$. long, the difference between the unequal sides varying from $\cdot 25-75 \mathrm{~mm}$.; petiole flattened above, $2 \cdot 5-3 \mathrm{~mm}$. long.

Stem with more or less developed internodes, terete, covered with stellate hairs.

Leaves simple, entire, showing a midrib only, covered more or less densely on both surfaces with white, stellate hairs.

1st to 5th pairs in the seedling state small, cauline, opposite and decussate, elliptic, subacute or obtuse.

\section{Bivonæa Saviana, Caruel.}

Hypocotyl terete, 4-5 mm. long, soon losing its epidermis by splitting.

Cotyledons shortly oblong, obtuse, minutely emarginate, tapering slightly at the base, petiolate, glabrous; the succulent lamina 5.5-7.5 mm. long, 4-5 mm. wide; petiole long, slender, spreading horizontally and upcurved, semiterete, channelled on the upper side, dilated at the base and slightly connate, $1 \cdot 6-2 \cdot 2 \mathrm{~cm}$. long.

Stem with the internodes undeveloped.

Leaves simple, radical, alternate, petiolate, glabrous, succulent, venation indistinct, veins radiating from the base and becoming incurved upwards, deep green above, paler beneath, with a more conspicuous venation; petiole very long, tapering upwards from a dilated base, channelled on the upper side.

Nos. 1-6. Reniform-cordate, obtuse, entire.

Nos. 7-10. Similar but having one or two angles or teeth near the base on each side.

\section{Menonvillea trifida, Steud.}

Hypocotyl erect, terete, glabrous, 2-3 $\mathrm{cm}$. long, light green or colourless.

Cotyledons long, linear, acute, curled at first, sessile, glabrous, pale green.

Stem with primary internodes undeveloped. 
First leaves simple, cauline, alternate, pinnati-fid or -partite; segments two, linear, acute, hairy.

Biscutella didyma, $L$.

Primary root tapering downwards, with numerous lateral rootlets.

Hypocotyl short, tapering sharply downwards, almost colourless, glabrous, from 1-2 mm. long.

Cotyledons fleshy, broadly oblong, obtuse, entire or very minutely crenate at the apex, rather unsymmetrically divided by the midrib, shortly petiolate, glabrous, green, indistinctly pinnatinerved like the leaves, cuneate at the base.

Stem with primary internodes undeveloped.

First leaves simple, radical, alternate, petiolate, subrotund or oblong, obtuse, crenate, hairy, green, pinnatinerved; petioles rather short, hairy, rather flat and channelled on the upper side.

\section{Iberis corifolia, Sweet.}

Primary root tapering downwards and branched.

Hypocotyl erect, terete, glabrous, 14-18 mm. long.

Cotyledons shortly and broadly oval, obtuse, entire, petiolate, glabrous; lamina opaque with an indistinct midrib, $10 \mathrm{~mm}$. long by $7 \mathrm{~mm}$. broad; stained purple beneath, petiole $4-4.5 \mathrm{~mm}$. long, slightly channelled on the upper side.

Stem herbaceous or subshrubby, erect in the seedling stage, afterwards procumbent, scabrous, otherwise glabrous ; 1st internode 4-5 mm. long.

Leaves simple, entire, cauline, alternate (1st pair opposite or nearly so), petiolate, narrowed to the base, glabrous, one-nerved, deep green, all narrower than the cotyledons.

Nos. 1 and 2. Obovate-spathulate, obtuse.

Nos. 3-5. Spathulate, obtuse.

Nos. 6-10. Linear, obtuse.

\section{Iberis Lagascana, $D C$.}

Hypocotyl 5-8 mm. long.

Cotyledons oval-oblong, fleshy, rather unsymmetrical.

Stem with primary internodes undeveloped.

Leaves pinnatifid, cauline, alternate, glabrous except on the petioles, light green, pinnatinerved; lobes entire, obovate, obtuse; petiole channelled on the upper side, with a few scattered liairs. 


\section{Iberis pectinata, Boiss.}

Hypocotyl 10-18 mm. long.

Cotyledons obliquely oval, very unequal at the base, obtuse, somewhat truncate at the apex, or faintly emarginate, glabrous or with a thin, faint line of adpressed colourless hairs along the back of the petiole; lamina in average specimens $9-10 \mathrm{~mm}$. long on one side of the midrib, and $8 \mathrm{~mm}$. on the other, about $7 \mathrm{~mm}$. wide; petiole 12-14 mm. long, channelled on the upper side.

Stem terete, hairy, with spreading or deflexed hairs; internodes variously developed from 1-15 mm.

Leaves cauline, hairy, with a distinct channelled midrib.

Nos. 1-7. Linear, obtuse, tapering gradually into the petiole at the base, deeply and bluntly toothed or pinnatifid.

Isatis tinctoria, $L$. (fig. 174).

Fruit laterally compressed, oblong-cuneate, broadest at the apex, somewhat winged at the base and apex, woody on each side of the

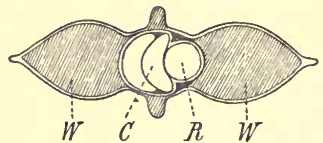

FIa. 174.-Isatis tinctoria. Transverse section of fruit, $\times 8: C$, cotyledons; $R$, radicle; $W, W$, woody portions of siliqua. cavity containing the seed, onecelled, one-seeded, indehiscent.

Seed cylindrical or oblong, tipped with the short funicle by which it is suspended from the apex of the cell ; hilum and micropyle contiguous, at the upper end of the seed, and nearest the base of the style.

Endosperm none, or forming an extremely thin film on the inner face of the testa.

Embryo large, filling and conforming to the seed, curved or bent upon itself, yellowish; cotyledons oblong, obtuse, entire; radicle spindle-shaped, narrowed to an obtuse point, lying along the back of the (incumbent) cotyledons and slightly longer by reason of its forming the curve at the apex of the seed while the cotyledons are straight.

\section{Ochthodium ægyptiacum, DC. (fig. 175).}

Fruit a nut-like silicula, broadly rhomboid, short, subquadrangular, laterally compressed, covered with hard tubercles on the four angles and smaller ones between; subcarinate on the back of each carpel, glabrous, pale grey, two-celled, two-seeded, indehiscent and remaining attached to the pedicel; pericarp hard, crustaceous, and somewhat brittle.

Seed broadly oblong, rounded at the apex, unequal at the base owing to a prolongation of the radicle beyond the cotyledons, com- 
pressed but convex dorsally, nearly flat ventrally, pale yellow ; testa thin, membranous ; micropyle superior, contiguous to, but a little higher up than, the hilum; chalaza forming a small, slightly
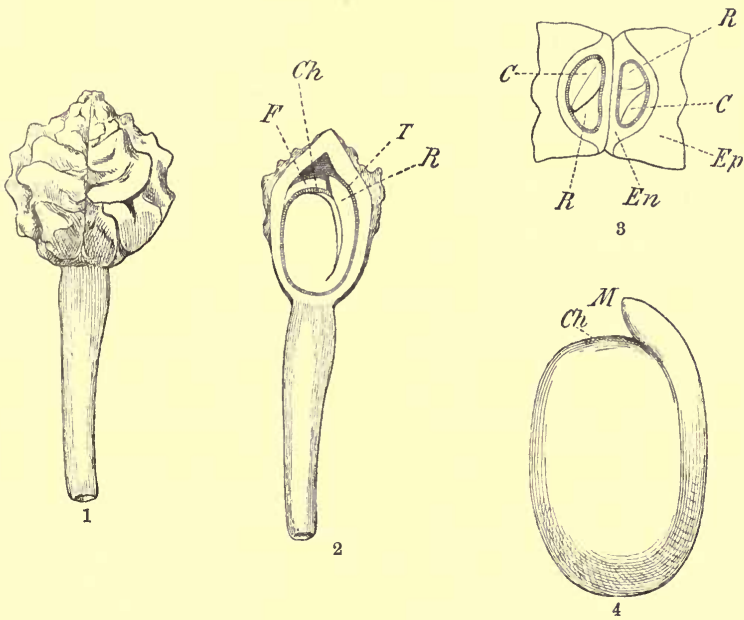

FIG. 175.-Ochthodium agyptiacum.

1, Fruit on its pedicel, $\times 6$, lateral aspect.

2 , Longitudinal section of fruit, $\times 6: F$, funiculus; $T$, testa; $R$, radicle; $C h$, chalaza.

3 , Transverse section of fruit, $\times 6: C, C$, cotyledons; $R, R$, radicles; $E p$, epicarp; $E n$, endocarp.

4, Seed, $\times 15: C h$, chalaza ; $M$, micropyle.

thickened deep brown spot, close to the sinus between the cotyledons and the radicle, in which the hilum is placed.

Endosperm absent.

Embryo comparatively large and filling the entire seed, doubled upon itself, pale yellow or nearly colourless; cotyledons oblongoval, obtuse, plano-convex, obliquely incumbent ; radicle somewhat curved, lying obliquely on the back of the cotyledons, but between the latter and the septum, that is on the ventral aspect, rather longer than the cotyledons.

Bunias orientalis, $L$.

Fruit nut-like, ovoid-tetragonous, laterally compressed, more or less tuberculated or rough at the angles, tipped with the persistent 
base of the style, woody, pale-coloured, indehiscent, one-to two-celled, with generally a seed in each cell.

Seed more or less cochleate by the shrinking of the testa to conform to the embryo, otherwise, when fresh and plump, nearly globose with the radicle appearing as an appendage at one side; micropyle close to and superior to the hilum; chalaza forming a broad orbicular discoloured patch on the ventral aspect.

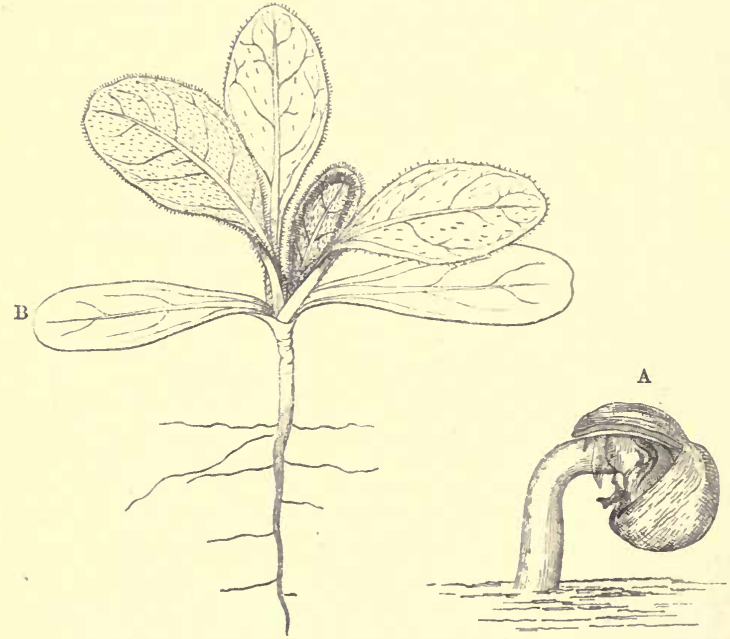

Frg. 176.-Bunias orientalis. A, Germinating seed, $\times 3$. B, Seedling, nat. size.

Endosperm in the mature seed forming a thin film lining the interior of the testa.

Embryo large, filling the seed, spirally coiled, pale yellow; cotyledons oblong, obtuse, entire, forming about a coil and a half, with their tips in the centre of the coil, and the edges of both touching the sides of the seeds, narrowed to the base; radicle cylindrical, obtuse, incumbent and curved round close to the hilum and beneath the base of the style, long, and well developed.

Seedling (fig. 176).

Hypocotyl very short, stout, erect, wrinkled transversely, pale green or colourless, $2-6.5 \mathrm{~mm}$. above the soil.

Cotyledons unequal in length, spathulate, obtuse, entire, or show- 
ing a tendency to become emarginate, tapering to a petiole-like base, with a few alternate, ascending slender nerves, the uppermost strong pair of which incurve and unite with the midrib below the apex, finely reticulate, and all the veins seen only by transmitted light, glabrous, light green above, paler beneath, petioles flattened above, convex beneath, slightly connate at the base; average length of three long cotyledons $4 \cdot 2 \mathrm{~cm}$, of three short ones $3 \cdot 33 \mathrm{~cm}$.

Stem herbaceous, developed when about to flower; primary internodes undeveloped.

Leaves simple, radical and cauline, alternate, petiolate, hairy on both surfaces, alternately and ascendingly incurvinerved; nerves uniting at the apex, obscurely reticulate; petiole tapering upwards from a rather broad, clasping base, channelled on the upper side, or finally becoming more or less flattened.

Nos. 1 and 2. Spathulate-obovate, or oblong, or oval, obtuse, entire, or with inconspicuous glandular teeth.

No. 3. Similar.

No. 4. Oblong, obtuse, entire, with glandular teeth.

\section{Zilla myagroides, Forsk.}

Fruit a nut-like silicula, ovoid or subglobose, slightly compressed laterally, shallowly ridged and furrowed longitudinally, tipped with the subulate or conical, persistent style, two-celled, two-seeded, indehiscent, glabrous, pale ashy grey, or more or less blackened; substance of pericarp differentiated into an outer, thick, pale-coloured, corky layer, and an inner, thick, hard and almost bony layer furnished with wings extending through the cortex to the circumference of the fruit.

Seed obovoid, conforming to the cavity of the loculus, somewliat compressed, but convex dorsally; much compressed and almost flattened ventrally, pale brown, smooth, almost shining, very unequal at the upper and basal end where it runs out at one side into an obtuse point; testa comparatively thin, coriaceo-membranous; hilum in the sinus formed by the curvature of the seed, that is between the radicle and the part containing the cotyledons; micropyle at the upper and most elongated point of the seed; chalaza lateral, forming a dark brown spot near the hilum, but on the opposite side of the latter from the micropyle.

Endosperm absent.

Embryo large and filling the seed, doubled upon itself.

Cotyledons rotund-cuneate, emarginate, conduplicate, and incumbent, probably about equal in size, as the inner one projects some way from beneath the outer, pale yellow; radicle cylindrical, sub- 
fusiform, slightly curved in conformity with one side of the seed, much longer than the cotyledons, and terminating in the pointed end of the seed, considerably curved at its union with the cotyledons, pale yellow, obtuse.

For further development see Goebel, 'Flora,' 1889, p. 32.

Seedling (fig. 177).

Hypocotyl erect, terete, glabrous, pale green, 6-18 mm. or more above the soil.

Cotyledons unequal, broadly cuneate, emarginate or broadly and shallowly bifid, petiolate, with one or two alternate, ascending, diffcultly discernible nerves entering the lobes, rather fleshy, glabrous, bright green; lamina of the smaller one $6.5-8 \mathrm{~mm}$. long and as wide; of the larger $8 \cdot 5-10 \mathrm{~mm}$. long and

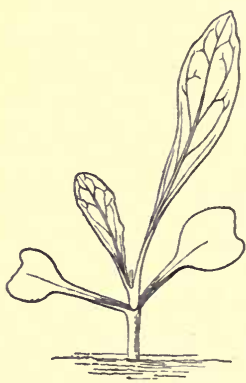

Fig. 177.

Zillamyagroides. Nat. size. 7·5-11 mm. wide; petiole semiterete, flattened above, slightly connate at the base, glabrous, light green; of the smaller cotyledon 8-10 mm.; of the larger $7 \cdot 5-8.5 \mathrm{~mm}$. long.

Stem erect, terete, glabrous, pale green, ultimately shrubby; first internode $\cdot 5-2 \mathrm{~mm}$. long.

Leaves simple, cauline, alternate, petiolate, alternately and ascendingly penninerved with the nerves incurved uniting at their apex and anastomosing indistinctly, with a prominent midrib, but the other venation best discernible on the under side, rather fleshy, glabrous, light subglaucousgreen, and somewhat shining when young; petioles slightly flattened above or biconvex with a prominent midrib, glabrous.

Nos. 1 and 2. Spathulate, obtuse, with rather long petioles, and one to two obscure or obsolete teeth on each side.

Cakile maritima, Scop. (fig. 178).

Hypocotyl erect, terete, glabrous, $4 \cdot 5-5 \mathrm{~cm}$. long, light green or colourless.

Cotyledons unequal, rather fleshy, linear, obtuse, entire, sessile, tapering to the base, but not petiolate, glabrous, light green, oneveined.

Stem erect, terete, herbaceous.

Cakile americana, Nutt.

Hypocotyl as in C. maritima but only $5-10 \mathrm{~mm}$. long. 
Cotyledons very unequal, linear-oblong, otherwise as in C. maritima.

Stem with primary internodes undeveloped.

First leaves simple, entire, cauline, alternate, narrowed to the base, exstipulate, ovate-oval, obtuse, very hairy, light green, pinnatinerved.

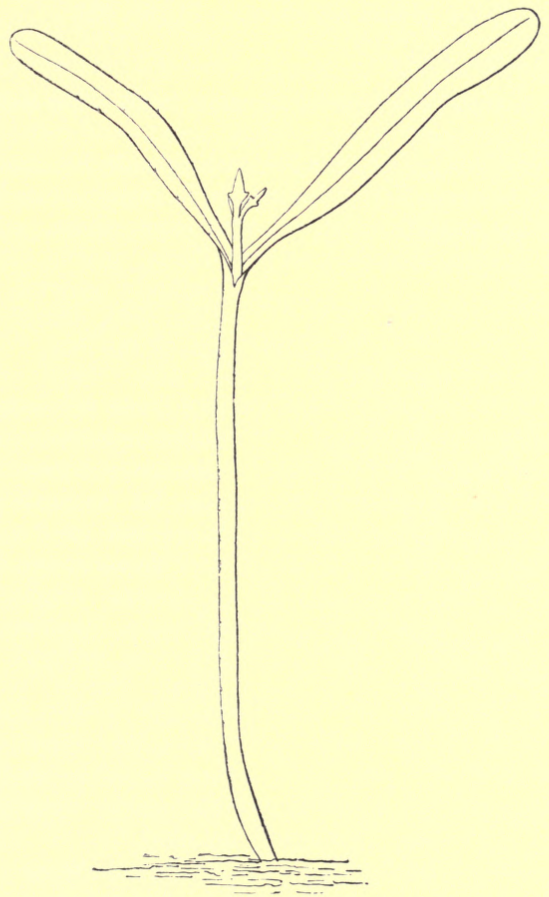

FIG. 178.-Cakile maritima, $\times 2$

Chorispora tenella, $D C$.

Hypocotyl short, erect, scarcely appearing above the soil obconical.

Cotyledons oval-oblong, obtuse, entire, petiolate, rather fleshy, glabrous, green, pinnatinerved like the leaves; petiole long, rather flat, slightly furrowed on the upper face. 
Stem with primary internodes andeveloped.

First leaves simple, cauline, alternate, petiolate, obovateoblong, obtuse, lobed (first one entire), slightly hairy, green, pinnatinerved; petioles rather long, channelled on the upper face.

Raphanus sativus, $L$.

For description of seed see above, p. 31 (fig. 62).

Seedling (fig. 179).

Primary root long, tapering, flexuose, with a few small lateral rootlets.

Hypocotyl short, stout, succulent, subsequently becoming swollen to form the edible radish, glabrous, purple, merging into the root.

Cotyledons opposite, foliaceous, with long petioles, penninerved, glabrous; lamina obcordate or obreniform; petiole broadly and

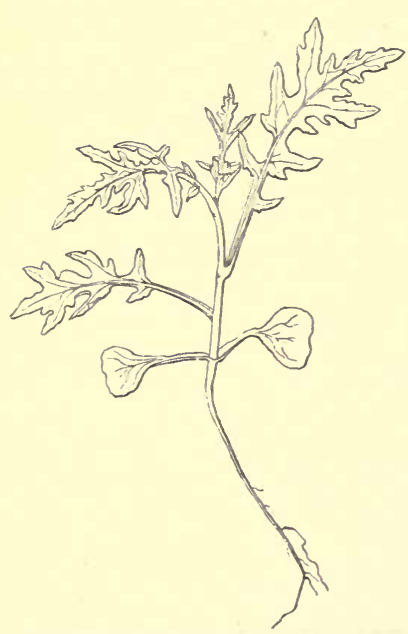

F1G. 179.-Raphanus sativus. Nat. size. shallowly grooved on the upper side, dilated and connate at the base.

Stem erect, shallowly ridged and furrowed, sparsely setose or scabrid, pale green, sometimes suffused with purple; 1st internode 2-6 $\mathrm{mm}$. long; 2nd 1.5-3.5 cm., very variable under cultivation.

Leaves simple, cauline, alternate, petiolate, sparsely setose or scabrous, oblong or linear, simply toothed or serrate or variously lyrate pinnatifid; segments obtuse and entire or variously and irregularly pinnatifid or toothed.

Note.-When there is abundance of moisture the plants grow freely and the leaves are little cut up, varying from spathulate or oval to oblong, lyrate-pinnatifid or pinnatisect. If the plants are crowded or the weather dry they swell but little at the root, run to flower, and at the same time produce leaves that are bipinnatisect or irregularly cut into narrow shreds or segments. 


\section{CAPPARIDEA.}

Benth, et Hook. Gen. Pl. i. 103.

Fruit and Seed.-The Order falls into two divisions according as the fruit is dry and capsular as in Cleome, Cleomella, Cristatella, and others; or on the other hand baccate like Capparis, Morisonia, and Mærua, or drupaceous as in the oneseeded fruit of Roydsia. In the capsular types, the Order approaches Cruciferæ very closely. The fruit is siliquose in all the genera of the Cleomer except Wislizenia and Oxystylis, where it is short, didymous, and brealis up into indehiscent one-seeded pieces. The Cappareæ have baccate and indehiscent fruits with the seeds embedded in pulp. The ovules in all cases are parietal, campylotropous or semiaratropous, and the seeds reniform in the dry fruits, reniform or angular in the baccate fruits. The angular condition may depend upon the number of seeds in a fruit and the effect of mutual pressure. When the pulp is plentiful, separating the seeds from one another, they retain the usual shape of the campylotropous ovules. Usually the seeds are exalbuminous, but there is a thin layer of endosperm surrounding the embryo of Capparis sandwichiana (fig. 182) and a thick layer in which the curved embryo is embedded in Tovaria, an anomalous genus containing only one species, referred to the Papaveraceæ by Eichler and compared with the Phytolaccaceæ by Bentham and Hooker. It is probable that a careful examination of many species would reveal the presence of endosperm in other cases besides Capparis sandwichiana. The testa is thick, coriaceous, and smooth or often rough in species with a capsular fruit. The embryo is bent or incurved, or spirally convolute, and the cotyledons are incumbent, plaited or convolute, and induplicate, as may be seen by reference to the transverse section of Capparis sandwichiana.

Cotyledons.-As far as observed (seeds and seedlings of different species being difficult to obtain) the cotyledons after germination are always broad, petiolate, obtuse, and entire, 
and in some cases at least unequal in size. The breadth is of course due to their being folded longitudinally, as well as to the comparatively large size of the seed and embryo.

The cotyledons of a species of Capparis (fig. 183) from Melbourne were large, foliaceous, shortly petiolate, ovate, obtuse, alternately incurvinerved and reticulate, glabrous, convex above, slightly unequal-sided, that is, the portion of lamina on each side of the midrib was not of the same width. They were evergreen and persisted for more than a year on the plant. In the case of Cleome violacea they fall away early.

Cleome violacea, $L$. (fig. 180).

Primary root tapering downwards, strongly tortuose, with a few lateral roots, annual.

Hypocotyl very short, stout, colourless, terete, subterranean, tapering into the root.

Cotyledons falling away early, slightly unequal, oblong or ovateoblong, obtuse, entire, petiolate; petioles a little shorter than the lamina.

Stem erect, terete, herbaceous, annual, pale green, densely glandular-pubescent; 1st internode $2.25 \mathrm{~mm}$. long; 2nd hardly

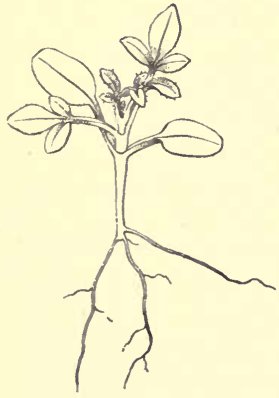

FIG. 180.-Cleome violacea $\times 2$. developed; 3rd $6 \mathrm{~mm}$. long; 4th $6 \mathrm{~mm}$.; 5th $9.5 \mathrm{~mm}$.; 6 th $1.7 \mathrm{~cm}$.; 7 th $1.6 \mathrm{~cm}$.; 8 th $8.5 \mathrm{~mm}$. ; 9th $1.15 \mathrm{~cm}$.; 10 th $1 \mathrm{~cm}$.; 11th $1.1 \mathrm{~cm}$.; 12 th $1.8 \mathrm{~cm}$.; 13 th $1 \cdot 1$ cm.; 14th $1.35 \mathrm{~cm}$.; 15 th $1.5 \mathrm{~cm}$.; 16 th $1.5 \mathrm{~cm}$.; 17 th $1.1 \mathrm{~cm}$.; 18 th $7 \mathrm{~mm}$.; 19th $4.5 \mathrm{~mm}$.; 20 th $2 \mathrm{~mm}$.

Leaves compound, digitately trifoliate, ultimately unifoliolate, cauline, alternate (first two opposite), exstipulate, petiolate, glandular-pubescent on both surfaces, deep green above, glaucous beneath; leaflets oblong-linear, obtuse or subacute with a deeply channelled midrib, very prominent beneath; petioles subterete, channelled on the upper side.

Nos. 1 and 2. Small, trifoliolate; leaflets subelliptic, the terminal one largest.

Nos. 3-6. Gradually larger, trifolioliate; leaflets linear.

No. 7. With one large terminal leaflet and a small lateral one. 
Nos. 8-14. With one rather long terminal leaflet.

The rest are bracts bearing flowers in their axils.

Cleome spinosa, L. (fig. 181).

Primary root with numerous strong lateral rootlets.

Hypocotyl erect, terete, glandular-pubescent near the top, otherwise glabrous, striated longitudinally, and marked with two lines of crystalline elevations running down from the edges of the cotyledonary petioles, deep dull red, 8-15 mm. long.

Cotyledons often, if not always, unequal, oblong or more often ovate-oblong, obtuse, entire, with a few alternate, ascending or subincurved nerves, dull green above, paler beneath, petiolate; lamina glabrous, 8-12 $\mathrm{mm}$. long, 3-6 $\mathrm{mm}$. wide; petioles semiterete, slightly channelled above, densely glandular - pubescent, each 3-5.5 mm. long.

Average length of 3 laminx, 10.3 mm. and $9 \cdot 3 \mathrm{~mm}$. in the longer and shorter cotyledons respectively.

Stem glandularhairy ; 1st internode hardly developed, or $\cdot 5-1 \mathrm{~mm}$. long.

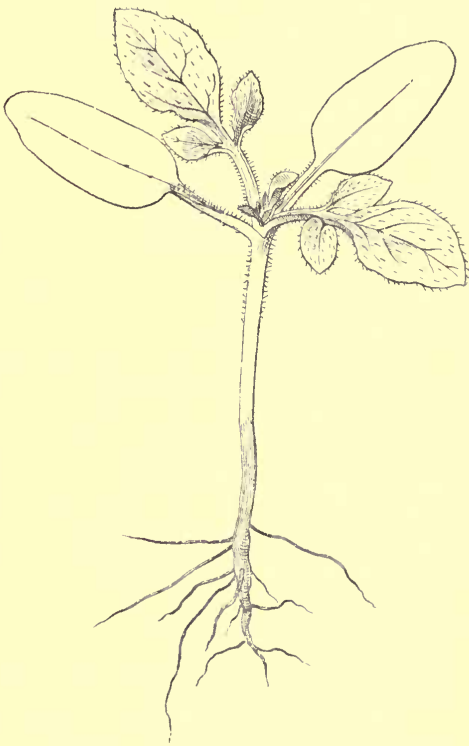

FIG. 181.-Cleome spinosa, $\times 2$.

Leaves ternately pinnate, alternate (first two opposite), glandular-pubescent on both surfaces, and rather strongly ciliate at the margin, alternately and ascendingly penninerved; petioles semiterete, channelled above, densely glandular-pubescent.

Nos. 1 and 2. Opposite, pinnately ternate; leaflets petiolulate; terminal one largest, elliptic, obtuse or subacute, slightly undulate at the margin or flat; lateral leaflets similar but much smaller. 
Capparis sandwichiana, DC. (fig. 182).

Fruit stipitate, globose or cylindrical, baccate, many-seeded, indehiscent.

Seed reniform, slightly flattened, embedded in pulp, with very unequal ends-the smaller containing the radicle, the larger the

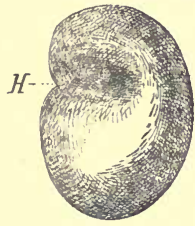

A

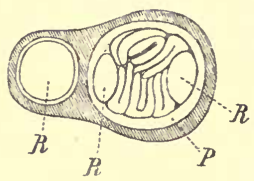

B

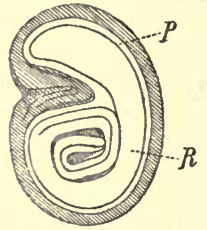

C

Fig. 182.-Capparis sandwichiana. A, seed, $\times 8: H$, hilum. B, transverse section of seed, $\times 8: R, R, R$, radicle; $P$, endosperm. C, longitudinal section of seed, $\times 8: P$, endosperm; $R$, radicle.

cotyledons; testa black, smooth, crustaceous; inner coat membranous; hilum in the basal notch.

Endosperm forming a thin layer surrounding the embryo.

Embryo large, spirally coiled, colourless; cotyledons oblong, each separately conduplicate, and then the double fold coiled spirally, one each side of the seed with its back to the endosperm, and both its edges lying in the centre of the seed and abutting against the edges of the other cotyledon ; radicle long, cylindrical, obtuse, incumbent, and forming a complete coil round the cotyledons and along the periphery of the seed.

Capparis, sp. (fig. 183).

Hypocotyl woody, erect, compressed, tapering upwards, glabrous, glaucous-green, $2 \cdot 8 \mathrm{~cm}$. long.

Cotyledons large, foliaceous, ovate, obtuse, alternately incurvinerved and reticulate, glabrous, deep green and convex above, shallowly concave and scarcely paler beneath, shortly petiolate; lamina $2.85 \mathrm{~cm}$. long, $1.7 \mathrm{~cm}$. broad; petiole $1.5 \mathrm{~mm}$. long, persistent. In the specimen sketched the halves of the cotyledons are of unequal widths by $1 \mathrm{~mm}$. The inequality of the one does not correspond to that of the other.

Stem woody, erect, terete, pubescent, pale green; 1st internode $8.5 \mathrm{~mm}$. long; 2nd $4 \mathrm{~mm}$.; 3rd $1 \mathrm{~mm}$.; 4 th $1.55 \mathrm{~cm}$.; 5 th $1 \mathrm{~cm}$.; 6 th $8 \mathrm{~mm}$. ; 7 th $1.15 \mathrm{~cm}$.; 8 th $3.25 \mathrm{~mm}$. First branch in axil of a cotyledon. 
Leaves simple, entire, cauline, alternate, exstipulate, shortly petiolate, ascending, alternately penninerved and obscurely reticulate, glabrous, and nearly of the same deep green on both surfaces; petioles very short (about $1 \mathrm{~mm}$. long), stout, articulated with the

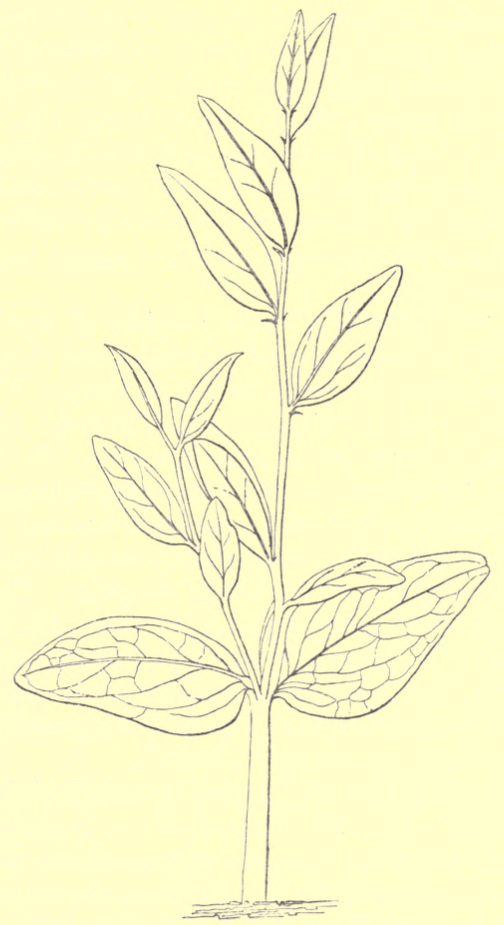

FIg. 183.-Capparis, sp. Nat. size.

stem; stipules small, spreading, spinous, pale yellowish-brown, absent from the first three leaves.

Nos. 1-3. Narrowly oblong, elliptic, obtuse, subapiculate.

No. 4. Lanceolate, obtuse.

Nos. 5 and 6. Lanceolate, acute.

Nos. 7 and 8. Small, lanceolate, obtuse. 


\section{RESEDACE $Æ$.}

Benth. et Hook. Gen. Pl. i. 110.

The Resedaceæ constitute a small Order, containing from thirty to sixty species according to the view taken by different authors. The greater part of them are natives of dry countries such as South Europe, North Africa, Syria, Asia Minor, and Persia, with a few in the outlying provinces of India, and three in Cape Colony. They consist of annual or perennial herbs, and a few are shrubby. The leaves are alternate and scattered, or crowded on short undeveloped branches, simple and entire or trifid or pinnatisect.

Fruit and Seed.-The ovary consists of from two to six carpels, with as many parietal placentas, and is closed at the top, or open during the whole or the greater part of its growth, as in Reseda, or gaping as in Caylusea. The ovules are numerous as in Reseda or one to two as in Astrocarpus. The latter is remarkable in the mature state when its four to six carpels divari eate in a stellate manner, each containing one seed only. The ovules are amphitropous or campylotropous, and inserted on the walls of the ovary or near the base of the cavity. The seeds are numerous, or few in Astrocarpus and Caylusea, and two to three in Randonia; they are reniform with a smooth testa or rough in Randonia, and are usually exalbuminous, but exceptions occur as in the Capparideæ. The fruit is capsular, follicular (Astrocarpus), or baccate (Ochradenus).

The embryo is large and curved or complicated, filling the interior of the seed. The cotyledons are incumbent, and in Reseda they constitute the greater part of the embryo, the radicle being extremely short. Caylusea abyssinica (fig. 184) forms an exception, inasmuch as an appreciable quantity of endosperm surrounds the large embryo, while in the sinus between the cotyledons and radicle lies a considerable thickness of it.

The seeds are reniform and slightly compressed laterally; and the cotyledons of the large embryo lie in the narrow plane of the seed, with their tips curved round to the hilum, but their backs to the placental axis. They are plano-convex and taken 
together are much thicker and wider than the terete or cylindrical radicle, which is about equal to the cotyledons in length.

Cotyledons. - The cotyledons of Reseda are broad and ovate in R. luteola, oblong or oval in R. odorata, and spathulate in R. alba (fig. 185). Those of the first named are somewhat succulent, taper into the petiole, have a few ascending veins on each side of the midrib, and are sometimes unequal in shape and size. The cotyledons in the other cases are also somewhat succulent with a faint midrib, but no other discernible venation in the fresh state. The embryo of Caylusea while in the seed is similar to that of Reseda in general outline.

Caylusea abyssinica, Fisch. et Mey. (fig. 184).

Seed almost orbicular, with a prominent basal notch, 1-1.25 $\mathrm{mm}$. in diameter ; testa crustaceous, brown at first, then bright shining black, smooth.

A

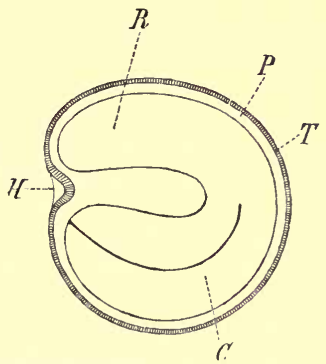

B

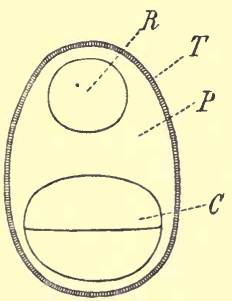

Fig. 184.-Caylusea abyssinica. A, longitudinal section of seed. B, transverse section, both $\times 30: P$, endosperm; $C$, cotyledon; $T$, testa; $R$, radicle; $H$, hilum.

Endosperm comparatively copious, surrounding the embryo, greyish-white.

Embryo curved or rounded on itself, surrounded by endosperm, colourless; cotyledons oval, entire, fleshy, plano-convex, sessile, with their edges towards the basal notch ; radicle terete, obtuse, superior, about the same length as the cotyledons.

Reseda alba, $L$. (fig. 185).

Primary root slender, tapering, fibrous.

Hypocotyl terete, elongated, pale green or colourless, glabrous, about $12-15 \mathrm{~mm}$. long. 
Cotyledons spathulate, obtuse, entire, petiolate, glabrous, light green, tapering into the petiole, about $17 \mathrm{~mm}$. long including the

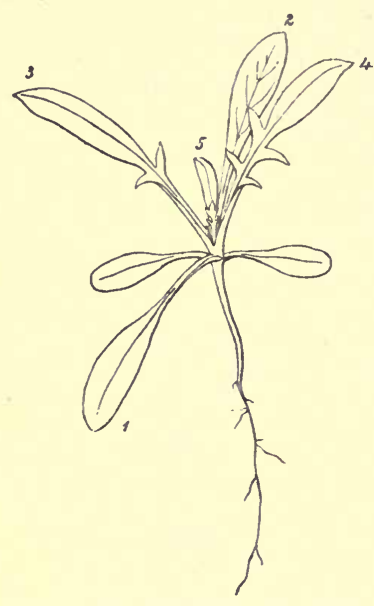

Fra. 185.-Reseda alba. Nat. size. petiole, one-nerved; petiole channelled above, dilated at the base and subperfoliate.

Stem herbaceous and developed when about to flower.

Leaves simple, radical and cauline, alternate, stipulate, petiolate, entire, glabrous, slightly scabrous at the margin, light green, indistinctly alternately and ascendingly penninerved and reticulate towards the margins ; petioles slightly channelled above, dilated and clasping at the base; stipules small, glandular, tooth-like and projecting from the upper edges of the petioles a little above their base.

Nos. 1 and 2. Spathulate, obtuse, entire, with a few ascending nerves and reticulate towards the margin.

No. 3. Oblong, with two small lateral, subulate, acute lobes near the base, and a nerve running into each lobe; middle lobe oblong, entire.

No. 4. Oblong, pinnatifid, with two alternate, subulate, acute lobes on each side, with branches running into them from the midrib ; middle lobe oblong-lanceolate, entire.

Ultimate leaves pinnatisect with linear more or less undulate segments, glaucous or green, glabrous.

Reseda luteola, $L$.

Primary root as in R. alba.

Hypocotyl decumbent, or more often erect, tapering slightly downwards, 4-8 mm. long.

Cotyledons ovate or oblong-ovate, somewhat succulent, sometimes unequal in size and shape; lamina 6-8 mm. long, 4.75-5.5 mm. wide; petiole rounded on the back, flattened or shallowly grooved above, 5-6.5 mm. long.

Stem as in R. alba, annual or biennial. 
Leaves as in R. alba, but stipules small, glanduliform, seated on the petiole some distance above the base, and often at unequal heights.

Nos. 1 and 2. Spathulate, obtuse, tapering to the base, alternately and ascendingly nerved.

Nos. 3-6. Similar.

Ultimate leaves linear, entire, obtuse, undulate at the margin, alternately incurvinerved, deep green, glabrous, shining, with a prominent midrib; the radical narrowed to a short, flattened, more or less winged petiole, the cauline sessile.

Reseda odorata, $L$.

Primary root long, wiry, tapering, with very few or no lateral rootlets for some distance.

Hypocotyl subterranean, stout, tapering downwards indistinguishably into the root.

Cotyledons oblong; lamina $9 \mathrm{~mm}$. long, $5 \mathrm{~mm}$. broad; petiole $4.5 \mathrm{~mm}$. long.

Stem herbaceous, erect, or ultimately decumbent, glabrous, green, slightly angled and furrowed, with lines of scattered, filiform, glandular appendages running down from the base of the leaves; 1st internode $1 \mathrm{~mm}$. long; 2nd $2.25 \mathrm{~mm}$.; 3rd $7 \mathrm{~mm}$.; 4 th $1 \mathrm{~mm}$.; 5 th $13 \mathrm{~mm}$.; 6th $9 \mathrm{~mm}$.; 7 th $5.5 \mathrm{~mm}$.

Leaves cauline, alternate (or first four opposite in two pairs), petiolate, or the uppermost sessile or subsessile, flat or subrevolute at the margin, alternately penninerved, glabrous, scabrous at the margin; petioles channelled above on either side of a prominent midrib, convex beneath ; stipules consisting of filiform glandular processes extending from the base of the petiole for some distance down the stem.

1st pair opposite, spathulate, entire.

2nd pair opposite, oblong-spathulate, entire.

Nos. 5-6. Nearly opposite (in specimen), linear-oblong, obtuse, entire.

Nos. 7-10. Oblong-spathulate, obtuse, entire.

Upper cauline leaves oblong, obtuse, entire or trifid or tripartite; segments oblong, obtuse, entire; lateral ones much broader on the posterior side of the midrib and decurrent on the petiole. 


\section{CISTINEE.}

Benth. et Hook. Gen. Pl. i. 112.

The ovary in this Order is free, consisting of three to five carpels united by their edges only, and is one- or partly threeto five-celled by the prominence or inflection of the three to five parietal placentas. The ovules are generally numerous on each placenta, but there are only two in Hudsonia and Lechea; ascending and projecting into the cavity of the ovary on long or rarely short funicles, and orthotropous, rarely semianatropous as in Lechea and Fumana by the funicles being partly adnate to the placenta. Orthotropous ovules are generally associated with one-seeded fruits as in Polygonaceæ, many Urticaceæ, and Juglandaceæ, so that Cistus and Helianthemum are very exceptional in possessing orthotropous ovules in a many-seeded ovary. The fruit is a capsule dehiscing by as many valves as there are carpels. The dehiscence being loculicidal, the seeds are borne along the centre of the valves as in the Violariex to which the Cistineæ are allied. The seeds are numerous in the two leading genera, Cistus and Helianthemum, and are ovoid or variously angled by mutual pressure. They contain a large quantity of a farinaceous or mealy endosperm, sometimes occupying one side of the seed only as in Cistus laurifolius, or in some cases almost equally distributed and completely surrounding the embryo. The latter is therefore generally excentric, and curved, spirally convolute, or conduplicate, rarely nearly straight as in Lechea. The cotyledons are plano-convex, nearly flat or narrow, and semiterete.

Cistus laurifolius, which may be taken as typical of the group, has a spirally coiled, excentric, comparatively large embryo, with linear, obtuse, semiterete, incumbent cotyledons lying in the narrow plane of the somewhat flattened seed, with their backs to the placenta. The cotyledons are equal, the inner one in this case at least being more coiled than the outer. The embryo of C. villosus seems to be more central than usual, and the cotyledons are linear-oblong, incumbent, and shorter than the radicle. The embryo of Helianthemum, according to Bentham and Hooker, is uncinate, biplicate, or circumflexed. 
Those coming under my notice are spirally coiled much in the same way as in Cistus, but the cotyledons are usually broader and lie in the broader plane of the seed when that is flattened in any way. There are a few slight modifications. They are incumbent as usual, but the radicle in $\mathrm{H}$. Spachii and $\mathrm{H}$. violaceum is displaced at its upper end and lies obliquely over the edges of the cotyledons. This is carried further in $\mathrm{H}$. polifolium, and the broadly oval cotyledons are almost strictly accumbent, lying in the broader plane of the seed with their edges to the hilum. The radicle, as in all the other species examined, is longer than the cotyledons, in some instances about twice as long.

Cotyledons.- There are two leading types of cotyledons represented by the two leading genera, Cistus and Helianthemum; in the former they are comparatively narrow, in the latter broad. Taking Cistus laurifolius (fig. 186) as an illustration, the cotyledons are linear-lanceolate, obtuse or subacute, entire, flat or convex above, and subrevolute at the margins, dotted with minute scales on both surfaces, otherwise glabrous, deep green, opaque, with an indistinct midrib, narrowed at the base or shortly petiolate, and connate forming a little cup surrounding the plumule. The seed-leaves of C. undulatus, C. ladaniferus, and C. albidus agree closely in all the leading characters with the above, except that in C. undulatus they are less distinctly petiolate. It may also be noted that the hypocotyl of the latter is finely pubescent, as are both the hypocotyl and petioles of the cotyledons in C. albidus.

The broad type of cotyledons may be represented by Helianthemum vulgare or H. apenninum (fig. 187). They are broadly oblong or obovate in the latter, distinctly petiolate, entire, trinerved in the basal half, but indistinctly so upwards, with the lateral nerves running parallel to the margin, deep green, and glabrous with the exception of the petioles, which are thinly hairy. The hypocotyl is also pubescent. The cotyledons of H. vulgare are broadly oval or subobovate, and one-nerved, but otherwise correspond closely to those of H. apenninum. The lateral veins probably exist, although indiscernible owing to the opaque character of the cotyledons. These are oval-oblong, very large and one-nerved, with hairy petioles shortly connate 
at the base in $\mathrm{H}$. rosmarinifolium, and form a contrast to the narrow leaves of the species. In germination the testa in Cistus and Helianthemum splits widely to allow the exit of the cotyledons.

\section{Cistus laurifolius, $L$.}

Fruit a one-celled, many-seeded, loculicidal capsule.

Seeds numerous, on the parietal placentas, polygonal, pale brown, glabrous, on a long funicle; hilum at the basal end; raphe none; chalaza rather prominent and projecting into the interior of the seed.

Endosperm granular or subfarinaceous, extending from the base up one side of the seed.

Embryo spirally coiled, eccentric, pale yellow, very large for the seed; cotyledons linear, obtuse, entire, equal, the inner one being much more coiled than the outer, situated

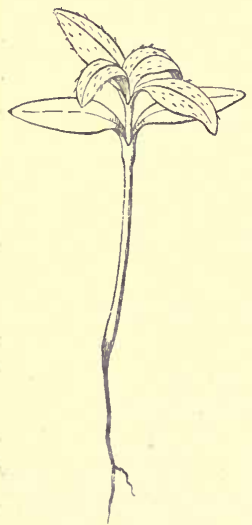

FIg. 186.-Cistus laurifolius, $\times \mathbf{2}$. with their backs to the placenta, and their edges towards the sides of the seed, planoconvex, or semiterete; radicle cylindrical, obtuse, stout, somewhat shorter and narrower than the cotyledons.

Seedling (fig. 186).

Hypocotyl erect, terete, glabrous, 13-18 $\mathrm{mm}$. long.

Cotyledons linear-lanceolate, obtuse or subacute, entire, flat or convex above, and subrevolute at the margins, dotted with minute scales on both surfaces, otherwise glabrous, deep green, opaque, with an indistinct midrib, narrowed to the base and perfoliate, forming a little cup round the plumule, $6 \cdot 5-8 \mathrm{~mm}$. long, $1 \cdot 75-2 \cdot 25 \mathrm{~mm}$. broad.

Stem erect, terete, stellately hairy, pale green, ultimately shrubby; 1 st internode $2 \cdot 5-6.5 \mathrm{~mm}$. long.

First leaves simple, entire, cauline, opposite, decussate, exstipulate, petiolate, with a few hairs on both surfaces, alternately and ascendingly penninerved; petioles very short, channelled above, perfoliate or connate at the base forming a little cup.

1st pair small, lanceolate, obtuse, entire, subtrinerved at the base, otherwise alternately penninerved.

2nd pair similar. 
Cistus undulatus, Dunal.

Hypocotyl 12-18 mm. long, finely pubescent, reddish.

Cotyledons linear-lanceolate, acute, tapering at the base but scarcely petiolate, entire, glabrous, light green, indistinctly oneveined. green.

Stem herbaceous, pubescent; 1st internode 1-2 mm. long, light

First leaves entire, linear-lanceolate, acute, tapering to the base, sessile, pubescent, light green, one-veined.

\section{Cistus ladaniferus, $L$.}

Hypocotyl glabrous, 5-8 mm. long, reddish.

Cotyledons linear, subacute, otherwise as in C. undulatus.

Stem as in C. undulatus.

First leaves linear-oblong, shortly petiolate, slightly hairy, green, distinctly one-veined.

\section{Cistus albidus, $L$.} red.

Hypocotyl finely pubescent, $5-10 \mathrm{~mm}$. long, stained with

Cotyledons obtuse, glabrous with a few hairs towards the base, dark green, otherwise as in C. undulatus.

Stem as in C. undulatus.

First leaves oblong, obtuse, tapering to the base, ciliated, finely pubescent, dark green, pinnatinerved.

Helianthemum apenninum, $D C$. (fig. 187).

Hypocotyl erect, terete, pubescent, $1 \cdot 5-$ $2 \mathrm{~cm}$. long, reddish immediately above the ground, becoming light green near the cotyledons.

Cotyledons oblong or slightly obovate, 4-5 mm. long, petiolate, entire, obtuse,

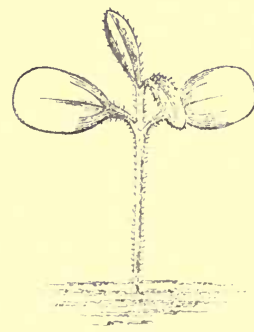

Fig. 187.-Helianthemum apenninum, $\times 2$. glabrous but with a few hairs on the petiole, dark green tinged with red beneath; midrib and two indistinct lateral veins running parallel to the edges conspicuous in the basal half.

Stem herbaceous, erect, terete, pubescent.

First leaves simple, entire, cauline, opposite, stipulate, lanceolate, obtuse, pubescent, light green, with a prominent midrib. 


\section{Helianthemum vulgare, Gaertn.}

Primary root long, tapering, with fleshy, stout, lateral rootlets, generally stouter than the primary one.

Hypocotyl erect, terete, hairy, reddish, sometimes decumbent (perhaps accidental) at the base.

Cotyledons broadly oval or subobovate-oval, rounded and obtuse at both ends, opaque green, one-nerved; lamina 4.5-5.5 mm. long, $3-4.5 \mathrm{~mm}$. broad; petiole subterete, slightly channelled above, hairy, reddish, about $2 \mathrm{~mm}$. long.

Stem shrubby, erect, ultimately decumbent, wiry, hairy or glabrous, but reddish and hairy in seedling stage; 1st internode $3 \mathrm{~mm}$. long.

Leaves shortly petiolate, subperfoliate at the base, more or less hairy on both surfaces and margin when young with bulbous-rooted hairs, ultimately glabrous or hairy in different varieties; petioles subterete, narrowly channelled above, glabrous, or hairy at least when young; stipules lanceolate, obtuse, slightly hairy, ultimately linear-lanceolate, acute, deep green, shining, hairy or glabrous, according to the leaves.

1st pair lanceolate, obtuse, channelled along the middle of the upper surface, with a prominent midrib.

Ultimate leaves oblong, obtuse or obtusely subcuspidate, more or less revolute at the margin, with a strong midrib, sunk on the upper surface and prominent beneath, deep green, and shining above when devoid of hairs, paler beneath; but when hairy they are greyish above, and more or less hoary or white beneath.

\section{Helianthemum rosmarinifolium, Pursh.}

Cotyledons large, oval-oblong, obtuse, deep green above, red beneath, glabrous except the petiole; lamina with a faint midrib, 6-7 mm. long, $3.5-4.5 \mathrm{~mm}$. wide; petiole hairy, slightly channelled above, $2-3 \mathrm{~mm}$. long, shortly connate at the base.

Stem ultimately shrubby; 1 st internode gradually developing to a length of 1,2 , or $3 \mathrm{~mm}$.

Leaves linear, with stellate hairs, at least in the young state, deeply channelled above, carinate beneath and revolute at the margins. 


\section{VIOLARIE E.}

Benth, et Hook. Gen. Pl. i. 114.

Fruit and Seed.--The ovary is free and one-celled with typically three parietal placentas as in Viola. The ovules are generally numerous, one to two as in Hymenanthera, Scyphellandra, and Isodendrion, anatropous and arranged along the slender placentas. The fruit is a capsule and splits loculicidally, more rarely septicidally, by as many valves as there are carpels. In Leonia, Gloiospermum, Tetrathylacium, Melicytus, and Hymenanthera it is however baccate and indehiscent. The seeds are obovoid or subglobose and fixed to the placentas by very short funicles; the raphe is in some cases much thickened and separates from the fruit when mature, forming an arillus; the testa is usually crustaceous, coriaceous, and shining as in Viola itself, rarely membranous. The endosperm is copious and fleshy except in the case of Corynostylis, where it is reduced to a thin layer. The embryo as far as observed is straight, central, somewhat club-shaped, nearly equalling the endosperm in length ; the cotyledons are planoconvex or flat, and generally moderately broad, longer or shorter than the radicle and distant from the hilum. They are unusually narrow in the species of Hymenanthera and very short in the Sauvagesieæ.

Viola tricolor and V. sylvatica may be taken as typical of the Order. They have obovoid, smooth seeds; and the cotyledons of the latter before germination are oval, obtuse, entire, planoconvex, and about the same length as the terete, obtuse radicle.

Variations from the type occur in Corynostylis, with flattened, rugose, nearly orbicular seeds; they are flattened, orbicular, and broadly winged in Anchietea ; flattened, winged, and imbricate in Agation; and small with an orbicular wing and a membranous testa in Schuurmansia. They are globose or nearly so in Paypayrola, Alsodeia, Leonia, Melicytus, Tetrathylacium, Hymenanthera, and Scyphellandra.

Several methods of dispersal of the seeds oceur in this Order. As already mentioned, some have winged seeds. I have observed that ants sometimes carry the seeds of Viola into 
their nests, and I am inclined to suspect that they mistake them for the pupæ of other ants.

Some Violets throw their seeds. In the Dog Violet (V. canina) the capsules, though pendent when young, at maturity raise themselves ${ }^{1}$ above the rest of the plant, and open by three equal valves resembling an inverted tripod. ${ }^{2}$ Each valve contains a row of three, four, or five brown, smooth, pear-shaped seeds, slightly flattened at the upper, wider, end. The two walls of each valve, as they become drier, contract, and approach one another, thus tending to squeeze out the seeds. These resist some time, but at length the attachment of the seed to its base gives way, and it is ejected several feet, this being no doubt much facilitated by its form and smoothness. I have known even a gathered specimen throw a seed nearly ten feet.

On the other hand, in Viola hirta the capsules hang down, and it has been said actually bury themselves in the ground. ' Now we naturally ask ourselves ${ }^{1}$ what is the reason for this difference between the species of Violets; why do V. odorata and $\mathrm{V}$. hirta conceal their eapsules among the moss and leaves on the ground while V. canina and others erect theirs and throw the seeds to a distance? If this arrangement be best for Viola canina, why has not V. odorata also adopted it? The reason is, I believe, to be found in the different mode of growth of these two species. V. canina is a plant with an elongated stem, and it is easy therefore for the capsule to raise itself above the grass and other low herbage among which Violets grow.

' V. odorata and V. hirta, on the contrary, have in ordinary parlance no stem, and the leaves are radical, i.e. rising from the root. This is at least the case in appearance, for, botanically speaking, they rise at the end of a short stem. Now under these circumstances if the Sweet Violet attempted to shoot its seeds, the capsules not being sufficiently elevated, the seeds would merely strike against some neighbouring leaf, and immediately fall to the ground. Hence, I think, we see that the arrangement of the capsule in each species is that most suitable to the general habit of the plant.'

Cotyledons.-The only seedlings I have seen of this Order

' Lubbock's Flowers, Fruits, and Leaves, p. 55 (fig. 38 c). $\quad 2$ Ibid. p. 56. 
belong to the genus Viola. The cotyledons of V. tricolor (fig. 188) are broadly oval, obtuse, entire, and petiolate. The lamina is proportionately longer and narrower in $\mathrm{V}$. canina, and $\mathrm{V}$. palustris (fig. 189), where it is oblong, obtuse, and in the latter mucronulate. The variations from these types are probably slight except in the cases of narrow or short cotyledons as mentioned above.

Viola tricolor, L. (fig. 188).

Primary root tapering, colourless, long, giving off lateral rootlets, annual.

Hypocotyl tapering indistinguishably into the root, subterranean, colourless.

Cotyledons oval, obtuse, glabrous, petiolate; lamina $6 \mathrm{~mm}$. long, $3 \cdot 5$ $\mathrm{mm}$. broad.

Stem developed when about to flower, herbaceous, annual; 1st, 2nd, and 3rd internodes undeveloped; 4th 1.5 mm. long; 5th $1 \mathrm{~mm}$. long.

Leaves simple, radical and cauline, alternate, stipulate, petiolate, glabrous, or finely pubescent at the margins, deep green above, paler beneath; petioles channelled on the upper side, and scaberulous, or finely pubescent, along the edge of the channel ; stipules large, foliaceous, unequally lyrate-pinna-

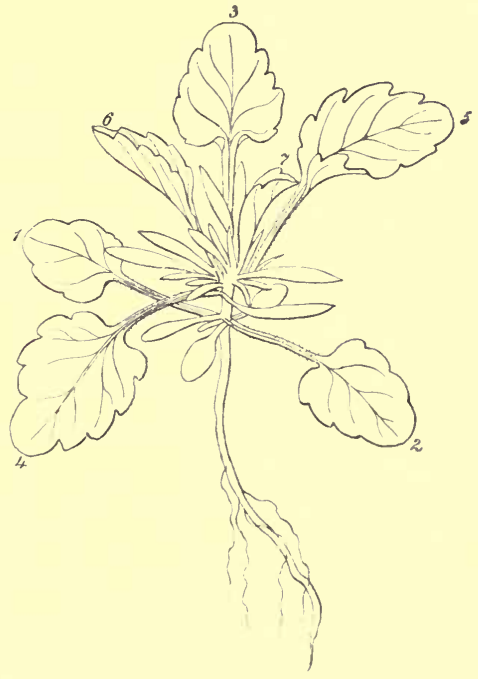

FIG. 188.-Viola tricolor. Nat, size. tifid or -partite, with linear, obtuse, or oblanceolate-linear segments--the middle lobe largest and entire, or in adult and robust specimens more or less crenate and spathulate.

No. 1. Broadly ovate, rounded at the end, shallowly crenate.

No. 2. Cordate-ovate, obtuse, shallowly crenate. 
No. 3. Oblong-cordate, obtuse, more deeply crenate.

No. 4. Cordate, obtuse, rather deeply crenate.

No. 5. A little more elongated than No. 4.

No. 6. Cordate-ovate, rather deeply crenate.

Ultimate leaves oblong-lanceolate, obtuse, serrate-crenate, or the uppermost lanceolate, elongated and narrowed to an obtuse point, with long ascending lateral veins; stipules foliaceous, very large, pinnately divided near the base, with the greatest number of lobes on the posterior side and almost surrounding the stem.

Viola palustris, L. (fig. 189).

Primary root as in V. tricolor.

Hypocotyl as in V. tricolor.

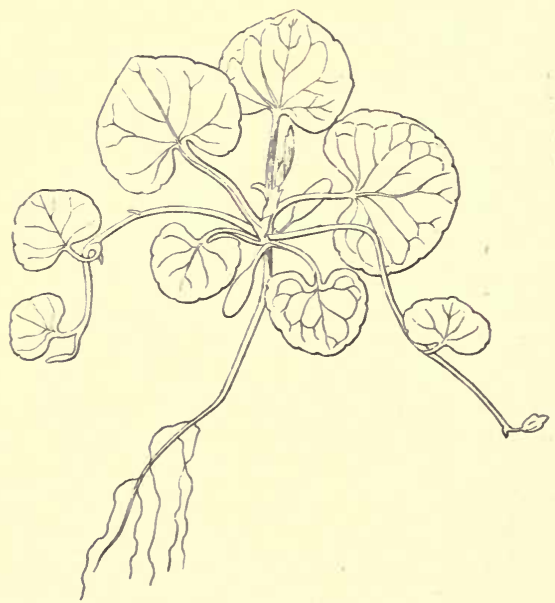

Fig. 189.-Viola palustris. Nat. size.

Cotyledons oblong, obtuse, mucronulate, glabrous ; lamina $6 \mathrm{~mm}$. long, $3.5 \mathrm{~mm}$. broad; petiole channelled above, $3.5 \mathrm{~mm}$. long.

Stem herbaceous, perennial, with undeveloped nodes, and throwing off numerous stoloniferous branches from the axil of the first leaf, upwards.

Leaves radical and cauline on the stolons, conspicuously nerved and reticulate; stipules small, ovate, serrulate, green, mottled with red; petioles channelled above, glabrous, pale green, mottled with red. 
Nos. 1-3. Reniform, rounded at the apex, three- to five-nerved, shallowly crenate.

Nos. 4 and 5. Reniform, obtusely angled at the apex; five-nerved on the lower half, shallowly crenate.

Ultimate leaves rather large, reniform, rounded at the apex, shallowly crenate, seven- to nine-nerved and reticulate.

\section{CANELLACE E.}

Benth. et Hook. Gen. Pl. i. 121.

Fruit and Seed.-The ovary is free, one-celled, with two to five parietal placentas, and contains from two to many ascending or horizontal ovules that are nearly but not quite anatropous. The fruit is indehiscent and a berry, and as is frequent in such cases the testa of the seed is hard or crustaceous, smooth and shining. Each berry contains from two to many seeds according to the species. The embryo is large, straight, or slightly, curved with oblong cotyledons and a short radicle situated close to the hilum, and is embedded in a fleshy, oily endosperm.

No seedlings have come under my observation.

\section{BIXINEA.}

Benth. et Hook. Gen، Pl. i. 122.

Fruit and Seed.-The ovary is superior, syncarpous, and made up of from two to many carpels with as many parietal placentas, one-, rarely many-celled, as in Flacourtia and Amoreuxia. The ovules are amphitropous or anatropous, rarely one, seldom two, generally many on each placenta; Aphloia is exceptional in having only one placenta and few ovules. The fruit is dry and capsular or baccate and indehiscent. Sometimes it is spiny resembling that of Asculus or some species of Datura, as is the ease with Bixa and Dendrostylis.

The seeds are usually globose or obovoid; but there are exceptions, the most remarkable of which occurs in Cochlospermum, the species of which have reniform or spiral seeds covered with long hairs or woolly on all sides; the testa itself 
is horny. In most cases, however, the seeds are smooth, while in Bixa and Dendrostylis they are covered with an aril or pulp. The interior is filled with a copious, fleshy endosperm surrounding the embryo. The seeds are arillate in Ryania and Lætia, and furnished with an arilloid membranous coat in Erythrospermum. They are more or less compressed in Bixa and Oncoba. Those of Aberia are densely covered with a villous tomentum.

The embryo is axile and straight or curved according to the form of the seed, to which it conforms to a certain degree, being curved in the curved seeds of Aphloia, and longitudinally grooved in Bixa, apparently owing to the raphe being deeply sunk in the side of the seed. This is best observed in transverse section. The embryo is always comparatively large and nearly equals the endosperm both in length and breadth, but not in thickness, and the cotyledons are flat, and more or less cordate. The seeds of Pangium edule are bluntly triangular vertically, and in longitudinal section the embryo is also seen to be of great size with bluntly triangular cotyledons, traversed longitudinally by five to seven diverging nerves. They are faintly notched or subcordate at the base; and the radicle is extremely short.

Cochlospermum Gossypium, DC. (fig. 190).

Hypocotyl erect, stout, subfleshy, glabrous, pale green, about 12-16 mm. above the soil.

Cotyledons linear-oblong, obtuse or subacute, glabrous, petiolate, seven- to eleven-nerved from the base or near it, slightly unequal;

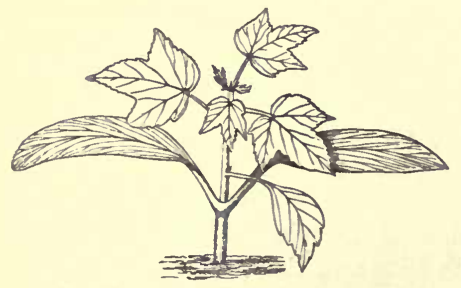

Fro. 190.-Cochlospermum Gossypium. Half nat. size.

lamina of the larger one about $4.7 \mathrm{~cm}$. long, 1.05 cm. wide; of the shorter one $4.5 \mathrm{~cm}$. long, and 1.05 cm. wide; petioles channelled above, connate at the base, slightly scurfy with brown scales or glands, 10-11 mm. long. Stem erect, terete, glandular-scurfy and slightly pubescent, much

thinner in the seedling stage than the hypocotyl; 1st internode $6 \mathrm{~mm}$. long ; 2nd $10 \mathrm{~mm}$.; 3 rd $3 \mathrm{~mm}$., and the next two or three also short. 
Leaves simple, cauline, alternate, stipulate, petiolate, palmatelynerved and lobed, thinly glandular-scurfy along the nerves on both surfaces; petioles subterete, slightly channelled on the upper surface, glandular-scurfy; stipules small, subulate, acute, soon becoming brown.

No. 1. Ovate or subelliptic, coarsely serrated above the middle or subtrifid with alternate ascending nerves.

Nos. 2-4. Palmately five-nerved and trilobed, or the 3rd and 4 th slightly five-lobed; lobes triangular, obtuse, and rounded or acuminate and subacute, crenate-serrate, with the terminal lobe the largest.

No. 5. With more elongated and more ovate leaves, otherwise similar.

Note.-The seed of Cochlospermum is cochleate-reniform or spiral. The embryo is incurved and the cotyledons ovate while still in the seed, which would account for their unusually elongated character after germination. The cotyledons of other members of the Order coming under my notice are short and very broad or rounded.

Aberia caffra, Hook. et Meyer (fig. 191).

Hypocotyl erect, terete, minutely pubescent, pale green, $2 \cdot 5-$ $3.5 \mathrm{~cm}$. long.

Cotyledons broad, almost rotund-obovate, foliaceous, petiolate, glabrous, entire or incipiently emarginate, alternately and incurvedly penninerved (each nerve uniting with the one next above it), reti. culate, bright shining green above, paler beneath; petiole slightly channelled above, minutely pubescent, subperfoliate at the base, $2 \cdot 5-3 \mathrm{~mm}$. long; lamina $2 \cdot 2-$ $2.5 \mathrm{~cm}$. long, $1.8-2 \mathrm{~cm}$. wide.

Stem erect, terete, finely pubescent, pale green, ultimately shrubby; 1 st internode $4-5 \mathrm{~mm}$. long.

Leaves simple, cauline, alternate (1st and 2nd opposite), stipulate, petiolate, alternately penninerved, with each nerve

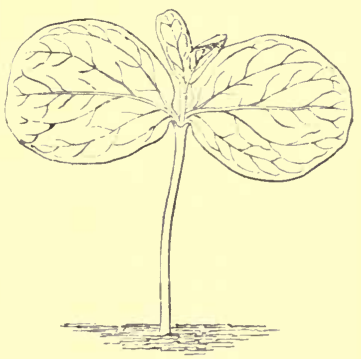

Fio. 191.-Aberia caffra. Nat. size. ascending at an acute angle, and uniting with the one next above it, hairy on both sides, light green; petioles very short, flattened above, hairy ; stipules minute, tooth-like at the base of the petioles.

Nos. 1 and 2. Oblanceolate-oblong, tapering to the base, emarginate, with a small tooth or mucro in the notch. 


\section{PITTOSPOREA.}

Benth. et Hook. Gen. Pl. i. 130.

Fruit and Seed.-The ovary is free, syncarpous, consisting of two carpels, more rarely of three to five, and is one-celled with parietal placentas, or the placentas are sometimes so much intruded as to form septa. The ovules are numerous, horizontal, anatropous. The fruit is dry and dehisces loculicidally, while the valves sometimes break away from the dissepiments, or baccate and indehiscent. The seeds are numerous, rarely few or solitary in the cells, and filled with a copious hard endosperm. The testa is thin and smooth, rarely rugose-muricate and often black. The embryo is very minute and embedded in the endosperm close to the hilum.

The embryo in Pittosporum undulatum is a minute nodular mass with hardly discernible cotyledons situated or embedded in the endosperm at the base of the reniform seed near a notch or depression at the hilum. As far as form is concerned it cannot be much influenced by the shape of the seed before germination. The seeds of Hymenosporum are flattened, reniform, and girt with a membranous wing.

Cotyledons.-As in the case of the seed-leaves in other Orders having a copious endosperm, whether the embryo is large or small while yet in the seed, the cotyledons after germination attain a considerable size. They vary from linear to linear-lanceolate, lanceolate, or oblanceolate. The broader ones are characteristic of Pittosporum, the type of the Order. In P. phillyræoides (fig. 192) they are linear-lanceolate, acute, sessile or narrowed to a very short petiole, hairy on the midrib beneath, the midrib only being discernible. They are rather persistent and with the exception of the venation resemble very closely the first six leaves.

The other two species observed are very exceptional and somewhat remarkable in character. The cotyledons of P. crassifolium are four in number, oblanceolate, narrowed to a short petiole, mucronate, rather unequal and apparently consisting of two divided to the base, pubescent on both 
surfaces, ciliate, rather persistent, with a sunk midrib and obscurely reticulate, and resemble in form the leaves that follow, but are very much smaller. Those of $\mathrm{P}$. erioloma are five in number, whorled, lanceolate, membranous, shortly petiolate, pubescent and penninerved like the leaves that follow, but larger.

A type distinct from the above is exhibited by Billardiera longiflora and B. fusiformis. In the former (fig. 194) the cotyledons are linear, acute, broadest above the middle, narrowed to the base, but not very distinctly petiolate, with a scarcely discernible midrib, glabrous, and $12 \cdot 5-22 \mathrm{~mm}$. long. The seed-leaves of B. fusiformis are linear, acute, glabrous, one-veined, sessile, and about the same length as those of B. longiflora.

Pittosporum phillyræoides, $D C$. (fig. 192).

Hypocotyl erect, terete, glandular-pubescent, deep red, $3-4.5 \mathrm{~cm}$. above the soil.

Cotyledons linear-lanceolate, acute, sessile or narrowed to an extremely short petiole, light green, pubescent on the midrib beneath, otherwise glabrous, slightly channelled at the base on the upper

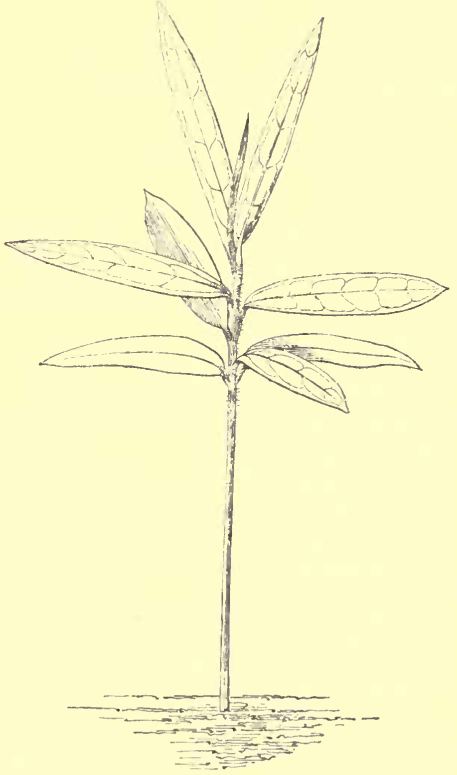

Fig. 192.-Pittosporum phillyraoides. Nat. size. side, and subcarinate on the under side, with midrib only discernible, about $24 \mathrm{~mm}$. long, 4-5 mm. wide.

Stem erect, terete, pubescent with adpressed hairs, deep red, somewhat flexuous; 1 st internode $1.5 \mathrm{~mm}$. long; 2nd $2 \mathrm{~mm}$.; 3 rd $3.25 \mathrm{~mm}$. 
Leaves simple, entire, cauline, alternate, exstipulate, shortly petiolate, alternately penninerved, with the nerves uniting at their apex and forming a continuous intramarginal line, glabrous, coriaceous, deep green above, pale beneath, shining on both surfaces; petioles short, channelled above, terete on the back.

No. 1. Lanceolate-oblong, cuspidately acute.

No. 2. Similar, larger.

Nos. 3-6. Lanceolate-linear, acute, or acuminate, gradually longer.

Pittosporum parviflorum, Putterl.

Hypocotyl glabrous.

Cotyledons two to three, lanceolate, obtuse, glabrous, shortly petiolate, obscurely penninerved, reticulate, foliaceous, rather persistent.

Stem terete, erect, soon becoming woody.

First three leaves obovate-lanceolate, entire, small, cuneate at the base.

Pittosporum crassifolium (?), Banks et Sol. (fig. 193).

Hypocotyl 3-4 cm. long, a little over $1 \mathrm{~mm}$. thick, woody, covered to the very base with a purplish pubescence (like Gynura aurantiaca).

Cotyledons two, three, or four, opposite or whorled, nearly equal, shortly petioled, $1 \cdot 5-2 \mathrm{~cm}$. long, about $1 \mathrm{~cm}$. broad, nearly flat, oblanceolate, produced at the base, with a short blunt mucro at the obtuse, slightly recurved apex, penninerved, with sunk midrib and obscurely reticulate veins, hairy on both sides, ciliated on margin and petiole, light green, rather persistent.

Stem like the hypocotyl, but darker and tomentose.

Leaves penninerved with the branches ascending, branching or incurved towards the tip, reticulate, with the principal nerves sunk on the upper surface, glabrous above, pubescent or tomentose on the margin, tomentose beneath with a prominent venation; petioles short, semiterete.

Nos. 1 and 2. Rotund-obovate, cuneate at the base.

Nos. 3 and 4. Obovate, obtuse, gradually becoming larger upwards.

Note.- I was at first disposed to think that the number of cotyledons in this species might be an accidental variation. There are other cases where occasionally three cotyledons occur instead of two. In Acer Pseudo-Platanus, for instance, this is not infrequently the case, and I have observed that such specimens occur especially often in the produce of particular trees. 
Pittosporum erioloma, Moore et F. Muell.

A seedling of this species also had five lanceolate, subacute, entire, pubescent, nearly sessile cotyledons.

Billardiera longiflora, Labill. (fig. 194).

Hypocotyl erect, terete, glabrous, brownish-purple, shining, 14-27 mm. above the soil.

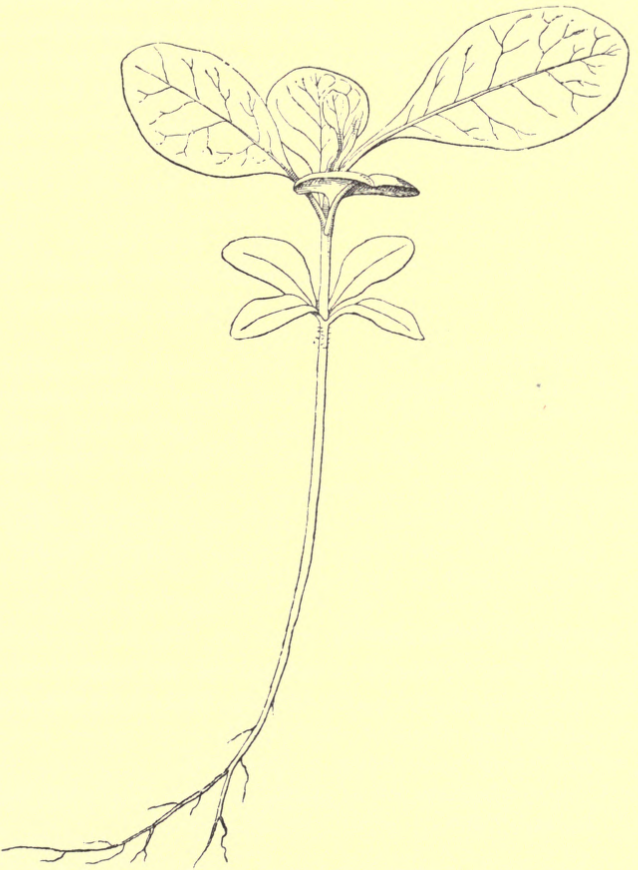

FIG. 193.-Pittosporum crassifolium. Nat. size.

Cotyledons linear, acute, or cuspidate, broader above the middle, narrowed to a slender, petiole-like base, deep green and shining above, with a scarcely discernible midrib, paler beneath, $12 \cdot 5-22 \mathrm{~mm}$. long, $\cdot 75-2 \mathrm{~mm}$. wide at the broadest part.

Stem erect, terete, somewhat flexuose (at least when young), pale 
green or soon becoming brownish-purple, pubescent, with hooked, bent, or branched hairs, ultimately shrubby, twining; 1st internode

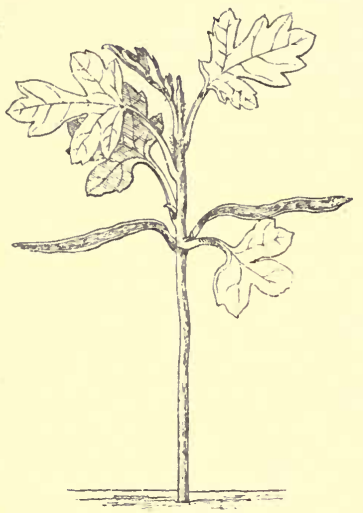

Fı. 194.-Billardiera longiflora.

One-sixth over nat. size. and frequently the 2nd undeveloped; 2nd when developed 1-2 mm. long; 3rd 3.5-4.5 mm. ; 4th 2-3 mm.

Leaves simple, cauline, alternate (first and second often opposite), exstipulate, petiolate, alternately penninerved, with the nerves running straight into the lobes or teeth, somewhat pubescent on the margins and nerves, especially when young, with bent, kneed, or forked hairs, deep green and shining above, pale beneath; petioles channelled above, convex on the back, slightly pubescent, deep green.

Nos. 1 and 2. Triangular, trilobed; lateral lobes cuneate, bidentate; middle lobe entire or tricuspidate. In very small weak seedlings the first two leaves are frequently merely cuneate, tricuspidate.

Nos. 3 and 4. Triangular-ovate, trilobed, longer and larger than the first two; middle lobe trifid or coarsely serrate; lateral lobes bifid or serrate, mostly on the posterior side.

\section{Billardiera fusiformis, Labill.}

Hypocotyl as in B. longiflora, stained red, 8-15 mm. long.

Cotyledons long, linear, acute, tapering to the base but scarcely petiolate, dark green, glabrous, one-veined.

Stem with primary internodes undeveloped.

First leaves alternate, ovate-oblong, obtuse, lobed, coarsely and obtusely serrate, glabrous, green, pinnatinerved.

\section{TREMANDREÆ.}

Benth. et Hook. Gen. Pl. i. 133.

Fruit and Seed.-The ovary consists of two carpels, and is two-celled with one to three pendulous anatropous ovules in 
each cell attached close to the apex of the axile placentas. The raphe is ventral. There are three genera belonging to the order ; one, Tetratheca, includes twenty species, the ovaries of which have from one to three ovules in each cell. When there are two they are superposed, but the third one is collateral. The fruit is a capsule dehiscing along the middle of each carpel, and the seeds have a shell-shaped twisted aril-like appendage at the chalaza. The testa is crustaceous, and in Tetratheca and Tremandra sparingly pilose. The seeds of Platytheca galioides are solitary in each cell and smooth.

The embryo is close to the hilum and embedded in a moderately hard endosperm, with the radicle superior; it is usually very small.

The Tremandreæ are slender, much branched shrubs, with alternate, opposite or whorled, narrow, and sometimes Heathlike leaves.

\section{POL YGALEL.}

Benth. et Hook. Gen. Pl. i. 134.

Fruit and Seed.-The pistil is superior, syncarpous, twocelled, consisting of two carpels. Exceptions to these general characters occur in Xanthophyllum with a one-celled ovary and parietal placentas, while there is only one carpel in Securidaca, several species of Monnina, and Krameria. In Trigoniastrum the ovary is three-celled, and in Moutabea often three- to five-celled. Typically the two cells each contain one ovule suspended from the top of the cavity; two collateral ovules occur in Krameria; and from two to six in Xanthophyllum. The pendulous and anatropous character is constant.

The fruit is capsular and loculicidally, rarely septicidally, dehiscent, or is dry or baccate and indehiscent. That of Securidaca and Trigoniastrum is a samara, that of Carpolobia and Mundtia a drupe. The fruit of Xanthophyllum, Moutabea, and Krameria is globose and indehiscent. That of Krameria, though primarily two-ovuled, is one-seeded and spiny or muricate. The seeds are pendulous, with a 
crustaceous testa, or velvety or pilose as in the case of Comesperma, and often furnished with an aril at the hilum as in Polygala. They also contain a large or small quantity of endosperm; but in a few abnormal genera such as Xanthophyllum, Moutabea, Krameria, and Securidaca, as well as in a few abnormal species of Polygala, there is no endosperm, and the cotyledons are large, thick and fleshy, so as to fill the

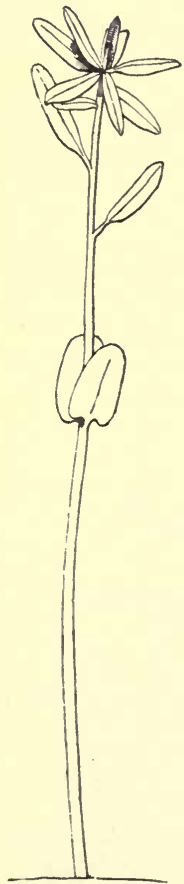

Fig. 195.-Polygala rarifolia. Nat. size. seed. Intermediate stages are met with in other species of Polygala and other genera where the endosperm is reduced to a thin stratum surrounding the fleshy embryo. The embryo is always axile and straight, with a short superior radicle. The cotyledons in the species of Polygala observed are oblong or oval, auricled at the base; the embryo nearly equals the endosperm in length and width but not in thickness, as the seed-leaves are flat or nearly so. In exalbuminous seeds the cotyledons become plano-convex and very thick, so as to fill the seed; they are then more markedly auricled at the base in order to occupy the seed and yet leave space for the radicle. An instance may be seen in a section of the fruit and seed of Krameria. Besides Comesperma above mentioned the following have more or less hairy or pilose seeds, namely, Bredemeyera, Trigoniastrum, and Carpolobia.

As regards the means of dispersion, the fruits of Securidaca and Trigoniastrum, which are tall, generally climbing shrubs, are samaras; while those of Mundtia are fleshy, edible drupes; and those of Krameria bear a number of hooked hairs.

Cotyledons.-The yellowish-green colour of the seed-leaves of Polygala rarifolia would seem to indicate that they are gradually becoming functionless after germination and tending to be subterranean, and to act merely as a storehouse for reserve- 
material. It is more than probable, although the fact has not come under my notice, that in many of the species with exalbuminous seeds the cotyledons are subterranean after germination.

Polygala rarifolia, DC. (fig. 195).

Hypocotyl suffruticose, erect, terete, pubescent, pale green, $5.5 \mathrm{~cm}$. above the soil.

Cotyledons broadly oblong, obtuse, shortly petiolate, cordate at the base, glabrous, pale yellowish-green, subcoriaceous; lamina $1.15 \mathrm{~cm}$. long, one of them rarely slightly smaller, $7 \mathrm{~mm}$. broad, petiole $2 \mathrm{~mm}$. long.

Stem suffruticose, erect, terete, hairy, pale green; 1st internode $2.5 \mathrm{~cm}$. long; 2nd $9 \mathrm{~mm}$.; 3rd $8 \mathrm{~mm}$.; 4th $1.25 \mathrm{~mm}$.; the numerous succeeding ones crowded. Individuals, however, differ in the relative lengths of the internodes.

Leaves simple, entire, cauline, alternate, exstipulate, shortly petiolate, hairy on both surfaces, pale green ; petioles terete, hairy, about $1-1.5 \mathrm{~mm}$. long.

Nos. 1 and 2. Oblong, obtuse, minutely cuspidate.

Nos. 3 and 4. Linear-oblong.

Nos. 5-7. Oblong, the numerous succeeding ones linear-oblong, obtuse, minutely cuspidate.

\section{FRANKENIACEÆ.}

Benth. et Hook. Gen. Pl. i. 140.

The ovary in this small Order consists of two to five carpels, but three is the most prevalent number. It is onecelled with as many parietal placentas as there are carpels, and the numerous small ovules are arranged in a double series. They are amphitropous or subanatropous, ascending on long slender funicles with an inferior micropyle. The fruit is a capsule dehiscing by as many valves as there are carpels. The small seeds are oblong or obovoid, with a crustaceous testa and a linear raphe.

The embryo is small, axile, and straight, the latter rather unusual in cases where the ovule is amphitropous. This is probably due to its small size, and the fact of its being 
embedded in the axis of the mealy endosperm. It is ovoid and cylindrical, and the radicle, which is close to the hilum, equals the cotyledons in length or is shorter.

There are from twelve to thirty species of Frankenia according to different authors, consisting of perennial evergreen herbs like our native F. lævis, or of much-branched suffruticose plants. No seedlings have come under my observation. The leaves of the older plant are small and opposite or fascicled on the shortened axillary shoots.

\section{CAR YOPHYLLEE.}

Benth. et Hook. Gen. Pl. i. 141.

The ovary is superior, syncarpous, of two to five carpels, and usually one-celled, with the ovules arising from a central or basal placenta. There are two carpels in Dianthus, Velezia, Tunica, Gypsophila, Acanthophyllum, and Saponaria; three in Silene, Cucubalus, Stellaria, Spergularia, and others ; and fire in Lychnis, Cerastium, and others. But many of these vary greatly in different species; for instance, there are generally three in Arenaria, but species occur with two, four, or five carpels. In the young condition of the ovary septa are often discernible, but vanish as a rule during development of the fruit. There are, however, exceptions; and amongst those observed Silene gallica, S. noctiflora, S. tatarica, and S. depressa are three-celled even when mature. The ovules are usually numerous, but vary from two to many, Queria, however, having only one. They are amphitropous and ascending with the micropyle inferior or transverse. The fruit is a capsule dehiscing by teeth or valves, rarely fleshy as in Cucubalus and indehiscent as in the latter, and in Drypis.

The seeds are usually numerous, or few by arrest, smooth, tubercular, muricate, or reticulate, sometimes winged, as in Spergularia marina, and marginate, as in Tunica pachygona, some species of Spergula, Dianthus, \&c. 
As far as structure and form are concerned, there are two leading types in the Order with several modifications. The first is that of Velezia, Dianthus, and Tunica, which have peltate, dorsally compressed or much flattened seeds, with the hilum on the ventral face, and a straight embryo. By far the larger number, however, have reniform, obovoid, or globose seeds, frequently compressed laterally, and attached to the placenta by the edge, which is really the ventral surface. In the latter type the embryo is curved and peripheral, while the cotyledons are incumbent, rarely accumbent. The endosperm is mealy and lies in the bend of the embryo, on its sides, or even surrounds the whole embryo in peltate seeds such as those of Dianthus and Tunica. Endosperm is wanting in some species of Velezia and Dianthus. The whole Order as far as concerns the shape of the seeds and embryo may be considered as consisting of the two leading types above given with their modifications. The first is well exemplified in Dianthus plumarius (fig. 196). The seeds are broadly oblong-orbicular, imbricating in one row or series, forming a complete covering to the central columnar placenta, peltate, much compressed dorsally, slightly concave on the ventral face, and elevated on the dorsal aspect, forming a convexity agreeing in outline with the contained embryo, and traversed by a shallow ridge along the whole of the ventral aspect; the hilum is situated a little above the middle; and the testa, which is smooth and black, is prolonged into a short point at the micropyle, but not winged anywhere. ${ }^{1}$

The embryo is straight or slightly curved towards the axis, and transverse to it and enveloped on all sides by a thin layer of endosperm; the cotyledons are oblong, obtuse and comparatively broad; the terete radicle is about half the length of the cotyledons, and points into the little projection at the micropyle. D. Caryophyllus, D. chinensis, and D. prolifer, Tunica Saxifraga, and T. pachygona agree in all the main particulars with D. plumarius, but the testa of D. prolifera is muricate or echinulate, and that of Tunica Saxifraga minutely striate-reticulate.

' Le Maout and Decaisne, Eng. Trans p. 256. 
The most marked modification of the above type met with occurs in Tunica pachygona, the seeds of which are oblong or suborbicular, slightly angled at the margins, and distinctly winged all round except at the micropyle, where there is a narrow and moderately deep sinus, into which a little point projects, containing the tip of the radicle. The wing results from the absence of endosperm, whereby the testa on the dorsal and ventral aspect of the seed is allowed to come together. Velezia also offers a rather marked modification inasmuch as the seeds are deeply grooved or umbilicate on the middle of the inner or ventral face, while they are ovate or oblong in outline, semiglobular, thick, and convex on the outer face; the embryo is, however, straight, and the endosperm copious. The reniform and laterally compressed type of seeds may be seen by reference to Cerastium arvense (fig. 199) and D. plumarius (fig. 196), showing vertical and horizontal sections, as well as their attachment to the central column. The flattened seeds of Dianthus and Tunica are subservient to the purpose of distribution by the wind, and allow of the arrangement of a large number in a capsule, by overlapping like slates on a roof. Relatively to the size of the capsule, however, a still greater number can be packed away where the seeds are reniform and laterally compressed. This may be observed in Saponaria officinalis, where the lateral flattening is due to mutual pressure, and a large number of ovules and seeds are packed away in a little space. The number is increased in cases where the capsule is inflated as in Lychnis and Silene. In L. vespertina the seeds are horizontal or displaced in various ways, and arranged in a double series one over the other, by the funicles of the two sets being of different lengths. A single ovary will contain from 250 to 400 , of which 240 to 370 or more reach maturity. They are ridged in the direction of the longer axis by the time they get ripe. Dianthus plumarius has 70 to 90 ovules, D. chinensis 70 to 80 , and D. prolifer 35 to 45 . D. prolifer, it may be remarked, is an annual species with small capsules.

Most or all of the species of the tribes Alsineæ and Polycarpeæ have small capsules with a moderate number of, sometimes with few, seeds. The capsule is one-seeded by arrest in 
Brachystemma and Sphærocoma, and in some species of Acanthophyllum and Stellaria, while Queria as above mentioned is one-ovuled and one-seeded.

The form of the embryo in reniform seeds is well shown in the vertical section parallel with the embryo of Cerastium arvense (fig. 199). The seeds are small, reniform, laterally compressed, with very unequal ends, the larger one containing the cotyledons, and the smaller one the radicle of the embryo. The testa is densely covered with small protuberances-an extremely common occurrence amongst the reniform seeds of this Order. The embryo is curved and peripheral, but surrounded on the back with a thin layer of endosperm, although it is usual in other seeds of this type for the embryo to lie in immediate contact with the testa. A globular mass of floury endosperm lies in the sinus of the embryo on the ventral aspect of the seed. The cotyledons are linear, semiterete, obtuse, incumbent, and lying in the narrow plane of the seeds; the terete radicle tapers gradually to a blunt point, and is somewhat shorter than the cotyledons. A small indentation at the hilum seems the only thing hindering the embryo from making a complete circuit of the seed.

With the above type the following agree in all main particulars, namely, Gypsophila repens, G. Rokejeka, Saponaria officinalis, S. orientalis, S. Vaccaria, Silene gallica, S. Villarsii, S. noctiflora, S. tatarica, S. depressa, Cucubalus bacciferus, Lychnis diurna, L. vespertina, the species of Stellaria, Arenaria graminifolia, and others. A slight variation is met with in Lychnis Githago, where the thicker end of the seed contains the radicle and the thinner one the eotyledons; the reverse is usually the case when the seed is not of the same thickness throughout. A striking modification occurs in the species of Holosteum which have their ovules very much curved and folded so that one half lies against the other. The morphologically apical end containing the radicle is very narrow and forms a keel adnate to the face of the other half, which is much compressed. The cotyledons are incumbent and brought so close to the radicle that they nearly or quite touch it. There is little or no endosperm between them, but a considerable thickness of it on each side of the cotyledons so that the latter 
although semiterete have plenty of room to develop laterally and become broad.

A very important deviation not only from the type represented by Cerastium arvense, but also from the Order generally, occurs in Arenaria procumbens. The embryo is curved as usual in the shape of a horse-shoe, but the cotyledons are accumbent. The seed is reniform, very much compressed laterally, with a distinct notch at the base, and a double coat, finely reticulated on the surface. The cotyledons lie round the periphery of the seed just within the endosperm, and in the broader plane of the seed, yet they are semiterete and very narrow. Perhaps the exceeding thinness of the seed, which in transverse section is oblong with slightly indented sides and ends, may account for this particular manner of folding, although the narrowness of the cotyledons would hardly justify the conclusion. Buffonia Oliveriana (fig. 202), B. brachyphylla, and B. macrosperma agree with the above in having accumbent cotyledons, but they differ slightly in the form of the seeds, which are always few, generally two, in a capsule. They are very deeply horseshoe-shaped, and vertitically, almost oblong or obovate. This unusual length is well marked in B. Oliveriana and B. macrosperma; and the latter has comparatively thick seeds. The cotyledons are always narrow and semiterete, or almost square in section in B. Oliveriana, and equal the radicle in length. The embryo as a whole is very much curved, almost encircling the whole of the greatest circumference of the seed.

A second most important variation occurs in some species with distinctly winged seeds, standing in the same relation to the reniform seeds with a curved embryo as Tunica pachygona does to Dianthus with flat seeds and a straight embryo. This type, which is very rare in the Order, is represented by Spergularia marina. The seeds are suborbicular, very much laterally flattened, and girt at the circumference by a moderately wide wing which is slightly notched at the hilum. In most cases winged seeds are adapted for dispersal by the wind, but in the case of Spergularia it perhaps serves the same object by enabling the seeds to float. The embryo is curved as usual, peripheral, and similar in all respects to 
others with incumbent cotyledons. S. marginata ${ }^{1}$ agrees very closely with S. marina; but S. rubra, another British species, has wingless seeds. In Spergula also some species have winged seeds and others not. Drypis spinosa ${ }^{2}$ stands in the same relation to the Caryophylleæ as Bunias orientalis does to the Cruciferæ. The embryo is spirally or circinately coiled, the cotyledons especially, and takes up the greater part of the seed. The radicle is simply hooked, with its tip brought round in contact with the cotyledons, while the small quantity of endosperm present lies in the sinus of the radicle. The seeds are somewhat compressed laterally.

Cotyledons.-There is considerable variation in the shape of the cotyledons after germination; but those observed may be roughly classed under six leading types or forms. All are entire, and they vary chiefly in size and outline. Some of them are moderately fleshy in character, while the greater number are so opaque that no venation is discernible, or at most a midrib only. Saponaria Vaccaria is exceptional, and it seems that the cotyledons of no two species of this genus are exactly alike.

Taking Dianthus Caryophyllus (fig. 197) as the first type, it is characterised by broadly oblong cotyledons, rounded at the apex, tapering into the petiole, glabrous, fleshy, pale green, opaque. D. prolifer and D. ciliatus agree in all the main points, but the cotyledons of the former are proportionately shorter, retuse, inclining to ovate, and minutely scabrid at the margin. Their form in all cases bears an evident relation to the shape of the peltate, flattened seed and embryo. The petioles, it may be noted, are short and connate at the base, forming a cup round the plumule, and this character is the prevailing one throughout the Order.

The next type is represented by Tunica prolifera (fig. 198), which has broad, suborbicular, petiolate, thin but opaque cotyledons, with obscure venation. They doubtless derive their shape from that of the seed, which is generally orbicular or discoid, or occasionally inclined to oblong as in T. pachygona. Saponaria orientalis may be placed here, as it has broadly ovate or suborbicular cotyledons when full grown; they also

1 Le Maout and Decaisne, p. 258.

${ }^{2}$ Ibid. p. 255. 
show an alternate, penninerved venation. While yet in the seed they are linear, longer than the radicle, incumbent, and otherwise resemble those usually found in the reniform or suborbicular and laterally flattened type of seeds, but after germination they become successively oblong-elliptic, elliptic, and ultimately suborbicular, so that their form is due to growth subsequent to germination, and does not depend upon that which obtains while yet in the seed.

A third type is shown by Saponaria Vaccaria. The cotyledons are narrowly oblong, obtuse, shortly petiolate and penninerved, and closely resemble the primary leaves in that respect as well as in form. The seed is large $(3-4 \mathrm{~mm}$. in width), suborbicular, and slightly flattened laterally. The embryo is also large and curved round the periphery, and the cotyledons in germination keep much the same shape but attain a large size on account of the large store of reserve material in the seed. They are also unequal in size in the proportion of 25 to $29 \mathrm{~mm}$. ; and this peculiarity no doubt takes its origin in the seed, where the outer cotyledon would be the longest. They are long and narrow during germination, but increase in width afterwards. Lychnis Githago has long and broadly spathulate, sessile cotyledons connate at the base. They are opaque and show a midrib only.

A large number of species have broad cotyledons of moderate length somewhat similar to those of Dianthus, but they are pointed and more or less evidently narrowed at both ends. Those that may be grouped under this head vary somewhat between ovate-lanceolate, ovate, and elliptic or oblanceolate; but all agree in being pointed. Cerastium arvense (fig. 200), Silene echinata, and Silene rubella may be given as representatives of the three subtypes respectively. The cotyledons of C. arvense are ovate-lanceolate, petiolate, obtusely pointed, slightly mucronate, tapered to the base, distinctly one-nerved, and connate at the very base. Those of Silene echinata are broadly ovate, short, moderate in size, shortly petiolate, and faintly trinerved. Those of $\mathrm{S}$. rubella are oblanceolate, tapered to a rather broad, connate base, and unequal in size in the ratio of 9.5 to $11 \mathrm{~mm}$, Silene 
Schweinfurthii agrees pretty closely with the latter, and Saponaria calabrica merely differs in being somewhat more elliptic.

The fifth type is represented by Sagina procumbens (fig. 201), which has small, subulate, acute cotyledons, broadest at the base, and connate there, forming a cup round the plumule, 1.5-2 mm. long, and $1 \mathrm{~mm}$. broad at the base. A sixth very distinct type is met with in Spergula arvensis, the cotyledons of which are linear, semiterete, acute, fleshy, glabrous, green, without discernible venation, about 22.5 $\mathrm{mm}$. long, and in all respects very similar to the primary leaves.

The Order Caryophylleæ consists of 800 to 1200 species according to different authors. They are chiefly confined to the northern hemisphere, and are found in greatest numbers in extratropical regions, extending into the arctic and alpine; they are rarer in the southern hemisphere and very rare in the tropics, where they occur only on mountains.

Dianthus plumarius, $L$. (fig. 196).

Fruit an oblong-cylindrical capsule, one-celled, many-seeded, dehiscing at the apex by four short valves or teeth.

Seeds broadly oblong-orbicular, imbricated on a central column, peltate, much compressed dorso-ventrally, slightly concave on the
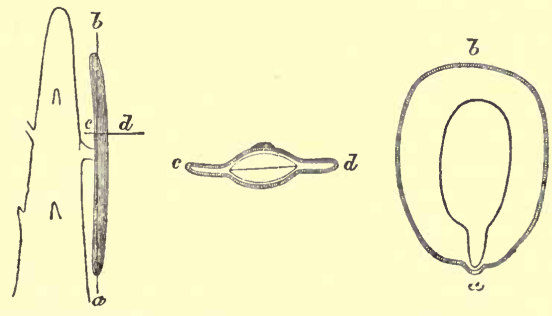

Fic. 196.-Dianthus plumarius, $\times 15$.

ventral aspect, and raised on the dorsal into a convexity agreeing in outline with the contained embryo, traversed throughout its longest axis on the ventral aspect by a ridge; testa black; hilum ventral a little above the middle of the seed, with a projection at 
either end, one of which towards the end farthest from the micropyle is the raphe; micropyle produced into a little point.

Endosperm copious, white, farinaceous.

Embryo comparatively large, slightly curved towards the axis; cotyledons oblong, obtuse, entire, broad ; radicle cylindrical, obtuse, pointing into a little projection at the micropyle.

Dianthus Caryophyllus, $L$. (fig. 197).

Hypocotyl very short, tapering into the root.

Cotyledons broadly oblong, obtuse, tapering into the petiole,

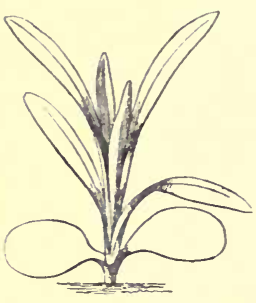

Fig. 197.-Dianthus

Caryophyllus. Nat. size. glabrous, fleshy, pale green; lamina 1.3 cm. long, $9.5 \mathrm{~mm}$. broad; petiole flattened, shallowly grooved above, perfoliate, $6 \mathrm{~mm}$. long.

Stem herbaceous or shrubby below, erect, ultimately decumbent, glabrous, terete; internodes crowded in the seedling stage; nodes thickened.

Leaves simple, entire, radical and cauline, opposite, decussate, perfoliate, glabrous, glaucous, exstipulate, sessile.

1st pair linear, spathulate, obtuse, channelled on the lower half, arching, subcarinate, especially on the lower half.

2nd pair linear, obtuse, broadest above the middle.

Dianthus prolifer, $L$.

Primary root long, tapering, with numerous short lateral rootlets.

Hypocotyl tapering insensibly into the root, short, glabrous.

Cotyledons broadly ovate, retuse, shortly petiolate, glabrous, minutely scabrous at the margin, light green, with an inconspicuous midrib and a few slender, incurved, lateral veins; lamina $6 \mathrm{~mm}$. long, $4.5 \mathrm{~mm}$. wide; petiole flattened, dilated at the base and perfoliate, $2 \mathrm{~mm}$. long.

Leaves subperfoliate at the base, spiny-ciliate at the margin and on the strong subcarinate midrib beneath, otherwise glabrous, deep green, shining, with a prominent midrib and a few lateral ascending nerves that unite with those next above them, but very indistinct in the first two pairs of leaves.

1st pair spathulate, obtuse.

2nd pair oblanceolate or narrowly spathulate, subacute.

3rd pair linear, obtuse. 
Tunica pachygona, Fisch. et Mey.

Capsule oblong-ellipsoid, glabrous, enclosed in the shortly fivetoothed, fifteen-ribbed, persistent calyx, which is nearly or quite as long, one-celled, with a central placenta, and many seeds, dehiscing at the apex by four valves.

Seed oblong-orbicular, thin and much flattened dorsally, entire or slightly angled at the margins, winged all round except at the tip of the radicle where a narrow shallow sinus is formed, glabrous, black. Except for an elevation conforming in outline to that of the embryo the seeds are nearly flat and attached to the placenta a little above the middle and much overlapping one another; hilum forming a little round spot above the middle of the seed on the ventral aspect; micropyle at the lower end of the seed, lying in the sinus; raphe and chalaza inconspicuous.

Endosperm forming a thin layer throughout the seed, except in the wing, but much thinner around the embryo, white, flesliy, or subfarinose.

Embryo straight, central, much narrower than the endosperm and a little shorter, colourless; cotyledons oblong-ovate, obtuse, entire, plano-convex or nearly flat, lying in the broad plane of the seed with their backs to the axis ; radicle terete, obtuse, about half as long as the embryo, embedded in a thin layer of endosperm close to the micropyle.

\section{Tunica prolifera, Scop. (fig. 198).}

Primary root slender, tapering, flexuose, with a few short lateral rootlets.

Hypocotyl suberect, herbaceous, about $2 \mathrm{~cm}$. long, $\cdot 5-1 \mathrm{~mm}$. thick, round, slightly pubescent under the seed-leaves.

Cotyledons nearly equal, stalked, including petiole about $1 \mathrm{~cm}$. long, $7 \mathrm{~mm}$. broad, suborbicular or somewhat spathulate, rounded, entire, with very obscure nervation, glabrous, not very thick nor persistent, dull green above, paler below.

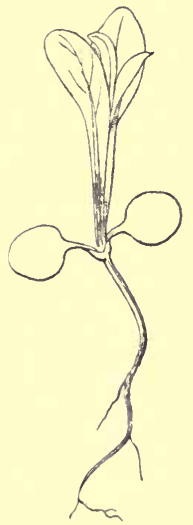

FIG. 198.

Tunica prolifera. Nat. size.

Stem very short, elongated when about to flower.

Leaves simple, entire, radical and cauline, opposite, exstipulate, petiolate in the early stages or very much narrowed at the base, ultimately narrow, sessile, with a distinct midrib and a few scattered lateral nerves, glabrous, deep green above, paler beneath.

1 st and 2 nd pairs spathulate, mucl narrowed to a petiole-like base. 
Saponaria Vaccaria, $L$.

Hypocotyl erect, terete, glabrous, 3-4 mm. long, light green or colourless.

Cotyledons somewhat fleshy, unequal, linear-oblong, obtuse, entire, shortly petiolate, glabrous, green, pinnatinerred like the leaves.

Stem erect, nearly square, herbaceous, glabrous; 1 st internode 5-7 mm. long, 2nd very short.

First leaves simple, entire, cauline, opposite, decussate, linearoblong, obtuse, sessile, tapering slightly to the base, where they are ciliate, glabrous, green, fleshy, indistinctly pinnatinerved.

Saponaria calabrica, Guss.

Primary root slender, tapering downwards, with numerous lateral rootlets.

Hypocotyl as in S. Vaccaria but 5-6 mm. long.

Cotyledons oblong, one-veined; petiole short, broad, scarcely channelled.

Stem with primary internodes undeveloped.

First leaves radical, petiolate, rotundly oblong or almost spathulate ; 2nd pair of leaves slightly hairy, one-veined like the cotyledons ; petioles broad, flat, sheathing at the base, shallowly channelled on the upper surface.

\section{Saponaria orientalis, $L$.}

Hypocotyl as in preceding species, erect, terete, glabrous.

Cotyledons ovate-oblong, indistinctly one-veined like the leaves.

Stem herbaceous, erect, square; primary internodes but slightly developed.

First leaves cauline, ovately-oval or oblong, obtuse, otherwise as in preceding species; petioles rather long, glabrous, deeply furrowed on the upper side.

\section{Silene echinata, Otth.}

Primary root tapering downwards, with short lateral rootlets.

Hypocotyl erect, very short, or tapering indistinguishably into the root, pale green or colourless.

Cotyledons ovate, obtuse, entire, petiolate, trinerred from the base, the lateral ones. submarginal, undulate or wavy, curved inwards and uniting with the midrib close to the apex, alternately nerved upwards and obscurely reticulate, glabrous, light green; lamina 6-8 mm. long, 4-5 mm. wide; petiole grooved above, connate at the base, $1 \cdot 5-2 \mathrm{~mm}$. long. 
Stem herbaceous, annual, erect, and developed when about to flower; primary internodes undeveloped.

Leaves simple, entire, radical and cauline, opposite, exstipulate, petiolate, obscurely, alternately incurvinerved, hairy on both surfaces, light green above, paler beneath; petioles channelled above, dilated and clasping at the base and slightly connate, coarsely hairy at the margins or edges of the channel.

1st pair short, obovate, very obtuse and rounded at the end.

2nd pair similar, but much larger.

3rd and 4th pairs spathulate, obovate, narrower and inclined to be oblong.

\section{Silene rubella, $L$.}

Primary root tapering downwards, with numerous long lateral rootlets.

Hypocotyl short, obconical, green or almost colourless.

Cotyledons rather fleshy, linear-oblong or lanceolate, indistinctly one-nerved like the leares, unequal. short.

Stem, 1st internode 1-1.5 mm. long; 2nd 6-7 mm.; 3rd very

First leaves entire, often wavy, cauline, spathulate or cuneate, tapering to the base, but scarcely petiolate, obtuse, glabrous, onenerved.

\section{Lychnis Githago, Lam.}

Hypocotyl short, hardly appearing above the soil.

Cotyledons broadly oblong, obtuse, entire, somewhat fleshy, petiolate, connate at the base, glabrous, dark green, indistinctly onenerved.

Stem with primary internodes undeveloped.

First leaves simple, entire, radical, opposite, oblong-lanceolate, subacute, exstipulate, pubescent, with the hairs very fine and silky, tapering to the base, sessile, light green, indistinctly pinnatinerved.

Cerastium arvense, $L$. (fig. 199).

Fruit a capsule, cylindrical or slightly curved and narrowed upwards, one-celled, many-seeded, dehiscing at the apex by ten teeth.

Seed reniform, with very unequal ends, appearing laterally compressed simply because curved, small, densely covered with small protuberances, brown; the smaller end containing the radicle, the larger one the cotyledons; hilum on the large end of the seed close to the edge of the basal notch; raphe none. 
Endosperm in the mature seed forming a round mass between the embryo and the basal notch, also an extremely thin layer round the periphery of the seed, and surrounding the embryo, floury, white.

Embryo long and narrow, curved round the periphery of the seed, pale yellow; cotyledons linear, obtuse, entire, semiterete,

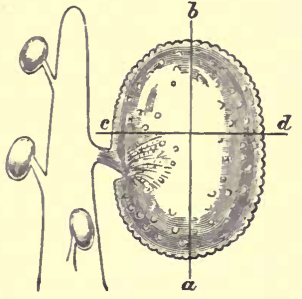

Fig. 199.-Cerastium arvense, $\times 15$.

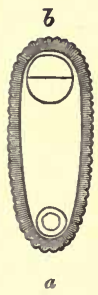

a

lying in the narrow way of the seed with their backs to the hilum; radicle cylindrical, slightly narrowed to an obtuse tip, somewhat shorter than the cotyledons and incumbent.

The form and arrangement of the seeds in Caryophylleæ has been already referred to (see ante, p. 25).

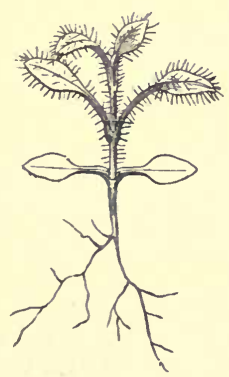

FIG.200.-Cerastiumarvense.

Half nat. size.

$\mathrm{mm}$. long.

Leaves simple, entire, cauline, opposite, exstipulate, petiolate, slightly hairy above and occasionally on the midrib beneath (at 
least in seedlings), indistinctly trinerved ; midrib with a few short, alternate, ascending nerves uniting with the longitudinal, lateral, slender, wavy submarginal ones ; petioles channelled above, subcarinate beneath, slightly hairy, connate at the base.

1st to 3rd pairs spathulate, or often broadly spathulate, obtuse, mucronate.

\section{Arenaria procumbens, Vahl.}

Fruit a capsule, small, ovoid, one-celled, several-seeded, dehiscing by the same number of valves as there are carpels.

Seed reniform, much compressed laterally, with a distinct notch at the base, very finely reticulated, pale brown; seed-coat double; the testa membranous, pale brown; the tegmen thinner, whitish; hilum and micropyle contiguous, basal in the notch.

Endosperm copious, farinaceous, white.

Embryo curved round just within the periphery of the endosperm, colourless; cotyledons accumbent, sometimes somewhat obliquely linear, obtuse, entire, plano-convex, lying in the broad plane of the seed with their edges to the axis (presumably on account of the seed being thin and much compressed laterally); radicle terete, obtuse, about equal in length to the cotyledons, and curved in conformity with the curvature of the seed.

Sagina procumbens, L. (fig. 201).

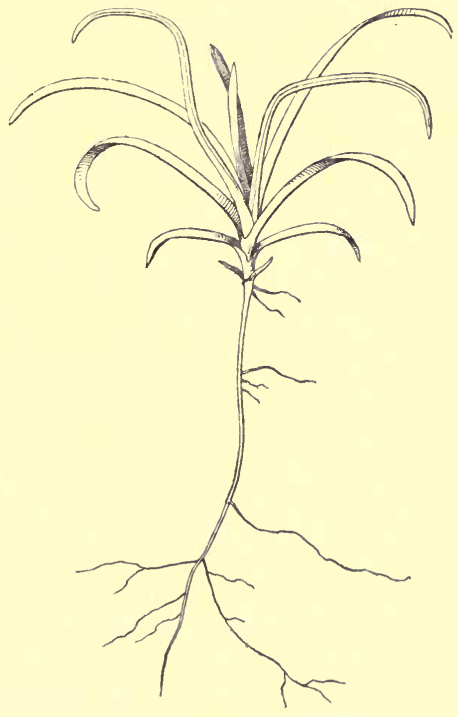

FIG. 201.-Sagina procumbens, $\times 3$.

Primary root tapering downwards, with numerous slender, lateral rootlets and abundantly provided with root-hairs.

Hypocotyl very short or completely suppressed.

Cotyledons small, subulate, acute, much broader at the base, 
where they are connate and form a little cup round the stem, about 1.5-2 mm. long, and $1 \mathrm{~mm}$. broad at the base.

Stem herbaceous, with the lower very slightly developed internodes covered by the connate and sheathing bases of the leaves; primary one remaining short and barren; lateral shoots or branches elongating and fruiting.

Leaves simple, entire, radical and cauline, opposite, exstipulate, sessile, dilated, connate and sheathing at the base, glabrous, and covered with numerous, elevated, very minute, hyaline points, bright green, without discernible venation, or with the midrib indicated by a slightly elevated ridge on the under side.
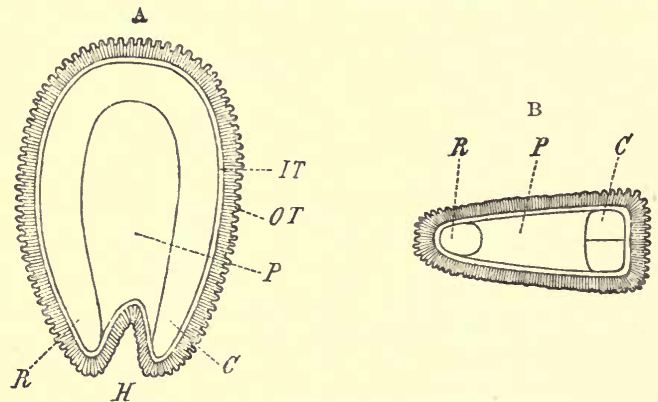

Fia. 202.-Buffonia Oliveriana, $\times 24$. A, vertical section of seed: $R$, radicle; $H$, hilum; $C$, cotyledon; $P$, endosperm; $O T$, testa ; $I T$, tegmen. $\mathrm{B}$, transverse section of seed: $R$, radicle, $P$, endosperm; $C$, cotyledon.

1st pair narrowly linear, acute, flattened above.

3rd to 5th pairs narrowly linear, but still much broader than the first pair, acute, or tipped with a slender hyaline seta or bristle, convex above and minutely revolute at the margins.

Buffonia Oliveriana, Ser. (fig. 202).

Fruit acapsule, obovoid, much compressed laterally, pale-coloured, glabrous, one-celled, generally two-seeded, dehiscing longitudinally by two valves.

Seed vertical, oblong, much compressed laterally, obtuse at the upper end, notched at the base, owing to the curvature of the ovule, finely and closely rugoso-reticulate and even developed into numerous small points or teeth round the margin; hilum and micropyle contiguous, basal ; raphe none. 
Endosperm central, copious, farinaceous, white.

Embryo much curved round the periphery of the endosperm, yellowish-white; cotyledons linear, plano-convex, or semiterete, obtuse, lying in the broader plane of the seed, accumbent with their edges to the lilum and placenta, the two together thicker than they are wide ; radicle terete, obtuse, as thick at the base as the cotyledons are broad, but thicker above the middle, and as long.

I figure this species because the cotyledons, like those of $\mathrm{B}$. brachyphylla and Arenaria procumbens, are accumbent.

Buffonia brachyphylla, B.H. (fig. 203).

Capsule small, ovoid, one-celled, generally two-seeded, but often one-seeded, dehiscing to the base by two valves.

Seed reniform, much compressed laterally, and comparatively

A

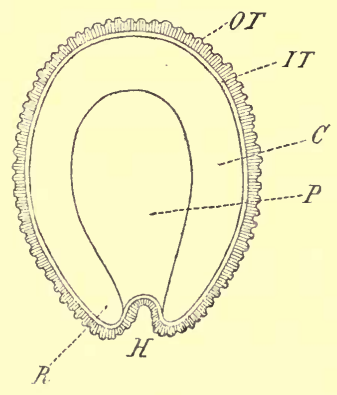

B

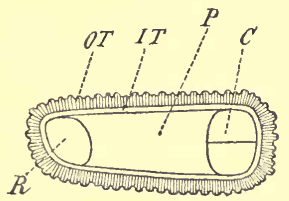

Frg. 203.-Buffonia brachyphylla, $\times 20$. A, vertical section of seed:

$R$, radicle; $H$, hilum; $P$, endosperm; $C$, cotyledon; $I T$, tegmen;

$O T$, testa. $\mathrm{B}$, transverse section of seed: $O T$, testa; $I T$, tegmen;

$P$, endosperm; $C$, cotyledon; $R$, radicle.

thin, with a basal notch, minutely and finely reticulated, brown; testa comparatively thick; tegmen thin, membranous.

Endosperm mealy or farinaceous.

Embryo as in the preceding species.

\section{Spergula arvensis, $L$.}

Hypocotyl erect, terete, glabrous, 5-8 mm. long, light green.

Cotyledons linear, semiterete, acute, entire, fleshy, glabrous, green, no venation apparent. 
Stem with primary internodes undeveloped.

First leaves simple, entire, radical, opposite, decussate, linear, cylindrical, acute, sessile, fleshy, glabrous, green, without any apparent venation; subsequent leaves in pseudo-whorls of from six to eight.

\section{PORTULACE E.}

Benth. et Hook. Gen. Pl. i. 155.

Fruit and Seed.-The pistil is syncarpous and free, or half inferior in Portulaca, one-celled, two- to many-ovuled, and consists of three, rarely two, carpels. The amphitropous ovules vary from two to many, except in Portulacaria, which has only one, and arise from the base of the ovary separately, or the funicles are connate into a central column.

The fruit is a capsule, splitting by as many valves as there are carpels, or dehiscing circumscissly as in Portulaca ; rarely indehiscent as in the one-seeded winged fruits of Portulacaria and Silvæa. The seeds are numerous or solitary by arrest, and reniform, or lenticular, laterally compressed, or obovoid ; testa generally crustaceous, shining and smooth or often granulate as in species of Portulaca, sometimes furnished with an arilloid, or swelling of the funicle, as in Talinum. The embryo is nearly always curved round the periphery of a scanty, farinaceous endosperm, when the cotyledons about equal the terete radicle in length.

A good type of the Order is furnished by Portulaca grandiflora, the seeds of which are reniform, laterally compressed, with a thick and a thin end, and a minutely granulate crustaceous and shining testa.

As regards means of dispersion, Portulacaria has winged fruits, and Grahamia winged seeds; in Anacampseros some species have seeds with three wings while others are wingless.

The embryo is curved round the periphery of the seed, enclosing in its sinus a small quantity of endosperm, and nearly encircling the greatest circumference; the cotyledons are plano-convex, linear-oblong, and being situated in the, 
wider end of the seed, are much wider than the terete radicle, which they equal in length. They are also incumbent and lie transversely to the wider plane of the seed.

Calandrinia umbellata, C. pilosiuscula, and Spraguea umbellata agree very closely with Portulaca except that the seeds of Spraguea are thickest in the middle and taper to each end, so that the cotyledons are narrower for the size of the seed than in the type given. A more remarkable exception occurs in Claytonia perfoliata (fig. 204), the embryo of which lies in the broader plane of the seed. The cotyledons are nevertheless very narrow, linear, plano-convex, and accumbent, perhaps for the reason suggested on page 69 . The embryo seems to originate with its cotyledons in the narrow plane of the seed while yet straight; but certainly as soon as it begins to curve in conformity with the outline of the seed, the cotyledons lie in the broad plane with their edges to the axis. When first observable with a simple lens, the embryo is a small, nodular, obcordate body, but it soon becomes oblong, and the cotyledons attain such a thickness as to become closely adpressed to one another; in the next stage it is cylindrical, and soon after commences to curve and ultimately attains a horse-shoe shape.

Exceptions to the general rule oceur in Grahamia, Talinopsis, and sometimes in Anacampseros, where the embryo is almost straight, and the seeds have only a scanty endosperm. The seeds of Grahamia are also irregularly oborate, subreniform, very much compressed laterally, and girt with a membranous wing; in Talinopsis they are obovate-oblong, incurved and hooked but wingless; while in some species of Anacampseros they are angled or compressed and three-winged, but in others wingless.

Cotyledons.-As far as observed there are two distinct types of cotyledons, namely, a broad and a narrow one. One of the broadest types occurs in Portulaca grandiflora, notwithstanding the extreme minuteness of the seeds. The cotyledons however lie in the narrow plane of the seed, but in its widest part, and they are consequently several times as wide as the radicle is thick. When fully dereloped after germination they are oblong-oval, obtuse, fleshy, shortly petiolate, 
about $17 \mathrm{~mm}$. long. and $4 \mathrm{~mm}$. broad. Calandrinia umbellata and Spraguea umbellata agree with the above in the relative width of the cotyledons, but the latter are only $2.25 \mathrm{~mm}$. long and $1.25 \mathrm{~mm}$. broad in Spraguea. They are oblongovate, obtuse, sessile, and subfleshy. There are a few notable points to be observed in the germination of the seeds. In some cases the testa splits along the side of the cotyledons, which, meeting with little resistance, emerge here, contrary to the usual rule in seeds that the radicle is first protruded. They continue to grow till the endosperm becomes exhausted through the medium of the radicle, when the seedling, unable to make any further progress, dies, unless the conditions are favourable for the emission of adventitious roots, whereby it can lay hold of the soil and become established. When however the seeds have been properly covered with soil the radicle emerges first, the arching hypocotyl pulls the cotyledons out of the testa, and after it has become straight these unfold to the light. The testa is however frequently carried up on the cotyledons, when it exhibits a vertical cleft of considerable size, thus allowing the escape of the cotyledons, which are comparatively broad, oblong, obtuse, and sessile. In the mature seed the cotyledons are long, narrow, and quite typical of the Order ; but after germination or during it, they develop more in breadth than length, and remain comparatively short. Sown under glass they germinated in ten days.

Several species of Calandrinia, including C. pilosiuscula and C. speciosa, agree with Claytonia in the narrowness of their cotyledons, also some species of Talinum, and it is probable that several other genera of the same habit have similar cotyledons; in C. umbellata they are broader, and some other species of Calandrinia which differ in habit and have broad, fleshy, mostly radical leaves, may possibly have different cotyledons.

\section{Portulaca grandiflora, Hook.}

Hypocotyl erect, terete, reddish, glabrous, $10-15 \mathrm{~mm}$.

Cotyledons oblong-oval, obtuse, fleshy, glabrous, stained with red underneath, shortly petiolate, about $17 \mathrm{~mm}$. long including the petiole, $4 \mathrm{~mm}$. broad.

Stem herbaceous, erect in the early stages, but afterwards pro- 
cumbent, terete, glabrous with tufts of long white hairs springing from the axils of the cotyledons.

Leaves simple, entire, flat, cauline, alternate, exstipulate, very shortly petiolate, fleshy, glabrous, often tinged with red beneath; petioles very short, slightly channelled above.

Nos. 1 and 2. Ovate, obtuse, or faintly mucronate, with small tufts of white hairs or setæ in their axils.

Claytonia perfoliata, Don (fig. 201).

Fruit a capsule, globose or ovoid, membranous, dehiscing by three valves.

Seed orbicular-subreniform, much compressed laterally, small, with the auricles on each side of the hilum nearly or quite equal; testa glabrous, shining, black, crustaceous; hilum basal in the sinus,

A

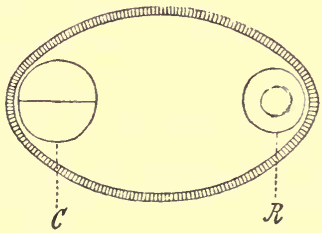

$\mathrm{B}$

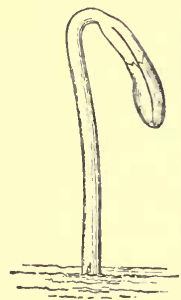

FIG. 204.-Claytonia perfoliata. A, transverse section of seed: $C$, cotyledons; $R$, radicle, $\times 15$. B, seedling, showing the thickness of the two cotyledons combined, $\times 6$.

and apparently equidistant from apex of cotyledons and radicle; funicle partly or wholly persistent.

Endosperm copious, farinaceous, white, forming a thin layer round the embryo, and a much larger mass inside.

Embryo much curved round the periphery of the seed, just within a thin layer of endosperm; cotyledons narrowly linear, obtuse, entire, colourless, accumbent; radicle cylindrical or terete, obtuse, curved round the periphery of the seed, about as long as the cotyledons.

Seedling (fig. 205).

Primary root normal, annual.

Hypocotyl terete, very short, reddish, glabrous, $2.5 \mathrm{~mm}$. long.

Cotyledons linear, elongated, fleshy, flattened, glabrous, pale 
green, becoming reddish when old, broadest above the middle, narrowed towards the base, then suddenly dilated, amplexicaul or

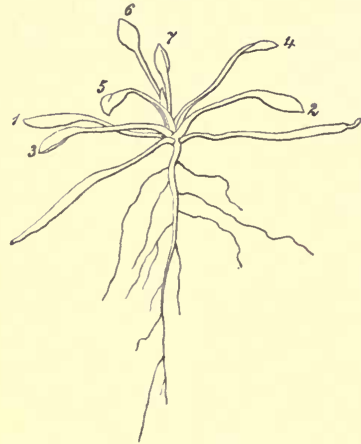

FIG. 205.-Claytonia perfoliata. Nat. size. slightly perfoliate, $2 \cdot 3 \mathrm{~cm}$. long, greatest breadth $1.5 \mathrm{~mm}$.

Stem herbaceous, annual, developed when about to flower; many primary nodes undeveloped.

Leaves simple, entire, radical and cauline, alternate, exstipulate, petiolate, glabrous, rather fleshy, bright green; petioles flattened above or shallowly grooved, long, slender, fleshy, glabrous, dilated and amplexicaul at the base.

Nos. 1 and 2. Narrowly spathulate with a long petiole.

No. 3. Much broader.

Nos. 4-8. Rhomboid, obtuse or subacute, on long petioles.

Spraguea umbellata, Torr. (fig. 206).

Fruit a globular capsule, compressed, several-seeded, dehiscing by two valves.

Seed reniform-orbicular, laterally compressed, thickest in the middle, and narrowed to the edge, especially towards the basal

A

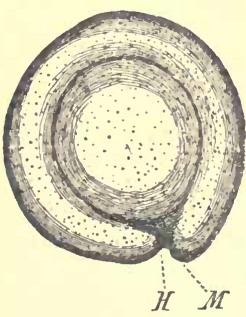

$\mathrm{B}$

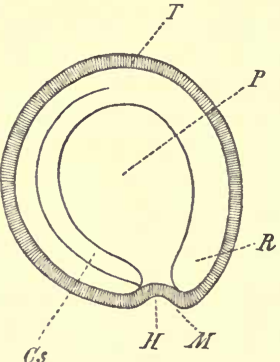

C

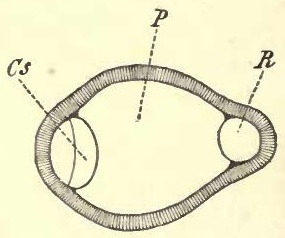

Fig. 206.-Spraguea umbellata, $\times 25$. A, seed, lateral aspect: $H$, hilum; $M$, micropyle. $\mathrm{B}$, vertical section of seed: $H$; hilum; $M$, micropyle; $C s$, cotyledons; $R$, radicle; $P$, endosperm; $T$, testa. C, transverse section of seed: $C s$, cotyledons; $P$, endosperm; $R$, radicle.

edge, glabrous, shining, minutely pitted all over ; testa rather thick, hard and crustaceous; hilum basal, but lying in a sinus which is 
not quite central, the radicle lying in the smaller auricle of the sinus and the cotyledons in the larger one; micropyle on one side of the hilum, the chalaza on the other.

Endosperm copious, farinaceous, white, lying in the centre of the seed and extending to the broader circumference only at the base.

Embryo comparatively large, much curved, occupying the circumference of the seed, except a small piece at the base peripheral and entirely outside the endosperm (in the specimens examined), colourless, but darker than the endosperm ; cotyledons linear, planoconvex, or semiterete, obtuse, entire, incumbent, lying in the narrow plane of the seed with their backs to the placenta, about as long and as broad as the radicle; radicle terete or cylindrical, obtuse, abutting with its tip against the micropyle.

Calandrinia pilosiuscula, $D C$.

Hypocotyl erect, terete, glabrous, colourless or faintly tinged with red, $8-10 \mathrm{~mm}$. long.

Cotyledons $15-22 \mathrm{~mm}$. long, linear, obtuse, tapering slightly at the base, entire, covered with a minute scarcely perceptible pubescence, green, without any apparent renation.

Stem with primary internodes undeveloped.

First leares simple, entire, radical, alternate (first pair apparently opposite), exstipulate, linear, obtuse, slightly tapering to the base, covered with a very minute pubescence, one-nerved, green.

\section{Calandrinia umbellata, $D C$.}

Hypocotyl 4-6 mm. long, stained with red.

Cotyledons fleshy, oblong-oral, obtuse, entire, shortly petiolate, glabrous, dark green, without any apparent venation.

Stem as in C. pilosiuscula.

First leaves linear-lanceolate, tapering to the base but hardly petiolate, covered with rather long glandular hairs, otherwise as in C. pilosiuscula.

\section{TAMARISCINEA.}

Benth. et Hook. Gen. Pl. i. 159.

Fruit and Seed.-The one-celled ovary consists of from three to five carpels, and as many parietal placentas, which project into the interior and often become more or less united with one another, thus imperfectly dividing it into loculi. The 
placentas also vary greatly in length in the different species, some rising but a short way above the base of the ovary, while in other cases they nearly equal the length of the cavity. The ovules vary from two to many on each placenta and are erect and anatropous, with the raphe on the ventral aspect and an inferior micropyle. The fruit is a capsule dehiscing by valves and liberating the seeds, which are furnished with a curious contrivance for their distribution. In some cases they are prolonged into a slender beak covered with long silky hairs, while others have no beak but are covered all over with long hairs, and a third type is furnished with wings. The seeds contain a mealy or fleshy endosperm, sometimes in very small quantity, or there may be none at all as in Tamarix and Myricaria. The embryo is straight with flat cotyledons, and a short radicle close to the hilum; and where endosperm is wanting it entirely fills the seed, to which it conforms in shape.

The Tamariscineæ include some forty species distributed amongst five genera, and consist of very finely branched shrubs, rarely trees or rigid herbs. The leaves are alternate, minute, and often scale-like.

\section{ELATINE 死.}

Benth. et Hook. Gen. Pl. i. 162.

Fruit and Seed.-The ovary contains from two to five cells, corresponding to the number of the sepals and petals in the different species. The ovules are numerous on the inner angle of the cells, horizontal or ascending, anatropous, with a lateral or nearly superior raphe. The fruit in dehiscing splits along the inner edge of the septa, leaving a central column bearing the seeds, or often along the outer edge, leaving the septa attached to the central column. The seeds are numerous, cylindrical, straight, or slightly curved as in Elatine triandra, or very much curved like the head of a shepherd's staff as in E. Hydropiper, strongly and closely striated transversely, and exalbuminous or with a thin layer only of endosperm. In 
some of the species of Bergia they are smooth, and these species are sometimes placed in a separate genus, Merimea.

The embryo is cylindrical, conforming in outline to that of the seed, which it wholly occupies. The radicle is close to the hilum, much longer than the cotyledons and equalling them in width.

The Elatineæ include twenty species of slender aquatic or marsh herbs or small shrubs, creeping or spreading diffusely. They are widely dispersed throughout the world, but most abundant in the Old World, growing in shallow water like our native Elatine Hydropiper, and E. lrexandra.

\section{HYPERICINEE.}

Benth. et Hook. Gen. Pl. i. 163.

Frnit and Seed.-The carpels vary from three to five; rarely reduced to one, as in Endodesmia calophylloides. The ovules are usually numerous, ascending or horizontal from parietal or axile placentas, and anatropous with a lateral or superior raphe. The fruit is a capsule in the tribes Hypericeæ and Cratoxyleæ, but baccate and indehiscent in the Vismieæ. That of Endodesmia, containing only one pendulous seed, is a drupe, while that of Haronga forms a drupe with five woody pyrenes as in Cratrgus. The seeds are exalbuminous, straight or rarely curved, with a crustaceous, or more often membranous, testa expanded into a wing in Eliæa and Cratoxylon. The embryo is generally straight, but incurved in a few of the species of $\mathrm{Hy}$ -

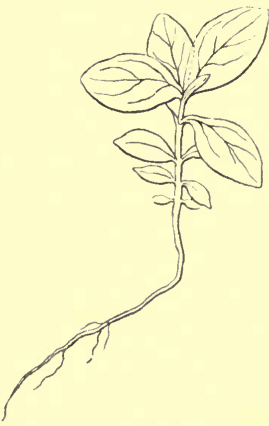

Rig. 207.-Hypericum Androscemum. Nat. size. pericum, and always conforms to the seed. The cotyledons are flat, except in Endodesmia, where they are thick and fleshy; they are longer than the radicle 
except in the tribe Hypericex, where they are usually shorter. The radicle is close to the hilum.

Hypericum Androsæmum, L. (fig. 207).

Primary root slender, wiry, flexuous, brownish, with few lateral rootlets.

Hypocotyl erect, terete, glabrous, brownish, 3-5 $\mathrm{mm}$. long.

Cotyledons very small, ovate, obtuse, cuneate at the base, glabrous, shortly petiolate; lamina $2 \mathrm{~mm}$. long, $1.5 \mathrm{~mm}$. broad; petiole $1 \mathrm{~mm}$. long.

Stem suffruticose, erect, terete, or slightly two-angled by lines decurrent from the bases of the leaves, glabrous, green or reddish, ultimately brown; 1st internode $1.5 \mathrm{~mm}$. long; 2nd $1.75 \mathrm{~mm}$.; 3rd $2.5 \mathrm{~mm}$; 4 th $2 \mathrm{~mm}$.

\section{GUTTIFER\&.}

Benth. et Hook. Gen. Pi. i. 167.

Fruit and Seed.-The ovary of the Guttiferæ varies from two to many cells, except in Calophyllum and Kayea, where it is one-celled and one-ovuled. There is only one ovule in each cell of Tovomita and in the tribe Garcinieæ, otherwise almost without exception the ovules vary from two to many in each cell, and are erect and anatropous, attached to a central placenta or arising from the base of the cavity, with the micropyle inferior. The fruit is fleshy, leathery, or pulpy, and rarely dehisces at maturity except in the tribe Clusieæ, where it splits into valves at the septa. The seeds are large, frequently solitary in each cell, sometimes numerous amongst the species of Clusia, and often enveloped at the base by a lobed or corrugated aril or arillode. The testa is membranous and leathery, rarely spongy as in some species of Calophyllum ; in the Mangosteen (Garcinia Mangostana) it is covered with a thick pulpy aril, forming the edible part. Endosperm is wanting.

The embryo is large, filling the seed, to which it conforms : it presents a remarkable and abnormal case, inasmuch as it often consists mainly of a swollen and fleshy radicle with small and scale-like inconspicuous cotyledons at its apex as in the tribe Clusiex, while they are said to be absent in the 
Noronoheæ and wanting or very minute in the Garcinieæ. The radicle is always inferior, and in the Calophylleæ it is very short with large cotyledons sometimes grown together in a mass. In Quiina they are large and fleshy but distinct, while the radicle is very short.

Seedlings.-In the seedlings observed the cotyledons where present are subterranean in germination, and this generally obtains where seeds are large, exalbuminous, and contain a fleshy embryo. The cotyledons of Calophyllum Inophyllum (fig. 209) occupy a large globular seed, and their fleshy petioles are just long enough to allow the plumule to get clear out of the seed. They are also subterranean. The first pair of leaves are reduced to scales, as are also generally the second pair, or these are imperfectly developed. Then follow two pairs of narrowly elliptical, obtuse leaves, after which the seedling stops growing for the season. The penninerved venation is remarkable on account of the dense arrangement of the reins in parallel lines.

Xanthochymus pictorius (fig. 208) and Mesua ferrea agree with the above in all general particulars; but in the former the first four pairs of leares are reduced to small, orate, or subulate, black scales, and only one pair of lanceolate acuminate leaves are produced in the first year. The reins of the leaves are parallel but wider apart than in Calophyllum. In Mesua ferrea the first four pairs of leares are small, scaly, and caducous, followed by two pairs of lanceolateoblong very finely penninerved leaves, after which growth ceases for a time. When growth recommences the terminal bud is blind, and two axillary branches are developed bearing a single pair of narrower, oblong leaves, and again terminate in a blind bud. The branching is therefore strictly cymose from a very early stage, that is, from the end of the first year's growth of the seedling.

Xanthochymus pictorius, Roxb. (fig. 208).

Primary root long, stout, fleshy, yellowish, giving rise to a few strong adventitious roots near the upper end.

Hypocotyl short and merging into the root, subterranean.

Cotyledons subterranean, large. fleshy, filling the large seed and not leaving the testa. 
Stem woody, erect, terete, striate, minutely tuberculate, glabrous, deep green; 1st internode subterranean; 2nd $1.9 \mathrm{~cm}$. long; 3rd $2 \cdot 3 \mathrm{~cm}$.; 4 th $3.7 \mathrm{~cm}$.; 5 th $2.9 \mathrm{~cm}$.

Leaves simple, entire, cauline, stipulate, opposite, decussate, petiolate, glabrous, penninerved, coriaceous, deep green, with a raised prominent midrib on both surfaces; petioles short, stout, with the flattened midrib occupying nearly the whole of its upper surface and thickened above at the base, covering and protecting the bud, prominently convex on the back, articulated with the stem; stipules small, interpetiolar, triangular.

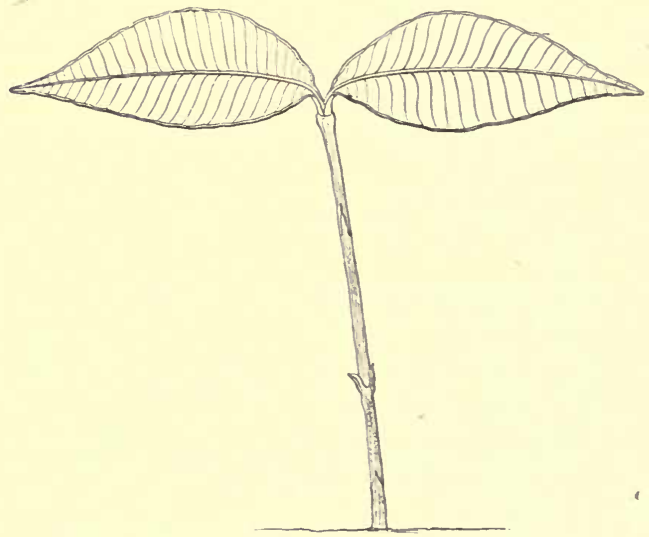

Fig. 208.-Xanthochymus pictorius. Half nat. size.

1st to 4 th pair of leaves inclusive reduced to small, ovate, or the uppermost subulate, acute, carinate, black scales.

5th lanceolate, elliptic, acuminate, with a prominent midrib and thickened nerve-like margin, $8 \mathrm{~cm}$. long, $3 \mathrm{~cm}$. broad towards the middle.

Ultimate leaves oblong-elliptic, entire, subacuminate, obtuse, penninerved, with parallel veins, deep green, coriaceous, evergreen, stipules small, triangular, interpetiolar.

Calophyllum Inophyllum, L. (fig. 209).

Hypocotyl undeveloped.

Cotyledons thick and fleshy, remaining in the testa after germination, shortly petiolate with strong fleshy petioles, subterranean. 
Stem erect, somewhat compressed on opposite sides between each internode (the greater diameter being in the plane of the pair of leaves immediately above each internode), glabrous, deep green, more or less mottled with minute colourless dots, ultimately woody; 1 st internode $1.4-1.7 \mathrm{~cm}$. long; 2nd $2.5-2.8 \mathrm{~cm}$; 3rd $4 \mathrm{~cm}$; 4 th $1 \cdot 8-2 \mathrm{~cm}$.

Leaves simple, entire, cauline, opposite, exstipulate, petiolate, densely and alternately or often oppositely and ascendingly penninerved, with slender, parallel nerves, resembling striæ, that run straight and unbranched from the midrib to the margin-rarely do two contiguous ones coalesce close to the margin to form a single nerve-shining on both surfaces, deep green above, light green beneath, hyaline and finely glandular-pubescent at the margin, otherwise glabrous and soon losing the

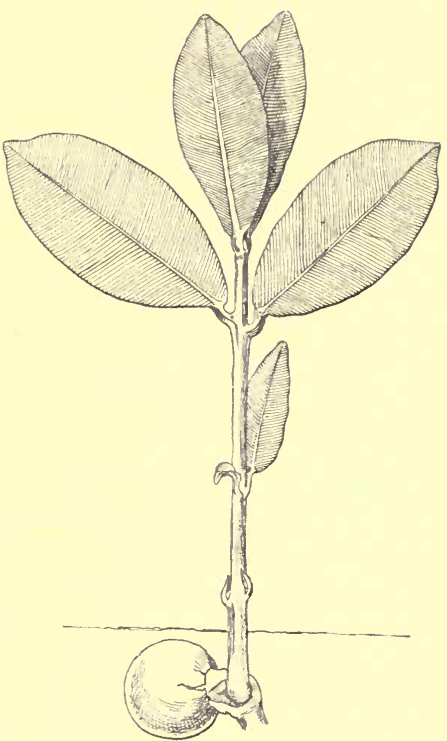

FIG. 209.-Calophyllum Inophyllum. Half nat. size. glands; petioles short, stout, glabrous, light green, semiterete, flattened above, slightly thickened at the insertion on the stem.

1st pair small, scale-like and reduced to their midrib.

2nd pair similar or sometimes much better developed, and sometimes unequal, when the larger one is oblong or oblonglanceolate and obtuse.

3rd and 4th pairs narrowly elliptical, obtuse, perfect and normal.

Mesua ferrea, $L$.

Hypocotyl subterranean, very short or hardly developed.

Cotyledons large, fleshy, subterranean, and remaining in the broadly amygdaloid seed until they decay. 
Stem terete, strong, tapering upwards, glabrous, green, soon becoming woody, brown and striated longitudinally; 1st internode $4 \cdot 3-4.5 \mathrm{~cm}$. long; 2nd $3.5-3.8 \mathrm{~cm}$.; 3rd 2-2.5 cm.; 4th and 5 th about $2 \cdot 3-2 \cdot 5 \mathrm{~cm}$. ; 6 th $2 \cdot 5-3 \mathrm{~cm}$.

Leaves simple, entire, cauline, opposite, stipulate, petiolate, closely and alternately or almost oppositely penninerved, with the nerves simple or slightly forked and proceeding almost at right angles from the midrib to a slender, continuous, and submarginal nerve, with numerous intermediate, very slender nerves, and finely almost indiscernibly reticulate, coriaceous, glabrous, deep green above, glaucous beneath, with the midrib prominent on both surfaces, evergreen; petioles short, subterete, slightly flattened above or obsoletely channelled, glabrous, furnished at the base with two minute, deltoid, obtuse auricles or stipules, connate around axillary buds.

1st to 4th pairs of leaves reduced to small, caducous scales.

5th and 6th pairs lanceolate-oblong, acuminate, rounded at the base.

Here the stem ends in a blind bud and two axillary buds are developed, which become branches, bearing each a pair of leaves at their apex, ending in a blind terminal bud, and again developing a pair of axillary buds. The leaves on these branches are narrower than those of the stem, oblong, acuminate, obtuse, and rounded at the base.

\section{TERNSTRCMIACE E.}

Benth. et Hook. Gen. Pl. i. 177.

Fruit and Seed.-The ovary is free, rarely immersed in the torus as in Anneslea and Visnea, generally three- to five-celled except in Ternstrœmia and in a few species of allied genera where it is imperfectly septate. The ovules vary in number exceedingly from two to many in a cell, rarely solitary as in Caryocar, Anthodiscus, Omphalocarpum, Pelliciera, and Haploclathra. They are either erect or horizontal, or pendulous and anatropous, sometimes campylotropous, or laterally affixed and amphitropous with the micropyle superior or inferior. The ovary is two-celled in Pelliciera, many-celled in Anthodiscus, Actinidia and Omphalocarpum. The fruit is fleshy, 
leathery or almost woody, or a loculicidal or septicidal capsule, the septa often breaking away, leaving a central columella.

The seeds are solitary or more often several or numerous, and attached to axile placentas, which are usually stout and spongy or fleshy; and they also rary exceedingly in size, some being very large as in Ternstrœmia, Caryocar, Pyrenaria, Pelliciera, Camellia, Kieimeyera, and Caraipa. The woody or bony character of the testa is very marked in most of these large seeds; and their rariability in shape and in the direction of the longer axis is rell seen in Camellia reticulata. Some seeds are more or less winged, as in Pentaphylax, Stuartia, Schima, Gordonia, Laplacea, Kielmeyera, and Marila, in the last of which the wing is fimbriate; while others are fleshy, and probably adapted for dispersion by animals. The endosperm is generally scanty or absent, and this may rary eren in the same genus, as in Camellia, for instance, where endosperm is said to be absent. In Camellia theifera it is, indeed, altogether wanting, as rell as in Pyrenaria, Gordonia, Laplacea, Caraipa, Pelliciera, Marila, and others. The testa is so thin in Pelliciera as to be almost evanescent. Endosperm is, however, very copious in Actinidia, Saurauja, and Stachyurus. The embryo varies exceedingly; being short and straight, curved, replicate, inflexed, horseshoe-shaped, or spiral, and the cotyledons and radicle also vary in their proportionate lengths, the complications which they undergo, depending greatly upon the shape and other characters of the seed.

The embryo is straight and axile with very short cotyledons in Actinidia, similar or slightly incurred in Saurauja, and straight, nearly equalling the endosperm, in Stachyurus, with elliptic cotyledons; also in Stuartia, where the cotyledons are oval; in Laplacea, where they are oblong and flat; and in Microsemma, where they are ovate and flat. Linear and slender, straight seeds (to which the embryo conforms) occur in Bonnetia, Archytæa, Mahurea, and Marila, but the cotyledons are generally broad and the radicle short. The seeds are without endosperm or almost so, and the embryo is slightly curved in the Maregravieæ. In the tribe Gordoniex, to which the Camellia belongs, there is considerable variation in the form of 
the embryo, for besides Stuartia, Laplacea, and Microsemma mentioned above with a straight and flat embryo, it is nearly flat in Gordonia, or the cotyledons are slightly undulate-plicate, and slightly curved or oblique. This leads to another group in which the cotyledons are folded, plaited, or undulated longitudinally, as in Camellia reticulata. Here the seeds are extremely variable in outline and variously angled by mutual compression, flattened on one side and convex on the other, or flattened on both sides ; again they are more or less falcate and drawn out to an obtuse three- to four-angled point, at the opposite end from the hilum, oblong or oblate, with the broadest end always next the placentas. There are two seedcoats, the outer woody or bony, and the inner membranous. The embryo is large, fleshy, straight, colourless, and lies along the longer axis of the seed whether that is at right angles or transverse to the placentas. The cotyledons are oblong, obtuse, somewhat auricled at the base, much plaited longitudinally, lying in the broader plane of the seed, with their edges to the placenta in the oblate seeds, but with the radicle to the hilum or placenta in the long and narrow ones. The seeds in these cases would seem to be amphitropous and anatropous respectively. Schima and Pyrenaria agree with this type in having large embryos and corrugated cotyledons; but the radicle here is long and incurved or inflexed. Pelliciera has broad, thick, and fleshy cotyledons with a straight radicle. The tea-tree (Camellia theifera) offers a remarkable exception amongst its congeners in having a large, fleshy, and globular embryo, with the small radicle and plumule completely surrounded or covered by the hemispherical cotyledons. The radicle of C. reticulata projects considerably beyond the cotyledons. Pelliciera is also remarkable in having a highly evolute plumule.

Hippocrepiform or much curved embryos occur in Visnea, Anneslea, Ternstromia, Adinandra, Cleyera, Freziera, Eurya, and Pentaphylax, all belonging to the tribe Ternstrœmieæ. This is due to the seeds, which are curved or horseshoe-shaped, and generally of no great thickness, the cotyledons being semiterete and shorter than the radicle. The elongation of the radicle is carried to excess in Caryocar and Anthodiscus, where the cotyledons are extremely reduced in length and 
hamato-inflexed. The radicle is of great size, thick, fleshy, and bent or incurved in Caryocar, and very long and spirally coiled in Anthodiscus, with the short cotyledons in the centre of the helix.

Cotyledons.-Very few of this Order are cultivated in gardens, and still less often are they raised from seeds. The Camellia is most common, while Maregravia and Stuartia are sometimes grown. The cotyledons of Camellia theifera (fig. 210) swell up somewhat during germination, bursting the woody testa, but otherwise do not alter in size and shape. They form a hemispherical mass occupying the interior of the seeds, and are subterranean. They assume more or less of a green colour should they be exposed to light during germination by the bursting of the testa and removal of the soil.

It is probable that the cotyledons of other species and genera are subterranean even after germination, as for instance in the case of Caryocar, Pelliciera, Kielmeyera, and others.

\section{Camellia theifera, Griff.}

Capsule woody, dehiscing loculicidally, few-seeded.

Seeds large, globose-ovoid, more or less flattened around the hilum, and frequently much flattened on one side by mutual pressure, attached to the axile placentas, and pendulous; seedcoat woody brown, of two layers, the imner, tegmen, of a deep shining chocolate colour; hilum oval, frequently if not always attended by three more or less deep and conspicuous depressions which probably indicate the positions of aborted ovules; raphe (best seen when the inner coat separates from the outer) consisting of a broad trunk proceeding from the hilum close to the upper end of the seed, where the chalaza ramifies extensively and spreads over the testa on both sides of this main trunk; radicle superior, close to the hilum.

Endosperm absent.

Embryo large, fleshy, straight, pale yellowish-white; cotyledons equal and each occupying half the interior of the seed, to the shape of which it conforms, flat on the opposed faces and much rounded on the back in the round seeds, but more or less and variously angled when the seed liappens to be compressed on one or more sides; plumule very small, towards the base of the cotyledons; radicle very small, included between their base.

Seedling (fig. 210).

Primary root long, stout, tapering very slightly, becoming 
woody, colourless, ultimately giving off numerous flexuose and branching rootlets.

Hypocotyl similar to the radicle, but stouter, $1.5 \mathrm{~cm}$. long, $3 \mathrm{~mm}$. thick.

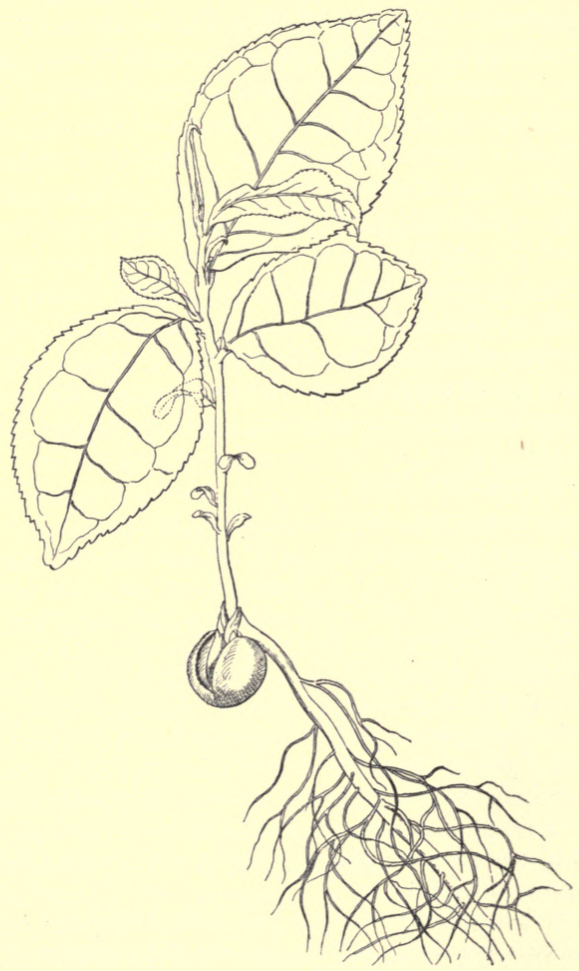

Frg. 210.-Camellia theifera, var. Assam hybrid. Half nat. size.

Cotyledons opposite, turned on one side, folded or crumpled, fleshy, and remaining in the testa a long time while the plant gains strength.

Stem erect, terete, woody, pubescent, pale green, becoming brown; 1st internode $1.2 \mathrm{~cm}$. long; 2 nd $2.5 \mathrm{~mm}$.; $3 \mathrm{rd} 6 \mathrm{~mm}$.; 4 th 
$8 \mathrm{~mm}$; 5 th $1.3 \mathrm{~cm}$; 6 th $1.3 \mathrm{~cm}$.; 7 th $7 \mathrm{~mm}$.; 8 th $8 \mathrm{~mm} . ; 9$ th $4 \mathrm{~mm}$.; 10 th $3 \mathrm{~mm}$.; 11th $4 \mathrm{~mm}$.

Leares simple, cauline, alternate, exstipulate, petiolate, coriaceous, evergreen, glabrous except on the midrib.

Nos. 1 and 2. Oblanceolate, obtuse, $7 \mathrm{~mm}$. long, $3 \mathrm{~mm}$. broad.

Nos. 3 and 4. Spathulate, emarginate, obtuse; largest one $8 \mathrm{~mm}$. long, $5 \mathrm{~mm}$. broad.

No. 5 . Obovate, emarginate, $1.6 \mathrm{~cm}$. long, $1 \mathrm{~cm}$. broad, obscurely serrate.

No. 6. Elliptic, obtuse, emarginate, obtusely serrate, with apiculate serratures, $5 \cdot 5 \mathrm{~cm}$. long, $3 \cdot 7 \mathrm{~cm}$. broad.

Nos. 7 and 8. Elliptic, subacuminate, emarginate, bullate, serrate, with apiculate serratures; petioles $1.5 \mathrm{~mm}$. long; lamina of No. 7, 7.7 cm. long, $4.5 \mathrm{~cm}$. broad; lamina of No. $8,8.8 \mathrm{~cm}$. long, $5 \cdot 1 \mathrm{~cm}$. broad.

\section{Camellia reticulata, Lindl.}

Capsule large, but short, woody, three- to five-celled, with one or more seeds in each cell, dehiscing loculicidally when mature.

Seeds very variable in outline, and variously angled by mutual pressure, somewhat flattened on one side and convex on the other, or flattened on two sides, more or less falcate in outline and drawn out to an obtuse, three- to four-angled point at the opposite end from the hilum, oblong or oblate, with the broadest end always next the placenta ; hilum forming a large scar, linear or oblong, or variously angled in outline, pale coloured; micropyle contiguous to or on the basal scar; seed-coat double; outer (testa) woody or bony, thick, brown, and shining externally ; inner (tegmen) thinner, paler, membranous.

Endosperm said to be absent in mature seeds, but in the specimens examined there was an evident though thin layer of fleshy, white endosperm, lining the inner coat of the testa.

Embryo very large, straight, colourless, lying in the longer axis of the seed whether that is transverse or at right angles to the receptacle; cotyledons oblong, obtuse, somewhat auricled at the base, otherwise entire, much plaited longitudinally, lying in the broader and longer axis of the seed, and consequently in the oblate seeds with their edges to the placenta or hilum, and in the long narrow seeds with the radicle next the hilum; radicle short, oblong, stout, obtuse, projecting slightly beyond the auricles of the cotyledons, pointing to the micropyle at the hilum or transversely to it in the oblate seeds. 


\section{DIPTEROCARPEÆ.}

Benth. et Hook. Gen. Pl. i. 189.

Fruit and Seed.-The ovary is generally three-, rarely twoor one-celled as in Ancistrocladus and Lophira, the former having one ascending ovule and the latter eight to twelve erect ovules from a short central placenta. In all other cases the ovules are geminate in each cell, pendulous and anatropous or inserted on the placenta by their sides and subanatropous with a ventral raphe and superior micropyle. Almost the same variability is met with as amongst the Ternstrœmiaceæ. The fruit is free or enclosed in the enlarged persistent tube of the calyx as in Dipterocarpus, two out of the five lobes of which form wings of considerable size, while the other three remain small. A third form is met with in Ancistrocladus, Anisoptera, and Pachynocarpus. The mature fruit contains one, rarely two, seeds, and dehisces very slowly or not at all. The seeds are large, pendulous, and anatropous, rarely erect; they are exalbuminous.

The embryo is always large, and, when the cotyledons are thick and fleshy, it conforms to the seed. It varies greatly, however, in different genera. The cotyledons are equal, or unequal and straight, or lobed and plaited. In some cases they are thin, and in the effort to fill the seed become thrown into remarkably twisted or corrugated folds. The radicle points to the hilum and is slightly exserted, or in other cases elongated, but included between the cotyledons.

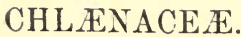

Benth. et Hook. Gen. Pl. i. 194.

There are but eight species in this Order, distributed amongst four genera, and all are natives of Madagascar. The three-celled ovary contains two pendulous or in a few cases horizontal anatropous ovules. The fruit is a capsule, nearly 
always enclosed in an enlarged involucre and three-celled with one or two seeds in each loculus, or one-celled and one-seeded by abortion as in Leptolæna. The seeds are pendulous or attached by the sides, with a coriaceous testa and a fleshy or horny endosperm.

The embryo is straight and embedded in the centre of the endosperm, and has foliaceous, flat or wavy cotyledons.

The Chlænaceæ are small trees, except Rhodolæna, which is a shrubby climber supporting itself on tall trees. The leaves are alternate, generally stipulate, and have a penninerved and reticulate venation.

\section{MALVACE $R$.}

Benth. et Hook. Gen. Pl. i. 195.

Fruit and Seed.-The carpels vary from two to many, and in most cases are arranged in a whorl around the torus. They are solitary in a few species of Plagianthus, and in Malope, Palava, and Kitaibelia are very numerous, but confusedly arranged over the torus. The ovules are solitary and ascending in each carpel of the subtribes Malopeæ and Eumalveæ, solitary and pendulous in Sideæ, but vary from two to many in the Abutileæ with the exception of Wissadula divergens. They also vary in number in the other tribes. They are very frequently amphitropous, sometimes almost anatropous, and ascending or horizontal with a ventral, lateral, or superior raphe; in other cases they are pendulous with a superior or dorsal raphe.

The fruit is dry, rarely berried as in Malvaviscus, and falls away from the axis as indehiscent or dehiscent cocei, or it is a loculicidal capsule dehiscing by valves. There are a few exceptions in which the fruits are one-seeded and indehiscent, as in Cavanillesia and sometimes in Quararibea and Plagianthus.

The seeds are reniform in the more typical Malvaceæ; but in other cases are subglobose or obovoid. The testa is generally crustaceous, usually more or less wrinkled, and 
smooth or pilose or covered with long woolly hairs, as in most of the species of Gossypium.

In some of the species of the tribe Bombaceæ the seed has a fleshy or pulpy aril. Endosperm is present or absent, but is generally scanty and mucilaginous; it is fleshy and plentiful in a few cases only.

The embryo varies according to the character of the seed, reniform seeds having a curved and more or less folded embryo with the back of the cotyledons to the axis, and, as the result of the folding, their edges also. In obovoid seeds the embryo is straight as in the subtribe Fremontieæ, where the cotyledons are flat. In most cases however the cotyledons are foliaceous, of large size, and folded or twisted and plicate, enclosing the radicle. More rarely they are thick and fleshy as in Durio zibethinus.

The radicle in horizontal amphitropous seeds such as those of the Mallow lies in the lower part of the seed, and following the outline of the testa becomes more or less upturned towards the hilum. It is inferior in ascending seeds, and in those that are pendulous it becomes incurved, pointing downwards to the hilum.

The simplest and most typical form of seed and embryo is that seen in Malva sylvestris or Althæa rosea. The seeds are reniform and the embryo conforms to them in general outline; the tip being involute and lying between the outer parts. The radicle is more or less wrapped round by the base of the cotyledons.

The case becomes more complicated in Gossypium, where the seed is large and globose or angled. The embryo is short, and in making an effort to attain a large size to fill the seed, which contains but a small quantity of endosperm, the cotyledons have grown excessively in width, and in order to accommodate themselves to the shape of the seed, have become greatly folded and plaited, with their bases wrapped round the radicle. Other instances of large seeds and a complicated embryo may be seen in Bombax, Eriodendron, and Pachira.

Seeds containing a straight embryo and flat cotyledons have already been mentioned. In those the radicle is very short. 
Seedlings.-The cotyledons of the various types which have come under my notice are nearly all modifications of the same plan; but they may be classified under six headings, namely, cordate, roundly cordate, reniform, ovate, oblong, and transversely oblong.

Malva moschata (fig. 211) may be taken as a good representative of the first group. The cotyledons are slightly unequal in size, cordate, minutely emarginate, obsoletely tri-lobed or -angled towards the apex, and trinerved. The angled appearance is due to the manner of the folding while yet in the seed (see ante, p. 41). It is even more distinct in some species than in this. In species belonging to many other genera the cotyledons are merely slightly constricted below the tip instead of being angled. Malva sylvestris, M. rotundifolia, Sidalcea malvæflora, Malvastrum peruvianum, Navæa phœnicea, Lagunaria Patersonii, Abutilon asiaticum, and Eriodendron anfractuosum (fig. 216) agree generally with this type. The last named is notable for the size and persistency of its cotyledons.

Lavatera trimestris differs only in the depth of the apical notch or emargination. In several of the above species there is no apical notch at all. The cordate base is, however, a very persistent character and runs almost throughout the Order. It is due to the manner in which the cotyledons fold round the radicle.

Roundly cordate cotyledons are represented by Hibiscus pedunculatus (fig. 213). One feature here is that one of the cotyledons is inclined to be narrowed to an obsolete blunt point, while the other, generally the larger, is emarginate. Hibiscus Abelmoschus, H. brasiliensis, H. vitifolius, Calirrhoe pedata, Abutilon vitifolium, and Pavonia hastata agree with the above in all important particulars. The bluntness of the cotyledons seems to be due to the size of the seed, and the amount of folding, as seen in Hibiscus Sabdariffa.

The process seems to be carried still further in Hibiscus phœniceus, which represents the reniform type; where the cotyledons have grown more in width than length. Malvaviscus arboreus differs only in being slightly more rounded.

Modiola multifida (fig. 212) has small, ovate, trinerved 
cotyledons, while those of Sida fallax are larger, and those of Hibiscus Trionum are inclined to be broadly ovate-elliptic. The cotyledons of Adansonia digitata and A. Gregorii are broadly oblong, obtuse, entire, slightly cordate at the base, strongly five- to seven-nerved, somewhat concave and reticulate. Those of Paritium tortuosum are very much smaller with inconspicuous renation.

The transversely oblong type is represented by Gossypium barbadense (fig. 215), in which the cotyledons are large, foliaceous, transversely oblong, retuse, sometimes broadly and shallowly emarginate, strongly three- to five-nerved, and reticulate. G. arboreum agrees, while G. tomentosum sometimes differs in being more or less cuneate at the base. A curious instance of dimorphism occurs in Hibiscus phœniceus. One form of seedling has the first four leaves oblong and tridentate at the apex, followed by four larger and more oval ones. The second form has the first leaf oblong and nearly entire, the second trifid and trinerved, followed by six trinerved and tripartite ones. The leaves from the ninth to the sixteenth inclusive vary with three, four, and five nerves and as many segments, all of which are linear and entire.

In Pachira aquatica the cotyledons are subterranean. ${ }^{1}$

\section{Lavatera trimestris, $L$.}

Hypocityl 12-13 mm. long, erect, terete, glabrous, light green or colourless.

Cotyledons cordate or ovate from a cordate base, unequal, emarginate, obtuse, petiolate, glabrous, green, with a reddish spot near the petiole, very distinctly five-nerved.

Stem with primary internodes undeveloped.

First leaves simple, or roundly reniform, obtuse, cordate at the base, crenate, wrinkled, glabrous, green, pinnately trinerved, petiolate, stipulate; petioles stout, hairy, channelled on the upper side; stipules membranous, brownish, deciduous.

\section{Sidalcea malvæflora, Lindley.}

Hypocotyl terete, glabrous, fleshy, deep red, 3-5 mm. long, -5-1.5 mm. thick.

Cotyledons opposite, foliaceous, cordate, entire, obtuse, glabrous ;

1 Lynch, Journ. Linn. Soc. 1878, p. 147. 
lamina $11 \mathrm{~mm}$. long, $9 \mathrm{~mm}$. broad; petiole subterete, channelled above, glabrous, reddish, about $1.5 \mathrm{~cm}$. long.

Stem undeveloped.

Leaves simple, radical and cauline, alternate, stipulate, petiolate; stipules subulate.

Nos. 1 and 2. Reniform, crenate, sparsely pubescent on both surfaces, palmately five-nerved, reticulate, rather fleshy.

Ultimate radical leaves cordate-orbicular, coarsely crenate or lobulate with obtuse mucronate teeth, radiately seven- to elevennerved.

Cauline leaves gradually developing from the scarcely divided radical leaves, and each becoming more deeply lobed as the top of the stem is approached. Lower ones shallowly radiately lobed; middle ones five- to seven- to nine-lobed or -partite with oblong segments, coarsely and irregularly toothed above the middle; upper ones tripartite, and ultimate ones entire or slightly serrate, lanceolate.

Malva moschata, $L$. (fig. 211).

Primary root normal, tapering, ultimately much branched and fibrous.

Hypocotyl erect, terete, glabrous, pale green, 4-6 $\mathrm{mm}$. long.

Cotyledons somewhat unequal in size, cordate, minutely emarginate, obsoletely tri-lobed or-angled towards the apex, cordate at the base, trinerved, each nerve running into a lobe, glabrous, deep green, petiolate; lamina of larger cotyledon 1.3 $\mathrm{cm}$. long, $1.05 \mathrm{~cm}$. broad, of smaller cotyledon $1 \cdot 1 \mathrm{~cm}$. long, $.85 \mathrm{~cm}$. broad; petioles semiterete, slightly grooved above, glabrous, that of larger cotyledon $.85 \mathrm{~cm}$. long, that of smaller cotyledon $1 \mathrm{~cm}$. long. Cf. Cruciferæ, tribe Brassiceæ.

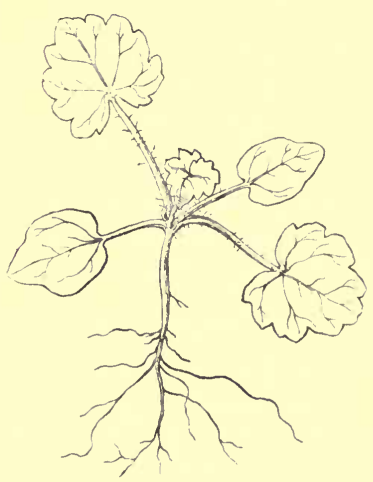

FIG. 211.-Malva moschata.

Nat. size.

Stem herbaceous, developed when about to flower, 12-18 inches long, ascending, erect or spreading.

Leaves simple, radical and cauline, alternate, stipulate (1st leaf 
exstipulate), petiolate, deep green, glabrous above, ciliate at the margin, thinly hairy or in young specimens sometimes glabrous beneath; petioles semiterete, channelled above, thinly hairy; stipules subulate, obtuse or subacute, membranous, thinly hairy, whitish in seedlings, absent on first leaf.

Nos. 1 and 2. Reniform, five-nerved, irregularly crenate or incipiently three- to five-lobed.

No. 3. Cordate, more decidedly five-lobed.

Ultimate leaves palmately seven-nerved; radical ones reniform or orbicular with a wide sinus at the base, irregularly crenate or incipiently lobulate; lower cauline ones more or less deeply lobed (generally from one-quarter to one-balf their radius); lobes broad, oblong, and again lobulate and subacutely toothed; upper cauline, seven-lobed nearly to the base-larger lobes rhomboid, pinnatifid, and acutely toothed, with alternate ascending nerves.

The cotyledons of M. sylvestris and M. rotundifolia resemble those of M. moschata, but in those I have seen the notch near the apex was somewhat less marked.

\section{Callirhoe pedata, A. Gray.}

Hypocotyl erect, terete, glabrous, 5-10 mm. long, light green or colourless.

Cotyledons unequal, membranous, rotund-cordate, slightly emarginate, obtuse, cordate at the base, petiolate, with rather long petioles, glabrous, light green, distinctly trinerved.

Stem with primary internodes undeveloped.

First leaves simple, radical, alternate, petiolate, stipulate, cordate at the base, subrotund, crenate, palminerved, covered with fine hairs; petiole rather thick with a furrow on the upper side; stipules small and deciduous.

\section{Navæa phœnicea, Webb et Berthelot.}

Hypocotyl erect, terete, pubescent, 2-3 cm. long, light green.

Cotyledons unequal, cordate or elongated, ovate and cordate at the base, subacute, entire, petiolate, covered with minute hairs, green, five-nerved; petiole unequal, channelled on the upper side, hairy.

Stem erect, quadrangular, herbaceous; 1st internode 1-2 mm. long; 2nd about the same length.

First leaves simple, cauline, alternate, stipulate, petiolate, ovate, acute, cordate at the base, coarsely serrate, pubescent, light green, palminerved. 


\section{Malvastrum peruvianum, A. Gray.}

Hypocotyl erect, terete, minutely pubescent, $1 \cdot 5-2 \mathrm{~cm}$. long, light green or colourless.

Cotyledons cordate, obtuse, unequal, petiolate, entire, glabrous, dark green; venation distinct, pinnatinerved, giving the cotyledon almost a variegated appearance.

Stem, primary internodes undeveloped.

First leaves suborbicular, simple, cauline, alternate, crenate or rather bluntly serrated, petiolate, stipulate, pubescent, light green, pinnatinerved, wrinkled.

\section{Sida fallax, Walp.}

Hypocotyl suffrutescent, erect, terete, finely pubescent, pale green, $1.5 \mathrm{~cm}$. long.

Cotyledons petiolate; petiole terete, channelled, pubescent, $5 \mathrm{~mm}$. long; lamina broadly ovate, obtuse, pubescent, pale green, $8 \mathrm{~mm}$. long, $8 \mathrm{~mm}$. broad near the base.

Stem suffrutescent, erect, terete, thickened upwards, finely pubescent, pale green; 1st internode $2 \mathrm{~mm}$. long; 2nd $2.5 \mathrm{~mm}$.; 3rd $4 \mathrm{~mm}$.; 4 th $8 \mathrm{~mm}$.; 5 th $1.25 \mathrm{~cm}$.; 6 th $1.4 \mathrm{~cm}$.; 7 th $1.3 \mathrm{~cm}$.

Leaves cauline, simple, alternate, stipulate, petiolate, glabrous above, pubescent on the nerves beneath, ciliate; petioles subterete, fiattened above, densely pubescent; stipules filiform, slender, hairy, deciduous.

No. 1. Rotund-cordate, coarsely serrate-dentate; limb $1 \cdot 2 \mathrm{~cm}$. long, $1 \cdot 1 \mathrm{~cm}$. broad.

No. 2. Cordate, irregularly dentate-serrate, penninerved, or subpalmatinerved at the base.

No. 3. Rotund-cordate dentate-serrate; nervation like No. 2.

No. 4. Cordate, dentate-serrate.

No. 5. Rotund-cordate, obtuse, coarsely dentate-serrate, more decidedly palmately five-nerved at the base.

No. 6. Similar to last but larger.

No. 7. Rotund-cordate, obtusely dentate-serrate or crenate-serrate, strongly palmately five-nerved at the base, and strongly penninerved upwards with subopposite nerves.

No. 8. Similar, but undeveloped when examined.

\section{Abutilon asiaticum, Don.}

Hypocotyl soon becoming woody, erect, terete, hairy, and glandular-pubescent, pale green, about $2 \cdot 2 \mathrm{~cm}$. above the soil. 
Cotyledons cordate, obtuse, entire, with long petioles, three- to five-nerved, with a thin glandular pubescence above ; margin ciliate with hooked hairs, thinly hairy beneath and glandular-pubescent; lamina $1.25 \mathrm{~cm}$. long, $1.2 \mathrm{~cm}$. broad; petiole $1.3-1.5 \mathrm{~cm}$. long, hairy and glandular-pubescent.

Stem woody, erect, subflexuous, hairy and glandular-pubescent; pale green; 1st and 2nd internodes $2 \cdot 25 \mathrm{~mm}$. long; 3rd $3 \mathrm{~mm}$.; 4 th $2.5 \mathrm{~mm}$.

Leaves simple, cauline, alternate, stipulate, petiolate, stellately pubescent on both surfaces, palmately seven-nerved from the first, ciliate, greyish-green above, pale, almost glaucous, beneath, subreticulate; petioles subterete, slightly channelled on the upper side, densely hairy and glandular-pubescent, thickened at the base and also at the insertion of the lamina ; stipules small, subulate, hairy, caducous.

Nos. 1 and 2. Rotund-cordate, obtuse, dentate with mucronate teeth.

Nos. 3 and 4. Broadly cordate, subacute, dentate with mucronate teeth.

No. 5. Broadly cordate, subacute, slightly trilobed, dentate.

Pavonia hastata, Cav.

Hypocotyl erect, terete, covered with minute hairs, light green or colourless, $1 \cdot 5-2 \mathrm{~cm}$. long.

Cotyledons fleshy, cordate or rotund, oval, entire, obtuse, unequal (one being much more ovate than the other and cordate at the base), petiolate with hairy petioles and a very few hairs at the base, pinnatinerved.

Stem erect, terete, herbaceous, pubescent; 1 st internode 3-4 mm. long.

First leaves simple, cauline, alternate, ovate, obtuse, crenate, slightly cordate at the base, petiolate, stipulate, pubescent, light green, pinnatinerved.

Modiola multifida, Moench (fig. 212).

Primary root tapering, flexuous, with lateral rootlets, annual.

Hypocotyl subterranean and tapering indistinguishably into the root.

Cotyledons petiolate, glabrous, somewhat fleshy; petioles channelled above, $5 \mathrm{~mm}$. long; lamina ovate, rather obtuse, faintly trinerved, $4 \cdot 75 \mathrm{~mm}$. broad, $6 \mathrm{~mm}$. long.

Stem annual, terete, hairy; 1 st and 2 nd internodes undeveloped; 3rd 2 mm. ; 4 th $4 \mathrm{~mm}$. long. 
Leaves simple, radical and cauline, alternate, stipulate, petiolate, thinly hairy when young, ultimately glabrescent, deep green above, paler beneath; petioles subterete, channelled on the upper side, hairy; stipules free, subulate, acute, broader upwards, hairy.

No. 1. Rotund, crenate, seven-nerved.

No. 2. Reniform, erenate, seven-nerved.

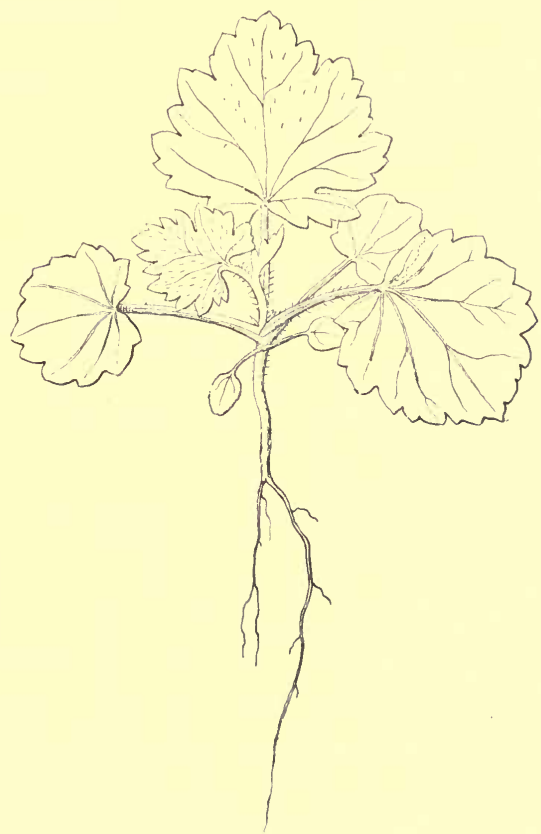

FIG. 212.-Modiola multifila. Nat. size.

No. 3. Suborbicular, shallowly cordate at the base, seven- to nine-nerved, deeply crenate.

No. 4. Broadly cordate, nine-nerved, lobulate and crenate.

No. 5. More deeply and decidedly lobed than the last.

Intermediate forms are orbicular, cordate at the base, seven- to nine-nerved, lobed on the upper half, lobulate towards the base, serrate-dentate, with obtuse, apiculate teeth. 
Ultimate leaves palmately seven-nerved, with five or seven lobes or ultimately reduced to three ; middle lobe rhomboid-oblong, inciseserrate from the middle upwards; lateral lobes oblong, oblique, serrate mostly on the posterior side; basal lobes always small.

\section{Malvaviscus arboreus, Cav.}

Hypocotyl erect, terete, pubescent, $2 \cdot 5-4 \mathrm{~cm}$. long, light green or colourless.

Cotyledons reniform or transversely oblong, obtuse, entire or minutely emarginate, cordate at the base, especially the larger one; petiolate, glabrous, light green, palmatinerved; petioles long, terete, pubescent.

Stem erect, terete, herbaceous, pubescent ; 1 st internode 6-8 $\mathrm{mm}$. long.

First leaves simple, cauline, alternate, ovate, acute, serrate, petiolate, stipulate, pubescent, light green, pinnatinerved; petioles short, terete, pubescent; stipules small, scarious, deciduous.

\section{Hibiscus Sabdariffa, $L$.}

Fruit a capsule, five-valved, many-seeded, dehiscing longitudinally.

Seed reniform, subtrigonous like the segment of an orange, somewhat biconvex dorsally, that is, longitudinally and transversely, tapering wedge-like to the ventral edge, glabrous, deep brown, striated longitudinally or following the curvature of the seed; hilum median on the ventral aspect with the remains of the funicle attached to it; micropyle inferior; seed-coat double-outer (testa) thick, coriaceous ; inner (tegmen) very thin, paler coloured.

Endosperm scanty, occupying the vacant space about the middlc of the seed, on the ventral aspect, and forming an extremely thin layer along the ventral side of the cotyledons and radicle, fleshy, white.

Embryo curved, large, occupying nearly the whole of the seed, yellowish-white ; cotyledons cordate-orbicular, slightly trilobate, with deep auricles, emarginate, unequal, reaching the apex of the seed in the course of their growth, then folding at the sides with the edges of both towards the placental axis; at the same time the apex becomes folded or doubled in between the sides and in this way grows nearer to the apex of the seed than the sides do. Nerves five from the base, the two stronger of which proceed to the minute lateral lobes of the cotyledons and are slightly branched; the midrib is alternately branched upwards. Radicle cylindrical, tapered to 
an obtuse point and curved round the dorsal aspect of the seed, between the auricles of the cotyledons towards the micropyle.

\section{Hibiscus pedunculatus, Cav. (fig. 213).}

Primary root long, brittle, with fleshy, branched, colourless rootlets.

Hypocotyl about $1.5 \mathrm{~cm}$. long, and a little over $1 \mathrm{~mm}$. thick, terete, slightly uneven, pubescent, bright green.

Cotyledons shortly petioled, $25-1 \mathrm{~cm}$. long and as broad, broadly cordate at the base, emarginate, otherwise entire, obscurely

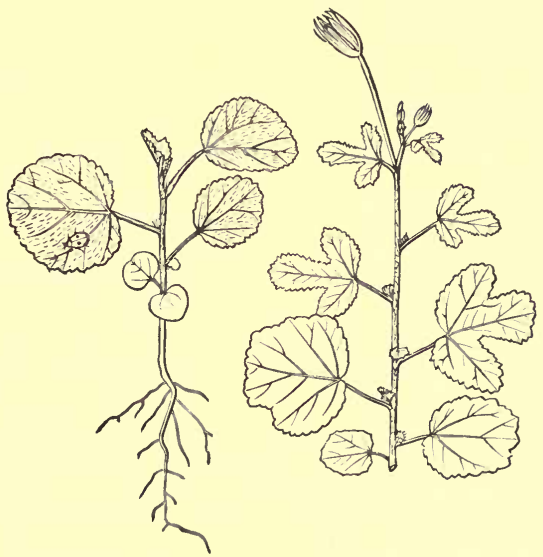

Frg. 213.-Hibiscus pedunculatus. Half nat. size.

trinerved, concave, thin, pubescent, including petioles, yellowishgreen, not very persistent.

Stem rather firm, terete, with stellate hairs ; first few internodes $\cdot 5-1 \mathrm{~cm}$. long, $1.5 \mathrm{~mm}$. thick.

Leaves simple, cauline, alternate, stipulate, petiolate, pubescent all over, crenate in the earlier, and crenate-serrate in the adult leaves, palmately five-nerved from the base with all the principal veins ramified upwards, reticulate; petiole tapering slightly upwards, subterete, pubescent; stipules membranous, small, subulate, acute, deciduous.

No. 1. Rotund-elliptic, crenate, palmately five-nerved.

No. 2. Suborbicular, cordate at the base, crenate. 
No. 8. Somewhat similar.

No. 4. Trilobate, crenate-serrate.

Older plants of this species have trifid leaves, but an undivided one at the base of each shoot, and one, two, or more cordate below the trifid ones.

\section{Hibiscus vitifolius, $L$.}

Hypocotyl as in H. pedunculatus.

Cotyledons rotund, obtuse, trinerved; lamina glabrous, $1 \cdot 1 \mathrm{~cm}$. long, $1 \mathrm{~cm}$. broad, truncate or subcordate at the base; petiole subterete, slightly channelled above, pubescent, $8 \mathrm{~mm}$. long.

Stem succulent, erect, terete, pubescent; 1st internode 8-12 $\mathrm{mm}$. long.

Leaves.-No. 1. Rotund or rotund-oblong, irregularly crenate, obtuse, with mucronate crenatures, subcordate at the base, glabrous, ciliate; petiole terete, pubescent, pale green, succulent, about 1.5 cm. long.

No. 2. Rotund-palmate, cordate at the base, shallowly trilobed, irregularly crenate, obtuse, otherwise like No. 1.

No. 3. Rotund, cordate at the base, five-nerved, shallowly trifid, crenate-dentate.

No. 4. Larger, otherwise similar.

No. 5. Broadly cordate, obtuse, seven-nerved, shallowly trifid, crenate-dentate.

Nos. 6-8. Palmately seven-nerved and shallowly three- to fivelobulate, crenate-dentate with obtuse, mucronate teeth, reticulate, stellately pubescent on both surfaces.

\section{Hibiscus Abelmoschus, $L$.}

Hypocotyl stout, terete, pale green, suffused with red, covered with a deflexed pubescence, $3 \mathrm{~mm}$. thick and becoming woody.

Cotyledons palmately three- to five-nerved and glabrous, very similar to those of $\mathrm{H}$. pedunculatus; petiole terete, tapering upwards, slightly channelled on the upper side, pubescent, $1.8 \mathrm{~cm}$. long, curved upwards near the apex to bring the lamina horizontal.

Stem terete, pubescent with deflexed hairs, pale green with purple blotches at the axils of the leaves, about $2 \mathrm{~mm}$. thick; 1st internode $1.3 \mathrm{~cm}$. long; 2nd $1 \mathrm{~cm}$.; $3 \mathrm{rd} \cdot 7 \mathrm{~cm}$.

Leaves cauline, alternate, stipulate, petiolate; stipules small, subulate, deciduous.

No. 1. Palmately five-nerved, obscurely lobed or merely five- 
angled and crenate, deeply cordate at the base with slightly overlapping auricles, light green above and sparsely pubescent, paler below and pubescent on the nerves; petiole semiterete, channelled above, tapering upwards, pubescent.

No. 2. Larger, palmately five-lobed and -nerved ; lobes triangularovate, basal ones shallow, all obtuse and tipped with a mucro; otherwise like No. 1.

No. 3. More decidedly palmate, with deeper and narrower lobes than No. 2.

No. 4. Similar to the last but smaller.

Buds are present in the axils of the cotyledons as well as in those of the true leaves.

\section{Hibiscus brasiliensis, $L$.}

The seedling closely resembles that of $\mathrm{H}$. Abelmoschus.

\section{Hibiscus Trionum, $L$.}

Hypocotyl glandular-pubescent, pale green, $2 \cdot 2 \mathrm{~cm}$. above ground, $2.25 \mathrm{~mm}$. thick.

Cotyledons rotund, ovate, obtuse, trinerved, glabrous, $1.25 \mathrm{~cm}$. long, $1 \cdot 1 \mathrm{~cm}$. broad; petiole subterete, glandular-pubescent, very pale green, $1 \cdot 1 \mathrm{~cm}$. long.

Stem herbaceous, annual, erect, terete, glandular-pubescent and hairy, pale green; 1st internode 1.25 cm. long; 2nd 1.85 cm. ; 3rd $3.4 \mathrm{~cm}$. ; 4 th $3.65 \mathrm{~cm}$.

Leaves sparsely pubescent on the nerves and margin, but almost glabrous; petioles subterete, slightly grooved on the upper side, glandular-pubescent, pale green; stipules linear-subulate, hairy, caducous.

No. 1. Rotund, crenate, cordate at the base, five-nerved, with ascending and incurved nerves.

Nos. 2 and 3. Similar, but larger.

No. 4. Cordate, obtuse, crenate.

No. 5. Cordate, obtuse, crenate, and slightly lobed on one side, foreshadowing a divided condition of the leaf.

No. 6. Palmately five-nerved and -lobed, cordate at the base; basal lobes small ; middle lobes subdentate-serrate, oblong; terminal lobe oblong, broader above the middle, irregularly dentate-serrate from the middle upwards.

Ultimate leaves tripartite; lateral lobes cuneate-ovate, obtuse, pinnatifid and toothed upwards or almost lobed on the posterior, basal side ; terminal lobe ovate-oblong, cuneate at the base, pinnatifid, with oblong somewhat toothed secondary lobes. 


\section{Hibiscus phœnicens, Willd.}

Hypocotyl pubescent, 11-15 $\mathrm{mm}$. above the soil.

Cotyledons slightly unequal, reniform, emarginate, trinerved from the base with a few alternate nerves upwards, pubescent all over, dull green above, paler beneath; lamina of larger one $10 \mathrm{~mm}$. long, $13.75 \mathrm{~mm}$. wide; petiole of larger one semiterete, shallowly channelled above, slender, pubescent, $5.5 \mathrm{~mm}$. long; lamina of smaller one $9.5 \mathrm{~mm}$. long, $13.25 \mathrm{~mm}$. wide; petiole of smaller one $6.5 \mathrm{~mm}$. long.

Stem erect, terete, closely pubescent, pale green, soon becoming grey, striated longitudinally and woody; 1st internode $5 \cdot 5-7 \mathrm{~mm}$. long; 2nd 6-8 mm.; 3rd and 4th 10-12 mm.

Leaves undivided or slightly toothed, or more or less deeply three- to five-lobed, and -nerred, somewhat reticulate, pubescent on both surfaces, deep, dull green above, paler beneath, with the midrib and principal nerves more or less stained red on both surfaces, at least at certain stages; petioles subterete, shallowly and narrowly channelled above, tapering slightly upwards, horizontal or ascending, slightly thickened at the base of the lamina, pubescent; stipules linear, hairy, membranous, pale green or slightly stained with red, soon falling away.

\section{Seedlings dimorphic.}

(1) More advanced type.

No. 1 leaf. Oblong obtuse, generally with a tooth on each side a little below the apex, rounded at the base.

No. 2. Shortly trifid, with the terminal lobe longest.

No. 3. Deeply trilobed; lateral lobes oblong, obtuse; middle lobe lanceolate-oblong, obtuse.

No. 4. Similar, but segments oblong-linear.

Nos. 5-7. Tripartite, gradually larger, with linear, obtuse segments; middle one longest.

No. 8. Similar to seventh, but there is a small lateral lobe on one side near the base making the leaf four-lobed.

No. 9. Five-nerved and -lobed, with the middle lobe longest, and the basal ones very small.

Nos. 10 and 11. Trilobed.

Nos. 12 and 13. Four-lobed.

No. 14. Five-lobed.

No. 15. Four-lobed.

Nos. 16 and 17. Five-lobed and similar to the ninth.

(2) The second form retains the simpler form of leaf for a much longer period. 
Nos. 1-4. Oblong, obtuse, rounded at the base, tridentate at the apex.

Nos. 5 and 6 . Similar, but somewhat larger and broader above the base, inclined to be oval.

Nos. 7 and 8. Similar, but with one to two teeth on each side near the apex.

\section{Hibiscus tortuosus, Roxb.}

Hypocotyl woody, erect, terete, pubescent, pale green, $1 \cdot 8-2 \cdot 4 \mathrm{~cm}$. above the soil.

Cotyledons broadly oblong or subcordate, emarginate, deep green, glabrous; lamina $1 \mathrm{~cm}$. long, $8.5 \mathrm{~mm}$. broad; petiole variable in length both in young and adult conditions, pubescent.

Stem woody, erect or subflexuose, terete, pubescent, pale green ; 1st internode $2 \mathrm{~mm}$. long; 2nd 1.65 cm.; 3rd 1.4 cm.; 4th $6 \mathrm{~mm}$.

Leaves deep green, glabrous on the upper side, sparsely pubescent on the nerves beneath; petioles terete, faintly grooved on the upper side, pale green, hairy ; stipules slender, subulate or linear, obtuse, pubescent.

No. 1. Oblong, subcordate at the base, four-nerved, obsoletely crenate, unequally and obtusely tridentate at the apex.

No. 2. Cordate, obtuse, crenate, four-nerved; nerves ascending and incurved.

No. 3. Similar, but much larger.

Ultimate leaves cordate, acuminate, obtuse, five- to seven-nerved, with a small or obscure lobe on each side above the middle, irregularly crenate-dentate.

\section{Lagunaria Patersonii, Ait. (fig. 214).}

Hypocotyl erect, terete, pale green, glabrous, $3-4 \cdot 5$ or $5 \mathrm{~cm}$. above the soil.

Cotyledons ovate, obtuse, very nearly or quite equal, obsoletely trilobulate near the apex, subcordate at the base, otherwise entire or minutely emarginate, five-nerved at the base; nerves alternate, ascending, obscurely reticulate, coriaceous, deep green above, paler beneath, glabrous, petiolate; lamina 12.5-18.5 mm. long, 10-16 $\mathrm{mm}$. wide; petioles subterete, shallowly channelled above, slightly pubescent in the furrow, 1-5 $\mathrm{mm}$. long.

In some seedlings the cotyledons are unequal when young, but this inequality seems to disappear when they are fully grown.

Stem erect, terete, densely covered with scurfy, peltate scales, more or less jagged or stellate at the margin, ultimately woody, and 
arborescent; 1st internode 5-10 mm. long; 2nd 17-20 mm.; 3rd 5-8 $\mathrm{mm}$.

Leaves simple, entire, cauline, alternate, exstipulate, petiolate, three- to five-nerved upwards, with incurved nerves, slightly branching and anastomosing within the margin, where the leading ones unite with one another; coriaceous when fully developed, and opaque, with a difficultly discernible venation, deep green above, and closely

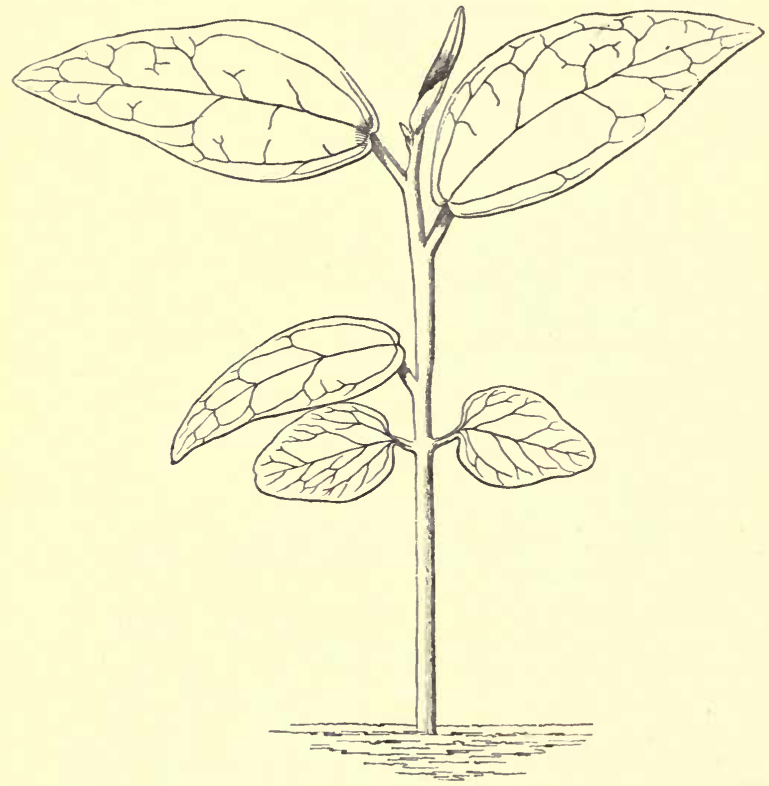

Fig. 214.-Lagunaria Patersonii. Nat. size.

dotted, but not covered, with peltate, lacerated, fringed, or stellate scaly hairs, densely felted or tomentose on both surfaces with small scaly hairs and hoary or white; petioles short, stout, subterete, shallowly grooved above, densely felted with stellate, peltate, scaly hairs, tapering slightly upwards; stipules obsolete.

No. 1. Lanceolate, obtuse, trinerved at the base.

Nos. 2 and 3. Ovate, obtuse, three- to five-nerved, slightly cordate at the base. 
Gossypium barbadense, $L$. American Upland Cotton (fig. 215).

Hypocotyl $7 \mathrm{~cm}$. long, suffrutescent, erect, terete, sparsely pubescent, punctate with black dots, pale green.

Cotyledons large, foliaceous, transversely oblong, shortlypetiolate; lamina three- to five-nerved, punctate with black dots, subemarginate or shortly and very obtusely pointed at the apex, $2 \cdot 5 \mathrm{~cm}$. long, $4.35 \mathrm{~cm}$. broad.

Stem suffrutescent, erect, terete, hairy, punctate with black dots, pale green ; 1st internode $6.8 \mathrm{~cm}$. long; 2 nd $1.8 \mathrm{~cm}$; $3 \mathrm{rd}, 4 \mathrm{th}$, and 5 th $1 \cdot 1 \mathrm{~cm}$.

Leaves simple, cauline, alternate, stipulate, petiolate, five- to

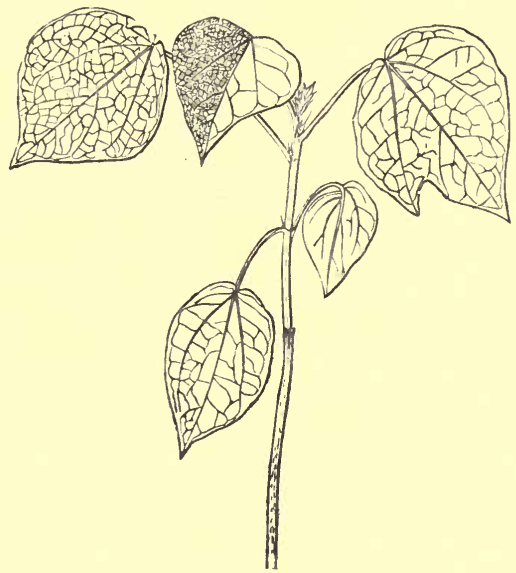

FIG. 215.-Gossypium barbadense. One-fourth nat. size.

seven-nerved and reticulate, hairy on both surfaces and minutely punctate with black dots on the under surface; petioles terete, hairy, pale green, punctate like the lamina; stipules lanceolate, acute, subcarinate, hairy, pale green, and punctate.

No. 1. Ovate, slightly acuminate, subcordate at the base, trinerved, entire.

No. 2. Cordate, entire, subacute, suddenly and shortly subacuminate, five-nerved.

Nos. 3 and 4. Palmately five-nerved, trifid, broad, cordate at the base.

No. 5. Similar, but larger and seven-nerved. 
Gossypium tomentosum, Nutt.

Hypocotyl woody, and closely punctate, with small, black, elevated glands $8.5 \mathrm{~cm}$. long, otherwise as in G. barbadense.

Cotyledons $2.4 \mathrm{~cm}$. long, $3.4 \mathrm{~cm}$. broad, transversely suboval, subcuneate at the base, rather sinuous and almost truncate at the upper edge, palmately five- to seven-nerved, pale green above, glabrous, but closely punctate like the hypocotyl; petiole subterete, slightly channelled above, dilated at the base of the lamina, similarly glandular, $1.5 \mathrm{~cm}$. long.

Stem becoming somewhat woody, erect, terete, pubescent and covered with black dots and glands like the hypocotyl ; 1st internode $1 \mathrm{~cm}$., 2nd $9 \mathrm{~mm}$. long.

Leaves.-No. 1. Rotund-cordate, cuspidate, obtuse, subpalmately five-nerved, glabrous, entire, pubescent at the margin, pale green and covered with small protuberances above, paler beneath and covered with black dots; petiole terete, pubescent, tapering upwards, covered with small black glands like the stem; stipules subulate, acute, pubescent, deciduous.

No. 2. Similar to the last.

\section{Adansonia Gregorii, F. Muell.}

Hypocotyl short, stout, soon becoming woody.

Cotyledons rather persistent, large, foliaceous, broadly oblong, obtuse, entire, strongly seven-nerved from the base and reticulate, concave from the greater growth of the middle portion, petiolate, glabrous, or sparingly ciliated on the petiole; lamina $3.5-3.8 \mathrm{~cm}$. long, $2-2.5 \mathrm{~cm}$. wide; petiole very stout, slightly channelled above, 8-9 $\mathrm{mm}$. long.

Stem erect, terete, soon becoming woody, green, glabrous; 1 st internode $3.5 \mathrm{~mm}$. long; 2nd $4 \mathrm{~mm}$.; 3rd 1.8-2 $\mathrm{cm}$.; 4th 2.2$2.4 \mathrm{~cm}$. ; 5th longer.

Leaves compound, digitate (1st to 3rd simple), cauline, alternate, stipulate, petiolate, glabrous ; stipules subulate, acute, soon becoming brown, deciduous; petioles subterete, slightly flattened above, especially at the base; venation of the leaves ascending, incurved, anastomosing.

No. 1. Oblong, lanceolate, acute, very small and soon withering away, entire.

No. 2. Larger, oblanceolate.

No. 3. Large, palmately tripartite, with a strong rib running into each segment; segments oblong-lanceolate, acute, serrate above the middle. 
Nos. 4-7. Digitately trifoliolate; lateral leaflets oblong-lanceolate, acuminate, somewhat oblique on the anterior side, tending to be

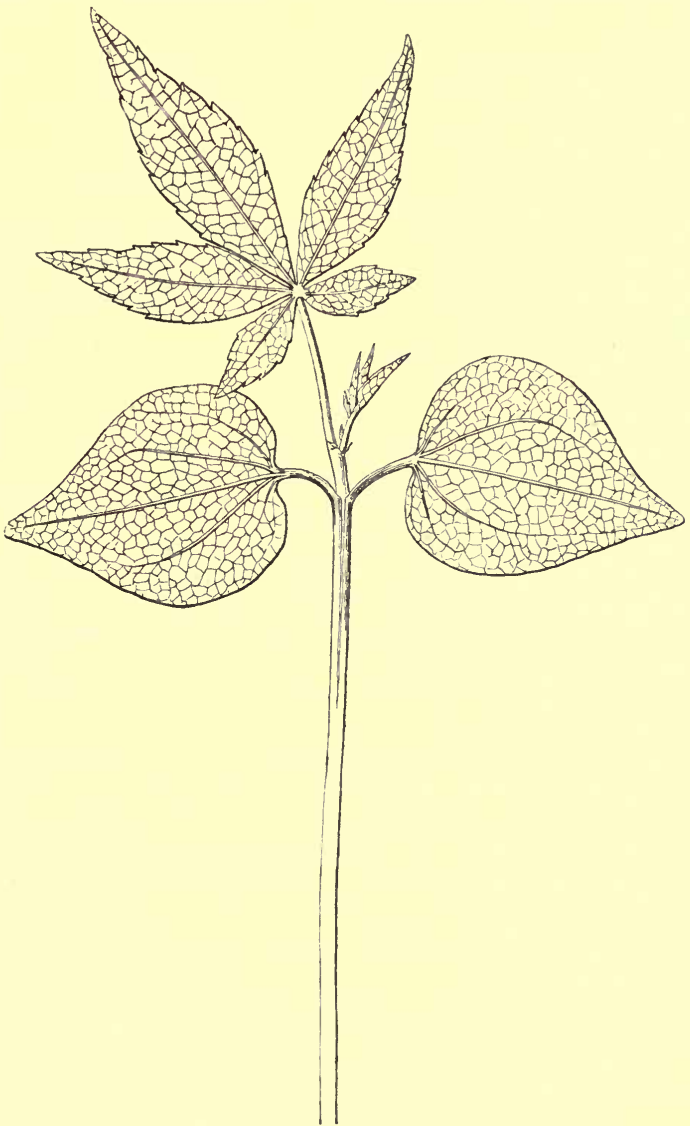

Fia. 216.-Eriodendron anfractuosum. Nat. size.

dimidiate, serrate upwards; terminal leaflet oblanceolate, acuminate, serrate above the middle. 


\section{Adansonia digitata, $L$.} long.

Hypocotyl stout, short, erect, terete, glabrous, green, 6-8 $\mathrm{mm}$.

Cotyledons very large, $4 \mathrm{~cm}$. long by $3.5 \mathrm{~cm}$. broad, broadly or roundly oblong, obtuse, entire, slightly cordate at the base, petiolate, glabrous, green, trinerved with numerous lateral veinlets, petioles thick, scarcely furrowed on the upper side, short.

Stem square, herbaceous, ultimately woody; 1st internode $2.5 \mathrm{~cm}$. long; 2nd 8-10 mm.; 3rd shorter.

First leaves simple, entire; first two lanceolate, acute; others spathulate or cuneate, glabrous, light green, pinnatinerved; petioles short, with the midrib projecting on the upper face; stipules small, acute, brown, deciduous.

The sixth leaf becomes digitate.

\section{Eriodendron anfractuosum, $D C$. (fig. 216).}

Hypocotyl ereot, 5-8 cm. long, about $2 \mathrm{~mm}$. thick, firm, terete near the base, obtusely four-angled from the middle upwards, glabrous, the lower half brownish-green, lighter above.

Cotyledons long-petioled, about $5 \mathrm{~cm}$. long and nearly $3 \mathrm{~cm}$. broad, subcordate, obtusely acuminate, entire, convex, quite gla brous on both sides, palmately seven-nerved and reticulated in a peculiar, honeycomb-like manner, leathery, dark shining green above, greyish-white below.

Stem terete, firm, about $2 \mathrm{~mm}$. thick, very short, glabrous, yellowish-green.

Leaves.-No. 1. Stipulate, digitate with five divisions; petiole about $3 \mathrm{~cm}$. long by $1 \mathrm{~mm}$. thick, glabrous; divisions unequal, from 1.5-5 cm. long, lanceolate, acuminate, remotely serrate ; teeth adpressed; penninerved and reticulately veined, with prominent midrib, glabrous on both sides, somewhat leathery, dark green above, light green below.

Nos. 2 and 3. Similar to No. 1. 


\section{STERCULIACE E.}

Benth. et Hook. Gen. Pl. i. 214.

Fruit and Seed.-The ovary is free and syncarpous, but the carpels are frequently only partly united at the base, or so united as to form a two- to five- rarely ten- to twelve-celled ovary. The ovary is however reduced to a single carpel in Waltheria. The ovules vary in number from two to many, rarely solitary, and are (Heritiera) fixed to the inner angles of the loculi, ascending or horizontal, anatropous or amphitropous, with the raphe ventral or lateral, and the micropyle inferior. Exceptions occur in Sterculia fœetida, S. Balanghas, and a few other species, where the ovules are orthotropous with the micropyle superior. The ovule of Heritiera macrophylla is amphitropous, and the radicle superior. The fruit is dry, dehiscing loculicidally, rarely baccate, or woody and indehiscent, or when mature it often breaks up into cocci, indehiscent or with valvular or follicular dehiscence. In Helicteres the carpels are curiously twisted. The seeds are naked or woolly, or embedded in pulp in the baccate fruits; they are often furnished with an arilloid, and sometimes laterally compressed and drawn out into a membranous wing. The testa is coriaceous, crustaceous, or has a fleshy or succulent external covering as in Sterculia; and the endosperm is fleshy and copious, or reduced to a thin stratum, or entirely wanting.

The embryo is large and straight, or bent according to the form of the seed; the cotyledons are generally foliaceous, flat, plicate-corrugate or spirally convolute, more rarely thick and fleshy; the radicle is short, inferior, and pointing to the hilum, except in some species of Sterculia, which have orthotropous ovules and seeds, in Heritiera littoralis, with amphitropous seeds and possibly some others where the radicle is at the apical end of the seed.

Two well-marked types of seeds occur in the tribe Sterculieæ. In Sterculia itself the ovary consists of five nearly distinct twoto many-ovuled carpels, which separate when mature into one- 
seeded, indehiscent nutlets, as in S. ramiflorum and S. fœtida (fig. 217), or in many-seeded fruits the five carpels form as many rays dehiscing by two valves, or in a follicular manner along the ventral suture only. The fruit of S. ramiflorum consists of five achenes or nuts, densely covered with stalked and stellately-branching hairs. The seed is oblong, and conforms closely to the interior of the nutlet, which it entirely fills. The testa is membranous and creamy yellow; while the micropyle is superior and apical. The endosperm in the mature seed is copious, fleshy, white, and almost separated into two equal halves by the cotyledons; but the halves are connected by a collar encircling the short radicle. The embryo is large, straight or nearly so, axile, and of a dirty yellowishwhite. The cotyledons are oblong, obtuse, rounded at the apex, slightly auricled at the base, otherwise entire, equal in length and breadth to the endosperm, except the small portion occupied by the radicle, with their dorsal faces closely applied to the endosperm, and traversed longitudinally by three indistinct nerves and two other short lateral ones near the base. The radicle is very short, stout, embedded between the auricles of the cotyledons, projecting through the endosperm with its tip, and together with the plumule forming a globular mass. From this type S. fœetida (fig. 217) differs only in detail. The nut is bluish-black and glabrous. The cotyledons are oblong or obovate, slightly emarginate owing to a thickening of the chalaza, and surround the plumule and radicle by their bases, leaving only a small opening for the short radicle to protrude; five slightly branching nerves pass upwards from their junction with the hypocotyl. The genus Tarrietia agrees with Sterculia in having the endosperm divided by the cotyledons.

The fruit of Heritiera littoralis consists of one to five obovoid, unequal-sided, shortly stipitate, brown, woody, oneseeded indehiscent carpels or nuts, composed of a dense mass of interlacing fibres, packed with brown cortical matter and laterally compressed, diverging outwards and more nearly in line with the dorsal than the ventral suture. Each nut is about the size of a pigeon's egg. The seed is ovoid, conforming to the interior of the carpel; the testa is brown, thick, 
and brittle, resembling bark; the raphe ventral, composed of tough fibres, separable from the seed, and extending from near the apex to the base of the cavity of the nut; micropyle superior; endosperm absent. Embryo straight, very large and fleshy, filling the seed, pale pink or flesh-coloured. Cotyledons thick, plano-convex, sometimes slightly wrinkled, frequently if not always unequal, broadly oblong-oval in outline, auricled at the base and embracing the radicle. The largest one is sometimes placed with its back to the ventral, sometimes to the dorsal suture, or irregularly. The embryo is frequently abnormal, assuming various shapes, while the cotyledons are of different lengths, variously twisted and deformed, or they may even be deeply lobed, divided or multiplied, and irregular in size and number. The radicle when normal is short, stout, and grasped by the auricles of the cotyledons, beyond which it does not protrude. The plumule is small and densely covered with short, brown hairs.

The species of Cola and Herrania agree with Heritiera in having exalbuminous seeds and thick cotyledons, but the radicle is close to the hilum. Myrodia has exalbuminous seeds and unequal, conferruminate or amalgamated cotyledons, the larger including or partly enclosing the smaller one.

A third type is presented by Reevesia, in which the seeds have a fleshy endosperm, a straight embryo, and flat foliaceous cotyledons. The seeds are also laterally fixed and produced into a wing on the back. Physodium and Abroma have also a straight embryo, broad, flat, cordate cotyledons, and albuminous seeds; flat, foliaceous cotyledons, and a straight embryo, also occur in Melochia, Dicarpidium, Waltheria, Rulingia, Com mersonia, Seringia, Thomasia, Guichenotia, and Lasiopetalım, but the embryo varies considerably in shape both before and after germination.

A fourth type, having exalbuminous seeds and spirally convolute cotyledons, is presented by Kleinhovia and Buettneria, the cotyledons being folded round the radicle, at any rate in the latter. Slightly different from this are those seeds having a thin layer of endosperm, which is even altogether absent in all the species of Helicteres, Eriolæna, and Ayenia. The cotyledons also vary in being convolute or contorted and plicate. 
They are corrugate or plicate in Pterospermum, and the seeds are produced into a wing on the top. The seeds are exalbuminous in Theobroma, and the cotyledons are lobed and corrugate. Here also may be placed Guazuma, with albuminous seeds, and a slightly curved embryo with foliaceous, inflexedplicate cotyledons.

A fifth very distinct type is represented by Hermannia and Mahernia, which have reniform albuminous seeds, with a curved embryo, oblong cotyledons, and the radicle close to the hilum. Taking Pentapetes phœnicea as a type, we find that all of the tribe Dombeyeæ agree with it in having albuminous seeds, foliaceous, bipartite cotyledons, and the radicle close to the hilum. The cotyledons are folded and contorted in Cheirolæna, Trochetia, Pentapetes, and Melhania; they are rarely flat. It seems probable that the species of Ruizia have also bipartite cotyledons. The fruit of Pentapetes phœnicea is a crustaceous capsule, shortly globose-oblong, five-celled, many-seeded, with the anatropous seeds arranged horizontally in two dense rows; dehiscing loculicidally with the valves separating from the plumose midrib. The seed is obovoid, bluntly trigonous or variously angled, and minutely reticulated, with the raphe on the upper side, $2.5 \mathrm{~mm}$. long, $2 \mathrm{~mm}$. wide, and as thick. The endosperm is copious, forming a white layer round the inner face of the seed, while all the rest lying in the middle of the seed and between the folds of the embryo is transparent and mucilaginous, swelling up in water when it becomes white.

The embryo is large, folded, or doubled upon itself a short way above the insertion of the cotyledons. The cotyledons grow till they reach the apex of the seed, then they first become concave on the side towards the raphe (upper side of the horizontal seed), then strongly folded in the same direction. Growth at the apex is then arrested for want of space, but the embryo still grows, and attains a comparatively large size by lateral extension of the cotyledons, each forming two long lobes, which extend round the sides of the seed sometimes in one direction sometimes in the other, so that when mature the cotyledons are deeply bipartite with oblong, obtuse lobes. They are seven-nerved, the midrib being very 
short, and ending in the sinus, which is the real apex of the cotyledons. A slender nerve is given off from each side of the apex of the midrib and runs up close to the contiguous edges of the sinus; two short lateral ones are also given off from the base; and between the two pairs a strong nerve runs to the apex of each lobe, giving off a few short branches on each side.

A curious case occurs in Hannafordia, containing a single species only. The arilloid of the seed is cut up into numerous segments.

Cotyledons.-The seedlings present four well-marked types - the first, that of Sterculia heterophylla (fig. 218), having large, leathery, foliaceous cotyledons, which are broadly oblong, obtuse at either end, petiolate, five-nerved with a well-marked, reticulate venation, glabrous except the base and petioles, which are shortly pubescent with glandular hairs. The hypocotyl is also shortly pubescent and of moderate length. A considerable number of the Sterculiacex conform to this type. Even Hermannia agrees in all the main characteristics except in being much smaller, and in the discernible venation being reduced to an indistinct midrib.

The cotyledons of Heritiera, being large, thick, fleshy, and occupying the whole of the exalbuminous seed, are, most probably, subterranean during and after germination. The conferruminate cotyledons of Myrodia, and the fleshy ones of Cola and Herrania, doubtless correspond with those of Heritiera. A third and well-marked type occurs in the tribe Dombeyeæ, with deeply bifid cotyledons, well represented by Pentapetes phœnicea (fig. 219). The seed-leaves of the latter after germination are deeply bifid with ovate-oblong, obtuse, diverging lobes, five-nerved at the base with two lateral ones given off from the midrib near the sinus, thinly glandularpubeseent at the margin, as well as on the rather slender petioles. The cause to which the fission is due has been described under 'Seeds.' A fourth type occurs in Lasiopetalum dasyophyllum and L. ferrugineum (fig. 220). Here the cotyledons are linear, entire, acute, sessile, slightly narrowed to both ends, minutely scaberulous with small ele vations, slightly connate at the base, or forming a shallow ridge around the 
plumule, showing a distinct midrib, but no other venation. From the structure and form of the seed and embryo of the other members of the Lasiopetaleæ they would evidently closely resemble the species of Lasiopetalum in germination.

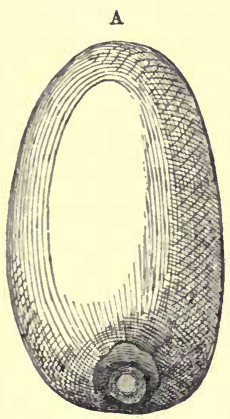

C

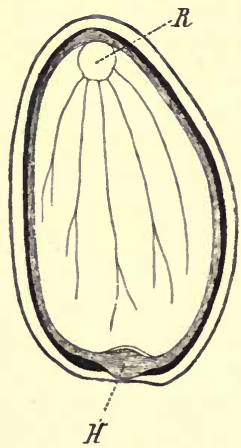

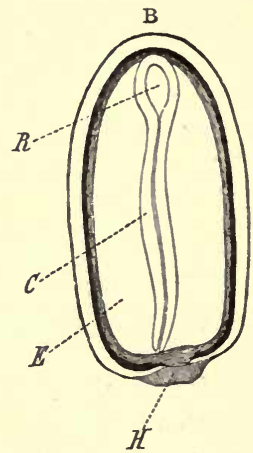

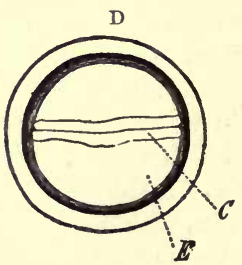

Fio. 217.-Sterculia fatida, $\times 2$. A, ripe carpel or nutlet, one of five forming the fruit. B, longitudinal section of same through the cotyledons. C, longitudinal section in the plane of the cotyledons. $D$, transverse section: $E$, endosperm; $C$, cotyledon; $R$, radicle ; $H$, hilum.

Sterculia fœtida, $L$. (fig. 217).

Fruit of five separate carpels, each oblong, broad and obtuse at both ends, seated on the thickened receptacle, smooth, bluish-black, 
one-seeded, indehiscent ; epicarp thin, membranous, dark-coloured ; mesocarp much thicker, corky, brown; endocarp black, hard and crustaceous.

Seed large, oblong, conforming in outline to that of the carpel, basal, erect; testa brown; raphe immersed; chalaza thickened, causing an emargination of the cotyledons; hilum basal in the centre of the cavity of the carpel and attached immediately to the chalaza.

Endosperm copious, fleshy, whitish, divided into two equal pieces by the cotyledons, to which they adhere, resembling two thick cotyledons.

Embryo large, straight, central, equal to the length and breadth of the cavity of the seed; cotyledons oblong or obovate, obtuse, emarginate by the thickening of the chalaza, surrounding the radicle and plumule at the base, and leaving only a small orifice for the radicle to protrude, five-nerved from near the base, with ascending slightly branching nerves; radicle very short, included, stout, close to the upper end of the seed; plumule short, stout.

Sterculia heterophylla, Beauv. (fig. 218).

Hypocotyl erect, terete, pubescent with glandular hairs, pale green, soon becoming reddish.

Cotyledons broadly oblong, obtuse and rounded at the end, often truncate or even slightly emarginate, suddenly tapered or almost truncate at the base, petiolate, five-nerved from the base of the lamina, with the nerves incurved at the apex forming a series of intramarginal reticulations, glabrous except at the base, subcoriaceous, deep green above, paler beneath ; lamina $2 \cdot 3-2 \cdot 6 \mathrm{~cm}$. long, 1·5-1.7 $\mathrm{cm}$. wide; petiole channelled above, convex beneath, pale green, pubescent with glandular hairs, 10-12 $\mathrm{mm}$. long.

Stem erect, terete, pale green or brownish, pubescent with glandular hairs, ultimately woody; 1 st internode $3-4 \mathrm{~cm}$.; 2 nd $1 \cdot 3 \mathrm{~cm}$. long.

Leaves cauline, alternate, stipulate, petiolate, alternately, irregularly penninerved, much reticulated, with pale veins and a pale subcartilaginous margin, coriaceous, shining, deep green above, paler beneath; petioles semiterete, channelled above, convex beneath, slightly tapered upwards from a rather stout base, pubescent with glandular hairs ; stipules small, subulate, glandular-hairy, pale-coloured, soon becoming dried up and falling away.

No. 1. Lanceolate, acute, entire, small.

Nos. 2-4. Ovate, elliptic, acute or acuminate, entire, gradually becoming larger. 
Cola sp.

Primary root long, tapering, stout, giving off few or no lateral rootlets in the young state.

Hypocotyl very short and indistinguishable from the root, or undeveloped.

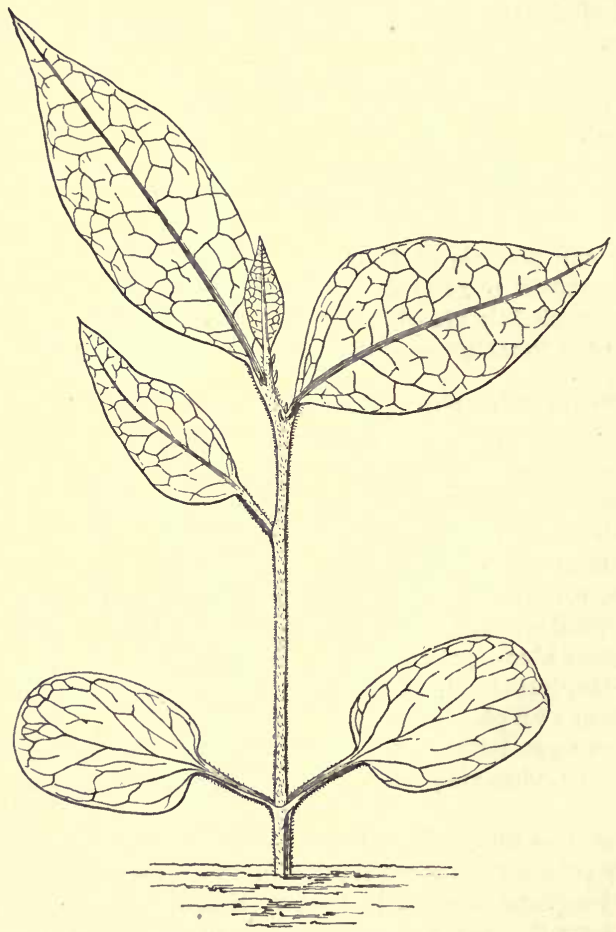

Fig. 218.-Sterculia heterophylla. Nat. size.

Cotyledons four, each forming the quadrant of an oblongspherical mass, fleshy, very large, occupying the seed and subterranean during germination, white if left uncovered, or pink, reddish, or deep green according to exposure to light, petiolate. Each of the four cotyledons has a roughly trigonal outline owing 
to mutual pressure, and each is emarginate or auricled at the base with the auricles more or less closely applied to one another while in the seed and hardly separating during germination. Petioles terete, rather slender (compared with the lamina), 12$14 \mathrm{~mm}$. long and attached to the inner face of the laminæ about 5 $7 \mathrm{~mm}$. above their base, that is at the upper end of the fissure between the auricles.

Stem erect, stout, woody, more or less scaly, at least in the young state.

Leaves alternate, stipulate, cauline, penninerved, scaly, petiolate.

Nos. 1 and 2. Opposite or subopposite, scaly, brown.

Nos. 3 to 6. Alternate and similar.

No. 7. Ovate, foliaceous, penninerved.

\section{Heritiera littoralis, Ait.}

Fruit of one to three, rarely four to five, obovoid, unequal-sided, shortly stipitate, brown, rough, woody, one-seeded carpels, composed of a dense mass of interlacing fibres packed with brown corky loose matter, and ending in a stout curved beak, which is laterally compressed, diverging outwards and much more nearly in line with the dorsal than the ventral suture. Hence the ventral side of the fruit appears almost ventricose.

Seed roughly obovoid and conforming to the interior of the carpel ; testa brown, thick, brittle, resembling bark; raphe ventral, composed of tough fibres separable from the seed, extending from near the apex to the base of the cavity of the carpel; micropyle superior ; hilum large, oblong, ventral, below the apex and extending downwards.

\section{Endosperm absent.}

Embryo straight, when mature very large, fleshy, filling the whole interior of the seed, pale pink or flesh-coloured; cotyledons very thick, plano-convex, slightly wrinkled or uneven, sometimes furrowed along the back of the midrib, frequently if not always unequal, oval or oblong-oval in outline, but often assuming various shapes, auricled at the base and embracing the radicle. The largest cotyledon is sometimes placed with its back to the ventral suture, sometimes to the dorsal suture or irregularly. In some instances the cotyledons are of different lengths or variously twisted and deformed or even multiplied, and irregular in size and number.

The radicle when normal is stout, very short, grasped by the auricles of the cotyledons, beyond which it does not protrude; it is superior.

Plumule small, densely covered with short brown hairs. 


\section{Pentapetes phœenicea, $L$.}

Fruit a capsule, shortly globose-oblong, five-celled, many-seeded, with the seeds arranged horizontally in two rows, dehiscing loculicidally from base to apex, separating from a plumose nerve (the midrib of the carpel); epicarp crustaceous, brown; endocarp thinner, membranous, pale.

Seed obovoid, subtrigonous or variously angled, minutely reticulated; seed-coat double; outer (testa) crustaceous, brown ; inner (tegmen) thin, pale; micropyle and hilum basal; chalaza apical; raphe on the superior side of the horizontal seed, facing the apex of the ovary. Seed $2.5 \mathrm{~mm}$. long, $2 \mathrm{~mm}$. broad, and $2 \mathrm{~mm}$. thick.

Endosperm copious, forming a white layer round the inner face of the seed, while all the rest lying in the middle of the seed and between the folds of the embryo is transparent and mucilaginous, swelling up in water, when it becomes white.

Embryo large, folded or doubled upon itself, definitely in the lower half, but somewhat indefinitely above; cotyledons deeply bifid, growing till they reach the apex of the seed, when they become first concave on the side towards the raphe (upper side), and then strongly folded in that direction. Growth at the apex is here stopped for want of space, but the embryo continues to develop and is able to attain a much larger size by lateral extension of the cotyledons round the sides of the seed, sometimes in one direction, sometimes in another, producing the oblong lobes above mentioned. The venation consists of five nerves, the middle one of which is very short and ends at the apex, giving off a slender nerve up each side of the apical sinus; the two nerves, one on each side of the midrib, are the strongest and run to the apex of the lobes; the lateral nerves are very short and not very conspicuous. Radicle straight, oblong, obtuse, occupying the greater part of the length of the seed.

\section{Seedling (fig. 219).}

Hypocotyl erect, terete, thinly glandular-pubescent, pale green, $2 \cdot 5-4.5 \mathrm{~cm}$. long.

Cotyledons petiolate; lamina deeply bifid with ovate, obtuse, diverging lobes, each binerved, while the midrib forks in the sinus, thinly glandular-pubescent at the margin, pale green; petiole semiterete, shallowly grooved above, thinly glandular-pubescent, 4$7 \mathrm{~mm}$. long ; lamina 8-12 mm. long, 8-10 mm. broad.

Stem herbaceous, erect, thinly glandular-pubescent, pale green; 1st internode $6 \mathrm{~mm}$. long; 2nd 1.75 mm.; 3rd $1 \mathrm{~mm}$. 
Leaves simple, cauline, alternate, stipulate (1st leaf exstipulate !), petiolate, glabrous or nearly so ; petioles semiterete, slightly grooved above, thinly hairy; stipules small, subulate, obtuse, glandularpubescent.

No. 1. Obovate-cuneate, obtusely serrate with aristate teeth, five-nerved at the base.

Nos. 2 and 3. Rhomboid-ovate, serrate, with aristate teeth; five-nerved at the base and alternately nerved upwards.

Hermannia cuneifolia, Jacq.

Hypocotyl erect, terete, minutely pubescent, 7-12 mm. long, light green or colourless.

Cotyledons oblong, obtuse, entire, petiolate, glabrous, dark green, fleshy, indistinctly one-nerved.

Stem erect, terete, herbaceous, pubescent; 1 st internode $1.5-2 \mathrm{~mm}$. long.

First leaves simple, cauline, alter-

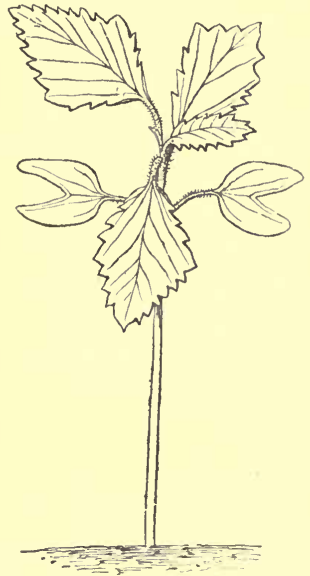

FIg. 219.- Pentapetes phœnicea. Nat. size. nate, obovate, obtuse, crenate near the apex, petiolate, stipulate; stipules deciduous, pubescent, light green, pinnatinerved.

Lasiopetalum dasyophyllum, Sieb.

Hypocotyl erect, terete, soon becoming brown, $1 \cdot 1-2 \cdot 2 \mathrm{~cm}$. long.

Cotyledons linear, entire, acute, sessile, slightly narrowed at both ends, showing a distinct midrib but no other venation, glabrous, minutely scaberulous, bright green above, paler beneath, slightly c onnate at the base around the plumule, $15-30 \mathrm{~mm}$. long.

Stem erect, somewhat obtusely angled, minutely glandularpubescent, scaberulous, pale green, becoming brown; 1st internode about $2.5 \mathrm{~mm}$. long; 2nd $1.25-1.5 \mathrm{~mm}$.; 3rd $5 \mathrm{~mm}$.; 4 th $9.5 \mathrm{~mm}$.; 5 th and 6 th about $1 \cdot 4-1 \cdot 6 \mathrm{~cm}$.

Leaves simple, cauline, alternate, exstipulate, petiolate, alternately incurvinerved, glabrous, scaberulous on the upper surface with small, glandular elevations, shiny when young, bright green above, paler and shiny beneath; stipules apparently obsolete; petioles extremely short or almost none, while the leaf is so much narrowed towards the base as to resemble a petiole. 
Nos. 1-3. Cuneate-obovate, obtuse, serrate or dentate along the apex, gradually tapering or cuneate at the base, where it is more or less glandular-dentate, with small or minute teeth.

No. 4. Narrowly obovate-cuneate, much narrowed at the base, irregularly dentate near the apex, minutely so below.

Nos. 5 and 6. Oblong or lanceolate, obtuse, with a few large teeth, or minutely dentate only.

No. 7. Linear-lanceolate, obtuse, tapering to both ends, but especially to the base, slightly revolute at the margin as is the one below it, but more especially the younger ones above, which gradually become narrower and more elongated.

Lasiopetalum ferrugineum, Sm. (fig. 220).

Hypocotyl erect, terete, more or less scabrous, soon becoming brown and losing its epidermis by splitting in longitudinal fissures.

Cotyledons tapering to a narrow base and forming a very

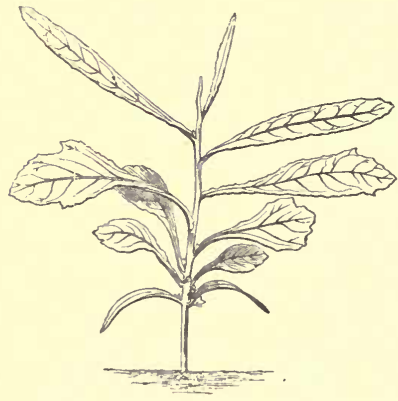

Fia. 220.-Lasiopetalum ferrugineum. Half nat. size. slender line around the first and somewhat thickened node, not very distinctly petiolate, slightly channelled above, 1.7-2.4 cm. long, 1.5$2.5 \mathrm{~mm}$. wide, otherwise as in L. dasyophyllum.

Stem as in L. dasyophyllum; 1 st internode $2-8 \mathrm{~mm}$. long ; 2nd 1-6.5 mm.; 3rd 1-12.5 mm.

Leaves as in L. dasyophyllum; petioles very short, channelled above, gradually becoming shorter, as the leaves develop, from the first one upwards.

Nos. 1-4. Obovate-cuneate, tapering to a long base, variously and obtusely dentate along the obtuse apex.

No. 5. Rhomboid or cuneate, variously and obtusely dentate for the greater part or the whole of its length, tapering much to the base.

No. 6. Spathulate, obtuse, tapering to a long base, with one to two coarse teeth at the apex and small ones throughout the greater part, or at the base only.

Nos. 7-9. Linear, obtuse or cuspidate, gradually tapered to the base and minutely toothed throughout or subcrenate. 


\section{TILIACE A.}

Benth. et Hook. Gen. Pl. i. 228.

Fruit and Seed-The ovary in the Tiliacex is superior, syncarpous, $t w o-$ to ten-celled. The ovules are solitary or geminate in each cell, inserted at the inner angle, and pendulous from the top, or ascending from the base; sometimes the orules are few, attached to the middle of the placenta and ascending or pendulous, or in other genera they are numerous and arranged in two to many ranks, anatropous or subanatropous with the raphe rentral or lateral. An abnormal form occurs in Sparmannia, where the ovary is half inferior, and almost onecelled by the abortion or suppression of the septa. The carpels are nearly free in Christiana and Bromnlowia. The fruit varies in different species from two- to ten-celled, or may be one-celled by abortion; sometimes the loculi are spuriously divided by longitudinal or transterse divisions dereloped between the seeds. When mature it is a nut as in Tilia, a drupe as in Grewia and Elæocarpus, or a berry as in Aristotelia and Muntingia. In all these cases it is indehiscent; but in Columbia it divides or splits into cocci, or it is capsular and dehisces loculicidally, more rarely septicidally as in Dubouzetia.

The seeds rary from one to many in each cell and are ascending, pendulous, or transverse. The testa is leathery, crustaceous, and smooth or densely hairy or pilose as in Berrya, Carpodiptera, and at the margin only in Belotia : in certain genera it is thickened and hardened at the chalaza as in Tilia, Berrya, and others. The endosperm is fleshy and copious or thin, very rarely entirely absent as in Brownlowia. The embryo varies, but is generally straight, with ovate or roundly-cordate foliaceous rarely fleshy and almond-like cotyledons; and a short radicle, rarely longer than the cotyledons, close to the hilum.

The seeds may be roughly divided into four groups according to the form and other characters of the embryo. The first group has fleshy or almond-like cotyledons as in Brownlowia, in which endosperm is absent. Others in this category are Sloanea and Prockia. The radi le in Prockia is 
longer than the cotyledons, and the latter are very small in Muntingia, continuous with, and scarcely broader than, the thick and fleshy radicle.

A large number of genera have a copious endosperm surrounding a slightly shorter embryo with broad, foliaceous, and ovate or rotund-cordate, straight and flat cotyledons which are foliaceous in germination. This group would include Christiana, Columbia, Erinocarpus, Triumfetta, Heliocarpus, Honckenya, Luhea, Glyphæa, Apeiba, Echinocarpus, Tricuspidaria, and others. There is, however, some variation even in the same genus, as in Elæocarpus and Aristotelia, the cotyledons of which are flat in some species and undulate in others. These latter lead to a third group in which the embryo is not entirely flat but has the cotyledons variously curved or bent. Berrya Ammonilla may be taken as a type of this group. The seed is obovoid, pale brown, much thickened and black at the chalaza, and contains a copious, colourless endosperm, which becomes white and swollen when steeped in water. The cotyledons are obovate or orbicular in different seeds and deeply cordate at the base, including the hypocotyl in the notch, five-nerved from the base, the nerves giving off smaller branches; from being longer than the endosperm they are sharply curved or bent to one side below the apex. They are, however, otherwise flat, closely adpressed face to face till they come in contact with the thickening of the chalaza, when they bend towards the dorsal aspect of the seed. The hypocotyl and radicle together are about twice the length of the blunt auricles of the cotyledons, beyond which they project. A transverse section of the seed shows that the cotyledons are sometimes at least slightly incurved so as to be concave along the median line. Several others may be placed in this group inasmuch as the embryo is more or less bent. Entelea has the cotyledons nearly flat and the radicle inflexed or but slightly bent; the embryo of Sparmannia is plicate or nearly flat and straight; in Corchorus it is incurved; and in Schoutenia the margins of the cotyledons are involute.

The above are scattered through different tribes, several of them belonging to the Tiliex, in which the extreme limit of 
comparative size and complication is met with in the genus Tilia itself, which may be taken as the type of a fourth group. The ovary is five-celled with tro ovules in each cell, but as it matures into fruit, one seed generally takes the lead, outgrowing all the others, which, together with four out of the five cells of the ovary, remain small and get crushed on one side. The fruit is an indehiscent nutlet, with one, rarely two seeds; the latter are obovoid or subglobose, deep brown, and have the testa thickened at the chalaza. The endosperm is copious, fleshy, pale yellow, or nearly white. The embryo is at first obtusely orate, with entire undivided cotyledons, which as growth goes on become deltoid and subpalmately five-lobed. When the apex comes in contact with the testa in the chalazal region of the seed, the cotyledons bend and then become folded or doubled upon themselves with the loop of the fold sharply deflected on the rentral aspect. The terminal lobe then grows in the opposite direction, and curves round the apex of the seed, with the tip so nearly exposed as to be quite visible through the endosperm. The two pairs of lateral lobes reach the sides of the seed, and become curved round it to the dorsal aspect, where their tips also become quite visible through the endosperm. The lobes are narrowly ovate, obtuse, and each has a strong median nerve running through it; the lower pair springs from the base of the lamina, while the pair above them arises from the side of the primary nerve; the basal pair and the terminal lobes are considerably larger and longer than the middle pair. The hypocotyl and radicle are cylindrical and obtuse or somewhat clavate. The above characters have been taken from $T$. vulgaris (fig. 223 , which shows the form of the embryo separated from the endosperm). T. petiolaris differs only in minute particulars; a section of the fruit shows (fig. 224) the relative position of the embryo and seed to the fruit; the embryo as a whole is less folded than in T. vulgaris. The basal and terminal lobes of the cotyledons are shorter, blunter, and more rounded, while the median pair is relatively very small. The median nerve of the latter sometimes arises from the base of the lamina, in which case the renation and divisions are truly palmate.

The folding of the various parts of the embryo is easily 
accounted for, since it grows too large to lie flat in the seed. An indication of this condition is seen in Berrya Ammonilla, where the cotyledons become slightly curved at the apex, while in Schoutenia they are involute at the margin. This is precisely what happens in Tilia, and the differences consist in the larger embryo, the greater amount of folding, and above all in the division of the cotyledons into five lobes. The only apparent reason for the lobing is to facilitate folding, not only at the apex, but all round the sides. The seed being oboroid or globose, the embryo assumes the form of a half-closed fist in order to accommodate itself to that shape.

Cotyledons.-The cotyledons may be grouped under four headings, namely, oborate, ovate, lanceolate or oblong-lanceolate, and lobed. The first type is seen in Berrya Ammonilla (fig. 221), which has rotund-obovate, obtuse cotyledons, suddenly tapered into the petiole, five-nerved, reticulate, glabrous except on the principal nerves and the petiole, which are finely pubescent. The hypocotyl is also similarly pubescent-not a common occurrence. Before germination they vary according to the shape of the seed from obovate to orbicular with a deeply cordate base, but subsequently lose the latter peculiarity, as in many or most of the Labiatæ and in Cuphea among the Lythrarieæ.

Ovate cotyledons are more common, perhaps the commonest form in the Order. Those of Corchorus olitorius (fig. 222) are ovate, obtuse, five-nerved at the base, subfleshy, glabrous except the petiole, which is occasionally thinly pubescent like the hypocotyl. Those of C. capsularis differ in being broadly or rotundly ovate and, sometimes at least, turned to one side of the stem, which would indicate a tendency to become fleshy and functionless, except as a storehouse for reserve-material. Aristotelia racemosa agrees more nearly with Corchorus olitorius except in being membranous, indistinctly nerved, and glabrous.

In some species of Elæocarpus the cotyledons after leaving the seed grow to a considerable size. Those of E. oblongus (fig. 226) are oblong-lanceolate, obtuse, very shortly petiolate, trinerved in the lower half, reticulate, subcoriaceous, glabrous, with red veins, very persistent like the true leaves, about $6 \mathrm{~cm}$. long, and $2.5 \mathrm{~cm}$. wide at the base. Those of 
E. cyaneus are also foliaceous, but much smaller, lanceolate, obtuse, opaque, coriaceous, obscurely penninerved and reticulate, $1.9 \mathrm{~cm}$. long, and about $7.25 \mathrm{~mm}$. broad; the petiole is only $1 \mathrm{~mm}$. long.

The fourth type is that of Tilia vulgaris (fig. 223) and others of the same genus. The cotyledons of the former after germination are foliaceous, rhomboid-subtriangular, five-lobed, five-nerved at the base with the two lower pairs of nerves running into the basal pair of lobes, alternately nerved upwards with two strong nerves running into the middle and small pair of lobes, thinly pubescent on both surfaces, $1 \cdot 5-2 \cdot 1 \mathrm{~cm}$. long, and $1 \cdot 7-2 \cdot 5 \mathrm{~cm}$. from tip to tip of the basal pair of lobes; the petiole is rather slender, semiterete, and pubescent. Occasionally three perfect cotyledons occur, and, corresponding exactly in shape to those of normal seedlings, indicate that the 5-lobed character is of long standing and has become thoroughly fixed by heredity; otherwise if they depended directly upon the conformation of the seed for their peculiar shape, the presence of three would have caused some modification of the normal type.

The Tiliaceæ include some 330 species, dispersed over the whole world, most numerous within the tropies of both hemispheres, less so in temperate regions both north and south of the equator.

\section{Berrya Ammonilla, Roxb.}

Fruit a capsule, subglobose, three-celled, each cell one- to twoseeded; dehiscing loculicidally by three valves.

Seed obovoid, glabrous, pale brown and often with darker brown stripes from the hilum upwards; seed-coat double-testa thin, membranous, easily separable from the tegmen which is much thicker, crustaceous, deeper brown, much thickened and hardened at the chalaza where it is nearly or quite black; micropyle and hilum contiguous, basal; raphe ventral, separable from the testa ; chalaza apical.

Endosperm copious, colourless, and shrunk away from the dorsal aspect when dry, white when moist.

Embryo central, curved or bent above the middle owing to its being slightly longer than the endosperm, pale yellow; cotyledons cordate-orbicular, five-nerved from the base, with a few short alternate nerves proceeding from the midrib, broad, flat, closely adpressed face to face, straight until they come in contact with the thickening 
at the chalaza, when they bend towards the dorsal aspect of the seed; auricles rounded, obtuse ; radicle stout, oblong, obtuse, about twice as long as the auricles of the cotyledons, with its tip embedded in the endosperm close to the micropyle.

Seedling (fig. 221).

Hypocotyl erect, terete, densely and finely pubescent, pale green, $1 \cdot 8-2 \cdot 1 \mathrm{~cm}$. above the soil.

Cotyledons rotund-obovate, obtuse, entire, suddenly tapered into the petiole at the base ; five-nerved and reticulate, glabrous except

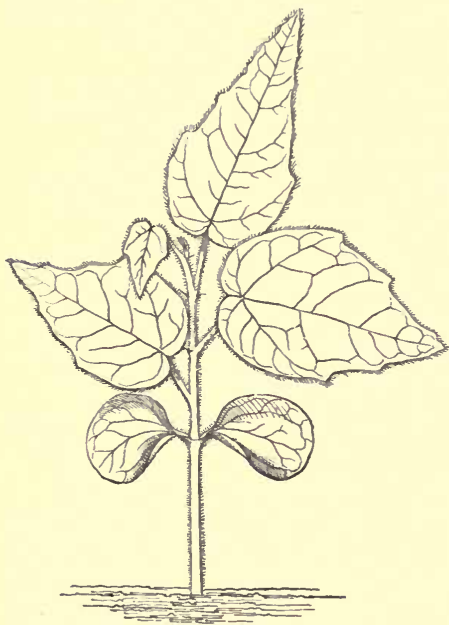

Fig. 221.-Berrya Ammonilla. Nat. size.

on the principal nerves and the petiole, which are pubescent, light green ; lamina 10-13 mm. long, 9-11 mm. broad; petiole semiterete, flattened above, densely pubescent, 2.5-3 mm. long.

Stem erect, terete, densely and finely pubescent, pale green, ultimately woody; 1st internode 4-5 $\mathrm{mm}$. long; 2nd 4-6 mm.; 3rd 5-7 mm.

Leaves simple, cauline, alternate, stipulate, petiolate, five- to seven-nerved and reticulate, light shining green, pubescent on the nerves on both surfaces; petiole terete, tapering upwards from a rather stout base, densely pubescent, pale green; stipules small, subulate, slender, green, deciduous, inserted at the very base of the petiole of the leaf or on the stem.

No. 1. Ovate, with a cordate base, five-nerved, and obsoletely toothed above the two large lateral obtuse teeth, into which the middle pair of strong nerves is directed.

No. 2. Similar, but broader.

No. 3. Acuminate, and (at least in the young stage) narrower than the first and second; venation the same.

Corchorus olitorius, $L$. (fig. 222).

Hypocotyl erect, terete, rather fleshy, thinly pubescent, about $8 \mathrm{~mm}$. long. 
Cotyledons ovate, obtuse, five-nerved at the base, rather fleshy, glabrous, petiolate; lamina $7 \mathrm{~mm}$. long, $5 \mathrm{~mm}$. broad ; petiole thinly pubescentor glabrous, flattened above, convex beneath, $3 \cdot 25 \mathrm{~mm}$. long.

Stem erect, terete, thinly pubescent, pale green; 1st internode $6.5 \mathrm{~mm}$. long, 2nd and 3rd each $1.5 \mathrm{~mm}$.

Leaves simple, cauline, alternate, stipulate, petiolate, glabrous, plicate in vernation, alternately penninerved, a deep shining green above, paler beneath; petioles semiterete, flattened on the upper side, pubescent; stipules subulate, slender, entire, free, glabrous.

No. 1. Small, ovate, serrate, subcuneate at the base.

Nos. 2-4. Ovate, acute or subacute, round and trinerved at the base, serrate.

Tilia vulgaris, Hayne (fig. 223).

Fruit an ovoid or subglobose nut, fifteen-angled, tomentose, with somewhat rufous hairs, one-celled by the rupture of the septa, oneseeded, tipped with the persistent base of the style, attached to a large deciduous bract which ensures dispersion by aid of the wind.

Seed ascending or erect, obovoid or subglobose, deep brown, smooth with a firm or crustaceous coat of two distinct layers; hilum, raphe, \&c. as in T. petiolaris.

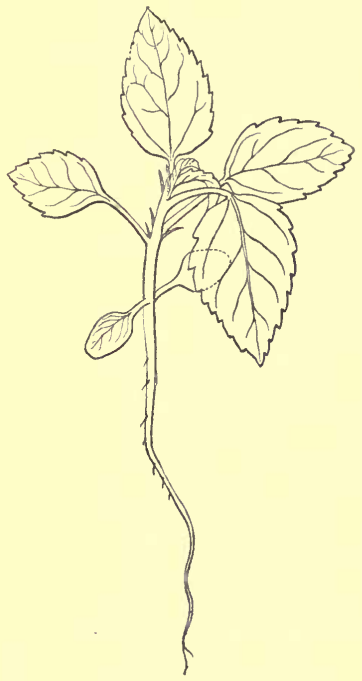

FIa. 222.-Corchorus olitorius. Nat. size.

Endosperm copious, firm, fleshy, pale yellow or nearly white, surrounding the embryo, which pierces it in several places, and is almost naked at those points.

Embryo primarily straight, ultimately large, bent, divided, with its parts curved or arched: cotyledons applied face to face, originally ovate, obtuse, entire, ultimately five-lobed from an ovate or deltoid subcordate base, deflexed bodily downwards towards the ventral aspect of the radicle, then again upturned with the tips of the segments arched over to the dorsal aspect and piercing almost through the endosperm at those points. Each cotyledon has two basal subopposite nerves running into the basal segments, and two alternate onos running 
into the middle segments, and also a strong median nerve; segments narrowly ovate, obtuse - terminal one longest and narrowest; radicle cylindrical, obtuse, about $2 \cdot 5-2 \cdot 75 \mathrm{~mm}$. long.

\section{Seedling.}

Hypocotyl erect, terete, pubescent or almost glabrous, pale green, or afterwards red, $2 \cdot 8$ to $4 \cdot 5 \mathrm{~cm}$. long.

Cotyledons broad, foliaceous, rhomboid and palmately five-lobed, five-nerved at the base, with the outer and lower pair of nerves slender, alternately nerved upwards, reticulate, shining and thinly pubescent on both surfaces, deep green above, paler beneath, petiolate; lobes oblong, obtuse, with a strong nerve running into each, the basal ones always largest and sometimes ovate, the middle pair of lobes always the smallest and oblong or subulate; lamina $1 \cdot 5-2 \cdot 1 \mathrm{~cm}$. long,
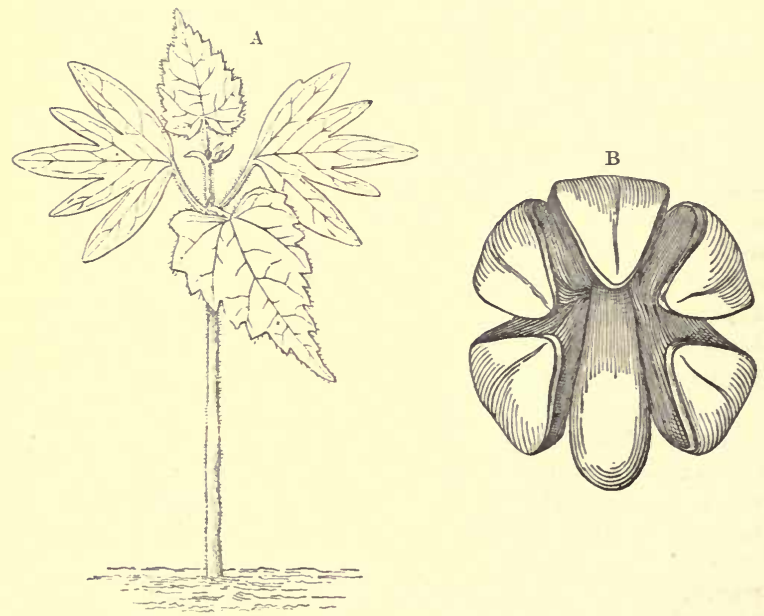

FIG. 223.-Tilia vulgaris. A, seedling, nat. size. B, embryo, $\times 8$.

$1 \cdot 7-2.5 \mathrm{~cm}$. from tip to tip of the basal pair of lobes; petiole semiterete, shallowly channelled above, pubescent, $6-8 \mathrm{~mm}$. long.

Stem erect, flexuous or bent at each node, densely pubescent; hairs simple or stellate, pale green, ultimately woody; 1st internode 75-1 mm. long; second 2-5.5 mm.

Leaves simple, cauline, alternate, stipulate, petiolate, five- to 
seven-nerved at the base, and alternately nerved upwards, reticulate, pubescent on both surfaces in the seedling stage, becoming glabrous in the adult plant, with woolly tufts at the junction of the lateral nerves and the midrib on the under side, more or less shiny on both surfaces, deep green above, paler beneath; stipules oblong, obtuse, seated at the union of the petiole with the stem, pale-coloured or scarious, deciduous; petioles terete, tapering upwards from a stout base, densely pubescent with simple or stellate hairs.

No. 1. Cordate-ovate, acuminate, five- or faintly seven-nerved from the base, irregularly serrate, slightly oblique at the base or almost equal, with strong axillary buds.

No. 2. Cordate, acuminate, obtuse or subacute, more or less oblique at the base, irregularly serrate, with strong axillary buds.

\section{Tilia petiolaris, $D C$. (fig. 224).}

Fruit five-celled, one-seeded, globose, tomentose or downy and pale greenish-white, thick-walled, woody or corky internally, indehiscent.

Seed globose or subobovoid, pale white, pushing the other cells aside and monopolising the greater part of the fruit; hilum ventral somewhat above the base; raphe ventral ; chalaza apical or rather towards the dorsal aspect of the upper end of the seed, marked externally with a clear or nearly transparent space, but very prominent internally, forming a shortly conical projection with a broad base; radicle inferior.

Endosperm in the young seed pale, transparent, and soft or fleshy, according to age.

Embryo in a very young stage straight, with a stout, obtuse, radicle and two ovate, obtuse, plano-convex, fleshy, pale green cotyledons.

\section{Aristotelia racemosa (fig. 225).}

Root long, woody, branched, with

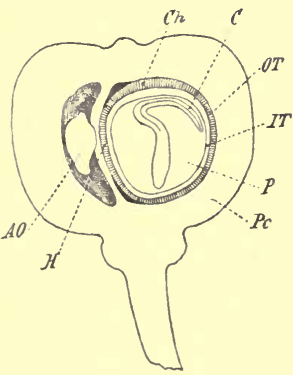

FIG. 224.-Tilia petiolaris, $\times 4$. Longitudinal section of fruit: $C h$, chalaza ; $C$, cotyledons; $O T$, testa; IT, tegmen; $P$, endosperm ; $P c$, pericarp; $H$, hilum ; $A O$, aborted ovule. many brown fibrous lateral rootlets.

Hypocotyl woody, 1-2 cm. long, $1 \mathrm{~mm}$. thick, terete, smooth, yellowish-brown.

Cotyledons shortly stalked, 5-6 mm. long, 3-4 mm. broad, broadly ovate or oblong-ovate, rounded at base and apex, entire, flat, 
indistinctly nerved, membranous, dull green above, paler below, glabrous.

Stem, lower part like the hypocotyl, upper somewhat succulent, downy, terete.

Leaves simple, cauline, alternate or mostly opposite or subopposite, exstipulate (?), petiolate, glabrous above, pubescent beneath, coriaceous, alternately penninerved and reticulate; stipules apparently obsolete.

Nos. 1 and 2. Opposite, shortly stalked, $1 \mathrm{~cm}$. long, $4 \mathrm{~mm}$. broad, ovate-lanceolate, acuminate, prominently penninerved, thin, with a

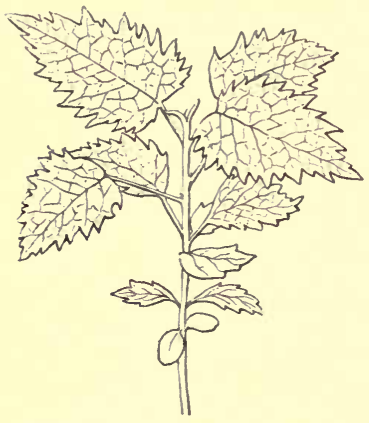

Fig. 225.-Aristotelia racemosa.

Nat. size. few hairs on the deeply serrated margin and on the pale lower surface; upper surface glabrous and dull green.

Nos. 3-8. Alternate, larger.

Nos. 9-12. In pairs, 4-5 cm. long, $2.5 \mathrm{~cm}$. broad, with long, stout, pubescent petioles, coloured like the stem; lamina cordate-ovate, acuminate or cuspidate, irregularly and very deeply serrated, with acute teeth; penninerved, with very distinct, reticulate veins, upper surface as in the first pair, lower with red midrib and nerves.

Elæocarpus oblongus, $S m$. (fig. 226).

Hypocotyl about $8 \mathrm{~cm}$. long, $4 \mathrm{~mm}$. thick near the base, $2.5 \mathrm{~mm}$. just beneath the cotyledons, firm, terete, glabrous, red, brownish towards the root.

Cotyledons very persistent, subsessile, nearly equal, $6 \mathrm{~cm}$. long, $2.5 \mathrm{~cm}$. broad, oblong or oblong-lanceolate, subacute at the base, rounded at the apex, entire, trinerved, the two lateral nerves very short in comparison with the very prominent midrib, reticulate, subcoriaceous, glabrous, light green with raised venation on the upper surface, paler, smooth, and shining below; nerves and veins red on both surfaces.

Stem firm, terete, pubescent, red, the first few internodes $5 \mathrm{~mm}$. long, 2-3 mm. thick.

Leaves simple, cauline, opposite or subopposite, stipulate, shortly petiolate, ciliate, pubescent on the upper surface and on the nerves beneath when young, alternately incurvinerved and reticulate, 
coriaceous; petioles very short, semiterete; stipules very small, black, bristle-like, inconspicuous.

No. 1. A little smaller than the cotyledons, shortly stalked, elliptic-lanceolate, acuminate, shallowly serrate with adpressed apiculate teeth, and one black mucro at each side of base of the lamina; venation incurvinerved and reticulate with the nerves and veins red on both sides, silky with adpressed hairs on the margin and upper surface, as well as on the nerves of the lower, coloured like the cotyledons, but showing the nervation and venation equally well on both sides.

Nos. 2-5. Similar, only larger and more elliptic, subacuminate.

\section{Elæocarpus reticulatus, Sm.}

Hypocotyl woody, erect, terete, glabrous, pale brownish, $1 \cdot 8 \mathrm{~cm}$. above the soil.

Cotyledons persistent, lanceolate, obtuse, opaque, coriaceous, obscurely penninerved and reticulate, glabrous; lamina $1.9 \mathrm{~cm}$. long, $7 \cdot 25 \mathrm{~mm}$. broad ; petiole broad, semi-amplexicaul, $1 \mathrm{~mm}$.long.

Stem woody, erect, terete, pubescent, pale brown; 1 st internode $3 \mathrm{~mm}$. long; 2nd $2 \mathrm{~mm}$.; 3rd 5.25 mm.; 4th 5.25 mm.; 5th $7 \mathrm{~mm}$.; 6 th $5 \mathrm{~mm}$.; 7 th $5 \mathrm{~mm}$.; 8 th $7.5 \mathrm{~mm}$.; 9 th $7 \mathrm{~mm}$.

Leaves alternate, serrate; teeth incurved; mucronate, thinly pubescent when young, ultimately coriaceous, glabrous, alternately penninerved, reticulate prominently above, but not prominently beneath, with the midrib prominent on both surfaces; petioles very short, stout, flattened above with a prominent midrib, much thickened beneath at the very base and decurrent on the stem forming a ridge, pubescent when young, ultimately glabrous; stipules minute, tooth-like.

No. 1. Smaller than the cotyledons, lanceolate, acute, deep green above, paler beneath, as are the others.

Nos. 2-5. Lanceolate, acuminate, mucronate.

Nos. 6-9. Lanceolate-elliptic, acuminate, obtuse, mucronate.

Ultimate leaves oblong, shortly acuminate, acute, tapered a little to both ends ; petiole rigid, channelled above, thickened at its insertion both with the lamina and the stem. 


\section{LINEA.}

Benth. et Hook. Gen. Pl. i. 241.

Fruit and Seed.-The ovary is superior, syncarpous, and typically five-celled, but often becoming spuriously ten-celled by an outgrowth from the inner face of each carpel. Exceptions to the general rule occur in Radiola millegrana, where the flower is tetramerous. The ovary of Reinwardtia tetragyna is also typically four-celled, but that of R. trigyna and Anisadenia is three-celled. The ovules are geminate and collateral, rarely superposed, suspended from the inner angle of each cell near the top, and are anatropous, with the micropyle superior, and the raphe ventral. The loculi of several species of Erythroxylon and Durandea are one-ovuled.

The fruit is a capsule breaking up into as many cocci as there are carpels, and dehiscing along the ventral suture or separating along the dorsal suture, thus forming twice as many pieces as there are carpels. It is membranous, one-seeded by abortion, and said to be indehiscent in Anisadenia. The fruit of the tribes Hugonieæ and Erythroxyleæ is drupaceous or baccate, with as many pyrenes as there are carpels, or with one only by suppression and then one-seeded. The fruits of the Ixonantheæ are subdrupaceous, but ultimately dehisce at the apex. The cocci of Phyllocosmus are not septate. The seeds are solitary or geminate in each cell, pendulous, anatropous, often compressed laterally with the ventral edge and raphe to the placenta, obovoid or oblong, with the testa sometimes, though rarely, drawn out into a membranous wing. The endosperm is fleshy or cartilaginous, copious, scanty, or altogether wanting; and the embryo is straight or rarely incurved, almost equalling the cavity in length; the cotyledons are flat, plano-convex, ovate, elliptic, or linear, and foliaceous, and the superior radicle nearly equals them in length, with some exceptions such as Anisadenia and Sarcotheca, in which it is short.

The seeds are always laterally compressed when the earpels number three, four, or five with twice as many seeds, but when the carpels are reduced to one, they are thick, oboroid, 
and even or angled. Winged seeds are met with in Hebepetalum and some species of Ixonanthes, while those of Phyllocosmus and occasionally of Ixonanthes are furnished with a lacerated, mitriform aril. Normally the embryo is axile, that is, it lies in the centre of the endosperm, but there is an exception in Ixonanthes, where it is lateral. Hugonia and Roucheria are exceptional in their embryo being sometimes more or less incurved; in the mature seeds of Anisadenia and Linum it is green.

Linum may be taken as a type of those with a dry capsular fruit. In the early stage of the ovary it is five-celled, with two ovules in each of slightly different ages and slightly superposed. The ovules at first are represented by small papillæ, and as the integuments are developed and they become anatropous, a false partition begins to grow towards the interior from the inner face of the carpel and separates the ovules immediately they have become anatropous. Endosperm is wanting in the mature seed, and the cotyledons of the embryo are elliptic, conforming in shape to that of the seed. The drupaceous type is represented by Hugonia Mystax. The fruit is globose, fleshy externally, with a bony endocarp, spuriously ten-celled with one or two seeds in each true cell. As it ripens the interior becomes pulpy, and the dissepiments obliterated. The laterally flattened seeds differ from those of Linum in containing endosperm. The embryo almost equals the latter in length, and is pale yellow, and slightly incurved; the cotyledons are oblong, flat, foliaceous, thin, and alternately penninerved. The seeds of Linum when moistened emit a copious mucilage, which attaches them to the soil, and probably serves to facilitate the exit of the young plant.

Cotyledons.-Just as there is very little variation of any importance amongst the seeds, so with the cotyledons of those seedlings coming under my notice. They are broadly oval or roundly obovate, trinerved, suddenly narrowed into a very short petiole. Those of Linum perenne are oval, rather opaque, with an obscure venation, about $5 \cdot 25 \mathrm{~mm}$. long, including the petiole, and $3.25 \mathrm{~mm}$. wide. They are longer and several times wider than the primary leaves. Those of L. campanu- 
latum agree, except in being rather smaller, while those of $\mathrm{L}$. monogynum (fig. 227) and L. Leoni are rery much larger. Those of the latter are entire or inclined to be slightly emarginate, fleshy, and indistinctly trinerved.

\section{Linum perenne, $L$.}

Hypocotyl erect, terete, glabrous, white below ground and purplish-brown above it, $1.5 \mathrm{~cm}$. long.

Cotyledons oval, obtuse, entire, tapering to a very short petiole, glabrous, deep green, often stained brown, about $5.25 \mathrm{~mm}$. long including the petiole, $3.25 \mathrm{~mm}$. wide.

Stem herbaceous, erect, terete, glabrous, minutely scabrous, pale green or brownish; internodes very short, 1 st and 2 nd undeveloped; 3rd $4 \mathrm{~mm}$. long; 4th $1 \mathrm{~mm}$. long; 5th $75 \mathrm{~mm}$.; 6th, 7th, \&c., $1 \mathrm{~mm}$. long.

Leaves simple, entire, radical and cauline, alternate, exstipulate, sessile, or slightly narrowed to the base, deep glaucous green, glabrons, subfleshy, one-, ultimately threenerved, minutely scabrous at the margin, convex on the back, slightly concave above by reason of the upturned margins.

Nos. 1 and 2. Decussating with and close to the cotyledons, appearing opposite, linearoblong, obtuse, or subacute.

Nos. 3-20. Linear-oblong, obtuse, alternate, separated by short internodes, minutely scabrous beneatl, one-nerved.

Ultimate leaves on barren shoots linear, obtuse, generally minutely cuspidate, one-

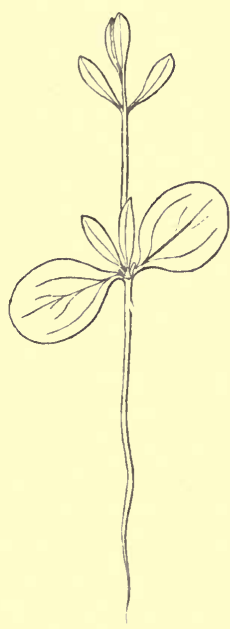

FIg. 227.

Linum monogynum.

Nat. size. or obscurely three-nerved, subfleshy; on flowering shoots linear, acute, rather elongated, trinerved.

Linum monogynum, Forst. (fig. 227).

Primary root a long tap-root, colourless, unbranched in its early stages.

Hypocotyl as in L. perenne, about $2 \mathrm{~cm}$. long, $1 \mathrm{~mm}$. thick, firm.

Cotyledons subsessile, $1.5 \mathrm{~cm}$. long, about $1 \mathrm{~cm}$. broad, rotundobovate, trinerved, entire, glabrous, thin, light greyish-green.

Stem like the hypocotyl ; 1st internode $1 \mathrm{~mm} . ;$ 2nd undereloped; 3rd $2 \mathrm{~cm}$. 
Leaves very similar to those of L. perenne, sometimes opposite (as in the first two to three pairs), tapering to the base in the seedling stage, ultimately more strictly sessile, generally one-nerved, pale green.

Nos. 1 and 2. Only $1 \mathrm{~mm}$. above the cotyledons, subsessile, $7.5 \mathrm{~mm}$. long, $3 \mathrm{~mm}$. broad, oblanceolate, subacute at the apex, entire, with distinct midrib, glabrous, thin, light greyish-green.

Nos. 3 and 4. Similar.

\section{Linum campanulatum, $L$.}

Hypocotyl mostly subterranean, tapering indistinguishably into the root.

Cotyledons obovate, otherwise as in L. monogynum, petiolate; lamina $7.5 \mathrm{~mm}$. long, $5 \mathrm{~mm}$. broad; petiole flattened or slightly grooved above, convex on the back and subscabrous, $3.5 \mathrm{~mm}$. long.

Stem herbaceous, erect, terete, glabrous, brown; 1 st internode $1.7 \mathrm{~cm}$. long; 2nd $3 \mathrm{~mm}$.; above this $1 \mathrm{~mm}$. each or crowded.

Leaves tapering to the base, trinerved from base almost to apex, obscurely alternately penninerved above the middle, opaque, deep glaucous-green on both surfaces, crowded, ascending.

Nos. 1 and 2. Small, opposite, spathulate, obtuse, apiculate.

All above this obovate, obtuse, apiculate, crowded.

\section{HUMIRIACE}

Benth. et Hook. Gen. Pl. i. 246.

The five-, rarely six- to seven-celled ovary contains a solitary, pendulous, anatropous ovule in each cell, or two, rarely three, in Vantanea, while Humiria has sometimes two superposed ovules. The raphe is ventral. The fruit is drupaceous with a bony endocarp, one- to three-celled and -seeded by abortion, and indehiscent. Where two seeds occur in a loculus of Humiria they are separated from one another by a spurious transverse septum. The seeds are oblong, with a membranous testa, and contain a copious, fleshy endosperm.

The embryo is straight in the axis of the endosperm, and has short, blunt cotyledons and generally an elongated, superior radicle.

The Order contains about twenty species of large or small trees, with alternate, entire or crenulate, exstipulate leaves. 


\section{MALPIGHIACEA.}

Benth. et Hook. Gen. Pl. i. 247.

Fruit and Seed.-The ovary is superior, generally consisting of three carpels, rarely two or four, more or less connate into a three-celled ovary, or apocarpous, with one ovule in each cell; the ovule is almost orthotropous or semianatropous in Hiptage Madablota, ascending from a lroad pendulous funicle, and straight or curred; the raphe is on the ventral aspect, and the micropyle is superior. The mature carpels are three in number or fewer, one-seeded and coherent into a fleshy or woody drupe, distinct and separating into usually winged samaras, rarely two-valved. The seed is obliquely suspended from the inner angle of each cell, and is exalbuminous. The seed-coat is double, both coats being as a rule membranous. The embryo varies in being straight, curved, or hooked, very rarely circinate; and the cotyledons are flat, or fleshy and thick, filling the seed, and often unequal. The radicle is short, superior, and the plumule is but little developed.

The seeds may be roughly classified into six groups according to the form of the embryo, which is exceedingly variable. Those characteristies however by which the groups are distinguished are not constant, while in many cases two or three of them apply to one genus, or to different species of a genus, so that the groups frequently overlap one another. The embryo is straight in Bunchosia, Aspidopterys, Jubelina, and some species of Malpighia. More often however the cotyledons are more or less curved, as in Lasiocarpus, Verrucularia, Acridocarpus, Ryssopterys, Peixotoa, Aspicarpa, Camarea, Janusia, Schwannia, and in some species of Hiptage, while in Banisteria they may be straight, incurved, or inflexed. This forms a transition to the next group, in which the cotyledons are inflexed or uncinate about the middle or towards the apex. Some of the species of Malpighia, Tristellateia, and Tetrapterys also have their cotyledons inflexed at the apex. The species generally of Diacidia, Clonodia, Jophanthera, Ptilochata, Triaspis, Triopterys, Hiræa, and Diplopterys have the cotyle- 
dons inflexed; while those of Janusia are fleshy and curved, but are somewhat exceptional in having the inner one uncinate at the tip. A fourth type has the cotyledons circinate, those of Byrsonima and Dinemandra being linear and semiterete. Pterandra is very exceptional in the Order in having the seedleaves flattened and convolute, while the inner one is longer and rolled up in a spiral of many coils.

The seeds are often large, and as they contain no endosperm, the embryos in numerous cases are thick and fleshy. The gynoecium in Hiptage Madablota consists of three carpels, and is three-celled, with one ovule in each cell. The ovule is campylotropous or semi-anatropous, suspended from the middle by a broad obliquely attached funicle. The fruit is samaroid with three strong wings diverging from its upper edges, and when mature splits into three pieces. The seed is transversely and broadly oblong-reniform, large, and conforming to the seedeavity of the samara. The embryo is large, slightly curved, thick, fleshy, pale yellow or white, and the cotyledons are unequal, plano-convex, with the smaller one uppermost, lying in the sinus of the curve; both lie in the narrow plane of the seed, with their edges to the ventral suture of the carpel. The radicle is superior, and so short as to be hardly noticeable, just serving to unite the cotyledons. Other genera agreeing with Hiptage in having fleshy seed-leaves are Acmanthera, Acridocarpus, Brachypterys, Stigmaphyllon, Tetrapterys, and Hiræa.

Hiptage Madablota may be again referred to as a type having unequal cotyledons. Others agreeing with it in this respect are Burdachia, Dicella, Thryallis, Galphimia, Heteropterys, Stigmaphyllon, Tetrapterys, and Pterandra. This inequality is sometimes carried so far that one of the cotyledons becomes quite minute, as in Hiræa. The embryo of Brachypterys appears undivided, but one cotyledon becomes aborted, and the other thick, and hooked at the apex. According to Grisebach ${ }^{1}$ this is what takes place in Glandonia, a genus containing a single species from northern Brazil. According to other authorities ${ }^{2}$ the cotyledons have become

${ }^{1}$ Griseb. in Mart. Fl. Bras. Malpigh. p. 23.

${ }^{2}$ Gen. Plant. i. 252. 
amalgamated or conferruminate. These three cases may be considered exceptional in the Order or abnormal, and the gradual outcome of the curved or twisted condition of the ovary, which is neither strictly anatropous nor orthotropous, but partly both. The outer cotyledon becomes the larger, and folded round the inner one to a greater or less extent, and the latter therefore becomes gradually smaller and finally more or less aborted, as in Abronia belonging to the Nyctagineæ. Other curious cases occur in several species of Banisteria, Heteropterys, and Stigmaphyllon.

The seeds of Stigmaphyllon are also remarkable in containing two or three embryos.

\section{Hiptage Madablota, Gaertn.}

Fruit separating when mature into three samaras, each onecelled, one-seeded, and furnished at the upper edges with three strong diverging wings and an apical much smaller one; walls of ovary dry, coriaceous to woody, and tough.

Seed transversely and broadly oblong-reniform, comparatively large, conforming to the interior of the samara, suspended at or near its centre by a broad funicle, which arises from the ventral side of the samara, below the middle of the cell, and is obliquely and slightly attached to the testa; raphe short, broad at the upper edge of the ventral aspect of the seed; micropyle superior, contiguous to the hilum; chalaza on the opposite side of the hilum from the micropyle; testa and tegmen both thin and membranous, pale brown.

Endosperm absent.

Embryo large and conforming to the interior of the seed, which it closely fills, slightly curved, fleshy, pale yellowish or white; cotyledons unequal, curved, plano-convex, fleshy, filling the seed, obtuse, entire, with the smaller one uppermost and in the inner angle of the curve, both lying in the narrower plane of the seed, which is deeper than wide, so that both the cotyledons go to make up the depth of the seed, and have their edges to the ventral suture of the carpel ; radicle extremely short, superior, hardly prominent. 


\section{ZYGOPHYLLEÆ.}

Benth. et Hook. Gen. Pl. i. 262.

Fruit and Seed.-The ovary of the Zygophylleæ is four- or five-, rarely two- to twelve-celled, and the ovules vary from two to many in each cell. They are pendulous and anatropous or sometimes ascending with a ventral raphe, have a superior micropyle, and are often filiform. A remarkable exception occurs in a few species of Tribulus, where the carpels opposite the petals are transversely three- to five-locellate, both in the young and the mature state, so that the seeds lie in an ascending direction one above the other with partitions between them.

The fruit is very variable in the Order, coriaceous or crustaceous, dividing into dehiscent or indehiscent cocci, which are connate, or separate from the placental axis; at other times it is a capsule dehiscing loculicidally, and in a few the endocarp is horny. The fruit of Nitraria is drupaceous when mature, one-celled and one-seeded although two- to six-celled in the young state. The seeds are pendulous, and solitary in most cases, oblong or linear, with a membranous, crustaceous, or thick and slimy testa. They contain a thin layer of endosperm, often fleshy or horny, and are rarely exalbuminous.

The embryo is straight or nearly so, green, and equalling the endosperm in length. The cotyledons are foliaceous and oblong or linear, the radicle rather short.

\section{GERANIACEN.}

Benth. et Hook. Gen. Pl. i. 269.

Fruit and Seed.-The gynœeium of the Geraniaceæ is superior and syncarpous, consisting of three to five, rarely two carpels. The ovary is three- to five-lobed, three- to five-celled, and in the tribes Geranieæ and Pelargonieæ the carpels are in most cases prolonged above into a long beak, attached to the central axis, which is also greatly prolonged between and beyond the seed-bearing portion : in the other tribes the beak is usually absent. The ovules are geminate and contiguously superposed, 
or solitary and pendulous, with the micropyle superior and the raphe ventral, or transverse with the raphe lateral. Where the thalamus is flat, as in Limnanthes, the ovule is solitary and ascending with the micropyle inferior. The ovules vary from two to many in the tribes Wendtieæ and Oxalideæ, are horizontal or pendulous, and arranged in a single or double series along the placenta. The fruit is a schizocarp in many cases, three- to five-lobed, and breaking away from the axis in as many one-seeded pieces, the beak of which becomes revolute carrying the seed upwards with it. In other cases, such as that of Limnantheæ and Tropæolum, the fruit breaks up into three to five indehiscent, hardened cocci. The two- to many-seeded fruits are capsular, dehiscing loculicidally with persistent valves, as in Oxalis, or the valves break away with elasticity from the placentas, as in Impatiens. In a few cases the fruit is baccate, many-seeded, and indehiscent, as in Averrhoa.

The seeds are pendulous, horizontal, or ascending, the first and last being characteristic of one- or few-seeded fruits. The testa is thin, rarely somewhat crustaceous. Endosperm is absent or rarely present in some quantity and fleshy. The embryo is curved or straight, often green, and the cotyledons are foliaceous and variously convolute longitudinally or twisted, flat, plaited, or plano-convex, or they are thick and fleshy as in Tropæolum. The radicle is short in straight embryos, and pointing to the hilum, or, as in the Geranieæ and Pelargonieæ, is long and incumbent upon the back of the cotyledon next to the raphe, and, together with the tips of the cotyledons, points to the base of the fruit. The whole Order may be roughly divided into five groups according to the form of the embryo and the presence or absence of endosperm. On the amount of the latter present in the seed depends to a large extent the size, form, and modification of the embryo. The larger the quantity present, the smaller and simpler the embryo. The groups may be characterised as follows:-(1) endosperm present, embryo straight; (2) endosperm present, embryo curved; (3) endosperm present, cotyledons plicate; (4) endosperm absent, embryo fleshy, straight; (5) endosperm absent or rarely present in small quantity, cotyledons convolute or induplicate-plicate. These characters do not in all cases 
indicate the genera which are regarded as most closely allied, but they are all well marked in the seeds, and the members of different tribes do not much overlap one another.

To the first group belong Rhynchotheca, Oxalis, Averrhoa, and perhaps Dapania. The seed of Rhynchotheca contains a small quantity of endosperm, a straight embryo, flat cotyledons, and belongs to the tribe Wendtieæ; Wendtia itself does not seem to have been described, and I have had no opportunity of examining it. The others belong to the tribe Oxalideæ. Oxalis has a capsular, loculicidally dehiscent, five-celled fruit with one or many seeds in each cell. The outer integument of the seed is fleshy and breaks away elastically in the form of an aril, while the testa is crustaceous. The endosperm is fleshy, and the small embryo straight with broadly ovate cotyledons. The fruit of Averrhoa is baccate and indehiscent, containing numerous naked or arillate seeds, with a small quantity of fleshy endosperm, and a straight embryo. The fruit of Dapania is fleshy and five-lobed, and the seed it contains is covered by a lacerated, somewhat two-lipped aril, and has a fleshy endosperm. The embryo is slightly curved, leading to the next group ; and the oval cotyledons are cordate at the base.

2. The curved embryo is represented by Biebersteinia and Viviania, belonging to distinct tribes (Geranieæ and Vivianeæ respectively). The seed of the former is curved and contains a thin, fleshy, somewhat one-sided layer of endosperm. The arched or bent embryo has rather thickened cotyledons, a scarcely shorter, superior radicle, and conforms in outline to that of the seed. Viviania has closely superposed geminate ovules in each cell, and when both mature into seeds, the one is ascending and the other descending, and they contain a fleshy endosperm. The embryo is narrow, linear, and strongly curved or circinate.

3. The third type, represented by Balbisia, also contains a thin fleshy layer of endosperm in its seeds, which are small, many-angled by mutual compression, and arranged in a double series. Its chief distinction consists in the cotyledons being plicate and in the radicle being laid over the back of them or enclosed in their folds. 
4. Endosperm is wanting and the embryo straight and fleshy in Tropæolum, Limnanthes, Flœrkea, Impatiens, and Hydrocera, belonging to three different tribes, which some authors consider distinet Orders. The ovary of Tropæolum is trilobed, three-celled, and contains a single pendulous ovule in each cell, with a superior micropyle. The fruit is at first fleshy, but when mature becomes a schizocarp, breaking up into three indehiseent cocci, which fall away from the short persistent axis, and have hardened, rugose walls, ultimately becoming dry and cortical. The seed is exalbuminous, and the straight embryo consists of two thick and fleshy closely applied or almost conferruminate cotyledons, which, together with the extremely short radicle, completely fill the cavity of the seed, which again fills the carpel.

When the embryo is still very young, the cotyledons are oval or transversely oblong, entire, deep green, and diverging widely. Later on they become broadly cordate, and deeply concave on the imner faces. At a further stage they become fleshy, and form more or less completely a sphere, while the notch at the base becomes deeper until distinct auricles are produced. Finally they become closely applied to one another but separable, while the basal auricles become quite close, embedding the radicle, and leaving only its extreme tip exposed. At the same time they lose their green colour, and, being globose, completely fill the seed. The fruit, seed, and embryo of Flcrliea conform very closely in structure to those of Tropæolum, while Limnanthes differs in having five earpels. The fruit of neither is fleshy, and the receptacle or thalamus is nearly flat, while the carpels are beakless. The cotyledons are thick, fleshy, and cordate at the base, cnelosing the very short radicle. The fruit of Impatiens is a five-celled capsule, the valves of which on maturity spring elastically from the placentas, from the base upwards, and roll backwards or downwards from the top inwards. The seeds of I. parviflora (fig. 233) are pendulous, auatropous, obovoid, and marked longitudinally with lines of minute protuberances. The chalaza is apical, forming a small thickiened knob externally to the testa, which is here slightly indented. The embryo is straight, and the cotyledons obovate-oblong, fleshy, plano-convex, subcordate at 
the base, partly surrounding the radicle, and minutely emarginate, apparently owing to the indentation of the testa at the thickened chalaza. In I. chinensis there is sometimes a slight depression at the chalaza, which occasionally is quite marked. The seeds of I. Roylei are pyriform with a small depression at the broad apical end, and rough with small points. The embryo is similar to that of I. parviflora, and the cotyledons are broadly obovate with the apical notch well marked.

5. The fifth group, in which endosperm is absent, and the cotyledons convolute or induplicate-plicate, is represented bv Geranium, Erodium, Monsonia, and Sarcocaulon, of the tribe Geranieæ, and Pelargonium of the Pelargonieæ. The various species of Geranium have the most complicated embryo of the three better known genera, and constitute the best type of the group. The ovary consists of five carpels, is deeply five-lobed, five-celled, and ten-ovuled. The axis is greatly prolonged between the carpels, and each of the latter is produced into a long beak attached to the axis, except near the top where they separate into five branches, which are stigmatose along their inner face. The geminate orules are slightly superposed, incurved, and semianatropous. The hilum is ventral, and abore the middle of the seed, and the micropyle is on the upper side of this. One of the two ovules only becomes fertilised, and in a number of specimens examined it has always been the upper one. The seed is oblong or subcylindrical, finely tuberculated, about equally thick at both ends, and fixed to the placenta a little above its middle. The chalaza is at the lower end close to the base of the carpel. Endosperm is absent, and the curred embryo, which is green, at least while fresh, occupies the whole of the seed.

Taking G. Wallichianum as a type, we find that the radicle is the only part that is curved; and assuming that the embryo starts from near the micropyle above the middle of the seed, then it would grow until it reached the upper end, when the apex curves downwards until it reaches the base, and here we always find the apex of the cotyledons pointing to the base of the earpels or ovary. There still being room for the cotyledons to develop laterally, they commence to coil longitudinally round the sides of the seed in the 
direction of the sun when the seed is held in its natural position.

The result is that one longitudinal half of each cotyledon grows faster than the other, and grows over, enclosing the smaller half of the other, so that when the embryo is fully grown, a transverse section shows each of the cotyledons coiled in the shape of the letter S, but the small coil of each is inserted in the large coil of the other, thus-

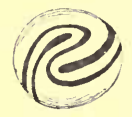

The eoils are, however, closely drawn together so as to fill the seed compactly, and the radicle is incumbent on the back of the cotyledons, but on the rentral face of the seed ; there is a small notch or cavity in the centre of the bundle or coil at its lower end into which the rather prominent chalaza fits. When flattened out the cotyledons are transversely oblong or reniform, slightly sinuate at the apex, with the midrib excurrent, forming a small tooth, and five nerves radiating from the base of the lamina and becoming slightly incurved. The base is deeply cordate, and the deep green radicle on the ventral aspect points towards the base of the ovary. The two halves of the cotyledons are unequal, the smaller one occupying the interior of the coil. The cotyledons are even already petiolate, and examination shows that this is necessary in order to allow of their becoming convolute. The inner or upper faces of the cotyledons are always applied to one another, but the coils or smaller enfolded half of each prevents the two midribs from coming in contact as they would do if the cotyledons were flat. Hence the necessity for petioles while yet in the seed. Other species agreeing with G. Wallichianum in the form of the embryo are G. pratense, G. sylvaticum, G. sanguineum, and G. bohemicum. It is more than probable that none of the species differ very widely from the type. There seems to be, however, a variation in the insertion of the ovule, for whereas G. Wallichianum has the hilum on the ventral face a little above the middle, 
according to a figure of Le Maout and Decaisne ${ }^{1}$ a species of Geranium has the hilum close to the base. G. Endresii has the ovule attached as near as possible at the middle, and the radicle is of moderate length. In G. Wallichianum, the ovule being attached above the middle and campylotropous, the radicle is very short. In Le Maout and Decaisne's figure above-mentioned the ovule is practically erect and anatropous, while the radicle elongates until it almost equals the cotyledons in length.

In Erodium there is the same variation in the attachment of the seed. It is pendulous and attached above the middle in E. trichomanefolium, which is half anatropous, with the radicle and the apex of the cotyledons uppermost, while that of E. Manescavi is attached almost by the base, while the radicle is greatly elongated and reaches to the hilum, the seed being erect and almost anatropous with the micropyle inferior. The seed of E. Manescavi tapers downwards, whereas that of E. trichomanefolium tapers upwards. The wider end always includes the radicle, which in this genus is greatly thickened. There is a corresponding reduction in the width of the cotyledons, which taper somewhat towards the apex and are much less perfectly convolute than in Geranium. In E. trichomanefolium the two cotyledons are folded separately with their edges towards one another, or they slightly overlap with the thick radicle squeezed in the hollow between them. While yet in the seed there is a moderately deep notch on the margin, but below the middle on each side of both cotyledons, or the longer side only may be so notched.

The cotyledons are petiolate while yet in the seed for the same reason as in Geranium. In Erodium Manescavi one cotyledon folds over and almost completely encloses the other, which is accordingly somewhat smaller, while the much thickened radicle is flattened against the back of the outer and larger one. The embryo of $\mathrm{E}$. gruinum is nearly as convoluted as that of Geranium ; but both cotyledons are somewhat foreshortened on the edges next the radicle, which is thick, fleshy, subtrigonous, and occupies a considerable amount of space.

1 Le Mrout and Decaisne, Eng. edit. 1876, pp. 306-7. 
The ovule and seed correspond to those of E. Manescavi. The cotyledons of E. moschatum are convolute, plicate, and pinnatifidly lobed. ${ }^{1}$ The ovules of Pelargonium australe are geminate in each cell, suspended from the inner angle and anatropous, with the micropyle considerably above the middle on the ventral face. The seed is broader at the end farthest from the hilum as in the case of Erodium, a circumstance due to the radicle being thickest at that point and to the fact that the cotyledons taper to the apex like those of Erodium. The cotyledons are convolute longitudinally with one folded over the other. Both are shaped like the letter $L$ at the apex, but only the outer one towards the base, the inner being hooked or crumpled inside the angle of the outer. They taper to the apex, which is minutely emarginate beneath the thickened portion of the chalaza ; the margin is crenate, and they are shortly petiolate for the same reason as Pelargonium and Erodium. The radicle is incumbent on the cotyledons on the ventral aspect, where the testa is bulged out to accommodate it, the inflated portion tapering to a point above the middle.

Cotyledons.-About half a dozen distinet types of cotyledons may be noted, and modifications are frequent in that represented by Erodium and Pelargonium. The simplest are those occurring in exalbuminous seeds, and especially where the embryo is straight and has its cotyledons simply thickened so as to fill the seed. The least complex of the types observed is represented by Oxalis corniculata (fig. 232). The cotyledons are small, oblong-ovate, very obtuse, shortly petiolate, glabrous, and have a very indistinet venation. Those of 0 . sensitiva are sessile, and slightly pubescent at the margin, but otherwise similar to the above. Some species have broadly oblong, slightly emarginate, trinerved, petiolate cotyledons, dependent probably on the robustness of their growth and the enlargement of all parts.

The seeds of Impatiens all seem to be modelled upon the same plan; they are pendulous and anatropous, with the radicle superior and the cotyledons always occupying the lower lroader end of the seed. Hence the cotyledons vary

1 Gaertner, De Fructibus et Seminibus, i. 383, and t. 79, fig. 5. 
in breadth and the shape of their apex according to the corsponding variations of the seed. The general outline is obovate or roundly obovate and emarginate, tapering gradually or suddenly into the moderately long petiole. Those of I. fruticosa (fig. 235) are broadly, almost roundly, obovate, glabrous with hairy petioles, ciliate at the margin, and obscurely trinerred with the lateral nerves incurved so as to join the middle one in the notch. This notch, as has already been observed, is due, at least partly, to the thickening of the chalaza and the indentation of the testa at that part. There can be little doubt, however, that it deepens by a subsequent more rapid derelopment of the parts on each side of the apex, where the three principal nerves end in the water-gland. A small or minute tooth is also observable in the notch. The cotyledons of I. Balsamina (fig. 234) are also obovate, with a tendency to be broadly ovate or oval, emarginate, slightly narrowed towards the apex at times, more or less cuneate at the base, and glabrous. They are three- or faintly five-nerved. Five slender or indistinct nerves also occur in a species with lilac flowers, and the lateral ones join the midrib in the rather prominent notch. The lamina is oborate-orbicular, and appears sessile from the fact that the petioles are erect and closely applied to the stem throughout their length. The cotyledons of I. tenella are very broadly obovate, emarginate, and trinerred, while those of I. tricornis appear to be somewhat anomalous in being obliquely emarginate or shallowly and obtusely trilobed at the apex and indistinctly one- to two-nerved.

A third and somewhat more complicated type occurs in Limnanthes Douglasii (fig. 230), which evidently bears considerable affinity with Tropæolum, the type of the next group. The cotyledons are roundly cordate, nearly always minutely emarginate, and marked at the apex with a small black scar, tipped with white, rather succulent, glabrous, convex above, and striated with numerous broad, shallow, ridge-like reins curring off laterally from the midrib. The petioles are rather deeply inserted in the basal notch of the lamina, and are broad at the base, sheathing the plumule. The hypocotyl is stout and subterranean, so that here again there is a necessity 
for petioles, which when full grown are about $1 \cdot 2 \mathrm{~cm}$. long. Geranium Wallichianum (fig. 228), G. polyanthus and Pelargonium australe (fig. 229) afford other good instances in this Order, and Delphinium elatum, already mentioned in Ranunculaceæ, is also a case where petioles are required to carry up the laminæ of the cotyledons to the light.

A fourth type is represented by Tropæolum majus (fig. 231). Here the cotyledons are subterranean even after germination, large, fleshy, filling the testa, and shortly petiolate, so as to facilitate the exit of the plumule.

The seed then lies on one side of the seedling, and the hypocotyl is undeveloped as in the case of other seedlings with subterranean cotyledons. In this respect $\mathrm{T}$. aduncum, T. minus, and other species agree with the type just given.

The fifth type is represented by Erodium and Pelargonium, which have broadly ovate-oblong or suborbicular cotyledons, generally distinctly narrowed towards the apex. This type varies exceedingly however in different species, from cotyledons of nearly equal or symmetrical form to others that are strongly asymmetrical, while in a third modification they are lobed or pinnatifid. The least complicated type may be represented by Pelargonium bipinnatifidum, which has broadly oblong or oval, finely pubescent cotyledons, rounded or faintly emarginate at the apex, and cordate at the base, but otherwise entire, with rather long slender petioles, and a symmetrical lamina. P. humifusum agrees with the last, while $\mathrm{P}$. vitifolium has suborbicular but otherwise similar cotyledons. A more generally typical form occurs in Erodium verbenæfolium, in which the cotyledons are broadly ovate-oblong, emarginate, unequally cordate at the base, where they are five-nerved, pemninerved upwards, unsymmetrical, glandular, eiliate, and glandularpubescent beneath. The auricle on one side is about $1 \mathrm{~mm}$. longer than the other, a circumstance due to its being on the outside of the coil of the seed, where it has more room to develop. The channelled petioles are also of unequal length, in the proportion of 8.75 to $5.25 \mathrm{~mm}$. E. gruinum and E. malacoides have altogether larger cotyledons, more deeply emarginate and more asymmetrical, but otherwise similar to the last. Lobed cotyledons are represented by Erodium 
trichomanefolium. Here they are oblong, incipiently emarginate, cordate at the base, asymmetrical, entire at the sides, or with a deep incision on one or both sides at or below the middle, usually very unequal at the base, fleshy, glandularpubescent above and on the petioles. E. moschatum agrees with this, and E. cicutarium merely differs in being perhaps more deeply lobed with one or two incisions on each side. E. Manescavi merely differs in being very shallowly crenate along the sides. Pelargonium australe (fig. 229) is comparable to the last in being shallowly crenate at the sides, but is sub. lobate at the base. The fission, toothing, or lobing seems to be intended to facilitate folding in the seed. It will be noticed that the fission is always most pronounced towards the base where the cotyledons are broadest, and that the lobes are directed towards the narrower apex, so that by this means the greater width at the base is reduced. One large lobe or deep incision would accomplish in this respect what a number of smaller ones would, so that both types answer the same purpose.

The sixth type is represented by Geranium, the difference between which and Erodium has perhaps reference to the fact that while the seeds of Erodium are arranged so as to be selfsowing, and terminate in a sharp point, which more readily pierces the ground, this is not the case in Geranium, the seeds of which are rounded at both ends. The different species, as far as my observations go, agree in the relatively large size of the cotyledons, and the amount of folding which they undergo in the seed. They differ chiefly in size and vigour, and in the relative length of the hypocotyl and the petioles of the cotyledons. G. Wallichianum (fig. 228) may be taken as a representative of seedlings with a short hypocotyl and long petioles. The cotyledons are obliquely reniform, asymmetrical, deeply cordate at the base, shallowly sinuate at the apex, with the midrib excurrent, forming a small tooth, five-nerved, thinly pubescent above, ciliate at the margin, equalling one another in size, but the two halves of each unequal. The average length of the longer half of five cotyledons is $12.8 \mathrm{~mm}$. and the width $8.6 \mathrm{~mm}$.; on the contrary the average length of the shorter half is $11.5 \mathrm{~mm}$. and the width 
$8 \cdot 15 \mathrm{~mm}$. The petioles are long, terete, or slightly flattened on the upper surface near the base, and mostly equal in length. In the short hypocotyl and long petioles, G. polyanthus agrees with G. Wallichianum, whereas G. bohemicum and G. sanguineum are types with elongated hypocotyls and short petioles, while in G. amphuloideum both hypocotyl and petioles are elongated. All the above-mentioned however agree in general characters including asymmetry. Others agreeing with the above are G. Traversii, G. pratense, and G. tuberosum. ${ }^{1}$

The cotyledons are all broader than long, a circumstance due to the manner of folding in the seed. The larger auricle is on the outside of the coil, and has consequently more room to develop. The apical sinus is due in part at least to a thickening of the chalaza, against which it abuts. Petioles are necessary to admit of the folds of the smaller half of each cotyledon being accommodated inside the coiled embryo, and after germination to carry the cotyledons up to the light, especially if the hypocotyl is but little developed.

Geranium Wallichianum, Sweet (fig. 228).

Primary root stout, fleshy, colourless, tapering, furnished with fleshy flexuose lateral rootlets.

Hypocotyl erect, terete, stout, fleshy, hairy or downy, pale towards the base and reddish upwards, partly or quite subterranean, about $5 \cdot 5 \mathrm{~mm}$. long.

Cotyledons obliquely reniform, deeply cordate at the base, shallowly sinuate at the apex with the midrib excurrent in the form of a small tooth, unequal-sided, five-nerved (the three inner nerves the strongest), thinly pubescent above, glabrous beneath, densely ciliate at the margin,

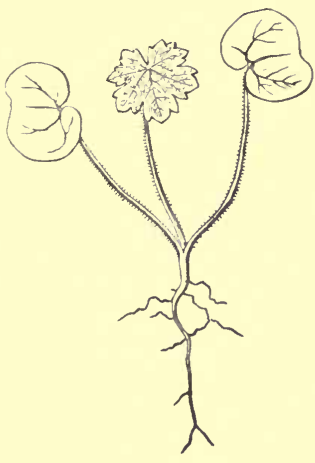

FIG. 228.

Geranium Wallichianum.

Nat. size. light opaque green, obscurely reticulate; lamina $1.4 \mathrm{~cm}$. long, $1.9 \mathrm{~cm}$. wide, about equal, but the two halves of each cotyledon are unequal.

' See Irmisch, Bot. Zeitung, 1874, p. 545. 
Average length of five longer halves $12 \cdot 8 \mathrm{~mm}$.

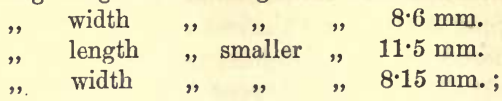

petioles long, terete, hairy, the dilated base slightly flattened on the upper side, perfoliate, mostly equal in length.

Stem herbaceous, developed when about to flower, procumbent.

Leaves simple, radical and cauline, alternate, stipulate, petiolate, palmatinerved, eight-lobed, and reticulate, hairy all over; stipules ovate, membranous, seated on the base of the petiole or attached for half its length, but in adult specimens attached to and surrounding the node of the stem.

No. 1. Palmately seven-nerved and -lobed, reticulate; lobes cuneate-terminal one deeply tridentate or trifid; lateral lobes generally tridentate; teeth obtuse, mucronate.

The cotyledons of G. sanguineum differ from the present ones only in their smaller size.

\section{Geranium sanguineum, $L$.}

There are two ovules, of which only one, usually the upper, is fertilised. The hilum is on the ventral face of the ovule a little below the middle. The raphe is also ventral and proceeds from the hilum to the base of the seed, where it terminates in the chalaza. The micropyle is close to the hilum on its upper side. The embryo originates about the middle of the ventral face of the seed with its radicle embedded in a separate cavity or tube ending in the micropyle. It grows to the upper end of the seed, and, curving round the apex, commences to grow downwards till the cotyledons rest with their apex against the chalaza. The cotyledons commence to fold by the time they reach the upper end and while there is yet plenty of room in the young seed, which is occupied by a copious, pulpy, and watery endosperm. The embryo is bright green or yellowishgreen in the very early stages.

G. pratense conforms very closely to $\mathrm{G}$. sanguineum.

The seedling of this species closely resembles that of $G$. Wallichianum.

Erodium moschatum, L'Herit.

There are two ovules in each loculus of the ovary; they are slightly superimposed, and the upper one seems in all or most cases to be that which is fertilised and reaches maturity. 
The carpels are oblanceolate with two oblique, glandular, depressed spots at the apex, and covered with a dense array of brownish-yellow or fuscous hairs pointing upwards.

The ovule is attached to the axile placenta near the base of the cavity of each loculus; the hilum is ventral and very close to the base of the seed; the raphe proceeds from the hilum to the base of the seed on the ventral face, terminating in the chalaza there, so that it is very short.

The radicle of the embryo is embedded in tissue or a tube close to the micropyle immediately above the hilum. The embryo grows to the upper end of the seed as in Geranium, and then bends towards the base. The curvature takes place in the radicle or rather the short hypocotyl. The cotyledons are shortly petiolate to permit of folding. They are deeply concave only on the inner face, not rolled round one another as in Geranium. This is due to the narrowness of the fruit and seed. The thickest part of the seed, that is the uppermost, is occupied by the bent part of the hypocotyl, the petioles, and base of the cotyledons. The latter are deeply concave on the inner face, and fit into one another edgeways; they are also pinnatifid with the lobes more or less imbricated and pointing towards the apex. They are nearly, although not quite, of equal width throughout after germination; but while yet in the seed the fission admits of their being folded into narrower space. This is necessary on account of the seed being very narrow and pointed like the fruit; whereas in Geranium the lower end of the fruit and seed is equally as wide as the upper end.

\section{Erodium trichomanefolium, L'Herit.}

Hypocotyl erect, terete, or somewhat decumbent at the base owing to the horizontal position of the seed from which it emerged, and which persists around the base of the seedling after it has attained some size, stout or somewhat succulent, glandular-pubessent, 5-9 mm. long.

Stem herbaceous or suffruticose, very short.

Cotyledons cordate or oblong-cordate, obtuse, entire at the apex or incipiently emarginate, entire at the sides or with a deep incision on one or both sides about the middle or lower down, usually very unequal at the base, thick, fleshy, glandular-pubescent above and on the petioles, glabrous beneath; lamina, 7-10.5 mm. long, 5-6 $\mathrm{mm}$. wide; petiole subterete, slightly grooved above, glandular-pubescent, $1 \cdot 2-1 \cdot 35 \mathrm{~cm}$. long.

Leaves simple, radical and cauline, alternate, stipulate (1st leaf 
almost or quite exstipulate and stipules usually very small in the 2nd leaf), petiolate, much divided, glaucous-green or somewhat cinereous, glandular-hairy all over; petioles subterete, channelled above, dilated and amplexicaul at the base, glandular-pubescent; stipules mostly adnate to the petioles, with membranous, colourless free tips.

No. 1. Ovate-cordate in outline, pinnatifid, with two to three oblong slightly toothed segments on each side.

Nos. 2 and 3. Cordate in outline, deeply bipinnatifid; basal pair of primary segments unequally ovate, the others oblong; secondary segments oblong or lanceolate, obtuse.

Ultimate leaves cordate-ovate, obtuse, interruptedly bipinnatisect; primary and basal pair of segments unequally or half ovate, the others subelliptic in outline, interrupted with small, irregularsized, entire or cut segments between; secondary segments somewhat similar, smaller; tertiary segments small, subulate or lanceolate, obtuse or subacute, mucronate.

\section{Erodium verbenæfolium, $D e l$.}

Hypocotyl erect, terete, glandular-pubescent, pale green, $3 * 5 \mathrm{~mm}$. long.

Cotyledons ovate-oblong, emarginate, unequally cordate at the base, where they are five-nerved, and alternately penninerved upwards, glabrous above except towards the base, glandular-ciliate, and glandular-pubescent beneath, light green; lamina $9 \mathrm{~mm}$. long on one side and $8 \mathrm{~mm}$. on the other, $7.5 \mathrm{~mm}$. broad ; petiole channelled above, dilated at the base and amplexicaul or perfoliate, glandular-pubescent and hairy, very unequal in length, one being sometimes twice as long as the other.

Average length of two long ones 8.75 mm.
,$" \quad$ short, $5.25 \mathrm{~mm}$.

Stem herbaceous, annual, developed when about to flower.

Leaves simple, radical and cauline, alternate, stipulate, petiolate, glandular-pubescent on both surfaces, greyish ; petioles semiterete, shallowly grooved above, dilated at the base and amplexicaul, glandular-pubescent and hairy; stipules adnate to the petiole, with rounded, hyaline, or membranous, glandular-ciliate, free points.

No. 1. Ovate-oblong, cordate at the base, bifid at the apex, deeply pinnatifid, alternately or suboppositely penninerved with the nerves directed straight into the lobes; segments obtusely dentate. 
No. 2. Similar but emarginate with a tooth in the notch or tridentate at the apex.

\section{Pelargonium australe, Willd. (fig. 229).}

Primary root normal, tapering, fibrous, annual.

Hypocotyl erect, terete, glandular-pubescent or -hairy, pale green or suffused with red, $6-8 \mathrm{~mm}$. above the soil.

Cotyledons ovate-oblong, emarginate, minutely mucronate in the notch, unequally subcordate at the base, shallowly crenate at the sides, glandular-hairy all over, light green ; lamina 9 $15 \mathrm{~mm}$. long, $7 \cdot 5-10 \cdot 5 \mathrm{~mm}$. broad; petiole subterete, shallowly grooved above, glandular-hairy, $1 \cdot 5-2 \cdot 1 \mathrm{~cm}$. long.

Stem herbaceous, annual, developed when about to flower.

Leaves simple, radical and cauline, alternate, stipulate, petiolate, light green, glandular-hairy all over, alternately and ascendingly penninerved; stipules adnate to the petiole for more

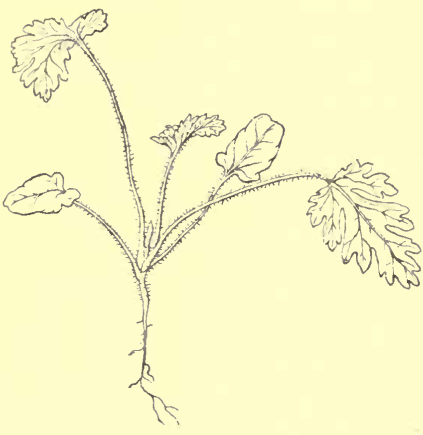

FIG. 229.-Pelargonium australe. Half nat. size. than half their length, with membranous, free, whitish, glandularciliate, tooth-like tips; petioles semiterete, channelled above, glandular-hairy and villous, pale green.

Nos. 1 and 2. Ovate, obtuse, cordate at the base, pinnatifid; segments again alternately penninerved, coarsely and obtuselytoothed or the lower sublobulate.

\section{Pelargonium bipinnatifidum, L'Herit.}

Primary root fibrous, well developed.

Hypocotyl herbaceous, $1 \mathrm{~cm}$. long, $2 \mathrm{~mm}$. thick, pubescent, reddish-green.

Cotyledons oval or obovate; lamina $1 \cdot 25-1 \cdot 5 \mathrm{~cm}$. long, $1 \cdot 25 \mathrm{~cm}$. broad, cordate at the base, slightly emarginate at the apex, otherwise entire, with obscure midrib, succulent, pubescent, bright green above, paler and reddish beneath; petiole pubescent and shallowly channelled, $1 \mathrm{~cm}$. long, $1 \mathrm{~mm}$. thick. 
Stem undeveloped in the early stage of the plant.

Leaves alternate, or more often opposite, three- to five-nerved at the base and alternately nerved upwards, reticulate, pubescent, membranous ; petioles generally long, tapering upwards.

No. 1. Long-stalked, cordate-ovate, obtusely serrate, lower half with palmate nerves, upper pinnatinerved, $3-4 \mathrm{~cm}$. long, $1.75 \mathrm{~cm}$. broad, pubescent, thin, bright green above, paler beneath.

Nos. 2 and 3. Pinnatifid with three to five lobes, otherwise as in No. 1.

Limnanthes Douglasii, R. Br. (fig. 230).

Primary root tapering, small, furnished with lateral rootlets at the base, or these are adventitious on the end of the hypocotyl. Numerous strong adventitious roots also given off at the end of the hypocotyl close to the base of the cotyledons; annual.

Hypocotyl stout, subterranean, terete or more or less flattened,

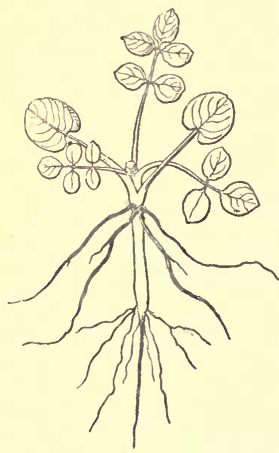

Fia. 230.

Limnanthes Douglasii. Nat. size. colourless, succulent, $1 \cdot 4-2 \mathrm{~cm}$. long.

Cotyledons petiolate, rotund-cordate, usually minutely emarginate, and marked at the apex with a small black scar, tipped with white, rather succulent, convex above and striate with broad shallow ridge-like veins, glabrous, deep green, subconcave beneath and minutely wrinkled, paler green; petiole semiterete, channelled above, dilated and sheathing at the base, seated rather deeply in the sinus of the leaf, glabrous. Lamina variable in size, $5-7 \mathrm{~mm}$. long and as broad.

Stem herbaceous, annual and developed when about to flower.

Leaves simple, radical and.cauline, alternate, exstipulate, petiolate, glabrous, rather succulent, simply or bi-pinnatifid or -sect; petioles semiterete, channelled above, dilated and sheathing at the base, glabrous.

No. 1. Ternately pinnatisect, often with five segments, which are shortly stalked but inarticulated, with the rachis rotund ; mucronate, obscurely alternately veined.

Nos. 2 and 3. Pinnatisect, each with five or more segments; segments rotund, mucronate.

Ultimate radical leaves ovate or oblong-lanceolate, bipinnati- 
petiolate and allowing the plumule to pass out between them on one side.

Stem herbaceous, perennial, succulent, flexuose, ultimately climbing or scrambling amongst other vegetation, glabrous, terete, pale green; first internode very variable in length according to the depth the seed is buried in the soil ; second undeveloped, bringing two leaves opposite.

Leaves simple, cauline, alternate (first two opposite), exstipulate (first two stipulate), petiolate, peltate, radiately-nerved, lobulate, deep green above, with a narrow, red or yellow margin, pubescent on the nerves, ultimately glabrous, glaucous beneath, glabrous, and densely corered with sessile glands; petioles succulent, terete, glabrous, shining, tapering from a very stout base to the thinnest part immediately at the insertion of the blade; stipules of the first two leaves small, subulate, coloured like the stem, $1.5 \mathrm{~mm}$. long.

Nos. 1 and 2. Opposite, peltate, with eight radiating nerves, shallowly trilobulate; lobes rounded, entire or minutely emarginate.

No. 3. Peltate, eight-nerved, seven-lobulate, with the eighth nerve running into the sinus at the base of the leaf; lobes shallow, rounded, emarginate.

Nos. 4 and 5. Similar to No. 3.

Ultimate leaves peltate, seven-nerved and lobulate, with two short nerves running into the broad shallow basal sinus; lobes broad, shallow, emarginate.

\section{Tropæolum aduncum, $S m$.}

Primary root long, fleshy, colourless, with few lateral rootlets.

Hypocotyl and cotyledons as in T. majus.

Stem erect, otherwise as in T. majus; 1st internode in the specimen examined $4 \cdot 6 \mathrm{~cm}$. long, but variable according to conditions and capable of elongating considerably if the seed is deeply buried in the soil; 2nd internode varying from 1-3.5 mm. or more.

Leaves palmately or subpedately nerved and lobed, reticulate, glabrous, light green above, paler beneath; petiole terete, tapering upwards from a stout base, glabrous, pale green.

Nos. 1 and 2. Tripartite, with the lateral lobes again deeply bifid ; middle segment oblong-oval, obtuse, entire ; ultimate lateral lobes oblong, obtuse, entire.

No. 3. Tripartite; middle segment cuneate, trifid, with obtuse lobes; lateral segments again bifid with the anterior lobe more or less toothed, teeth obtuse. 
knob externally to the testa, which is slightly indented at this point, thus apparently causing the emargination of the cotyledons.

Endosperm none, or forming an extremely thin membranous covering adhering to the inner surface of the testa.

Embryo straight, large, filling the eavity of the seed and conforming to it in shape, pale yellowish-white ; cotyledons obovateoblong, minutely emarginate, subcordate at the base, plano-convex, and rather fleshy; radicle very short, subglobose, stout, obtuse, much shorter than the cotyledons, which envelope half of it together with the plumule, the other half protruding.

\section{Impatiens Balsamina, L. (fig. 234).}

Primary root a short tap-root, succulent, colourless, unbranched, while many nearly horizontal rootlets spring from base of the hypocotyl.

Hypocotyl about $4 \mathrm{~cm}$. long, $2 \mathrm{~mm}$. thick, terete, succulent, glabrous, reddish near the base, greenish-white above.

Cotyledons shortly stalked, not quite equal, $2-2.5 \mathrm{~cm}$. or more long, about $1.5 \mathrm{~cm}$. broad, broadly ovate, cuneate at the base, apex rounded and emarginate, otherwise entire, obscurely palmatinerved with sunk midrib, convex, quite glabrous, light green above, paler below, somewhat succulent, not very persistent.

Stem erect, herbaceous, annual, stout, succulent, terete, densely pubescent, pale greenish-yellow; 1st internode $1 \cdot 5-2$ or $3 \mathrm{~cm}$. long, $2 \cdot 5 \mathrm{~mm}$. thick ; 2nd 2-3 mm. long.

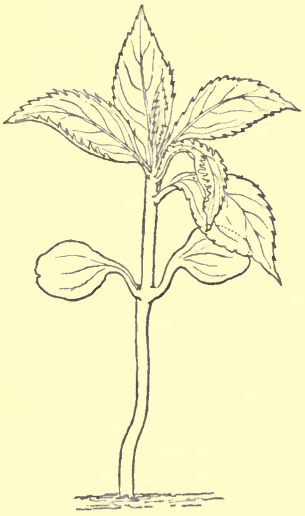

Frg. 234.-Impatiens Balsamina. Half nat. size.

Leaves simple, cauline, opposite or subalternate, petiolate; stipules obsolete; lamina lanceolateelliptic, acute, acutely serrate, with small, subincurved, gland-tipped serratures, pale green above and shining, paler beneath, glabrous ; nerves ascending and incurved, mostly alternate; petiole rathor broad and widening towards the leaf, flattened above, convex and pubescent beneath, 2-3 $\mathrm{mm}$. long; pubescence often extending on to the midrib of the leaf underneath.

1 st to $3 \mathrm{rd}$ pairs lanceolate-elliptic, subacuminate, acutely serrate, cuneate or tapering at the base. 
Impatiens fruticosa, Lesch. (fig. 235).

Hypocotyl succulent, terete near the base, obtuse-quadrangular just below the seed-leaves, glabrous, about $5 \mathrm{~cm}$. long, 3-4 $\mathrm{mm}$. thick, brownish.

Cotyledons very similar to those of I. Balsamina, obscurely trinerved, plane, fleshy, glabrous except the broad, reddish, slightly downy petiole, yellowish-green above, pale and shining beneath.

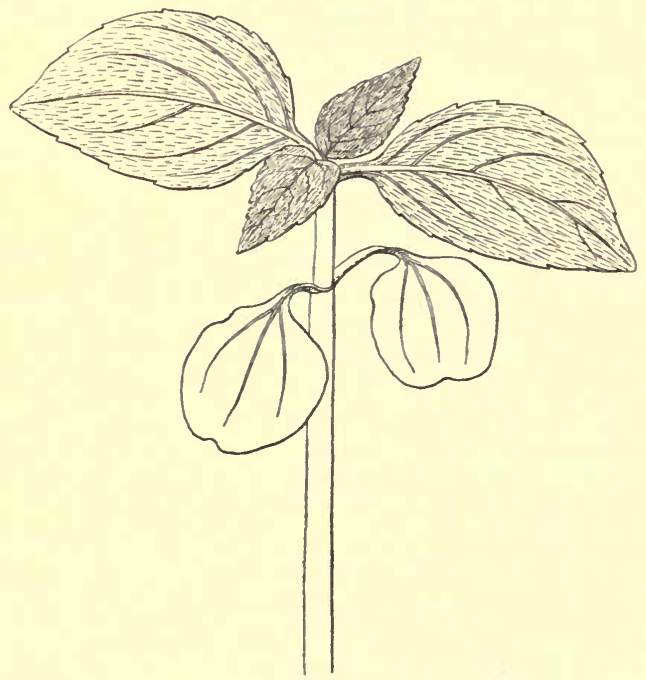

Fig. 235.-Impatiens fruticosa. Nat. size.

Stem succulent, terete, glabrous, light green; 1st internode 2 or $3 \mathrm{~cm}$. long, $3 \mathrm{~mm}$. (or more) thick, 2nd shorter.

Leaves.-Nos. 1-6. All alike; 5-6 cm. long, including the stout, hairy, short petiole; $2.5 \mathrm{~cm}$. or more broad, ovate-elliptic, subacute at base, acuminate at apex, equally shallowly serrate, teeth mucronate; very distinctly penninerved, covered all over with a long soft pubescence (woolly to touch), bright green above, paler beneath. 


\section{RUTACE E.}

Benth. et Hook. Gen. Pl. i. 278.

Fruit and Seed.-The carpels forming the ovary in this Order vary from three to five, rarely more or less as in Thamnosma and Atalantia, some species of which have dimerous oraries. Whatever the number of carpels, they are united into an ovary with as many cells, except in Galipea, Zanthoxylum, and a few others, where the carpels are quite free. The ovules in each cell are very frequently two and superposed, but they also vary from three or four to many. They are pendulous, anatropous, or semianatropous. The raphe is ventral, the micropyle superior. The fruit varies greatly, but is capsular in the more typical Rutaceæ, opening by valves along the back or at the top as in Ruta, or breaking up into coeci which dehisce along the ventral suture. In many cases the exocarp breaks away elastically from a coriaceous, horny, crustaceous, or cartilaginous endocarp. In the tribe Toddalieæ the fruit is often baccate or drupaceous; instances of the latter are to be seen in Skimmia, Toddalia, and Phellodendron. The fruit of Ptelea, belonging to this tribe, is an orbicular samara, and in Helietta it consists of three samaras. That of the tribe Aurantiex is most often pulpy with a coriaceous separable rind.

The seeds are oblong as in Ptelea trifoliata, or often reni. form as in Monnieria, Ruta, and Bœenninghausenia, or obovoid as in Dictamnus, Skimmia, Citrus, and others. They are usually suspended from the top or the middle of the placentas. The testa is spongy, or more often crustaceous and shining as in Dietamnus, or it is pitted and granular. The outer coat is said to resemble an aril in Hortia. Endosperm is scanty or wanting in a large number of genera; but in the tribes Ruteæ, Boronieæ, Toddalieæ, and in most of the Zanthoxyleæ it is present in some quantity and fleshy, sometimes also oily. The embryo is very frequently curved according to the shape of the seed, or straight where the latter is obovoid. The radicle is superior and varies in length, being as long as 
the cotyledons in Ruta, with a reniform seed, and very short in Citrus and Dictamnus with obovoid seeds.

A very abnormal condition prevails in the seed of the Orange (Citrus Aurantium). Each contains from two to four embryos sufficiently developed to germinate and grow into plants, besides a similar or even greater number of very small ones that are unable to germinate. The large ones are fleshy, colourless, and nearly always have very unequal cotyledons of various shapes owing to mutual compression. There is usually one large cotyledon in each seed, belonging probably to the true embryo, while all the rest are smaller, and packed on to the face of the large one, completely filling the seed. The large cotyledon is often deeply concare with the others packed into the cavity. Strasburger states that the supernumerary embryos are developed by prolification from the tissue of the nucellus bordering on the embryo-sac.

A similar case occurs in Triphasia trifoliata, and is probably due to the same cause. The seed is exalbuminous as in the Orange, and generally contains two embryos of different sizes, with usually very unequal cotyledons. The larger cotyledon is concavo-convex or in some cases infolded at the sides. Three embryos are also not unusual, when one or other of the cotyledons is infolded and often more or less deeply lobed. This is due sometimes to one cotyledon becoming folded over the edge of the other.

Seedlings. - The seedlings I have met with all belong to the shrubby or arboreal types of Rutacer. Amongst them two leading types of cotyledons may be observed, namely, an aerial and a subterranean one. Those of Correa Colvillei are lanceolate, one-nerved, and taper to a very short petiole. The cotyledons of $\mathrm{C}$. viridiflora differ in being narrower and linearoblong. Ptelea trifoliata has more foliaceous, unequally oblong, finely crenulate cotyledons. Those of P. aptera differ in being proportionately longer and oblong-lanceolate. In Limonia acidissima we have a type that is intermediate between those having strictly aerial and strictly subterranean cotyledons. Although they are carried to a considerable height above the soil they are fleshy, pale green, and fall away early. Their function is evidently to constitute a storehouse 
for reserve-material and not to assimilate after germination. They are nearly always alternate, and two, rarely three in number. Murraya exotica agrees in the deciduous nature of its cotyledons.

The subterranean type may be represented by Calodendron capense, which has very large seeds and fleshy, shortly petiolate cotyledons. Those of Citrus Aurantium are much smaller, opposite or frequently alternate, colourless, fleshy, often compressed and of variable shape owing to the presence of several embryos in the seed, and strictly subterranean. In C. decumana they are oblong-elliptic, slightly falcate, plano-convex, fleshy, greenish-yellow, and both directed to one side of the stem as in some other cases where the cotyledons are subterranean. Egle Marmelos has similar, but smaller, rounder seeds with cotyledons like those of the Pea.

There is considerable variation in the first leaves. The first one of Correa Colvillei is oval, the three succeeding ones roundly-elliptic. Those of C. viridiflora are obovate; and they differ but little in the adult stage, as the leaves of all the Correas are of very simple forms and quite entire. The leaves of Ptelea trifoliata are digitately trifoliolate from the first, or the primary leaf may be imperfect and have only two leaflets. Their margins are doubly and bluntly denticulate or crenulate, bearing some resemblance to those of the cotyledons, but the latter differ in being merely simply crenulate with distinctly rounded crenatures. The first leaf of $\mathrm{P}$. aptera is simple and acuminate-lanceolate, followed by one that is digitately trifoliolate or imperfectly so, and that again by one having four or five leaflets. The first two or three leaflets of Limonia acidissima are ovate and alternate, opposite, or verticillate; the second and third digitately trifoliolate or pinnate, in other individuals with five opposite elliptic leaflets, and winged midribs. Murraya exotica differs in the first two leaves being opposite and triangular-ovate, and in the succeeding ones being pinnate with three or four alternate entire leaflets.

The first six leaves of Calodendron capense are reduced to small scales, a case of frequent occurrence where the seeds are large with subterranean cotyledons. Those that succed 
are opposite, lanceolate, and entire, whereas those of the adult are acutely crenulate. The first two leaves of Citrus Aurantium are opposite, orbicular, emarginate, while succeeding ones are elliptic. C. decumana differs only by sometimes having the first four leaves in a whorl. The first and second of Egle Marmelos are nearly opposite, broadly ovate, and doubly crenate.

Calodendron capense, Thunb.

Hypocotyl undeveloped.

Cotyledons large, thick and fleshy, occupying the whole interior of the seed, subterranean, and remaining in the seed till they are absorbed or decayed, shortly petiolate; petioles stout and subfleshy, their presence being necessary to allow the plumule to emerge from the seed.

Stem erect, terete, densely pubescent, pale green, soon becoming brownish, and dotted with small corky spots, ultimately woody and arborescent; primary internodes variable, with the primary leaves undeveloped.

Leaves simple, cauline, opposite or verticillate in threes, exstipulate, petiolate, decussate, alternately penninerved (with the nerves in the young plant at least irregularly disposed), reticulate, closely punctate, with pellucid glands, and a marginal, rather conspicuous row of larger ones, deep green above, much paler beneath, minutely pubescent on both surfaces; petioles very short, subterete, flattened or convex on the upper side, densely pubescent.

First six leaves in the specimen described reduced to scales.

Nos. 1-3. On the same level, falling away early, very small.

No. 4. Alternating with the others, small.

Nos. 5 and 6 . Alternate or nearly opposite, green, lanceolate, obtuse, densely pubescent, about $3 \mathrm{~mm}$. long.

4 th to 11 th pairs opposite.

4th pair foliaceous, lanceolate, obtuse, minutely auricled at the base.

5th pair much larger, lanceolate-elliptic, obtuse, slightly auricled at the base.

6th to 11th pairs lanceolate-elliptic or oblong-elliptic, obtuse, narrowed to both ends but especially to the base, where they are distinctly auricled. Younger ones developing unequally.

Correa Colvillei, Hort.

Primary root long, slender, flexuous, with much branched, long, lateral rootlets. 
Hypocotyl $1 \cdot 5-2 \cdot 5 \mathrm{~cm}$. long, $1 \mathrm{~mm}$. thick, terete, glabrous, light green, firm.

Cotyledons nearly equal, $1 \cdot 5 \mathrm{~cm}$. long, $\cdot 5 \mathrm{~cm}$. broad, obtuse, lanceolate, entire, with obscure nervation but distinct midrib, glabrous, dark green on the upper surface, pale on the under, coriaceous, with large brownish buds in the axil.

Stem firm, terete, with scattered brown stellate hairs, giving it a woolly appearance; internodes only a few millimetres long, $1 \mathrm{~mm}$. thick.

Leaves simple, entire, cauline, opposite or sometimes alternate in individual plants, exstipulate, shortly petiolate, more or less densely covered with a stellate pubescence, at least in the young state, obscuring the not very distinct venation, coriaceous, deep green above when the stellate tomentum is removed, whitish beneath; petioles short, stellately tomentose.

Nos. 1 and 2. More or less opposite, shortly petioled, with swollen light brown buds in the axil of the woolly petiole; lamina $1.25 \mathrm{~cm}$. long, $\cdot 5 \mathrm{~cm}$. broad, obtuse, elliptic, entire, with sunk midrib and covered with whitish dots formed by woolly stellate hairs, coriaceous, flat, with revolute margin, dark green above after disappearance of hairs, whitish below.

Nos. 3-5. Similar, but alternate and suborbicular.

\section{Correa viridiflora, $A n d r$.}

Hypocotyl erect, terete, about 10-12 mm. above the soil.

Cotyledons linear-oblong, obtuse, entire, narrowed at the base to a short petiole about $15 \mathrm{~mm}$. long, $2 \cdot 5-3 \mathrm{~mm}$. wide.

\section{Ptelea aptera, Parry.}

Hypocotyl about $2 \mathrm{~cm}$. long, 1-1.5 mm. thick, firm, quadrangular at the base, terete just under the seed-leaves, verrucose, green.

Cotyledons subsessile, $3-3.5 \mathrm{~cm}$. long, $1 \mathrm{~cm}$. broad, oblonglanceolate, acute at the base, obtuse at the apex, minutely crenate, with distinct midrib and verrucose, glandular surface, dark green above, rather paler beneath.

Stem terete but scabrous-verrucose, green; 1 st internode $\cdot 5 \mathrm{~cm}$. long, $1 \mathrm{~mm}$. thick, 2nd and 3rd $1 \mathrm{~cm}$. long, less than $1 \mathrm{~mm}$. thick.

Leaves compound, digitately trifoliolate or pinnately five-foliolate, cauline, alternate, exstipulate, petiolate, alternately penninerved with the nerves somewhat incurved towards the tip, reticulate, coriaceous, glabrous, deep green above, paler beneath, with 
characteristically strong-smelling stems and leaves; petioles semiterete, channelled above.

No. $1.2 \cdot 5-3 \mathrm{~cm}$. long (including petiole $5 \mathrm{~mm}$.), 6-8 $\mathrm{mm}$. broad, lanceolate, acuminate at both ends, crenulate or bicrenulate, pinnatinerved, rugose, firm, not very thick, dark green above, light shining green beneath, with a tomentose bud in axil of petiole.

No. 2. Similar, but larger, and with a small leaflet at base of blade.

No. 3. Similar, ternately pinnate with large terminal leaflet, sometimes two large and two small leaflets.

\section{Ptelea trifoliata, $L$.}

Hypocotyl finely and minutely pubescent, 8-15 mm. long.

Cotyledons unequally oblong, obtuse, shortly petiolate, finely crenulate, deep green, rather opaque, alternately and ascendingly penninerved, glabrous except on the midrib beneath ; lamina 10-15 $\mathrm{mm}$. long, 5-7 mm. broad ; petiole slightly grooved above, pubescent beneath only, 2-2.75 $\mathrm{mm}$. long.

Stem pubescent with curved or curled hairs, ultimately woody ; 1st internode $3 \cdot 5-5 \cdot 5$ or $6 \mathrm{~mm}$. long, $2 \mathrm{nd} \cdot 5-1 \cdot 25 \mathrm{~mm}$.

Leaves trifoliolate, hairy on the midrib and margins of leaflet and petiole when young, ultimately glabrous; leaflets alternately and ascendingly penninerved; petioles semiterete, channelled above.

Nos. 1 and 2. Usually trifoliolate ; terminal leaflet elliptic, obtuse, irregularly and obtusely dentate ; lateral leaflets smaller, sometimes very much smaller, oblong-elliptic, obtuse, irregularly and obtusely dentate. Sometimes one of the lateral leaflets of the first leaf is wanting.

\section{Limonia acidissima, $L$.}

Hypocotyl becoming woody, erect, terete, finely pubescent, wiry, pale green, $2 \cdot 3-2 \cdot 9 \mathrm{~cm}$. long.

Cotyledons two, rarely three, mostly alternate, fleshy, oblong, obtuse, pale green, finely pubescent, sessile or subsessile, somewhat notched at the base.

Stem woody, erect, terete, finely pubescent, wiry ; 1 st internode variable, 1.6-2.3 cm. long; 2nd $2 \mathrm{~mm}$.; 3rd $3 \mathrm{~mm}$.; 4 th $7 \cdot 5 \mathrm{~mm}$.

Leaves compound, cauline, alternate, exstipulate, petiolate, glabrous, deep green, shining, pubescent on the nerves beneath when young, permeated with translucent glands, doubly crenulate, emarginate; petioles subpubescent, winged with a prominent midrib, - and tapering towards the base. 
Nos. 1 and 2. Unifoliolate, frequently also Nos. 3 and 4. All alternate at greater or less distances from each other, or in pairs, or all four verticillate, ovate, obtuse, emarginate, articulated at the top of their petioles, or the lowest pair articulate at the base only.

Nos. 3 and 4. Frequently digitately trifoliolate, the terminal leaflet being lanceolate-elliptic, attenuate at the base; the lateral leaflets arise by segmentation from the terminal one.

No. 4. In some instances five-foliolate; the rachis between the basal and next pair of leaflets winged and tapering towards the base in the same way as the primary petiole; leaflets sessile, lanceclateelliptic, emarginate, minutely and doubly crenulate, smaller than the leaflets of unifoliolate leaves.

Murraya exotica, $L$.

Stem woody, pubescent and rerrucose when young, becoming corky; 1st internode $3.1 \mathrm{~cm}$. long; 2nd $1.4 \mathrm{~cm}$.; 3rd $7 \mathrm{~mm}$.; 4 th $4 \mathrm{~mm}$.; 5th $5.5 \mathrm{~mm}$.

Leaves compound, imparipinnate, cauline, alternate (Nos. 1 and 2 opposite and simple), exstipulate, petiolate, evergreen, glabrous, deep green.

Nos. 1 and 2. Triangularly ovate, obtuse, entire, penninerved, with a sunk midrib, convex above, provided like the rest with internal resin or oil glands; petiole deeply channelled above, $4 \mathrm{~mm}$. long.

No. 3. Pinnately trifoliolate; lateral leaflets rotund-elliptic ; terminal one elliptic; all obtuse, coriaceous ; petiole flattened above, pubescent, subverrucose; rachis between leaflets similar to petiole and articulated with the leaflets.

No. 4. Similar to No. 3, but muclı smaller.

No. 5. Imparipinnate; leaflets four, alternate, irregular in size and sliape, oblong or lanceolate, obtuse, entire-the terminal one much the largest.

No. 6. Imparipinnate; leaflets four, irregular oval, oblong, or subelliptic, obtuse.

Jltimate leaves three- to five-foliolate; leaflets alternate, ovate, subacuminate, emarginate, slightly narrowed to the base, coriaceous, evergreen, petiolulate, shining; petioles, petiolules, and midrib pubescent on both surfaces.

Citrus Aurantium, Risso.

Primary root stout, tapering, twisted, furnished after a time with a few lateral rootlets, longitudinally ridged and furrowed, at least when dry. 
Hypocotyl subterranean, short, stout, curved, longitudinally ridged, colourless, $2-3.5 \mathrm{~mm}$. long.

Cotyledons two, opposite or frequently alternate, colourless, fleshy, not leaving the testa, but very often compressed and shapeless owing to the presence of two, three, or four embryos in the seed.

Stem woody, erect, terete (striate when dried and somewhat twisted), pale green, glabrous or minutely pubescent; 1 st internode $2.5-4 \mathrm{~cm}$. long; 2 nd, and sometimes the $3 \mathrm{rd}$ and $4 \mathrm{th}$, undeveloped, or the 3 rd $3 \mathrm{~mm}$. and the 4 th $2.25 \mathrm{~mm}$. long.

Leaves simple, cauline, alternate, exstipulate, petiolate, evergreen, shining, coriaceous, thickly dotted with immersed glands, strongly odoriferous when bruised, glabrous.

Nos. 1 and 2. Generally opposite by the non-development of the internode, more or less obliquely obcordate and appearing deformed very shortly petiolate.

Nos. 3 and 4 (in specimen examined). Alternate, elliptic, obtuse, obsoletely serrate, minutely emarginate, with alternate, ascending, lateral nerves; petioles channelled above, narrowly winged, articulated with the stem below and the leaf above.

Ultimate leaves oblong-ovate, acuminate, emarginate, minutely and obsoletely serrate, pellucidly punctate, with a thin marginal line of larger glands ; lamina articulated with the winged petiole, which is ovate in outline, with a short, stout, not winged base.

Citrus decumana, $L$.

Hypocotyl very short, subterranean.

Cotyledons subterranean, and remaining in the seed till they decay, oblong-elliptic, obtuse, plano-convex, fleshy, sessile and both directed to one side, greenish-yellow above, yellowish beneath, somewhat falcate, $13 \mathrm{~mm}$. long, and $6 \mathrm{~mm}$. wide.

Stem soon becoming woody, covered with a short, very fine pubescence ; 1 st internode $5-5 \cdot 5 \mathrm{~cm}$. long; the one to three following ones suppressed, or from two to four of the leaves on the same level; succeeding ones again elongated.

Leaves as in C. Aurantium.

1st pair opposite, orbicular, emarginate, subsessile, not articulated with the short petiole, crenate.

2nd pair often on the same level as the first two, so that there is a whorl of four. When distinct oblong or elliptic, obtuse, otherwise like the two preceding. base.

5th (where the first four are whorled) elliptic, cuneate at the 
6th obovate-elliptic, more elongate and cuneate at the base, with a swelling of the midrib some distance above the base, corresponding to articulation.

7 th leaf ovate, bluntly pointed, articulated with an oblanceolate, winged petiole, obsoletely crenate.

\section{Egle Marmelos, Corr.}

Hypocotyl short, subterranean.

Cotyledons subterranean, fleshy, plano-convex, rotund-oval in outline, $7.25 \mathrm{~mm}$. long including the very short petiole, $5.25 \mathrm{~mm}$. broad.

Stem erect, terete, woody, pubescent, pale green; 1st internode $3.1 \mathrm{~cm}$. long; 2nd $1 \mathrm{~mm}$.; 3rd $8 \mathrm{~mm}$.

Leaves simple, cauline, alternate, exstipulate, petiolate or subsessile, glabrous, alternately penninerved and reticulate, perforated with glands, deep green above, paler beneath, tapering to the base; petioles short or none.

Nos. 1 and 2. Broadly ovate, obtuse, emarginate, doubly crenulate, nearly opposite.

No. 3. Elliptic, obtuse, emarginate, doubly crenulate.

Further stages show leaves obovate and rotund-elliptic, large, obtuse, emarginate, doubly crenate.

Ultimate leaves digitately trifoliolate, lateral leaflets ovate or ovate-elliptic, crenate; terminal one slightly larger, elliptic, obtuse, emarginate, crenate, or obscurely doubly crenate, penninerved and reticulate.

\section{SIMARUBEE.}

Benth. et Hook. Gen. Pl. i. 306.

Fruit and Seed.-The ovary in this Order is made up of two to five carpels, rarely one as in Cneoridium and Amaroria, and is more or less deeply two- to five-lobed, or the carpels are altogether free. When the carpels cohere they form an ovary with as many cells as there are carpels; the cells in Cneorum tricoccum are sometimes spuriously bilocellate with superposed ovules and cavities. The ovules are generally solitary, rarely four to five as in Dictyoloma or numerous as in Kœberlinia; and they are pendulous, anatropous, amphitropous, or variously curved. The raphe is ventral, and the micropyle superior as a 
rule, but there are cases where it is inferior as in Suriana and Cneoridium. In Dictyoloma and Kœberlinia they are numerous, ascending, with the raphe dorsal. The fruit is drupaceous or dry and indehiscent," sometimes with a woody endocarp as n Cneorum and Simaba, or it is capsular and dehiscent as in Dictyoloma and Brunellia, or samaroid as in Ailanthus and Soulamea. The seeds are generally solitary and pendulous, with a membranous or sometimes crustaceous testa as in Cneorum. Endosperm is copious and fleshy, or scanty, or altogether wanting. The embryo is straight with flat or planoconvex cotyledons, more or less semiterete. In rare cases they are twisted, and in the large-seeded Simaba they are thick, fleshy, and plano-convex.

A longitudinal section of one of the cocci of Cneorum tricoccum shows the curious manner in which the seed and embryo are curved so as to accommodate themselves to the interior of the bony endocarp. The testa is not folded, while the tegmen containing the fleshy endosperm and the embryo is doubled up on itself. A transverse section of another coccus shows two seeds occupying the cavity. In Dictyoloma the seed is winged. The fruit of Ailanthus glandulosa consists of one to five samaras, but, in Britain at least, only one is usually brought to maturity although two are not unusual. The samara is oblong or oblanceolate, nearly straight on the ventral edge with a small indentation above the middle, where the solitary seed is located, and more or less rounded on the back, laterally compressed and membranous. The seed lies in a slightly elevated cavity of the samara, and is obliquely pendulous, anatropous, and laterally flattened. The embryo lies in the broader plane of the seed, embedded in endosperm, which it nearly equals in length and width. The cotyledons are obovate, nearly flat, and conform to the shape of the seed, with their edges to the placenta. The superior radicle is several times shorter than the cotyledons.

Seedlings.-This Order is mainly tropical, and with exception of a few species of some medicinal importance, together with the hardy Ailanthus glandulosa and Cneorum tricoccum, are seldom seen in a living state in this countr5, consequently seedlings seldom come under observation. The cotyledons of 
Cneorum tricoccum are sessile, linear, one-nerved, and subcoriaceous. The primary leaves are lanceolate-elliptic or oblong, obscurely penninerved, and entire, as they are in the adult state.

The cotyledons of Ailanthus glandulosa are also aerial, foliaceous, obovate, and shortly petiolate. The first two leaves are pinnately trifoliolate, and remind one of those of Rhus typhinus. Young trees are vigorous; the leaves vary from eighteen inches to three feet in length, with numerous pairs of leaflets.

\section{Ailanthus glandulosa, Desf.}

Fruit consisting of one to five samaras comparable to those of Fraxinus. Samaras indehiscent, thin or membranous, strongly winged, oblong or oblanceolate, obtuse, tapering downwards and suddenly narrowed to the receptacle on the dorsal edge at the base, notched on the ventral aspect close to the attachment of the seed, and elevated into a hemispherical swelling where the latter is situated.

Seed obovate, biconvex, flattened, conforming to the cavity pretty closely when fresh, but shrinking considerably when dry, pale whitish, descending obliquely; hilum a little below the pointed upper end, and on the ventral edge of the seed; raphe ventral ; chalaza pale brown at the lower and broader end of the seed ; testa thin, membranous.

Endosperm moderately copious, fleshy, surrounding the embryo.

Embryo straight, colourless, large, almost as long as the endosperm.

Cotyledons broadly obovate, slightly auricled at the base so as to accommodate the radicle; the latter stout, obtuse, several times shorter than the cotyledons, embedded in endosperm close to the pointed end of the seed, and consequently a little above the hilum.

\section{A. glandulosa, var. rubra.}

Hypocotyl erect, terete, glabrous, 2:3-3 cm. long, light green or colourless.

Cotyledons coriaceous, broadly obovate, obtuse, entire, shortly petiolate, glabrous, light green, distinetly and alternately pinnatinerved.

Stem erect, herbaceous, ultimately woody, slightly flattened, covered with fine hairs, light green ; 1st internode 5-8 mm. long.

First leaves compound, trifoliolate, petiolate, exstipulate ; ter- 
minal leaflet acuminate, subacute, entire; lateral ones slightly toothed, ultimately glabrescent, petiolulate, light green, alternately pinnatinerved ; petioles ribbed or striated, covered with short, glandular hairs; the young leaves are also covered with fine silky hairs near their edges.

\section{Cneorum tricoccum, $L$.}

Fruit separating from the gynophore into three cocci, each ovoid, with a free projecting base, which is by far the thickest part, and from which it gradually tapers to the tip, where it is crowned by the base of the persistent style; one- to two-seeded, indehiscent ; epicarp deep green before maturity, and retaining that colour if picked; mesocarp fleshy, moderately thin; endocarp very thic $\mathrm{k}$, bony, brown when dry, and deep reddish-brown when mo ist.

Seed oboroid, suspended obliquely from near the top of the inner angle of the cell; testa thick-walled, crustaceous, adhering closely to the endocarp and deeper than it in colour; tegmen thin, membranous, adhering more to the endosperm; micropyle and hilum basal at the upper end of the seed; chalaza at the apex of the curve of the endosperm, leaving a brown mark there when the latter containing the embryo is removed from the testa.

Endosperm copious, fleshy, white, curved nearly in the middle so as to bring the apex near to a level with the basal end containing the radicle, surrounding the embryo.

Embryo much curved, surrounded on all sides by endosperm, colourless when moist; cotyledons linear, obtuse, entire, planoconvex, curved, about equal in length to the radicle, accumbent, and placed with their edges to the placental axis or slightly obliquely to it ; radicle cylindrical, obtuse, less curved than the cotyledons, which about equal it in length, extending a little beyond the cotyledons and nearer the hilum.

\section{Seedling.}

Primary root long, wiry, tapering, colourless, with a few lateral rootlets.

Hypocotyl woody, erect, terete, glabrous, green above ground, $1 \cdot 5-2 \mathrm{~cm}$. long.

Cotyledons sessile, linear, plano-convex, or with the sides somewhat upturned, making them grooved, subacute, cuspidate, or suddenly and obtusely pointed, subcoriaceous, not very persistent, deep green above, paler beneath, $1 \cdot 5 \mathrm{~cm}$. long, $2 \cdot 5 \mathrm{~mm}$. broad.

Stem shrubby, flexuous, much branched from an early stage 
onward, terete, minutely pubescent, green; 1st internode $7 \mathrm{~mm}$. long; 2nd 4.5 mm.; 3rd $3 \mathrm{~mm}$.; 4 th $4 \mathrm{~mm}$.; 5th $5.75 \mathrm{~mm}$.

Leaves simple, entire, cauline, alternate, exstipulate, sessile, coriaceous, evergreen, with a prominent midrib on both surfaces, glabrous or minutely pubescent at the base of the midrib beneath, slightly revolute at the margin, shining, deep green above, paler beneath.

Nos. 1-5. Lanceolate-elliptic, obtuse, gradually larger from the base upwards.

Ultimate leaves lanceolate-oblong, obtuse, mucronate, about $3-4 \mathrm{~cm}$. long.

\section{OCHNACEE.}

Benth. et Hook. Gen. Pl. i. 316.

Frnit and Seed.-The ovary is central or excentric, short and two- to ten-lobed, or elongated and one- to ten-celled, with axial or parietal placentation, or the ovules are inserted on the inflexed margins of the carpels. Instances of the short ovary are seen in Gomphia and Ochna, a few of which are grown as stove-plants in this country. The carpels are seated on a large receptacle, round the sides of which they are arranged and connected at the extreme base with the central style. They are so widely separated in the ripe fruit of Ochna that they appear apocarpous. The usual number of ovules in each cell is one or two, sometimes many; they are ascending and andtropous, with an inferior micropyle and ventral raphe, rarely pendulous with a superior micropyle. A one-celled ovary with three parietal placentas occurs in Wallacea.

The fruit consists of three to ten drupes arranged in a whorl, as in Oclneæ, with one ovule in each cell, and exalbuminous seeds. In Euthemis it consists of five portions having a woody endocarp, and albuminous seeds. It is capsular in the tribe Luxemburgieæ with albuminous seeds. Where present the endosperm is fleshy. The testa is membranous in most cases, but is winged in Luxemburgia, thick in Wallacea, and produced into a linear sheath in Cespedesia.

The embryo is generally straight and terete, but there are exceptions, especially amongst the exalbuminous seeds. The 
cotyledons are very thick and plano-convex in Ochna, Gomphia, and Elvasia, with an exceedingly short radicle. Both the seed and the embryo are annular in Brakenridgea, while the cotyledons are linear. Where endosperm is wanting, as in the Ochneæ, the embryo conforms in outline to that of the seed; and when the latter is solitary it is large, and conforms to the

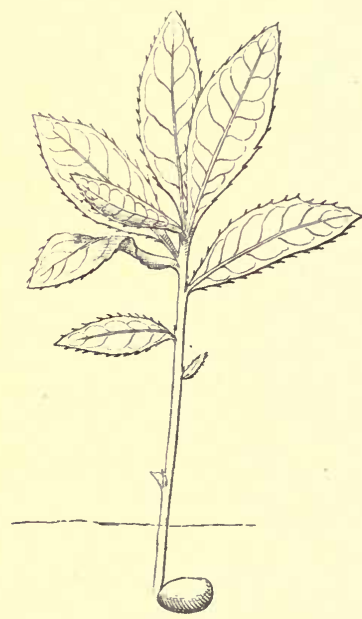

Fig. 236.

Ochna Kirkii. Nat. size. cavity of the carpels. In albuminous seeds the embryo where known is generally slender.

A good instance of the exalbuminous type is Ochna Kirkii.

Seedlings.-The cotyledons of Ochna Kirkii (fig. 236) are thick, fleshy, subterranean, and represent the exalbuminous type. Here it will be noted that the first two leaves are reduced to scales.

\section{Ochna Kirkii, Oliv.}

Fruit of three to ten drupes arranged around a central, large, elevated torus or disk, with a gynobasic style, best seen in the young condition; drupes shortly oblong, slightly laterally compressed, fixed to the torus by an oblique lateral scar near the base, and diverging outwards, glabrous and shining black when mature, and falling away separately; walls of drupe comparatively thin with very little pulp; endocarp subcrustaceous, dull greenish, and reticulated internally when fresh.

Seed solitary in each cell, large, and conforming to the interior of the drupe, which it closely occupies ; testa thin, membranous, brown; hilum and micropyle contiguous, close to or at the lateral scar of the drupe, where it is fixed to the axis.

Seedling (fig. 236).

Hypocotyl short or none, subterranean.

Cotyledons fleshy, plano-convex, filling the seed, which fills the 
carpel, remaining in the ground attaching the seedling to the fruit till the latter is exhausted.

Stem woody, shrubby, erect, terete, pale green, glandular-pubescent; 1st internode $1.2 \mathrm{~cm}$. long; 2nd $1.4 \mathrm{~cm}$.; 3rd $5 \mathrm{~mm}$.; 4 th $6 \mathrm{~mm}$.; 5 th $2.5 \mathrm{~mm}$; 6th $1.5 \mathrm{~mm}$.; 7 th to 10 th crowded or undeveloped.

Leaves simple, glandular-ciliate, serrate, cauline, alternate, stipulate, subsessile, thickened at the base and articulated with a raised knob or projection of the stem, glabrous, deep shining green, and finely reticulate above, paler beneath and shining; midrib prominent on both surfaces; stipules small, brown, scarious, rigid, subulate, connate by their edges for two-thirds of their length or throughout, and lying between the leaf and the stem.

Nos. 1 and 2. Reduced to small, subulate scales.

No. 3. Small, foliaceous, oblanceolate-linear.

No. 4. Much larger, lanceolate, serrulate.

Nos. 5-9 inclusive. Lanceolate-elliptic, acute, serrulate.

\section{BURSERACEE.}

Benth. et Hook. Gen. Pl. i. 321.

Fruit and Seed.-The typical Burseraceæ have two to five carpels, united to form an ovary with the same number of cells. Amyris and Hemprichia are exceptional, inasmuch as the ovary is one-celled. The ovules are attached to an axial placenta, above the middle and generally near the top, and are pendulous, anatropous, collateral, with a ventral raphe and superior micropyle; rarely ascending. The usual number is two, but there is only one in each cell of Filicium, and one in the unilocular ovary of Hemprichia. The fruit is drupaceous, consisting of two to five connate or separable pyrenes. The epicarp is persistent, or splits open by two to four valves, leaving the pyrenes naked. The latter consist of the woody or bony endocarp. In some cases, however, the endocarp is not bony, and may even dehisce irregularly.

The seeds are generally if not always solitary in each loculus, by abortion, very large, and exalbuminous with a membranous testa. The seed of Santiria is peltate, and the 
fruit of species of that genus grows very unequally, so that the style is sometimes turned on one side till close to the pedicel. As might be expected, the seed generally conforms in shape to the loculus of the bony endocarp. The embryo is large, and occupies the whole of the seed. The cotyledons are in most cases foliaceous, aerial, and more or less contorted or twisted so as to occupy the whole of the available space; the short radicle is superior. Hedwigia and Amyris have thick, fleshy, plano-convex, or almond-shaped straight cotyledons.

Some genera present still more remarkable exceptions; such as Trigonochlamys, which has deeply lobed cotyledons; Santiria, with irregularly cut cotyledons; Bursera, where they are sometimes trifid; and Boswellia, where they are multifid. In Canarium commune they are tripartite, auricled at the base, where they clasp or sheathe the radicle, which is stout, fleshy, and projects slightly beyond them. Two of the cotyledonary lobes occupy the dorsal aspect of the seed, while the rest occupy the ventral part, and are confusedly contorted or twisted one with another. In the mature seed they are soft, fatty, and taste like the kernel of the Brazil Nut (Bertholletia excelsa). One species of Bursera has the cotyledons curved like a horse-shoe, while the embryo of Crepidospermum Sprucei is green and similarly curved.

Seedlings. - The Order consists of about 150 species, natives of the tropical parts of both hemispheres, and, not being very popular for horticultural purposes, seedlings are seldom to be seen in this country. I have only met with those of Canarium strictum (fig. 237).

In this species the first and several succeeding leaves are simple, ovate, acuminate, and serrate. The adult ones are imparipinnate, with opposite and very coriaceous, serrate leaflets. A few species have leaves consisting of one or three leaflets in the adult stage, and in some cases the leaflets are entire.

\section{Canarium commune, $L$.}

Fruit drupaceous, ovoid or ellipsoid, trigonous, three-celled but only one-seeded by abortion of all the ovules except one, which conforms to the single cell, outgrowing and crushing the others; epicarp 
fleshy, thin ; endocarp bony, 3-4.5 mm. thick, brown and nearly smooth externally, smooth or slightly uneven internally, shining red, closely amalgamated with the small cord-like axis.

Seed oblong. compressed, almond-shaped, two-edged, even or variously indented, furrowed sometimes along the ventral aspect by pressure against the axis ; testa thin, brown, easily broken; hilum round, near the apex on the ventral aspect of the seed and collateral with the remains and point of attachment of the abortive ovule; raphe ventral, double, forming a slightly depressed, black line, diverging from the hilum.

Endosperm wanting.

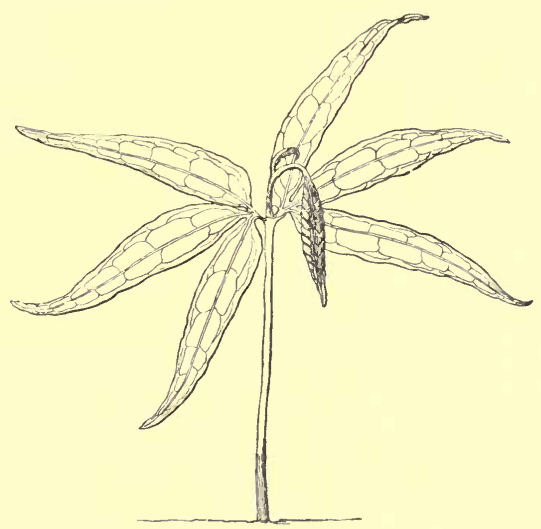

Frg. 237.-Canarium strictum. Half nat, size.

Embryo large, fleshy, conforming to the shape of the seed, fatty, pale yellowish-white, soft, and tasting like the kernel of the Brazil Nut; cotyledons tripartite, depressed at the base and grasping the radicle, then ascending, oblong - two segments occupying almost the whole of the dorsal aspect with their tips incurved and grasping the top of the other lobes, which are also decurved at the base and then ascend on the ventral aspect, becoming confused and variously twisted together; radicle stout, fleshy, projecting slightly beyond the cotyledons and compressed antero-posteriorly.

Canarium strictum, Roxb. (fig. 237).

Hypocotyl 6-8 cm. long, 2-3 mm. thick, terete, succulent, glabrous, pale green. 
Cotyledons stalked, tripartite; segments $5-6 \mathrm{~cm}$. long, 1-1.25 cm. broad, the middle one lanceolate, lateral ones oblique-lanceolate, long-acuminate, entire, with slightly undulate margin, distinct midrib, and alternate, incurved nerves and veins, quite glabrous, light shining green, somewhat persistent.

Stem terete, shallowly ridged and furrowed, covered with a dense patent pubescence, pale green, becoming woody; 1st internode $2 \mathrm{~cm}$. long, $1.5 \mathrm{~mm}$. thick ; 2nd internode $6 \mathrm{~mm}$. long.

Leaves cauline, alternate, exstipulate, petiolate; petiole terete, slightly channelled above, tapering upwards, ascending, densely pubescent, $2 \cdot 7 \mathrm{~cm}$. long; lamina ovate, acuminate, or almost oval with an acuminate, subacute point, serrate, penninerved, with alternate ascending nerves ultimately curving forwards, coarsely hairy and pale green on both surfaces, shining above, horizontal.

\section{MELIACE $Æ$.}

Benth. et Hook. Gen. Pl. i. 327.

Fruit and Seed.-The carpels vary from three to five, and are united into an ovary of as many cells. The most frequent number of ovules is two, and they are collateral or superposed, pendulous or ascending, with a ventral raphe and a superior micropyle. Exceptions to the above characters occur in Elutheria, which has a one- or imperfectly four-celled ovary; and in Chisocheton, which has one ovule in each cell; the same thing sometimes occurs in Aglaia, Milnea, Amoora, and Guarea. The ovary of Turræa varies in different species with from five to twenty loculi. Numerous ovules occur in each cell of the ovaries of the species belonging to the tribes Swietenieæ and Cedreleæ. The fruit is baccate, capsular, or less often drupaceous. Instances of the latter occur in Melia, Mallea, and Owenia.

The seeds are albuminous or exalbuminous, varying however in the same genus in some cases; the endosperm when present is fleshy. The testa is drawn out into a wing in Soymida, Chickrassia, Cedrela, Chloroxylon, and Flindersia. A curious case occurs in Swietenia and Khaya, where the cotyledons and endosperm are closely adherent. The cotyledons are fleshy and more or less flattened. They are bipartite in Milnea 
apiocarpa and others; in several cases they lie transversely to the seeds ; and in Carapa, Trichilia, and some others the cotyledons are conferruminate. They are unequal-sided in Chickrassia, which has flattened seeds winged on the back. The flattening is due to the mutual compression of the large seeds, which vary from two to five in each cell of the capsule. An aril is present in many genera, and in some cases it is united or confluent with the testa; but more frequently it simply surrounds the whole seed.

Seedlings. - This Order numbers some 270 species, but few are of frequent occurrence in this country, with exception perhaps of Melia Azedarach (fig. 238). There are several types of seedlings. In Walsura piscidia (fig. 239) the cotyledons are fleshy, shortly petiolate, and strictly subterranean. The first pair of leaves in Melia Azedarach is tripartite, with cuneate, cut, or deeply toothed segments. Succeeding ones vary in the amount of division till they become bi- to tri-pinnate. Althongh the

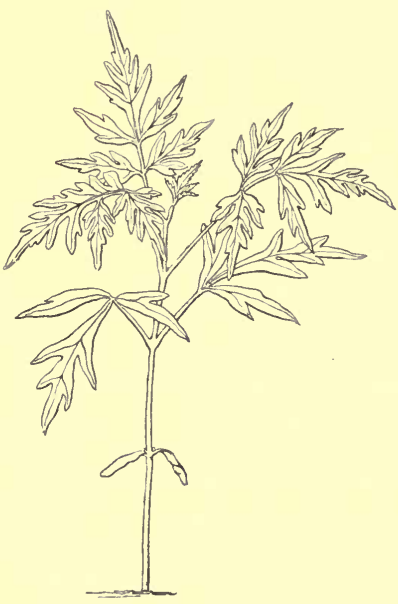

FIg. 238.-Melia Azedarach. Half nat. size. first four are in opposite pairs, the rest are alternate. A noticeable point in Walsura piscidia is that the first pair of leaves is small and scaly, followed by two pairs of small but foliaceous ones. Succeeding ones to the ninth are larger, alternate, and entire. Some species of Walsura have trifoliolate or pinnate leaves.

Melia Azedarach, L. (fig. 238).

Hypocotyl erect, terete, pale green, pubescent, about $3.4 \mathrm{~cm}$. above the soil. 
Cotyledons linear-oblong, obtuse, narrowed to a short petiole, glabrous except the upper side of the petiole, ultimately revolute at the sides, falling away early, about $1.2 \mathrm{~cm}$. long including the petiole, $2.5 \mathrm{~mm}$. broad.

Stem erect, terete, pale green, covered with short upwardly incurving hairs; 1st internode $1.65 \mathrm{~cm}$. long; 2nd $1.5 \mathrm{~cm}$.; 3rd $1 \cdot 1 \mathrm{~cm}$.

Leaves compound, cauline, alternate (1st and 2 nd and sometimes the $3 \mathrm{rd}$ and 4 th in almost opposite pairs), exstipulate, petiolate, thinly and finely pubescent above, slightly revolute at the margin, deep or bright shining green above, pale and glabrous beneath; petioles convex on the back, with a

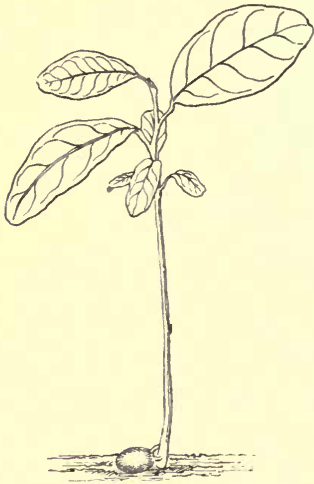

Fig. 239.-Walsura piscidia.

Nat. size. slender channel on each side of the prominent midrib on the upper face. pubescent with upwardly incurving hairs.

Nos. 1 and 2. Subopposite, tripartite; lateral segments oblonglanceolate, subacute, with a large tooth on the middle of the posterior side; terminal lobe cuneate-rhomboid, pinnatifid.

Nos. 3 and 4. Alternate or subopposite, pinnate, pinnatifid; basal pair of leaflets ovate, acute, deeply pinnatifid at the base and less deeply so or toothed upwards; terminal leaflet triangular pinnatipartite at the base and pinnatifid upwards, with the basal and larger segments lobed, the rest entire.

No. 5. Pinnately five-foliolate; basal pair of leaflets pinnatipartite at the base and less deeply cut upwards; middle pair ovate, cuneate at the base, pinnatifid; terminal leaflet triangular, acuminate, cuneate, and pinnatipartite at the base, becoming gradually less deeply cut upwards.

Ultimate leaves bipinnate; leaflets ovate, acuminate, coarsely and obtusely serrate, frequently lobed or segmented on the posterior basal side.

Walsura piscidia, Roxb. (fig. 239).

Hypocotyl generally subterranean.

Cotyledons fleshy, remaining in the seed. 
Stem woody, erect, terete, pubescent, soon becoming brown and throwing off the epidermis; 1st internode $2.9 \mathrm{~cm}$. long; 2nd $3.45 \mathrm{~cm}$.; 3rd $1.5 \mathrm{~mm}$.; 4 th $3.75 \mathrm{~mm}$.; 5 th $1.5 \mathrm{~mm}$.; 6 th $2.25 \mathrm{~mm}$.; 7 th $5 \mathrm{~mm}$.; 8 th $6 \mathrm{~mm}$.

Leaves simple, ultimately pinnate, cauline, alternate, exstipulate, petiolate, glabrous, coriaceous, penninerved, deep green above, paler beneath ; petioles channelled above, pubescent, short.

Nos. 1 and 2. Opposite, reduced to small, brown scales.

Nos. 3-6. Small, aggregated, oval, emarginate, entire.

Nos. 7-9. Much larger, oval, emarginate, otherwise entire.

\section{ILICINEE.}

Benth, et Hook. Gen. Pl. i. 355.

Fruit and Seed.-The Order contains some 150 species, all of which belong to the genus Ilex with four exceptions. The ovary is mostly made up of three to five carpels, rarely six to eight as in some species of Ilex. The three species of Byronia however vary with ten to eighteen carpels. The ovules are solitary or geminate in different species of Ilex, pendulous from the tip of axile placentas, collateral and anatropous; in Nemopanthes they are solitary. The raphe is dorsal, rarely lateral, with a superior radicle. The fruit is drupaceous, with a very thin succulent layer surrounding a bony, crustaceous, or rarely cartilaginous endocarp. When the carpels are mature they are separable into as many pyrenfs, each containing a solitary pendulous seed conforming to the cavity. The testa is membranous, surrounding a copious fleshy endosperm, in which the minute embryo is embedded close to the superior hilum. The embryo is straight. The common Holly (Ilex Aquifolium) is a good type. The fruit consists of four pyrenes, and is small, as in all other species of the Order. The embryo is globose or obovoid, with the cotyledons about equal to the blunt radicle. The funicle forms a little cap surmounting the upper end.

Ilex Aquifolium, $L$. (fig. 240).

Primary root long, tapering downwards, colourless, with a few lateral rootlets. 
Hypocotyl woody, erect, terete, glabrous, colourless at the base and green upwards, $3 \cdot 8 \mathrm{~cm}$. long.

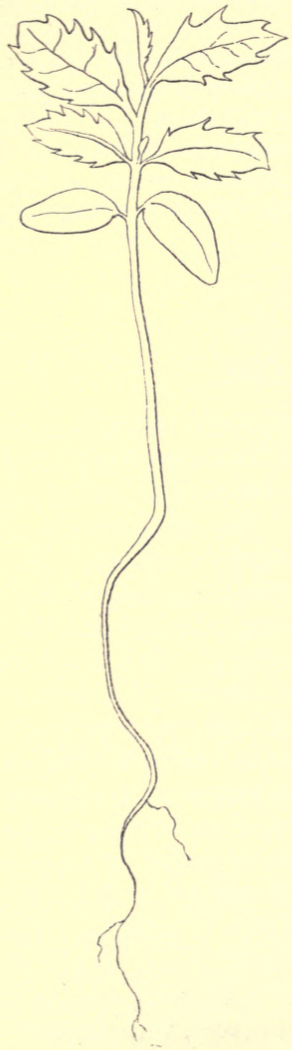

Fig. 240.-Tlex Aquifolium. Nat. size.

Cotyledons ovate, obtuse, entire, coriaceous, glabrous, deep green, shortly petiolate; petiole about $1 \mathrm{~mm}$. long; lamina $13 \mathrm{~mm}$. long, $6 \mathrm{~mm}$. broad.

Stem woody, erect, terete or slightly angled from the decurrent nature of the petioles, glabrous, green; 1st internode $3 \mathrm{~mm}$. long; 2nd $1 \mathrm{~mm}$.; 3rd and 4th, both belonging to a second year's growth, each $1 \mathrm{~mm}$. long; 5th $4 \mathrm{~mm}$.; 6th $3.5 \mathrm{~mm}$.

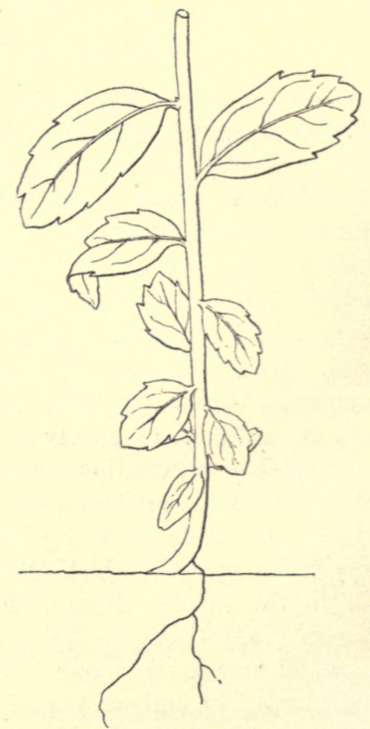

Fig. 241.-Tlex myrtifolia. Nat. size.

Leaves simple, cauline, alternate, stipulate, petiolate, evergreen, coriaceous, glabrous, dark green above, somewhat paler beneath; petiole short, channelled above, thickened at the margin, as are the eaves; stipules small, ovate, acute, black, deciduous (stipules are 
said to be absent from the Order, but in seedlings and in the young growth of the above-named species small stipule-like bodies are present as described).

No. 1. Oblong-ovate, serrate, teeth acute, spiny.

No. 2. Lanceolate-oblong, teeth similar.

End of growth of first season.

Nos. 3 and 4. Spathulate, serrulate scales.

No. 5. Broadly oblong, obtuse, cuneate at the base, serrate, teeth spiny.

No. 6. Oblong, acuminate, cuneate at the base, serrate, teeth rather distant and spiny.

Ilex myrtifolia, Lam. (fig. 211).

Hypocotyl woody, erect (or decumbent-accidental ?), dull green, $1 \cdot 3 \mathrm{~cm}$. above the soil.

Cotyledons ovate, obtuse, emarginate, persistent, shortly petiolate, glabrous, deep green, alternately but obscurely penninerved; lamina 7-9 mm. long, $3-4.5 \mathrm{~mm}$. broad; the cotyledons of some of the seedlings are so narrow as to be oblong, otherwise they do not differ from the type; petiole flattened or slightly grooved above, $1 \cdot 25-2 \cdot 25 \mathrm{~mm}$. long.

Stem woody, erect, terete, dull green, minutely pubescent; 1 st internode $4 \mathrm{~mm}$. long; 2nd $2 \mathrm{~mm}$.; 3rd $3 \mathrm{~mm}$.; 4 th $4 \mathrm{~mm}$.; 5 th $5.25 \mathrm{~mm} . ; 6$ th and 7 th each $8 \mathrm{~mm}$.; 8 th $9 \mathrm{~mm}$.; 9 th $1.2 \mathrm{~cm}$.; 10 th $1.5 \mathrm{~cm}$.

Leaves obscurely, alternately penninerved, with the midrib and primary veins somewhat of a milky-white, paler beneath; petioles very short, channelled above; stipules small, subulate, acute, black, deciduous, or rather caducous.

Nos. 1-5 inclusive. Oval, obtuse, apiculate, with a few acuto serratures on each side.

Nos. 6-10 inclusive. Oblong, obtuse, apiculate, distantly and acutely serrate on the upper half.

\section{CELASTRINEE.}

Benth. et Hook. Gen. Pl. i. 357.

Fruit and Seed.-The ovary is two- to five-, very frequently four-celled as in many species of Euonymus, although this is not constant even on the same tree. One-celled ovaries are exceptional, but occur in Llavea, Glossopetalum, and Cathastrum. 
The ovules generally number two in each loculus, ascending from the base of an axile placenta, anatropous, with a ventral raphe and an inferior micropyle. In other cases they vary with one to many ascending ovules, while another type has pendulous ovules with a dorsal raphe and superior micropyle. Solitary erect ovules occur in Hartogia, Ptelidium, Myginda, Fraunhofera, Schæfferia, and Caryospermum. From four to six or more ovules occur in a number of genera, including Lophopetalum, Cathastrum, Kokoona, Alzatea, Putterlickia, Denhamia, Wimmeria, and Goupia. The number varies considerably in different species of Euonymus, although two are most common. In Cassine the solitary ovule is pendulous from the top of the placenta. The fruit is capsular (more or less winged in Euonymus) or baccate, drupaceous, or samaroid and indehiscent with one-seeded cells. The testa is crustaceous, membranous, fleshy, or spongy, and in Perrottetia it is manyribbed, with a moderately prominent raphe and more or less covered with a large cap- or boat-shaped arilloid funicle, or sometimes it is winged, as in Kokoona, Alzatea, and Hippocratea. The seeds of many of the genera, including Caryospermum, Schæfferia, Mortonia, Tripterygium, Elæodendron, and some species of Myginda, are not furnished with an aril. The endosperm is generally copious and fleshy. The embryo is usually very large, flat, and straight, often nearly equal to the endosperm in length and breadth. Sometimes it is linear and axile, and in Perrottetia it is minute and basal. An exceptional case occurs in Euonymus fimbriatus, which has more or less undulated or twisted cotyledons, and a curved radicle. In some genera the embryo is green. The cotyledons are mostly flat and foliaceous; and the radicle is generally inferior with the exceptions mentioned in which the ovules and seeds are pendulous.

Euonymus europæus (fig. 242) may be given as a good type of the Order. Euonymus latifolius has larger seeds and a relatively broader embryo. To this type belongs E. fimbriatus. Both have pendulous ovules.

Maytenus boaria agrees with Euonymus europæus in the insertion and direction of its ovules, but the seeds are oblong or oval; and the coty edons are oblong, rounded at both ends, and trinerved. 
Seedlings.-The seedlings observed were all similar in habit and agree in all main particulars, having aerial, foliaceous, rather persistent cotyledons alternately penninerved and reticulate with incurved veins. In Euonymus europæus (fig. 243) they are entire; in Maytenus boaria (fig. 244) broadly oblong, blunt, shortly petiolate, and emarginate. They are also emarginate in Celastrus paniculatus, in which they

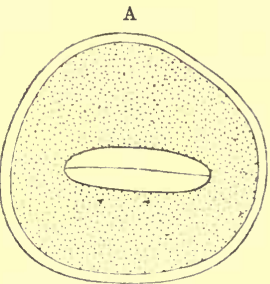

B

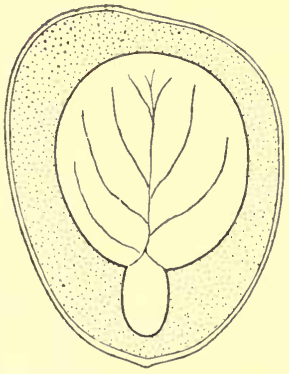

C

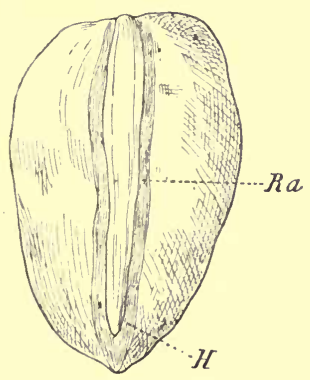

Fig. 242.-Euonymus europæus.

A, vertical section of seed, $\times 8$. B, transverse section of seed, $\times 8$ (from bolow middle). C, ventral aspect of seed, $\times 8: H$, hilum; $R a$, raphe.

do not otherwise materially differ from those of Euonymus europæus. The leaves of the seedlings in all the three cases are very similar to those of the adult plant. The stipules of the primary leaves are more evident in Celastrus paniculatus than in the other cases where they seem to be absent.

\section{Euonymus europæus, $L$. (fig. 242).}

Pistil syncarpous, superior ; ovary of four to five carpels, four- to five-, usually four-celled, with two collateral ovules in each cell; 
ovules erect, anatropous, surrounded at the base by a funicular aril, cupular at first, but after fertilisation growing up and entirely surrounding the seed.

Fruit a capsule four- to five-celled, two- to five-seeded, as one of the ovules, sometimes both, is always abortive, four- to five-lobed, subturbinate, glabrous, green, becoming red as it matures, dehiscing loculicidally.

Seed obovoid, slightly compressed laterally, smooth, white and shining, closely and entirely invested with a scarlet, slightly

B

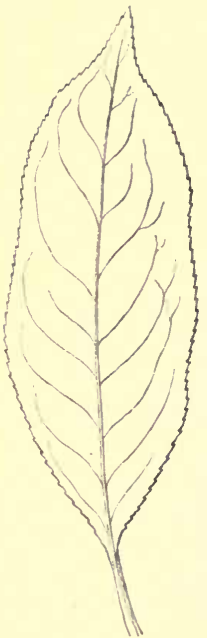

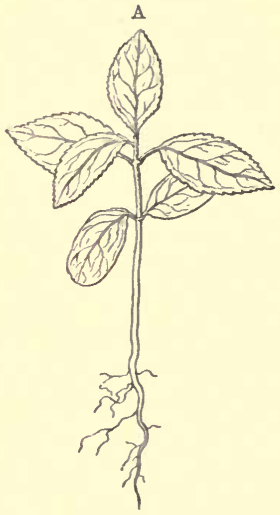

C
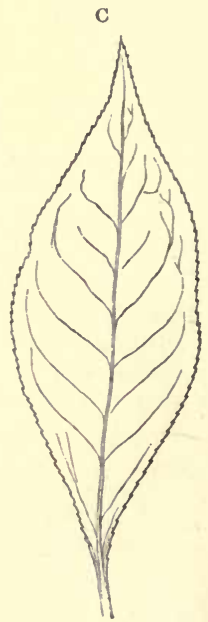

Frg. 243.-Euonymus europaus.

A, seedling. Half nat. size. B and C, ultimate leaves, showing two shapes.

wrinkled, funicular aril, which is attached to the oblong-linear hilum stretching along nearly the whole side of the seed to the inner angle of the cell; raphe pale yellow, continued from the hilum along the broad upper end of the seed to the chalaza seated at the top of the dorsal aspect. Seed albuminous.

Endosperm abundant, fleshy, firm, and white, entirely surrounding the embryo.

Embryo straight, flat, central, pale green, extending from the micropyle to within $\cdot 25 \mathrm{~mm}$. of the apex of the endosperm; cotyledons 
foliaceous, ovate or oblong-ovate, obtuse, flat, applied to each other face to face, pale green, $4.25 \mathrm{~mm}$. long, $3 \mathrm{~mm}$. broad; radicle cylindrical, obtuse, $1 \cdot 25-1.5 \mathrm{~mm}$. long.

Seedling (fig. 243).

Primary root tapering, flexuous, giving off flexuous lateral rootlets.

Hypocotyl woody, erect, terete, glabrous, deep green, with scattered white points and short lines, about $3.8 \mathrm{~cm}$. long.

Cotyledons large, foliaceous, oval-oblong, rounded at the end, alternately penninerred and reticulate, petiolate, glabrous, deep green above, pale beneath, coriaceous, rather persistent; lamina $2 \cdot 1 \mathrm{~cm}$. long, $1.3 \mathrm{~cm}$. broad; petiole grooved above, $2.5 \mathrm{~mm}$. long.

Stem woody, erect, subangled, deep green, glabrous, marked with white spots (lenticels); 1st internode $1.5 \mathrm{~cm}$. long; 2nd $3.5 \mathrm{~mm}$.

Leaves simple, serrulate, cauline, opposite, stipulate, petiolate, glabrous, irregularly penninerved, reticulate, deep green abore, paler beneath; petioles semiterete, grooved above; stipules very small, lacerated, brownish.

1st pair lanceolate-elliptic, acute, irregularly serrulate.

2nd pair similar but smaller.

Ultimate leaves ovate-oblong or oblong, suddenly narrowed at both ends, or lanceolate-elliptic, tapering to both ends and acute, slightly irregularly crenate-serrulate, glabrous, deep green above, paler beneath.

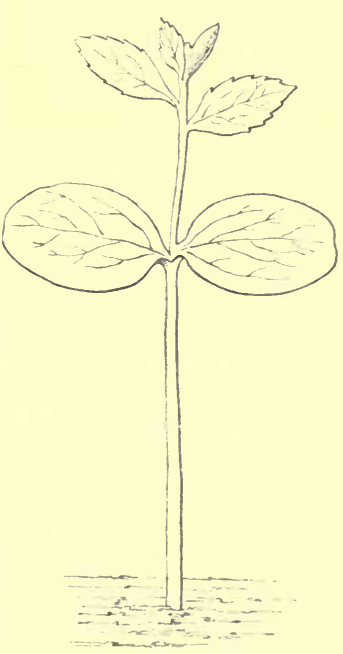

FIG. 244.

Maytenus boaria.

Nat. size.

\section{Celastrus paniculatus, Willd.}

IIypocotyl woody, erect, terete, densely pubescent, soon becoming brown, $1.5 \mathrm{~cm}$. above the soil.

Cotyledons foliaceous, oblong, obtuse, more or less distinctly emarginate, petiolate, coriaceous, obseurely penninerved with alternate, ascending nerves, glabrous, green above, much paler, almost 
yellowish, beneath; lamina $2.6 \mathrm{~cm}$. long, $1.5 \mathrm{~cm}$. broad; petiole grooved above, pubescent on the back, $2.5 \mathrm{~mm}$. long.

Stem woody, erect, terete, much kneed and flexuous in a zigzag manner, densely pubescent, pale green, soon becoming brown;

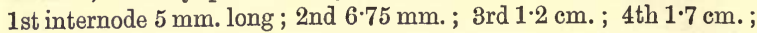
5th $2.15 \mathrm{~cm}$.; 6 th $3 \mathrm{~cm}$.; 7 th $2.65 \mathrm{~cm}$.

Leaves simple, cauline, alternate, stipulate, petiolate, deep green and glabrous above, paler and pubescent beneath, alternately and incurvedly penninerved, reticulate, serrate, the serratures with incurved glandular or mucronate tips; stipules small, triangular, serrate or lacerated, soon becoming brown, caducous ; petioles short, channelled above, rounded on the back, pubescent.

Nos. 1 and 2. Small, elliptic, subacuminate, obtuse, apiculate.

Nos. 3-6 inclusive. Gradually and successively larger, elliptic, acuminate, obtuse, tapering almost equally to both ends, apiculate.

Maytenus boaria, Molin. (fig. 244).

Hypocotyl erect, terete, glabrous, 3-6 $\mathrm{cm}$. long, reddish.

Cotyledons oval, obtuse, emarginate, shortly petiolate, coriaceous, 1.5-2 cm. long, glabrous, dark green, reticulate, like the first leaves.

Stem herbaceous, erect, square, rough with minute hairs; 1st internode 4-10 mm. long; 2nd and succeeding ones 2-4 mm.

First leaves simple, cauline, alternate, shortly petiolate, oval, dentate or slightly serrate, acute, glabrous, bright green, somewhat paler beneath; midrib with numerous branched veinlets.

\section{RHAMNEA:}

Benth. et Hook. Gen. Pl. i. 371.

Fruit and Seed.-The ovary is usually three-celled, but two to four cells also occur. The ovules are solitary, erect, and anatropous. Exceptions occur in Karwinskia, where there are two ovules in each cell, and the same thing happens in Condalia when two cells of the ovary become confluent in one. The raphe is dorsal or rarely lateral, and the micropyle inferior. The fruit is superior or more or less submerged in the receptacle, and when mature is three-, rarely one- to four-celled, and capsular, drupaceous, or separating more or less into cocci with a woody endocarp opening at the top. The seeds are ovoid or 
more or less flattened, sometimes arillate at the base. The testa is loose and membranous, or crustaceous or leathery. Endosperm is nearly always present, and fleshy. The embryo is large and straight, with flat, rarely curved or bent cotyledons, as in Rhamnus davuricus; and the inferior radicle is short. Striking exceptions in the Order occur in Ventilago and Smythea, which have a one-celled, one-seeded fruit, and exalbuminous seeds. Those of Ventilago are globose, and the

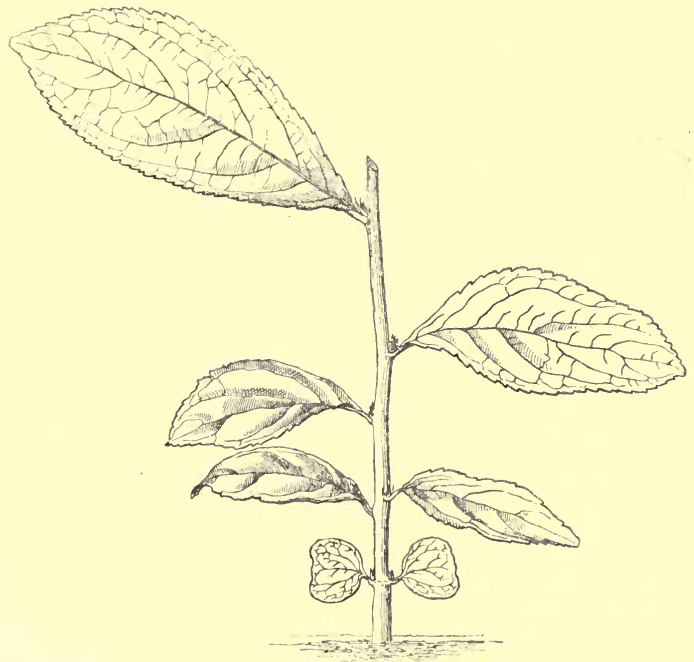

FIG. 245.-Rhamnus davuricus. Half nat. size.

cotyledons are thick and fleshy; but the seeds of Smythea are more flattened. The fruit of Ventilago is produced into a long wing.

Seedlings.-There are several types of seedlings in this Order judging from the variation amongst the seeds and their contained embryos, but they do not often come under ob. servation in this country. Rhamnus davuricus (fig. 245) may be given as one type having aerial foliaceous cotyledons. The broad, shallow sinus at their apices seems to be 
due to the form of the seed and the way they are bent in conformity with it. Colletia cormuta (fig. 246) differs chiefly in the cotyledons being suborbicular and rounded at the apex.

\section{Rhamnus davuricus, Pall. (fig. 245).}

Hypocotyl erect, terete, rather short, soon becoming brown and woody, $12-18 \mathrm{~mm}$. above the soil.

Cotyledons broader than long, almost obreniform, with a broad shallow apical sinus, suddenly cuneate at the base, five-nerved, the middle nerve bifurcate some distance below the apex, and the lateral ones much branched laterally and incurved at the apex, where they unite with the middle one, enclosing an obcordate space, the basal ones short and slender, uniting upwards with the lateral branches of the last two, glabrous, much reticulated, as seen when examined by transmitted light, shining on both surfaces, deep green above, paler beneath; lamina 10-12 mm. long, 14-16 mm. wide; petiole

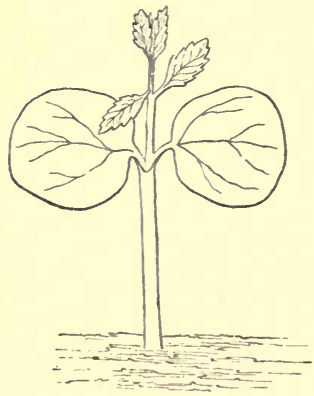

Fig. 246.-Colletia cornuta, $\times 2$. semiterete, flattened above, 3-4 mm. long.

Stem erect, terete, glabrous, green, soon becoming brown and striated or reticulated by splitting of the bark, woody; 1st internode about 15-16 mm. long ; 2nd 4-6 mm.; 3rd 18-20 $\mathrm{mm}$.

Leaves simple, cauline, alternate, stipulate, petiolate, alternately incurvinerved, subcoriaceous, shining on both surfaces, deep green above, paler beneath, and closely reticulated, glabrous, or glandular-pubescent at the margin when young; petiole short, semiterete, flattened above; stipules slender, subulate, acuminate, pale green, seated on the junction of petiole and stem, soon becoming brown, deciduous.

Nos. 1 and 2. Oblong-lanceolate, shallowly and distantly serrate with intermediate minute serratures or setæ.

Nos. 3 and 4 . Oblong, otherwise similar, but larger.

Nos. 5-9. Oblanceolate-oblong, acuminate, tapering at the base.

Colletia cornuta (fig. 246).

Hypocotyl erect, terete, glabrous, 10-14 mm. long, green, almost colourless near the soil. 
Cotyledons subrotund or oval, obtuse, entire, sometimes slightly cordate at the base, coriaceous, shortly petiolate, glabrous, dark green, pinnatinerved, the lower veins much longer than the others.

Stem erect, terete, glabrous, herbaceous at first; 1 st internode 3-6 min. long, 2nd shorter.

First leaves simple, opposite, cauline, lanceolate, acute, serrate, petiolate, stipulate, glabrous, light green, pinnatinerved.

\section{AMPELIDEA.}

Benth. et Hook. Gen. Pl. i. 386.

The ovary here is also more or less sunk in the receptacle, and consists of tro to six carpels united so as to form as many cells. In the genus Vitis, which includes by far the largest number of species, the ovary is mostly two-, rarely three- or four-celled. The ovules are geminate, collateral, ascending, and anatropous in Vitis and Pterisanthes, where the ovary is most frequently bilocular ; but in Leea, where the ovary is from three- to six-celled, the ovules are solitary and erect. The raphe is ventral and the micropyle inferior. The fruit is always baccate with from one to six cells according to the genus, or it may become one-celled by the destruction of the septa during ripening; each cell contains one or two seeds. The latter are always solitary in the loculi of Leea. The outer coat of the seed is bony, the inner one membranous, and both are often pushed into the endosperm, making it ruminate. In Vitis vinifera, there are two longitudinal furrows or indentations of this kind on one side of the seed with a corresponding ridge between them. The embryo is minute with oval cotyledons, and lies embedded in the cartilaginous endosperm close to the hilum. The seeds of Leea have a more decidedly ruminate albumen, and the straight or slightly curved embryo although small has subfoliaceous cotyledons.

The cotyledons are ovate or subcordate, obtuse or acute, and five-nerved. The middle pair of nerres does not, however, always spring from the base of the lamina, but sometimes at a greater or less distance above it. Vitis cebennensis (fig. 248) 
may be given as a good type of those with short-petioled cotyledons. V. cebennensis and V. Cynthiana agree both in the cotyledons and the primary leaves. The first one is cordate and coarsely dentate-serrate, the second subtrifid. The first leaf of V. Cynthiana is sometimes at least as far advanced as the second in other cases. A very distinct type is met with in V. hypoglauca (fig. 247), where the hypocotyl remains undeveloped and the broadly cordate, obtuse cotyledons are carried up on very long petioles. The first leaf is a small scale.

Parthenocissus tricuspidata is probably a species of Vitis, as its cotyledons agree very fairly with those of V. cebennensis. The first leaf is tripartite, with cuneate, serrated, hairy segments.

\section{Parthenocissus tricuspidata, Planch.}

Hypocotyl erect, terete, glabrous, $2-2.5 \mathrm{~cm}$. long, red.

Cotyledons almost triangular, with rounded edges, obtuse, entire, petiolate, glabrous, green, pinnatinerved, with the nerves near the base more prominent; petioles $1 \cdot 5-2 \mathrm{~cm}$. long, channelled on the upper side.

Stem erect, herbaceous, ultimately woody, red; 1st internode 1-1.5 mm. long.

First leaves simple, digitate, cauline, alternate, petiolate, stipulate, trifoliolate, trinerved; leaflets lanceolate, acute, coarsely serrate, ciliate, covered with short stiffish hairs, green with a reddish tinge, pinnatinerved; petioles long, reddish, channelled on the upper side, slightly hairy; stipules membranous, reddish, oblong, entire.

\section{Vitis hypoglauca, F. Muell. (fig. 247).}

Hypocotyl short and subterranean, terete, tapering downwards.

Cotyledons large, unequal, cordate or rotund-cordate, obtuse, strongly trinerved with two lateral, shorter ones at the base, reticulate, petiolate, glabrous, shining on both surfaces, deep green above, paler or subglaucous beneath; lamina of the larger one $2 \cdot 9-3 \cdot 9 \mathrm{~cm}$. long, $2 \cdot 6-3 \cdot 1 \mathrm{~cm}$. wide; lamina of the smaller one $2 \cdot 8-3 \cdot 4 \mathrm{~cm}$. long, $2 \cdot 4-2 \cdot 9 \mathrm{~cm}$. wide; petioles long, semiterete, shallowly grooved above, glabrous, colourless or pinkish, $6-8 \cdot 5 \mathrm{~cm}$. long, often slightly unequal, with the larger one having the longest petiole by $3-7 \mathrm{~mm}$.

Stem erect at first, terete, slender, glabrous, pale green, ulti- 
mately climbing and woody, zigzag or flexuose at the nodes; 1 st internode 1-9 mm. long ; 2nd 7-31 mm. long.

Leaves simple, cauline, alternate, stipulate, petiolate, three- to five-nerved at the base, strongly alternately nerved upwards, reticulate, shining on both surfaces, at least when young, deep green above, paler or glaucous beneath, glabrous; stipules half-ovate, membranous

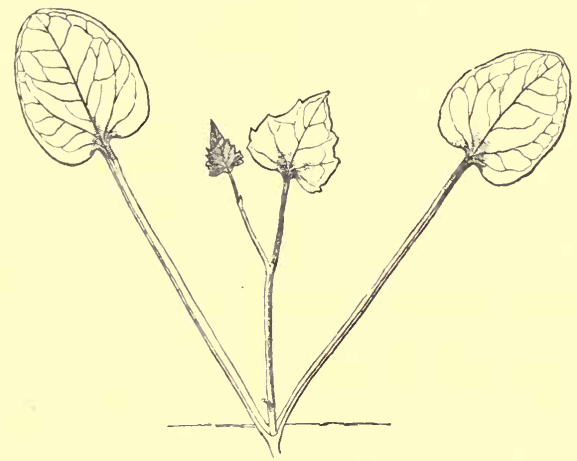

FIG. 247.-Vitis hypoglauca. Half nat. size.

colourless, small; petioles semiterete, channelled above, tapering slightly upwards, glabrous, pale green or stained with red.

No. 1. (following a short internode). Very small or minute, lanceolate, acute, entire, or one- to twotoothed at the sides, much reduced and scale-like.

No. 2. Triangular acute, cordate or almost truncate and five-nerved at the base, and alternately nerved upwards, irregularly dentate with rather cuspidate, acute teeth.

Vitis cebennensis, Jord. (fig. 248).

Hypocotyl suffrutescent, erect, terete, soon becoming brown, glabrous, $1-2 \mathrm{~cm}$. long.

Cotyledons ovate, entire, subacumi-

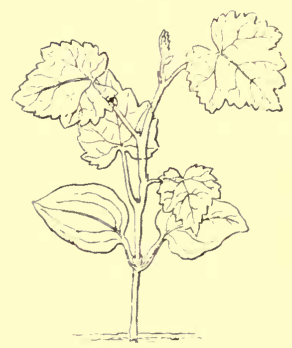

FIG. 248.-Vitis cebennensis. Half nat. size. nate, glabrous, five-nerved, nerves incurved, $2 \cdot 35 \mathrm{~cm}$. long, $1 \cdot 65 \mathrm{~cm}$. broad; petiole deeply grooved above, suberect, $8 \mathrm{~mm}$. long. 
Stem erect at first, afterwards climbing, suffrutescent, pale green suffused with red when young, glabrous, flexuose, thickened at the nodes, succulent when young; 1st internode $1.35 \mathrm{~cm}$. long; 2nd $7 \mathrm{~mm}$.; 3rd $9 \mathrm{~mm}$.; 4 th $1.5 \mathrm{~cm}$.

Leaves palmately five-nerved, glabrous except for the minutely ciliate margin, subrugose; petioles subterete, reddish; stipules ovate, subacute, serrulate at the margin, hyaline, deciduous, membranous.

No. 1. Cordate, subacuminate, with large mucronate teeth.

No. 2. Cordate, subtrilobate, otherwise like No. 1.

No. 3. Broadly cordate, palmately five-lobulate.

No. 4. Similar to the last.

Ultimate leaves broadly cordate, mucronate, palmately fivenerved and -lobulate, serrate-dentate with mucronate serratures, pubescent on the principal nerves on both surfaces; petiole pubescent, terete, striate, crimson, as are the principal nerves.

\section{SAPINDACE 2.}

Benth. et Hook. Gen. Pl. i. 388.

Fruit and Seed.-The carpels vary from one to four, but three is the most common number. There are usually two in the species of Acer and Negundo, although three occasionally occur. In Dodonæa there are five or six. Dobinea is a remarkable exception, inasmuch as the ovary consists of a single carpel with a solitary erect ovule. In other cases the carpels are united to form an ovary of many cells with axile placentas, or the ovary may be deeply lobed, sometimes divided to the base into as many lobes as carpels, arranged excentrically around a gynobasic style, as occurs in some Ochnaceæ and Phytolaccaceæ. The ovules are one or two, rarely more, in each cell, anatropous, campylotropous, or amphitropous, attached to an axile placenta, and ascending with a ventral raphe and inferior micropyle. They are very rarely horizontal and numerous, or inverted. The fruit contains as many cells as there were carpels in the ovary, but is sometimes one-celled by abortion, and in Dobinea is always one-celled. When 
mature it forms a woody, coriaceous, or membranous capsule dehiscing in various ways, or is indehiscent. In other cases it is baccate or drupaceous, undivided or lobed, or consists of two or three samaras as in Acer and Negundo. The fruit of Dobinea is an achene. The seed is globose, or laterally compressed, sometimes arillate; exalbuminous in Sapindeæ, Acerineæ, and Dodonææ ; and albuminous in Meliantheæ and Staphyleæ. The testa is woody, crustaceous, or membranous. The embryo is generally very large and flat, or more often spirally or circinately coiled or conduplicate, transversely biplicate, wrinkled or wavy, with green or yellow foliaceous cotyledons, or the cotyledons are thick and fleshy, sometimes conferruminate, and occasionally unequal. The radicle is short and inferior, sometimes elongated and straight, or curved upwards, or ascending towards the micropyle.

The leading types of the Order may be roughly classified by the form and characters of their fruits. Capsular, inflated, or bladdery fruits with exalbuminous seeds occur in Cardiospermum, Valenzuelia, Kœlreuteria, and Aitonia. The fruits of Erythrophysa differ in being indehiscent. The seeds of Cardiospermum Halicacabum (fig. 249) are perfectly globular, with a large reniform hilum and a transversely twice folded embryo completely filling them. Staphylea pinnata, having bladdery capsules, and globose or obovoid, albuminous seeds and a straight embryo, may be noted as a striking contrast to the above.

Spiny capsular fruits occur in Castanella and Esculus, excluding the species belonging to the old genus Paria. The fruit of Esculus Hippocastanum is globose, larger than a pigeon's egg, densely covered with strong spiny emergences and dehiscing loculicidally. Each of the three cells is twoovuled (one ovule being erect and one pendulous). Either one or the other may get fertilised; and each cell matures one seed only. Sometimes only one ovule gets fertilised in the whole ovary, and the cell containing it grows at the expense of the others, which remain small. The seed is large, depresso-globose, or rariously flattened by compression, and its shining chestnutbrown testa is thick and leathery. The embryo occupies the whole of the interior, and has thick, conferruminate cotyledons, 
separable with difficulty when mature. The latter are petiolate; the two-leaved plumule is well developed, and the large conical radicle lies in a separate cavity in the thick testa. Spiny indehiscent fruits consisting of one to three globose, free or connate cocci occur in some species of Nephelium, and N. Litchi, having a crustaceous, brittle, tuberculated pericarp and a pulpy, edible aril, is often met with in British fruit markets. The embryo is fleshy, and the cotyledons planoconvex.

Fleshy indehiscent fruits are met with in Sapindus and others, while those of Spanoghea are fleshy, but burst open transversely. Those of Melicocea, Lecaniodiscus, and Lepisanthes are drupaceous and indehiscent. The fruits of Euphoria and Schmidelia break up into indehiscent cocci, while the cocei of Diplopeltis are dehiscent. Triangled and trilobed fruits are very frequent, but those of Bridgesia and Paullinia are three-winged.

Samaroid fruits are not unusual, and, although not typical of the Order, are frequent and important. Bridgesia, Urvillea, Toulicia, Serjania, Thouinia, and Atalaya have fruits consisting of three samaras, while those of Acer and Negundo have only two. With exception of Thouinia, all are indehiscent.

The species of Acer ${ }^{1}$ may be grouped into five or six very distinct types according to the form of the fruit, seed, and embryo, but more particularly of the latter. The ovules are campylotropous in all cases, with the micropyle inferior, except in A. circinatum, where it is variable, ascending or horizontal, with the raphe ventral, and ascending more or less along the upper edge or surface.

The first type may be represented by A. Pseudo-Platanus. The seed-vessel is tumid on both surfaces, and the seed ovoid, slightly compressed laterally. The embryo commences by coiling round the circumference of the seed, but the cotyledons finally become transversely twice folded with their backs to the placenta and the incumbent radicle in the lower part of the seed. In rare cases the cotyledons 1885.

'See an interesting memoir on this group by Pax, Engler's Bot. Jahrb. 
become circinately coiled with their tips in the centre of the coil.

Other species agreeing with this type are A. monspessulanum, A. opulifolium, A. neapolitanum and A. obtusatum. The embryo is sometimes more folded in large seeds of the same species.

A. macrophyllum may be given as another type. The seed-ressel is rather tumid and densely covered with bristly or spiny spreading hairs. The interior of the seed is furnished with an irregularly conical outgrowth of the inner coat from the region of the hilum, and although the embryo originates in the same way as that of A. Pseudo-Platanus, its growth is obstructed by the process above mentioned, around which it coils, with the edges and not the backs of the cotyledons to the placenta. The cotyledons are circinately coiled or imperfectly biplicate transversely. A. insigne behaves in the same way, but the cotyledons are more decidedly twice folded transversely, and the outgrowth from the region of the hilum is much smaller.

A third type is represented by A. pennsylvanicum. The seed-ressel is inflated or gibbous on one side, and concave on the other, the seed conforming to this peculiarity. The embryo originates in the same way as that of A. PseudoPlatanus, but, owing to the thinness or flattening of the seedvessel and seed, the cotyledons during their development become twisted round into a vertical position with their tips close to the hilum. The cotyledons are generally flat, but sometimes become folded at the tip. A. montanum, A. tataricum, and $\mathrm{A}$. hircanum agree with this type, but the cotyledons generally become more or less undulated longitudinally owing to the seed-vessel and seed being more deeply concave. They are even sometimes longitudinally plicate and more or less folded at the tip.

A fourth type is seen in A. campestre. This agrees in general particulars witl A. pennsylvanicum; but the embryo is larger and undergoes a greater amount of longitudinal and oblique folding, so that in transverse section a number of folds of the cotyledons are cut through. The seed-vessel is much compressed laterally, but not, however, concave on 
either side. A. campestre, A. austriacum, A. platanoides, and A. Lobelii agree pretty closely with this type, except that the last-named undergoes a considerable amount of longitudinal folding or plaiting.

A. dasycarpum seems to constitute a fifth type, but only dried herbarium specimens were examined. The seed-vessel is laterally flattened, with the seed conforming to the interior. The embryo originates like all the foregoing, and during its derelopment it becomes twisted round, so that the cotyledons place themselves in the broad plane of the seed with their edges rertical; but they are flat, as shown in transrerse section, and often oblique or not exactly opposite one another, or the tip is, sometimes at least, again reversed from the hilum towards the end of the seed away from the placenta.

The sixth type is shown in A. circinatum. The seedvessel is tumid, not indented, and the oblong seed conforms to the interior. The curred portion of the seed containing the radicle is inferior, or in other seeds is twisted round to the side, rising obliquely, and in some cases is lateral or in others almost or quite superior. The raphe is in this case often lateral or inferior, passing round the lower instead of the upper side of the seed. The cotyledons have their edges vertical, with their backs to the radicle (incumbent), and are more or less transversely biplicate. The folds are less regular or compact than in A. Pseudo-Platanus, owing to the greater length and different shape of the seed, which conforms to the cavity containing it.

Seedlings. - There is considerable variety in this extensive Order; but the seedlings coming under my notice may be classed into three distinct groups, namely, those where the cotyledons become aerial and more or less foliaceous, those where they are subterranean, and those where they are aerial but do not leave the testa.

The strictly aerial kinds exhibit four or more forms. The cotyledons of Cardiospermum Halicacabum (fig. 250) are small, oblong, truncate, and very caducous, which may be ascribed to their character and mode of folding in the seed. The fact of their falling early points to their losing 
the faculty of assimilation, acting ehiefly as a store-house of reserve-material, and to a tendency to become subterranean. The first two leaves are opposite and tripartite with the middle segment again trifid. Succeeding leaves are alternate and more deeply divided; the fifth one being biternate.

The oblong or strap-shaped, sessile, five-nerved cotyledons of Acer Pseudo-Platanus (fig. 252) present quite a distinct type in the Order. Their shape and size are due to the manner of folding in the seed and the shape of the latter.

The first pair of leaves of A. Pseudo-Platanus are ovate, acuminate, and cordate at the base, near which they are doubly serrate-dentate. The cotyledons of A. campestre are shorter than those of its congener and proportionately broader. The same may be said of the first pair of leaves.

The cotyledons of Dodonæa viscosa (fig. 253) in being linear-lanceolate and one-nerved remind us very forcibly of those of Billardiera amongst the Pittosporeæ. The first three or four cuneate, trifid leaves also point in the same direction. The fifth, sixth, and seventh leaves are elliptic and nearly entire.

The broadly obovate, emarginate, five-nerved and reticulate cotyledons of Melianthus major constitute a well-marked type. The foliaceous stipules, in being intrapetiolar and connate in the upper portion, are also very striking. The first two leaves are digitately trifoliolate, and succeeding ones imparipinnate with more or less winged petioles.

The subterranean type of cotyledons is represented by Sapindus inæqualis (fig. 251). The petioles are of some considerable length, although the cotyledons do not leave the large globular seed. The first four leaves are greatly reduced and scale-like, while eight succeeding ones are lanceolate, acuminate, and quite entire. In the adult state some species of Sapindus have leaves consisting of one entire leaflet, while others are abruptly pinnate. The cotyledons of Atalaya diversifolia are also strictly subterranean. The form of the leaves is rather remarkable for this Order. The first three are lanceolate and small, succeeded by two linear-lanceo- 
late ones, and those by at least nine others which are linearlanceolate, very narrow, and of great length.

The third group or type of cotyledons is met with in Æsculus Hippocastanum. The large fleshy cotyledons are petiolate, but do not leave the seed; and the latter is carried some considerable height above ground during germination owing to the great length of the hypocotyl. The case is quite unusual, because in the majority of seedlings, where the cotyledons do not leave the testa, the hypocotyl remains undeveloped. The first pair of leaves is compound and digitately five-foliolate. This high development may be due to the amount of reserve in the fleshy cotyledons; and the elongation of the hypocotyl is necessary to carry the true leaves up to the light, because the primary ones are not reduced to scales, as most frequently occurs where the cotyledons are fleshy and do not leave the testa. The opposite leaves of Esculus, Acer, and Negundo are quite unusual in the Order.

\section{Blepharocarya involucrigera, F. Muell.}

Hypocotyl erect, terete, glabrous, green, soon becoming woody, brown, and covered with pale brown lenticels, $1 \cdot 5-2 \cdot 8 \mathrm{~cm}$. above the soil.

Cotyledons subovate, obtuse, falcate, somewhat unequally and shallowly cordate at the base, slightly cut away on one side and with a shallow sinus about the middle of the other, obscurely, but quite evidently alternately incurvinerved and reticulate, glabrous, deep green above, paler beneath, petiolate ; lamina $1 \cdot 3-1 \cdot 5 \mathrm{~cm}$. long, 7-8.25 mm. wide near the base; petiole slender, semiterete, channelled above, glabrous, or nearly so, slightly connate at the base in the early stages, about $1 \cdot 5-2 \mathrm{~mm}$. long.

Stem erect, terete, covered with a silky, adpressed, persistent pubescence, pale green, soon becoming brown, woody, and covered with small, pale brown, elevated lenticels; first twelve internodes varying from $3-8 \mathrm{~mm}$. long, increasing in length upwards.

Leaves compound, imparipinnate (first seven or eight simple and entire), cauline, alternate, exstipulate, petiolate, glabrous except the petioles and petiolules, coriaceous, deep shining green abore, paler beneath and shining; leaflets lanceolate, acuminate, rounded or suddenly and slightly tapering at the very base, alternately incurvinerved and reticulate with the lateral nerves slightly ascending, incurved, branched: and anastomosing near their summit 
with the branches ending in a colourless cartilaginous margin; petioles tapering upwards from a very stout base, which is flattened above, while upwards it becomes more slender and nearly terete, deep brownish-red, and more or less densely covered with adpressed pubescence ; petiolules short, subterete, narrowly channelled above, otherwise like the petioles.

Nos. 1-7 or 8. Simple, entire, ovate-lanceolate, acuminate, obtuse, having a pulvinus at the base of the lamina, which is articulated with the petiole, proportionately broader than the leaflets of the following compound leaves.

No. 8. Uni- to tri-foliolate.

No. 9. Trifoliolate.

No. 10. Five-foliolate.

Nos. 11 and 12. Five- to seven-foliolate, and gradually larger.

Cardiospermum Halicacabum, L. (fig. 249).

Fruit a capsule, triangular, with globose, membranous lobes, each one-celled, one-seeded, dehiscing loculicidally.

Seed globose, deep brown, shining, glabrous, very hard; hilum broad, reniform, transverse, whitish; raphe none; chalaza very large, broad, lunate, lying along the upper side of the hilum, and indicated by a slight elevation or thickening ; testa very hard, crustaceous ; tegmen thin, closely adhering to the testa.

Endosperm absent.

Embryo filling the interior of the seed, transversely plaited; cotyledons cuneate-spathulate, entire, minutely auricled at the base, with a few large transverse folds to accommodate themselves to the globose seed, thick and fleshy, pale yellow. In the transverse section two segments of the cotyledons appear thicker than the central two lobes, owing to the former being cut obliquely ; radicle very short, oblong-ovoid, obtusely pointed, seated in a small, shallow notch at the base of the cotyledons, and forming an impression near the tip of the back of the inner cotyledon, embedded in the testa at its tip.

\section{Seedling (fig. 250).}

Primary root vertical, with a few thin, lateral, branched, horizontal rootlets, firm, colourless.

Hypocotyl herbaceous at first, 3-4 cm. long, a little over $1 \mathrm{~mm}$. thick, round, pubescent, light green.

Cotyledons sessile, about $1 \mathrm{~cm}$. long, 2-3 mm. broad, thick, ligulate, truncate and broad at the apex, yellowish-green, glabrous, caducous.

Stem herbaceous, terete, $1 \mathrm{~mm}$. thick; 1 st internode $1 \cdot 5-2 \mathrm{~cm}$. 
about $1.5 \mathrm{~cm}$. long, $1 \mathrm{~mm}$. thick, shallowly channelled, pubescent; terminal segment of lamina about $2.5 \mathrm{~cm}$. long, $1 \cdot 25-1.75 \mathrm{~cm}$. broad, cuneate at base, trifid, with a few coarse teeth; lateral segments about $2 \mathrm{~cm}$. long, $\cdot 75 \mathrm{~cm}$. broad, obliquely oblong, cuneate at base, obtuse at apex, entire or obtusely serrated, or bi- or tri-fid; the common margin pubescent, and a few hairs on the nerves of the lower surface of the segments, otherwise glabrous, thin, bright green above, a little paler below.

Nos. 3 and 4. Similar, but more deeply cut, and with acuminate apices.

Nos. 5 and 6. Similar, bi-ternatisect, with rhomboid, acuminate, serrate lobes.

Leaves biternate or decomposite in the adult state, cauline, alternate (first two opposite), exstipulate, petiolate, alternately or oppositely penninerved, with ascending, branching nerves, membranous, pubescent on the margins and nerves beneath; petiole semiterete, channelled above, somewhat dilated at the base.

Atalaya diversifolia, ? F. Muell.

Hypocotyl subterranean.

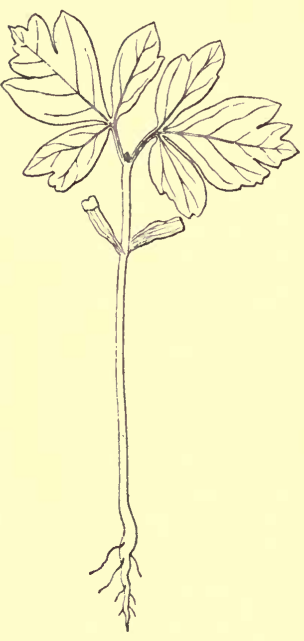

FIG. 250.

Cardiospermum Halicacabum. Two-thirds nat. size.

Cotyledons subterranean.

Stem woody, erect, terete, flexuous, leafy, pale green, pubescent ; 1st internode $2 \cdot 3 \mathrm{~cm}$. long; 2nd $\cdot 5 \mathrm{~mm}$.; 3rd undeveloped; 4th $8 \mathrm{~mm}$.; 5 th $2.5 \mathrm{~mm}$.; 6 th $4 \mathrm{~mm}$.; 7 th $6.75 \mathrm{~mm}$.; 8 th $3.5 \mathrm{~mm}$.; 9 th $4.75 \mathrm{~mm}$.; 10 th $3 \mathrm{~mm}$.; 11 th $3 \mathrm{~mm}$.; 12 th $2 \mathrm{~mm}$.; 13 th $3 \mathrm{~mm}$.; 14th $4 \mathrm{~mm}$.; 15th $3 \mathrm{~mm}$.

Leaves simple, entire, cauline, alternate, exstipulate, very shortly petiolate, glabrous, alternately penninerved and reticulate, with the midrib prominent on both surfaces, thin, coriaceous, deep green above, paler beneath ; petioles very short, thickened at the articulation, flattened above with a prominent midrib.

Nos. 1-3. Small, lanceolate, obtuse.

Nos. 4 and 5. Small, linear-lanceolate, subacute.

Nos. 6-8. Linear-lanceolate, acute.

Nos. 9-14. Long, linear, acute, arching. 
Sapindus inæqualis, $D C$. (fig. 251).

Hypocotyl undeveloped.

Cotyledons large and fleshy, filling the seed, which they do not

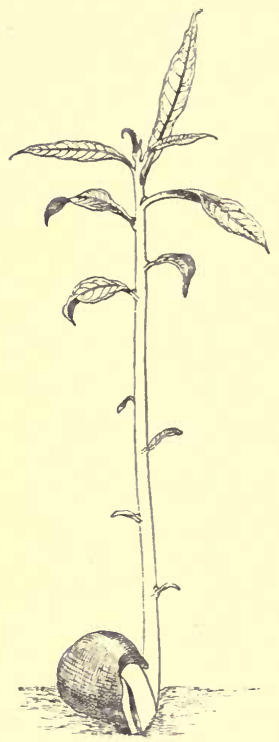

Fig. 251.-Sapindus inaqualis. Half nat. size. leave in germination; petioles thick, fleshy, colourless, semiterete, pushed out of the seed or elongated to convenience the radicle and plumule.

Stem erect, terete, green, hairy, soon becoming glabrous, ultimately woody; 1st internode $2.5 \mathrm{~cm}$.; 2nd $.95 \mathrm{~cm}$.; 3rd $2 \mathrm{~cm} . ; 4$ th $95 \mathrm{~cm}$.; 5 th $2.1 \mathrm{~cm}$.; 6 th $\cdot 55 \mathrm{~cm}$.; 7 th $\cdot 75 \mathrm{~cm}$.

Leaves cauline, alternate, exstipulate, petiolate, irregularly and alternately penninerved with ascending nerves, thinly hairy on both sides, soon becoming glabrous above, pale green and shining above; petioles short (in the seedling), semiterete, furrowed above on each side of the midrib, slightly hairy.

Nos. 1-4. Linear-lanceolate, acute, small and scale-like.

Nos. 5-7. Lanceolate, broadest above the middle, cuspidately acute or shortly acuminate, tapering into a short petiole.

Nos. 8-11. Lanceolate, acuminate, petiolate, much larger than any of the preceding.

\section{Acer Pseudo-Platanus, $L$.}

Pistil syncarpous, superior; ovary of two carpels, two-celled, each cell two-ovuled; ovules collateral or slightly superimposed, ascending, campylotropous; radicle inferior, close to the hilum. Only one ovule in a cell is habitually fertilised, generally, if not always, the upper one when they are superimposed.

Seed ovoid, slightly compressed laterally, somewhat narrowed to an obtuse point at the upper end; testa thin, ultimately membranous; hilum about the middle of the ventral aspect; micropyle inferior but pointing slightly upwards and contiguous to the hilum ; chalaza very large, superior, covering nearly or quite the whole of the upper part of the seed. 
Endosperm, from the earliest stages till it is wholly absorbed, thin, watery, or jelly-like. (See Linn. Journ. xxii. 399, fig. 133.)

Embryo originating in a short tubular prolongation near the micropyle, and at first straight, with an extremely short, turbinate radicle, and ovate, obtuse, closely adpressed cotyledons. It then continues to grow along the lower side of the seed, close to the testa, and, the outline of the seed being curved, the embryo gradually curves also. The cotyledons are now lanceolate or oblong-lanceolate. When the cotyledons have reached the upper and narrow end of the seed they curve rather suddenly downwards. This is continued until the tips reach the radicle, leaving the front and upper part of the seed under the chalaza empty except for the endosperm. The embryo is now a considerable size, with an elongated radicle and oblong, obtuse cotyledons. The next stage is characterised by a second curving of the cotyledons, and it depends whether the latter now curve inwards or outwards, as to the form the embryo shall ultimately assume. If they curve inwards the mature embryo will be circinate. If they now curve outwards the mature embryo will be transversely twice folded (conduplicate, 'Genera Plantarum'), and this is the commoner form.

In this case the tips of the cotyledons curve outwards and upwards to the chalaza. The embryo enlarges considerably after this, and the double portion of the cotyledons is now pushed into the centre of the seed, with the radicle on the lower side and the middle of the cotyledons on the upper side abutting against the chalaza, while the tips, still continuing to elongate, grow outward and upwards, reaching as far as the lower end of the chalaza.

In August the embryo is well formed, but the endosperm not yet all absorbed.

Seedling (fig. 252).

Primary root tapering, flexuous, rather stout, with a few lateral rootlets.

Hypocotyl 3-4 cm. long, $\mathbf{1} \cdot 5 \mathrm{~mm}$. broad (because of its being slightly compressed), glabrous, firm, reddish-brown.

Cotyledons two, often three (when two, one of them is frequently split), sessile, $3 \cdot 5-5 \mathrm{~cm}$. long, about $8 \mathrm{~mm}$. broad, strapshaped, obtuse, entire, obscurely trinerved, glabrous, pale green, rather persistent.

Stem soft, but soon becoming woody, erect, terete, glabrous, pale or brownish-green; 1st internode $2-3.5 \mathrm{~cm}$. long; 2 nd $1.5-2 \mathrm{~cm}$. ; 3rd 6-8 $\mathrm{mm}$. 
Leaves simple, cauline, opposite, rarely three at the same level and verticillate, exstipulate, petiolate, glabrous except at the very base on the under side; petioles terete, generally slightly channelled on the upper side when young, ultimately not channelled.

1st pair ovate, acuminate, cordate, and palmately five-nerved at the base, reticulate, irregularly and obtusely serrate.

2nd pair palmately five-nerved and lobed or lobulate, irregularly

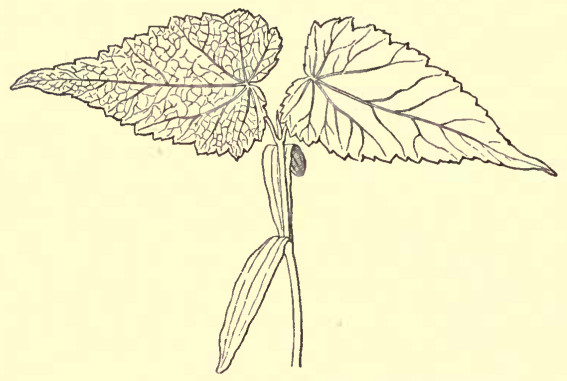

FIg. 252.-Acer Pseudo-Platanus. Half nat. size.

and coarsely dentate-serrate ; terminal lobe triangular ovate, obtuse ; middle lobes very broad and short, obtuse; basal lobes small or merely tooth-like and obtuse.

3rd pair similar.

Ultimate leaves large, palmately five-nerved and -lobed, subcordate at the base; lobes triangular-ovate, acuminate, obtuse, rather coarsely, irregularly, and distantly serrate; basal lobes smallest.

\section{Acer macrophyllum, Pursh.}

Fruit of two, rarely three samaras; wings ascending, oblong, obtuse, asymmetrical or half-elliptic, reticulate, nearly glabrous except on the thickened portion along the lower side, which is covered with adpressed hairs or bristles; seed-bearing portion of fruit ovoid, densely covered with rigid spreading bristles or spiny hairs, rather tumid.

Seed nearly horizontal or slightly ascending, short, deep, somewhat obovate in vertical section at right angles to the placenta, and triangular in vertical section parallel with the placenta, rather tumid and conforming to the cavity of the fruit, exalbuminous; tegmen enormously thickened near the hilum, forming an irregularly conical process projecting into the middle of the seed. 
Embryo originating in the apical, neck-like, curved portion of the seed; cotyledons ascending with their backs to the placenta as in A. Pseudo-Platanus, till they reach the thickening and enlarging process of the inner seed-coat, round which they twist across the cavity of the seed with their edges to the placenta, as do those of A. insigne, with their broad plane in consequence at right angles to the placenta and conduplicate as in A. Pseudo-Platanus ; radicle rather long, terete, bluntly pointed, inferior, and slightly descending or nearly horizontal.

Acer insigne, Boiss. et Buhse.

The two samaras are often or always of unequal size, owing to the non-development of the ovules in one of the cells; wings ascending or suberect, obliquely or half obovate, rounded at the apex, reticulate, slightly pubescent or nearly glabrous; seed-vessel tumid, ovoid in outline.

Seed slightly ascending, ovoid, obtuse, somewhat flattened laterally from the base towards the end distant from the hilum, conforming to the cavity of the fruit; tegmen thickened in proximity to the hilum and chalaza, but the outgrowth much smaller than in A. macrophyllum.

Embryo behaving in the same way as in A. macrophyllum, but the cotyledons are more decidedly transversely biplicate.

Acer pennsylvanicum, $L$.

Fruit.-The portion of the fruit containing the seed is rather inflated or gibbous on one side and concave on the other; this concavity sometimes occurs on the same side of both halves of the fruit, or on alternate sides of them.

Seed broadly oblong in outline, more or less compressed laterally but conforming to the cavity of the ovary and therefore concave towards its indentation and convex to its gibbous side; seed-coat double; hilum on the basal end of the seed.

Embryo large, filling the cavity of the seed ; cotyledons straight and plane or nearly so, but often folded back at the tip; concave in conformity with the fruit and seed; radicle about equal to the seed in length, terete, straight, or eurved at its base only, the fold being chiefly in the base of the cotyledons.

A. tataricum conforms to the same type, but the cotyledons are thrown into one or two folds, owing to the greater concavity of the seed-vessel and seed.

A. hircanum also agrees, but the seed being considerably flattened 
and the linear-oblong cotyledons broader than its width, these are thrown into various contortions, lying in the broad plane of the seed.

\section{Acer campestre, $L$.}

Seeds suborbicular, rather broader on the attached side, much compressed laterally, and conforming to the shape of the cavity of the samara; seed-coat double; hilum on the basal edge.

Embryo large, filling the cavity of the seed ; cotyledons incumbent, with their backs to the placenta, originating in the narrow plane of the seed; but as they get too large for the space, becoming twisted round so as to lie in the broad plane with their edges to the placenta; finally getting too long for the seed, they form two large folds in the middle, and the tips are thrown back over the basal portion close to the radicle, between which and the edges of the basal portions they always lie; radical inferior, terete, rather pointed, curved at its base, or gradually throughout its length.

\section{Acer dasycarpum, Ehrh.}

Seed broadly oblong, laterally flattened, conforming to the cavity of the carpel, exalbuminous; seed-coat double; testa moderately thick and black; tegmen thin and membranous.

Embryo large, filling the seed, yellowish ; radicle terete, occupying the lower side of the seed; cotyledons incumbent originally, that is with their backs to the placenta, but ultimately turning round with their edges vertical to the axis of the fruit and their tips towards the placenta; by so doing they place themselves in the broad plane of the laterally compressed seed. After reaching the base of the seed close to the hilum they become folded back again towards the farther end, and in so doing one apical half is folded inside the other. In the specimen examined, the two cotyledons were not strictly opposite, but placed obliquely. There was, however, no plaiting or folding. Radicle filiform, straight, occupying the lower edge of the compressed seed. Petioles of the cotyledons slightly curved.

\section{Acer circinatum, Pursh.}

Seed oblong, obtuse at either end, tumid, conforming to the cavity of the ovary ; seed-coat double; hilum at one end of the seed ; raphe encircling the whole basal portion of the seed ; funicle'short, thick, and with a development of cortical tissue.

Embryo originating in the neck-like portion of the ovule, which is curved round against a cortical development of tissue from the funicle; radicle terete and stout, equal to the neck of the ovule 
in length, obtuse, somewhat constricted where the cotyledons commence, horizontal and occupying the base of the seed, or rising obliquely, or almost superior (contrary to the usual rule), and hence lying on the upper side of the seed. Hence the cotyledons and radicle are not always in the same vertical plane.

Cotyledons usually vertical, that is, lying on their edges in the base of the seed, incumbent, following the outline of the cavity of the seed as they grow, curving round the end distant from the hilum, and then growing into the cavity of the endosperm somewhat loosely till they touch the end next the hilum, and, growth continuing, become too long for the space, and so get doubled up against their own basal portion and the infolded portion of the seed. Their apex then recurves and grows backwards away from the hilum.

The cotyledons still have their backs to the placenta, as in A. Pseudo-Platanus, although they are in this particular instance vertical to the axis of the pistil.

Dodonæa viscosa, L. (fig. 253).

Hypocotyl erect, terete, minutely and rather densely pubescent, pale green or reddish, $1 \cdot 5-3 \mathrm{~cm}$. above the soil.

Cotyledons linear-lanceolate, acute or subacute, entire, sessile, or appearing shortly stalked by being narrowed at the base, with a distinct midrib but no other discernible venation, horizontal, glabrous, light green above, paler beneath, $1 \cdot 9-2 \cdot 5 \mathrm{~cm}$. long.

Stem erect, terete, flexuous, densely pubescent with upcurved and incurved hairs, and more or less densely dotted with sessile glands, pale green, becoming reddish, ultimately woody; 1st internode 2-4 mm. long; 2nd $1 \cdot 5-2$ mm. ; 3rd 3-4.5 mm.; 4th 4-6 mm.; 5 th and 6 th each 5-6 $\mathrm{mm}$.

Leaves simple (at least in the seedling), cauline, alternate, exstipulate, petiolate, alternately and ascendingly penninerved, more or less pub-

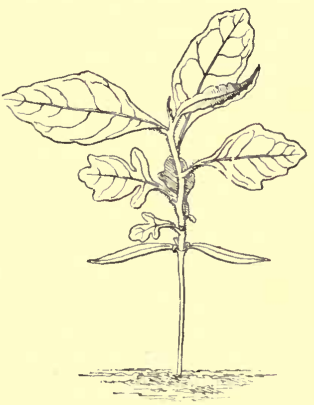

Fie. 253.-Dodonaa viscosa.

Half nat. size. escent on both surfaces, especially on the nerves, slightly scabrous on the principal nerves, light or deep green above, paler beneath and shining, often with a glaucous hue; petiole short, stout at the base and more slender upward, slightly channelled above with an 
elevated midrib, pubescent, winged upward by the decurrent lamina of the leaf.

No. 1. Cuneate, trifid or tripartite, with obtuse segments.

Nos. 2 and 3. Similar, but larger-terminal lobe largest, cuneate, and generally again more or less trifid.

No. 4. Rhomboid, obtuse, cuneate or decurrent at the base on the petiole, with two to three coarse obtuse teeth on each side.

Nos. 5-7. Rhomboid or elliptic or oblong, variable, obtuse, obtusely toothed or shallowly sinuate or entire, tapering into the petiole at the base, forming a wing to the latter.

Melianthus major, $L$.

Primary root a vertical, succulent, colourless tap-root; stout, colourless adventitious roots spring from the thickened base of the hypocotyl.

Hypocotyl about $2 \mathrm{~cm}$. long, 1.5-2.5 mm. thick, terete, glabrous, brownish above ground, colourless below.

Cotyledons subsessile, nearly equal, about $2.5 \mathrm{~cm}$. long and $1.75 \mathrm{~cm}$. broad, obovate, cuneate at the base, emarginate with a short blunt mucro, with very distinct whitish incurved nerves on each side of the midrib, quite glabrous, thin, rather firm, bright green above, paler and shining beneath.

Stem erect, terete, glabrous, succulent, stout, pale green; 1st internode $1.2 \mathrm{~cm}$. long, $3 \mathrm{~mm}$. thick; 2nd internode $6 \mathrm{~mm}$. long, $2 \mathrm{~mm}$. thick.

Leaves cauline, compound, pinnate, alternate, stipulate, glabrous, petiolate.

No. 1. Lamina digitately trifoliolate; lateral leaflets sessile, oblong, acute, serrate, unequal on the posterior basal side, penninerved, bright green above, paler or subglaucous beneath with prominent nerves; nerves alternate or opposite; serratures acute, tipped with a yellow mucro; terminal leaflet obovate-elliptic, acutely serrate, narrowed to the base, penninerved with opposite or alternate nerves; free part of petiole terete, pale green; stipules large, foliaceous, and amplexicaul at the base, adnate to the petiole for more than half their length, then connate by their edges, leaving only their two acute tips free.

No. 2. Exactly similar; petiole similar; stipules forming a sheath to the next younger leaf and bud. In some plants the petiole of the first and second leaf has a foliaceous, decurrent wing, somewhat toothed or distantly serrate, and its uppermost part produced into a semi-triangular acuminate lobe.

No. 3. Five-foliolate; basal leaflets oblong, incise and irregularly 
serrate, oblique on the posterior basal side; middle pair of leaflets similar but decurrent on the petiole; terminal leaflet oblong, cuneate at the base, grossly serrate.

No. 4. Seven-foliolate.

Staphylea pinnata, $L$.

Fruit a large, inflated, membranous capsule, strongly reticulated, with a strong midrib to each carpel, glabrous, two- to threecelled with generally one large horizontal seed in each cell, dehiscing at the apex on the ventral side of the persistent styles.

Seed large, globoso-obovoid, horizontal, shining, pale brown, glabrous; testa bony, thick; tegmen thin, membranous, palecoloured; hilum large, forming a circular depression in the outer coating of the seed; micropyle conspicuous, contiguous to the depressed hilum, and terminating a basal ridge or lobe of the seed, into which the radicle is directed; raphe lateral, forming a ridge along the side or edge of the slightly horizontally compressed seed; chalaza broad, apical.

Endosperm copious, fleshy, colourless.

Embryo large, straight, pale green, embedded in the axis of the endosperm ; cotyledons broad, somewhat obliquely obovate, obtuse, shallowly auricled at the base, otherwise entire, plano-convex, falling a little short of the length and breadth of the endosperm, lying across the seed obliquely; radicle very short, globose, obtuse, or more or less flattened horizontally, pointing into the micropyle at one side of the hilum, inferior in ascending seeds but apparently always horizontal in this species like the seeds.

\section{SABIACE $A$.}

Benth. et Hook. Gen. Pl. i. 413.

Fruit and Seed.-The two- to three-celled ovary contains one or two superposed or collateral ovules in each cell, which are horizontal or pendulous with a ventral raphe and an inferior micropyle. The fruit consists of one or two drupaceous, or dry, indehiscent pieces, which in the typical genus Sabia are reniform and compressed. The endocarp is bony or crustaceous, nut-like, and contains a single nut-like seed. The latter conforms to the cavity of the endocarp and is compressed or globose with a membranous or leathery testa. It is exalbuminous or 
contains a small quantity of endosperm adhering to the testa. The embryo is large, with rather fleshy, wavy, conduplicate, or variously twisted cotyledons, and a fleshy, descending, incurved or flexuous radicle, pointing upwards to the hilum. The latter is broad and conspicuous.

Ophiocaryon paradoxum is known as the Snake Nut, from the manner in which the embryo is coiled up in the seed resembling a snake. The cotyledons are membranous and foliaceous.

Seedlings.-The species of this Order are natives of tropical and subtropical countries north of the equator, and seedlings do not often come under observation. The cotyledons of Meliosma pùngens (fig. 254) are foliaceous, aerial, and penninerred with incurved reins. They are oblong in outline and glabrous, whereas those of M. Arnottiana are oval or elliptic

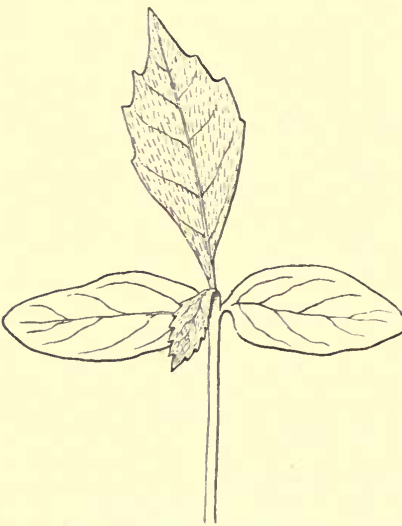

Fis. 254.-Meliosma pungens.

Two-thirds nat. size. and ciliated at the margin. The first leaf of M. pungens is cuneate-elliptic, that of M. Arnottiana lanceolate and simple.

Meliosma pungens, Wall. (fig. 254).

Hypocotyl somewhat woody, terete, 3-4 cm. long, $1.5 \mathrm{~mm}$. thick, pubescent, brownish-grey.

Cotyledons unequal, subsessile, $2 \cdot 5-3.5 \mathrm{~cm}$. long, 1.5-2 cm. broad, oblong, obtuse, rounded at the base, penninerved, with incurving veins, reticulate, glabrous, coriaceous, dark green with brownish spots above, paler and shining beneath, rather persistent.

Stem short, like the hypocotyl, but with longer hairs. 1st internode $1 \mathrm{~mm}$. long.

First leaves simple, cauline, alternate, exstipulate, petiolate, alternately penninerved, hispid or hairy above, and deep shining green, tomentose beneath; petioles short, at least in early stages of the plant. 
No. 1. 3-4 cm. long, 1·5-2 cm. broad, elliptic, narrowed to both ends, sinuate-serrate, with reclined points, penninerved, thin, hispid above, tomentose on the margin and beneath, shining green.

No. 2. Ditto.

\section{Meliosma Arnottiana, Wight.}

Hypocotyl as in M. pungens, but minutely pubescent and greenish or slightly tinged with red.

Cotyledons oval-oblong or elliptic, acute, entire, shortly petiolate, ciliate, otherwise glabrous, light green, pinnatinerved as in the leaves.

Stem erect, terete, pubescent, herbaceous; 1 st internode $2-3 \mathrm{~mm}$. long.

First leaves ovate-lanceolate, acute, almost acuminate, coarsely serrate, coarsely hairy, green, pinnatinerved.

\section{ANACARDIACER.}

Benth. et Hook. Gen. Pl. i. 415.

Fruit and Seed.- The ovary in this Order generally consists of one carpel and is therefore one-celled; but in the tribe Spondiex the ovary is syncarpous, consisting of two to five carpels and containing as many cells. From the occurrence sometimes of several distinct carpels in one flower, the onecelled ovaries may be considered as reduced types. This is strengthened by the fact that a three-celled ovary occurs, though rarely, in some of the species of Pistacia, where the one-celled condition is the rule. The flowers are polygamo-diœecious or unisexual, and in some of the potentially male flowers there are four or five aborted carpels or a four- to five-partite ovary in the same condition. The ovules are solitary in each ovary or in each cell of the plurilocular ovaries, and pendulous, or attached to the side walls of the carpels or suspended by a funicle arising from the base of the cell. The micropyle is inferior and the raphe dorsal or passing round one end of the horizontal seed and along the dorsal edge for some distance, as in Buchanania latifolia, where it is very thick and prominent. In Pistacia the ovule is erect, with a ventral raphe and an inferior micropyle. 
The fruit is superior or partly submerged in the receptacle, one- to five-celled and nearly always drupaceous and indehiscent. The endocarp is bony, crustaceous, or leathery, and sometimes bursts open by two valves, as in Mangifera indica and Buchanania. In some of the species of Pistacia it behares in the same way. The tissue of the fruit often contains large cavities filled with an oily or caustic juice as in Schinus Molle and Schinus terebinthifolius. A curious case occurs in Anacardium occidentale, where the receptacle becomes very large, pyriform, and fleshy, forming a pseudo-fruit, bearing at its apex the very much smaller, reniform, true fruit. The other five species, as well as those of Gluta, have also a stipitate fruit.

The seed is horizontal and lies across the receptacle, or erect, or pendulous, with frequently a swollen or umbilicate funicle.

The testa is generally if not always membranous, and is occasionally united firmly with the endocarp. Endosperm is nearly always absent, or forms a thin layer as in some species of Schinus and in Smodingium. The cotyledons are thin and plano-convex, or of great thickness and fleshy. The short radicle is straight or variously curred, pointing upwards or downwards to the micropyle.

Types with comparatively thin cotyledons are represented by Schinus Molle (fig. 259) and S. terebinthifolius (fig. 260). Their thinness is explained by the narrowness of the eavity of the endocarp and by the presence of a moderate quantity of fleshy endosperm. Thick cotyledons of peculiar form are exhibited by Buchanania latifolia (fig. 258). A stout cord-like funicle runs along the basal end and half-way round the upper edges of the cotyledons, forming a deep furrow.

Seedlings.-There are two leading types of seedlings, namely, those with aerial and those with subterranean cotyledons. The most prevalent form of eotyledons is ovate, obtuse, trinerved, shallowly sinuate on one side, otherwise entire and shortly petiolate. This is well represented by Schinus terebinthifolius (fig. 260) ; the cotyledons besides showing the characters abore mentioned are more conspicuously reticulate than happens in many others which are more opaque. 
Schinus Molle (fig. 259) and Duvaua dependens agree in all essential points. The mode of germination of the seed from the drmpaceous fruit is shown in Schinus Molle. Duvaua dependens differs in the obscure venation and the cotyledons not being sinuated on one side. This shallow sinus owes its origin to the indentation of the lower side of the horizontal seed in Schinus by a thickening or elevation of the receptacle in that region.

The trinerved character and the shallow sinus of the cotyledons prevail in species of other genera, where the outline differs considerably from that of Schinus. This is so in the case of Rhus typhina (fig. 256), with spathulate-oblong cotyledons, and in Odina Wodier, having long, lanceolate, falcate cotyledons with short broad petioles.

A departure from the strictly aerial and foliaceous cotyledons is met with in Anacardium occidentale. Here they are large, fleshy, falcate, and directed to one side of the young stem, plano-convex, trinerved, and slightly reticulate on the back, but showing no trace of nerves on the upper surface. Another nearly similar case occurs in Buchanania latifolia (fig. 258), having obovate, unequal-sided, fleshy cotyledons with a thick and a thin edge. They conform to the interior of the seed and that again to the endocarp, to which they owe their peculiar shape. Immediately after germination they are both directed to one side of the stem as in subterranean cotyledons; but they ultimately spread out right and left. Thick, fleshy, and truly subterranean cotyledons occur in Rhus Thunbergiana (fig. 255), a South African species with almost dry, one-celled, one-seeded fruits from three-quarters to one inch broad. A more remarkable instance occurs in Mangifera indica (fig. 257), the fleshy, oblong, subterranean cotyledons of which are often lobed and sometimes proliferous, as shown in the figure.

The primary leaves of the seedling show considerable variation in the different types of the Order. Those observed may be grouped under three very distinct types, namely, (1) those reduced to scales, (2) simple but foliaceons leaves, and (3) compound leaves. The first five leaves of Rhus Thumbergiana are minute scales; while all succeeding ones are simple, and penninerved. The first six at least of 
Mangifera indica are scale-like; the ultimate ones long, simple, and entire.

Where the primary leaves are foliaceous and simple, the first two are opposite, although succeeding ones are alternate. Examples of this occur in Buchanania latifolia, Schinus terebinthifolius, Odina Wodier, and Duvaua dependens. An exception occurs in Anacardium occidentale, where the first four leaves are cromded together and oblong-elliptic. The ultimate ones are also simple and entire, while those of Duraua are entire or sinuate. The third leaf of Schinus terebinthifolius is trifoliolate, while the eighth one in Odina Wodier is the first to attain that state of derelopment.

The only case of the primary leaves being compound coming under my observation, occurs in Rhus typhina, where the first three at least are trifoliolate, with the terminal leaflet much

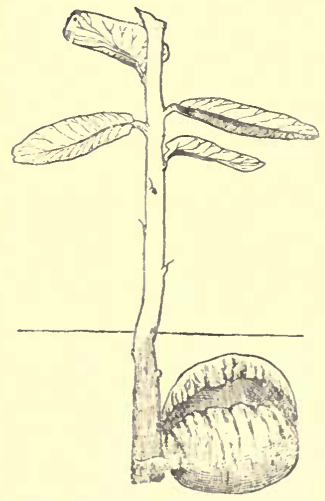

Fig. 255.-Rhus Thunbergiana. Half nat. size. the largest and deeply incised. The first two only are opposite. Compare this with the seedling of Ailanthus glandulosa amongst the Simarubeæ.

Rhus Thunbergiana, Schult. (fig. 255).

Hypocotyl subterranean.

Cotyledons large, fleshy, persistent, plano-convex, subterranean, wrinkled, pale yellow, petiolate, and both lying on the same side of the stem, $2 \cdot 6 \mathrm{~cm}$. long, $1 \cdot 3 \mathrm{~cm}$. wide, $8-10 \mathrm{~mm}$. thick; petiole about $6 \mathrm{~mm}$. long,

Stem woody, erect, terete, glabrous, reddish at first, then becoming covered with a glancous-white bloom, then pale green, ultimately brown; internodes short: 1 st $1.7 \mathrm{~cm}$. long; 2 nd $5.75 \mathrm{~mm}$.; $3 \mathrm{rd} 1.15 \mathrm{~cm}$.; 4th $6 \mathrm{~mm}$.; 5th 7.5 mm; 6th $4 \mathrm{~mm}$.; 7th $6 \mathrm{~mm}$.

Leaves simple, cauline, alternate, exstipulate, petiolate, glabrous, coriaceous, rigid, horizontal, alternately penninerved with numerous parallel veins at right angles to the midrib and running straight to the margin, simple, or more often forked and sometimes forking again near the margin, brown and glossy at first, becoming covered with 
a glaucous bloom, ultimately light green; petioles very short, subterete, shining.

Nos. 1-5. Reduced to small, subulate, acute, discoloured scales.

Nos. 6-22. Oblong-oval, obtuse, emarginate, otherwise entire, gradually larger in order of development.

Rhus typhina, $L$. (fig. 256).

Primary root tapering downward at an obtuse angle into the soil, dark-coloured, with a few lateral rootlets, and soon equalled or superseded by strong lateral rootlets immediately beneath the soil, covered with root-hairs.

Hypocotyl erect, terete, glabrous, crimson, 12-28 mm. long.

Cotyledons spathulate-oblong, obtuse, tipped with a glandular mucro, slightly falcate, petiolate, trinerved from the base, glabrous except the petioles, dull green above, paler beneath, when fading of a rusty red or crimson colour ; lamina $5-9.5 \mathrm{~mm}$. long, $2 \cdot 5-4 \cdot 5$ $\mathrm{mm}$. wide; petioles channelled above, convex beneath, dilated and slightly connate at the base, and again dilated into the lamina, slightly hairy on the margins above, $1 \cdot 75-4.5 \mathrm{~mm}$. long.

Stem erect, terete, hairy, with simple glandular hairs; green, reddish, or crimson, ultimately slirubby; 1st internode $2.25 \mathrm{~mm}$. long; 2nd and 3rd each about $\cdot 5$ $\mathrm{mm}$.

Leaves compound, imparipinnate, cauline, alternate, exstipulate, petiolate, alternately and ascendingly penninerved with the nerves running straight into the

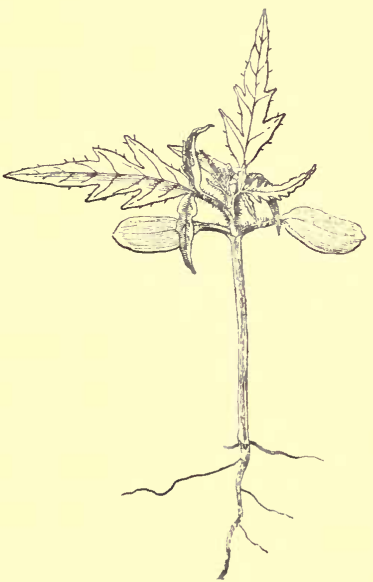

Fig. 256.-Rhus typhina. Nat. size. teeth and divisions, somewhat hairy above and at the margins; hairs simple, glandular; deep green above, glaucous beneath, when fading of a rusty red or yellow and crimson colour; petioles semiterete, channelled above, coarsely hairy with simple glandular hairs, generally red.

Nos. 1-3. Trifoliolate ; lateral leaflets narrowly lanceolate, acuminate, acute or subacute, more or less distinctly serrate in the lower half, sessile ; terminal leaflet rhomboid-lanceolate, acuminate, sub- 
acute, cuneate at the base and very shortly petiolate, coarsely serrated on the lower half, with two ovate, subacute, decurrent serratures on each side on the first two leaves, and three or more on the third leaf.

\section{Anacardium occidentale, $L$.}

Hypocoty $l$ erect, terete, fleshy, covered with minute points, $2 \cdot 5-$ $3 \mathrm{~cm}$. above the soil.

Cotyledons aerial, large, fleshy, falcate, directed to one side of the seedling stem, plano-convex, but deeply channelled at the base on the upper side, glabrous, yellowish-green, trinerved on the back, where they also distinctly show the short lateral nerves, and are slightly reticulate, nerveless on the upper surface, sessile, $4.4 \mathrm{~cm}$. long in the bent condition, 10-12 mm. wide.

Stem erect, tapering upwards very much in the seedling stage, covered with minute glandular points, fleshy, ultimately woody ; 1st internode $4-4.5 \mathrm{~cm}$. long, appearing as if jointed to the apex of the hypocotyl above the cotyledons, where a bud is given off in the axil of each, thickened on one side with two elevated processes as if furnished with a sheath ; 2nd and 3rd internode 2-3 mm. long ; 4th shorter.

Leaves simple, entire, cauline, alternate, exstipulate, shortly petiolate, closely and alternately incurvinerved, bronze-coloured in the young state, and ultimately deep green, shining, glabrous.

Nos. 1-4. Oblong-elliptic, shortly acuminate, crowded.

\section{Mangifera indica, $L$. (fig. 257).}

Primary root very stout, tapering downwards, and giving off slender, lateral rootlets, dark-coloured.

Hypocotyl very short, stout, terete, glabrous, pale-coloured, with dark markings, $6-8 \mathrm{~mm}$. long, 7-8 $\mathrm{mm}$. wide.

Cotyledons oblong, obtuse, thick, fleshy, plano-convex, subterranean, cut away on the upper side at the base, and slightly auricled on the under and basal side, very shortly petiolate, about $5 \cdot 7 \mathrm{~cm}$. long, $2.5 \mathrm{~cm}$. wide; petioles stout, fleshy, plano-convex, curved at right angles to the radicle to accommodate the latter in germination, 12-13 $\mathrm{mm}$. long, $7 \cdot 5 \mathrm{~mm}$. wide.

They often become lobed, and sometimes proliferous, splitting transversely and forming a second embryo with two cotyledons corresponding to half the original ones or less.

When this is the case, a second plumule and radicle are developed similar to the original. 
Stem erect, terete, glabrous, stout, tapering upwards, ultimately woody; 1st internode $5.4 \mathrm{~cm}$. long; 2nd $4 \mathrm{~mm}$. long; 3rd $4 \mathrm{~mm}$. Leaves simple, entire, cauline, alternate, exstipulate, petiolate. Nos. 1-6. Small, reduced to scales.

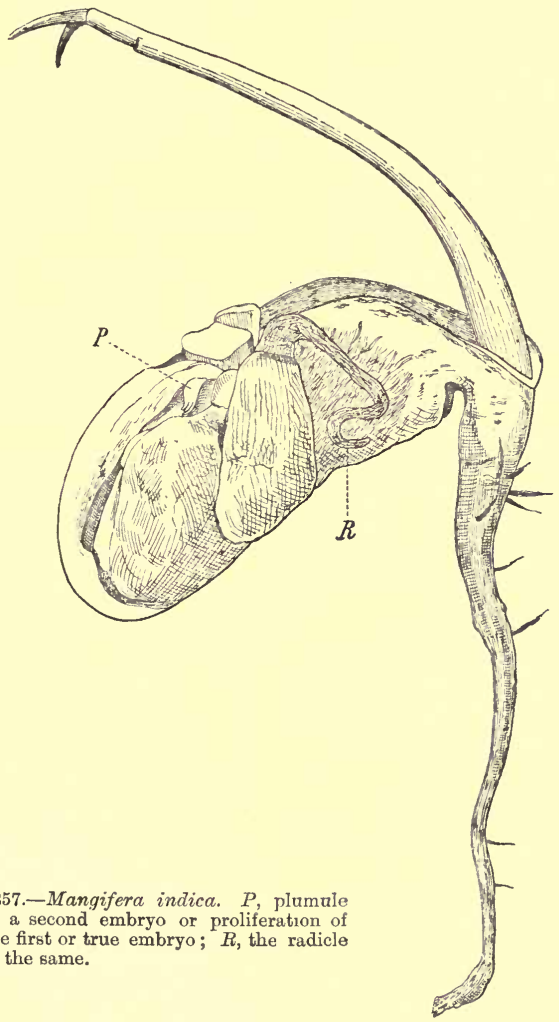

Fig. 257.-Mangifera indica. $P$, plumule of a second embryo or proliferation of the first or true embryo; $R$, the radicle of the same.

Buchanania latifolia, Roxb.

Fruit a drupe, with a small quantity of fleshy sarcocarp, onecelled, one-seeded, solitary by abortion ; endocarp hard, bony, late- 
rally compressed, especially near the apex, splitting vertically into two pieces during germination.

Seed transversely oblong, much compressed laterally, especially near the top, and conforming to the interior of the endocarp; testa thin, pale brown, marked on both sides by the branching chalaza, where the seed is discoloured; funicle stout, lying in an indentation round one end of the seed; micropyle superior.

Endosperm none.

Embryo large, curved, transverse to the axis, pale greenishyellow or almost colourless, fleshy; cotyledons conforming to the interior of the seed and each occupying about a half of it, lying transversely to the basal placenta with their very much thickened edges towards it, and their thin indented edges to the apex of the endocarp, which is also indented and always much compressed, causing the cotyledons to be more or less asymmetrical ; radicle at one

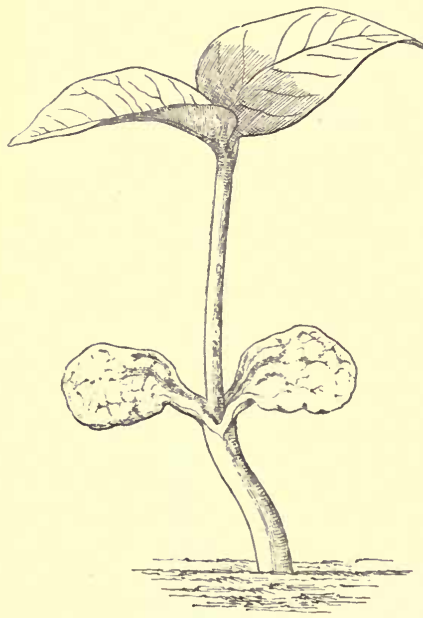

Frg. 258.-Buchanania latifolia, showing thin edge of cotyledons. Nat. size. end of the embryo, terete, obtuse, curved round the basal end of the cotyledons and pointing upwards.

\section{Seedling (fig. 258).}

Hypocotyl erect, terete, fleshy in a very young state, glabrous, pale green, or tinged with red, soon becoming brown, $18 \mathrm{~mm}$. long.

Cotyledons fleshy and soon falling away, obovate, very oblique or unequalsided and also having one edge thin and the other thick, petiolate, glabrous, wrinkled or corrugated on the upper surface and margin, ribbed more or less conspicuously on the undersurface; lamina $6 \cdot 5-7 \cdot 5$ $\mathrm{mm}$. long, 5-5.5 $\mathrm{mm}$. wide, $2 \mathrm{~mm}$. thick at one edge and $\cdot 25 \mathrm{~mm}$. thick at the other; petioles connate at the base, grooved above, convex on the back, 2-4 mm. long. 
Stem erect, terete, succulent, ultimately woody, finely pubescent, pale green or reddish, soon becoming brown; 1st internode $1 \cdot 5-3 \cdot 3$ cm. long.

Leaves simple, entire, cauline, alternate (first two opposite), exstipulate, petiolate, glabrous, or thinly glandular-pubescent on the midrib on both surfaces, alternately incurvinerved, with the nerves branching towards the margin and ending in a colourless cartilaginous line surrounding the leaf, slining green above, paler and shining beneath ; petioles short, semiterete, channelled above, thinly glandular-pubescent.

Nos. 1 and 2. Lanceolate, obtuse, suddenly tapering to the base.

Schinus Molle, L. (fig. 259).

Fruit a drupe, one-celled, one-seeded; mesocarp fleshy or pulpy, very scanty; endocarp of two layers, of which the outer on the sides of the fruit is hollowed in several places forming oil receptacles; inner hard and bony.

Seed transverse to the receptacle of the fruit, irregularly oblong or subovate, suspended from the side of the cell, laterally compressed and conforming to the interior of the endocarp; testa thin; hilum and micropyle at one side of the ovary and superior or nearly so.

Endosperm irregular, surrounding the embryo, thick in some places and thin at others, fleshy, white.

Embryo comparatively large, nearly equalling the length and breadth of the endosperm, yellowish; cotyledons ovate, obtuse, entire, nearly or quite of the same thickness across

A

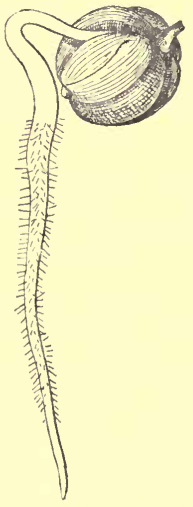

Frg. 259.-Schinus Molle, $\times 3$. A, germinating seed. B, seedling four days after germination. the breadth of the seed, trinerved, often undulated in accordance with the undulated or wavy interior of the endocarp, with their basal edges to the 
placenta; radicle terete, obtuse, ascending at the basal ends of the cotyledons.

Germination.-The primary root in germination pushes out at the side of the fruit through a narrow longitudinal slit between two of the numerous obtuse ridges formed by the swollen vittæ or oil-containing cavities. The primary root and hypocotyl are already stout, and the former is well furnished with root-hairs. The hypocotyl, having elongated and straightened, pulls the cotyledons out of the fruit.

\section{Seedling.}

Hypocotyl woody, erect, terete, finely pubescent, pale brown, about $13 \mathrm{~mm}$. above soil.

Cotyledons ovate, obtuse, petiolate, coriaceous, glabrous, trinerved, reticulate; lamina slightly unequal at the base, $14 \mathrm{~mm}$. long, $7.5 \mathrm{~mm}$. broad; petioles channelled above, pubescent, $1.5 \mathrm{~mm}$. long.

Stem woody, erect, terete, finely pubescent, pale brown ; 1st internode $14.5 \mathrm{~mm}$. long; 2nd $11 \mathrm{~mm}$.; 3rd $8 \mathrm{~mm}$.; 4th $11 \mathrm{~mm}$; 5 th $8 \mathrm{~mm}$; 6th $18 \mathrm{~mm}$.; 7 th $14.5 \mathrm{~mm}$.; 8 th $18.5 \mathrm{~mm}$.; 9 th $13.5 \mathrm{~mm}$.; 10 th $11 \mathrm{~mm}$.

Leaves compound (primary simple), cauline, alternate (first two opposite), exstipulate, petiolate, pubescent on the petiole and midrib above; leaflets alternately penninerved, subreticulate, deep green above with paler nerves, paler beneath; petioles semiterete, channelled above.

Nos. 1 and 2. Opposite, lanceolate, acute, acutely serrate, as are all the succeeding ones.

No. 3. Alternate, lanceolate, with a lobe on one side at the base.

No. 4. Lanceolate, with a lobe on each side at the base.

Nos. 5 and 6. Digitately trifoliolate; leaflets lanceolate, with the terminal one many times larger than the lateral ones.

No. 7. Imperfectly trifoliolate.

Nos. 8-12. Digitately trifoliolate; lateral pair small, lanceolate; terminal one lanceolate, elongate or oblong-lanceolate, many times larger than the lateral ones.

Ultimate leaves imparipinnate with eight to thirteen pairs of opposite or alternate, lanceolate, acute, acutely serrate leaflets; sessile and frequently cut away at the base on the posterior side; basal ones longest, gradually becoming smaller to the uppermost pair ; terminal leaflet longest of all, lanceolate, acute, acutely serrate. 
Schinus terebinthifolius, Raddi.

Fruit a drupe, globose, glabrous, bright scarlet when mature, tipped with the persistent base of the terminal style; epicarp thin, crustaceous; mesocarp pulpy; endocarp with oil receptacles as in S. Molle.

Seed conforming to the interior of the endocarp, transverse to the fruit, reniform, with the sinus lateral, laterally compressed and somewhat undulated, glabrous, pale brown; testa thin, membranous; funicle suspending the seed at one end; hilum and micropyle contiguous; raphe ventral as well as the chalaza, both lying in the sinus, deeper brown than the rest of the testa.

Endosperm as in S. Molle but much thicker at the backs of the cotyledons.

Embryo curved, large in proportion to the size of the seed, greenish-yellow, lying in the broadest plane of the seed, transversely to the axis of the fruit; cotyledons oblong or ovate-oblong, slightly cordate at the base, otherwise entire, accumbent, trinerved at the base, flat and closely applied face to face, often slightly twisted, lying with their edges to the base of the fruit and their lower edges obliquely to the lateral placenta; radicle terete, rather elongated, descending and parallel with the funicle and with its tip close to the micropyle.

\section{Seedling (fig. 260).}

Cotyledons ovate-oblong, subfalcate, very similar to those of S. Molle.

Stem as in S. Molle.

Leaves.-Nos. 1 and 2. Opposite, simple, ovate, acute, acutely serrate, alternately penninerved, with the nerves running straight into the teeth.

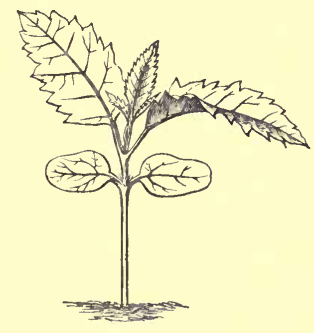

Fig. 260.

Schinus terebinthifolius.

Two-thirds nat. size.

No. 3. Alternate, trifoliolate; terminal leaflet much the largest, lanceolate, acute, acutely serrate; lateral ones similar, much smaller.

Odina Wodier, Roxb.

Hypocotyl erect, terete, glabrous, pale green, $2 \cdot 5-3 \cdot 5 \mathrm{~cm}$. long.

Cotyledons lanceolate, falcate, obtuse, petiolate, entire, with a wide very shallow sinus on one side; lamina trinerved from base 
to apex, subcoriaceous, glabrous, deep green above, much paler beneath, $2 \cdot 3-2 \cdot 7 \mathrm{~cm}$. long, $7-8 \mathrm{~mm}$. wide about or below the middle; petiole flattened above, convex on the back, 3-3.5 mm. long.

Stem erect, terete, glabrous, green in the young state; 1 st internode about $11.5 \mathrm{~mm}$. long; 2nd $7 \cdot 5 \mathrm{~mm}$.; 3rd $6.5 \mathrm{~mm}$.; 4 th $8 \mathrm{~mm}$.; 5 th $8 \mathrm{~mm}$. ; 6 th $6 \mathrm{~mm}$.; 7 th $2 \mathrm{~mm}$.

Leaves simple at first, ultimately imparipinnate, cauline, alternate (first two opposite), exstipulate, petiolate, alternately incurvinerved and reticulate, glabrous, deep shining green above, much paler beneath; leaflets opposite (crenate-serrate in specimen, said to be entire); petioles semiterete, channelled above with rather acute edges, narrowed upwards from a stout base, glabrous, green.

Nos. 1 and 2. Lanceolate, subacuminate, obtuse, opposite, crenate-serrate, as are the following.

Nos. 3-7. Broadly ovate, subacuminate, obtuse, varying in size, rounded at the base or sometimes shallowly cordate.

No. 8. Trifoliolate; leaflets subelliptic, obtuse, sometimes shortly acuminate.

\section{Duvana dependens, Kunth.}

Hypocotyl erect, terete, finely pubescent, pale green or usually reddish; $1 \cdot 6-3.5 \mathrm{~cm}$. above the soil.

Cotyledons oblong-oval or subovate, entire, obtuse, glabrous, deep green above, paler beneath, shortly petiolate, indistinctly trinerved at the base and with a few short alternate nerves upwards, all of which are seen only from the under side of the cotyledon; lamina 6-10 mm. long, 5-7 mm. wide; petiole about $1.5 \mathrm{~mm}$. long, flat or slightly grooved above.

Stem woody, erect in seedling, terete, finely pubescent with decurved hairs, pale green or reddish; 1st internode $1 \cdot 15-1.55 \mathrm{~cm}$. long ; 2nd generally undeveloped; 3rd 1-1.3 cm.

Leaves simple, cauline, alternate (first and second opposite), exstipulate, shortly petiolate, glandular-pubescent on the petiole and midrib, otherwise glabrous or nearly so, alternately penninerved, deep green, shining; petioles short, slightly channelled above.

Nos. 1 and 2. Ovate, acute, irregularly serrate.

Nos. 3-9. Ovate, acute, doubly serrate. 


\section{MORINGEE.}

Benth. et Hook. Gen. Pl. i, 429.

Fruit and Seed.-The one-celled ovary of this Order is syncarpous, consisting of three carpels, with as many parietal placentas, and numerous, pendulous, anatropous ovules arranged in a double series. The raphe is ventral, and very prominent. The fruit is a long, torulose, three- to six- to twelve-angled, 'one-celled pod, bursting by three valves when mature.

The seeds are large, ovoid, three-winged or wingless, seated in a single row upon each of the placentas, and separated by a spongy development of the same; the wings and chalaza are corky or membranous. Endosperm is wanting, and the large fleshy embryo with almond-shaped cotyledons occupies the whole interior of the seed. The extremely short radicle is included between the bases of the cotyledons, and lies close to the micropyle at the hilar end of the seed. The plumule is well developed, and shows the primary leaves, which are compound.

Seedlings. - The Moringeæ constitute a very small Order, including only three species belonging to Moringa, the only genus.

The fleshy cotyledons of Moringa aptera are subterranean, and never leave the testa. The first six leaves are pinnately trifoliolate with entire or tridentate leaflets and linear, caducous stipules that appear filiform from being longitudinally revolute.

In other species the stipules are absent, or consist of glands sometimes stipitate.

The leaves of the adult are bipinnate, or simply pinnate towards the end of the branches, and ultimately simple and spathulate. All fall early, and the tree becomes leafless. The root of the seedling forms a fleshy tuber with a pungent taste like a radish, and is edible.

Moringa aptera, Gartn.

Hypocotyl subterranean.

Cotyledons subterranean and remaining in the testa, planoconvex, fleshy. 
Stem succulent in the seedling stage, soon becoming woody, erect, terete, glabrous, pale green suffused with red; 1st internode varying in length from $5-8.5 \mathrm{~cm}$.; 2nd about $2 \cdot 3 \mathrm{~cm}$. ; 3rd $1 \cdot 2 \mathrm{~cm}$. ; 4 th $8 \mathrm{~mm}$; 5 th $5 \mathrm{~mm}$; 6 th $3 \mathrm{~mm}$.

Leaves compound, cauline, alternate, stipulate, glabrous, glaucous; leaflets articulated, deciduous, or caducous; petiolules minutely stipellate; petioles terete, tapering upwards, glabrous, glaucous; stipules linear or revolute longitudinally and appearing filiform, acute, reddish, caducous, and quite free from the petiole.

Nos. 1 and 2. Trifoliolate, less often five-foliolate; lateral leaflets oval, cuspidate, entire ; terminal leaflet rhomboid, cuspidate, obsoletely serrate along the upper half.

Nos. 3 and 4. Trifoliolate; lateral leaflets as in Nos. 1 and 2; terminal leaflet obovate or subelliptic, minutely cuspidate, entire.

Nos. 5 and 6. Trifoliolate; lateral leaflets as before; terminal leaflet subrhomboid, trinerved, trifid, with triangular cuspidate lobes or teeth, the middle one of which is much the largest, otherwise entire.

Leaves of adult (a tree of $\mathbf{1 2}$ feet) bipinnate or simply pinnate towards the apex of the branches; ultimately on the slender branches they are opposite, simple, spathulate, entire, shortly petiolate, and hoary.

\section{LEGUMINOS E.}

Benth. et Hook. Gen. Pl. i. 434.

Frit and Seed.-The pistil is monocarpellary with a few exceptions such as Swartzia dicarpa, Pultenæa obovata, and a few of the Cæsalpinieæ where there are two carpels. From two to five occur in Affonsea. The ovary is one-celled, and bears usually several or numerous ovules, arranged in one or two rows along the ventral suture, rarely only one ovule is present. The ventral suture faces the odd petal termed the vexillum in papilionaceous flowers. The ovules are superposed, amphitropous, or anatropous, and transversely ascending or pendulous. 'The fruit is termed a legume, and is strictly so when it is dry and dehisces along both the ventral and dorsal suture; but it is sometimes fleshy or pulpy, as in Tamarindus 
indicus, or dry, thick, leathery, and indehiscent, as in Ceratonia Siliqua, nut-like as in Arachis hypogæa, or rarely drupaceous. Sometimes it dehisces by the ventral suture only, like a follicle; in other cases, as in Hedysarum and in some species of Desmodium, it is lomentaceous. The internal cavity is continuous, or divided transversely by spurious septa, as in Entada, Tamarindus, some of the Cassias, Ceratonia Siliqua, and others.

The testa is coriaceous, bony, or greatly thickened, rarely membranous. The funicle is thickened, or arillate in many instances, or there is a thickened process near the hilum, termed a strophiole. Endosperm is wanting or scanty in the suborders Papilionaceæ and Mimoseæ; when present it is unequally distributed, and collected in greatest quantity round the radicle, so as to occupy the space not filled by the embryo. Swartzia madagascariensis, belonging to the Papilionaceæ, is exceptional in having small seeds with a copious endosperm. Albuminous seeds are the rule in the suborder Cæsalpinieæ, and in many of the species belonging to it the endosperm is copious and cartilaginous.

The embryo is large and occupies the whole of the seed where endosperm is wanting. The cotyledons are flat or plano-convex, and foliaceous, or thick, fleshy, and frequently subterranean in germination. The radicle in this case is superior, incurved, accumbent, and where it is of appreciable length it is so much curved as to come down on the rentral face. In such cases the ovule and seed are amphitropous. In some rare cases the radicle is inferior. The embryo is generally straight in the Cæsalpinieæ, particularly where a copious endosperm is present.

The seeds observed may be divided into two groups, namely those with, and those without, endosperm. This does not always indicate the closest affinities, although in most cases the two groups belong to different suborders. It may be convenient to subdivide the latter group into two, according to some peculiarity of the cotyledons. Phaseolus multiflorus (fig. 289) may be given as a type where the cotyledons are slightly unequal at the base, owing to the space being occupied by the radicle. This is more markedly the ease in many 
or most species of Lupinus both before and after germination, including L. mutabilis, L. micranthus, and L. sulphureus. The cotyledons of the latter are also connate at the base. To this type the following agree in all general particulars, namely, Hedysarum neglectum, H. coronarium (fig. 280), Lathyrus macrorhizus, Vicia sativa, Astragalus galegiformis, and Canavalia virosa.

The seeds of those mentioned vary considerably in size and shape, in the amount of space occupied by the radicle, and the shape of the latter. In Lupinus mutabilis the radicle is trigonous, and in L. micranthus it is flattened and biconvex owing to pressure. In most cases the seeds are laterally flattened, and many of them are oblong, while others, such as Lathyrus odoratus, and L. macrorhizus, are globular. Those of Canavalia virosa and Phaseolus multiflorus are notable for their size. A rather exceptional case occurs in Caragana arborescens, where the cotyledons, although normally accumbent, are often obliquely so, and sometimes even incumbent. The cotyledons are occasionally unequal in thickness. The segments of the lomented fruit of Hedysarum coronarium and others are remarkable for the number of outgrowths or excrescences, often hooked, from their surface and sutures.

The second subgroup includes a considerable number of species the cotyledons of which are more or less indented on one side owing to a thickening or indentation at the hilum. This type may be represented by Clitoria Ternatea (fig. 286), which has a transversely oblong seed. The base of the cotyledons is also more or less unequal, or cut away on one side, owing to the space being occupied by the radicle as in the last subgroup. Here may be classed Ononis arvensis, Medicago sativa, M. rigida, Æschynomene aspera, and Swainsonia galegifolia.

In all these cases the seeds vary greatly in shape. Those of Ononis arvensis are nearly globular, and covered with small tubercles; in the species of Medicago there is a special development of the testa on nne side of the seed to accommodate the radicle. The indentation on the side of the seeds of Eschynomene aspera is so deep as to make them curved or reniform. Those of Swainsonia galegifolia are broadly cordate and 
laterally compressed, unequally auricled at the base. The cotyledons are oblong, plano-convex, and unequal-sided, owing to the basal notch of the seed; the radicle is bent at right angles to the cotyledons along the basal edge of which it lies, and then projects beyond them into the smaller auricle of the seed, where it becomes embedded in a thickened portion of the testa at the micropyle.

Seeds containing endosperm may be subdivided into those haring a curved or bent radicle, and those having an entirely straight embryo. The first is represented by Laburnum rulgare (fig. 266), Sesbania ægyptiaca, and Kennedya rubicunda. The cotyledons of all are unequal at the base owing to the position of the radicle, and indented at the sides owing to a thickening at the hilum. All three belong to the suborder Papilionacex, and have a small quantity of endosperm, except in the case of Sesbania ægyptiaca (fig. 276), where there is a considerable quantity on the backs of the cotyledons, which are therefore thin. A remarkable exception occurs in Scorpiurus sulcata, and other species, in which the embryo is variously twisted and narrow, with the intervening spaces occupied by endosperm.

The seeds having a straight embryo belong to the suborder Cæsalpinieæ. The radicle is slightly bent or curved in Cassia Sophora, and accumbent, thus forming a transition state between this and the last subgroup. A good type of the subgroup is shown in Cassia Fistula (fig. 301). The cotyledons are here more or less twisted. The outer coat of the seed becomes separated from the rest, forming a broad, white, torn band down the middle of both surfaces. Cassia Absus and Cercis Siliquastrum have orbicular cotyledons, notched at the base to accommodate the radicle. Cassia obovata is remarkable for the small size of its embryo, which may be due to the fact that the seeds are ruminated to a considerable depth from the periphery. The cotyledons are orbicular. In all the species of Cassia mentioned the endosperm is rather copious and cartilaginous or horny when dry.

Seedlings. - The prevailing type of cotyledons throughout the Order is oblong; but there are several important modifica- 
tions, such as those having an indentation at the sides making them falcate, while others are unequal at the base. A third modification consists in cotyledons which are cordate or auricled at the base. Others are worthy of note, but it may be convenient to class them under the head of exceptional cases. Even in the typical oblong form there are numerous minor variations such as linear-oblong, broadly-oblong, oval-oblong, obovate-oblong, or spathulate-oblong. In all cases they conform to the shape and size of the seed, and the modifications to some peculiarity of the same, the development of the embryo, the presence or absence of endosperm in the seed, or in a few cases to subsequent growth, i.e. during or after germination. Forms of one, two, or three kinds are peculiar to certain tribes, so that in the subjoined classification it would be convenient to notice the various kinds occurring in their respective tribes as far as they have come under observation, and to note there the exceptional cases. This applies more particularly to the suborder Papilionaceæ than to the Cæsalpinieæ and Mimoseae, where endosperm is more frequently present, and the embryo is often straight.

\section{Suborder Papilionaces.}

Tribe Podalyriece.-The cotyledons of Chorizema cordifolium (fig. 261) and C. ilicifolium are narrowly oblong and one-nerved. The first two leaves are sometimes opposite and obovate, emarginate, or obcordate, succeeding ones being alternate. Four pairs of the primary leaves of Pultenæa daphnoides are opposite, narrowly obovate, generally apiculate, and all are simple. Podalyria australis has broadly oblong cotyledons and alternate leaves, the first being obovate and simple, while succeeding ones are digitately trifoliolate. A very striking exception occurs in Viminaria denudata (fig. 262 ), with linear cotyledons. The leaves show a curious case of the gradual abortion of the lamina and the elongation of the petioles. The seventh, eighth, and ninth have three minute teeth at the apex of the petiole as the representatives of as many aborted leaflets.

Tribe Genistea.-Cotyledons conforming to the leading, 
oblong type are shown by Hovea longifolia, Goodia lotifolia, Retama Rœtam, Ulex europæus (fig. 268), and species of Cytisus. The first three leaves of Goodia lotifolia are pseudoverticillate, a very rare circumstance. Two are broadly ovate and simple, while the third leaf is pinnately trifoliolate and inserted at right angles to the other two, but on the same level, owing to the internode not being developed. The first seven leaves of Retama Rotam are simple, alternate, and smaller than the cotyledons. A remarkable amount of variation is noticeable in the leaves of different seedlings of Ulex europæus. In some the leaves are all simple, in others the primary leaves are simple, while those that succeed them are trifoliolate; in other cases the leaves are all trifoliolate. They are opposite or alternate apparently indiscriminately. All ultimately become modified into simple spines, or may be altogether aborted, while the branches form compound or branching spines.

Two of the leading modifications occur in this tribe, with some exceptional cases. Bossiæa linophylla (fig. 263) shows oblong cotyledons slightly indented at the sides, a peculiarity due to a thickening or an indentation at the chalaza of the seed. Others agreeing with this type are B. rufa, Laburnum alpinum, L. vulgare (fig. 267), Genista, Crotalaria quinquefolia, and other species of Crotalaria. The indentation is very marked in the last genus. Spartocytisus nubigenus has spathulate cotyledons and is somewhat exceptional in that respect; the first four leaves are digitately trifoliolate with narrowly linear leaflets. Bossiæa linophylla has the first three leaves like those of Goodia lotifolia except that the odd one, like the two following, is simple. All the five are obcordate, while the ultimate leaves are linear. The first five leaves of B. rufa are oval-elliptic, the first pair being opposite, the rest alternate. The first leaf of Crotalaria quinquefolia is obovate, obsoletely trifid, and alternate, but in other species the first pair are opposite. The leaves of the two common species of Laburnum are alternate and digitately trifoliolate from the first. A second well-marked modification is met with in the genus Lupinus. The cotyledons are unequal at the base, a peculiarity due to the radicle being sharply bent round 
their basal end in the seed, thus occupying the space that would otherwise be appropriated by them. Lupinus arboreus (fig. 264), L. elegans, L. micranthus, and others represent this type. The cotyledons are generally petiolate; but in L. linifolius they are subsessile and strongly faleate, being quite exceptional. A more unusual case occurs in L. sulphureus (fig. 265) and L. recurvatus, where the cotyledons are strictly sessile and connate along the whole of their basal edges. Those of the former are suborbicular, and the peculiarities exist while the embryo is still in the seed. The leaves of the various species of Lupinus are digitately compound from the first, with linear or lanceolate leaflets varying greatly in number.

Tribe Trifoliea.-As far as shape is coneerned, the leading type of cotyledons is the prevalent one in this tribe; they are usually small and narrowly oblong. The first leaf is simple or consists of one leaflet, while succeeding ones are pinnately trifoliolate. To this tribe belong Pocockia cretica, Trigonella corniculata, T. gladiata, Medicago maculata, M. orbicularis (fig. 271), Melilotus officinalis, M. parviflorus, M. albus, M. leucantha, Trifolium Boissieri (fig. 272), T. repens, T. redenakum, T. minus, T. subterraneum, and others. The lamina of the cotyledons is often articulated with its petiole, notably in the species of Trigonella, Melilotus, and Trifolium. A slight departure from the above type is met with in Ononis Natrix (fig. 270) and 0. ornithopodioides, where the cotyledons are broadly oblong or broadly ovate and hairy, or glandularpubescent. The first three leaves of Ononis rotundifolia and first four of 0 . ornithopodioides and 0 . Natrix are simple, while those that succeed are pinnately trifoliolate; but these numbers may vary in different individuals. The cotyledons of Trigonella Fœnum-græcum are chiefly notable for their size.

Cases of severe competition amongst the seedlings of a single fruit occur in species of Medicago where the indehiscent spirally coiled pod contains a large number of seeds. This is well represented by M. orbicularis.

Tribe Lotea.-A few cases occur in this tribe, as in the Genisteæ where the cotyledons are falcate, as in Lotus biflorus, 
or indented on the sides, as in Anthyllis Vulneraria (fig. 273). The first three leaves at least of the latter species are elliptic and entire. An exception to the prevalent form occurs in Lotus peliorhynchus, where the cotyledons are linear or linearoblong, and the first leaf is digitate with five narrowly linear hairy leaflets. A more remarkable deviation, not only from the type in the tribe, but from the Papilionaceæ generally, occurs in Lotus Tetragonolobus, where the cotyledons are broadly oblong and cordate at the base. The leaves are pinnately trifoliolate from the first. Instead of one axis taking the lead in this species, two stems, apparently of equal strength, are developed, together with a pair of smaller ones, as if the plumule before or during germination divided into four. This was so in the case of seventy-six out of one hundred and nine seedlings observed. It is most probable, however, that the supernumerary axes arise from the axils of the cotyledons. A similar thing takes place in L. biflorus, where four or more axes are developed at an early stage of the seedling. A better illustration is afforded by L. peliorhynchus, where the primary axis becomes decumbent, but maintains its supremacy while other axes varying in number from three to seven spring up in succession, apparently by adventitious budding from the same level as the primary.one or even below it, displacing the latter.

Tribe Galegea.-A large number of species belonging to this tribe have cotyledons of the prevailing type of the Order. A number of them resemble those of the Trifolieæ generally in being narrowly oblong; and a good proportion recall Laburnum by the cotyledons being indented on the sides. Narrowly oblong types are represented by Indigofera australis (fig. 274) and other species, also by Galega officinalis, Carmichælia pilosa, Sesbania ægyptiaca, S. coccinea, and Swainsonia oncinotropis. The elongated and oblong-spathulate cotyledons of the latter appear to be due to growth after germination. A curious case occurs in Sesbania coccinea, where the cotyledons have an interpetiolar, subulate stipule. Out of thirty seedlings twenty-one had the first pair of leares simple and opposite, while the other nine had the first leaf only simple. The solitary leaflet always terminated the petiole, but from the third leaf onwards the 
leaves are abruptly pinnate. The first pair of leaves in this species and in Indigofera australis (fig. 274) being opposite and simple recalls what occurs in the tribe Phaseoleæ as described below. The early stage of Galega officinalis recalls that of a Trifolium or Melilotus. This is also the case with Carmichælia pilosa, but the first four leaves at least are simple, obcordate, and small. The leaves of the adult plant are often exactly similar to the primary ones, but some of them are pinnately trifoliolate or imperfectly so. Broadly oblong-oval cotyledons occur in Robinia Pseud-Acacia (fig. 275) and in some species at least of Colutea. The first leaf of the former is simple and the second pinnately trifoliolate. Both this species and Indigofera australis as well as Galega officinalis show a gradual evolution of the leaves.

Large and broadly oblong cotyledons more or less falcate and sinuate on the sides or unequal at the base occur in Psoralea sp., Sesbania tomentosa (fig. 277), S. grandiflora, Calophaca grandiflora, in a new, unnamed species of Calophaca, Astragalus juvenalis, and A. thianschanicus (fig. 278). Those of A. sulcatus are much smaller, and both turned to one side of the stem, as are also those of the unnamed species of Calophaca, and Astragalus juvenalis. This phenomenon, together with the shortness of the petioles and the fleshy character of the lamina generally, indicates a tendency on the part of the cotyledons to become subterranean. The first leaf of Astragalus sulcatus is generally digitately trifoliolate, while the second bears only the terminal leaflet, but individuals may vary; and there is a gradual evolution of the leaves from those of the small or weak seedling to the adult plant which has imparipinnate leaves with very numerous leaflets. The other species of Astragalus abovementioned also show a very gradual evolution of the leaves. The two first leaves of Psoralea sp. are cordate and opposite. All the four species of Sesbania above-mentioned show a remarkably abrupt form of evolution. The first leaf of S. grandiflora is lanceolate-oblong, of considerable size, and simple, while the second leaf is abruptly pinnate with four pairs, and the third with five pairs of narrowly oblong leaflets. The first leaf of S. tomentosa is obovate-oblong 
and simple, while the second and third are abruptly pinnate with three and four pairs of small, oblong leaflets respectively.

Two well-marked exceptions in this tribe occur in Amorpha glabra and Indigofera hirsuta, which have oblong trinerved cotyledons with a cordate or auricled base. The first four leaves of Amorpha glabra bear only one suborbicular leaflet, while the fifth and sixth are pinnately trifoliolate. All have stipules at the base of the petiole and stipellæ near the base of the leaflets. The first two leaves of Indigofera hirsuta are lanceolate and opposite, and succeeding ones alternate.

Tribe Hedysarea.-Two well-marked types of cotyledons occur in this tribe as well as some remarkably abnormal forms. In the species of Hedysarum the cotyledons are rotund-obovate, very broad, fleshy, and opaque, with rather obscure venation, and both very strongly directed to one side. They owe their size and shape to that of the seeds, which again is due to the interior of the one-seeded segments of the lomented indehiscent fruits. In these respects Hedysarum coronarium (fig. 281), H. capitatum, H. obscurum, H. denticulatum, and H. flexuosum agree. The first leaf of H. flexuosum and $H$. capitatum is pinnate with five small lanceolate and oblong leaflets respectively. The first three leaves of H. coronarium are simple, entire, and orbicular to oval-oblong ; but the third one is pinnately three- to five-foliolate, with similar-shaped leaflets.

In germination the radicle pushes itself through the end of the lomentum or through one suture, while the cotyledons make their exit by the other, as in H. coronarium (fig. 281) and H. obscurum. The wall of the fruit in H. denticulatum (fig. 279) is thin or membranous and reticulate, and the radicle generally pierces one valve, while by the swelling of the cotyledons and the elongation of the hypocotyl the lomentum is burst open and the upper valve pushed upwards, permitting the exit of the seedling. The testa is frequently carried up on the cotyledons, but the breadth of the latter and their increasing size soon splits it open and gets rid of it. Whatever the mode of exit of the radicle and cotyledons, the wall of the fruit nearly always gets pinned to the ground while the seedling rises clear 
above it. Thick-walled fruits last a long time in good condition after the germination of the embryo. Desmodium canadense has ovate-oblong, subfalcate cotyledons, and behaves exactly in the same way as Hedysarum during germination, but more frequently carries the fruit and seed above ground before it divests itself of them. Broadly-oblong subfalcate cotyledons with the sinus on one side occur in Eschynomene aspera (fig. 282), Lourea Vespertilionis (fig. 283), Lespedeza striata, and L. angustifolia. The leaves of Eschynomene aspera are abruptly pinnate from the first with numerous oblong leaflets. The first five at least of Lourea are transversely oval or oblong, gradually increasing in size. Those of the adult are simple or trifoliolate, with the lateral leaflets very small and as a rule falling very early. The cotyledons of Lespedeza are turned to one side and densely pubescent. The two primary leaves of L. striata and L. juncea are simple and opposite, followed by alternate and trifoliolate ones. In the other two species the first leaf only is simple. Several remarkable exceptions to any of the prevalent types of the Order occur in this tribe. The cotyledons of Lespedeza juncea are subterranean, or if they rise above ground they perish early. Those of Coronilla juncea and Ornithopus repandus are obovate-spathulate, tapering to the base and shortly connate there, reminding us of what occurs in Pocockia cretica amongst the Trifolieæ and in Swainsonia oncinotropis amongst the Galegeæ, but here more pronounced, and evidently due to the same cause. The first leaf of the Coronilla is obovate and simple, while that of the Ornithopus mentioned is oval-oblong. The second leaf in both cases is trifoliolate, but the lateral leaflets of Ornithopus are minute and suborbicular and quite distinct from the subulate stipules, which are connate by their posterior edges and sheathe the stems. The cotyledons of Adesmia muricata are cordateoblong and succulent. The first leaf is five-foliolate, while succeeding ones are abruptly pinnate with a varying number of leaflets.

The cotyledons of Hippocrepis ciliata are narrowly linear, fleshy, tapering downwards, and from 1.8 to $3 \mathrm{~cm}$. long. Their shape seems to be due to that of the seed and to sub- 
sequent growth in length while still retaining a similar shape. The first leaf bears three leaflets, and succeeding ones a greater number, on the imparipinnate plan. The most remarkable exception, however, occurs in Scorpiurus sulcata, where the cotyledons are cylindrical, fleshy, and deeply furrowed on the upper side. The primary cause of this is the manner in which they are twisted about in the albuminous seed. They elongate greatly during and after germination, but retain their original form. Two days after leaving the seed they measure from $1 \cdot 8-2 \cdot 2 \mathrm{~cm}$. in length, and after twenty-four days from $7 \cdot 5-8 \cdot 2 \mathrm{~cm}$.

Tribe Viciece.-Of all the seedlings belonging to this group and coming under my observation, Abrus precatorius is the only species observed which conforms to the prevalent type of the Order in having oblong-obovate, aerial cotyledons. Even these show a tendency to become subterranean in being fleshy, opaque, sessile, and both slightly directed to one side. The first two leaves are opposite, and all are abruptly pinnate, with numerous opposite pairs of oval or oblong leaflets.

Other members of the tribe have globose or oblong seeds with fleshy, hemispherical or plano-convex subterranean cotyledons. Species conforming to this type are Vicia andicola, V. Faba, V. sativa, Lathyrus Nissolia (fig. 284), L. Aphaca (fig. 285), L. sylvestris, L. latifolius, L. odoratus, L. brachypterus, and L. articulatus. The first three leaves of Vicia andicola are small and tridentate, the lateral teeth being the stipules. The next three leaves are abruptly pinnate with one pair of leaflets, the midrib of the fourth ending in a curved point, and succeeding ones in a tendril. The cotyledons of V. Faba are oblong as are those of Lathyrus brachypterus. The first four leaves of the latter are trifid, small and scalelike, while the next one bears a pair of leaflets. The stem of L. Nissolia is erect, and generally if not always hooked or twisted at the apex. The first two leaves are scale-like, subulate, and carinate. Succeeding ones are narrowly linear, entire, sessile, stipulate, and convolute in bud, enclosing the younger leaves. A very similar case is presented by L. articulatus, but the leaves gradually increase in length from the first (which is very short) to the fifth; and as the stem 
increases in length, requiring support, the tip of the leaf from the fifth or the sixth onwards forms a small, simple tendril. The stem is four-winged owing to the leaves being decurrent at their bases. The stipules on the lower leaves are more or less adnate to the edges of the latter, with subulate, free points, becoming triangular higher up, and ultimately becoming wholly adnate or entirely aborted.

Tribe Phaseolece.-As far as the cotyledons are concerned, there are two very distinct types of seedlings in this tribe, with several intermediate forms. All, however, agree in the first two leaves being simple and opposite, with generally very short petioles. The ultimate leaves are pinnately trifoliolate.

The type with aerial cotyledons is represented by Clitoria Ternatea (fig. 286). They are oblong, falcate or indented on one side, a peculiarity already described. Others agreeing with this are Butea frondosa, Pueraria Thunbergiana (fig. 288), and Centrosema Plumieri. Dolichos falcatus differs in having oval, fleshy cotyledons; Erythrina monosperma in having oblong, fleshy, and slightly concave cotyledons; and Phaseolus vulgaris (fig. 290) in having them oblong, falcate, fleshy, and directed to one side of the stem. In all three cases they exhibit a tendency to become subterranean, but are carried above ground by the extraordinary vigour of the plants and the elongation of the hypocotyl. The first pair of leaves in Dolichos falcatus are cordate; those of Erythrina monosperma are very much larger and rotund-cordate, emarginate, and very deeply auricled, almost sagittate at the base, with the third leaf compound. Phaseolus vulgaris conforms very nearly to the latter. Those of Pueraria Thunbergiana are roundly rhomboid, and those of Centrosema Plumieri oblong-cordate. A case of more gradual evolution occurs in Clitoria Ternatea, which has the first pair of leaves small and lanceolate, while the third is obovate, emarginate, and much larger. The fourth is broadly oblong, emarginate, and many times larger than the first two, but in some individuals the fourth leaf is trifoliolate or imperfectly so. The fifth and sixth leaves are pinnately trifoliolate, with small oval or elliptic leaflets.

The cotyledons are strictly subterranean in Erythrina Vespertilio, Phaseolus multiflorus, Vigna lutea, V. vexillata, 
Pachyrhizus angulatus, Rhynchosia viscosa, Flemingia Grahamiana, \&c. The first pair of leaves in the last species are small and rotund, while those of Rhynchosia viscosa are cordate. The lamina of the first pair in Pachyrhizus angulatus is broadly triangular. Immediately above these the stem becomes slender and twining, as also in Vigna vexillata. The first pair of leaves and the leaflets of the succeeding ones in the latter are comparatively small and lanceolate. The first pair in V. lutea are ovate-subcordate. Lateral shoots from the axils of the cotyledons in Phaseolus multiflorus are produced if the primary axis gets destroyed, and the first leaf on them is simple and subrotund. The first four leaves of Erythrina Vespertilio are transversely rhomboid; the fifth has small rhomboid leaflets. Many of the above species have small subulate stipules and stipellæ. A very curious case occurs in a plant questionably named Erythrina suberosa (fig. 287). The cotyledons are subterranean, and the first pair of leaves opposite; but four at least of the primary ones are simple, trifid, or trilobed, subpalmate and palmately five-nerved.

The most striking exception observed in the tribe occurs in Kennedya Marryattæ. The cotyledons are linear-oblong, fleshy, sessile, furrowed beneath, and $2 \cdot 6-3 \mathrm{~cm}$. long. The first pair of leares are suborbicular, simple, and often unequal in size.

Tribe Dalbergiea.-Few of the species of this tribe have come under my notice, and those show modifications of the leading type. Dalbergia hupeana has obliquely ovate cotyledons cut away at the base on one side. The first two leaves are opposite with five obovate leaflets. The cotyledons of Lonchocarpus latifolius (fig. 292) are fleshy, but aerial and falcate by an indentation on one side. The first two leaves are opposite, ovate, and simple, reminding one of what occurs in the Phaseolex. The third leaf is alternate. The sixth to the eleventh inclusive have eleven leaflets.

Tribe Sophorece.-All the species observed in this tribe have subterranean, fleshy cotyledons, varying considerably with the seed in shape, size, and thickness. Sophora secundiflora (fig. 293) has obovate somewhat oblique cotyledons, and the first seven leaves at least are alternate, simple, 
entire, and variable in shape and size. The cotyledons of Edwardsia chilensis (fig. 294) are fleshy and green; and the leaves show a gradual evolution from the first, which is small, obovate, and simple. A rather exceptional case occurs in Castanospermum australe (fig. 295), which has depresso-globose, fleshy cotyledons of enormous size. It is comparable to a species of Cola, ${ }^{1}$ one of the Sterculiaceæ, but in the latter there are four cotyledons.

Myroxylon peruiferum has also subterranean cotyledons. The two first leaves are five-foliolate and opposite, succeeding ones have more numerous leaflets, the uppermost of which are the largest and the basal ones the smallest. The leaflets are all lanceolate.

\section{Suborder Cessalpinieze.}

Tribe Euccesalpinier.-In the suborder Papilionacer cotyledons with a cordate base are comparatively rare, while in the Cæsalpinieæ they are very frequent. This is due to a difference in the seed and embryo, the former generally containing endosperm, while the latter is straight, and the radicle is included between the auricles of the cotyledons, or projects slightly beyond them. The embryo is nearly as long as the endosperm, but differs considerably in outline in different species according to the shape of the seed.

The cotyledons of Cæsalpinia tinctoria (fig. 297) are orbicular with a cordate base, strongly trinerved, with the nerves branched. The leaves are stipulate and stipellate; the first two are abruptly pinnate with four pairs and three pairs of leaflets respectively. The third leaf is abruptly bipinnate, with one pair of pinnæ, each of which bears three pairs of leaflets. The cotyledons of Poinciana Gilliesii (fig. 298) differ in being oblong and five-nerved. The first leaf is abruptly pinnate.

One of the most remarkable exceptions occurring in the whole Order is met with in Hæmatoxylon campechianum (fig. 296). The cotyledons are bipartite, with divaricate unsymmetrical lobes of membranous texture.

Tribe Cassiece.-The various species of the genus Cassia 
differ considerably amongst themselves. The cotyledons of C. mimosoides represent the typical form of the Order in being oblong, and those of C. Fistula (fig. 302) differ only in being obovate-oblong. In both cases the primary leaves are abruptly pinnate. A departure from the type is met with in Cassia obovata (fig. 300), which has broadly obovate, retuse, trinerved cotyledons. C. Absus is more in accordance with the type of the suborder, having orbicular trinerved cotyledons with a cordate base. C. circinata (fig. 299) differs from the latter only in the cotyledons being entire. The leaves are abruptly pinnate, the first having a single pair of leaflets, and the next four two pairs.

Tribe Bauhiniece. - There is a considerable similarity amongst the seedlings of the representative genus Bauhinia, the chief differences being in minor details. The cotyledons are broadly oblong or obovate-oblong, usually sessile and three- to five-nerved, sometimes indistinctly. Bauhinia tomentosa (fig. 303) and B. Carronii are good representative types. The shape of the cotyledons is due to that of the seed, which is oblong or suborbicular and flattened, with the contained cotyledons flat, but rather fleshy. Those of B. Carronii show a tendency to become subterranean. The seeds of this species measure $9-10.5 \mathrm{~mm}$. long, $6-8.5 \mathrm{~mm}$. wide, and $2 \cdot 25-2 \cdot 75 \mathrm{~mm}$. thick, while those of B. tomentosa, having decidedly aerial cotyledons, are smaller in every way. The cotyledons of B. corymbosa and B. Hookeri agree in general particulars with the above, but are rather fleshy and do not readily unfold to the light.

The leaves of B. Hookeri and B. Carronii are abruptly pinnate from the first, and consist of one pair of obovate, sessile leaflets, differing only from those that succeed them in being smaller. Those of B. corymbosa and B. tomentosa consist of one pair of leaflets united in a single bifid or bipartite piece; and in all or most cases the midrib projects as a short bristle between the leaflets or lobes. The cotyledons of Cercis Siliquastrum (fig. 304) are orbicular, entire, shortly petiolate, and trinerved; while the leaves are reniform, or roundly cordate and five-nerved.

Tribe Amherstiea.-The only seedlings of this tribe which 
have come under my notice are Hymenæa Courbaril (fig. 305) and Peltogyne sp., having plano-convex, fleshy, erect, oblong, and emarginate cotyledons, with auricles at the base clasping the stem. Cotyledons possessing the last-named character are met with amongst the Acacias. The leaves in Hymenæa Courbaril are compound, and consist of one pair of leaflets. Those of the first leaf are suborbicular, emarginate, exstipulate, and sessile, owing to the adhesion of the petiole to the stem, giving them the appearance of simple, opposite leaves; but they are both inserted towards one side of the stem. The second leaf is stipulate with a pair of obliquely-ovate leaflets, while the adult one has obliquely-oblong or falcate leaflets. The first two leaves of Peltogyne are opposite and abruptly pinnate, with three pairs of lanceolate leaflets and the midrib prolonged between them.

Tribe Cynometrea.-The cotyledons of Copaifera officinalis are very similar to those of Hymenæa Courbaril. The leaves are abruptly pinnate, coriaceous, glabrous, evergreen and full of pellucid dots, and penninerved, with short, stout, cylindrical petioles. The first leaf has three pairs of lanceolate, falcate leaflets, oblique on the posterior and more or less cut away on the anterior side at the base, especially the uppermost pair. Succeeding leaves have more numerous leaflets.

\section{Suborder Minosees.}

Tribe Adenantherce.-The cotyledons of Adenanthera Pavonina (fig. 306) are broadly obovate, sessile, erect, fleshy, auricled at the base, and in this respect resemble those of the two above-mentioned species. The leaves are alternate except the first pair, which are opposite and abruptly pinnate, with numerous alternate leaflets. The leaves of the adult are large, and abruptly bipinnate with three to four pairs of pinnæ. The cotyledons bear small buds in their axils. Those of Prosopis juliflora are broadly oblong, subsessile, and caducous. The first leaf is abruptly pinnate, with four pairs of small, oblong leaflets like those of an Acacia. The second to the seventh leaves inclusive are abruptly bipinnate, with .numerous small leaflets, and the midrib generally prolonged as a small bristle beyond the pinnæ. The cotyledons of 
Dichrostachys cinerea are oblong-ovate, cordate at the base, shortly petiolate, and in this respect unusual in the tribe. The first leaf is inserted nearly on the same level as the cotyledons, and is abruptly pinnate with numerous very small leaflets. The second leaf is abruptly bipinnate with one pair of pinnæ, but the number of the latter increases in succeeding leaves.

Tribe Eumimosea.-The cotyledons of Leucæna glauca (fig. 307) are obovate, sagittate at the base, shortly petiolate, five-nerved, and horizontal, differing in this respect from most of its allies. The first leaf is abruptly pinnate, with numerous pairs of unequal-sided leaflets. The three succeeding ones are bipinnate with a pair of pinnæ each.

The cotyledons of Mimosa lanata are roundly oblong, three- to five-nerved, truncate at the base and auricled. The first leaf has three pairs of leaflets ; the second is like that of Leucæna glauca.

Tribe Acaciea.-The species of Acacia differ remarkably even in the shape and character of the cotyledons; indeed, no two species have the latter exactly alike. In A. dodoneæfolia they are broadly oblong, sessile, and connate at the base, recalling those of Lupinus sulphureus. The first leaf is abruptly pinnate with four pairs of leaflets, as happens also in A. acanthocarpa. The cotyledons of the latter have a broad shallow sinus at the base. The first leaf is also abruptly pinnate in A. dealbata (fig. 310), A. lophantha, and A. Oswaldi. Two succeeding leaves in the latter case are pinnate, but it seems that subsequent ones gradually or immediately lose all their pinnæ, and their leaves are represented by lanceolate trinerved phyllodes.

The second leaf in A. lophantha, and A. dealbata (fig. 310), is bipinnate. The short, linear-oblong, caducous cotyledons of the latter seem quite unusual in the genus. Those of A. Oswaldi are obovate-oblong, and sagittate at the base. A most remarkable development of the basal auricles occurs in A. Burkittii (fig. 308). T'he first six leaves are bipinnate, with one pair of pinnæ each and numerous pairs of narrowly oblong leaflets.

Tribe Ingea.-The cotyledons of Pithecolobium Saman are caducous. The first leaf is abruptly pinnate, and succeeding ones bipinnate, with one pair of pinnæ and a varying number 
of leaflets. The latter are chiefly noticeable on account of the much greater size of the terminal ones compared with those towards the base of the pinnæ, where the pairs are often unequal. Their size, shape, and arrangement seem planned so as to economise space and at the same time expose a maximum surface to light.

\section{Tribe Podalyriez.}

Podalyria australis, Vent.

Hypocotyl short, 3-4 mm. long, erect, terete, glabrous, bluish.

Cotyledons oblong, obtuse, entire, shortly petiolate, glabrous, green, one-nerved; petioles short, broad, furrowed on the upper side.

Stem erect, terete, herbaceous, ultimately shrubby ; 1st internode $3-3.5 \mathrm{~cm}$. long; 2nd rather shorter.

First leaf simple (rarely bi- or tri-foliolate), entire, cauline, stipulate, petiolate, obovately oblong, obtuse,

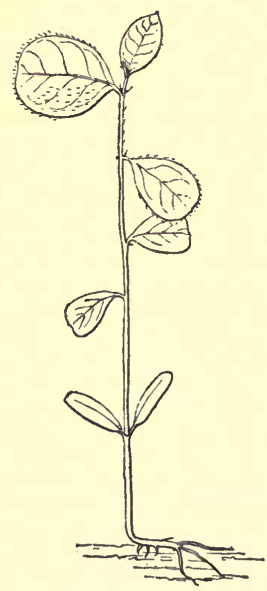

Fra. 261.

Chorizema cordifolium. Nat. size. glabrous, green, pinnatinerved; subsequent leaves trifoliolate, cauline, alternate; leaflets obovately oblong, obtuse, petiolulate, occasionally slightly emarginate; petioles very short, furrowed on the upper side; stipules free, linear-lanceolate, acute, rather large.

Chorizema cordifolium, $F$. Muell. (fig. 261).

Hypocotyl erect, terete, glabrous, pale green, $1 \cdot 3-2 \cdot 5 \mathrm{~cm}$. long.

Cotyledons oblong, obtuse, fleshy, shortly petiolate, deep green above, paler beneath, shining on both surfaces, falling away early; lamina $8.5 \mathrm{~mm}$. long, $3 \mathrm{~mm}$. broad; petiole $1.5 \mathrm{~mm}$. long.

Stem erect, terete, pubescent, ulti. mately woody; 1st internode $1.8 \mathrm{~cm}$. long ; 2nd $5 \mathrm{~mm}$.; 3rd $1 \mathrm{~cm}$.; 4 th $7 \mathrm{~mm}$.

Leaves simple, cauline, alternate, stipulate, petiolate, thinly pubescent on both surfaces and ciliate, ultimately glabrous or pubescent beneath and spiny-serrate, obscurely alternately penninerved, deep green above, subglaucous beneath; petioles terete, very short; stipules linear, slender, pubescent, caducous. 
No. 1. Small, narrowly obovate, retuse, apiculate.

No. 2. Broadly obovate, emarginate, apiculate.

No. 3. Similar, and larger.

Nos. 4 and 5. Broadly oval, subemarginate, apiculate.

Ulimate leaves cordate, apiculate, spiny-serrate, irregularly alternately penninerved, with the nerves incurved and uniting with each other at or near the margin, reticulate, especially when dry, glabrous above or thinly pubescent, but pubescence denser beneath.

The seedling of Chorizema ilicifolium, Labill., closely resembles the preceding, but the cotyledons are quite sessile.

Viminaria denudata, Sm. (fig. 262).

Hypocotyl erect, torete, glabrous, pale green : $1 \cdot 3-2 \mathrm{~cm}$. above the soil.

Cotyledons linear, obtuse, entire, sessile, articulated with the stem, glabrous, subfleshy, subconnate at the base or forming a ring round the plumule or stem; about 8-9 mm. long, 2-2.5 mm. wide, deciduous at the joint.

Stem erect, terete, somewhat thickened at the nodes from the decurrent foot of the petiole, glabrous, deep shining green, ultimately shrubby; 1 st, 2nd, and 3rd internodes each about $3 \mathrm{~mm}$. long; 4th $3 \cdot 25$ mm. ; 5th 9-10 mm.; 6th 21 mm.; 7th $13.5 \mathrm{~mm} . ; 8$ th $8.5 \mathrm{~mm}$.

Leaves simple or compound (uni- to tri-foliolate), cauline, alternate, stipulate, petiolate, glabrous, three- to five-nerved at or close to the base, alternately incurvinerved upwards, obscurely reticulate, deep green above, paler beneath or glaucous; stipules small, subulate, subfleshy, glabrous, partly or almost wholly adnate to the stem

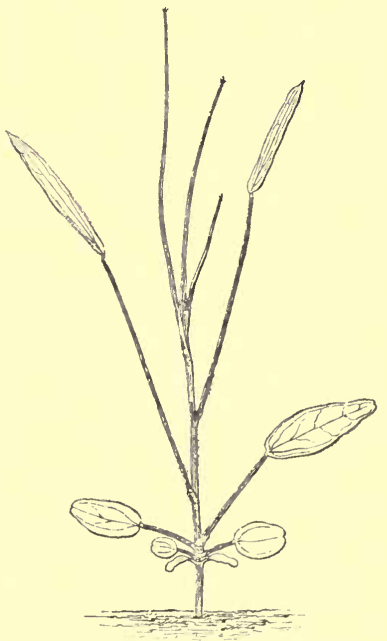

Fig. 262.-Viminaria denudata.

Half nat. size. and foot of the petiole; petioles subterete, shallowly grooved above in the lower leaves and short, but gradually attaining a considerable 
length $(6-11.4 \mathrm{~cm}$.) about the fourth and fifth leaf and upwards, nearly or quite terete, slightly angled or striate, bright green, glabrous, articulated to the stem with a foot-like process and also with the lamina.

No. 1. Small, oval, obtuse, emarginate, trinerved at the base.

No. 2. Similar, somewhat larger, and emarginate at both ends.

No. 3. Oblong, obtuse and slightly notehed at both ends, threeor faintly five-nerved.

No. 4. Lanceolate, obtuse, cuspidate, faintly five-nerved.

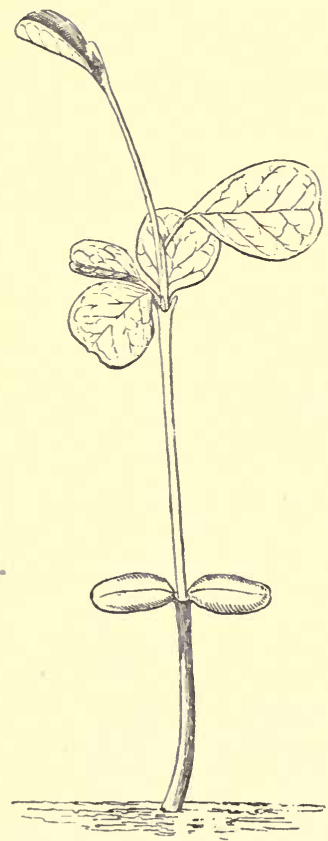

No. 5. Linear-lanceolate, suddenly narrowed to a subulate acute tip, trinerved.

No. 6. Linear, otherwise as No. 5 .

No. 7. Reduced to a petiole tipped with three small, subulate, acute points or processes, diverging above the middle and corresponding to three reduced leaflets.

Nos. 8-10. Similar.

\section{Tribe Genistere.}

Bossiæa linophylla, $R$. $B r$. (fig. 263).

Hypocotyl erect, terete, glabrous, tapering upwards, green at first, soon becoming stained with red, 6-14 mm. above the soil.

Cotyledons oblong, obtuse, entire, petiolate, slightly indented on one side a little above the middle, fleshy, deep green and shining above, glaucous beneath; lamina $3 \cdot 5-4.5 \mathrm{~mm}$. long, $2 \mathrm{~mm}$. wide; petiole grooved above, convex on the back, perfoliate at the base, 1-1.25 mm. long.

Stem erect, terete, glabrous, pale Fra. 263.-Bossica linophylla, × 3. green, ultimately woody; 1st internode $5-13.5 \mathrm{~mm}$. long; 2nd and 3rd undeveloped ; 4th 2.5-7 mm. ; 5th 4-8 mm.

Leaves simple, entire or merely slightly emarginate, cauline, alternate (first three on same level), stipulate, petiolate, alternately 
and ascendingly penninerved, reticulate, glabrous, deep subglaucousgreen above, glaucous beneath; petioles biconvex or subterete (those of first pair flattened), glabrous, green or slightly tinged with red, very short, especially those of the first pair of leaves; stipules small, subulate, acute, glabrous, green, absent from the third leaf or amalgamated with those of the first two leaves.

Nos. 1 and 2. Opposite, broadly obovate, shallowly and broadly emarginate, with a small deltoid tooth in the sinus.

No. 3. On the same level as the first two, but at right angles to them, with a slightly longer petiole and somewhat narrower, but otherwise similar.

Nos. 4-6. Similar both in shape and size, or somewhat larger and having longer stipules.

Bossiæa rufa, $R . B r$.

Hypocotyl as in last species but only 2-3 mm. above ground.

Cotyledons very similar to those of last species; lamina $5 \mathrm{~mm}$. long, $2 \cdot 25 \mathrm{~mm}$. wide; petiole $\cdot 5 \mathrm{~mm}$. long.

Stem as in last species; 1st internode $6 \mathrm{~mm}$. long; 2nd $1 \mathrm{~cm}$.; 3rd $1.3 \mathrm{~cm}$.

Leaves.-Nos. 1 and 2. Opposite, oval, entire, apiculate, deep glaucous-green above, glaucous beneath.

Nos. 3-5. Alternate, obovate, apiculate, coloured like the first two.

\section{Hovea longifolia, $R . \mathrm{Br}$.}

Hypocotyl 1.5-2 cm. long, 1-2 mm. thick, firm, terete, glabrous, colourless near the base, bright green under the cotyledons.

Cotyledons sessile, inserted above the free base, $\cdot 75 \mathrm{~cm}$. long, $.5 \mathrm{~cm}$. broad, $1 \mathrm{~mm}$. thick, oblong, split at base, rounded and reflexed at apex, obscurely nerved, glabrous, light green, not very persistent.

Stem terete, firm, tomentose, bright green ; 1st internode 1-2 cm. long, $1 \mathrm{~mm}$. thick; 2nd and 3rd longer or shorter.

Leaves simple, entire, at least in early stages, cauline, alternate (first pair opposite), stipulate, very shortly petiolate, alternately and ascendingly penninerved, reticulate, a few hairs on both surfaces, at least when young, deep green above, paler or glaucous beneath; stipules small, subulate, inconspicuous.

Nos. 1 and 2. Nearly opposite, shortly stalked, $1.5 \mathrm{~cm}$. long, and as broad, suborbicular or broadly ovate, retuse, with sunk pinnate nervation and beautifully reticulate, thin, with a few hairs 
scattered over both surfaces, dark green above, almost glaucous beneath.

Nos. 8 and 4. Nearly opposite, more elongated, ovate, pubescent.

Nos. 5 and 6 . Tomentose when young.

Goodia lotifolia, Salisb.

Primary root very long, tapering finely, with lateral rootlets on which are a few ovoid fleshy tubercles.

Hypocotyl suffrutescent, erect, terete, glabrous, about $9 \mathrm{~mm}$. above ground, $1.5 \mathrm{~mm}$. thick, proportionately very succulent and thick shortly after germination.

Cotyledons thick, fleshy, subobovate-oblong, shortly petiolate, flat on the upper faces, with a cavity at the base, in which the young plumule was at first protected, convex on the back, with a median longitudinal ridge and two furrows, purplish-green, $6.5 \mathrm{~mm}$. long, $3 \mathrm{~mm}$. broad.

Stem erect, terete, suffrutescent, glabrous, pale green, and suffused with red at the base; 1st internode $3.35 \mathrm{~cm}$. long; 2 nd undeveloped ; 3rd $1.6 \mathrm{~cm}$.; 4 th $8 \mathrm{~mm}$.; 5 th $1.3 \mathrm{~cm}$; 6 th $1.35 \mathrm{~cm}$.

Leaves compound, pinnately trifoliolate (first two unifoliolate resembling foliaceous cotyledons), alternate (first three on the same level or almost so in a great number of specimens), stipulate, petiolate, glabrous, deep green above, paler and subglaucous beneath, folding downwards at night as well as the leaflets; petiole terete, smooth, reddish, with a green pulvinus at the base; stipules subulate, attenuate, free.

Nos. 1 and 2. Unifoliolate; leaflets large, broadly ovate, obtuse or minutely emarginate, subcordate at the base, otherwise entire.

No. 3. Pinnately trifoliolate; leaflets obovate, minutely apiculate, otherwise entire, with a small pulvinus, and articulated with the rachis, folding downwards at night ; rachis between the leaflets, $4 \mathrm{~mm}$. long.

Nos. 4-9. Similar, but successively larger.

NотE.-The leaflets ultimately become broadest about the middle, and consequently change gradually from obovate to elliptic.

Crotalaria quinquefolia, $L$.

Hypocotyl erect, terete, downy, 1-1.5 $\mathrm{cm}$. long, light green or colourless.

Cotyledons oblong, falcate, obtuse, fleshy, shortly petiolate glabrous, except on the petioles, dark green, indistinctly trinerved. 
Stem erect, terete, herbaceous, downy; 1st internode 4-7 mm. ong ; 2nd 6-10 mm.

First leaves simple, cauline, alternate, obovate, obtuse, almost trilobed, downy, especially on the under side, finely ciliated, light green, petiolate, exstipulate, alternately pinnatinerved; petiole terete, downy.

\section{Crotalaria sp.}

Hypocotyl more slender than in preceding species, 4-8 $\mathrm{mm}$. long, and reddish-green.

Cotyledons rather narrower and constricted about the middle, with a prominent midrib only.

Stem, 1st internode from 1.5-2 cm. long; 2nd internode only $2-4 \mathrm{~mm}$.

Leaves opposite, acutely ovate, eiliate; hairy petioles about half the length of the leaf, exstipulate, slightly drooping. 264).

Lupinus arboreus, Sims. (fig.

Primary root a rather long, fleshy, colourless tap-root, with a few thick lateral rootlets, often tuberculated.

Hypocotyl 2-3 cm. long, 2-3 mm. thick, fleshy, terete with horizontal ridges or articulations, shining white where covered by soil, purplish-red above, quite glabrous.

Cotyledons equal, or nearly so, including the petiole $1 \cdot 5-2$ cm. long, 6-8 mm. broad, oblong, oblique at the base, rounded at the apex, entire, obscurely

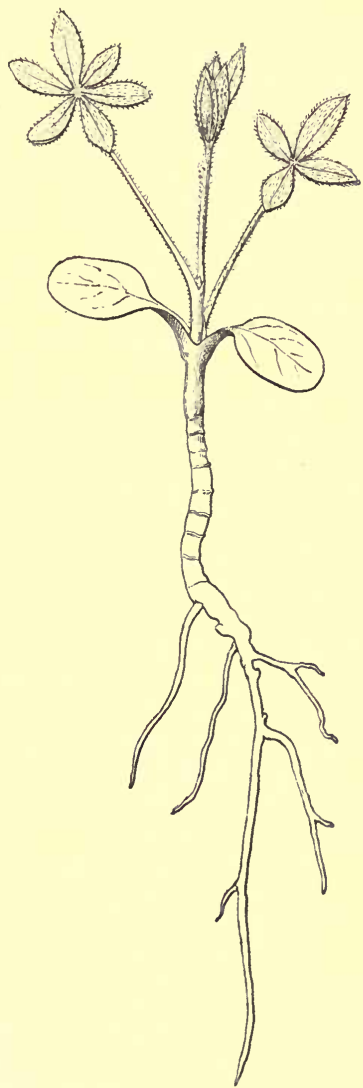

FIG. 264.-Lupinus arboreus. Nat. size. penninerved, fleshy or succulent, glabrous and dark green on 
both sides, somewhat persistent; petiole glabrous, $1.5 \mathrm{~mm}$. thick, channelled, purplish-red.

Stem very short, ultimately elongated and woody.

Leaves digitate, radical and cauline, alternate, stipulate, petiolate, pubescent, with a distinct midrib and other inconspicuous venation; petiole semiterete, channelled above, sheathing at the base by its adnate stipules, which have a subulate, free point.

Nos. $1-3$. With reddish, pubescent petiole, 2,4 , or more $\mathrm{cm}$. long, 1-2 mm. thick, and sheathing at base, with a digitate lamina composed of four, six, or more obovate-lanceolate, acute, pubescent, deep green leaflets, $\cdot 5-1 \cdot 5 \mathrm{~cm}$. or more long, by $\mathbf{3}-\mathbf{5}$ or more mm. broad.

Iupinus micranthus, Douglas.

Primary root similar to that of L. arboreus.

Hypocotyl erect, terete, very short, glabrous, 4-5 mm. long.

Cotyledons very similar to those of L. arboreus, with a flexuose midrib and alternate, flexuose, and anastomosing lateral veins, all sunk in the tissue, deep opaque green above, paler beneath ; lamina 9-11 mm. long, 6-7 mm. broad ; petiole semiterete, channelled above, dilated and perfoliate at the base.

Stem annual, developed when about to flower.

Leaves glabrous above or nearly so, ciliate at the margin, silky beneath, thick and subfleshy; petiole terete, slightly flattened on the upper side, dilated and amplexicaul at the base, slightly hairy ; stipules, in the seedling at least, adnate to the petiole for two-thirds their length, with narrowly subulate, obtuse, or subacute free points and hairy where free.

No. 1. Digitate, with three linear, obtuse leaflets, involute at the sides so as to be deeply channelled, as are all the others, at any rate up to the seventb.

Nos. 2 and 3. With four linear, cuspidate leaflets.

No. 4. With five acute or aristate leaflets.

No. 5. With six acute leaflets.

Nos. 6 and 7. Similar.

Lupinus sulphureus, Douglas (fig. 265).

Hypocotyl erect, terete, glabrous, 2-2.5 cm. long, light green.

Cotyledons suborbicular, thick, fleshy, connate at the base, slightly denticulate, glabrous, dark green, very indistinctly trinerved.

Stem with primary internodes undeveloped. 
First leaves compound, digitate, five-foliolate, petiolate, with rather long petioles, alternate, with small stipules; leaflets simple, entire, lanceolate, acute, ciliate, hairy, green, apparently one-nerved.

Laburnum vulgare, Griseb. (fig. $266)$.

Fruit a legume, linear, acute, stipitate, much compressed laterally and torulose when mature, irregularly veined longitudinally or subreticulate, thickened at the sutures, silky, dehiscing longitudinally by both sutures and somewhat twisted, many-seeded.

Seed persisting for some time on the placentas of the unopened or opened legume, horizontal, oblong, tumid, hooked at the upper end; seed-coat crustaceous or very hard; testa black or deep brown, shining; tegmen pale-coloured, membranous; chalaza below the middle; hilum

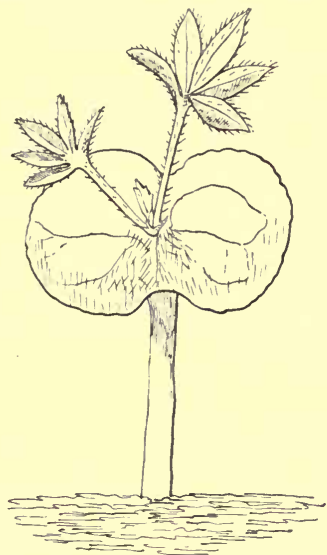

FIG. 265.-Lupinus sulphureus. Nat. size. near or at the middle; the micropyle above it on the ventral aspect.

Endosperm in the mature seed forming a thin layer surrounding the embryo, but much thicker at the sides, that is on the backs of the cotyledons, almost transparent or colourless when dry, and very hard, almost horny.

Embryo comparatively very large, curved, fleshy, yellow; cotyledons oblong, subfalcate, obtuse, slightly notched or indented at about the middle on one edge, unequal at the base, with the larger auricle on the same side as the radicle, while the other side is cut away at the base owing to the shape of the seed, planoconvex, fleshy, each filling about half the interior of the seed, except

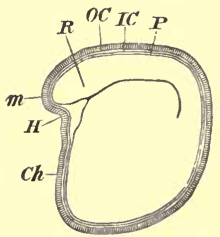

FIG. 266.-Laburnum vulgare, $\times 6$. Longitudinal section of seed: $C h$, chalaza ; $H$, hilum ; $m$, micropyle; $R$, radicle; $O C$, outer coat (testa); $I C$, inner coat (tegmen); $P$, endosperm. that occupied by the radicle and endosperm, notched at one side owing to a mass of endosperm under the hilum, and also slightly to 
a thickening of the chalaza, accumbent, lying in the broader plane of the seed with their edges to the placenta ; radicle cylindrical-oblong, obtuse, passing round the upper end of the seed and pointing downwards to the micropyle on the ventral aspect, much shorter than the cotyledons.

\section{Seedling (fig. 267).}

Primary root tapering downwards, long, with a few lateral rootlets.

Hypocotyl erect, terete, very stout, slightly tapering upwards, passing suddenly below into the primary root, glabrous, pale green or stained with red, $1 \cdot 3-2 \cdot 5 \mathrm{~cm}$. long.

Cotyledons broadly oblong, obtuse, entire, slightly falcate and shallowly indented on one side (by a thickening in the testa of the

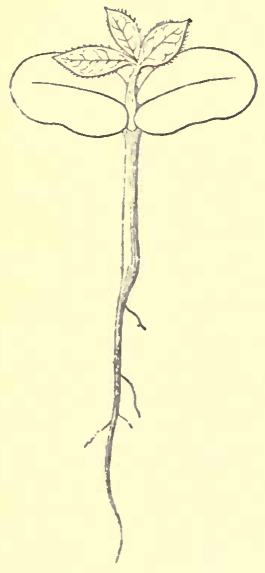

Fig. 267.

Laburnum vulgare. Nat. size.

seed), entire, slightly asymmetrical at the base, on one side of which they are gradually tapered, and on the other truncate, owing to the position of the radicle in the seed, shortly petiolate, thick, fleshy, deep green, opaque, and obscurely trinerved at the base, glabrous ; lamina $1.4-1.5 \mathrm{~cm}$. long, 7·75-8.25 $\mathrm{mm}$. wide; petiole deeply grooved above, convex on the back, about $.5 \mathrm{~mm}$. long.

Stem erect, terete, silky, pale green or somewhat hoary, ultimately woody ; 1st internode 5-8 $\mathrm{mm}$. long.

Leaves compound, digitately trifoliolate, cauline, alternate, stipulate, petiolate, silky on the under side with adpressed hairs, ciliate at the margin, glabrous above or nearly so ; leaflets closely and alternately penninerved, with the nerves branching and uniting within the margin, forming numerous reticulations; stipules small, subulate, silky, at the very base of the petiole.

No. 1. Digitately trifoliolate; lateral leaflets elliptic or ovateelliptic, often, if not always, unequal in size with a difference varying fror $5-4 \mathrm{~mm}$. in length, acute or cuspidate, shortly petiolate; terminal leaflet lanceolate-elliptic, acute, longer and larger than the lateral ones, shortly petiolate.

Ultimate leaves digitately trifoliolate ; leaflets elliptic-lanceolate, 
cuspidate, narrowed to both ends, but especially to the base ; lateral ones often slightly unequal in length; terminal one always the largest.

\section{Retama Rœtam, Webb et Berth.}

Hypocotyl erect, terete, glabrous, $4-4.5 \mathrm{~cm}$. long, light green or colourless with a reddish tinge near the base.

Cotyleclons oblong, obtuse, entire, shortly petiolate, thick, fleshy, glabrous, light green, indistinctly pinnatinerved like the leaves.

Stem erect, ribbed, herbaceous, hairy ; 1st internode $2 \cdot 5-2 \cdot 6 \mathrm{~cm}$. long; 2nd 5-7 mm.; 3rd 1.5-1.6 cm. ; 4th 4-7 mm.

First leaves simple, entire, cauline, alternate, exstipulate, shortly petiolate or subsessile, oval-lanceolate, subacute, covered with long silky hairs which give it a white appearance, pinnatinerved.

\section{Genista sp.}

Hypocotyl erect, terete, glabrous, pale green, about $1 \cdot 8-2 \cdot 4 \mathrm{~cm}$. long.

Cotyledons broadly oblong or oval, obtuse, entire, very shortly petiolate, showing a midrib but no other venation, horizontal on erect petioles, very slightly indented on one side, glabrous, light green; lamina $10.5 \mathrm{~mm}$. long, $8 \mathrm{~mm}$. wide; petiole erect, grooved above, $\cdot 5-1 \mathrm{~mm}$. long.

Stem erect, terete, striate, hairy, pale green when young; 1st internode $17 \mathrm{~mm}$. long; 2nd $5 \mathrm{~mm}$.; $3 \mathrm{rd} 10.5 \mathrm{~mm}$.; 4 th $4 \mathrm{~mm}$.; 5 th $11.5 \mathrm{~mm}$.

Leaves simple and compound, cauline, alternate, stipulate, with the first one petiolate, the others very shortly so or subsessile, alternately penninerved and obscurely reticulate, with the lateral nerves uniting at their apices to form a submarginal nerve, hairy above, silky beneath, with loosely adpressed whitish hairs, glaucous on both surfaces; petiole of first leaf subterete, channelled above, hairy, articulated with the stem; above the first leaf the petioles are reduced to a minimum and articulated with the stem; stipules small, tooth-like, ovate or subulate, obtuse, hairy.

No. 1. Digitately trifoliolate, with oblanceolate, acute leaflets, petiolate.

No. 2. Subsessile, digitately trifoliolate, and similar to the first.

Nos. 3-6. Oblong-elliptic, cuspidate, simple, entire, subsessile.

Ulex europæus, $L$. (fig. 268).

Primary root long, tapering, with lateral rootlets.

Hypocotyl glabrous, terete, green or whitish, $5 \mathrm{~mm}$. to $1 \mathrm{~cm}$. long. 
Cotyledons oblong, obtuse, entire, fleshy, deep green, $8 \mathrm{~mm}$. to 1.1 $\mathrm{cm}$. long, 4-6 mm. broad.

Stem succulent, soon becoming shrubby, pale green, very hairy, ridged and furrowed; 1 st and 2 nd, or even to the 4 th internode, undeveloped; 5th $2 \mathrm{~mm}$. long; 6th undeveloped; 7 th $2 \mathrm{~mm}$. long; 8th $1 \mathrm{~mm} . ; 9$ th $4 \mathrm{~mm}$. : 10th $2 \mathrm{~mm}$.; 11th-13th $3.25 \mathrm{~mm} . ;$ 14th $2 \mathrm{~mm}$.; 15th $3.25 \mathrm{~mm}$.; 16th $3 \mathrm{~mm}$.; 17th $2.5 \mathrm{~mm}$.; 18th and 19th each $2 \mathrm{~mm}$.; 20 th $4 \mathrm{~mm}$. ; 21st and 22 nd each $2.25 \mathrm{~mm}$.; 23rd $1.75 ; 24$ th $1.5 \mathrm{~mm}$. Different specimens vary in these lengths,

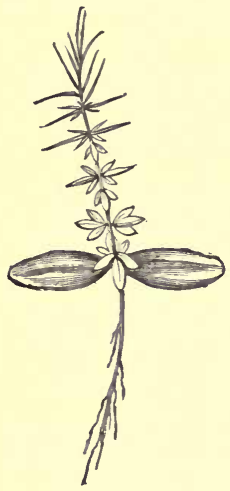

Fig. 268.

Ulex europaus.

Nat. size. but specimens that bear a close resemblance to one another fairly coincide in the lengths of the internodes.

Leaves simple or digitately trifoliolate (in the seedling stage soon becoming simple), and ultimately reduced to spines, alternate, or the first four or six in opposite decussate pairs, hairy, deep green, or subglaucous on the upper surface; leaflets or simple leaf incurved at tbe margins and grooved or concave on the upper face, with the lower ones petiolate, the upper sessile; petioles grooved above, convex beneath.

First Specimen.-Leaves all simple, spathulate, with the first four in two opposite pairs.

Second Specimen.-1st pair linear-oblong, obtuse, simple.

2nd pair bifoliolate (one terminal and one lateral leaflet).

No. 5. Spathulate, entire.

No. 6. Trifoliolate.

No. 7. Spathulate.

No. 8. Bifoliolate.

No. 9. Bifoliolate.

No. 10. Spathulate.

Third Specimen.-Nos. 1-6. Trifoliolate; the first four in two opposite pairs.

Nos. 7-11. Spathulate.

Fourth Specimen.-Nos. 1 and 2. Trifoliolate, opposite.

Nos. 3 and 4. Spathulate, opposite.

No. 5. Bifoliolate, alternate.

No. 6. Spathulate.

Nos. 7 and 8. Bipartite.

Nos. 9-18. Spathulate or lanceolate, linear. 
Fifth Specimen.-Nos. 1-6 in three opposite pairs. One of 1st pair bipartite, the other trifoliolate; of 2 nd pair one is spathulate the other bipartite; 3rd pair trifoliolate.

No. 7. Tripartite.

No. 8. Bifid.

No. 9. Bipartite.

Nos. 10-14. Spathulate.

Nos. 15-25. Linear-lanceolate, spiny-pointed.

The branches are spinous from the first, their leaves spiny. pointed, and the secondary branches small and also spinous.

Spartocytisus nubigenus, Webb et Berth., var. roseus.

Hypocotyl erect, terete, glabrous, $3-3 \cdot 5 \mathrm{~cm}$. long, dark brownishred.

Cotyledons oblong, obtuse, entire, sessile, unequal, glabrous, brownish-red, indistinctly one-nerved.

Stem erect, striated, herbaceous, ultimately woody, covered with rather silky hairs ; 1st internode 7-8 mm. long ; 2nd rather shorter.

First leaves compound, trifoliolate, cauline, alternate, exstipulate, petiolate; leaflets linear-lanceolate, acute, entire, very shortly petiolulate or subsessile, hairy, light green, one-nerved ; petioles long, hairy, slightly channelled on the upper side.

A
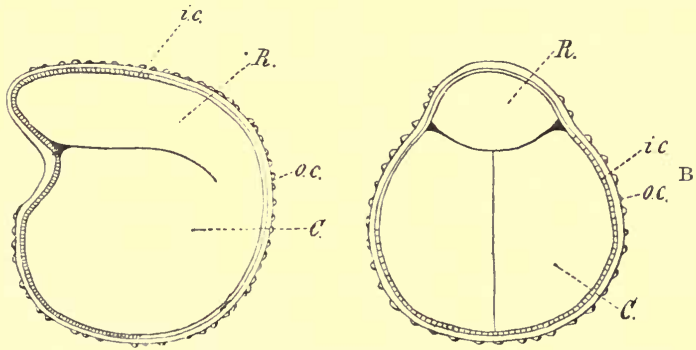

Frg. 269.-Ononis altissima, $\times 16$. A, longitudinal section. B, transverse section: $R$, radicle; $C$, cotyledons; o $c$, outer coat of testa ; $i c$, inner coat of testa.

\section{Tribe Trifolies.}

Ononis altissima, Lam. (fig. 269).

Seeds almost orbicular, with a prominent basal notch; testa tubercled, dark brown. Seed exalbuminous, $1 \cdot 5-2 \mathrm{~mm}$. in diameter. 
Embryo curved or rounded on itself, filling the whole interior of the seed, yellowish-white.

Cotyledons oval or nearly round, fleshy, sessile with their edges to the hilum; radicle accumbent on the edges of the cotyledons, angled, obtuse, rather longer than the cotyledons. Owing to the thickening of the testa near the basal notch there is probably a slight oblique emargination in the cotyledons.

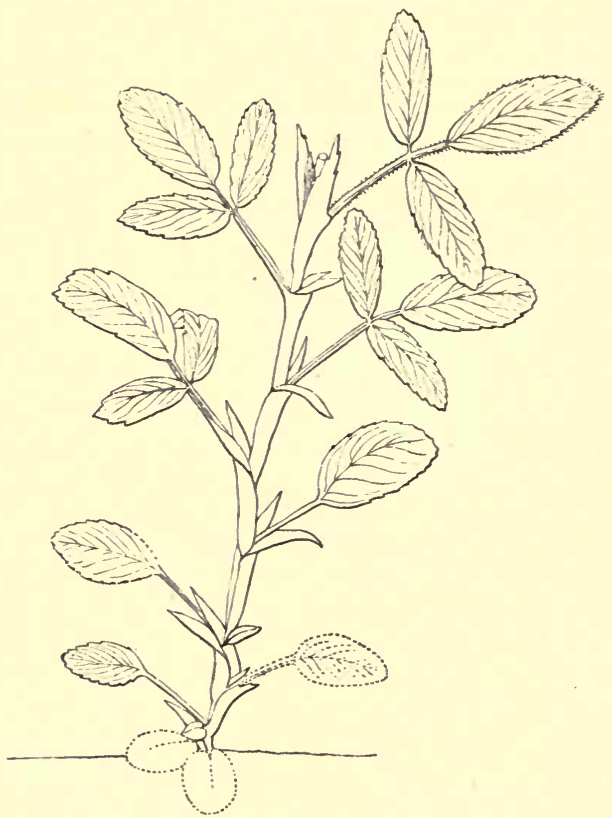

Fig. 270.-Ononis Natrix. Nat. size.

Ononis Natrix, DC. (fig. 270).

Hypocotyl subterranean.

Cotyledons shortly and broadly oblong, obtuse, densely hairy, $8.5 \mathrm{~mm}$. long, $7 \mathrm{~mm}$. broad; petiole $1 \mathrm{~mm}$. long.

Stem erect, terete, glandular-hairy, suffruticose at the base mostly covered by the large sheathing stipules; 1st internode $2 \mathrm{~mm}$. long; 2nd 3.5 mm. ; 3rd 4.5 mm.; 4 th 7.5 mm. ; 5 th $9 \mathrm{~mm}$.; 6 th $8 \mathrm{~mm}$.; 7 th $1.15 \mathrm{~cm}$.; 8 th $1.15 \mathrm{~cm}$.; 9 th $1.25 \mathrm{~cm}$.; 10 th $1.05 \mathrm{~cm}$. 
Leaves compound, pinnately trifoliolate, cauline, alternate, stipulate, petiolate, glandular-hairy, smelling strongly ; petioles channelled above, glandular-hairy; stipules adnate to the petioles for three-quarters their length, glandular-hairy, with ovate-subulate free points, entire or distantly serrate on the upper part of the stem.

Nos. 1-4. Unifoliolate; the three lower ovate, entire or slightly serrate towards the apex; the upper one ovate, oblong, cuspidate, serrulate with ascending parallel veins running into the serratures, as in all the other leaves.

No. 5. Pinnately trifoliolate ; leaflets oblong, cuspidate, serrulate above the middle; terminal leaflet twice as broad as the lateral ones.

Nos. 6 and 7. Similar, but leaflets serrulate for three-quarters of their length.

Nos. 8-12. Leaflets more nearly equal in size and inclining to be oblong-elliptical.

\section{Pocockia cretica, Ser.}

Primary roct long, tapering, fleshy, colourless, giving off numerous lateral rootlets which frequently have little white fleshy tubercles attached to them, annual.

Hypocotyl stout, tapering downwards, slightly wrinkled transversely, white, $1.2 \mathrm{~cm}$. long, glabrous.

Cotyledons: lamina oblong, obtuse, articulated with its petiole, fleshy, bright green above, much paler beneath, $1.2 \mathrm{~cm}$. long, $7 \mathrm{~mm}$. broad, glabrous; petioles fleshy, slightly channelled above, dilated at the base and connate, $5 \mathrm{~mm}$. long.

Stem herbaceous, annual.

Leaves compound, pinnately trifoliolate (first one simple or rather unifoliolate), radical and cauline, alternate, stipulate, petiolate, fleshy, glabrous, bright green above, glaucous or almost white beneath; petiole subterete, channelled, reddish and minutely pubescent above, pale green beneath, articulated above the stipules; stipules large, sheathing, adnate for two-thirds of their length to the petiole, with the upper third free, ovate, lacerated or deeply and sharply toothed, very pale, almost colourless.

No. 1. Unifoliolate; leaflet rotund, entire, or obsoletely dentate, bright green above with a crimson spot at its base, convex above, concave below and glaucous, articulated with the petiole.

No. 2, and all following it, pinnately trifoliolate ; leaflets rotundcuneate, emarginate with a tooth in the notch, obsoletely dentate, bright green above with a crimson spot at the base, glaucous beneath; terminal leaflet largest; rachis between the leaflets $4 \mathrm{~mm}$. long. 


\section{Trigonella corniculata, $L$.}

Primary root a short colourless tap-root with a few fibrous lateral rootlets.

Hypocoty $l$ herbaceous, $2 \mathrm{~cm}$. long, $\cdot 75 \mathrm{~mm}$. thick, terete, glabrous, greenish-grey.

Cotyledons sessile and semi-amplexicaul, 1.25-1.5 $\mathrm{cm}$. long, $3 \mathrm{~mm}$. broad, linear-obovate, rounded at the apex, entire, with no visible nerves, glabrous, stout but not thick, light green.

Leaves pinnately trifoliolate (the first simple), cauline, alternate, stipulate, petiolate, alternately and ascendingly penninerved with the nerves running out into teeth, glabrous, pale or deep green above, paler beneath; petioles slender, glabrous; stipules small, adnate to the petiole with a free point.

No. 1. With a long slender petiole, simple; lamina $1 \mathrm{~cm}$. long, and as broad; orbicular, mucronate, slightly denticulate, penninerved, glabrous, thin, uneven, yellowish-green above, slightly paler below ; petiole about $2 \mathrm{~cm}$. long, $\cdot 5 \mathrm{~mm}$. broad, articulated near the apex, glabrous.

\section{Trigonella Fœnum-græcum, $L$.}

Hypocotyl much stouter than in T. cormiculata, light green or colourless.

Cotyledons oval-oblong, obtuse, entire, flesby, petiolate, glabrous, green, indistinctly pinnatinerved; petiole thick, short, channelled on the upper face, sheathing and connate at the base, suddenly becoming thin near the base of the leaf, so that the cotyledon appears articulated with it.

Stem erect, terete, glabrous; primary internodes but slightly developed.

Leaves trifoliolate, as in preceding species; leaflets obovate, shortly petiolulate, green, pinnatinerved.

No. 1. Simple, slightly toothed, obovate, shallowly emarginate; petiole hairy, deeply channelled on the upper side, becoming suddenly thin near the base of the lamina with which it is articulated; stipules thin, rather large, hairy, ending in a point.

\section{Trigonella gladiata, Stev.}

Primary root long and tapering, colourless, fleshy, throwing off numerous secondary rootlets towards its growing point, with occasionally small white fleshy tubercles, annual.

Hypocotyl subterranean, fleshy, tuberous, colourless, about $3 \mathrm{~cm}$. long. 
Cotyledons very similar to those of T. Fœnum-græcum, articulated with the petiole, $13 \mathrm{~mm}$. long, $6 \mathrm{~mm}$. broad; petiole $4 \mathrm{~mm}$. long.

Stem herbaceous, annual, erect or flexuous, terete, pale green hairy ; 1st internode $4.5 \mathrm{~mm}$. long; 2nd $10 \mathrm{~mm}$.; 3rd $5 \mathrm{~mm}$.

Leaves as in other species, glabrous above, sparsely hairy beneath when young, glabrescent; petiole subterete, channelled above, articulated above the sheathing stipules, hairy, pale green slightly tinged above with red; stipules adnate to the petiole for twothirds their length, hairy, pale green or almost colourless, with ovate, acuminate, free tips, entire.

No. 1. Unifoliolate; leaflet articulate with its petiole, rotund, entire, succulent like all the rest.

No. 2, and all succeeding. Pinnately trifoliolate ; leaflets obovatecuneate, emarginate, finely serrulate from the middle upwards, with numerous ascending, parallel nerves ending in the serratures, bright green above with a red midrib, glaucous beneath; middle leaflet largest; rachis between the leaflets $4 \mathrm{~mm}$. long.

Medicago sativa, $L$.

Fruit a legume spirally twisted into two or three coils, severalseeded.

Seeds oblong with a notch near the hilum, exalbuminous, 2-3 mm. long ; testa smooth, yellowish; hilum inconspicuous, near the micropyle.

Embryo curved or rounded on itself, filling the whole of the seed, colourless; cotyledons oblong with a tendency to become falcate, fleshy, entire, sessile, with their edges towards the lilum; radicle square or triangular, acute, considerably shorter than the cotyledons and accumbent.

\section{M. lupulina, $L$.}

Legume small, kidney-shaped, not spirally twisted, black.

Seed smaller than in M. sativa, rather more orbicular, 1.5-2.5 mm. in diameter.

\section{Medicago orbicularis, All. (fig. 271).}

In germination the spirally coiled legume splits readily along the dorsal suture, and the radicles of the various seeds seem all to make their exit along one side, while the cotyledons push out along the opposite side. By this means the fruit is effectually fixed to the soil while the embryos have no difficulty in getting out. The 
testa is, however, sometimes carried up by the cotyledons and splits

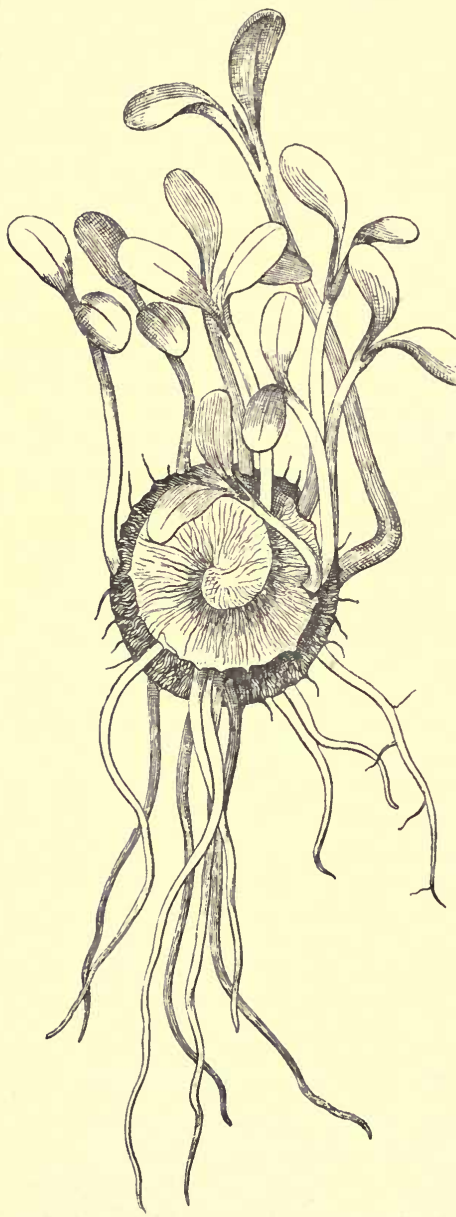

Fia. 271.-Medicago orbicularis, $\times 2$.

Nine seedlings, all from one fruit. irregularly as the cotyledons expand.

Twelve to sixteen seedlings from one fruit are not infrequent. A few instances occur (two to three out of fifty-six) where the radicle and cotyledons emerge together at one side of the fruit, and consequently stand out free from it. One instance occurred amongst fifty-six seedlings where the cotyledons gotclearaway from the fruit and seed, but the radicle failed to get out and consequently the seedling did not make the same progress as the rest and most likely perished. The cotyledons at this stage are oblong, obtuse, entire, petiolate, narrowed to the base, glabrous, somewhat fleshy, showing a midrib indistinctly, but no other venation, deep green above, paler beneath, but often suffused with purple. Hypocotyl glabrous, slender, purplish or ultimately green.

Melilotus officinalis, Willd.

Primary root normal, slightly tuberculated, annual or biennial. 
Hypocotyl erect, terete, glabrous, colourless when subterranean, red when rising out of the soil, tapering gradually into the root.

Cotyledons oblong, obtuse, fleshy, petiolate, glabrous, deep green ; lamina $7 \mathrm{~mm}$. long, $3.5 \mathrm{~mm}$. broad; petiole articulated with the lamina, fleshy, channelled above, $1 \mathrm{~mm}$. long.

Stem herbaceous, erect, terete, glabrous or thinly pubescent, green or purplish; 1 st internode $2.4 \mathrm{~cm}$. long; 2nd $2.7 \mathrm{~cm}$.; 3rd $1 \cdot 15 \mathrm{~cm}$.

Leaves pinnately trifoliolate (1st unifoliolate), cauline, alternate, stipulate, petiolate, glabrous above, thinly pubescent on the under surface, deep or intensely glaucous-green above, glaucous beneath, alternately penninerved, with numerous, ascending, parallel, simple or forking veins; petioles trigonous, channelled on the upper side, thinly pubescent; stipules subulate, attenuate, entire, minutely ciliate.

No. 1. Unifoliolate, rotund, subemarginate, minutely notched at the base, obsoletely crenate, with the tips of the nerves depressed.

No. 2. Trifoliolate; terminal leaflet obovate, emarginate, obscurely toothed in the notch, obsoletely crenate; lateral leaflets obovate-oblong, otherwise like the terminal one.

Nos. 3-5. With rather longer, narrower, more evidently serrulate or denticulate leaflets.

Ultimate leaves pinnately trifoliolate; leaflets emarginate, toothed in the notch, denticulate; terminal one ovate, lateral ones oblong-elliptic.

Melilotus leucantha, Koch, closely resembles the preceding species but has rather larger cotyledons.

Trifolium Boissieri, Guss. (fig. 272).

Primary root long, tapering, with lateral rootlets and a few tubercles.

Hypocotyl tapering, fleshy, terete, colourless below the soil and purple above, glabrous, tapering insensibly into the root.

Cotyledons glabrous, fleshy ; lamina oblong, obtuse, deep green, articulated with its petiole, $8 \mathrm{~mm}$. long, $3.75 \mathrm{~mm}$. broad; petioles dilated and connate at the base, channelled above, $2.5 \mathrm{~mm}$. long.

Stem herbaceous, erect, flexuous, wiry and purple at the base, stouter upwards, angled, pale green, sparsely pubescent; 1st internode $1 \cdot 2 \mathrm{~cm}$. long; 2nd $1 \cdot 2 \mathrm{~cm}$.; 3rd $6 \mathrm{~mm}$.

Leaves pinnately trifoliolate (No. 1 unifoliolate), cauline, stipu- 
late, alternate, petiolate, minutely and sparsely pubescent, at least when young; stipules very shortly adnate to the petiole, one- or

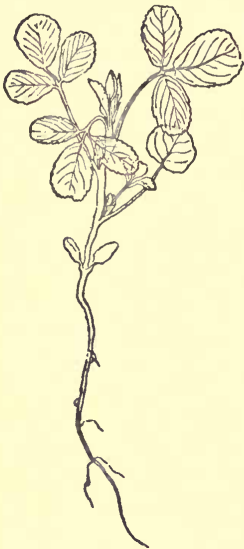

FIG. 272.

Trifolium Boissieri.

Half nat. size.

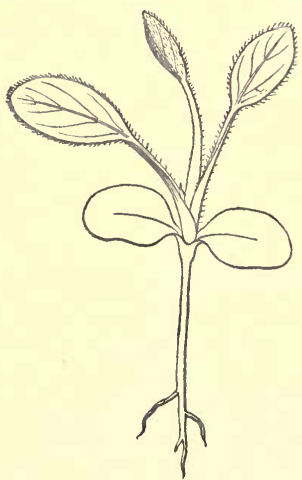

Fıa. 273.-Anthyllis Vulneraria. Nat. size.

petiole shallowly grooved long. two-toothed at the basal posterior side, with a long, linear, subulate point.

No. 1. Unifoliolate; leaflet large, transversely oval, apiculate, obsoletely crenulate; petiole like the others, subterete, channelled above, subamplexicaul at the base.

No. 2, and the rest. Pinnately trifoliolate; leaflets obovate, emarginate, with a tooth in the notch, serrulate, except on the basal third or half, rounded or emarginate at the base, deep green above and obscurely nerved, glaucous beneath, with parallel, ascending nerves running into the serratures; rachis between the lateral and terminal leaflets $3 \mathrm{~mm}$. long.

\section{Trifolium subterraneum, $L$.}

Cotyledons oblong, obtuse, petiolate.

Leaves pinnately trifoliolate, radical and cauline, villous on both surfaces as well as the petiole, with ascending, parallel, simple, or forked veins.

No. 1. Unifoliolate, rotund, emarginate, toothed in the notch, obsoletely denticulate.

No. 2. Trifoliolate; leaflets rotundobovate, otherwise as in No. 1.

Ultimate leaves pinnately trifoliolate; leaflets obovate, emarginate.

\section{Tribe Lote开.}

Anthyllis Vulneraria, L. (fig. 273).

Hypocotyl erect, terete, glabrous, pale green, $6 \mathrm{~mm}$. to $1 \cdot 7 \mathrm{~cm}$. long.

Cotyledons large, fleshy, glabrous, obliquely oval, obtuse, suddenly narrowed at the base to a short petiole, 1-1.4 cm. long, 6-9.25 $\mathrm{mm}$. wide; above, subperfoliate, about $3 \mathrm{~mm}$. 
Stem short, herbaceous.

Leaves compound (the first few are simple), radical, alternate, stipulate, petiolate, silky at the margin, otherwise glabrous, somewhat fleshy, thick, alternately and ascendingly penninerved, deep subglaucous-green; petioles deeply channelled above, gradually dilated to a wide amplexicaul base, hairy; stipules almost wholly adnate to the petiole (in young seedling) with small, subulate, brown free tips.

No.1. Simple, entire, narrowly obovate-elliptic, minutely cuspidate

No. 2. Simple, oblong-elliptic, minutely cuspidate.

\section{Lotus Tetragonolobus, $L$.}

Primary root stout, fleshy, tapering downwards, with a few fleshy lateral rootlets, and comparatively large flesh-coloured tubercles.

Hypocotyl erect, terete, stout, colourless, glabrous, partly subterranean, $2 \cdot 8-3 \cdot 2 \mathrm{~cm}$. long.

Cotyledons broadly oblong, cordate at the base, rounded at the apex, petiolate, fleshy, glabrous, five-nerved but very indistinctly and seen only on the under side, deep opaque green above, paler beneath and shining; lamina directed slightly to one side, 1.3-1.5 $\mathrm{cm}$. long, 1-1.1 cm. wide; petiole very broad, grooved above, convex beneath, connate at the base, pale green almost colourless, minutely dotted with red, glabrous, articulated with the lamina, $5 \mathrm{~mm}$. long, $3 \mathrm{~mm}$. broad.

Stem herbaceous, annual, erect, dividing into four immediately above and between the cotyledons, pale green, densely hairy, almost villous; two branches take the lead and are the strongest; primary internode of the stronger pair of branches 1-1.4 cm. long; of the weaker pair $4-7 \mathrm{~mm}$.

Leaves compound, cauline, alternate, stipulate, petiolate, somewhat hoary with pale-coloured or whitish hairs on both surfaces, glaucous-green above, paler beneath ; leaflets alternately and ascendingly penninerved with the nerves discernible by transmitted light only, articulate with the petiole, the lateral one sessile, the terminal one shortly petiolulate; stipules foliaceous, obliquely triangular, obtuse, radiately nerved from the base, hairy on both surfaces like the leaves, sessile, not articulated with the petiole, but seated at its base and partly on the stem, semi-amplexicaul.

No. 1 on the larger branches. Ternate; terminal leaflet obovate, obtuse, entire or minutely emarginate, petiolulate; lateral leaflets sessile, obliquely obovate, unequal-sided, with the broadest half on the posterior side of the midrib, minutely cuspidate.

No. 2. Similar, but the terminal leaflet entire. 
No. 1 on the smaller pair of branches similar to those of the larger pair of branches.

NoтE.-Out of one hundred and nine seedlings, seventy-six had the plumule divided into four stems or branches immediately it emerged from between the base of the cotyledons. The remaining thirty-three were either damaged or not sufficiently advanced to determine whether they would have two or four stems. There is every appearance, however, that it is a constant character of this species to bave four instead of one primary stem.

Lotus peliorhynchus, Hort. brous.

Hypocotyl erect, terete, $2-3.5 \mathrm{~cm}$. long, greenish-brown, gla-

Cotyledons linear-oblong, entire, petiolate, obtuse, glabrous, greyish-green, with no apparent venation.

Stem erect, terete, berbaceous, downy, greyish ; 1st internode 4-8 mm. long.

First leaves compound, digitate, shortly petiolate, downy; leaflets five, linear, acute, entire, sessile, greyish.

\section{Tribe Galeges.}

\section{Psoralea sp.}

Hypocotyl erect, terete, glabrous, $\mathbf{1} \cdot 5-\mathbf{2} \cdot \mathbf{c m}$. long, light green or colourless.

Cotyledons subfleshy, oblong, obtuse, falcate, petiolate, glabrous, light green, pinnatinerved; petioles $1 \cdot 5-2 \mathrm{~cm}$. long, channelled on the upper side.

Stem erect, square, herbaceous, with a few short silky hairs; 1st internode $1-1 \cdot 2 \mathrm{~cm}$. long.

First leaves simple, entire, cauline, opposite, ovate or cordate, obtuse, petiolate, stipulate, ciliate, covered with minute hairs, dark green, pinnatinerved, with the lateral veins very much branched; petiole $2-3 \mathrm{~cm}$. long, covered with minute hairs, channelled on the upper side; stipules small, acute, entire, hairy.

Succeeding leaves are pinnate and alternate.

Indigofera australis, Willd. (fig. 274).

Hypocotyl erect, terete, suffruticose, 8-12 $\mathrm{mm}$. long.

Cotyledons caducous.

Stem erect, terete, suffrutescent, pale green; 1st internode $1 \mathrm{~cm}$. long; 2nd $1.8 \mathrm{~cm}$.; 3rd $2 \mathrm{~cm}$.; 4 th $2.2 \mathrm{~cm}$., minutely pubescent when young. 
Leaves compound, imparipinnate (first two opposite and unifoliolate), alternate, stipulate, petiolate, deep green, glabrous, minutely pubescent at the margin, but all over when young; petioles subterete, channelled above as well as the rachis; stipules small, subulate, acute; leaflets stipellate.

Nos. 1 and 2. Opposite, unifoliolate; leaflets oblong-obovate, emarginate.

No. 3. Sometimes unifoliolate, but most frequently pinnately trifoliolate; terminal leaflet obovate, emarginate; lateral leaflets oval.

No. 4. Pinnately trifoliolate; leaflets oblong, emarginate ; terminal one largest.

No. 5. Pinnately five-foliolate; lowest pair of leaflets oval, the rest larger and oblong.

No. 6. Pinnately seven-foliolate.

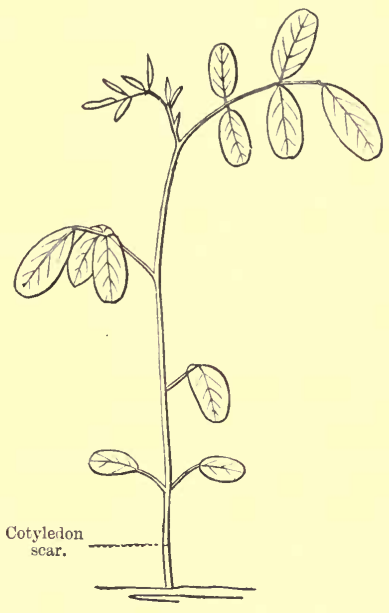

FIG. 274.-Indigofera australis.

Two-thirds nat. size.

\section{Galega officinalis, $L$.}

Primary root long, tapering, fleshy, colourless, giving off numerous lateral rootlets, and furnished with numerous oblong-ovoid, fleshy tubercles.

Hypocotyl subsucculent at first, erect, terete, glabrous, mostly subterranean, tapering gradually into the root.

Cotyledons obovate-oblong, obtuse, subfleshy, tapering at the base to a short broad petiole, glabrous, spreading or arching, $1.4 \mathrm{~cm}$. long including the petiole, $6 \mathrm{~mm}$. broad.

Stem herbaceous, erect, terete at the base and angled upwards and striate, slightly thickened at the nodes, glabrous and shining, green suffused with purple, especially at the nodes; 1 st internode $2 \mathrm{~mm}$. long ; 2nd $4 \mathrm{~mm}$.; 3rd $1.2 \mathrm{~cm}$.; 4 th $1.2 \mathrm{~cm}$.; 5 th $1.3 \mathrm{~cm}$.

Leaves imparipinnate (1st unifoliolate), cauline, alternate, stipulate, petiolate, glabrous, glaucous-green on both sides, paler beneath ; petioles subterete, channelled above, sparsely pubescent; stipules free, subulate, attenuate, acute, pale green, glabrous, becoming broader upwards, and many-veined; leaflets entire with 
numerous parallel, ascending veins, forking towards the margin, obtuse or retuse and apiculate at the tip.

No. 1. Unifoliolate; lamina obovate-elliptic.

No. 2. Abruptly bifoliolate; terminal leaflet wanting; lateral leaflets oval or elliptic.

Nos. 3 and 4. Pinnately trifoliolate; leaflets elliptic.

Nos. 5 and 6. Pinnately five-foliolate; leaflets oblong-elliptic, upper three subapproximate.

Ultimate leaf of five or more pairs of leaflets and a terminal one; leaflets mostly opposite, ovate, obtuse, subcordate at the base, apiculate, glabrous, glaucous-green above, glaucous beneath; stipules ovate, acuminate.

Robinia Pseud-Acacia, L. (fig. 275).

Hypocotyl erect, terete, glabrous, pale green, slender, $1 \cdot 6-2 \mathrm{~cm}$. long.

Cotyledons oblong-oval, obtuse, entire, equal or very slightly unequal at the base, alternately incurvinerved, petiolate, thick with

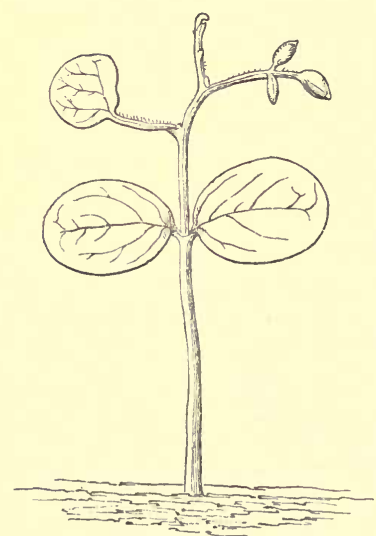

Fig. 275,-Robinia Pseud-Acacia, $\times 2$. very obscure venation, glabrous, light green on both surfaces; lamina 8-9 mm. long, 5·5-6.5 $\mathrm{mm}$. wide; petiole ascending, semiterete, channelled above, glabrous, $1 \mathrm{~mm}$. long.

Stem erect, terete, zigzag or flexuous, thinly pubescent in seedling stage with upwardly adpressed hairs, pale green, ultimately arborescent; 1 st internode 5-7 mm. long, 2nd 2-3 mm.

Leaves compound (first one unifoliolate), imparipinnate, cauline, alternate, stipulate, petiolate, alternately and ascendingly penninerved and finely reticulate, thinly or more or less conspicuously pubescent on the margins and petioles, deep glaucous-green above, paler and glaucous beneath; leaflets entire, more or less conspicuously stipellate in the adult plant, articulated with the rachis; stipules small, subulate, inconspicuous or sometimes wanting; petioles subterete, shallowly channelled above, more or less pubescent, articulated with the stem and also with the leaflets. 
No. 1. Rotund, obtuse, entire or shallowly emarginate (apparently deformed in specimen sketched).

No. 2. Pinnately trifoliolate; lateral leaflets opposite, elliptic, small, shortly petiolulate; terminal leaflet similar but much larger and with a longer petiolule.

Nos. 3-5. Pinnately trifoliolate, very similar to the 2nd. Branches in the axils of the first and second leaves similar to those of the primary stem.

\section{Carmichælia pilosa, Col.}

Hypocotyl erect, terete, slender, about $7 \mathrm{~mm}$. long.

Cotyledons opposite or subalternate (perhaps accidental), oblongspathulate, obtuse, entire, narrowed to the base.

Stem shrubby, slender, spreading, or diffuse and branching at the base, striate, terete at the base, and becoming dilated and flattened upward, deep brown and covered with an ascending, adpressed, white pubescence.

Leaves cauline, simple and ternately compound, alternate, stipulate, distichous, petiolate and petiolulate, pubescent on both surfaces as well as the petioles, becoming glabrous on the upper surface when old ; pubescence adpressed upwards ; petiole subterete, channelled above, about 5-8 $\mathrm{mm}$. long, articulated at the base and apex below the leaf or leaflets; stipules small, scarious, and greyish, triangular or rounded and toothed, adpressed to the stem and petiole.

No. 1 to some indefinite number. Simple, obcordate, entire, articulate with the petiole, indistinctly penninerved.

Ultimately some leaves show a terminal with one lateral leaflet. Occasionally a few leaves have three leaflets; lateral ones similar but much smaller than the terminal one; petiolule of terminal leaflet about $2 \mathrm{~mm}$. long; lateral ones much shorter. As the branch weakens towards the tip, the leaves are again reduced to a single leaflet.

Sesbania ægyptiaca, Pers. (fig. 276).

Fruit a legume, linear, terete or tetragonous, transversely septate between the seeds, dehiscing by two valves or not at all.

Seed transversely oblong, terete, obtuse at each end, smooth, shining, pale yellow; testa thin; hilum conspicuous above the middle on the ventral aspect, thickened, brown; chalaza ventral, towards the opposite end, but not quite basal.

Endosperm in the mature seed rather copious, cartilaginous, 
subtransparent, forming a thick layer at the back of each cotyledon, and a thin continuous layer at their edges and ends.

Embryo large, curved, nearly equal in length to the endosperm, central, conforming in general outline to that of the seed, pale yellow ; cotyledons linear-oblong or oblong, obtuse, entire, slightly
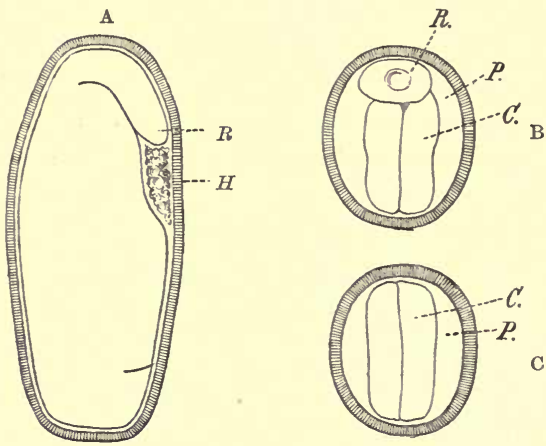

FIG. 276.-Sesbania agyptiaca, $\times 13$. A, longitudinal section of seed : $R$, radicle; $H$, hilum. B, transverse section of seed near the end containing the radicle, $R: P$, endosperm; $C$, cotyledons. C, transverse section of seed towards end opposite the radicle: $P$, endosperm; $C$, cotyledons.

indented near the middle owing to a thickening at the hilum, and somewhat unequal at the base owing to the position of the radicle, rather thick, but flat, and both taken together presenting a somewhat rectangular appearance in transverse section; radicle stout, oblong, obtuse, accumbent and curved round to the micropyle at the base of the ventral aspect and outside the cotyledons.

Sesbania tomentosa, Hook. et Arn. (fig. 277).

Primary root long, nearly vertical, with many lateral branches thickened near their ends.

Hypocotyl erect, woody, 3-4 cm. long, about $1 \mathrm{~mm}$. thick, terete near its base, ridged higher up by reason of the decurrent petioles of the cotyledons, densely covered with red dots especially below, otherwise of a paler green below.

Cotyledons subsessile, 1·5-2 $\mathrm{cm}$. long, 8-10 mm. broad, unequal, ${ }^{1}$ one oblong, the other oblong-obovate, entire, convex, obscurely penninerved, rather thick, glabrous, dull green above, paler beneath, not very persistent.

${ }^{1}$ Inequality of cotyledons probably accidental. 
Stem herbaceous, ultimately woody, erect, about $1 \mathrm{~mm}$. thick; 1st internode $1.5 \mathrm{~cm}$. long; 2nd and third shorter; otherwise much like the hypocotyl.

Leaves compound, abruptly pinnate (1st one entire), cauline, alternate, stipulate, petiolate, alternately incurvinerved and reticulate, pubescent in the young state, ultimately glabrous; leaflets oblong, entire, shortly petiolulate, opposite; stipules small, subulate, acute, caducous.

No. 1. Stipulate, petiolate, resembling the seed-leaves but larger, $3-3 \cdot 5 \mathrm{~cm}$. long, $1 \cdot 25-1.5 \mathrm{~cm}$. broad, oblong-obovate, acute at base, truncate and mucronate at apex, entire, irregularly penninerved and reticulately veined, with sunk midrib, flat, thin, glabrous.

No. 2. Abruptly pinnate, $3.5 \mathrm{~cm}$. long, $2 \mathrm{~cm}$. broad, with three pairs of subsessile, linear-oblong, oblique, mucronate leaflets, slightly pubescent beneath, $\cdot 75-1 \cdot 25 \mathrm{~cm}$. long and 2.5-5 mm. broad; rachis terminating in a long mucro, channelled, as well as the petiole.

Nos. 3 and 4. Similar, but with four pairs of leaflets.

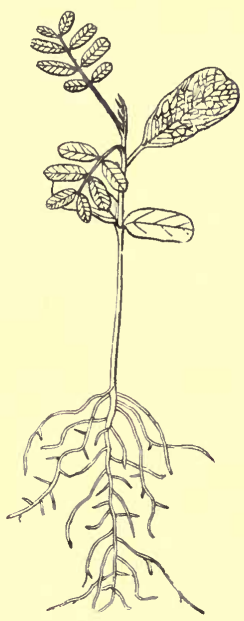

Fig. 277.

Sesbania tomentosa. Half nat. size.

Youngest leaves pubescent on the under side of blade and petiole.

\section{Sesbania grandiflora, Poir.}

Hypocotyl erect, terete, glabrous, pale green, mottled with purple, $5.7 \mathrm{~cm}$. long or shorter, $1 \cdot 5-2 \mathrm{~mm}$. thick.

Cotyledons petiolate, oblong, obtuse, entire, falcate, thick, fleshy, deep green, glabrous, $2 \cdot 7 \mathrm{~cm}$. long, $1 \cdot 2 \mathrm{~cm}$. broad; midrib sunk above, prominent beneath; petiole about $1 \mathrm{~mm}$. long.

Stem erect, terete, glabrous, pale green, mottled with purple; 1st internode variable in length, 1-4 cm. long, $2 \mathrm{~mm}$. thick; 2nd 2-5 mm. long.

Leaves cauline, alternate, stipulate, petiolate.

No. 1. Simple, articulated at the base of the petiole and at the base of the lamina; petiole terete, channelled above, purplish, 8.5 mm. long; lamina oblong-lanceolate, obtuse, mucronate, obscurely penninerved with ascending nerves, glabrous and deep green above, 
glabrous and glaucous beneath; stipules subulate, acute, falcate or recurved, reddish.

No. 2. Compound, abruptly pinnate, petiolate, glabrous; leaflets in four (sometimes five) pairs, oblong, obtuse, mucronate, penninerved, entire, deep green above, paler beneath, rather fleshy, opposite, petiolulate ; petiolules slender, $1 \mathrm{~mm}$. long, articulated at both ends; primary petiole and primary midrib subterete, channelled above, ending in a mucro between the last pair of leaflets; stipules as above.

No. 3. Abruptly pinnate, with five pairs of leaflets.

Swainsonia oncinotropis, $F$. Muell.

Hypocotyl $1 \mathrm{~cm}$. long, $1 \mathrm{~mm}$. thick, herbaceous, terete, glabrous, greyish-green.

Cotyledons subsessile, $1 \cdot 5 \mathrm{~cm}$. long, $\cdot 5 \mathrm{~cm}$. broad, $\cdot 5 \mathrm{~mm}$. thick, obovate-spathulate, rounded at apex, entire, obscurely nerved, glabrous, light green, rather persistent.

Stem herbaceous, terete, pubescent, light green ; internodes 1-3 $\mathrm{cm}$. long, $1 \mathrm{~mm}$. thick.

Leaves compound, imparipinnate, cauline, alternate, stipulate, petiolate, alternately penninerved with ascending nerves, thin or membranous; leaflets entire, exstipellate; stipules herbaceous, generally broad at the base.

No. 1. Pinnately trifoliolate; leaflets $\cdot 5 \mathrm{~cm}$. long, $\cdot 25 \mathrm{~cm}$. broad, obcordate ; terminal one twice as large, obcordate; petiole slender.

No. 2. Similar or imparipinnate, like the rest.

Calophaca, sp. nov.

Hypocotyl erect, terete, glabrous, soon becoming woody, with a dry, white appearance, $2-3 \mathrm{~cm}$. above the soil, stout.

Cotyledons oblong, obtuse, falcate, with a shallow indentation or sinus on the contiguous sides, otherwise entire, petiolate, fleshy, with a few obscure, alternate, ascending nerves, deep opaque green above, lighter green beneath, glabrous, both rather conspicuously directed to one side of the plumule; lamina $1 \cdot 5-1 \cdot 7 \mathrm{~cm}$. long, $7 \cdot 5-$ $8.5 \mathrm{~mm}$. wide; petioles grooved above, convex on the back, glabrous, pale green, soon becoming pale or colourless, 4-5 mm. long.

Stem erect, terete, glandular-pubescent and hairy or villous, pale green, soon becoming woody and white; 1st internode $8 \mathrm{~mm}$. long ; 2nd about $.5 \mathrm{~mm}$.; $3 \mathrm{rd} 3.5 \mathrm{~mm}$.; 4 th $3.5-4 \mathrm{~mm}$.

Leaves compound, imparipinnate, cauline, alternate, stipulate, exstipellate, petiolate and shortly petiolulate, villous beneath and more or less dotted with sessile glands on the nerves, glaucous above 
paler beneath and glaucous; leaflets emarginate, with a tooth in the notch, or entire and cuspidate, with numerous alternate, ascending, pale-coloured nerves; stipules linear or linear-subulate, obtuse, acute, or acuminate, soft, pale green, glandular-pubescent and villous, fringed or ciliated with gland-tipped hairs, shortly adnate to the stem by one edge and also the base of the petiole, but mostly below the articulation; petioles terete, glandular-hairy and villous, tapering upwards from a stout articulated base.

Nos. 1-4. Pinnately trifoliolate; lateral leaflets narrowly obovate, obtuse, entire, minutely cuspidate; terminal leaflet larger and broader, obtuse or minutely cuspidate; all very shortly petiolulate.

Nos. 5-7. Pinnately five-foliolate; leaflets obovate, cuspidate or emarginate, with a tooth in the notch ; terminal one largest.

\section{Caragana arborescens, Lam.}

Fruit a legume, cylindrical, sessile, terete or turgid, glabrous, pale green, or straw-coloured when mature, dehiscing elastically along both sutures and twisting longitudinally, glabrous internally; seeds many, or few by abortion.

Seed transversely oblong, rounded and obtuse at both ends, glabrous, shining, pale yellow; testa coriaceous; micropyle and hilum contiguous on the ventral aspect above the middle; raphe elongated, forming a deep green line; chalaza at the lower end very conspicuous and prominent in the young growing seed, but shrinking considerably and distinguishable in the mature seed by a dark spot.

Endosperm absent.

Embryo large and occupying the whole interior of the seed, green when mature; cotyledons oblong or oval in outline, plano-convex, and usually, if not always, unequal, and, together with the radicle, conforming in outline to the interior of the seed, entire at the apex, not auricled, but variously indented or impressed by the radicle according to its position, lying in the slightly broader plane of the seed, which is influenced by the shape of the legume, with their edges directly or obliquely to the placenta; radicle very short, obtuse, compressed or subterete according to position, accumbent or obliquely or wholly incumbent, very much shorter than the cotyledons, and only reaching from their upper and basal end to the micropyle near the upper end of the ventral aspect of the seed.

The different positions of the radicle are apparently due to there being no defined and allotted space for it; it is accommodated merely by being squeezed against the edges of both 
cotyledons, or the edge or the back of one, which is impressed by its outline accordingly.

\section{Astragalus thianschanicus, Regel (fig. 278).}

Primary root tapering downwards, flexuous, furnished with short lateral rootlets, and producing more or less numerous sessile, fleshy, tubercules; sometimes the primary root is overpowered by strong lateral rootlets.

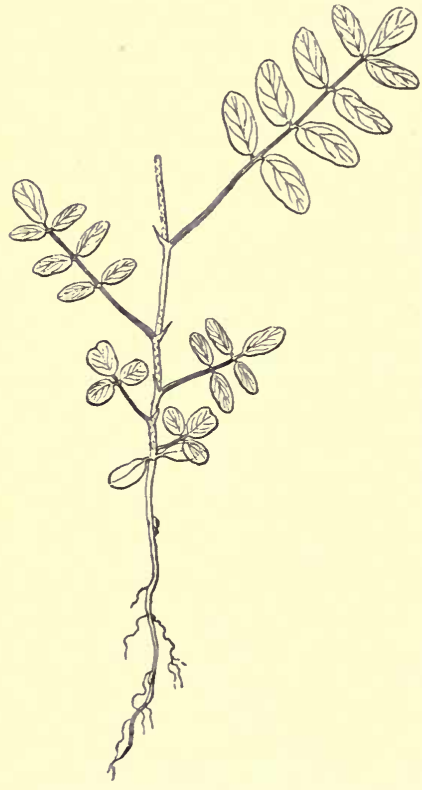

Fig. 278.-Astragalus thianschanicus. Half nat. size.

Hypocotyl erect, terete, glabrous, subterranean, colourless, $1 \cdot 75 \mathrm{~cm}$. long.

Cotyledons obliquely obovate, obtuse, glabrous, petiolate, subfleshy, deep subglaucous-green above, paler beneath; lamina 9 $\mathrm{mm}$. long, $5 \mathrm{~mm}$. broad; petiole subchannelled above, $3.5 \mathrm{~mm}$. long, connate at the base and sheathing.

Stem erect or ascending, herbaceous, terete at the base, angular upwards, covered with a pale adpressed pubescence, ultimately glabrous or nearly so, and shining; 1st internode $1.5 \mathrm{~mm}$. long, sometimes longer ; 2nd $7 \mathrm{~mm}$.; 3 rd $6.5 \mathrm{~mm}$.; 4 th $1.2 \mathrm{~cm}$.; 5 th 2.15 cm.; 6 th $3.2 \mathrm{~cm}$.; 7 th $2 \cdot 7 \mathrm{~cm}$.

Leaves compound, imparipinnate, cauline, alternate, stipulate, petiolate, deep subglaucous-green and glabrous above, glaucous beneath and thinly pubescent with adpressed hairs; petioles subterete, slightly channelled on the upper surface, pubescent, as well as the rachis ; stipules subulate, acuminate, slender, hyaline, with a few scattered hairs, connate by their posterior edges, and forming a kind of sheath opposite to the leaf in the seedling stage, sometimes, though rarely, splitting apart in the adult plant; leaflets petiolulate. 
No. 1. Trifoliolate; lateral leaflets broadly oval, rounded at both ends ; terminal leaflet broadly oblong-obovate, emarginate.

No. 2. Sometimes trifoliolate, at other times five-foliolate.

No. 3. Five- or seven-foliolate; leaflets broadly oblong, obtuse, sometimes minutely apiculate; terminal one largest.

No. 4. Seven-foliolate.

No. 5. Nine-foliolate; leaflets oblong, obtuse, subcordate at the base; terminal leaflets broadest above the middle.

No. 6. Nine-foliolate.

No. 7. Fifteen-foliolate; leaflets oblong, obtuse, apiculate, subcordate at the base; those on the middle of the leaf largest.

No. 8. Seventeen-foliolate.

No. 9. Seventeen-foliolate.

Ultimate leaves with twenty-one to twenty-nine or more leaflets, which are oblong-lanceolate, minutely cuspidate, petiolulate, penninerved with alternate ascending nerves, deep green and glabrous above, glaucous and slightly pubescent with adpressed hairs beneath.

\section{Astragalus sulcatus, $L$.}

Primary root tapering, flexuose, reddish, giving off fleshy, colourless lateral rootlets, which soon become stouter than the primary one.

Hypocotyl wiry, terete, 2-6 $\mathrm{mm}$. long.

Cotyledons oblong, obtuse, fleshy, most frequently oblique or falcate.

Stem undeveloped.

Leaves simple and compound, radical when described, alternate, somewhat silky with long whitish hairs, especially when young.

No. 1. Digitately trifoliolate; leaflets oval-the terminal one largest and emarginate; petiole subterete, channelled above, hairy ; petiolules $.5 \mathrm{~mm}$. long; stipules ovate or oblong, obtuse, hairy.

No. 2. Most frequently with the terminal leaflet only.

No. 3. Similar or digitately trifoliolate.

Intermediate forms are pinnately three- to five-foliolate ; terminal leaflet obovate or oblong, emarginate ; lateral leaflets obovate-oblong or oval, emarginate.

Ultimate leaves with many pairs of opposite (rarely alternate), linear-lanceolate, obtuse, emarginate, shortly petiolulate leaflets, glabrous, deep green; stipules subulate, acute, thinly pubescent, small. 


\section{Tribe Hedysarea.}

\section{Scorpiurus sulcata, $L$.}

Primary root tapering downwards, with a few lateral rootlets.

Hypocotyl erect, terete, glabrous, about 1-1.25 mm. long, colourless below ground, yellowish-green above.

Cotyledons cylindrical, fleshy, from 4-4.5 mm. long, with a deep longitudinal furrow on the upper side, obtuse at the apex, dark green, one-nerved.

First leaves arising immediately between the cotyledons, oval or slightly obcordate, tapering to the base or subpetiolate, entire, subacute, with a few minute hairs on the edges, reticulate, dark green.

\section{Coronilla juncea, $L$.}

Hypocotyl erect, terete, glabrous, 1-2.2 cm. long, pale green or almost colourless.

Cotyledons fleshy, entire, obovate-oblong, petiolate, obtuse, glaucous-green, glabrous, indistinctly one-nerved.

Stem erect, terete, herbaceous, glabrous ; 1 st internode 3-4 mm. long; 2nd considerably shorter.

Leaves cauline, alternate.

No. 1. Simple, obovate, emarginate, obtuse, petiolate, stipulate, glabrous, light green, pinnatinerved.

No. 2. Compound, digitately trifoliolate; leaflets oblong or slightly obovate, obtuse or sometimes subacute, opposite, sessile; sometimes the first leaf is similar to the second.

\section{Ornithopus repandus, Lam.}

Primary root annual, long, slender, thread-like, with a few lateral rootlets, and numerous ovoid, fleshy tubercles.

Hypocotyl tapering downwards, terete, glabrous, colourless at base and brownish upwards, $2 \mathrm{~cm}$. long.

Cotyledons foliaceous, fleshy, spathulate, oblong, obtuse, tapering into a short petiole, glabrous, deep green, $2.7 \mathrm{~cm}$. long including the short petiole, $8 \mathrm{~mm}$. broad.

Stem annual, slender, erect (at least when young), terete, glabrous, pale green; 1st internode $2 \cdot 2 \mathrm{~cm}$. long; 2nd $1.3 \mathrm{~cm}$.

Leaves compound, digitately trifoliolate (first leaf unifoliolate), cauline, alternate, stipulate, sessile, glabrous, deep subglaucous-green, 
succulent; stipules subulate, subacute, connate two-thirds of their length on the side of the stem opposite to the leaf.

No. 1. Oblong, obtuse, entire, minutely apiculate, $2.4 \mathrm{~cm}$. long, $1 \cdot 2 \mathrm{~cm}$. broad.

No. 2. Digitately trifoliolate; lateral leaflets sessile, rotund, minutely apiculate, $3 \mathrm{~mm}$. long, $4 \mathrm{~mm}$. broad ; terminal leaflet large, rotund, elliptic, obtuse, $1 \cdot 8 \mathrm{~cm}$. long, $1 \cdot 4 \mathrm{~cm}$. broad.

Branches from axils of cotyledons similar to the stem; 1st and 2nd leaves also precisely the same.

Hedysarum denticulatum, Regel (fig. 279).

Fig. 1 shows the embryo germinating and splitting open the pericarp of a segment of the fruit. The radicle has pierced the lower valve of the pericarp.

Fig. 2. A case in which two segments have remained united. One embryo is dead; the other has forced open the pericarp of both
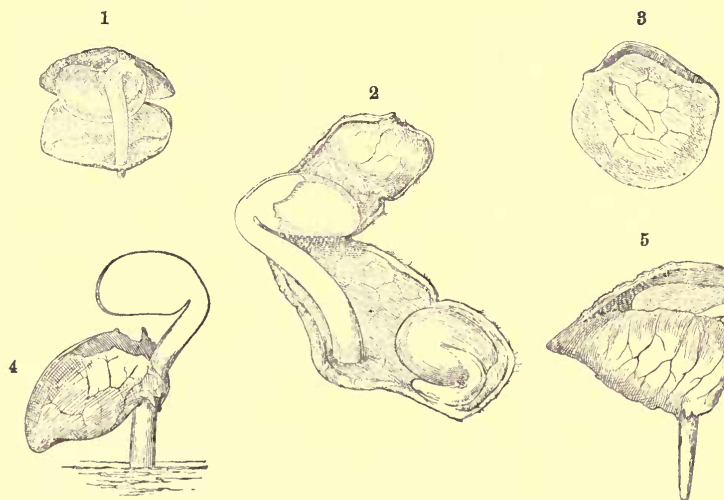

Fic. 279.-Hedysarum denticulatum, $\times 2 \frac{1}{2}$.

segments, and its radicle has pierced the lower valve, a frequent occurrence.

Fig. 3. Another segment of the fruit where the radicle has already advanced considerably through the wall ; the two halves of the fruit have just commenced to split open.

Fig. 4. Another mode of germination similar to what occurs in 
$\mathrm{H}$. coronarium, the radicle emerging at one side of the fruit and the cotyledons at the other; cotyledons at this stage oblong, obtuse, entire. One day after germination.

Fig. 5 shows the ragged margin of the fissure made by the radicle through the walls of the fruit during germination.

Hedysarum coronarium, L. (fig. 280).

Legume linear or oblong-linear, much compressed laterally, constricted between each seed, and consequently moniliform, covered all over with short, stout, straight or hooked bristles, and having the edges of both ventral and dorsal sutures produced into revolute or hooked teeth, many-celled by the constrictions between each seed, and falling into separate, indehiscent pieces each containing a seed.
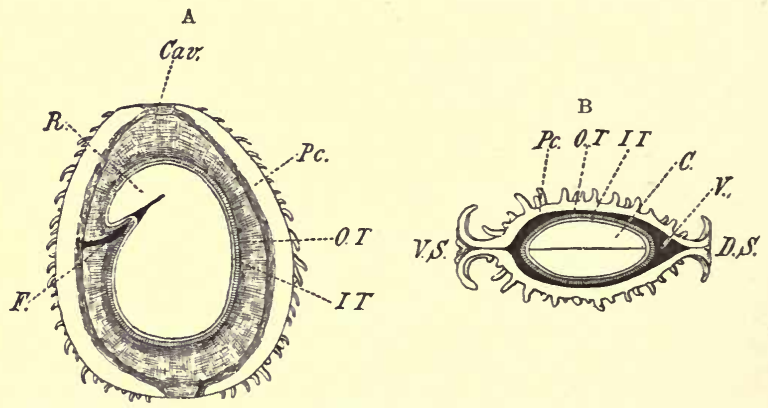

Fra. 280.-Hedysarum coronarium, $\times 6$. A, longitudinal section of seed: Cav, cavity of the legume, and the only part where the internal cavity is nearly but not quite continuous; $P c$, pericarp; $O T$, testa; $I T$, tegmen; $R$, radicle; $F$, funicle. $B$, transverse section of seed: $\nabla S$, ventral suture; $D S$, dorsal suture; $P c$, pericarp; $O T$, testa; $I T$, tegmen; $C$, cotyledon; $\nabla$, empty space.

Seed reniform, somewhat laterally compressed in conformity with the interior of the segment of the fruit, thicker in the middle than at the sides and in transverse section accordingly elliptic, glabrous, obtuse at either end, pale yellow; testa pale brownishyellow, rather thin, closely applied to the tegmen and embryo ; tegmen thin, membranous, paler; hilum small, annular, situated in a small sinus formed by the curvature of the ovule about the middle of the ventral edge of the seed; micropyle and chalaza contiguous to, and on each side of, the hilum, with the former on the upper side, that is towards the apex of the ovary.

Endosperm absent. 
Embryo transverse to the placenta, large and completely filling the seed, curved, pale yellow; cotyledons more or less distinctly obovate in outline, sessile, plano-convex, rounded at the apex, somewhat tapered towards the base, lying in the broader plane of the seed, with their edges to the placenta; radicle about half as long as the cotyledons, oblong, obtusely pointed at the upper end of the seed and consequently superior, but again curved downwards to the micropyle close to the hilum.

Seedling (fig. 281).

Primary root long, flesliy, tapering slightly downwards, colourless, with a few lateral rootletsat irregular intervals.

Hypocotyl very short or soon indistinguishable from the root, emerging between the valves of the fruit, which remain attached to it long after germination.

Cotyledons oblique, broadly rotund-obovate, entire, fleshy, convex above, subrevolute at the margins, sessile, perfoliate at the base, forming a short turbinate tube, alternately penninerved with few incurved nerves, cartilaginous and subscabrousat the margin, $1-1 \cdot 2 \mathrm{~cm}$. long, $1-1 \cdot 2$ or $1.3 \mathrm{~cm}$. broad.

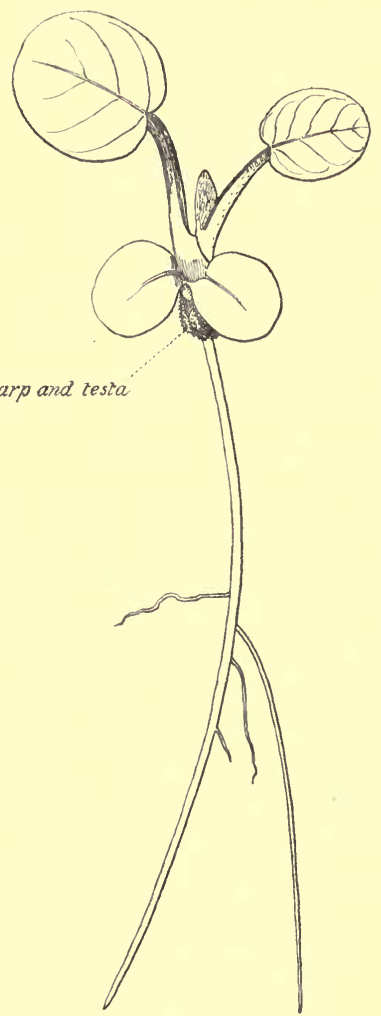

FIG. 281.-Hedysarum coronarium. Nat. size.

Stem herbaceous, elongated when about to flower, arising from a perennial rootstock.

Leaves compound, radical and cauline, alternate, stipulate, petiolate (leaflets petiolulate, exstipellate), alternately and incurvi- 
penninerved, with the tips recurved and uniting, each with the one above it, glabrous and deep glaucous-green above, cartilaginous and ciliate at the margin, hairy beneath with adpressed hairs and paler ; petioles channelled above, dilated at the base, hairy with adpressed hairs, semiterete in the seedling, angled and striate in the adult leaf; stipules scarious, adnate by one edge to the petiole, free only at the apex in the seedling stage, but having a subulate-ovate, acuminate free part in the adult plant, and one- to three-nerved or more.

No. 1. Orbicular, slightly cordate at the base, otherwise entire.

No. 2. Rotund-oblong, emarginate, cordate at the base.

No. 3. Broadly oval-oblong, cordate at the base, emarginate at the apex.

No.4. Pinnately three- to five-foliolate; leaflets broadly oval or oblong-oval, slightly emarginate at the apex, terminal one the largest.

Radical leaves on the adult plant simple and cordate-orbicular, or much more frequently imparipinnate, with cordate, minutely cuspidate, entire, alternate or opposite pinnules; terminal one largest.

\section{Hedysarum capitatum, Desf.}

Hypocotyl erect or decumbent, terete, glabrous, pale green mottled with crimson, $8 \mathrm{~mm}$. to $2 \mathrm{~cm}$. above ground and projecting between the valves of the prickly seed-pod, which is often borne up by it.

Cotyledons large, foliaceous, glabrous, subcoriaceous or fleshy, rising above ground, petiolate; lamina obliquely obovate, obtuse, obscurely trinerved or binerved, entire, $1.4 \mathrm{~cm}$. long, $1 \mathrm{~cm}$. broad ; petioles connate by their contiguous edges and lying to one side of the stem, broad, 2-4 mm. long.

Stem herbaceous, short, decumbent or suberect, pubescent, terete, slightly ridged, pale green, mottled with crimson; internodes irregular and frequently undeveloped.

Leaves compound, imparipinnate, cauline (at first appearing radical from the non-development of the internodes), alternate, stipulate, petiolate, glabrous above but pubescent or almost silky on the underside, and also on the rachis and petioles; petioles subterete, channelled above, dilated at the base ; stipules adnate to the petiole for one-half their length, with ovate-subulate, acuminate points, crimson; leaflets shortly petiolulate.

No. 1. Five-foliolate; leaflets oblong, obtuse, apiculate, opposite.

No. 2. Seven-foliolate; leaflets opposite, oblong-oval, obtuse, apiculate.

No. 3. Ten-foliolate; leaflets alternate; lower obovate, small; upper larger, oblong, obtuse, apiculate. 
No. 4. Thirteen-foliolate; leaflets opposite, oval, obtuse, apiculate.

No. 5. Fifteen-foliolate, otherwise like the last.

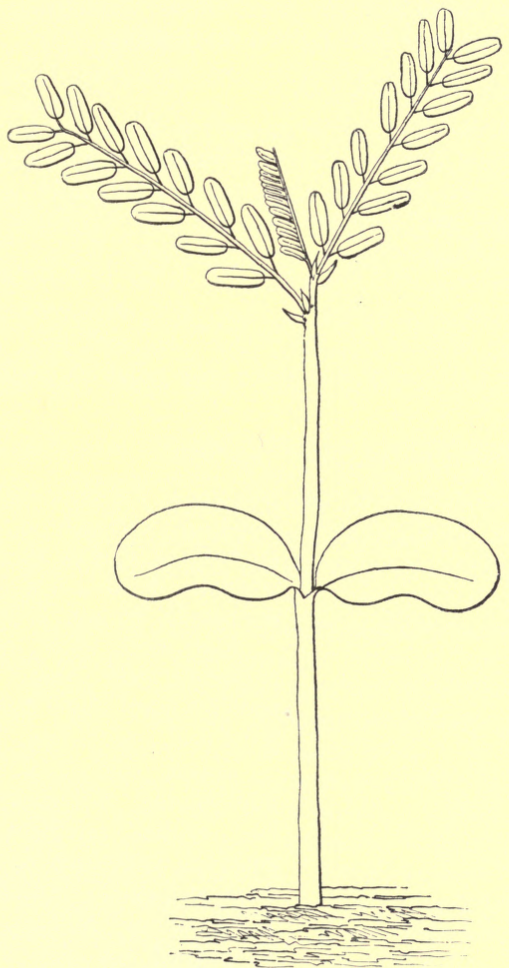

FIG. 282.-Aschynomene aspera, $\times 2$.

Æschynomene aspera, L. (fig. 282).

Hypocotyl erect, terete, glabrous, $1 \cdot 5-2 \mathrm{~cm}$. long light green or colourless.

Cotyledons oblong, falcate, obtuse, fleshy, sessile, glabrous, light green, one-nerved. 
Stem erect, terete, herbaceous, ultimately woody, light green, glabrous.

First leaves compound, abruptly pinnate, petiolate, alternate, stipulate; leaflets entire, oblong, obtuse, shortly petiolulate, opposite, from seven to nine in number; stipules ovate-subulate, acute, rather broad at the base and tapering to a sharp point.

\section{Desmodium canadense, $D C$.}

Germination.-The radicle emerges at the dorsal suture of the fruit, or breaks through the side walls. It fixes itself in the ground, and the lengthening hypocotyl generally carries the lomentum and seed up with it. All the coverings, however, finally drop off, leaving the seedling free. Where the radicle pierces the sides of the lomentum the latter is fixed to the soil. The cotyledons on becoming free are ovate-oblong, obtuse, subfalcate, or rounded on the upper edge and with a shallow sinus on the lower edge, subfleshy, pale yellowish-green, shining, glabrous.

Lourea Vespertilionis, Desv. (fig. 283).

Hypocotyl terete, pubescent, pale green, 2-4 mm. above soil.

Cotyledons shortly oblong, falcate, or subreniform, pubescent

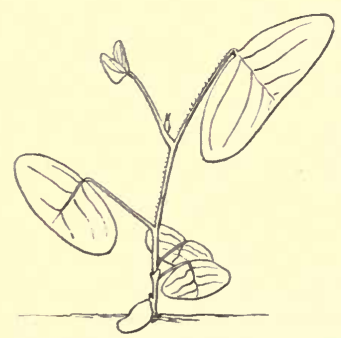

Fig. 283.-Lourea Vespertilionis. Nat. size. on both sides, pale green, shortly petiolate, $6 \mathrm{~mm}$. long including the petiole, $3.5 \mathrm{~mm}$. broad.

Stem erect, terete, herbaceous, pubescent, pale green; 1 st intersnode $2.5 \mathrm{~mm}$. long; 2nd $1.5 \mathrm{~mm}$.; 3rd $4 \mathrm{~mm}$.; 4 th $9 \mathrm{~mm}$.

Leaves compound (first ones unifoliolate, ultimately trifoliolate), cauline, alternate, stipulate, petiolate, pubescent on both surfaces and ciliate; petioles slender subterete or filiform, shallowly channelled on the upper side, pubescent, pale green; stipules subulate, acute, hairy; secondary stipules small,-subulate, acute, pubescent.

Nos. 1-5. Unifoliolate; 1st leaflet transversely oval, penninerved, $4 \mathrm{~mm}$. long, $1 \mathrm{~cm}$. broad.

No. 2. Transversely oblong, penninerved and closely reticulate with reddish veins.

Nos. 3 and 4. Similar but larger, pendent from an ascending 
petiole, with a rather stout pulvinus ; leaflet of No. $4,9.5 \mathrm{~mm}$. long, $2.65 \mathrm{~cm}$. broad.

Ultimate leaves uni- or tri-foliolate; terminal leaflet very broad and short, apiculate, falcate, trinerved and reticulate, bronze-green suffused with red and white along the principal nerves, thinly pubescent on both surfaces and covered with minute hooked hairs; lateral leaflets small, most frequently absent, their stipules being present or absent.

\section{Lespedeza angustifolia, Ell.}

Hypocotyl terete, pubescent, very short.

Cotyledons oblong, obtuse, fleshy, subfalcate, turned to one side, faintly trinerved, densely pubescent, sessile, $6 \mathrm{~mm}$. long, $4.25 \mathrm{~mm}$. road.

Stem herbaceous, ultimately shrubby, erect, terete, pale green, ultimately reddish or brown, densely covered with patent hairs; 1 st internode $4.5 \mathrm{~mm}$. long; 2nd $7 \mathrm{~mm}$.; 3rd $1.5 \mathrm{~cm}$.; 4 th $2.9 \mathrm{~cm}$.; 5 th $1.8 \mathrm{~cm}$.

Leaves compound, pinnately trifoliolate (1st unifoliolate), cauline, alternate, stipulate, petiolate, glabrous above, ciliate, thinly pubescent beneath; petioles slender, subterete, channelled above, hairy like the stem ; stipules free, slender, subulate, acute, hairy, scarious, brownish; leaflets petiolulate, having a pulvinus and folding downwards at night.

No. 1. Unifoliolate; leaflet rotund, emarginate, shortly petiolulate, minutely apiculate, deep green.

No. 2. Pinnately trifoliolate; terminal leaflet rotund-obovate, emarginate; lateral leaflets oblong-obovate, emarginate, much smaller than the terminal one-all deep green.

No. 3. Pinnately trifoliolate, deep green ; leaflets obovate, apiculate, more nearly equal than those of No. 2; rachis between the leaflets $1.5 \mathrm{~mm}$. long; nerves of leaflets ascending, parallel, slightly forking and anastomosing upwards; pulvini prominent.

No. 4. Pinnately trifoliolate, pale green (because very young); terminal leaflet obovate, apiculate; lateral leaflets oblong-obovate, apiculate; pulvini prominent.

\section{Tribe Vicie五.}

Lathyrus Nissolia, L. (fig. 284).

Primary root long, tapering, fleshy, colourless, with short, stout, fleshy lateral rootlets, and occasionally fleshy tubercles. 
Hypocotyl subterranean, fleshy, colourless, very short (about $1.75 \mathrm{~mm}$. long).

Cotyledons subterranean, plano-convex, fleshy, each occupying half the interior of the seed, unequal-sided, so that the petioles or point of attachment to the plumule are at one side, horizontal, rotund, about $2 \mathrm{~mm}$. in diameter, yellow and wrinkled after germination;

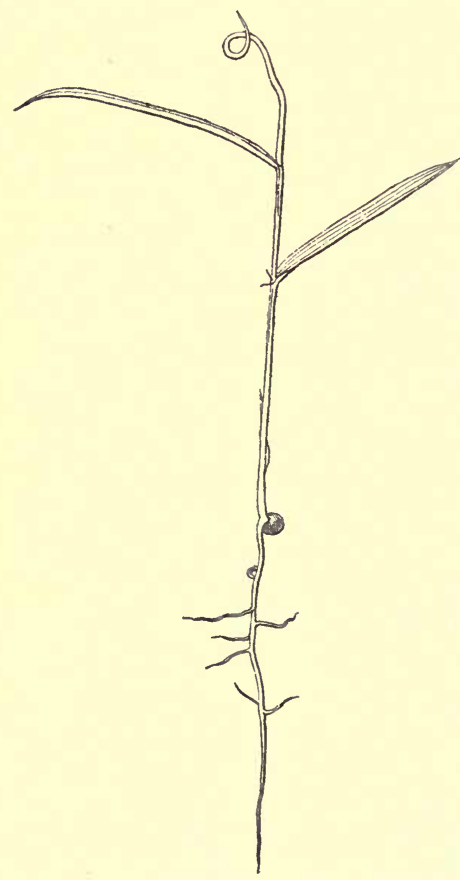

Frg. 284.-Lathyrus Nissolia. Nat. size.

petioles unequal or the lower one undeveloped, while the upper one is developed and curved just as much as will allow the cotyledons to lie horizontally. The cotyledons do sometimes stand vertically on their edges and then both petioles are equally developed.

Stem erect, but always hooked, curved or twisted at the tip, together with the youngest visible leaf, by which it hangs on to an object for support, with the internodes alternately flattened and angled on opposite sides, the angle running down the centre of the flattened face of the internode beneath it, pale green, glabrous; 1st internode $4.5 \mathrm{~mm}$. long; 2nd 7.5 mm.; 3rd 1.9 cm.; 4th $1.5 \mathrm{~cm}$.; 5 th $1.35 \mathrm{~cm}$.

Leaves simple, entire, cauline, alternate, distichous, stipulate, sessile and slightly decurrent, thinly and minutely ciliate at the margin, otherwise glabrous, light green; stipules small, subulate, acute, inserted where the leaf is free from the stem, except in the case of the first two scale-like leaves, where they are seated above the base, or may be altogether inconspicuous in the first.

Nos. 1 and 2. Small, subulate, acute, scale-like and adpressed to the stem, carinate. 
Nos. 3-6. Linear acute or acuminate, five-nerved, convolute at first and rolled round the growing point, gradually becoming nearly or quite flat.

\section{Lathyrus articulatus, $L$.}

Primary root very similar to that of L. Nissolia.

Hypocotyl undeveloped or scarcely elongated. solia.

Cotyledons rotund-obovate, very similar to those of $\mathrm{L}$. Nis-

Stem herbaceous, annual, erect, ultimately climbing by means of its leares, tetragonous at the base and narrowly winged upwards as in L. Nissolia, glabrous, pale glaucous-green; 1 st internode $9 \cdot 5$ mm. long; 2nd $1.35 \mathrm{~cm}$. ; 3rd $2.9 \mathrm{~cm}$.; 4 th $3.12 \mathrm{~cm}$.; 5 th $4.5 \mathrm{~cm}$.; the rest gradually longer.

Leaves very like those of L. Nissolia, glaucous, linear, acute, or afterwards acuminate and finally cirrhous at the apex, seven-nerved longitudinally (three strong and four intermediate nerves), slightly scabrous at the margin; stipules adnate to the sides of the leaves for some little distance above their insertion, with slender, subulate, free points, becoming triangular on the leaves a short way up the stem, and finally wholly adnate, obsolete, or inconspicuous.

No. 1. Subulate, acute, carinate, concave above, inconspicuously five-nerved.

No. 2. Ditto, but a little larger.

No. 3. Linear, acute, five-nerved.

No. 4. Linear, acuminate, trinerved with four intermediate, inconspicuous ones.

No. 5. Linear, produced at the apex into a short, simple cirrhus. Sometimes the 6 th is the first to attain this stage, which represents apparently the ultimate form of the leaf.

Lathyrus Aphaca, L. (fig. 285).

Primary root long, tapering, fleshy, with numerous fleshy or succulent tubercles, and long lateral rootlets.

Hypocotyl undeveloped.

Cotyledons subterranean, fleshy, persistent, plano-convex or almost hemispherical, very unequal-sided by the petioles being attached to one corner, mostly vertical during and after germination, rarely horizontal, yellowish-white, afterwards more yellow and wrinkled; lamina truncate, $4 \mathrm{~mm}$. long, $4.5 \mathrm{~mm}$. wide; petioles very short, developed equally when the cotyledons are vertical, but when these are horizontal one petiole becomes longer than the other to allow the upper cotyledon to assume this position. There are 
intermediate positions where the cotyledons are oblique, and one petiole becomes somewhat elongated accordingly.

Stem annual, erect, tetragonous, with obtuse angles, glabrous, a pale glaucous-green above ground, while the subterranean part is colourless; 1st internode subterranean or partly so, 1-2 cm. long ; 2nd 3.5-6 mm.; 3rd 7-10 mm.; the rest similarly short.

Leaves simple and compound, or reduced to scale-like organs or elongated, forming a slender, filiform, or obtusely-angled tendril, cauline, alternate, distichous, stipulate, petiolate or sessile, or reduced to a petiole, glabrous, glaucous-green ; petiole of third and fourth leaf convex on the back, channelled above, and projecting beyond, or

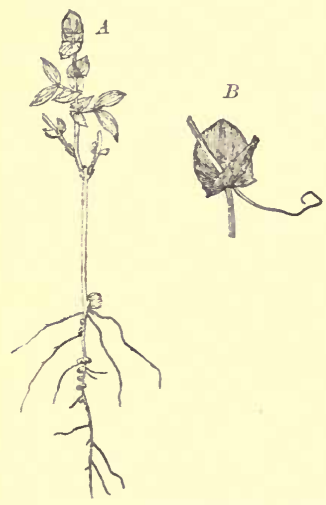

Fig. 285.-Lathyrus Aphaca. A, seedling; $B$, tendril and stipules from upper part of plant. Both half nat. size.

then somewhat invard, where rather between, the leaflets in the form of a small, subulate, acute point; stipules of the first and second leaf subulate, acute, attached by one side for about one-third their length to the leaf, entire or furnished with an acute, ascending tooth on the side away from the leaf - those of the third and fourth leaf half-ovate or sagittate, acuminate, with one to two acute teeth at the lower angle on the posterior side, entire on the anterior side-those of the rest of the leaves large, foliaceous, performing the functions of leaves, deltoid, subhastate, cuspidate or apiculate, with one to two minute teeth at the base on each side, otherwise entire, glaucous, furnished with numerous parallel nerves that are directed first outward from the base, and upward, then somewhat inward, where they unite with those immediately above them close to the margin, while the few lowest are directed into basal teeth or angles, and are entire or forked; a branch from the lowest curved nerve is frequently directed straight into the tooth.

Nos. 1 and 2. Subulate, acute, very small, and appearing trifid owing to the adnate and similar stipules.

Nos. 3 and 4. Compound, pinnate, with one pair of leaflets and a subulate point; leaflets oblong-elliptic, acute, trinerved longitudinally with smaller intermediate nerves, concave owing to the upcurved sides, entire, glaucous.

Immediately above this the leaves are reduced to small subulate points concealed by the foliaceous stipules. 
When the stem has attained some length the leaves on the upper part are developed into tendrils (fig. 285, $B$ ) as described above, and enable the plant to climb.

\section{Tribe Phaseolez.}

\section{Clitoria Ternatea, $L$.}

Fruit a legume, linear, compressed, more or less thickened at the sutures, dehiscing longitudinally by two valves, many-seeded.

Seed transversely oblong, rounded at either end, much compressed laterally, thicker along the ventral aspect, smooth, black, somewhat shining, minutely reticulate; hilum a little below the middle of the seed on the ventral aspect, forming a depression and partly overlying a thickened part of the testa corresponding to the chalaza ; micropyle contiguous to the hilum on the ventral aspect, inconspicuous ; raphe none.

Seed $7 \cdot 25 \mathrm{~mm}$. long, $4 \cdot 75 \mathrm{~mm}$. wide.

Endosperm absent.

Embryo curved, large, and occupying the whole interior of the seed to which it conforms, brownish-yellow ; cotyledons accumbent with their edges to the placenta, oblong, obtuse, entire, minutely and rather unequally auricled at the base, rather unequal-sided owing to the radicle and the thickening of the chalaza on the ventral aspect, closely applied face to face, thicker along the ventral than the dorsal aspect, equal in length to the interior of the seed ; radicle cylindrical, obtuse, curved round the ends and along the ventral aspect, partly beneath the edges of the cotyledons and having its tip slightly embedded in the micropyle.

In specimens examined the bases of the cotyledons were obliquely cut away owing to the curvature of the seed on the opposite side to that followed by the radicle, so that the auricles on that side were smaller than the others.

Seedling (fig. 286).

Hypocotyl 3 or $4 \mathrm{~cm}$. long, $1 \cdot 5-2 \mathrm{~mm}$. thick, terete, slightly pubescent, greyish-green, herbaceous.

Cotyledons nearly equal, shortly petioled, about $2 \mathrm{~cm}$. long, 1.25 $-1.5 \mathrm{~cm}$. broad, $1 \mathrm{~mm}$. thick, oblong, oblique at both ends, entire (one half of blade forming a sector or semicircle with the midrib as base, the other a very long, obtuse rectangle), obscurely penninerved, glabrous, fleshy, yellowish-green on the upper, whitish on the lower surface.

Stem herbaceous, nearly terete, pubescent, light green; internodes 1 or $2 \mathrm{~cm}$. long, 1-1.5 mm. thick.

Leaves.-Nos. 1 and 2. Opposite, $1.5 \mathrm{~cm}$. above the cotyledons 
and decussating with them, subsessile or shortly petiolate, stipulate, $2-3 \mathrm{~cm}$. long, about $1 \mathrm{~cm}$. broad, lanceolate, cuneate at base, ob-

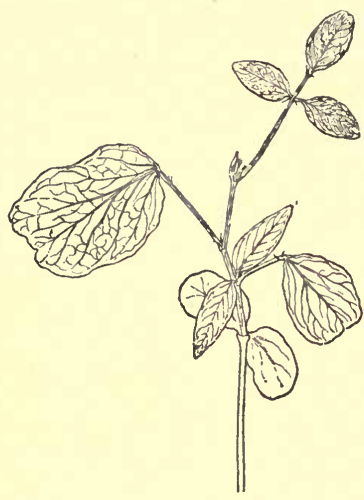

FIG, 286.-Clitoria Ternatea.

Half nat. size. tuse at the apex, entire, penninerved with sunk nerves, thin, pubescent, dark green above, dull green below; stipules setaceous.

No. 3. Inserted either at same level with Nos. 1 and 2 or $\cdot 5 \mathrm{~cm}$. above those, stipulate, long-petioled; blade sub-bilobed or more generally simple, $2-3 \mathrm{~cm}$. long, about $2 \mathrm{~cm}$. broad, palmatinerved, in nearly all cases showing more or less complete coalition of parenchyma between terminal and lateral leaflets, otherwise like Nos. 1 and 2 ; petiole 1 or $2 \mathrm{~cm}$. long, $1 \mathrm{~mm}$. thick, with a $2-3 \mathrm{~mm}$. long, thickened, semitransparent articulation at either end, and two setaceous stipules at the base,

somewhat channelled, pubescent.

No. 4. As No. 3, only two or three times larger ; or as No. 5 \&c., which are trifoliolate.

Sometimes only one of the lateral leaflets is free and the other united to the terminal one.

Erythrina suberosa, Roxb. (fig. 287).

Hypocotyl undeveloped, or subterranean, and very short.

Cotyledons fleshy and remaining in the oblong testa under the soil until they become exhausted.

Stem erect, stout, tapering upwards, pubescent with spreading or variously directed hairs, pale green, more or less warted or tuberculated from an early stage, with the brownish tubercules very small, soon becoming woody; 1st internode $3 \cdot 4-4 \cdot 2 \mathrm{~cm}$. long; 2nd $\cdot 8-1 \mathrm{~cm}$.

Leaves simple in the seedling state, cauline, alternate (1st and 2nd opposite), stipulate, petiolate, palmately five- to seven-nerved, or only the three primary and stronger nerves straight, while the others arise from their base, are more slender, and curve round in conformity with the broad, rounded auricles, much reticulate, pubescent on both surfaces, light green above, with somewhat prominent nerves, paler beneath with much more prominent nerves; petioles 
terete, slightly thickened at the apex under the leaf without any pulvinus, much thickened at its union with the stem; stipules slender, linear-subulate, acute, pale green, hairy, soon becoming brown and falling away early.

Nos. 1 and 2. Opposite, trilobed, with deltoid, acute, or subacute lobes, cordate at the base; middle lobe much the largest.

Nos. 3 and 4. Alternate, simple, much larger, trilobate, cordate at the base, strongly five-nerved; middle lobe somewhat constricted at the base making it rotund, cuspidately acuminate, sometimes

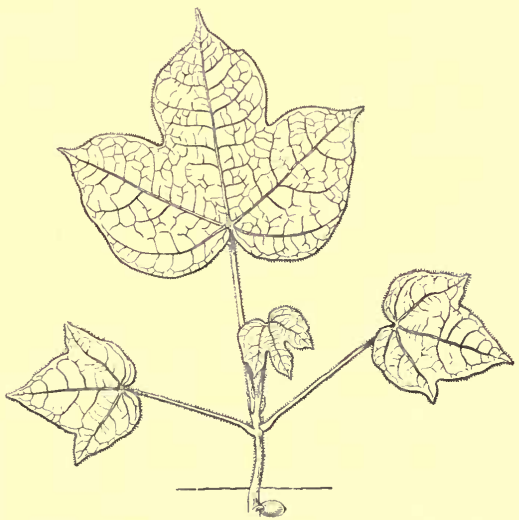

Fig. 287.-Erythrina suberosa. One-fourth nat. size.

showing an obtuse, small, or obsolete tooth on each side; lateral lobes triangular, cuspidately acuminate, with sometimes a small lateral tooth.

\section{Erythrina Vespertilio, Benth.}

Hypocotyl and cotyledons as in E. suberosa.

Stem soft and succulent, rather thin, erect, terete, glabrous, pale green; 1st internode $10 \mathrm{~cm}$. long; 2nd 1.8 cm.; 3rd $5 \mathrm{~mm} . ; 4$ th $4 \mathrm{~mm}$.

Leaves compound, alternate (first four simple, two opposite), glabrous, or pubescent in a very young state, pale green.

Nos. 1-4. Broadly deltoid, cuspidate, obtuse, entire, penninerved, glabrous; stipules ovate, acute, subserrulate; petioles terete, pale green, striped with darker green, glabrous, $1 \cdot 5-1 \cdot 8 \mathrm{~cm}$. long; 
secondary stipules minute, glandular; pulvinus cylindrical, $3 \mathrm{~mm}$. long.

No. 5. Compound, alternate, pinnately trifoliolate ; lateral leaflets rhomboid, acute, petiolulate ; terminal leaflet larger and more acuminate ; petiolules about $1.5 \mathrm{~mm}$. long ; rachis between the leaflets $7 \mathrm{~mm}$. long.

\section{Erythrina monosperma, Lam.}

Hypocotyl erect, terete, stout, woody, pale green, $7 \cdot 8 \mathrm{~cm}$. long, and $1 \mathrm{~cm}$. thick.

Cotyledons oblong, obtuse, thick, fleshy, flat or slightly concave above, convex beneath, pale yellow, $2 \mathrm{~cm}$. long, $1 \mathrm{~cm}$. broad.

Stem woody, erect, thick, tapering upwards, pubescent when young, pale green; 1 st internode $6.5 \mathrm{~cm}$. long; 2 nd $2.5 \mathrm{~cm}$. with a few small spines, as have also those above it; $3 \mathrm{rd} 1.35 \mathrm{~cm}$. long; 4th $8 \mathrm{~mm}$.

Leaves cauline, compound, alternate (first two simple and opposite) ; petiole terete, much thickened at the point of insertion, pubescent with brownish, stellately branching hairs; stipules slender, subulate, acute, pubescent.

Nos. 1 and 2. Simple, opposite, entire, rotund-cordate, obtuse or emarginate with a minute tooth in the notch, penninerved and reticulate, glabrous above, pubescent on the nerves beneath (at least when young), deep green above, paler beneath.

No. 3 and succeeding. Pinnately trifoliolate; lateral leaflets triangularly ovate, obtuse, frequently subcordate at the base, penninerved and reticulate, glabrous above, stellately pubescent on the nerves beneath, petiolulate; petiolule stout, cylindrical, covered with a stellately branched pubescence, $5 \mathrm{~mm}$. long; terminal leaflet reniform obtuse, often subcuspidate, entire, truncate at the base, otherwise like the lateral ones; rachis between the leaflets $1.9 \mathrm{~cm}$. long; petiole as in Nos. 1 and 2.

\section{Pueraria Thunbergiana, Benth. (fig. 288).}

Hypocotyl ascending or suberect, terete, pubescent, pale green, $1.2 \mathrm{~cm}$. long.

Cotyledons thick and rather succulent, oblong, obtuse, shortly petiolate, glabrous, pale green, $1 \cdot 5 \mathrm{~cm}$. long including petiole, $8 \mathrm{~mm}$. broad.

Stem succulent and tender, terete, zigzag or flexuous, hirsute, pale green; 1 st internode $2 \mathrm{~mm}$. long; 2nd $4 \mathrm{~mm}$.; 3rd $4 \mathrm{~mm}$.

Leaves cauline, compound, alternate (first pair simple and opposite), stipulate, petiolate. 
Nos. 1 and 2. Subrhomboid-rotund, obtuse, apiculate, penninerved, pubescent on both surfaces; petiole subterete, channelled above, hirsute, articulate at the base and apex, $1.8 \mathrm{~cm}$. long; stipules slender, subulate, acute, hirsute.

No. 3. Pinnately trifoliolate; lateral leaflets obliquely subelliptic, acute, irregularly penninerred, pubescent on both surfaces, entire; terminal leaflet rotund-elliptic acute, subtrinerved at the base, and penninerved upwards, pubescent on both surfaces, entire, petiolulate as are the lateral leaflets; petiolules about $1 \mathrm{~mm}$. long; rachis

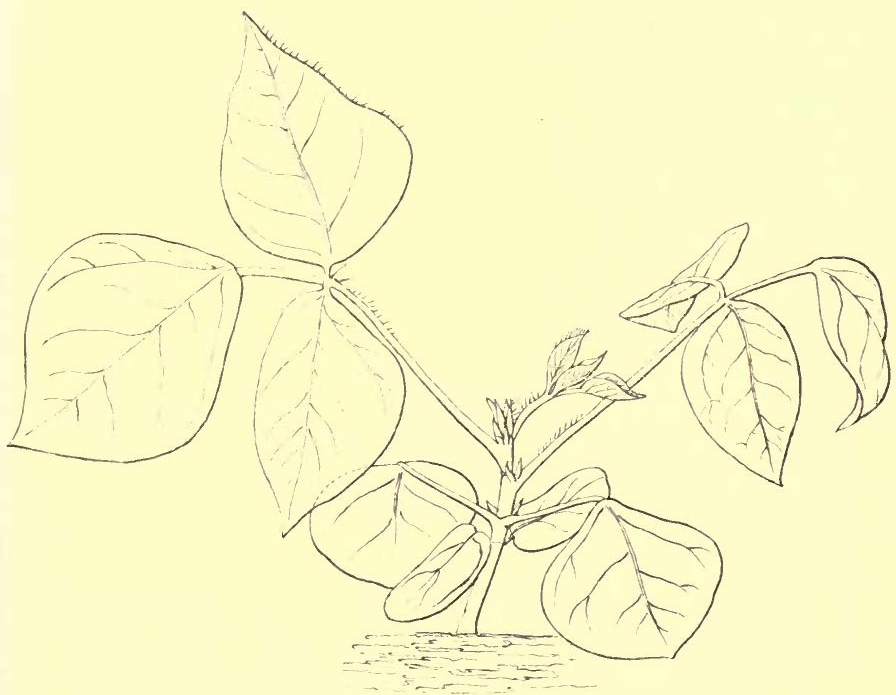

Fig. 288.-Pueraria Thunbergiana, Nat. size.

between the leaflets $8.5 \mathrm{~mm}$. long; petiole subterete, channelled above, hirsute, much thickened at the base, $3 \cdot 7 \mathrm{~cm}$. long.

No. 4. Similar to No. 3 but larger; leaflets stipellate, stipellæ filiform, slender, hirsute, deciduous; lateral leaflets very oblique with a strong nerve running into the oblique side.

Ultimate leaves large, pinnately ternate; terminal leaflet elliptic, cuspidate, acute, rounded at the base; lateral leaflets very ob. lique on the posterior side where a large nerve enters from the base of the leaflet. 
Phaseolus multiflorus, Willd. (fig. 289).

Fruit a legume, linear, laterally compressed, many-seeded, dehiscing along both sutures.

Seed transversely oblong, with unequal ends (the larger containing the apical ends of the cotyledons), much compressed laterally

A

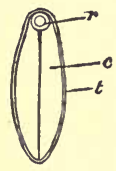

B

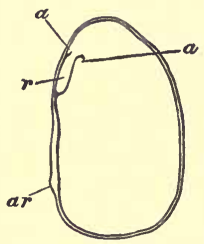

FIG. 289.-Phaseolus multiflorus. A, longitudinal section of seed through the cotyledons: $r$, radicle; $c$, cotyledon; $t$, testa. $\mathrm{B}$, longitudinal section of seed in plane of cotyledons, without removing a cotyledon: $a$, auricles of cotyledons; $r$, radicle; $a r$, minute arilloid. Three-quarters nat. size. but convex on both surfaces, smooth, shining, with black markings on a pink ground especially conspicuous towards the hilum, with two minute arilloid processes near the hilum on the ventral edge ; hilum oblonglinear, pale-coloured, near the middle of the ventral edge; micropyle rather conspicuous, near one end of the hilum.

Endosperm absent.

Embryo very large, curved, conforming in outline to that of the seed, pale creamy white; cotyledons large, fleshy, obovate

and plano-convex, or subconcave on the inner contiguous faces when dry, forming a hollow between them; radicle stout, tapering to an obtuse point, and curved round towards the micropyle, protruded from and accumbent to the cotyledons; plumule large and well developed, lying between the cotyledons.

\section{Phaseolus vulgaris, $L$., var. (fig. 290).}

Primary root tapering, flexuose, abundantly furnished with lateral rootlets, rather fleshy, colourless, annual.

Hypocotyl stout, fleshy, terete, pubescent, rooting at the base and suddenly narrowed into the root, $7 \mathrm{~cm}$. long, $4.5 \mathrm{~mm}$. thick.

Cotyledons carried above ground by the hypocotyl, fleshy, oblong, obtuse, falcate, turned to one side of the stem, longitudinally wrinkled, pale green, thick, never foliaceous.

Stem herbaceous, erect, subterete or slightly ridged by lines decurrent from the base of the petioles, pubescent; 1st internode $2 \cdot 4 \mathrm{~cm}$. long.

Leaves compound, pinnately trifoliolate (first pair opposite and unifoliolate), cauline, alternate, stipulate, petiolate, pubescent, petioles subterete, pubescent, channelled on the upper side, pale green; stipules lanceolate, acute, entire (those of the primary and 
opposite leaves interpetiolar and connate into a subulate acute, entire or bifid piece).

Nos. 1 and 2. Opposite, unifoliolate; leaflets subtriangular, obtuse, strongly five-nerved and reticulate, with a large wide open sinus at the base; nerves ascending and incurved, the basal ones branching into the auricles.

No. 2. Alternate, pinnately trifoliolate; leaflets stipellate.

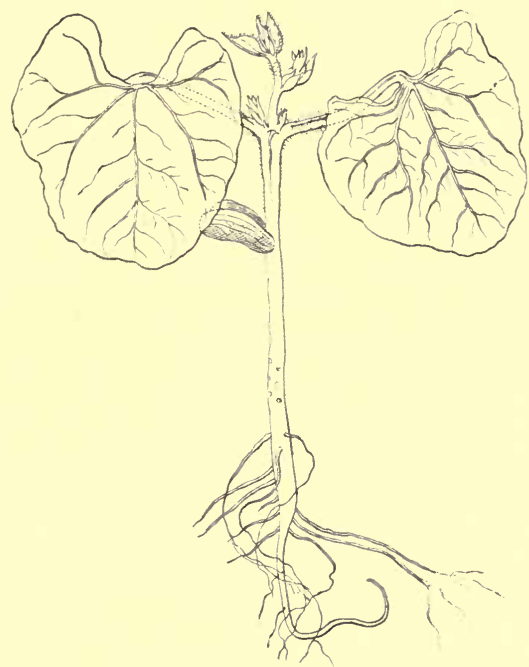

FIG. 290.-Phaseolus vulgaris, var. Half nat. size.

Vigna lutea, A. Gray.

Hypocotyl none.

Cotyledons subterranean.

Stem erect, terete below, then angled from the leaf-base downward with three decurrent nerves, pale green, frequently suffused with purple; 1 st internode $5.5 \mathrm{~cm}$. long; 2 nd $4 \mathrm{~mm}$.

Leaves cauline, compound, alternate (Nos. 1 and 2 simple and opposite), stipulate, petiolate, glabrous or with a few scattered adpressed hairs underneath when young, pale green and shining.

Nos. 1 and 2. Ovate, acute, entire, subcordate and trinerved at the base, reticulate; petiole flattened and pubescent above, 
$4 \mathrm{~mm}$. long ; stipules of first pair interpetiolar and connate, ovate, acute, entire or emarginate.

No. 3. Pinnately trifoliolate; leaflets ovate, acute, or apiculate, petiolulate, stipellate; petiolules $2 \mathrm{~mm}$. long; stipellæ small, ovate, acute; stipules triangularly ovate, acute, subauricled at the base; petiole angled, channelled above, $2 \mathrm{~cm}$. long.

Ultimate leaves pinnately trifoliolate, leaflets oblong-ovate or oval, obtuse, apiculate, entire, terminal one generally somewhat the largest.

\section{Vigna vexillata, Benth.}

Hypocotyl and cotyledons as in V. lutea.

Stem herbaceous, terete and striate or shallowly furrowed, pubescent, erect at first, climbing above the third internode ; 1st internode $6 \mathrm{~cm}$. long; 2nd $1.9 \mathrm{~cm}$.; 3rd $2.7 \mathrm{~cm}$. ; 4 th and others climbing or rather twining from right to left.

Leaves cauline, compound, alternate (first two simple, opposite); petiole subterete, channelled above, pubescent; stipules short, ovate, acute, subauricled at the base, pubescent.

Nos. 1 and 2. Lanceolate, acute, entire, penninerved, pubescent on both surfaces, caducous; petiole about $2 \mathrm{~mm}$. long; stipules interpetiolar, subulate, connate into one.

No. 3 and succeeding leaves. Pinnately trifoliolate; leaflets about equal, lanceolate, acute, penninerved, pubescent on both surfaces; petiole subterete, channelled above, pubescent; rachis between leaflets $3.5 \mathrm{~mm}$. long ; secondary stipules minute, subulate, acute.

\section{Pachyrhizus angulatus, Rich.}

Primary root tuberous; lower part tapering and giving off lateral rootlets.

Hypocotyl undeveloped, or subterranean.

Cotyledons reniform, subterranean, conforming to the shape of the seed.

Stem annual, twining against the sun, terete, striate, covered with an adpressed pubescence, green ; 1st internode about $3.5 \mathrm{~cm}$. long ; 2nd when developed, 1-9 mm.; 3rd 1.5-3.5 mm., commencing to twine and lengthening.

Leaves cauline, compound, alternate (first and second frequently opposite, always simple), stipulate, petiolate.

Nos. 1 and 2. Simple, opposite or alternate; petiole subterete, channelled on the upper side, pubescent; stipules and stipellæ 
subulate, slender; lamina triangular, cuspidate, truncate at the base, five-nerved, sparsely pubescent on both sides; nerves incurved.

No. 3. Pinnately trifoliolate, silky when young; lateral leaflets ovate, acuminate, entire ; terminal leaflet triangularly ovate, entire or with one or two teeth.

Ultimate leaves pinnately trifoliolate; lateral leaflets very obliquely triangular acuminate, entire, angled, or toothed on the posterior, oblique side; terminal one very broadly deltoid, suddenly acuminate, entire, or angled at the sides, or trifid and toothed.

Atylosia Candollei, W. et Arn. (fig. 291).

Primary root vertical, firm, long, with a few lateral fibres.

Hypocotyl undeveloped.

Cotyledons subterranean, minute, 4 $\mathrm{mm}$. long, $2 \mathrm{~mm}$. broad, sessile, oblong, obtuse.

Stem terete, pubescent, grey near the base, green higher up.

Leaves digitately or pinnately trifoliolate, cauline, alternate (first two opposite), stipulate, petiolate, alternately incurvinerved, reticulate, pubescent or hairy all over, but especially when young, bright green above, paler beneath, membranous, dotted beneath with resin glands; stipules thin, subulate, acute.

Nos. 1 and 2. Opposite, equal, simple, entire, subsessile, $2-3 \mathrm{~cm}$. long, about $1 \cdot 5$ $\mathrm{cm}$. broad, ovate or ovate-lanceolate, subcordate at base, more or less obtuse at apex, pubescent all over, thin, bright green.

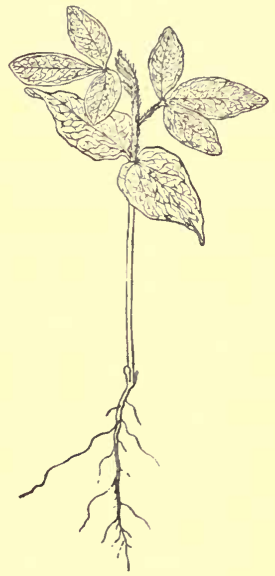

Fig. 291.

Atylosia Candollei.

Three-fifths nat. size.

Nos. 3-5. Ternate, alternate, more hairy ; leaflets elliptic, obtuse, sessile.

\section{Flemingia Grahamiana, W. et Arn.}

Hypocotyl none or subterranean.

Cotyledons subterranean.

Stem wiry, erect, terete, pubescent, and closely dotted with red sessile glands, as are the leaves on both sides and the petioles; 1 st internode $3 \mathrm{~cm}$. long; 2nd $6 \mathrm{~mm}$.; 3rd $1 \mathrm{~mm}$.; 4 th $4 \mathrm{~mm}$.; 5 th $4.5 \mathrm{~mm}$. 
Leaves cauline, compound, alternate (first two simple and opposite), stipulate, petiolate.

Nos. 1 and 2. Simple, opposite, rotund-ovate, obtuse or apiculate, ciliate, covered on both sides with small sessile red glands, opaque, subtrinerved ; petiole $2 \mathrm{~mm}$. long ; stipules free, interpetiolar, linearsubulate, acute, slender.

No. 3. Digitately trifoliolate ; lateral leaflets oblique, oval, obtuse, mucronate, penninerved with a strong nerve on the oblique side; terminal leaflet elliptic, obtuse, mucronate, trinerved, nerves ascending or slightly incurved; petiole deeply channelled above, dilated into a fleshy foot at the base, variable in length, averaging about $1.8 \mathrm{~cm}$. long; petiolules about $1 \mathrm{~mm}$. long; stipules opposite the leaf and more or less connate for two-thirds or three-fourths of their length, adpressed to the stem with ovate acute free teeth.

Nos. 4-6. Similar, but larger.

Ultimate leaves digitately or subpinnately trifoliolate; lateral leaflets obliquely ovate, apiculate; terminal one elliptic, obtuse at both ends, apiculate, trinerved.

Galactia glabella, Michx.

Cotyledons just emerging from the soil, shortly oblong, fleshy, convex on the back, flat on the face.

Leaves.-Nos. 1 and 2. Simple, cordate, cuspidate, entire, deep green, opposite.

No. 3. Alternate, pinnately trifoliolate; terminal leaflet oblong, obtuse, emarginate ; lateral leaflets oblong or ovate, obtuse, emarginate.

\section{Tribe Dalbergiez.}

Dalbergia hupeana, Auct.

Hypocotyl $3 \mathrm{~cm}$. long, erect, terete, glabrous, light green.

Cotyledons thick, fleshy, obtusely and obliquely ovate, wrinkled, dark green, glabrous, very shortly petiolate or subsessile, $8 \mathrm{~mm}$. long, $5 \mathrm{~mm}$. wide, distinctly one-nerved.

Stem herbaceous, ultimately becoming woody, erect, terete, slightly hoary; 1st internode from $2 \cdot 5-3 \cdot 5 \mathrm{~cm}$.; 2nd considerably shorter, about $1 \mathrm{~mm}$.

Leaves compound, pinnate, with seven or more leaflets, alternate, but so near together that they appear opposite, stipulate, though this genus is usually exstipulate.

Leaflets entire, alternate, obovate, with short petiolules, almost sessile, bright green, rather reflexed, slightly cuspidate; midrib with numerous ascending branched veinlets. 


\section{Pterocarpus Rohrii, Vahl.}

Primary root stout, long, tapering, unbranched in the younger stages.

Hypocotyl erect, terete, glabrous, 5-7 cm. long.

Cotyledons ovate-oblong, obtuse, unequal at the base, the longer side being rounded, and the other hastate, fleshy, glabrous, threeto five-nerved, but the venation obscure owing to their opaque character, ascending, flat at first, but soon becoming revolute at the

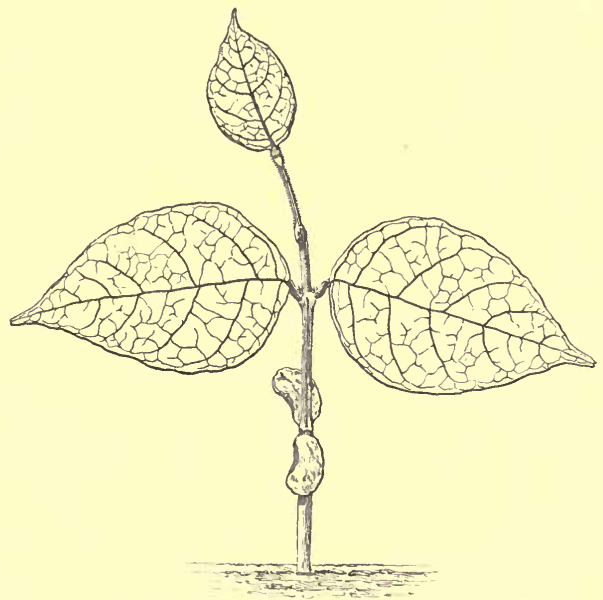

FIG, 292.-Lonchocarpus latifolius. Half nat. size.

sides and falling early, subsessile with a petiole or narrowed portion only $1 \mathrm{~mm}$. long.

Stem erect, bluntly subquadrangular in the young state, soon becoming woody, glabrous ; 1 st internode $4-5 \mathrm{~cm}$. long.

Leaves alternate, imparipinnate except the first pair, stipulate, petiolate, glabrous ; leaflets alternate or irregularly opposite, exstipellate, thinly coriaceous, shining above; petioles slender, semiterete, narrowly channelled above, slightly thickened at the base and pulvinate; stipules subulate, acuminate, slender, acute.

1st pair opposite, each leaf consisting of one cordate, strongly acuminate leaflet, with a slender point, and alternate, long, incurved lateral nerves not reaching the margin; there is a pulvinus at the 
base of the petiole, and another at the base of the lamina or leaflet; stipules interpetiolar and connate.

I have seen but few examples of the Dalbergieæ, and the semihastate cotyledons of this species are unique in the Order as far as observed. The first pair of leaves being opposite and consisting of only one leaflet point to an affinity with the Phaseoleæ, the tribe coming immediately before the Dalbergieæ in the arrangement of the 'Genera Plantarum.'

Lonchocarpus latifolius, $H$. B. et $K$. (fig. 292).

Hypocotyl erect, terete, glabrous, deep green, 3.4-3.8 cm. long.

Cotyledons falcate, obtuse, subsessile, both directed to one side cf the stem, aerial but fleshy, plano-convex, enlarging but slightly after germination, and deciduous at an early date, before which they become bright yellow, $1 \cdot 5-1 \cdot 8 \mathrm{~cm}$. long, $7-8.25 \mathrm{~mm}$. wide.

Stem erect, terete, deep green, densely and finely pubescent,

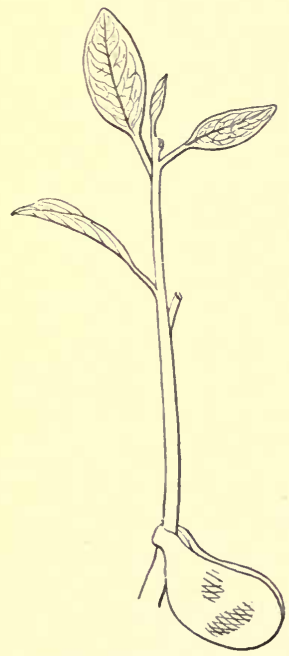

Frc.293. -Sophora secundiflora. Nat. size. ultimately woody and arborescent; 1st internode $3.25 \mathrm{~cm}$. long; 2nd undeveloped; $3 \mathrm{rd} 1 \cdot 15 \mathrm{~cm}$.

Leaves simple and compound, imparipinnate, cauline, alternate, stipulate, petiolate, pubescent at the margin and on the nerves above, alternately incurvinerved and reticulate, dull deep green above, paler beneath; stipules small, subulate, erect, or tooth-like and shorter, pubescent; petioles subterete, shallowly channelled above, densely pubescent, of the first two leaves short, of the rest much longer.

Nos. 1 and 2. Opposite, ovate, cuspidately acuminate, obtuse, simple and entire, or minutely emarginate.

No. 3. Alternate, ovate, acuminate, acute or subacute, simple and entire.

\section{Tribe Sophorem.}

Sophora secundiflora, Lag. (fig. 293).

Seeds scarlet, with a shell as hard as ivory.

Hypocotyl undeveloped.

Cotyledons remaining below the ground with their faces closely 
adpressed, $1-1.5 \mathrm{~cm}$. long, nearly $1 \mathrm{~cm}$. broad, 3-5 mm. thick, fleshy.

Stem slightly curved, terete, firm, glabrous, greyish-green; 1st internode 3-4 cm. long, 2-3 mm. thick; 3rd about the same; 2nd and 4 th very short.

Leaves imparipinnate (or one or more of the primary ones simple), cauline, alternate, stipulate, petiolate, alternately incurvinerved and reticulate, glabrous, deep green above ; stipules minute, apparently caducous.

No. 1. Shortly stalked, 2.5-3 cm. long, 5-6 mm. broad, linear or linear-lanceolate, more or less acute, thinly coriaceous, glabrous, dark green.

No. 2. Ditto.

Nos. 3 and 4. Ditto, but elliptic-lanceolate, acuminate at both ends with articulation between blade and petiole.

Edwardsia chilensis, Miers (fig. 294).

Hypacotyl subterranean.

Cotyledons notrising above ground, thick, fleshy, flat on one side and very convex on the other, conforming to the shape of the seed, greenish, $1.5 \mathrm{~cm}$. long, $1 \mathrm{~cm}$. broad.

Stem erect, terete, woody, verrucose, pubescent, deep green; 1st internode $6 \mathrm{~mm}$. long ; 2nd $3 \mathrm{~mm}$. ; $3 \mathrm{rd} 4 \mathrm{~mm}$.; 4 th $7 \mathrm{~mm}$.; 5th $7 \mathrm{~mm}$.; 6 th $9.5 \mathrm{~mm}$.; 7 th $1.2 \mathrm{~cm}$.

Leaves compound, imparipinnate, cauline, alternate,

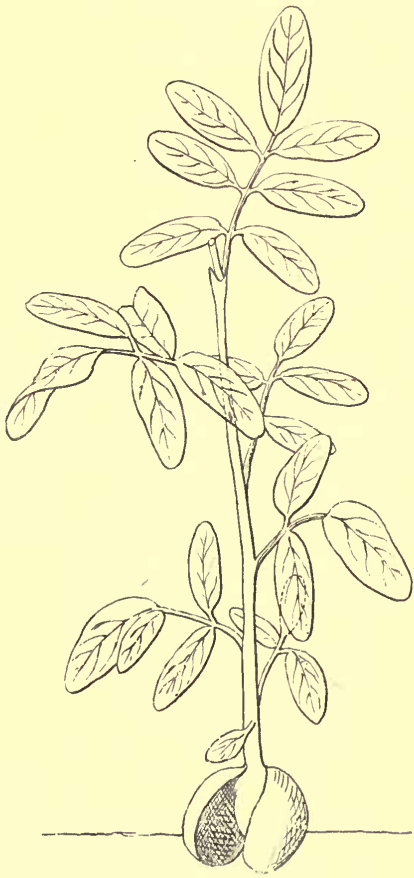

Fig. 294.-Edwardsia chilensis. Nat. size. stipulate, petiolate, glabrous above and dark green, sparsely pubescent on the under side, petiole and rachis paler green ; petiole-semiterete, channelled on the upper side; stipules small, tooth-like, inconspicuous. 
No. 1. Unifoliolate, small; leaflet obovate.

No. 2. Trifoliolate; leaflets unequal.

No. 3. Quadrifoliolate; an extra, small, lateral leaflet present at the base of the terminal one, but probably a malformation.

No. 4. Trifoliolate ; leaflets oblong, obtuse, minutely emarginate ; terminal leaflet largest. This applies to most or all of the leaflets that follow.

Nos. 5 and 6 . Five-foliolate.

Nos. 7-10. Seven-foliolate.

Castanospermum anstrale, A. Cunn. (fig. 295).

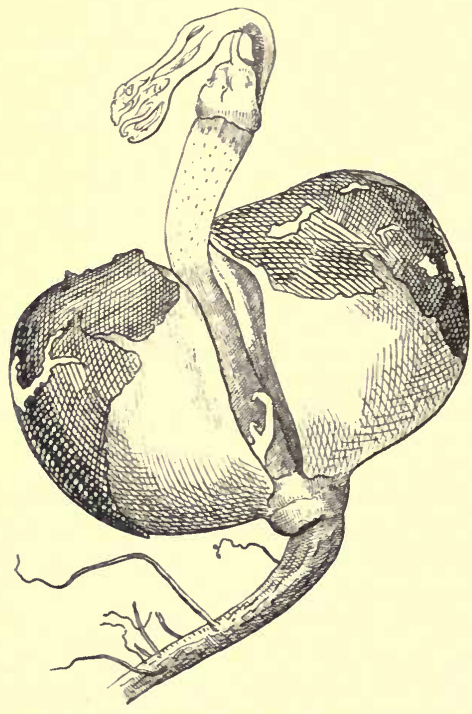

Fio. 295.-Castanospermum australe. Nat. size.

Primary root long, tapering, stout, giving off lateral, branched fibres.

Hypocotyl undeveloped.

Cotyledons enormously large, semiglobose, fleshy, filling the seed and conforming to it in shape, persistent and subterranean, remaining in the testa which splits irregularly.

Plumule very large and well developed, fleshy.

Stem erect, terete, ultimately woody, and forming a tall tree.

Leaves compound, imparipinnate, cauline, alternate, stipulate, petiolate; leaflets large, leathery, exstipellate.

Myroxylon peruiferum, $L$. fil.

Hypocotyl usually subterranean.

Cotyledons fleshy and remaining in the large seed till they are exhausted and decay.

Stem woody, erect, terete, pubescent, pale green, ultimately grey, 
slightly warted; 1st internode $7.65 \mathrm{~cm}$. long; 2nd $1.4 \mathrm{~cm}$.; 3 rd $1.05 \mathrm{~cm}$; 4 th $1.1 \mathrm{~cm}$; 5 th $1.25 \mathrm{~cm}$.; 6 th $8 \mathrm{~mm}$.

Leaves compound, pinnate with alternate leaflets (those of the first four to five leaves mostly opposite), cauline, alternate (first two opposite), stipulate, petiolate, permeated with small, linear-oblong, dot-like glands, ciliated on the margin, pubescent on the petiole and on the rachis and midrib of leaflets on both surfaces, deep green above, paler beneath, shining on both surfaces, evergreen, coriaceous, thin; leaflets slightly undulate, and subrevolute at the extreme margin, shallowly wavy or subcrenulate in the adult leaves; petioles terete, thickened at the base and articulated with the stem; stipules small, linear, obtuse, pubescent, tending to become obsolete as they proceed from the first pair of leaves upward.

Nos. 1 and 2. Opposite; leaflets five, lanceolate, obtuse, emarginate, as are those of the third to seventh leaf.

No. 3. With eight leaflets.

No. 4. With nine leaflets.

No. 5. Deformed.

No. 6. With nine leaflets.

No. 7. With eleven leaflets.

Ultimate leaves pinnate, with nine to thirteen alternate leaflets and a terminal elliptic, obtuse, emarginate one; lateral leaflets oblong, obtuse, emarginate, or a few of the lower ones ovate.

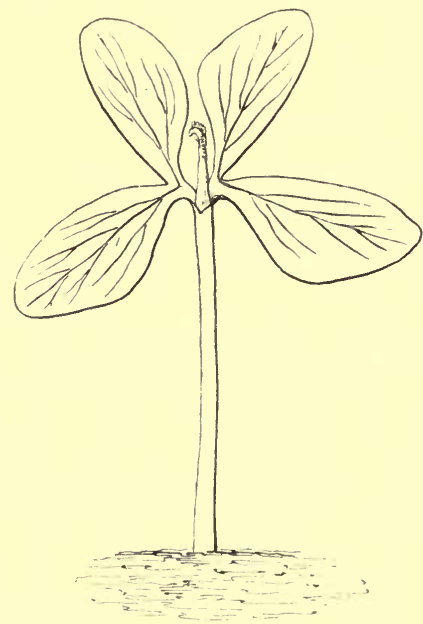

FIG. 296.

Hamatoxylon campechianum, $\times \mathbf{2}$.

Hæmatoxylon campechianum, $L$.

Fruit a legume, much flattened dorsally, one-seeded.

Seed oblong-oval, 8-12 mm. long, exalbuminous, very much laterally flattened; testa straw-coloured, smooth, thickened near the hilum; hilum rather conspicuous, ventral.

Embryo straight, filling the whole interior of the seed, yellowish ; cotyledons deeply bilobed, transversely oblong, consisting chiefly of two large auricles, obtuse, veined while still in the seed, lying the 
broad way of the seed, with their edges to the axis; radicle short, subquadrangular, subacute, lying between the two lobes of the cotyledon, but not incumbent on them.

Seedling (fig. 296).

Hypocotyl erect, terete, glabrous, $2-2.5 \mathrm{~cm}$. long, light green or colourless.

Cotyledons membranous, unequal, unsymmetrical, deeply bipartite, shortly petiolate; segments obliquely oblong, ovate, obtuse, entire, glabrous, dark green, distinctly pinnatinerved; the lateral veins very long.

Stem erect, terete, glabrous, herbaceous, ultimately woody.

\section{Tribe Euc瓜SAlPinie五.}

Cæsalpinia tinctoria, Domb. (fig. 297).

Hypocotyl long, woody, striated, 5-6 $\mathrm{cm}$. long, brownish.

Cotyledons obovately rotund, subfleshy, obtuse, entire, slightly auricled at the base, subsessile or very shortly petiolate, glabrous, dark green, trinerved, with the principal nerves again pinnatinerved.

Stem erect, square, herbaceous (ultimately woody) minutely pubescent; 1st internode 5-6 $\mathrm{mm}$. long; 2nd internode 7-9 $\mathrm{mm}$.

First two leaves compound, abruptly pinnate, cauline, alternate, petiolate, stipulate, ending in a short point; third leaf bipinnate; leaflets simple, opposite, oval-oblong, acute, ending in a sharp point or mucro, shortly petiolulate, stipellate, glabrous, green, pinnatinerved; petioles long, terete, pubescent; stipules and stipellæ straight, acute, thorn- or bristle-like.

Tubeuf ${ }^{1}$ figures and describes the seedling of Gleditschia triacanthos, which somewhat resembles the above, but the cotyledons are oval, $2.5 \mathrm{~cm}$. long, and $1.2 \mathrm{~cm}$. broad, and sessile. The first leaves have ten pairs of pinnæ, which are shortly stalked, have a delicate pointed apex, and are hairy.

Poinciana Gilliesii, Hook. (fig. 298).

Hypocotyl erect, square, with slightly winged ribs, and a few short brown hairs on the upper part, $4-5 \mathrm{~cm}$. long; light subglaucous-green.

Cotyledons broadly or obovately oblong, obtuse, entire, very

I Samen, Frilchte u. Keimlinge (Berlin, 1891), p. 127. 
shortly petiolate, glabrous, light subglaucous-green, five-nerved at the base, with the main nerve forking near the apex; petioles connate at the base.

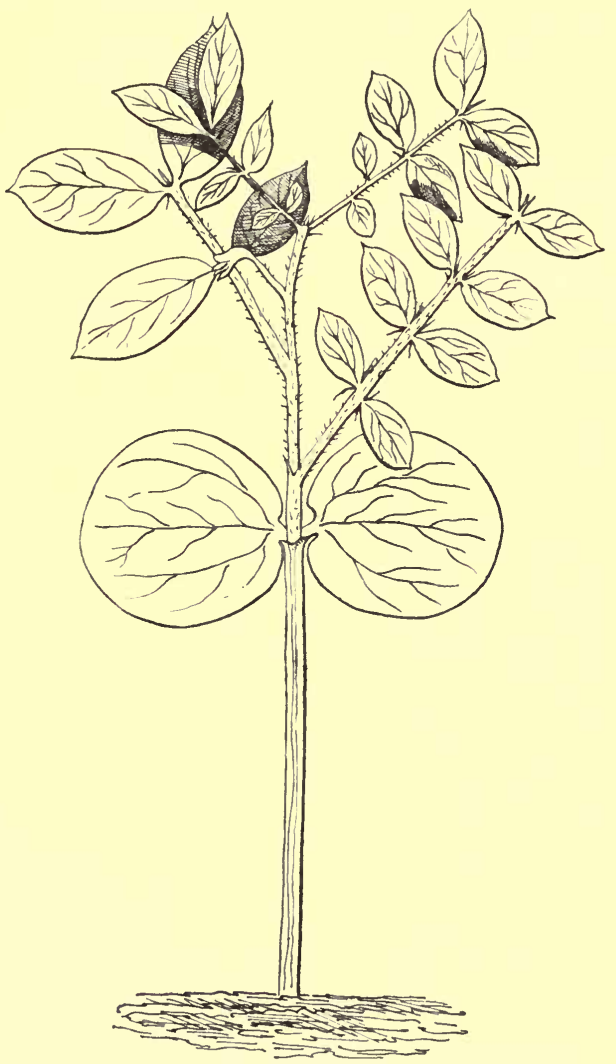

Fig. 297.-Casalpinia tinctoria. Nat. size.

Stem erect, terete, herbaceous, covered with short brown hairs; 1st internode 2.5-3 mm. long.

First leaves compound, abruptly pinnate, cauline, alternate with 
long petioles, stipulate; leaflets linear-oblong, obtuse, entire, shortly petiolulate, opposite (sometimes alternate), glabrous, light green,

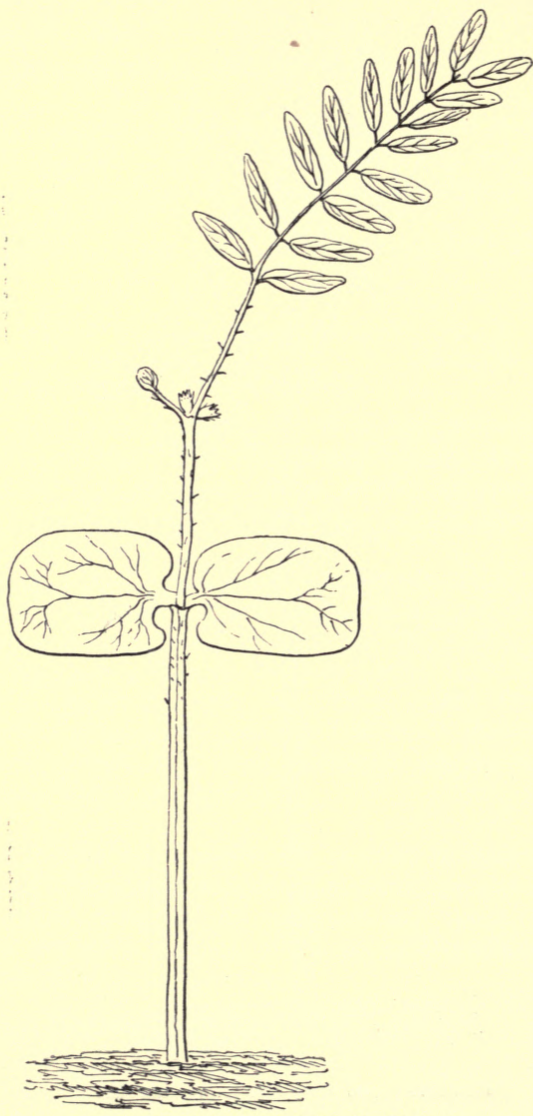

FIG. 298.-Poinciana Gilliesii. Nat. size.

pinnatinerved; petioles terete, with a few scattered hairs; stipules obovate, jagged or denticulate, minutely hairy. 
Tribe Cassiem.

Cassia circinata, Benth. (fig. 299).

Hypocotyl erect, terete, wiry, suffrutescent, pubescent, 2.5$4.5 \mathrm{~cm}$. long, pale green at first, ultimately brown.

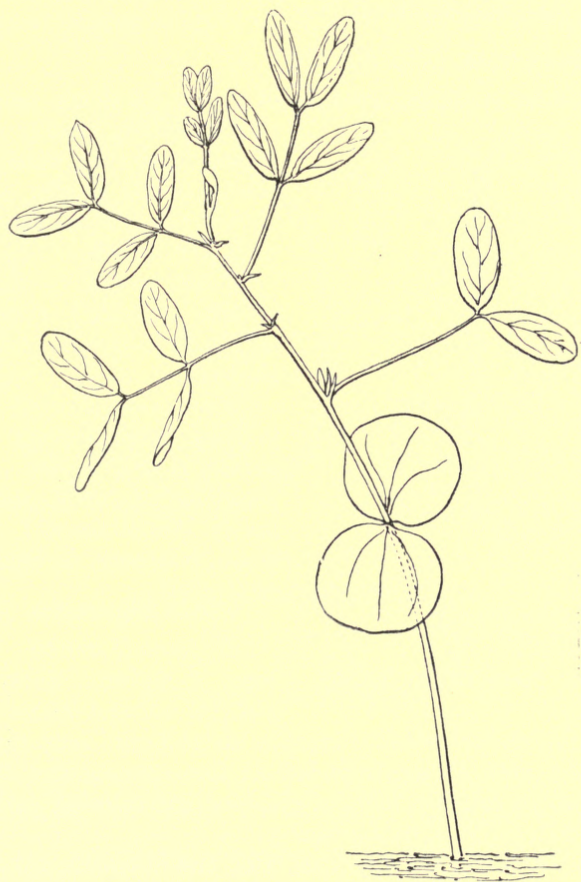

FIg. 299.-Cassia circinata. Nat. size.

Cotyledons foliaceous, shortly petiolate, rotund, deep green above, indistinctly three- to five-nerved, paler beneath; petiole about $1 \mathrm{~mm}$. long.

Stem wiry, suffrutescent, terete, pubescent, pale green ; 1st internode $1.8 \mathrm{~cm}$. long; 2nd $9 \mathrm{~mm}$. ; 3rd $6.5 \mathrm{~mm}$.; 4 th $7 \mathrm{~mm}$.

Leaves cauline, compound, alternate, stipulate, petiolate. 
No. 1. Pinnate, abrupt, with one or sometimes two pairs of leaflets ; leaflets oblong, or obovate-oblong, obtuse, pale green above, glaucous beneath, ciliate, petiolulate; petiole subterete, channelled above, pubescent, $1.5 \mathrm{~cm}$. long; petiolule $1 \mathrm{~mm}$. long; stipules linear, acute, pubescent.

Nos. 2-5 of two pairs of leaflets; leaflets opposite; rachis abrupt; otherwise similar to No. 1.

Cassia obovata, Coll. (fig. 300).

Hypocotyl stout, glabrous, light green, 1·5-2 cm. long, stout.

Cotyledons broadly obovate,

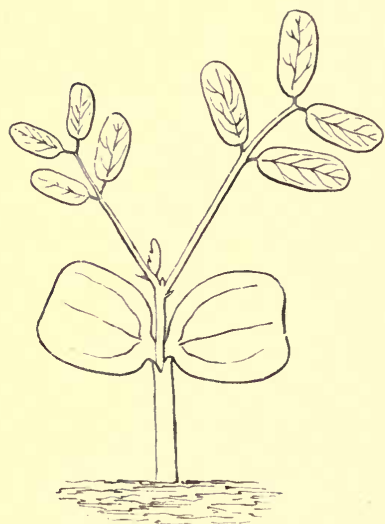

Fig. 300.-Cassia obovata. Nat. size. obtuse, entire or widely emarginate, nearly sessile, glabrous, light subglaucous-green, distinctly trinerved.

Stem erect, terete, herbaceous, ultimately woody; 1st internode 4-5 mm. long; 2nd shorter.

First leaves abruptly pinnate, petioles long; leaflets oblong, obtuse, entire, opposite, shortly petiolulate, glabrous, green, alternately pinnatinerved; stipules small, setaceous, deciduous.

Cassia mimosoides, $L$.

Hypocotyl slender, $1.5 \mathrm{~cm}$. long, $\cdot 5-75 \mathrm{~mm}$. thick, uneven but glabrous and terete.

Cotyledons horizontal, subsessile, about $9 \mathrm{~mm}$. long and $5 \mathrm{~mm}$. broad, obliquely oblong, rounded at the apex, entire, obscurely nerved, with a revolute margin, glabrous but showing dark brown dots on both surfaces, pale green.

Stem pubescent, not very firm, red ; first internode $2-3 \mathrm{~cm}$. long and $\cdot 5 \mathrm{~mm}$. thick.

Leaves abruptly pinnate; leaflets small, linear-oblong, obtuse, entire with an evident midrib; stipules small, scarious, subulate, acute.

No. 1. Abruptly pinnate, 1-2 cm. long, $\cdot 75 \mathrm{~cm}$. broad, with about seven pairs of oblique, linear-oblong, sessile leaflets 3-4 mm. long and 1-2 mm. broad.

No. 2. Similar. 
Cassia Fistula, L. (fig. 301).

Fruit a legume, linear, slightly compressed laterally, divided into many cells transversely by ingrowths of the carpel, many-seeded, thick, indehiscent.

Seed rotund-obovate, much compressed dorso-ventrally, glabrous, hard, shining; testa thin, pale-coloured, and separating from the tegmen, forming a broad white band down the middle of the

A

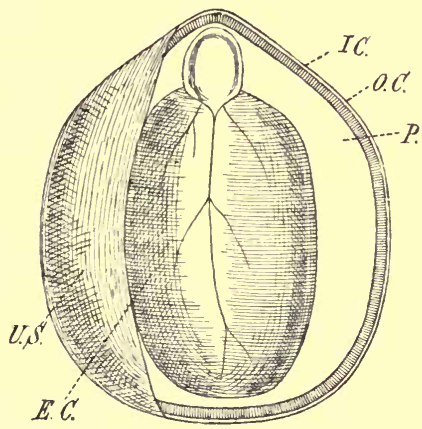

C
B

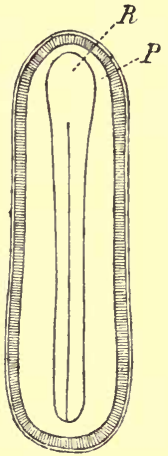

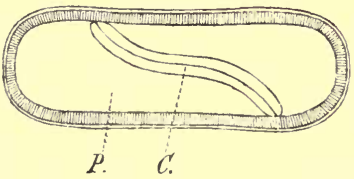

Fig. 301.-Cassia Fistula. A, oblique longitudinal section of seed, $\times 5: U S$, uncut surface; $E C$, edges of cotyledons; $P$, endosperm; $O C$, testa; IC, tegmen. B, longitudinal section of seed at right angles to the plane of the cotyledons, $\times 5: R$, radicle; $P$, endosperm. C, transverse section of seed, $\times 5: P$, endosperm; $C$, coty. ledons.

ventral aspect, and a broader one along the dorsal aspect, while round the edges it remains attached and appears deep buff or brownish-yellow; tegmen much thicker and brownish-yellow; micropyle and hilum contiguous, basal at the upper end of the seed; raphe ventral, forming a brown line almost obscured by the white testa; chalaza apical, at the farther end from the hilum. 
Endosperm copious, very tough and almost colourless when moist, hard and cartilaginous when dry, occupying the greater part of the interior of the seed.

Embryo large and nearly as long as the endosperm, straight, central, but obliquely twisted, so that in transverse section it traverses the endosperm diagonally by two curves, the edges of the cotyledons abutting against the inner wall of the seed and cutting the endosperm in two; cotyledons oblong, obtuse, entire, slightly cordate at the base, trinerved

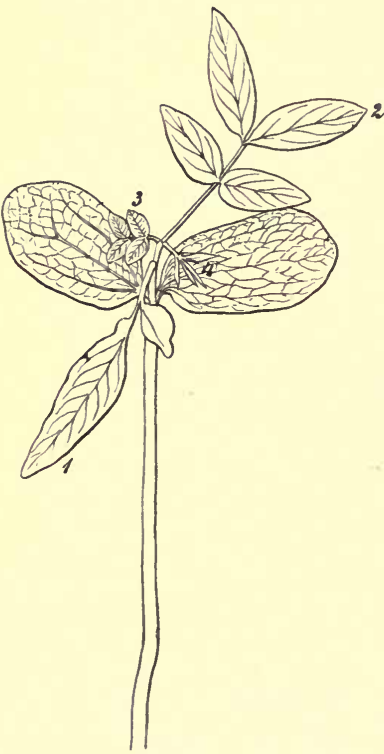

FIo. 302.-Cassia Fistula. Nat. size. longitudinally, while short, alternate, ascending nerves are given off from the midrib, closely applied face to face, thick, flat, rather fleshy, pale yellow; radicle very short, stout, obtuse, subovoid, lying in a cavity of the endosperm close to the micropyle, straight, many times shorter than the cotyledons.

Seedling (fig. 302).

Hypocotyl woody, erect, terete, substriate by the bursting of the epidermis, finely pubescent, glabrescent, green and afterwards becoming brown, 4-6 cm. long.

Cotyledons foliaceous, shortly petiolate, oblong or obovateoblong, rounded at the end, trinerved and reticulate, $2 \cdot 4 \mathrm{~cm}$. long, $1.4 \mathrm{~cm}$. broad.

Stem woody, erect, flexuous or zigzag at the joints, terete, pubescent, green; 1 st internode $5 \mathrm{~mm}$. long; 2nd, 3rd, and 4 th each about $1 \mathrm{~mm}$.; 5 th $2 \mathrm{~mm}$; 6 th $3.5 \mathrm{~mm}$.; 7 th $4 \mathrm{~mm}$.

Leaves cauline, alternate, compound, stipulate, petiolate, abruptly pinnate; petioles and under side of leaflets pubescent ; upper side glabrous, deep green; under side pale or glaucous.

No. 1. Consisting of one pair of deformed, unequal-sized leaflets. 
No. 2. Of two pairs of oblong-lanceolate, acute or subacute leafiets.

Nos. 3 and 4. Very small, each with two pairs of leaflets.

Nos. 5-7. Of two pairs of leaflets; lower pair ovate, obtuse, penninerved and reticulate, entire, petiolulate; upper pair ovateoblong or oblong-lanceolate, obtuse, otherwise like the lower pair; petiole subterete, slightly channelled above, 9-15 $\mathrm{mm}$. long; primary rachis $8-9 \mathrm{~mm}$. long, ending in a mucro between the upper pair of leaflets; petiolules about $1 \mathrm{~mm}$. long.

\section{Tribe Bauhinies.}

Bauhinia tomentosa, $L$. (fig. 303).

Seeds oblong, subrotund or orbicular, much compressed laterally, 6.5-8 $\mathrm{mm}$. long, 5-7 mm. wide, $2-2 \cdot 25 \mathrm{~mm}$. thick, not transverse to the placenta.

Hypocotyl erect, terete, subglabrous, pale green, $1 \cdot 25-1 \cdot 8 \mathrm{~cm}$. long.

Cotyledons foliaceous, obovateoblong, obtuse and rounded at both ends, five-nerved from the base in a somewhat radiating manner, glabrous and shining on both surfaces, light green above, paler beneath, subfleshy, sessile, $2 \cdot 1 \mathrm{~cm}$. long, $1 \cdot 2 \mathrm{~cm}$. wide.

Stem shrubby after a time, erect, terete, hairy, pale green when young; 1st internode $1.45 \mathrm{~cm}$. long.

Leaves simple, bilobed (apparently consisting of two united leaflets), cauline, alternate, stipulate, petiolate, more or less hairy on both surfaces (in the seedling), five-

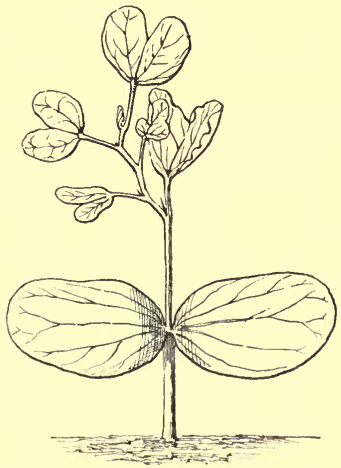

Fig. 303.-Bauhinia tomentosa.

Nat. size. nerved, reticulate, with the median nerve prolonged or aristate in the apical sinus, with strong branches running to the apex of the lobes, and the lateral ones ascendingly penninerved; petioles semiterete, channelled above, hairy ; stipules small, subulate, acute, colourless.

No. 1. Broadly obcordate, rounded at the base, divided at the apex for about one-fourth its length, with the lobes rounded and obtuse.

Nos. 2 and 3. (Deformed in specimen).

Nos. 4 and 5. Similar to No. 1, but smaller. 
Bauhinia Carronii, F. Muell.

Pods 8-10 cm. long, $2 \cdot 5-3 \mathrm{~cm}$. broad, scarlet when young, the colour of the flowers, which they resemble at a distance.

Seeds oblong or broadly oblong, much compressed laterally, smooth, shining, deep chestnut brown, glabrous, 9-10.5 mm. long, 6-8.5 mm. broad, $2 \cdot 25-2 \cdot 75 \mathrm{~mm}$. thick.

Hypocotyl subterranean.

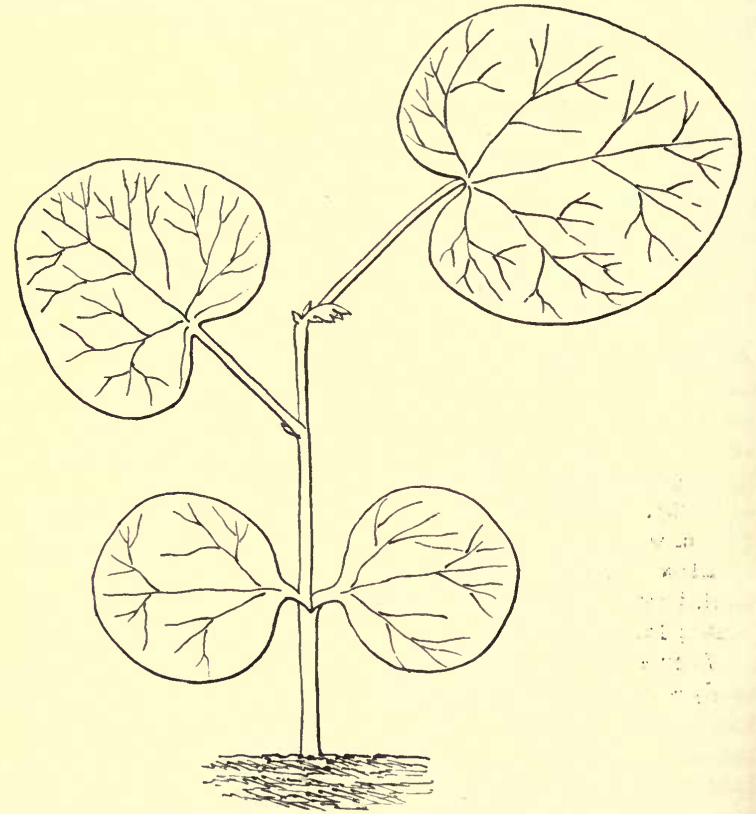

Fig. 304.-Cercis Siliquastrum, $\times 2$.

Cotyledons sessile, one below the earth, about $1.5 \mathrm{~cm}$. long, $1 \mathrm{~cm}$. broad, oblong or obovate, obtuse, entire, trinerved, subconcave, glabrous, succulent, light green above.

Stem herbaceous, terete, about $2 \mathrm{~mm}$. thick, very pale green; 1st internode $3.2 \mathrm{~cm}$. long; 2nd $2.1 \mathrm{~cm}$.; 3rd $2 \mathrm{~cm}$.; 4th $1.7 \mathrm{~cm}$.

Theaves.-No. 1. Very small, cauline, compound, of two leaflets ; 
petiole $1 \mathrm{~mm}$. long; leaflets oblanceolate or oblong, obtuse, $5 \mathrm{~mm}$. long, $2 \mathrm{~mm}$. broad, otherwise like No. 2 .

No. 2 \&c. Compound, cauline, stipulate, petiolate, of one pair of leaflets, glabrons, palmatinerved, reticulate; leaflets opposite, obovate, slightly oblique, entire, obtuse and rounded at the apex, subcuneate at the base, pale green and subglaucous on both sides, $1.5 \mathrm{~cm}$. long, $7 \mathrm{~mm}$. broad; stipules free, small, subulate, acute; petiole terete, or faintly channelled on the upper side, minutely pubescent, $3 \mathrm{~mm}$. long, produced beyond the bases of the leaflets into a slender, subulate, acute point.

Cercis Siliquastrum, ${ }^{1}$ Willd. (fig. 304).

Hypocotyl short, erect, terete, 5-6 mm. long, light green or colourless.

Cotyledons rotund, obtuse, entire, shortly petiolate, coriaceous, dark green, glabrous, pinnatinerved or rather trinerved, with numerous branched veinlets to the principal veins.

Stem erect, terete, lerbaceous, ultimately woody; 1st internode $1-1 \cdot 2 \mathrm{~cm}$. long; 2nd 5-7 mm.

First leaves simple, entire, cauline, alternate, petiolate, stipulate, cordate or ovate from a cordate base, obtuse, glabrous, light green, pinnatinerved or five-nerved; petioles rather long, slender, terete ; stipules small, acute, setaceous, deciduous.

\section{Tribe Aynerstiez.}

\section{Peltogyne sp.}

Primary root long, tapering, giving off numerous short lateral rootlets.

Hypocotyl erect, obtusely tetragonal owing to the lines running down from the cotyledons, $13 \cdot 5-14 \cdot 5 \mathrm{~cm}$. long, glabrous, soon becoming woody.

Cotyledons broadly oval, obtuse, fleshy, green but opaque, with obscure or indiscernible venation, sessile, rather strongly auricled at the base with the auricles connate for most of their length along the dorsal aspect, and deeply grooved in front so that they appear to be attached to the axis about $4.5 \mathrm{~mm}$. above their base, erect for some time after germination, then recurved and spreading a little above their insertion, rather caducous.

Stem soon becoming woody; 1st internode about $4 \mathrm{~mm}$. long.

Leaves compound, consisting of one pair of leaflets, like some species of Bauhinia, cauline, stipulate, petiolate, coriaceous, glabrous, shining; leaflets very unequal-sided or half-ovate, obtuse, sessile,

1 Cf. Tubeuf, loc. cit. p. 128, fig. 174. 
with the midrib near the inner edge or anterior margin, and a few strong incurved nerves (not reaching the margin) on the posterior side; petiole short, semiterete, grooved above in the first pair, and about $1.5 \mathrm{~cm}$. long; stipules slender, short, subulate, soon becoming brown.

Nos. 1 and 2. Opposite, with the characters as above given.

Hymenæa Courbaril, $L$. (fig. 305).

Hypocotyl erect, terete, stout, succulent, glabrous, pale brownishgreen, $8.5 \mathrm{~cm}$. long, $5 \mathrm{~mm}$. thick at the base.

Cotyledons thick, fleshy, plano-convex, oval in outline, slightly emarginate, pale brownish on the back, light green above (the green part being bordered by a narrow rim), glabrous, red on the back when quite young, semi-erect, auricled at the base behind, and forming a short sheath, $2 \cdot 2 \mathrm{~cm}$. long including the sheath, $1 \cdot 4 \mathrm{~cm}$. broad, $7 \mathrm{~mm}$. thick a little above the base.

Stem succulent at first, ultimately woody, green, glabrous ; 1st internode $3 \cdot 3 \mathrm{~cm}$. long; 2nd $4 \cdot 15 \mathrm{~cm}$.

Leaves.-Nos. 1 and 2. Simple, opposite, exstipulate, cohering nearly throughout the whole length of their petioles and adnate to the stem; lamina obliquely rotund, emarginate, 5-6-nerved longitudinally and finely reticulate, $5 \mathrm{~cm}$. long, $5 \cdot 5 \mathrm{~cm}$. broad, ascending.

No. 3. Alternate, abruptly pinnate, stipulate, with one pair of leaflets ; leaflets obliquely ovate, acuminate, obtuse, conduplicate in bud, and adpressed to each other by the backs of their narrow anterior sides, the posterior side being the broader.

Ultimate leaves abruptly pinnate with one pair of very shortly petiolulate leaflets, articulated with the petiole; leaflets obliquely oblong, or subfalcate, acuminate, obtuse, unequal-sided, glabrous, coriaceous, light or deep green, densely dotted with immersed glands on the under side, with a row of submarginal, larger, suboblong or oval ones, all of which are translucent when held up to the light; petioles thickened at the base and apex; stipules oblong-lanceolate, acute, pale green, with translucent glands and a finely ciliate margin; caducous.

\section{Tribe Cynometrea.}

Copaifera officinalis, $L$.

Hypocotyl aerial, erect, terete, stout, covered with short, minute hairs, soon becoming woody and deep brown, 4-5 cm. above ground.

Cotyledons aerial, but very fleshy, oblong, obtuse, entire, sessile, shortly auricled at the base, rounded on the back, flat on the inner 


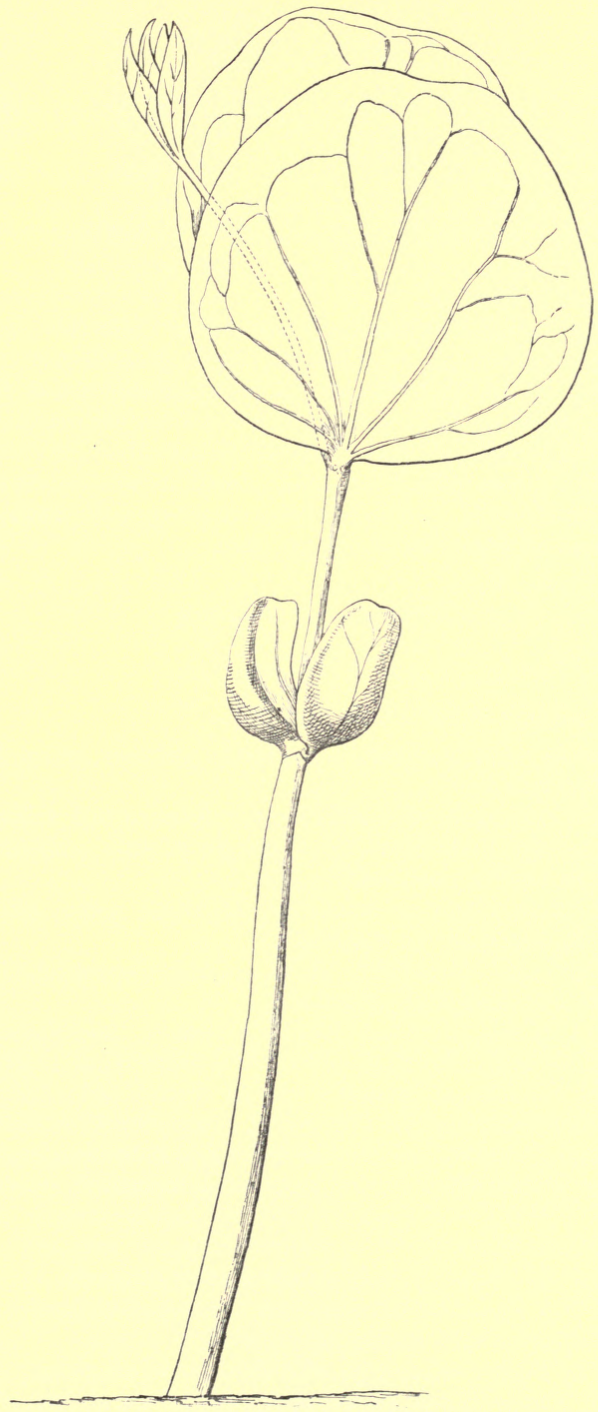

FIg. 305.-Hymenaa Courbaril. Nat. size. 
face or becoming concave by shrivelling, $1 \cdot 4-1 \cdot 6 \mathrm{~cm}$. long, 8-10 mm. wide, reddish or tinged with yellow.

Stem erect, terete, green, densely covered with short incurved hairs, soon becoming woody; 1st internode $3.5-4 \mathrm{~cm}$. long, together with the hypocotyl constituting the whole of the first season's growth and terminating in a small bud that appears to be lateral owing to the size of the first leaf.

Leaves compound, abruptly pinnate, cauline, alternate, stipulate, petiolate, evergreen, glabrous, full of pellucid glands, leathery, penninerved, reticulate, bright green and shining; stipules small, deciduous ; petiole very short, stout, eylindrical, finely pubescent between the leaflets like the midrib and the petiolules.

No.1. Of three pairs of lanceolate, obtuse, falcate leaflets, oblique on the posterior side, and more or less cut away on the anterior side at the base, especially the uppermost pair.

\section{SUBORDER MIMOSEA.}

\section{Tribe Adenantherea.}

Adenanthera Pavonina, $L$. (fig. 306).

Hypocotyl soft, succulent, erect, terete, glabrous, green, $1 \cdot 5 \mathrm{~cm}$. long, afterwards woody.

Cotyledons sessile, erect and clasping the stem with subsagittate auricles at the base, fleshy, thick, margin slightly undulate, olive green, with buds in their axils.

Stem erect, terete or substriate, glabrous, green, ultimately woody; 1 st internode $2.4 \mathrm{~cm}$. long.

Leaves compound, cauline, alternate (first two opposite), stipulate, petiolate; stipules minute, glandular.

Nos. 1 and 2. Pinnate; leaflets alternate, lanceolate-oblong, acute or cuspidate, entire, glabrous, pale green, largest about the middle of the leaf, and gradually smaller to each end ; petiole subterete, channelled on the upper side, $8 \mathrm{~mm}$. long; rachis of leaf terete, slightly channelled on the upper side at the base, ending in a slender, filiform point beyond the uppermost leaflet; point $4 \mathrm{~mm}$. long.

No. 8. Alternate.

Nos. 4-6. Alternate, paripinnate; leaflets alternate.

Nos. 7-9. Bipinnate with two pairs of opposite pinnæ; apex of rachis abrupt; leaflets alternate.

No. 10. Bipinnate, abrupt, with three pairs of pinnæ; leaflets alternate, unequal in size, rotund or oval at the base of pinna, oblong, obtuse and minutely cuspidate on upper part of pinna, pale green, 
glabrous; apex of pinnæ abrupt; petiole terete, subchannelled on the upper side, $2.8 \mathrm{~cm}$. long; rachis between the first and second pair of pinnæ $1.7 \mathrm{~cm}$. long; between second and third pair $1.9 \mathrm{~cm}$. long.

Ultimate leaves bipinnate and large, with three to four pairs of pinnæ.

\section{Prosopis juliflora, $D C$.}

Hypocotyl erect, terete, suffrutescent, slender, pale green becoming brownish, $1.6 \mathrm{~cm}$. above the soil.

Cotyledons broadly oblong, obtuse, subsessile, falling away rather early, glabrous.

Stem erect, suffrutescent, terete, glabrous, subflexuous, wiry ; 1 st

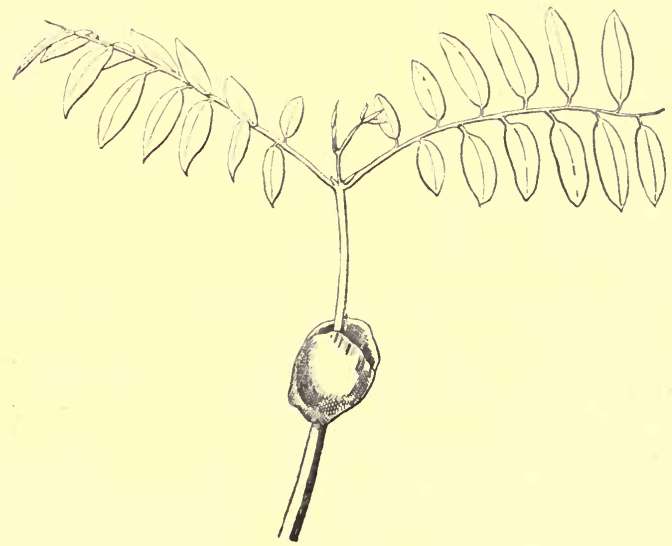

FIg. 306.-Adenanthera Pavonina. Nat. size.

internode $1.75 \mathrm{~mm}$. long ; 2nd $6 \mathrm{~mm}$.; $3 \mathrm{rd} 4 \mathrm{~mm}$.; 4 th $5.5 \mathrm{~mm}$. ; 5 th $3 \mathrm{~mm}$.; 6 th $4 \mathrm{~mm}$; 7 th $6.5 \mathrm{~mm}$.

Leaves compound, cauline, alternate, stipulate, petiolate, glabrous, glaucous-green; petioles slender, terete, almost filiform, glabrous, glaucous; stipules subulate, acute, pale green, glabrous.

No. 1. Abruptly pinnate with four pairs of oblong, obtuse, apiculate leaflets, the basal and uppermost pairs small.

No. 2. Abruptly bipinnate with one perfect pinna of four pairs of oblong leaflets and an abortive pinna; petiole terminating in a small subulate point between the pinnæ.

Nos. 3-8. Bipinnate with one pair of pinnæ; pinnæ abruptly 
pinnate; leaflets opposite, oblong, obtuse, apiculate, folding up face to face and imbricating longitudinally on their own rachis when the temperature is low or towards evening.

\section{Dichrostachys cinerea, Wight et Arn.}

Hypocotyl woody, erect, terete, thinly pubescent, soon losing it s epidermis and becoming greyish.

Cotyledons oblong-ovate, obtuse, cordate and three- or faintly five-nerved at the base, deep subglaucous-green above, paler bene ath, glabrous, erect, very shortly petiolate, $1 \mathrm{~cm}$. long, $8 \mathrm{~mm}$. broad.

Stem woody, erect, terete, pubescent, pale green; 1 st internode undeveloped; 2nd $1.25 \mathrm{~cm}$ long; 3rd $1.6 \mathrm{~cm}$; 4th $1.1 \mathrm{~cm}$.; 5 th $1.15 \mathrm{~cm}$.; 6 th $9 \mathrm{~mm}$.

Leaves abruptly uni- to bi-pinnate, cauline, alternate, stip ulate, petiolate, ciliate on the margins of the leaflets, deep glaucous-green above, glaucous beneath; leaflets folded upwards and forwards, imbricate with lower ones always outside the upper when the temperature is low ; petioles subterete, channelled above, pubescent, articulated with a large swollen base, excurrent between the pinnæ with a small subulate point; rachis with a small cylindrical gland on the upper side between each pair of pinnæ; stipules slender, subulate, attenuate.

No. 1. Pinnate with about ten pairs of opposite, linear-oblong, acute leaflets.

No. 2. Bipinnate with one pair of pinnæ.

No. 3. Bipinnate with two pairs of pinnæ.

No. 4. Ditto.

No. 5. With three pairs of pinnæ.

No. 6. With four pairs of pinnæ ; leaflets linear-oblong or oblong, acute, fewer than those of the four leaves immediately below; lower pair of pinnæ unequal, one pinna linear-oblong, acute, undivided, the other pinna divided into four leaflets on the posterior side, and undivided on the anterior side or that next the rachis.

This reversion is pretty frequent.

\section{Tribe Euminosez.}

Leucæna glauca, Benth. (fig. 307).

Hypocotyl rather woody, about $2.5 \mathrm{~cm}$. long and 1-1.5 mm. thick, terete, with a corky collar just above the surface of the ground, pubescent, whitish-green.

Cotyledons with short, connate, pubescent petioles, $1.5 \mathrm{~cm}$. long, $1 \mathrm{~cm}$. broad, and $1 \mathrm{~mm}$. thick, oval or obovate, sagittate at the 
base, rounded at the apex, entire, slightly convex, five-nerved, glabrous on both sides, dark green above.

Stem erect, herbaceous, terete, glabrous, dark green; 1st internode $1 \mathrm{~cm}$. long, and $1 \mathrm{~mm}$. thick; 2nd shorter and thinner.

Leaves. - No. 1. Abruptly pinnate, about $4 \mathrm{~cm}$. long and $2 \mathrm{~cm}$. broad; leaflets linearlanceolate, oblique, in about seven pairs, obscurely nerved and veined, thin, bright green above, paler below; leaflets $1 \mathrm{~cm}$. long and 2-3 mm. broad.

No. 2. Abruptly bipinnaie, petiole $1.5 \mathrm{~cm}$.long, $\cdot 5 \mathrm{~mm}$. thick, ending in a setaceous mucro; primary pinnæ two, about $2 \mathrm{~cm}$. long and $1.25 \mathrm{~cm}$. broad, with about six pairs of secondary ones; the latter subsessile, 6-8 $\mathrm{mm}$. long and $2 \mathrm{~mm}$. broad, otherwise like those of No. 1.

Nos. 3 and 4. Similar to No. 2.

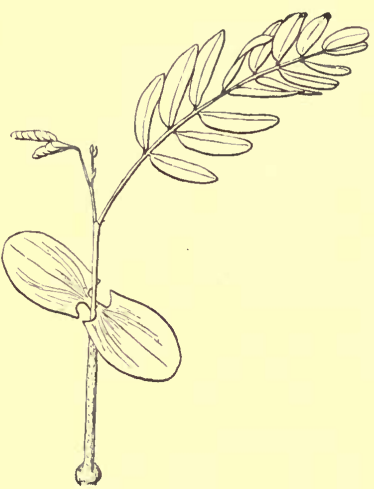

FIG. 307.-Leuccena glauca. Nat. size.

\section{Tribe Acaciem.}

Acacia Burkittii, F. Muell. (fig. 308).

Hypocotyl suffrutescent, erect, glabrous, pale green, suffused with purple at the base, $5.5 \mathrm{~cm}$. above the soil, $2 \mathrm{~mm}$. thick.

Cotyledons foliaceous, broadly triangular, obtuse, deeply auricled at the base, sessile, with half-ovate auricles, convex above, and deep subglaucous-green, rigid and fleshy, pale beneath with numerous irregular tortuose ridges along the middle, none of which are half the length of the leaf.

Stem succulent, ultimately fruticose, terete, stout immediately above the cotyledons, then suddenly becoming slender, pubescent with somewhat adpressed curved hairs, pale green; 1st internode $1.5 \mathrm{~mm}$. long; 2nd $4 \mathrm{~mm}$.; 3rd $1.1 \mathrm{~cm}$.; 4 th $1.35 \mathrm{~cm}$.; 5th $1 \cdot 15 \mathrm{~cm}$.

Leaves compound, cauline, alternate, stipulate, petiolate, bright green above, paler beneath; petioles subterete, channelled above, densely pubescent as well as the rachis of pinnæ when young, less so when older; stipules subulate, acute, free.

Nos. 1-6 inclusive. Bipinnate with one pair of pinnæ and nume- 
rous pairs of opposite, oblong, or obovate-oblong, minutely apiculate or subacute, shortly petiolulate leaflets; petiole excurrent between the pinnæ, with a subulate slender point; rachis of pinnæ excurrent in the form of a small subulate point.

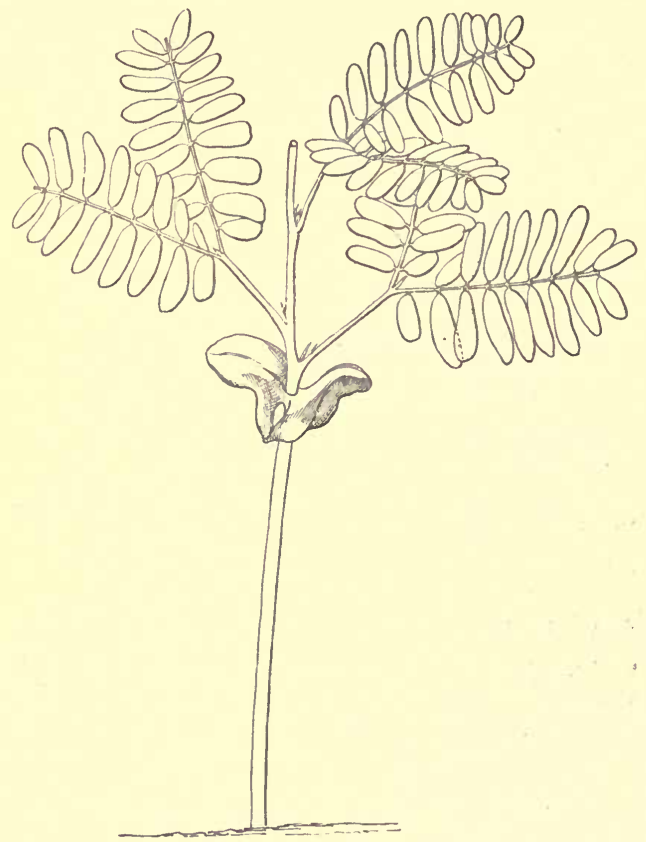

FIG. 308.-Acacia Burkittii. Nat. size.

Acacia Oswaldi, F. Muell.

Hypocotyl as in last species, substriate, $1 \cdot 3 \mathrm{~cm}$. to $2 \cdot 7 \mathrm{~cm}$. above ground, $1 \mathrm{~mm}$. thick.

Cotyledons obovate-oblong, obtuse, auricled or sagittate at the base, sessile, thickened at the margin, deep green above, paler beneath and wrinkled longitudinally, glabrous, fleshy, $1 \mathrm{~cm}$. long, $6 \mathrm{~mm}$. broad.

Stem suffrutescent, erect, terete, glabrous pale green ; internodes differing in length in different individuals. 
Plant No. 1.-1st internode $3 \mathrm{~cm}$. long; 2nd $2 \mathrm{~mm} . ; 3 \mathrm{rd}$ $1.5 \mathrm{~mm}$.; 4 th $2.25 \mathrm{~mm}$.; 5 th $7.5 \mathrm{~mm}$.; 6 th $3 \mathrm{~mm}$.; 7 th $1.1 \mathrm{~cm}$.; 8 th $5 \mathrm{~mm}$.; 9th $4 \mathrm{~mm}$.; 10th $5.5 \mathrm{~mm}$.

Plant No. 2.-1st internode $1.5 \mathrm{~mm}$. long; 2nd $1 \mathrm{~mm}$.; 3rd $5 \mathrm{~mm}$.; 4 th $1.15 \mathrm{~cm}$; 5 th $5 \mathrm{~mm}$.

Leaves compound and abruptly pinnate or reduced to phyllodes, cauline, alternate, stipulate, petiolate, glabrous; stipules small, slender, subulate, acute.

Plant No. 1.-No. 1. Pinnate, with one pair of pinnæ and excurrent at the apex to a filiform point; leaflets oblong, obtuse, subcuspidate.

No. 2. Dropped or broken off.

No. 3. Pinnate with three pairs of leaflets.

No. 4. With two small, ovate, acute, and one oblong leaflet; petiole laterally compressed.

Nos. 5-10. Reduced to lanceolate-oblong, acute phyllodes with their edges placed vertically, equally deep green on both sides, and longitudinally multinerved.

Plant No 2.-Nos. 1 and 2. With three pairs of oblong subcuspidate leaflets with subinvolute margins and unequal at the base on the posterior side.

No. 3. With two pairs of leaflets; petiole slightly compressed laterally and in a less degree than those of Nos. 1 and 2.

No. 4. With one pair of leaflets and a strongly projecting rachis ; petiole laterally compressed, linear-lanceolate with its edges vertical.

No. 5. Reduced to a phyllode.

Acacia verticillata, Willd. (fig. 309).

Hypocotyl erect, terete, green, soon becoming woody.

Cotyledons obovate, oblong, obtuse, subfleshy, deep green and shining, $4.5 \mathrm{~mm}$. long; $3.5 \mathrm{~mm}$. broad.

Stem woody, erect, terete, ribbed and furrowed or deeply striate, closely and minutely tuberculated, very sparsely pubescent, bright green at least when young; 1st internode undeveloped; 2nd $3 \mathrm{~mm}$. long; 3rd $6 \mathrm{~mm}$. ; 4th $6.5 \mathrm{~mm}$; 5th $2.5 \mathrm{~cm}$; 6th $1.6 \mathrm{~cm}$; 7th $8.5 \mathrm{~mm}$.; 8 th $7 \mathrm{~mm}$; 9 th $4.5 \mathrm{~mm}$.; 10 th $3 \mathrm{~mm}$.

Leaves at first pinnate, then bipinnate, then reduced to phyllodes, cauline, alternate (the phyllodes more or less verticillate, sometimes scattered), stipulate, petiolate, deep glaucousgreen above, glaucous beneath (phyllodes deep green like the petioles of the leaves), glabrous except the slightly pubescent petioles and midrib; petioles laterally compressed but less so than the phyllodes, deep green and shining, and projecting beyond the 


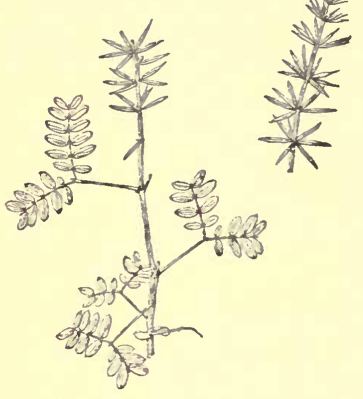

FI0. 309.-Acacia verticillata. Half nat. size.

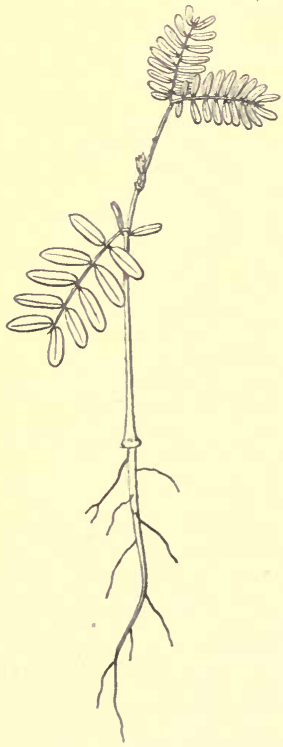

Fig. 310.-Acacia dealbata. Half nat. size. thick. pinnæ with a subulate acute aristate point; stipules small, subulate, acute, or lanceolate and aristate, reduced to small dark hairs where the phyllodes are verticillate or suppressed, but usually well developed where these are scattered.

No. 1. Pinnate with two pairs of leaflets.

Nos. 2-5 inclusive. Bipinnate with one pair of pinnæ; leaflets varying from obovate-oblong to oblong (the commoner form), obtuse, aristate, folding upwards and forwards face to face at night.

No. 6 (in specimen sketched). Reduced to a small laterally compressed phyllode, about $8 \mathrm{~mm}$. long.

Nos. 7-11. Forming a half whorl of phyllodes.

Nos. 12-16. Forming a broken or interrupted whorl.

No. 17. A solitary phyllode.

Nos. 18-23. A whorl of phyllodes.

Acacia dealbata, Link. (fig. 310).

Primary root tapering, with a few colourless lateral rootlets.

Hypocotyl terete, firm, glabrous, brownish, 3-4 $\mathrm{cm}$. long, $\cdot 5-1 \mathrm{~mm}$.

Cotyledons sessile, 6 or $7 \mathrm{~mm}$. long, $1.25 \mathrm{~mm}$. in diameter when rolled up, $3 \mathrm{~mm}$. when opened out, revolute, oblong, entire, obscurely nerved on the outer side, with a very prominent midrib below, thin, light green.

Stem firm, terete, but slightly uneven and downy, brownish-green; 1st internode undeveloped; 2 nd about $1 \mathrm{~cm}$. long, $5-1 \mathrm{~mm}$. thick. 
Leaves.-No. 1. Pinnate; leaflets linear-oblong, obtuse, entire, sessile or subsessile.

No. 2. Bipinnate; leaflets linear, obtuse, entire.

\section{Acacia acanthocarpa, Willd.}

Hypocotyl $2.5 \mathrm{~mm}$. long, light green or colourless.

Cotyledons thick, fleshy, broadly oblong, entire, slightly cordate at the base, obtuse, shortly petiolate, glabrous, trinerved.

Stem erect, terete, herbaceous at first, ultimately woody; 1 st internode $2-3 \mathrm{~mm}$. long, finely pubescent.

First leaves compound, abruptly pinnate, petiolate, stipulate, alternate, cauline ; leaflets opposite, shortly petiolulate, entire, ovaloblong, obtuse, eight in first leaf; the petiole and petiolules are slightly hairy.

NoтE.-The cotyledons are often three in number; out of eleven plants four had three cotyledons.

\section{Tribe INge玉.}

Pithecolobium Saman, Benth.

Hypocotyl woody, erect, terete, glabrous, $6.5 \mathrm{~cm}$. long, $2 \mathrm{~mm}$. thick, pale green.

Cotyledons (dropped).

Stem becoming woody, erect, terete, striate, densely hairy and almost woolly on the younger parts, pale green; 1st internode $2.5 \mathrm{~mm}$. long; 2nd $9 \mathrm{~mm}$.; 3rd $1.1 \mathrm{~cm}$.

Leaves cauline, compound, alternate (first two opposite), petiolate, stipulate and stipellate, ciliate, pubescent beneath and on the petioles, ultimately becoming glabrous except the petioles and apparently the margin.

No. 1. Simply and abruptly pinnate, with three pairs of opposite leaflets; lowest pair lanceolate, acute, slightly unequal at the base ; second pair oblong, obtuse, cuspidate ; third pair obovate, oblong, obtuse, cuspidate, all petiolulate; stipules free, subulate, acute.

The primary rachis of the first leaf frequently ends in a small, lanceolate, acute leaflet, thus making the leaf imparipinnate.

No. 2. Bipinnate, consisting of one pair of pinnæ or primary divisions, and terminating abruptly ; pinnæ of two pairs of leaflets with sometimes an odd one at the base laterally, terminating in a subulate acute mucro, stipellate at the base; leaflets unequal in size, oval, oblique, obtuse, or subcuspidate, unequal at the base; one of the basal ones is frequently very small, namely the one on the basal, anterior side of the pinna. 
No. 3. Similar to No. 2.

N.B.-The odd leaflet on the posterior basal side of the pinna is accounted for by the suppression of the corresponding anterior one.

\section{ROSACE $E$.}

Benth. et Hook. Gen. Pl. i. 600.

Fruit and Seed.-The carpels of which the ovary is composed in this Order vary from one to many, and are free or in some genera more or less connate and adherent to the tubular or variously concave receptacle. A monocarpellary type is represented by Prunus, while a two- to five-celled ovary is characteristic of the tribe Pomeæ.

Polycarpellary ovaries occur in Rubus, Potentilla, Fragaria, Geum, Spiræa, Rosa and others. Each carpel is one-celled or spuriously two-celled. The ovules are generally geminate, pendulous and anatropous, and superposed; and in this case the raphe is ventral and the micropyle superior. They are, however, solitary in the Potentilleæ, Roseæ, Poterieæ, and Neuradeæ. In some cases they are ascending with a dorsal raphe and inferior micropyle, as in the Chrysobalaneæ, Quillajeæ and others. Numerous ovules occur in Pyrus and others of the Quince type and in Spiræa. The fruit is extremely variable, being drupaceous in the Chrysobalaneæ, Pruneæ, and Rubeæ; in the latter the torus is elevated and conical. It is follicular in many of the Spiræeæ, consists of achenes in the Potentilleæ, Poterieæ, and Roseæ, and forms a pome in the Pomeæ. The receptacle of Fragaria is of considerable size and pulpy or succulent, while in Rosa ${ }^{1}$ it is urceolate, fleshy, and termed a ' hip,' while in the Poterieæ it is dry, coneave, cup-shaped or almost urceolate. In the Pomeæ it is fleshy and adherent to the ovary; and in certain cases is capsular, dehiscing by

1 There is some difference among botanical writers as to the use of these terms in the Rosaceæ, the concave receptacle being sometimes regarded as part of the calyz, and styled calyz-tube. 
valves. When greatly enlarged, as in Fragaria, Rubus, Rosa, some species of Potentilla and others, the carpels are numerous and small. In drupaceous and pomaceous fruits the endocarp is bony or woody, crustaceous or cartilaginous.

The seed is erect or pendulous in accordance with the ovule, with a membranous or coriaceous testa, occasionally winged. Endosperm is wanting in most cases, but not in all. The embryo is almost absolutely straight, with fleshy planoconvex cotyledons, resembling the almond, though in most cases very small. Rarely are the cotyledons large and foliaceous. The micropyle is close to the hilum, and the short radicle points to it.

All the seeds coming under notice are entirely exalbuminous, and their embryos amygdaloid. They may be classified according to relative size, character of the fruit, or peculiarities in the development of the receptacle. For instance, the species of Prunus, including the old genera Persica, Amygdalus, Armeniaca, Cerasus and Laurocerasus, all have very large amygdaloid embryos and a bony endocarp, and may be considered as the typical representatives of the Order as far as shape and general features of the seed and embryo are concerned. A very small type is met with in Spiræa, and endosperm occurs in some genera belonging to the same tribe, such as Neillia, Stephanandra, Gillenia, and Neviusa, as well as in Canotia, Eucryphia, and Euphronia belonging to the Quillajeæ.

The separate drupels of Rubus Balfourianus may be compared to those of Prunus on a small scale, and similarly the embryo which conforms closely to the shape of the seed and that again to the interior of the endocarp which is indehiscent and bony. The achenes of Potentilla insignis are laterally compressed, ridged and somewhat oblique, causing the embryo to assume the same general outline and the radicle to be bent on one side, a very unusual circumstance in the Order. The fruit of the Poterieæ consists of one to three achenes enclosed in the concave, urceolate or closed receptacle. When only one achene is enclosed it conforms to the interior of the cavity, but when two or three share the space they are more or less angled by mutual pressure. The receptacle of Agrimonia 
Eupatoria is turbinate and terminated by a great number of hooked processes. That of Acæna ovalifolia (fig. 318) is small, elliptic, and furnished below the apex with two to four strong, spine-like processes with barbed tips. The elliptic receptacle of Acæna myriophylla is covered all over with smaller barbed processes. That of Poterium Sanguisorba (fig. 320) is ovoid and smooth. The cotyledons of all the four types belonging to the Poterieæ are slightly auricled at the base so as to fill the space in the seed while at the same time accommodating the radicle. In the tribe Roseæ we have a higher development of what occurs in the Poterieæ unless we regard the latter as degraded forms of the Rosaceæ, which is not unlikely, and is, indeed, suggested by several circumstances in addition to those affecting the fruit. The achenes of the different species of Rosa are very numerous and included in an urceolate, ultimately baccate receptacle. The seed in the tribe Pruneæ is protected by a bony endocarp; but in the Rosex the enlarged receptacle only is fleshy, while the whole of the ovary wall in Rosa is bony, suberous, or coriaceous in order to protect the seeds. The achenes are corered with short bristly hairs along the dorsal suture in many species. The embryo resembles the Almond in miniature, and the seed being solitary in each achene conforms to the interior of the latter. The seeds and embryos in the tribe Pomex hare much in common with all of the foregoing, but they vary somewhat in different genera and species according to modifications of the true fruit or walls of the ovary. In Rosa, as already noted, the achenes or fruits are quite free from one another and from the surrounding hollow receptacle. The carpels in the Pomeæ vary from two to five and are generally quite free from one another or ultimately separable, but they are closely adnate to or united with the inner surface of the greatly enlarged, fleshy receptacle. We find two very distinct modifications of the ovary walls of Pyrus. Those of P. Malus are cartilaginous, those of P. communis often very thin and easily broken, while in P. Aria this is always the case. P. germanica and Mespilus grandiflora, often classed together under the genus Mespilus, have a bony endocarp, and the shape of the seed is modified by it. 
This may be seen by reference to Cratægus Pyracantha, where a similar condition prevails. The globose fruit consists of five carpels surrounded by the fleshy receptacle. The ralls of the carpels become greatly ossified or, properly speaking, lignified and thickened; and seeing that each carpel or pyrene constitutes the fifth part of a sphere, they are trigonous or wedge-shaped in transverse section, and modify the shape of the seed and embryo in conformity with their own. The loculi in the fruits of the species of Pyrus generally are proportionately large so that they do not affect the shape of the seed. In Pyrus Cydonia, P. japonica, and P. chinensis, the ovules, and afterwards the seeds, are very numerous in each loculus, a most unusual circumstance in the Order.

Seedlings.-As in the seeds so in the seedlings we find a great similarity prevailing amongst the cotyledons of different species and genera throughout the Order. The embryo is amygdaloid, varying for the most part in size, dependent upon the size of the seed, and that again upon the size of the endocarp or the achene. The cotyledons in the seedling stage are nearly all of the same general outline, varying between oral and oblong. They are for the most part shortly petiolate with a slender, rarely a broad petiole, and being either thick or opaque they do not often exhibit much of the venation beyond the midrib. Those which are more or less deeply emarginate form a second type; while a third form has the lamina cordate at the base. Taking the type, which varies between oblong, oval, and suborbicular, two species might be singled out as extreme modifications. These are the Cherry and Rosa berberidifolia (fig. 322). The first has spathulateoblong, fleshy, entire cotyledons with glands at the base. The second has narrowly oblong, glandular-ciliate cotyledons with a rather broad petiole. The Spiræas, having generally very small seeds, have small cotyledons. S. callosa (fig. 311) represents one of the shrubby tribe. The primary leaves are small and vary from cuneate to broadly ovate. The ultimate leares are lanceolate and unequally serrate.

The cotyledons of Rubus are moderately large, owing to the size of the seed. Those of Rubus phœnicolasius (fig. 312) are shortly oblong, while those of R. rugosus are broadly oval. 
Both show a very gradual evolution of the leaves, but particularly R. phœnicolasius where the first is ovate, the second and third reniform, and the fourth to the seventh inclusive are oblong-cordate, and more or less lobed.

The Potentilleæ have mostly small seeds and small cotyledons, but some striking rariations in this respect may be found amongst the species of Geum as represented by G. Freemontii (fig. 313) and G. coccineum, the latter of which has broadly oblong trinerred cotyledons. G. urbanum is intermediate between these extremes. All have pinnate leares ultimately, while the first one is reniform or triangular with many intermediate forms in the seedling stage. The fourth leaf of G. coccineum is cordate, and the fifth lyrate-pinnatifid. The cotyledons of all the species of Potentilla observed are small and rary from oral to oblong-oval and suborbicular. As far as the leaves are concerned two very distinct types may be noticed, namely, those with pinnate leares such as Potentilla anserina (fig. 316), P. fulgens (fig. 315), and P. bifurca (fig. 317), and those with digitate leaves represented by $P$. argyrophylla and P. reptans (fig. 314). The species of Rosa conform to the general type in having oval or oblong cotyledons. R. berberidifolia, as already mentioned, is an extreme type. The cotyledons are generally moderately large, and in R. moschata this is particularly the case; they are also minutely emarginate, trinerved and ciliate. All the leaves of $\mathrm{R}$. berberidifolia are cuneate, simple and doubly serrate. The first three of $\mathrm{R}$. moschata are trifoliolate. More typical examples are met with in $\mathrm{R}$. rugosa and $\mathrm{R}$. macrocarpa. The cotyledons are oral, the first leaf cuneate and simple, the second trilobed or trifoliolate, while a number of succeeding ones are trifoliolate.

The members of the tribe Pomeæ have moderately large cotyledons varying from oblong-oval to obovate in conformity to the seeds containing them. They are generally very shortly petiolate, sometimes subsessile, and more or less evidently trinerved though rather opaque. Pyrus Aucuparia (fig. 323) shows the trinerved character. The first leaf is ovate and trifid; the second tripartite, and succeeding ones pinnate. The cotyledons of Cratrgus Oxyacantha (fig. 324) and C. 
mexicana are also trinerved. The primary leaves of the first named are trifid, gradually increasing in size; the first two of the latter are oblong, succeeded by two other oblong-elliptic ones. The cotyledons of Cotoneaster Simonsii (fig. 325) agree strictly with the type. The leaves are ovate and entire from the first to those of the adult.

The second group includes a number of species belonging to different genera, the cotyledons of which do not differ materially from those of the last group except in being more or less deeply emarginate. This type is well represented by Spiræa opulifolia, having oblong-obovate, emarginate cotyledons. The first leaf is broadly ovate, succeeded by two broader trifid ones; all are palmately trinerved. The cotyledons of Agrimonia viscidula are transversely oblong or suborbicular, rather deeply emarginate, and cordate at the base. The first leaf is cordate-orbicular, and the second one pinnately trifoliolate. The cotyledons of Eucryphia cordifolia are broadly-oblong, trinerved, but very slightly emarginate. The first four leares are oblong. Rosa moschata might hare been placed here, but its cotyledons are only slightly emarginate. The same might be said of Rubus thyrsoideus, which has broadly oblong or oral, minutely emarginate, glandular-ciliate cotyledons. The first three or four leaves are broadly ovate, and others show gradual evolution.

The most distinct divergence from the type is that found in a number of closely allied plants constituting the tribe Poterieæ, and therefore forming a very natural group. The cotyledons are broadly oblong and short, or oblong-orbicular, deeply notched or cordate at the base, slightly emarginate, and petiolate. This type is well exemplified in Acæna myriophylla (fig. 319). The first leaf is pinnately five-foliolate, and the ultimate leares pinnate, pinnatisect with linear or subulate acute segments. To this may be added A. ovalifolia, Agrimonia Eupatoria, and Poterium Sanguisorba (fig. 321). The latter shows numerous incurved, slender veins proceeding from the midrib of the cotyledons. The two primary leaves are trifoliolate, the ultimate ones imparipinnate with numerous orbicular or shortly oblong, deeply toothed leaflets. The basal notch is due to the cotyledons becoming 
prolonged at the base in order to occupy the available space in the bluntly pointed upper end of the seed, while they at the same time accommodate the stout radicle in the sinus. Alchemilla aphanoides, also belonging to the Poterieæ, has oval, obtuse, entire, petiolate cotyledons, with the petioles connate and sheathing at the base, and therefore agrees with the pre-

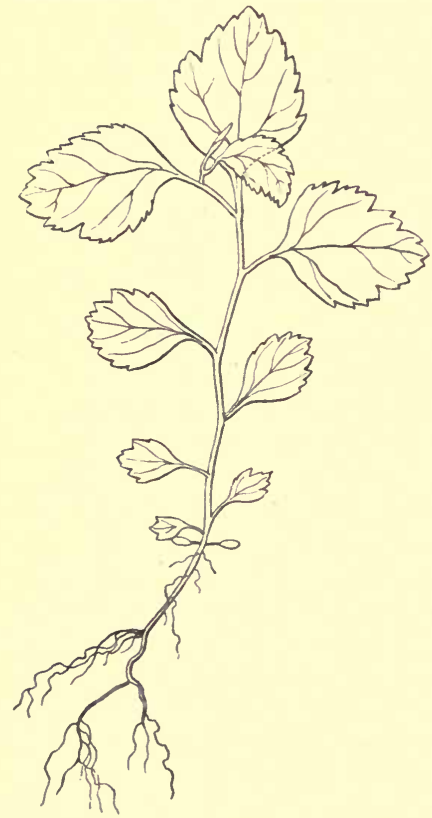

Fig. 311.-Spircea callosa. Nat. size. vailing type of cotyledon in the Order rather than with its allies. The first leaf is trifid with entire segments; the second more deeply so with the middle lobe tridentate; and the next three are tripartite with cuneate, variously toothed segments:

Spiræa callosa, Thunb. var. (fig. 311).

Primary root slender, flexuous, giving off secondary rootlets, yellowish.

Hypocotyl erect, terete, or ascending, short, glabrous, pale green, $3-6 \mathrm{~mm}$. long, very slender.

Cotyledons small, petiolate, glabrous, pale green ; lamina $2.5 \mathrm{~mm}$. long, 1.5 $\mathrm{mm}$. broad ; petiole $1.5 \mathrm{~mm}$. long.

Stem shrubby, wiry erect, flexuous, pubescent with upcurved and incurved hairs, pale green, soon becoming yellowish, ultimately brown; 1st internode $1.25 \mathrm{~mm}$. long; 2nd $2 \mathrm{~mm}$.; 3rd $5 \mathrm{~mm}$.; 4th $7 \mathrm{~mm}$; 5 th $7 \mathrm{~mm}$.; 6 th $1 \mathrm{~cm}$.; 7th $6.5 \mathrm{~mm}$.; 8 th $5 \mathrm{~mm}$.

Leaves simple, cauline, alternate, exstipulate, petiolate, sparsely pubescent, ultimately subglabrous except on the principal nerves and the margin; stipules obsolete or very caducous; petioles short, shallowly channelled on the upper side, pubescent. 
No. 1. Small, cuneate, tridentate.

Nos. 2 and 3. Cuneate and serrate along the upper half. half.

No. 4. Subelliptic, cuneate at the base, serrate along the upper

No. 5. Elliptic-cuneate, unequally serrate along the upper half.

No. 6. Broadly ovate, obtuse, becoming doubly serrate along great part of its length, somewhat oblique at the base and scarcely cuneate, subtrinerved.

No. 7. Orate, becoming doubly serrate, subtrinerred.

No. 8. Broadly orate, obtuse or subacute, becoming doubly serrate.

Ultimate leares lanceolate, acuminate, serrate and doubly so above the middle, with numerous ascending nerves, reticulate, deep green abore, glaucous beneath, subglabrous except on the margins and principal nerres.

\section{Spiræa opulifolia, $L$.}

Hypocotyl erect, terete, glabrous, green or reddish, 5-7 mm. abore the soil, and becoming stouter upwards.

Cotyledons oblong-obovate, emarginate, with two pairs of alternate, ascending, branching nerves, the uppermost incurving and uniting with the midrib under the apical sinus, petiolate, glabrous, rather opaque, and showing the renation best by transmitted light ; lamina horizontal or decurved, 5-6.25 mm. long, 3-4 mm. wide; petiole ascending or suberect, channelled above, slightly convex on the back, slightly connate at the base, about $1 \mathrm{~mm}$. long.

Stem erect, two-edged or tro-winged by the decurrent edges of the petioles, pale green, soon becoming brown, glabrous, ultimately shrubby ; 1st internode $2 \cdot 25-6.25 \mathrm{~mm}$. long ; 2nd 4-5 mm.

Leaves simple, cauline, alternate, stipulate, petiolate, alternately or suboppositely penninerred, with the nerves running straight into the tips of the lobes, glabrous and bright green above, paler beneath, shining when young; petioles semiterete, channelled abore, widening upwards, slightly winged at the edge on the upper half, glabrous; stipules half-ovate, acuminate, serrated on the posterior side, attached to the very base of the petiole.

No. 1. Broadly ovate, obtuse, palmately trinerved, dentateserrate, with obtuse, gland-tipped teeth.

Nos. 2 and 3. Trilobulate, dentate-serrate with obtuse, glandtipped teeth, palmately trinerved with strong alternate nerves above.

\section{Eucryphia cordifolia, Cav.}

Hypocotyl erect, terete, finely pubescent, $1 \cdot 5-2 \mathrm{~cm}$. long, reddish. 
Cotyledons coriaceous, slightly emarginate, broadly oblong or oval, shortly petiolate, minutely pubescent, dark green above, tinged with red beneath, trinerved.

Stem erect, terete, herbaceous at first, pubescent; 1 st internode 2-3 mm. long; 2nd 5-6 mm.

First leaves simple, cauline, opposite, oblong, acute, serrate, shortly petiolate, stipulate, pubescent, glabrous beneath, light green above, subglaucous-green or tinged with red beneath, pinnatinerved; venation very distinct on the under side.

\section{Rubus phœnicolasius, Maxim. (fig. 312).}

Hypocotyl erect, terete, sparsely glandular-pubescent or subglabrous, green, soon becoming brown and suffrutescent, 5-7 mm. above the soil.

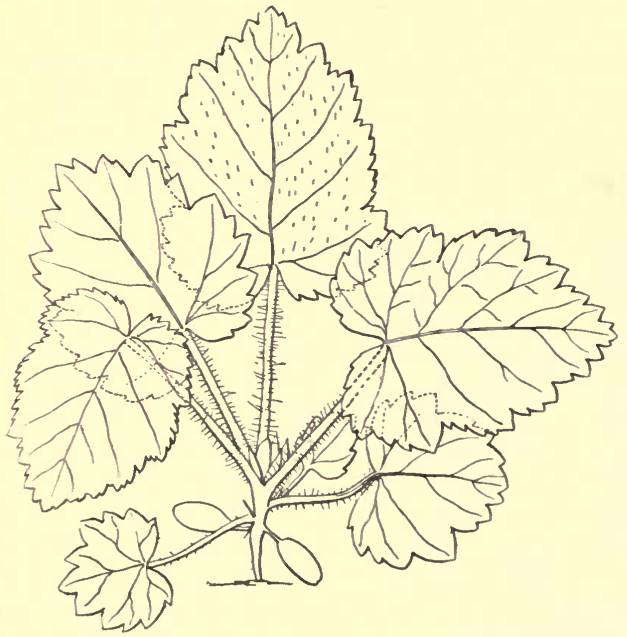

Fra. 312.-Rubus phænicolasius. Nat. "size.

Cotyledons petiolate, sparsely glandular-hairy; lamina shortly oblong, obtuse, $7 \mathrm{~mm}$. long, $4.5 \mathrm{~mm}$. broad ; petiole slender, tapering to a broadish base, channelled above, $3.5 \mathrm{~mm}$. long.

Stem suffrutescent, erect at first, terete, glandular-hairy, ultimately 8-12 feet long; 1st internode undeveloped; 2nd $1 \mathrm{~mm}$. long; 3rd $1 \mathrm{~mm}$. 
Leaves at first simple, ultimately trifoliolate, cauline, alternate, stipulate, petiolate, glandular-hairy on both surfaces, felted beneath with a white tomentum, penninerved with alternate or subopposite nerves; petioles semiterete, channelled above, densely glandularhairy and glandular-setose, the hairs and setæ of a reddish-purple hue; stipules slender, subulate, attenuate, glandular-hairy.

No. 1. Small, ovate, tridentate, trinerved.

No. 2. Reniform, five-nerved, dentate.

No. 3. Rotund-cordate, obtuse, irregularly dentate.

No. 4. Cordate, irregularly or doubly dentate.

No. 5. Cordate, acute, doubly dentate.

Nos. 6 and 7. Oblong-cordate, acute, doubly dentate or sublobulate with acute teeth.

Ultimate leaves pinnately trifoliolate, pubescent and dark green above, felted with white tomentum beneath, glandular-hairy and setose on the principal nerves; terminal leaflet very large, rotundcordate, acuminate, trifid and doubly dentate-serrate, strongly penninerved, much reticulate with the stronger nerves running into the lobes or large teeth; lateral leaflets broadly ovate, subacuminate, deeply dentate-serrate, oblique on the posterior side, smaller but otherwise like the terminal one, rather unequal but not cordate at the base.

Leaves on the flowering branches similar to the above, but gradually becoming smaller in size as the inflorescence is approached; petioles terete, very narrowly channelled on the upper side, densely glandular-hairy and setose; stipules subulate or linear, attenuate, slender, shortly adnate to the petioles.

\section{Rubus rugosus, Sin.}

Primary root tapering, slender, soon becoming wiry, and giving off numerous strong as well as small lateral fibres.

Hypocotyl terete, suffrutescent, thickened upwards, glandularhairy, $9 \mathrm{~mm}$. long.

Cotyledons shortly and broadly oval, glandular-hairy on the margin, otherwise glabrous, and similar to last species.

Stem as in last species, glandular-setose; 1st internode undeveloped; 2nd 1.5 mm. long; 3rd $6.5 \mathrm{~mm}$.; 4th $3 \mathrm{~mm}$.

Leaves simple, coarsely hairy on both sides and glandular-setose on the nerves and petioles; stipules free, linear, coarsely hairy.

No. 1. Subtriangular, coarsely dentate-serrate.

No. 2. Cordate, coarsely dentate-serrate.

No. 3. Cordate, lobulate, and coarsely dentate-serrate, palmately trinerved. 
No.4. Cordate elongated, lobulate but scarcely pinnatifid, coarsel y serrate with mucronate serratures, palmately five-nerved.

Ultimate leaves simple, palmately five- to seven-lobed and -nerved, cordate at the base, closely covered with bulbous-rooted hairs; lobes deltoid, acute or obtuse and more or less rounded, acutely and more or less doubly serrate.

Geum Freemontii, Hort. (fig. 313).

Primary root slender, tapering, brownish, with fibrous lateral rootlets, perennial.

Hypocotyl tapering, whitish, glandular-hairy, $4 \mathrm{~mm}$. long.

Cotyledons small, glandular-pubescent, lamina $2.75 \mathrm{~mm}$. long, $2 \mathrm{~mm}$. broad; petiole $2.5 \mathrm{~mm}$. long, dilated and sheathing at the base.

Stem herbaceous.

Leaves radical, simple, ultimately imparipinnate, alternate, stipulate, petiolate, glandular-hairy with hairs of very unequal length ; petioles slender, channelled above, and sheathing by means of the

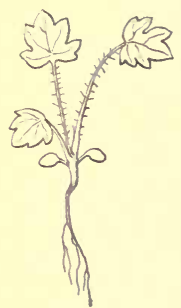

Frg. 313.

Geum Freemontii.

Nat. size. stipules; stipules wholly adnate to the petiole by one side.

No. 1. Reniform, palmately five-nerved, with rounded or obtuse teeth.

No. 2. Rotund-cordate, palmately seven-nerved and -fid, with suboval, mucronate lobes.

No. 3. Cordate, palmately seven-nerved and -fid, with oblong-ovate, mucronate lobes.

Ultimate leaves imparipinnate, oblanceolate in outline, hairy on both sides, light green above, paler beneath; leaflets gradually becoming smaller from the apex of the leaf towards the base with occasional minute, lanceolate, entire ones interposed, deeply incise-serrate, cut or subpinnatifid especially on the basal posterior side, with alternate, strong nerves running into the lobes and teeth; terminal leaflet elliptic; the pair below that obliquely ovate, cut away on the anterior basal side; below this the leaflets are ovate, then rotund-ovate, gradually becoming rotund and cuneate at the base; petiole semiterete, channelled on the upper side; stipules hyaline, ciliate, adnate to the petiole, with ovate, acute, free points.

The cotyledons of G. urbanum resemble those of G. Freemontii.

Geum coccineum, Sibth. et Sm.

Primary root and hypocotyl very similar to those of last species, but larger and flexuous. 
Cotyledons hairy; lamina broadly oblong, obtuse, $8 \mathrm{~mm}$. long, $6 \mathrm{~mm}$. broad ; petioles thin, grooved, dilated and connate at the base.

Stem herbaceous and always short, ultimately developing a flowerstem.

Leaves radical, hairy all over; petioles channelled above, semiterete; stipules mostly adnate to the petiole.

No. 1. Triangular, obtuse, crenate-serrate.

No. 2. Reniform, crenate-dentate, three- to five-nerved.

No. 3. Rotund-cordate, palmately five-nerved, crenate-dentate.

No. 4. Cordate, obtuse, crenate-dentate, palmately five-nerved, faintly lobulate, with a small isolated lobe on the petiole.

No. 5. Lyrate-pinnatifid ; terminal lobe cordate, obtuse, lobulate ; lateral segments small, irregular in size and shape.

Ultimate leaves lyrate-pinnatifid.

Potentilla reptans, $L$. (fig. 314).

Hypocotyl mostly subterranean, tapering into the root, short.

Cotyledons rotund, glabrous; $3 \mathrm{~mm}$. in length and breadth; petiole channelled above, $2.25 \mathrm{~mm}$. long.

Stem never developing, but throwing out long axillary branches or runners, bearing rosettes of leaves at definite points which reproduce the plant vegetatively.

Leaves compound, digitate (first two small, simple), radical and cauline, hairy on both sides; leaflets with alternate, ascending nerves running into the teeth ; petioles subterete, cliannelled above, dilated at the base, hairy, reddish at the base and green upwards; stipules adnate to the petiole for two-thirds their length, reddish, hairy with ovate, acuminate free points.

No. 1. Simple, reniform, three- to five-nerved, toothed.

No. 2. Rotund-reniform, subtruncate at the base, three- to fivenerved, deeply toothed.

Nos. 3-6. Digitately trifoliolate; terminal leaflet cuneate, bluntly and rather deeply toothed on the upper half ; lateral leaflets obliquely cuneate, and toothed like the terminal or subbifid, with two strong nerves foreshadowing further division on the posterior or basal side.

Ultimate leaves digitately or subpedately five-foliolate, hairy on both surfaces as well as the petioles, very variable in their size according to the conditions of cultivation; leaflets oblanceolate, serrate, or in vigorous specimens oblanceolate-oblong, coarsely inciseserrate; basal pair obtained by fission from the middle pair, to the petiolules of which they remain attached; stipules attached to the petiole for half their length, with subulate, acuminate, free points. 
Potentilla fulgens, Wall. (fig. 315).

Hypocotyl subterranean.

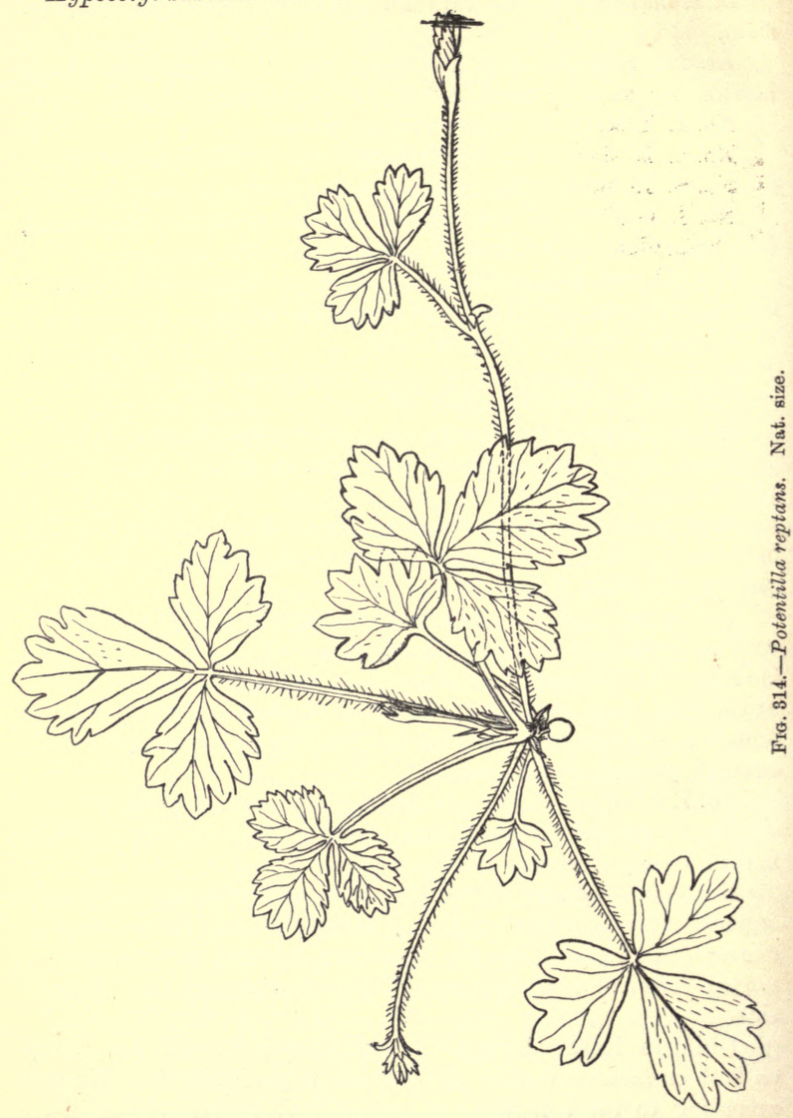

Cotyledons small, oval or obovate, $2.5 \mathrm{~mm}$. long, $2 \mathrm{~mm}$. broad ; petiole channelled above, $1.5 \mathrm{~mm}$. long.

Stem herbaceous and elongated when about to flower. No runners present. 
Leaves mostly radical, compound (except a few primary ones), alternate, hairy all over; petioles semiterete, channelled above; stipules hyaline and thin, with a green nerve, adnate to the petiole for about three-fourths of their length, with ovate, acute, free points, hairy.

No. 1. Simple, rotund-ovate, dentate-serrate.

No. 2. Simple, rotund, truncate at the base, dentate-serrate.

No. 3. Ternate; lateral leaflets oblong, subdimidiate, serrate on

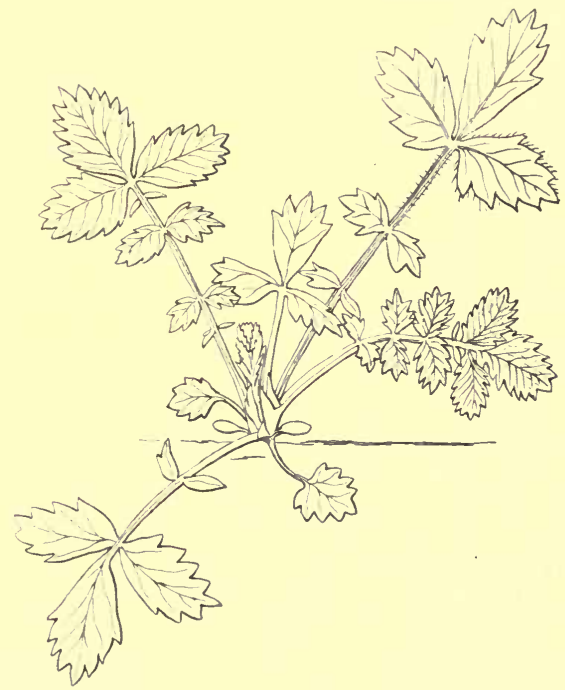

Fig. 315.-Potentilla fulgens. Nat. size.

the posterior side, and almost entire on the anterior side, subsessile ; terminal leaflet cuneate, serrate at the apex.

No. 4. Five-foliolate; basal pair of leaflets small, distant from the rest, lanceolate, acute; the other three similar to those of No. 3, but a little more serrate.

No. 5. Seven-foliolate; basal pair small, unequal, subalternate, one lanceolate, acute, the other subovate and trifid ; next pair small, ovate, serrate ; terminal three similar to those of No. 4.

No. 6. Eleven-foliolate; terminal three large, oblong, serrate; the pair next below minute, lanceolate, acute, entire; next pair 
larger, ovate, serrate; 4th pair below terminal leaflet small, ovate, serrate; basal pair minute, lanceolate.

No. 7. Eleven-foliolate; second pair below the terminal leaflet very small, lanceolate, acute, entire. All the others serrate and decreasing in size from the terminal one downwards.

Ultimate leaves long, linear-lanceolate, imparipinnate with very numerous leaflets, generally opposite in the upper part of the leaf and alternate lower down, silky on both sides; many of the uppermost leaflets decurrent on the rachis by their posterior basal side, oblong, serrate with long, subulate, acute, serratures; middle ones smaller and not decurrent; lower ones gradually becoming smaller towards the base, ovate and serrate, or the lowermost minute, lanceolate, acute, entire; stipules hyaline and hairy, one-nerved, attached for some distance to the petiole, with the free part oblong-subulate, acute.

\section{Potentilla argyrophylla, Wall.}

Hypocotyl 3-5 mm. long, $\cdot \tilde{v}-\cdot 75 \mathrm{~mm}$. thick, sparsely pubescent. Cotyledons similar to those of P. reptans, but rotund-oval.

Stem herbaceous, deciduous,

Leaves radical, toothed, lobed or ternate, or digitately five-foliolate.

No. 1. In weak seedlings trifid, in stronger ones five-fid, pale green above, and sparsely hairy, subglabrous below and pale, almost glaucous; lobes obtuse, mucronate; petiole terete, slightly channelled above, sparsely hairy; stipules adnate throughout their length to the petiole, and sheathing the younger leaves.

No. 2. Five- to seven-fid, palmately five-nerved.

No. 3. Seven- to nine-fid, and similarly palmately nerved, more densely clothed with long silky hairs.

Ultimate leaves digitately three- to five-, rarely seven-foliolate, pale green and silky above, felted with white tomentum beneath; leaflets obovate or more often oval, acutely and deeply serrate, basal pair obtained by fission from the middle pair; when seven leaflets are present, the three terminal ones are obtained by fission of the original one into three, and the uppermost pair are attached by their whole width to the primary midrib.

Radical leaves with small scarious stipules adnate to the long petioles for a great part of their length ; cauline leaves with gradually shortening petioles, the uppermost almost sessile, and having large, foliaceous, toothed stipules. 


\section{Potentilla anserina, $L$. (fig. 316).} flexuous.

Primary root tapering, wiry, with short lateral rootlets, sub-

Hypocotyl short, tapering indistinguishably into the root.

Cotyledons small, oval, obtuse, glabrous, $3.5 \mathrm{~mm}$. long, $2 \cdot 25 \mathrm{~mm}$. broad; petiole flattened above or slightly grooved, convex beneath, $3 \mathrm{~mm}$. long.

Stem short, herbaceous, throwing off procumbent, stoloniferous flowering branches.

Leaves compound (No. 1 simple), radical, green above and hairy in a young state, more or less densely silky and silvery below and on both surfaces in the adult, very densely beneath; petioles semiterete, channelled above, silky, ultimately densely so; stipules adnate to the petiole for two-thirds of their length, and connate throughout the other third, forming a sleath around the bud or next younger leaf, ultimately splitting and becoming lacerated along their edges on the side of the bud or leaf opposite to the leaf to which they belong, pale brown, scarious, glabrous or thinly hairy.

No. 1. Reniform-triangular, rounded at the base, obscurely five-nerved, three-, five-, to seven-toothed.

No. 2. Subpinnately or digitately trifoliolate.

No. 3. Pinnately five-foliolate; basal

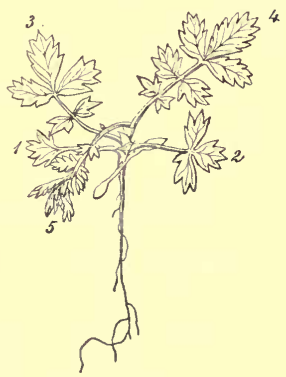

FIg. 316.-Potentilla anserina. Half nat. size. pair of leaflets much the smallest, deeply tridentate; terminal leaflet oval, incise-dentate, or serrate.

No.4. Pinnately seven-foliolate; leaflets incise-serrate, decreasing in size from the terminal three to the basal pair, which are small and three- to four-toothed.

No. 5. Interruptedly pinnate; leaflets incise-serrate except the miniature ones; terminal leaflet oval, next pair oblong, next pair minute, lanceolate, aristate, entire; fourth pair from apex oblong, then a minute leaflet, then an ovate pair, and at the base two minute ones.

Ultimate leaves obovate-oblong or oblong, interruptedly imparipinnate, with numerous alternate and opposite leaflets, which attain their maximum size above the middle of the leaf, and are smallest at the base with the exception of the miniature intermediate ones, 
which are entire or incise-serrate according to their size ; terminal three leaflets imperfectly divided at the base and decurrent on the primary midrib, acutely incise-serrate; middle ones and all the larger oblong, rounded at the apex, deeply and acutely incise-serrate.

Potentilla bifurca, L. (fig. 317).

Primary root fleshy and stout, suddenly tapering to a long slender point, and throwing off numerous branching adventitious rootlets.

Hypocotyl scarcely developed.

Cotyledons small, ovate-oblong, very obtuse, glabrous, $4 \cdot 5 \mathrm{~mm}$.

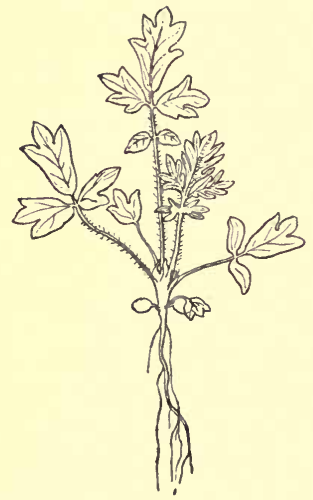

Fig. 317.-Potentilla bifurca. Half nat. size. long, $3.5 \mathrm{~mm}$. broad; petiole dilated, sheathing at the base, $4.5 \mathrm{~mm}$. long.

Stem herbaceous.

Leaves simple, more or less pinnati-fid or -sect, radical when the plant is young, sparsely hairy on both surfaces, bright green above, paler beneath; petioles subterete, flattened above or subchannelled, hairy, pale green; stipules adnate to the petiole nearly to the top, strongly ciliate at the margin, colourless, with an ovateacute greenish tip.

No. 1. Rotund, shallowly trifid. trifid.

No. 2. Similar, larger, more deeply

No. 3. Ternately pinnatisect; lateral lobes oval, obtuse; terminal lobe cuneate, trifid.

No. 4. Similar to No. 3, but larger, and the lateral lobes oblique, deeply bifid on the posterior side, with a tooth on the anterior side.

No. 5. Pinnately five-foliolate; basal pair of lobes small, ovate, entire; middle pair of lobes obliquely trifid ; terminal lobe large, cuneate-oblong, pinnatifid.

No.6. Bipinnatisect with narrowly oblong, obtuse, entire segments.

Alchemilla aphanoides, Mutis.

Primary root very long and branching freely.

Hypocotyl terete, glabrous, 4-6 mm. long.

Cotyledons oval, obtuse, entire, glabrous, petiolate ; lamina $2 \cdot 5-$ 
$3 \mathrm{~mm}$. long, $2-2.25 \mathrm{~mm}$. wide; petiole flattened above, connate and sheathing at the base, $1 \cdot 5-2 \mathrm{~mm}$. long.

Stem herbaceous, erect with the lower internodes scarcely at all developed, thinly and coarsely hairy.

Leaves radical and cauline, alternate, palmately nerved and divided, ciliate, sparsely pilose or almost glabrous, pale glaucousgreen above, paler and glaucous beneath; stipules adnate to the petiole for more than half their length, with the free portion subulate, acute, ciliate, green, sheathing the stem ; petiole channelled above, thinly hairy.

No. 1. Trifid with entire segments.

No. 2. More deeply trifid, with its terminal segment cuneate and trifid, and the lateral ones bifid.

No. 3. Tripartite, with the lateral segments more divided and toothed.

Nos. 4 and 5. Tripartite with cuneate segments; terminal one trifid and cut with obtuse segments; lateral ones unequally bifid and variously cut.

\section{Agrimonia viscidula, Bunge.}

Primary root long, tapering, colourless, giving off strong lateral fibres.

Hypocotyl extremely short, subterranean, colourless, glandularpubescent.

Cotyledons transversely oblong or suborbicular, rather deeply emarginate, cordate at the base, petiolate, thickened and rather fleshy, glandular-pubescent on both surfaces and on the petiole, green above with an indistinct indication of three nerves, whitish underneatl and gibbous with three or four incurved nerves on each side of the midrib; lamina $5-6.5 \mathrm{~mm}$. long, 6-7.5 $\mathrm{mm}$. wide; petiole channelled on the upper side, connate at the base, 6-7.25 $\mathrm{mm}$. long.

Stem herbaceous, erect, terete, hairy and glandular-pubescent; 1st internode undeveloped; 2nd $1.8 \mathrm{~cm}$. long, or shorter, varying as the seedlings are more or less crowded.

Leares compound (No. 1 simple) radical and cauline, alternate, penninerved, coarsely hairy and rather densely glandular on both surfaces; glands sessile; petiole channelled on the upper surface, semiterete; stipules in the seedling ovate, obtuse, hairy and glandular.

No. 1. Simple, orbicular, cordate at the base, radiately nerved, shallowly lobed or coarsely toothed with the teeth numerous and tipped with a mucro. 
No. 2. Pinnately trifoliolate; terminal leaflet obovate, cuneate, coarsely serrate; lateral leaflets unequally or obliquely ovate.

Acæna ovalifolia, Ruiz et Pav. (fig. 318).

Pistil apocarpous, superior, of one carpel which is one-celled, one-ovuled; ovule pendulous from near the apex of the ventral suture, anatropous; radical superior.

Fruit an achene, oblong-fusiform, enclosed in the receptacle

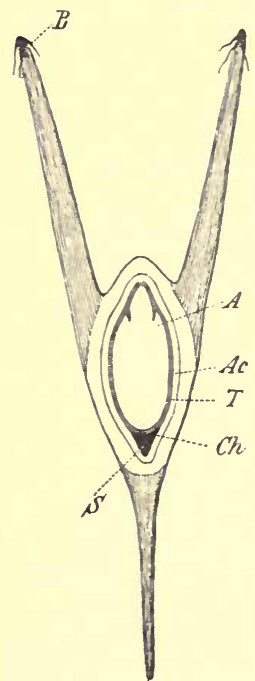

Fig. 318.-Acena ovalifolia, $\times 10$. Longitudinal section of the fruit: $A c$, achene; $T$, testa ; $C h$, chalaza; $S$, small empty space; $A$, auricle; $B$, barbs or bristlelike appendages.

which grows up around it, one-seeded, indehiscent, glabrous, dark-coloured ; receptacle oboroid or obconical, much narrowed to the base, and again contracted at the orifice enclosing the fruit, tipped with the small persistent calyx-teeth, subtetragonal and produced at its upper end into two to four unequal spine-like appendages tipped with small reversed barbs, glabrous, loosely reticulate, dark brown.

Seed conforming to the interior of the achene, oblong, suddenly tapered to a conical point just above its greatest diameter, which is considerably above its middle, pale straw-coloured, glabrous; testa thin, membranous; micropyle and hilum contiguous, inconspicuous, basal, superior; raphe forming a slender, slightly darker line passing along one side; chalaza apical and inferior, forming a brown spot on the lower end of the seed.

Endosperm absent.

Embryo straight, filling the whole of the interior of the seed, colourless ; cotyledons oblong, obtuse, entire, minutely auricled at the base, plano-convex with their edges generally to the two larger spines of the pericarp, but sometimes obliquely to them; radicle turbinate or shortly conical, obtusely pointed, lying in the conical tip of the seed, about a third or a quarter as long as the cotyledons.

Acæna myriophylla, Lindley (fig. 319).

Primary root simple, tapering.

Hypocotyl mostly subterranean, terete, glabrous, colourless below and green where exposed, 7-9 $\mathrm{mm}$. long. 
Cotyledons shortly and broadly oblong, or oblong-orbicular, obtuse, deeply cordate at the base, petiolate, minutely emarginate, radiately seven-nerved from the base, the two upper lateral nerves incurved and uniting with the midrib at the apex, finely reticulate (venation seen by transmitted light only) deep opaque green above, paler beneath, glabrous ; lamina $4-5 \mathrm{~mm}$. long, $3 \cdot 5-4 \cdot 5 \mathrm{~mm}$. wide; petiole semiterete, channelled above, subperfoliate at the base, thinly and minutely hairy, 7-9 $\mathrm{mm}$. long, the margin narrow and colourless with openings into the interior.

Stem herbaceous, procumbent ; primary internodes undeveloped.

Leaves compound, radical and cauline, alternate, stipulate, petiolate, thinly and coarsely hairy, light green above, paler beneath; petioles semiterete, channelled above, hairy, but sparsely in the seedling, dilated and amplexicaul at the base, proportionately mucl shorter in the adult plant than in the seedling; stipules none in the seedling or carried up a considerable way on the petiole and resembling two small, lanceolate, slightly lobed leaflets, adnate for some distance to the petiole in the adult plant with free lanceolate, acute, green and foliaceous tips, more or less cut.

No. 1. Trifoliolate or, from the position of the stipular segments, apparentiy five-foliolate; terminal leaflet cuneate, pinnatifid with narrow, subulate or lanceolate, subacute segments ; lateral leaflets opposite or nearly so,

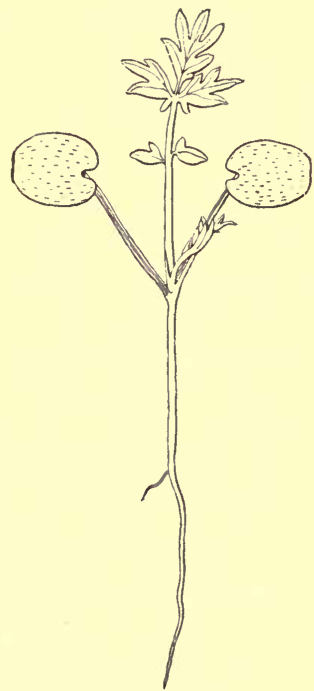

FıG. 319.-Accna myriophylla, $\times 2$. subovate, deeply pinnatifid with narrow, subacute or aristate segments.

Ultimate leaf oblanceolate-oblong in outline, pinnate; leaflets oblong, alternate, pinnatisect with numerous alternate, linear-subulate, acute, aristate segments cut nearly to the midrib.

The seedling of Acæna millefoliata is very similar to the last, but the hypocotyl is very short and the cotyledons are oval-oblong.

Poterium Sanguisorba, $L$. (fig. 320).

Pistil apocarpous, superior, enclosed in the hollow receptacle; 
ovary of one, two, or three free carpels, each one-celled, one-ovuled ; ovule pendulous, anatropous; radicle superior.

Fruit an achene, enclosed in the ovoid, tetragonal receptacle, ovoid, coriaceous and somewhat fibrous, glabrous, pale brownish, one-celled, one-seeded, indehiscent, closely conforming to the interior

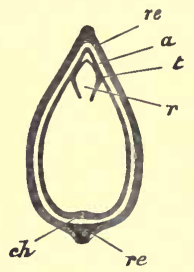

FIG. 320.-Poterium Sanguisorba. Longitudinal section of fruit, $\times 9: a$, achene; $t$, testa; $r$, radicle; $r e, r e$, hollow receptacle; ch, chalaza. of the receptacle both when solitary and when two or three achenes are present.

Seed obovoid, suspended from the apex of the achene to the interior of which it closely conforms, pale strawcoloured, except at the chalaza which is pale brown; testa thin, membranous; tegmen thinner, paler, almost white; hilum and micropyle basal, superior; raphe ventral; chalaza apical.

Endosperm absent.

Embryo straight, comparatively large, obovoid, colourless, conforming in shape to the seed; cotyledons rotund-obovate, plano-convex, retuse, minutely emarginate, cordate or shortly auricled at the base, fleshy in the seed ; auricles closely adpressed to the radicle, and produced to fill up the space in the seed caused by the cotyledons terminating rather abruptly at the base ; radicle turbinate, obtuse, stout, protruded into the narrow conical base of the seed and extending about two-thirds its length beyond the cotyledons.

\section{Seedling (fig. 321).}

Primary root slender, tapering, furnished with lateral fibres.

Hypocotyl erect, terete, glabrous, or with a few papillose hairs, colourless or stained red, passing insensibly into the root, about $7 \mathrm{~mm}$. long.

Cotyledons broadly oval, obtuse, minutely emarginate, deeply cordate at the base, faintly striate with numerous nerves arising from the indistinct midrib, glabrous, subfleshy, deep green ; lamina 5.25-5.5 mm. long, 4-4.75 $\mathrm{mm}$. wide; petiole subterete, channelled above, hairy, perfoliate at the base, $6 \cdot 5-7 \cdot 5 \mathrm{~mm}$. long.

Stem herbaceous, the persistent portion very short; primary internodes undeveloped.

Leaves compound, radical and cauline, alternate, stipulate, petiolate, glabrous or minutely pubescent beneath, deep glaucous-green ; petioles semiterete. channelled above, dilated and clasping at the 
base, hairy in the young stage, glabrous, or nearly so, in the adult ; stipules almost wholly adnate to the petiole and membranous with a minute free tip in the seedling, foliaceous in the adult, more or less ciliate at the margin.

No. 1. Pinnately trifoliolate; leaflets petiolulate, rotund, incise-serrate, alternately penninerved and reticulate with the nerves running directly into the subacute serratures-lateral ones subcordate at the base.

No. 2. Trifoliolate; leaflets shortly and broadly oblong, with the lateral ones subcordate at the base.

Ultimate leaves imparipinnate; leaflets numerous, alternate or opposite, varying even on the same leaf, rotund, cordate at the base and overlapping the rachis, and also one another when opposite, subacutely incise-serrate, with minutely mucronate serratures, the terminal one smaller and shorter than the lateral ones, all decreasing in size from the apex of the leaf

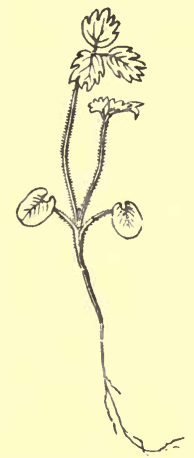

FIG. 321.-Poterium Sanguisorba. Nat. size. downwards, and often having small green pinnatifid segments near the base representing the free ends of the stipules.

Rosa berberidifolia, Pall. (fig. 322).

Primary root very long, tapering gradually downwards, with a few very short slender fibrils or none.

Hypocotyl tapering insensibly into the root.

Cotyledons oblong, obtuse, entire, rather thick and fleshy, minutely glandular-ciliate, otherwise glabrous, pale green, shortly petiolate, $1 \cdot 1 \mathrm{~cm}$. long including the petiole.

Stem suffrutescent, flexuose, glandular-pubescent and prickly ; prickles mostly in whorls immediately beneath the insertion of the leaves where the internodes are developed; 1 st to 5 th internode inclusive undeveloped; 6th $2 \mathrm{~mm}$. long; 7 th $1 \mathrm{~mm}$.

Leaves simple (in specimen sketched), cauline, alternate, exstipulate (or stipules reduced to glands), shortly petiolate, glandular-ciliate, otherwise glabrous, equally glaucous on both surfaces; petioles very short, 1-2 mm. long, dilated at the base and amplexicaul.

No. 1. Cuneate, three-toothed at the apex.

No. 2. Cuneate, five-toothed at the apex.

No. 3. Similar.

No. 4. Cuneate-obovate, six-toothed. 
No. 5. Narrowly obovate, six-toothed, much narrowed towards the base.

Nos. 6 and 7. Similar to No. 5 .

Rosa rugosa, Thunb. var. floribunda.

Hypocotyl suffruticose, erect, terete, glandular-pubescent, brownish, $1 \cdot 4 \mathrm{~cm}$. above the soil.

Cotyledons glandular-ciliate, oval-oblong, obtuse, with a mucrolike intramarginal mark at the apex, $7.5 \mathrm{~mm}$. long, $4.5 \mathrm{~mm}$. broad; petiole glandular-pubescent, channelled above, $3.5 \mathrm{~mm}$. long.

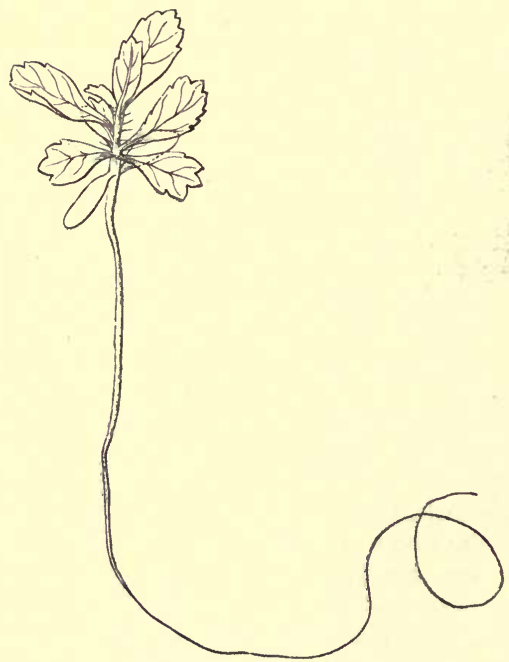

FIc. 322.-Rosa berberidifolia. Nat. size.

Stem suffruticose, erect, terete, glandular-pubescent, setose with the setæ mostly arranged in verticils immediately below the insertion of the leaves, pale green, ultimately brownish with white setæ; 1st and $2 \mathrm{nd}$ internodes undeveloped; $3 \mathrm{rd}$ and 4 th each $3 \mathrm{~mm}$. long ; 5 th $1 \mathrm{~mm}$. ; the rest hidden by the sheathing stipules.

Leaves compound, imparipinnate; leaflets serrate, glandularciliate, rugose, glabrous above and deep green, paler and subglaucous beneath, glandular-pubescent on the nerves in a young state; petioles channelled above, glandular-pubescent; stipules small and almost 
wholly adnate to the petioles of the first three leaves; above that they are foliaceous, almost crescent-shaped and free for the upper third of their length, glandular-ciliate, deep green, reticulate, semiamplexicaul.

No. 1. Very small, unifoliolate; leaflet cuneate, incise-dentate.

No. 2. Trifoliolate; leaflets small obovate-cuneate, serrate mostly above the middle.

No. 3. Similar, but larger and more serrate.

No. 4. Trifoliolate; leaflets oval or subelliptic.

Nos. 5 and 6 . Trifoliolate; lateral leaflets broadly oblong; terminal one elliptic.

No. 7. Trifoliolate; lateral leaflets broadly oblong-ovate; terminal one elliptic.

No. 8. Five-foliolate; basal pair of leaflets small, subovate; middle pair unequal-one oblong and the other subelliptic; terminal leaflet elliptic.

Pyrus Aucuparia, Gaertn. (fig. 323).

Primary root tapering, slender, very flexuose, with short, rather stout lateral, rootlets, dark-coloured.

Hypocotyl soon becoming woody, erect, terete, glabrous, subflexuose, brown, $8 \mathrm{~mm}$. to $1.5 \mathrm{~cm}$. long.

Cotyledons shortly petiolate, glabrous, deep green ; lamina oblong-oval, obtuse, $6 \mathrm{~mm}$. long, $4 \mathrm{~mm}$. wide; petiole grooved above, $1.5 \mathrm{~mm}$. long.

Stem soon becoming woody, erect, terete, hairy, slightly flexuose, pale green, ultimately becoming brown; 1 st internode $1.5 \mathrm{~mm}$. long; 2nd $1.5 \mathrm{~mm}$.; 3rd $2 \mathrm{~mm}$.; 4 th $2.5 \mathrm{~mm}$.

Leaves compound, ultimately imparipinnate, cauline, alternate, stipulate, petiolate, glabrous except on the petioles, under surface of the midrib and the rachis ultimately glabrescent; petioles subterete, channelled

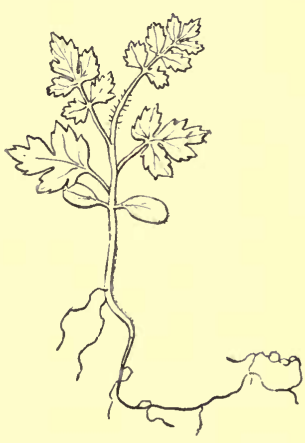

Fia. 328.-Pyrus Aucuparia. Nat. size. on the upper side; stipules small, ovate, acute, tooth-like.

No. 1. Triangular-ovate, trifid, lobes serrate.

No. 2. Triangular, tripartite; lateral divisions ovate, acute, serrate; terminal larger, obovate-cuneate, trifid and slightly serrate. 


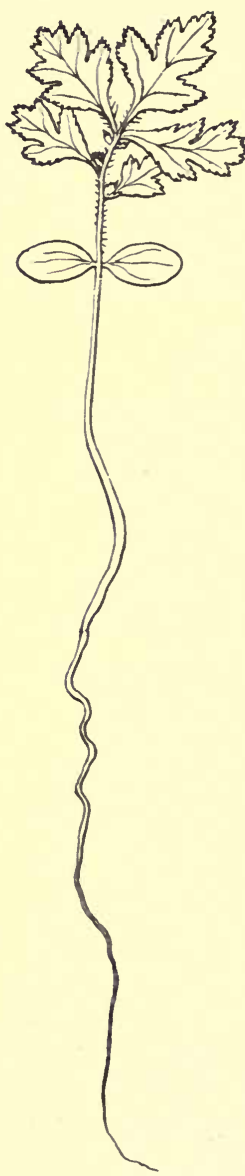

Frg. 824.

Cratagus Oxyacantha (from dry specimen). Nat. size.
No. 3. Pinnately five-foliolate; lateral leaflets ovate, acute, serrate; terminal leaflet cuneate, trifid and serrate.

No. 4. Similar; lateral leaflets acutely serrate; terminal leaflet triangular-ovate, acute, tripartite, acutely serrate.

Ultimate leaves pinnate, of seven to fifteen pairs of leaflets, deep green and glabrous above, whitish and downy on the underside and on the petioles and midrib; leaflets oblong, acute, unequal at the base of the posterior side, acutely and rather evenly serrate, in opposite pairs.

Tubeuf (1.c. p. 71) describes fruit and seeds of Pyrus communis (Pear), P. Malus (Apple), and Cydonia vulgaris (Quince), and also on page 125 the seedlings with figures of the two last. P. Malus has thick, rotund-ovate, almost sessile cotyledons, and doubly serrate, acute primary leaves. Cydonia vulgaris has roundly obovate cotyledons, an obtuse apex, and gradually tapering base. The primary leaves are oval to ovate and very finely serrate.

Cratægus 0xyacantha, ${ }^{1} L$. (fig. 324).

Primary root long, slender, tapering, wiry, with slender lateral fibres, flexuose.

Hypocotyl woody, erect, terete, brown, glabrous, $2 \cdot 5-4.5 \mathrm{~cm}$. long.

Cotyledons subfoliaceous, subcoriaceous, obovate-oblong, obtuse, glabrous, green, changing to brown, rather persistent, narrowed at the base or shortly petiolate, 1-1.2 $\mathrm{cm}$. long, 5-6 $\mathrm{mm}$. wide, obscurely trinerved.

Stem woody, erect, terete or subangled, hairy, brownish; 1st internode $6.5 \mathrm{~mm}$. long; 2nd $3.5 \mathrm{~mm}$.; $3 \mathrm{rd} 2.5 \mathrm{~mm}$.

Leaves simple, cauline, alternate, stipu- 
late, petiolate, hairy on both surfaces, ultimately glabrescent, subcoriaceous, deciduous; stipules foliaceous, variable, lanceolate or semi-ovate, acutely and more or less deeply serrate, with glandtipped serratures; petioles very short.

No. 1. Small, cuneate, trifid and slightly serrate (in some specimens oblanceolate, acute, and simply or slightly doubly serrate).

No. 2. Cuneate, trifid; terminal lobe doubly serrate; lateral lobes simply serrate.

No. 3. Cuneate, trifid, and becoming doubly serrate; terminal lobe again subtrifid.

No. 4. Ovate-oblong, cuneate at the base, lobulate and serrate.

No. 5. Triangular-ovate, trifid or almost tripartite, lobulate and serrate, cuneate at the base.

Ultimate leaves variable in different individuals, cuneate, trifid or pinnatifid and few- or many-lobulate, serrate.

\section{Cratægus mexicana, $D C$.}

Hypocotyl erect, terete, slender, $3-3.5 \mathrm{~cm}$. above the soil.

Cotyledons oblong-oval, with about two alternate incurved nerves on each side of the midrib, reticulate, thin, horizontal, $1 \cdot 3-1.5 \mathrm{~cm}$. long, 7-8 $\mathrm{mm}$. wide.

Stem erect, terete, woody ; 1 st internode 9-10 mm. long; 2nd, 3rd, and 4 th very short.

Leaves shortly petiolate, alternately

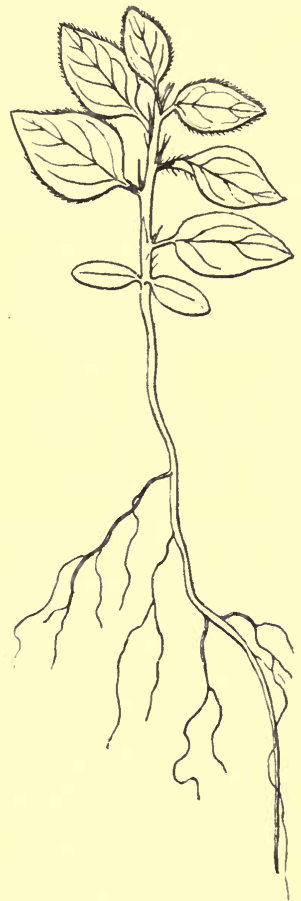

Fiq. 325.

Cotoneaster Simonsii.

Nat. size. penninerved, nerves ascending, reticulate; petioles very short or almost none in the primary leaves; stipules small in the seedling, subulate, acute.

Nos. 1 and 2. Oblong, acute, rather acutely, simply or doubly serrate.

Nos. 3 and 4. Oblong-elliptic, more or less cuneate at the base, acute, acutely and doubly serrate. 
Cotoneaster Simonsii, Hort. (fig. 325).

Primary root tapering, wiry, flexuose, with numerous flexuo se wiry rootlets, red or brownish.

Hypocotyl woody, erect, terete, glabrous, brownish, $2 \cdot 4 \mathrm{~cm}$. long.

Cotyledons oval-oblong, obtuse, glabrous, shortly petiolate, $1 \mathrm{~cm}$. long including the petiole, $5 \mathrm{~mm}$. broad.

Stem shrubby, erect, terete, densely hairy, brownish ; 1st internode $2.5 \mathrm{~mm}$. long; 2nd $4 \mathrm{~mm}$. ; 3rd $3.5 \mathrm{~mm}$.; 4 th $3 \mathrm{~mm}$.

Leaves simple, cauline, alternate, stipulate, petiolate, sparingly hairy on both surfaces, densely so on the margins, coriaceous, evergreen, deep green and shining above, paler beneath; petioles channelled above, hairy; stipules subulate, attenuate, free, hairy, brownish, entire.

Nos. 1-6. Ovate, acute, mucronate.

Ultimate leaves ovate, or elliptic-ovate, acute, mucronate.

\section{SAXIFRAGEE.}

Benth. et Hook. Gen. Pl. i. 629.

Fruit and Seed.-The more typical members of this Order have an ovary consisting of two carpels, or occasionally three; but in many, especially the shrubby and arboreal types belonging to the Escallonieæ and Hydrangeæ, the ovary consists of three to five carpels, very rarely more.

In the vast majority of cases the ovary is sunk in the receptacle and syncarpous, with as many cells as there are carpels, rarely one-celled; it is rarely free. We find all intermediate stages between a perfectly inferior, and a perfectly superior ovary in the genus Saxifraga alone. There are only a few species in that genus where the ovary is perfectly apocarpous, and not sunk in the receptacle; but this also happens in Astilbe, Tetracarpæa, Cephalotus follicularis, Pancheria, and Spiræanthemum. The ovules are generally very numerous, and arranged in a double series on the axile, rarely parietal, placentas; frequently they are few, but very rarely solitary and ascending from the base of the cavity of the ovary as in Eremosyne, or pendulous from the top of it as in Whipplea, or geminate and pendulous as in Ixerba. 
The fruit is capsular, or baccate, more rarely truly follicular or nut-like. Examples of the last type are met with in Ceratopetalum with a four-winged, bony nut, and in Aphanopetalum and Codia with nuts of a softer or less woody nature, and all one-seeded. The seeds are generally very numerous, and small or minute especially in the herbaceous types, with a membranous or leathery, smooth or pilose testa. Frequently they are more or less evidently winged ; and in Brexia madagascariensis the testa is crustaceous. Endosperm is nearly always present in considerable quantity, but in a few it is scanty, or sometimes altogether wanting in Brexia and Ixerba.

The embryo is in the majority of cases very small and ovoid, cylindrical or terete, with plano-convex cotyledons, often scarcely broader than the radicle. Exceptions occur in Brexia and Ixerba, which have a large embryo and flat cotyledons, and in Geissois with flattened seeds, and a large embryo with subfoliaceous cotyledons, equalling the length of the endosperm.

A moderately large embryo is met with in Saxifraga peltata, having linear-oblong cotyledons, which with the radicle are more or less three-fourths as long as the copious endosperm. A similar case is met with in S. crassifolia, which has oblong, longitudinally ribbed seeds from $\cdot 75-1 \cdot 25 \mathrm{~mm}$. in length, and an embryo nearly as long as the endosperm. A very different type is met with in Ribes, the species of which have numerous more or less angled seeds lying in the pulp. of a berry. The fruit is one-celled with parietal placentas. The testa is very thick, the outer layer being cartilaginous and hard when dry, but swelling up and mucilaginous in water, while the inner coat is thin and rather crustaceous, or brittle and black. The embryo is ovoid and very minute, lying close to the hilum embedded in a copious endosperm. Ribes glutinosum (fig. 330) represents this type.

Seedlings. - The cotyledons in this Order vary within very narrow limits from ovate to oblong and spathulate. They may also for convenience sake be classified under two heads, namely, large and small. Most if not all of the herbaceous types have very small seeds and small cotyledons. The leading 
form may be described as ovate, obtuse, entire, shortly petiolate, showing a midrib more or less distinctly, or without any discernible venation in the fresh state. Species agreeing with this type are Saxifraga greenlandica, S. Stracheyi (fig. 327), Rodgersia podophylla (fig. 326), Mitella Breweri, and Escallonia Berteriana (fig. 329). A slight divergence from this is met with in Saxifraga rotundifolia having minute oblongspathulate cotyledons, and in Heuchera Drummondi with minute, narrowly oblong cotyledons.

Saxifraga greenlandica is one of the mossy-leaved types with cuneate and divided or palmate leaves. The first four are spathulate and entire, followed by two which have each one lateral tooth, and by seven others which are cuneate and trifid. The first leaf of S. Stracheyi is oval and glabrous, while the second is larger and ciliate, and the third obsoletely serrate. The ultimate leaves are obovate, dentate-serrate, and very large. Rodgersia podophylla shows a more striking evolution. The first leaf is cordate with a few distant serratures, the second and third are roundly cordate, shallowly five-lobed and serrate. The ultimate form is peltate, and five-partite with obovate or cuneate, serrated segments, trifid near the apex, sometimes of immense size, and resembling a compound leaf. The first three leaves of Mitella Breweri are suborbicular, tapering to the base, and glandular-ciliate; while the ultimate form is suborbicular, shallowly five-lobed, crenate, deeply cordate at the base with overlapping auricles and a palmate venation. The first two or three leaves of Saxifraga rotundifolia are roundly cuneate and entire, followed by a number of obsoletely trifid ones. The ultimate form is reniform or rotund with an open sinus, dentate and showing numerous veins radiating from the base of the lamina. A very gradual evolution of the leaves is shown by Heuchera Drummondi. Sometimes as many as six of the primary leaves are roundly spathulate, and succeeding ones become larger by degrees, and finally assume a form similar to that of Mitella Breweri. A shrubby type is represented by Escallonia Berteriana having the first five leaves cuneate.

A shrubby type with much larger and more highly developed cotyledons is represented by Ribes saxatile (fig. 331) and R. 
glutinosum. The primary or leading ovate form is still preserved, but the cotyledons are rather distinctly five-nerved. Of the former the first two leaves are trifid, while succeeding ones are more or less deeply five-lobed. The cotyledons of R. nigrum are oblong, and the first two leaves are cuneate or lanceolate, often shallowly trifid; the ultimate form is palmately five-lobed and five-nerved.

The variety $R$. nigrum laciniatum has similar but much smaller cotyledons. A well-marked modification of this type occurs in Philadelphus gracilis (fig. 328) with broadly ovate and emarginate cotyledons. The first two leaves are ovate and entire, whereas the next two are serrulate.

Rodgersia podophylla, A. Gray (fig. 326).

Primary root slender, tapering downwards, flexuose, giving off slender lateral rootlets.

Hypocotyl undeveloped or indistinguishable from the root.

Cotyledons ovate, obtuse, entire, shortly petiolate, with a distinct midrib, glabrous, light green ; lamina $1 \cdot 5-2 \cdot 25$ mm. long, 1.25-2 mm. wide; petiole grooved above, convex on the back, dilated at the base and connate, forming a little cup around the plumule, about $1 \mathrm{~mm}$. long.

Stem herbaceous, producing underground a stout, scaly rhizome, and throwing up a stem when about to flower; primary internodes undeveloped.

Leaves simple, trilobed on the stem, five-sect on the rhizome, alternate, stipulate, petiolate, palmatinerved at the base in the seedling, alternately nerved upwards, palmately or peltately nerved in the adult leaves, glabrous or nearly so

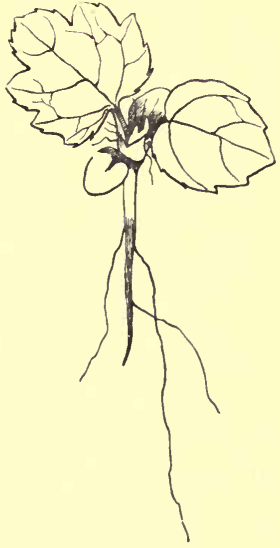

Frg. 326.

Rodgersia podophylla, $\times 3$. in the seedling stage; petioles semiterete, channelled above, more or less hairy, short in the seedling, very long on the rhizome of the adult plant, dilated and sheathing at the base; stipules membranous, attached to the petiole, fringed at the apex in the seedling stage. 
No. 1. Cordate, cuspidate, with two to three small serratures on each side, trinerved at the base with one to two alternate nerves upwards.

No. 2. Rotund-cordate, cuspidate, serrate with glandular mucronate serratures, five-nerved at the base with a few alternate nerves upwards.

No. 3. Similar, rather more deeply cut.

Saxifraga Stracheyi, Hook. f. et Thonus. (fig. 327).

Primary root slender, tapering, with slender lateral rootlets.

Hypocotyl terete, pink, $2 \cdot 25 \mathrm{~mm}$. long.

Cotyledons oblong-ovate, obtuse, shortly petiolate, coriaceous, glabrous, deep green above, paler beneath; lamina $3 \mathrm{~mm}$. long, $1.75 \mathrm{~mm}$. wide; petiole $\cdot 75 \mathrm{~mm}$. long.

Stem herbaceous, stout, slowly developed.

Leaves simple, radical and ultimately ele-

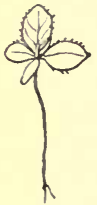

Fig. 327.

Saxifraga Stracheyi. Nat. size. vated on the short stem, alternate, stipulate, very shortly petiolate (or the petiole reduced to a sheath margined and topped by the stipules), glabrous, ciliate-serrate, coriaceous, obscurely alternately penninerved, deep green and shin ing above, pale and punctate beneath; petioles very short and almost reduced to the sheaths; stipules mostly adnate to the sheaths with free fimbriated tips.

No. 1. Ovate-oval, obtuse, entire, not ciliate.

No. 2. Oval, obtuse, entire, distantly ciliate.

No. 3. Oval, obtuse, distinctly ciliate, obsoletely serrate at the apex.

Further stages are developed by many successive gradations in shape and size, till the leaves become obovate, closely ciliate and obtusely serrate along the upper end or half.

Ultimate leaves very large, obovate, tapering to the base, dentateserrate, ciliate, with mucronate serratures, distinctly alternately penninerved, thick, coriaceous, deep green above with paler nerves, pale green beneath and more or less punctate, sublucid on both surfaces, $37 \mathrm{~cm}$. long, $16 \mathrm{~cm}$. wide including the sheath; serratures largest about the middle of the leaf; petioles almost reduced to the large sheath ; stipules adnate to the petiole nearly throughout, then connate by their contiguous margins in front of the leaf forming a hood, entire at the margin, and glabrous or thinly ciliate. 


\section{Saxifraga rotundifolia, $L$.}

Primary root as in last species.

Hypocotyl subterranean, very short.

Cotyledons minute, oblong-spathulate, obtuse, $2 \mathrm{~mm}$. long, $1 \mathrm{~mm}$. wide.

Stem herbaceous with undeveloped internodes, throwing up annual leafy flowering stems.

Leaves simple, radical and cauline, alternate, exstipulate, petiolate, hairy on both surfaces, pale green, paler beneath, often suffused with red; petioles terete, very hairy, dilated and sheathing at the base.

No. 1. Rotund, cuneate at the base, $2 \mathrm{~mm}$. long, $2 \cdot 25 \mathrm{~mm}$. wide, entire.

Nos. 2 and 3. Rotund, subcuneate at the base, slightly longer than broad, entire.

No. 3. Rotund, subcuneate at the base, with a tooth on one side. Other and numerous intermediate forms are reniform, entire or triangled or trinerved at the base and crenate with three to five rounded, broad teeth.

Ultimate leaves reniform or rotund, deeply cordate at the base, with rounded, more or less overlapping auricles, hairy on both surfaces, crenate-dentate, with broad, shallow, deltoid, obtuse, mucronate crenatures or teeth, and broad, radiating, entire or forked nerves.

\section{Mitella Breweri, A. Gray.}

Primary root slender, flexuose, giving off flexuose, branching lateral rootlets.

Hypocotyl terete, glabrous, reddish, about $3 \mathrm{~mm}$. long.

Cotyledons minute, ovate or oval, obtuse, subsessile, $2.25 \mathrm{~mm}$. long, $1.5 \mathrm{~mm}$. wide.

Stem herbaceous, very short, with stoloniferous branches.

Leaves simple, radical, alternate, stipulate, petiolate, coarsely hairy and glandular-pubescent, radiately nerved from the base, pale green above, paler beneath; petioles subterete, slightly channelled above, coarsely hairy and pubescent.

Nos. 1-3. Spathulate-rotund, or rotund with a cuneate base, coarsely hairy and glandular-ciliate.

First one $3 \mathrm{~mm}$. long including the petiole, $2 \mathrm{~mm}$. wide. Suc ceeding forms are small, reniform, entire or tridentate and trinerved; then five- to seven-nerved, and crenate, with obtuse mucronate teeth. 
Ultimate leaves rotund, subpalmate, deeply cordate at the base, five- to seven- to nine-nerved, shallowly lobed, and shallowly crenate with mucronulate crenatures, reticulate, pale green, thinly hairy, paler beneath and thinly hairy with prominent nerves; petioles terete, with a slender channel on the upper side, thinly hairy, dilated and clasping at the base; stipules adnate to the petiole, and connate by their edges near the top with two small, free, brownish points.

\section{Heuchera Drummondi, Hort.}

Primary root as in last species.

Hypocotyl short and indistinguishable from the primary root.

Cotyledons minute, narrowly oblong, obtuse or subacute, $2 \mathrm{~mm}$. long, $\cdot 5 \mathrm{~mm}$. wide.

Stem herbaceous, very short, with hairy internodes where developed in the seedling.

Leaves simple, radical, alternate, stipulate, petiolate, radiately nerved from the base, thinly glandular-hairy and glandular-pubescent above, densely glandular-ciliate with unequal-sized hairs, glandularpubescent beneath, paler and more conspicuously reticulate than on the upper surface; petioles terete, glandular-pubescent, dilated and sheathing at the base; stipules ovate, small, toothed and glandularhairy, hyaline or reddish.

No. 1. Rotund-spathulate, glandular-ciliate and -hairy, entire, $1.75 \mathrm{~mm}$. long, $1.5 \mathrm{~mm}$. wide.

No. 2, sometimes to No. 6, gradually larger than the first, rotund, spathulate, entire.

Other stages are reniform, entire or minutely tricrenate with mucronulate crenatures; then reniform, obviously tricrenate, trinerved; then reniform, five-nerved, five-crenate, and unequally and densely glandular-ciliate.

Larger forms are cordate, obtuse, and crenate with mucronulate crenatures.

Ultimate leaves palmate, deeply cordate at the base, five- to sevento nine-nerved and -lobed, simply or becoming doubly toothed, with obtuse, mucronate teeth, glandular-pubescent above, glandular-ciliate and paler beneath, coarsely hairy on the nerves and reticulate; stipules adnate to the petiole for more than half their length, with ovate, free, glandular, fringed points.

\section{Philadelphus gracilis, Hort. (fig. 328).}

Hypocotyl erect, striated, glabrous, 4-8 mm. long, light green or colourless. 
Cotyledons small, membranous, ovate, emarginate, shortly petiolate or subsessile, glabrous, green, indistinctly one-nerved.

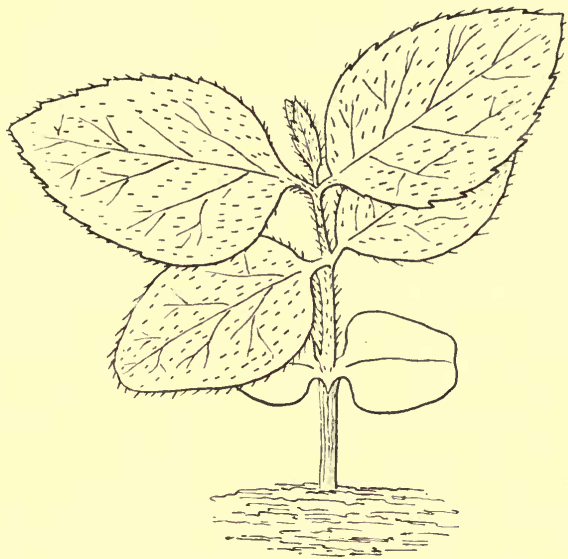

Fig. 328.-Philadelphus gracilis, $\times 2$.

Stem erect, terete, herbaceous, hairy; 1st internode $3-6.5 \mathrm{~mm}$. long ; 2nd 2-5 $\mathrm{mm}$.

First leaves simple, cauline, opposite, decussate, ovate, subacute, slightly serrate or almost entire in the first pair, petiolate, exstipulate, covered with rather long silky hairs, light green, pinnatinerved.

Escallonia Berteriana, $D C$. (fig. 329).

Hypocotyl erect, terete, pale green, pubescent with adpressed or incurved hairs, 3-6 mm. long.

Cotyledons ovate, obtuse, glabrous, shortly petiolate; lamina $2 \cdot 25 \mathrm{~mm}$. long, $1 \cdot 75$ $\mathrm{mm}$. wide; petiole $\cdot 5 \mathrm{~mm}$.

Stem erect, terete, ultimately

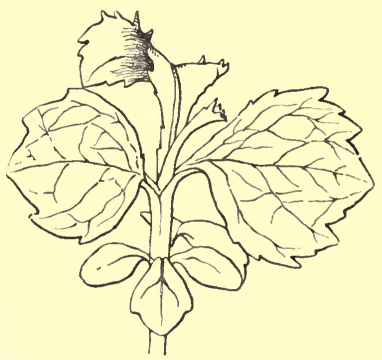

FIG. 329.-Escallonia Berteriana, $\times 4$. shrubby; 1st internode $5 \mathrm{~mm}$.; 2nd $75 \mathrm{~mm}$.; 3rd $1 \mathrm{~mm}$.

Leaves simple, cauline, alternate, exstipulate, petiolate, glabrous 
at least in the seedling state, evergreen; petioles very short, shallowly grooved above.

No. 1. Cuneate, trinerved, obtusely tridentate towards the apex, very small.

No. 2. Larger, cuneate or broadly subelliptic, obtusely three- to five-toothed.

Nos. 3-5. Cuneate-elliptic, obtusely or acutely serrate, gradually larger in each successive leaf, alternately penninerved and reticulate.

Ribes glutinosum, Jacq. (fig. 330).

Pistil syncarpous, inferior ; ovary of two carpels, one-celled with numerous ovules on two parietal placentas; micropyle basal ; ovules anatropous.

Fruit a berry, globose, one-celled, many-seeded, pulpy internally
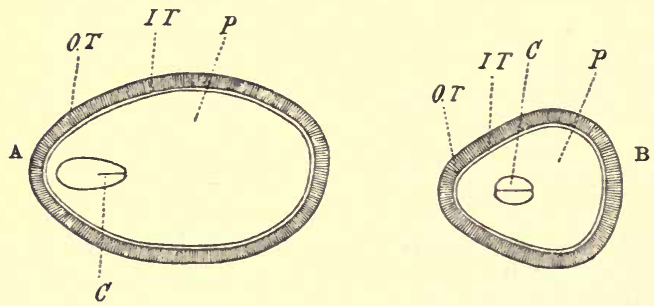

Fio. 830.-Ribes glutinosum, $\times 14$. A, longitudinal section of seed; $B$, transverse section of seed: $O T$, testa; $I T$, tegmen; $P$, endosperm; $C$, cotyledon.

with numerous horizontal seeds embedded in the pulp on two parietal placentas.

Seed subobovoid, variously angled with obtuse angles, glabrous, deep brown; testa thick, hard when dry, but swelling up and gelatinous when moist; tegmen thin, black, crustaceous; hilum and micropyle basal, contiguous.

Endosperm copious, fleshy, firm, colourless.

Embryo minute at the base of the endosperm, straight, colourless ; cotyledons short, oblong, obtuse, entire, plano-convex, sessile ; radicle stout, blunt, shorter than the cotyledons.

Ribes saxatile, Pall. (fig. 331).

Primary root long, tapering, with a few fibrous lateral rootlets, becoming brown and wiry. 
Hypocotyl woody, terete, brownish, sparsely glandular-pubescent, merging into the root.

Cotyledons foliaceous, rather persistent, petiolate, sparsely glandular-pubescent; lamina ovate, obtuse, mucronate, $11 \mathrm{~mm}$. long, $7 \mathrm{~mm}$. wide ;' petiole slightly channelled above, $7 \mathrm{~mm}$. long.

Stem suffrutescent, erect, terete, sparsely glandular-pubescent; 1 st internode $1.5 \mathrm{~mm}$. long; 2nd $6 \mathrm{~mm}$.; 3rd 1.5 $\mathrm{mm}$.

Leaves simple, cauline, alternate, exstipulate, petiolate, sparsely glandular-pubescent, pale green ; petioles subterete, channelled above, pale green, sparsely glandularhairy, dilated and amplexicaul at the base.

No. 1. Triangularovate, trifid, irregularly serrate.

No. 2. Palmately trinerved and shallowly fivelobed, and serrate.

No. 3. Reniform palmate, trinerved and sub-five-lobed, serrate.

No. 4. Reniform, palmate, five-nerved, fivelobed, serrate.

No. 5. Similar.

Ribes nigrum, $L$.

Hypocotyl erect, ter-

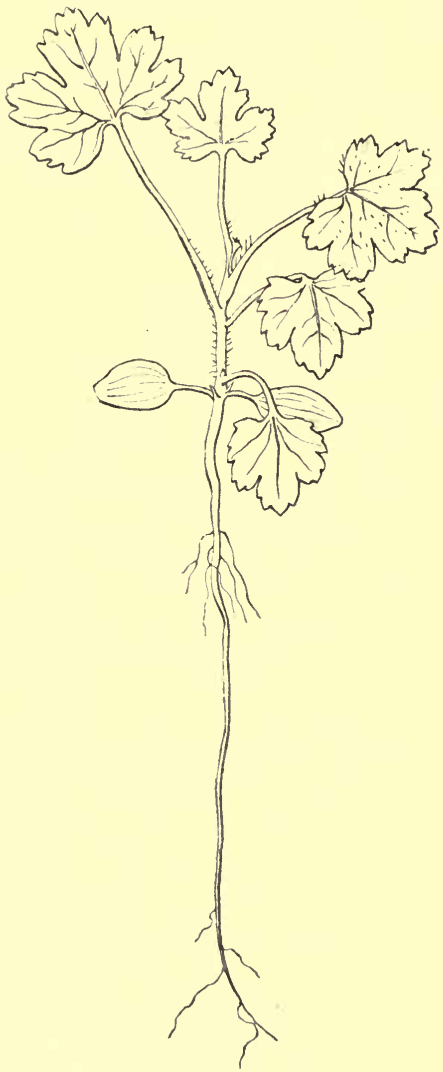

Fig. 831.-Ribes saxatile. Nat. size. ete, glabrous, pale green, soon losing its epidermis and becoming brown and woody.

Cotyledons smaller than in the last species and oblong, obtuse, 
thinly pubescent at the margin only; lamina $9 \mathrm{~mm}$. long, $5 \mathrm{~mm}$. broad; petiole $4 \mathrm{~mm}$. long.

Stem woody, and similar to that of R. saxatile; 1st internode $1 \mathrm{~mm}$. long; 2nd 1.75 mm.; 3rd $2 \mathrm{~mm}$.; 4 th $2 \mathrm{~mm}$.; 5 th $7 \mathrm{~mm}$.; 6th $9 \mathrm{~mm}$.; 7 th $13 \mathrm{~mm}$.

Leaves very similar to those of R. saxatile, exstipulate (or stipules adnate to the petiole and margined with long, somewhat feathery hairs), thinly glandular-pubescent on both surfaces, and dotted with sessile glands beneath, light green above, paler beneath, highly odoriferous, especially when bruised.

No. 1. Small, ovate, trifid, trinerved.

No. 2. Ovate, trinerved, slightly serrate, with a small lobe on one side.

No. 3. Triangular-ovate, five-nerved, trifid and slightly serrate.

No. 4. Palmately five-nerved and shallowly five-lobed, serrate.

Nos. 5-8. Similar, larger, more definitely lobed and serrate, with glandular-mucronate serratures.

Ribes nigrum, var. laciniatum.

Cotyledons smaller and narrower than in the type, and the leaves more deeply divided.

\section{CRASSULACE E.}

Benth. et Hook. Gen. Pl. i. 656.

Fruit and Seed.-The ovary consists of a varying number of carpels from three or five to thirty. The number corresponds to that of the petals, which in Sempervivum sometimes reaches as many as twenty. They are free, or more or less connate or sunk in the receptacle, and one-celled. The ovules are small, numerous, anatropous, and arranged in two or several series upon the ventral suture; more rarely are they few or solitary, as in a few species of Sedum and Tillæa. There are also few ovules in the carpels of Dinacria. When fow they may be erect or pendulous. The fruit consists of as many follicles as there are carpels, dehiscing along the ventral suture or, where the carpels are connate, along the dorsal suture. The seeds are minute, oblong, with a membranous or subcoriaceous finely reticulated testa, and contain a fleshy endosperm. The 
embryo is small and generally shorter than the endosperm, but that of Crassula magnoliæfolia occupies the whole of the seed, and has plano-convex cotyledons. As a rule the latter are very short and obtuse, while the radicle is also short, or sometimes elongated and terete.

The cotyledons in Sedum album are narrowly oblong, and about equal the terete radicle in length.

Seedlings.-The cotyledons observed are all succulent like the plants themselves, and vary in shape from broadly oval or ovate to orbicular. Like the leaves, the cotyledons of Crassula quadrifida are covered with glands secreting a white substance. They persist for a long time, attain considerable size, and generally are very unequal. Cotyledon Silversii is notable for the fleshy rootstock it produces while the cotyledons are still present. The first leaf is suborbicular with a cordate base, and the second is cordate. The cotyledons are rather unsymmetrical. Those of Sedum Rhodiola vary considerably in outline from oval or ovate to obovate, are trinerved and generally slightly emarginate. The first leaf is spathulate and very much smaller than the cotyledons. The two primary leaves of Sedum nicæense are elliptic, succeeded by others that become gradually oblong and then linear, and crowded owing to the non-development of the internodes. Sedum crassipes shows a considerable amount of evolution. The cotyledons are very small, and the first four leaves roundly cordate, almost or quite entire, while the ultimate leaves are linear, distantly toothed and densely arranged on the fleshy stems.

\section{Crassula quadrifida, Baker (fig. 332).}

Primary root slender, tapering, with slender secondary rootlets and most frequently supplanted by strong adventitious roots from the base of the hypocotyl.

Hypocotyl most frequently very short (in some cases almost none), generally about 1-2 $\mathrm{mm}$. long, succulent, glabrous.

Cotyledons persistent and becoming foliaceous, succulent, glabrous, pitted on both surfaces with gland-like organs secreting a white substance, rotund, obtuse, shortly petiolate, most frequently very unequal in size, green above, purplish beneath; smaller cotyledon 
including petiole $3.5 \mathrm{~mm}$. long, $6 \mathrm{~mm}$. wide; larger cotyledon including petiole $1 \cdot 1 \mathrm{~cm}$. long, $8 \mathrm{~mm}$. wide.

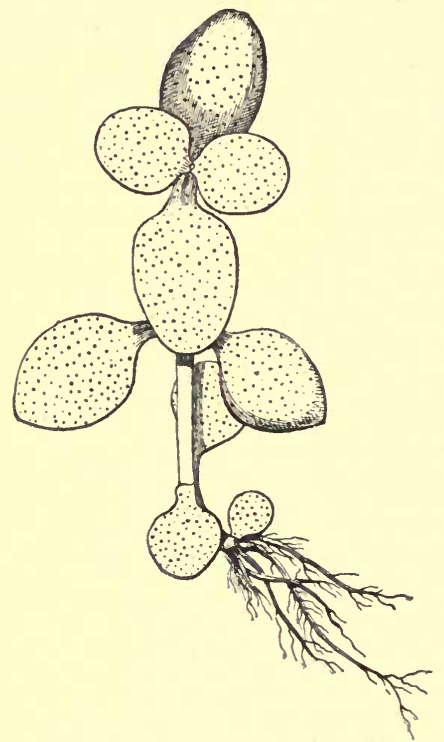

Fig. 332.-Crassula quadrifida. Nat. size.

Stem succulent, erect, perennial or slirubby, terete, minutely pubescent ; 1 st internode $5-8.5 \mathrm{~mm}$. long; 2nd $1.4-1 \cdot 8 \mathrm{~cm}$. ; 3rd about $1.9 \mathrm{~cm}$.

Leaves simple, cauline, opposite, decussate, exstipulate, petiolate or subsessile, glabrous, succulent, deep green above, paler beneath, eovered on both surfaces with gland-like organs secreting a white substance; petioles flattened above, convex beneath, connate at the base around the stem.

First pair rotund-spathulate or spathulate-elliptic, obtuse.

Second pair oval or rotund-oval, obtuse, cuneate at the base.

Third pair oblong, obtuse.

Fourth pair rotund, obtuse.

These forms vary greatly in individual seedlings.

Ultimateleaves oblong, very obtuse, faintly nerved, or ovate-oblong or rotund, shortly petiolate, covered on both sides with glands secreting a white substance; petioles short, convex beneath, and grooved on the upper side.

\section{Sedum Rhodiola, DC. (fig. 333).}

Primary root slender, tapering, with a few lateral rootlets, soon equalled, or even superseded, by strong adventitious roots from the base of the hypocotyl.

Hypocotyl short, glabrous, soon becoming ovoid or globose, and forming the primary rootstock of the plant, colourless or purplish, 2-5 mm. long, 2-4 mm. thick.

Cotyledons variable, ovate or rotund-ovate, obovate or elliptic, 
cuneate at the base, entire or shallowly emarginate, succulent, and continuing to grow for some time, glabrous, subglaucous-green above, paler beneath and glaucous, trinerved, with the lateral nerves curved and enclosing an elliptic space, arising near the base of the lamina and proceeding round the cotyledon parallel with the margin, and again uniting with the midrib close to the apex, best seen on the underside or by transmitted light, petiolate; lamina 4-9 $\mathrm{mm}$. long, 4-8 $\mathrm{mm}$. wide; petiole flattened above, convex on the back, dilated upwards into the lamina, suddenly dilated to a wide base, slightly connate around the plumule, pale green, almost colourless, $6-11 \mathrm{~mm}$. long.

Stem forming a fleshy, thickened rootstock, from which it sends up annual, succulent, flowering stems; primary internodes undeveloped.

Leaves simple, radical and cauline, alternate, exstipulate, petiolate, glabrous, succulent, glaucous,

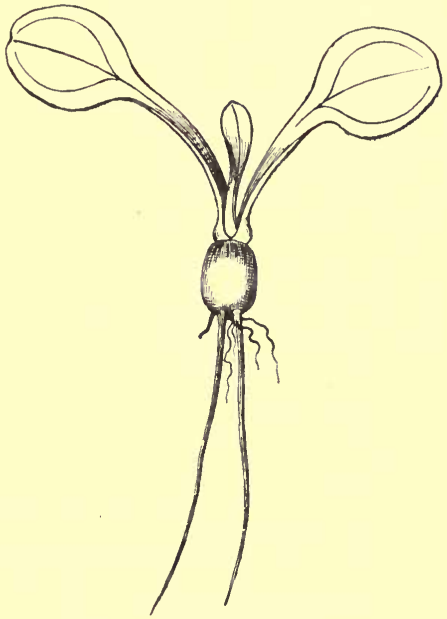

FIG. 333.-Sedum Rhodiola, $\times 2$. paler beneath and glaucous, with alternate, ascending nerves, discernible with difficulty ; petioles in the seedling grooved above, convex on the back, short, and as the plant grows gradually becoming shorter till the leaves are quite sessile.

No. 1. Much smaller than the cotyledons and both narrower and shorter, spathulate, obtuse, entire, with one to two short, alternate nerves on each side.

\section{Sedum asiaticum, $D C$.}

Primary root as in last species.

Hypocotyl stout, succulent, glabrous, purplish, $4 \mathrm{~mm}$. long.

Cotyledons suceulent, glaucous, glabrous; lamina broadly oval, obtuse, $3 \mathrm{~mm}$. long, $2.25 \mathrm{~mm}$. wide ; petiole flattened on the upper side, $6 \mathrm{~mm}$. long. 
Stem herbaceous, succulent; persistent part stout, dereloping slowly.

Leaves. Arrangement \&c. as in last species; petioles succulent, flattened slightly on the upper side, convex beneath.

Nos. 1-4. Rotund-ovate, obtuse, entire, but having marks on the under side foreshadowing teeth.

Ultimate leaves very densely arranged on the flowering stem only, scattered or almost pseudo-verticillate, lanceolate or linear, acute, with a median nerve, distantly serrate, horizontal, light green.

Grammanthes gentianoides, $D C$.

Hypocotyl erect, striated, glabrous, 1.2-2 $\mathrm{cm}$. long, light green or colourless.

Cotyledons subrotund, thick, fleshy, entire, very shortly petiolate, light green, glabrous, without any apparent venation.

Stem erect, terete, herbaceous; 1 st internode 5-6 mm. long; 2nd imperceptible at first,

First leaves simple, entire, cauline, opposite, oblong, thick, fleshy, green, glabrous, without any apparent venation.

\section{DROSERACE E.}

Benth. et Hook. Gen. Pl. i. 661 .

Fruit and Seed.-The ovary is one- to five-celled, the ovules are usually very numerous, anatropous, axile or parietal, sometimes basal, but very rarely suspended from the apex of the cavity. The raphe and micropyle vary accordingly. The fruit is a capsule with as many cells as the ovary, and dehisces loculicidally. The usually numerous seeds are small and albuminous, with a loose and reticulate or close-fitting testa, which is sometimes covered with granular elevations as in Drosera anglica, or is crustaceous, smooth, and shining. The embryo is straight in the centre of a fleshy endosperm, cylindrical, and about equal to the endosperm in length, with the radicle sometimes projecting beyond the latter. In Drosera anglica, and some other species, as well as in Dionæa muscipula, it is minute, and lies at the base of the endosperm close to the hilum. 
Seedlings.-According to Nitschke, ${ }^{1}$ Drosera rotundifolia does not start with a rosette of leaves. The young plant works its way up through the Sphagnum, and the first leares are similar in shape to those of D. anglica. The behaviour of the seedling appears to be dependent upon the medium upon or in which the seed germinates, or, in other words, to the convenience offered the plant to spread out its leaves in a rosette with full exposure to sunlight. It is a case of adaptation to surroundings. Seedlings belonging to other Orders and having large seeds are enabled to carry up their eatyledons or leaves, or both, to the light by the elongation of the hypocotyl or the lower internodes of the stem, while the primary leaves may be reduced to the condition of scales.

The cotyledons of D. rotundifolia are small and spathulate. Those of D. binata are minute and linear-spathulate. The first six or more leaves have an orbicular glandular-hairy lamina, followed by some which are obreniform or broadly triangular. The ultimate leaves are bifurcate with narrowly linear, glandular-hairy segments.

\section{Drosera binata, Labill.}

Primary root short, stout, blunt, covered with brown root-hairs, with one or two short stout lateral rootlets.

Cotyledons minute, linear-spathulate, glabrous, pale green, about 1-1.5 $\mathrm{mm}$. long.

Stem undeveloped.

Leaves simple, entire at first, then forked, ultimately bifurcate, radical, alternate, stipulate, petiolate, glandular-hairy and grooved above, thickened at the margin, glabrous, grooved beneath, green and shining; glandular hairs with the lower half pale green, the upper half more or less purple and tipped with purple globose glands; petioles compressed with rounded edges, glabrous, grass-green; stipules in the adult plant connate by their contiguous margins in front and at the base of the leaf, fimbriated at the margin, brown, scarious:

Nos. 1-6 or more. Very small with an orbicular glandular-hairy lamina that catches flies even in this small state; the glands secrete a fluid, and the stalks of the hairs incurve on the insect. 
Further stages of the leaves are broadly cuneate, then obtusely triangular; the upper two angles of the leaf gradually elongate until they become acute and slender. The elongated points even at this early stage are involute in vernation, with unusually long hairs very sensitive to contact with an insect. The glands however are quite dry until the points of the leaf are fully expanded.

Ultimate leaves bifurcate, with long petioles, dividing, at the apex of the glabrous petiole into two branches which again divide into two branches about $1 \cdot 1 \mathrm{~cm}$. above the first fork; branches linear, attenuate, glandular-hairy above, grooved on both surfaces, thickened at the margin--two anterior branches shortest, diverging -two posterior ones ascending, and diverging upwards.

\section{Drosophyllum lusitanicum, Link.}

Primary root long, slender, blackish or brown, with numerous brown root-hairs, but unbranched when young.

Hypocotyl subterranean, colourless, naked, $2 \mathrm{~mm}$. long.

Cotyledons subterranean, and remaining in the seed after germination, petiolate ; petioles directed to one side of the stem, colourless, short, but sufficiently long to readily permit of the plumule escaping from the seed.

Stem erect, terete, pale green and glabrous in the early stages; 1st internode 1-1.2 cm. long; 2nd very much shorter.

Leaves simple, entire, cauline, alternate except the first pair, stipulate, sessile, linear, circinate in vernation and rolled backwards, with numerous sessile glands apparently immersed in the tissue of the edges and upper surface, and with stalked and capitate glands on the back and edges but particularly on the latter in the seedling stage.

First pair opposite or on slightly different levels, slightly connate at the base, linear, acute, shallowly grooved above, with a distinct midrib, and stalked glands on the edges, and a few on the back.

Nos. 2 and 3. Alternate, but otherwise very similar, and at this early stage circinate at the tip.

Seedlings with four leaves like the above were densely covered with flies of various sizes both dead and alive, often fixed to the glands by their feet only and struggling to escape. The viscid secretion of the glands may be drawn out to a length of some inches. 


\section{HAMAMELIDEA.}

Benth, et Hook. Gen. Pl. i. 664 .

Fruit and Seed.-Ovary of two carpels forming a more or less perfectly two-celled fruit, more or less inferior, seldom quite superior.

The ovules are numerous, few or solitary, pendulous, anatropous, and fixed to axile placentas in one or more series, with a superior micropyle and ventral raphe. The woody capsule is bilobed at the apex and dehisces by two bifid valves to the middle or base of the fruit. Sometimes the exocarp separates from the horny endocarp which contains the seeds. Where these are numerous they are imbricated, angled, compressed and winged; but when solitary in each cell they are oblong with a bony or crustaceous testa. A small or moderately thick fleshy layer of endosperm is present embedding the large embryo which is straight with foliaceous cotyledons, and a terete radicle. The latter is equal to, shorter, or longer than the flat cotyledons in different species.

Winged seeds containing the large embryo characteristic of this Order are represented by Rhodoleia Championi (fig. 331). The cotyledons in this case, as in Hamamelis, are subcordate at the base.

Seedlings.-The size and shape of the cotyledons after germination in those cases where the embryo is of proportionately large size while still in the seed, seem to alter less than those with a small embryo embedded in endosperm. An example of this is met with in Bucklandia populnea (fig. 335), which has oblong, entire, subemarginate petiolate cotyledons. They are oblong and flat while still in the seed.

Rhodoleia Championi, Hook. (fig. 334).

Pistil syncarpous, inferior; ovary of two carpels, two-celled, many-ovuled; ovules pendulous or horizontal; micropyle superior or horizontal.

Fruit a capsule, cuspidate, glabrous, woody, two-celled, manyseeded, deliscing by two bifid valves.

Seeds imbricate in two rows, much compressed, variously shaped 
and angled, sometimes slightly winged, glabrous, pale brown ; testa thicker than the tegmen, subcrustaceous when dry, cortical interiorly ; tegmen thin, membranous, pale brown, closely applied to the endosperm; hilum and micropyle basal, contiguous.

Endosperm moderately copious, fleshy, colourless when moist.

Embryo large, straight and axile, embedded in the endosperm, and falling a little short of it in length and breadth, colourless; cotyledons oblong-ovate, very obtuse, rounded at the base, entire, plano-convex, lying in the broader plane of the seed with their backs to the placenta if the seed is pendulous, but with the radicle pointing in that direction if the seed is horizontal, with a distinct midrib and
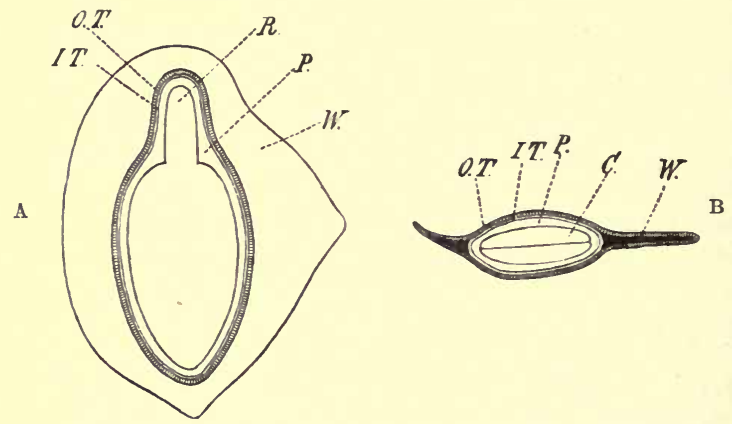

Fro. 334.-Rhodoleia Championi, $\times 7$. A, longitudinal section of seed. $\mathrm{B}$, transverse section of same: $O T$, testa; $I T$, tegmen; $C$, cotyledon; $R$, radicle; $P$, endosperm, $W$, wing.

a few alternate ascending lateral nerves ; radicle oblong or cylindrical, obtuse, several times shorter than the cotyledons, imbedded in endosperm close to the micropyle.

Bucklandia popalnea, R. Br. (fig. 335).

Hypocotyl woody, erect, terete, pubescent or covered with short, fleshy, hyaline hairs, $8 \mathrm{~mm}$. above the soil.

Cotyledons oblong, obtuse, entire or minutely emarginate, petiolate, coriaceous, glabrous, deep green above, purplish-red beneath ; lamina $1.25 \mathrm{~cm}$. long, $6.5 \mathrm{~mm}$. wide; petiole flattened above, pubescent like the hypocotyl, $3 \mathrm{~mm}$. long.

Stem woody, erect, terete, purplish, densely covered with brown hairs; first internode $1 \cdot 15 \mathrm{~cm}$. long.

Leaves simple, entire, cauline, alternate, stipulate, petiolate, 
thinly hairy and deep green above, ciliate at the margin, paler beneath and glabrous except on the midrib, coriaceous; petioles subterete, slightly channelled above, purplish and covered with brown hairs; stipules ovate-oblong or oblong, obtuse, pale green or reddish, thinly hairy along the midrib and margin, enclosing and protecting the younger bud or leaf, very large in the adult plant, obliquely oval with three to four nerves on one side of the midrib, and four to five on the other, deciduous.

No. 1. Ovate-subcordate, subacute, trinerved and slightly reticulate.

Ultimate leaves large, cordate, acuminate, five- to seven-nerved, nerves incurved, reticulate, coria-

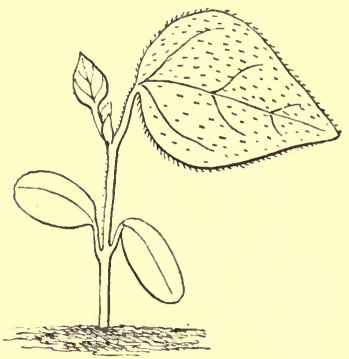

FIG. 335.-Bucklandia populnea. Nat. size. ceous, glabrous, cartilaginous at the margin and subundulate, light green, often suffused with crimson; petiole subterete, slightly flattened above, thickened at base and apex, glabrous.

\section{HALORAGE}

Benth. et Hook. Gen. Pl. i. 673.

Fruit and Seed.-Ovary of one to four carpels with as many cells, but a three-celled condition is rare. Ovules pendulous, anatropous, and solitary in each carpel. Fruit small and nut-like or baccate, compressed, ribbed, angled, or winged, one- to three-celled, indehiscent, or breaking up into as many cocci as there are carpels. The testa is thin and membranous, enclosing a copious layer of fleshy endosperm. The embryo is somewhat cylindrical, straight, and almost equal to the endosperm in length. The radicle is elongated and stout, the cotyledons proportionately very short and blunt, as in Hippuris vulgaris. In Gunnera scabra and other species the embryo is minute, obcordate, and embedded in endosperm close to the upper end of the seed. In Loudonia the seeds are comparatively very large. 
Seedlings.-The cotyledons of Gunnera chilensis (fig. 336) are oblong, trinerved, petiolate, and ciliated. The first leaf is cordate and crenate-serrate.

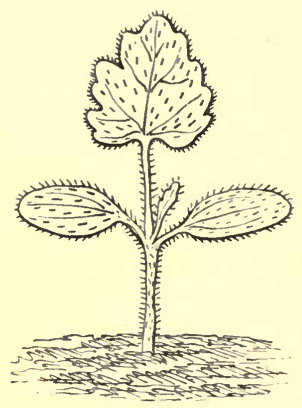

FIG. 336.-Gunnera chilensis. Nat. size.

Gunnera chilensis, Lam. (fig. 336).

Hypocotyl erect, terete, finely pubescent, greenish, $5-10 \mathrm{~mm}$. long.

Cotyledons oblong-oval, obtuse, entire, petiolate with flat petioles, ciliated, minutely pubescent, light green, indistinctly trinerved.

Stem with primary internodes undeveloped.

First leaves simple, radical, alternate, petiolate, exstipulate, ovate, obtuse, cordate at the base, obtusely serrate, ciliate, pubescent, light green, palminerved; petioles long, furrowed on the upper side.

\section{COMBRETACEE.}

Benth. et Hook. Gen. Pl. i. 693.

Ovary inferior, one-celled. Ovules two or rarely five, pendulous from the top of the cell, with long funicles, short in the tribe Gyrocarpex, anatropous. Fruit drupaceous, often winged longitudinally. Seed usually solitary by arrest; testa membranous, thin; tegmen swollen, intruded between the folds of the cotyledons. Embryo exalbuminous, straight; cotyledons foliaceous, rolled into a spiral, or thick, folded lengthwise, or crumpled. Radicle near the hilum, superior.

\section{Combretum sundaicum, Miq.}

Hypocotyl undeveloped or very short and subterranean, cotyledons subterranean.

Stem erect, terete, pubescent, soon becoming woody, first internode very short, or more often elongated.

Leaves simple, cauline, alternate, exstipulate with short petioles, nerves alternate and incurved, entire, glabrous, except the pubescent petiole. 
No. 1. Sometimes small, subterranean and colourless, or aerial and green, or the first as well as the second is foliaceous, small and ovate.

No. 3. Generally considerably longer and ovate-elliptic, acuminate.

Nos. 4 and 5. In strong seedlings elliptic and generally acuminate, but with an obtuse apex. Much longer than the preceding.

\section{MYRTACEA.}

\section{Benth. et Hook. Gen. Pl. i. 690 .}

Fruit and Seed.--The syncarpous ovary is entirely sunk in the receptacle, rarely half or wholly superior with the exception of its broad base. The exceptions are Fropiera with a wholly superior ovary, while it is also almost superior in several species of Tristania, Hypocalymna, Bæckea, and Xanthostemon. It is most often two- to many-celled with axile placentas, but some times it is one-celled owing to an imperfect dissepiment, with a basal placenta, or the latter is filiform and fixed to the base and apex of the cavity. Very rarely is it one-celled with two parietal placentas. The ovules are campylotropous or anatropous, and vary from two to many, and are arranged in two or more series on each placenta.

The fruit is sometimes capsular, dehiscing vertically by as many valves as there are cells. In other cases it is dry, baccate or drupaceous, one- or many-seeded and indehiscent. The seeds vary greatly in size and form even in the same genus. They have sometimes a membranous (as in the case of Eucalyptus), crustaceous, fleshy, or woody testa. Endosperm is nearly always absent, or when present occupies a small portion of the seed close to the hilum; it is said to be copious in a few cases. The embryo is straight, curved in a circinate manner, or spiral ; sometimes it is thick and fleshy with minute cotyledons at the smaller end of the seed, or hooked or almost absent. In other cases the cotyledons are foliaceous, longer than the radicle, sometimes coiled round it; and sometimes they are fleshy, flat, twisted, plaited, or thick and free, or soldered together in a solid mass.

An exceptional case occurs in the genus Feijoa which 
contains a solitary Brazilian species with angled, albuminous seeds and a straight embryo with flat, foliaceous cotyledons.

The embryos of species of Eucalyptus coming under my notice are remarkable for the way in which the cotyledons are deflexed and become folded or coiled round the radicle. The latter is straight in E. Globulus (fig. 338), as are the petioles for part of their length, while the upper portion is bent at right angles to reach the base of the cotyledons. The whole length of the seed is occupied by the radicle, the straight portion of the petioles, and the real length of the cotyledons which is not great. The size of the latter and their lobed appearance is due to their being deflexed and growing in a lateral direction till they reach the base of the seed while their apical edge becomes coiled round the radicle. The middle portion through which the midrib runs cannot coil round the radicle and is therefore short, thus giving rise to the apical sinus. This will be better understood by reference to the seedlings. A closely similar or identical case occurs in E. marginata, a transverse section of which shows the manner of coiling round the radicle. Although the section showing the coil is transverse to the seed, it is really through the longitudinal plane of the cotyledons. E. stellulata (fig. 341) has very much smaller and narrower seeds, and the coiling is therefore less extensive. The radicle is club-shaped, thickest at the point, and central to the cotyledons.

A very different case is met with in Couroupita guianensis (fig. 347), where the clavate radicle occupies the periphery of the seed, passing entirely round it and girdling the foliaceous, much plaited, or folded and crumpled cotyledons. The seed is large, suborbicular, laterally compressed and oval or elliptic in transverse section.

Seedlings.-The cotyledons in the seedling stage differ greatly according to the size and shape of the seed. Amongst those observed, three types with some remarkable exceptions may be cited; but there can be little question that if an exhaustive series of species were examined the number both of types and exceptions would be considerably increased. The simplest type is that represented by Callistemon rigidus (fig. 337), having small, elliptic or subrhomboid cotyledons. 
This type is also exemplified in C. speciosus, C. Cunninghamii, Psidium, and strikingly so in Tristania conferta (fig. 345). There is a slight departure or modification of the type in Callistemon Cunninghamii where the cotyledons present the appearance of being obscurely trifid. Those of Psidium are much larger than usual, and leaf-like, and those of Melaleuca hypericifolia obovate or roundly ovate.

All of the above species agree in having the first pair of leaves opposite, while a number of them have several pairs with this arrangement. In the seedling stage the species of Callistemon have small, myrtle-like leaves, very different from the adult form which is linear or lanceolate, and rather rigid, with the edges vertical by a twisting of the very short petiole. The primary leaves of Tristania conferta and Psidium are also small and myrtle-like. Those of Melaleuca hypericifolia are small and lanceolate.

Most of the species of Eucalyptus observed have characters in common in the form of the cotyledons. They are transversely oblong, with or without a shallow sinus at the apex, with a short midrib terminating in the sinus, and a longer lateral nerve running along the centre of the lateral lobes. They are practically, therefore, trinerved; but the whole of the venation is sometimes obscure or indiscernible owing to the opacity of the cotyledons. The real apex of the latter is in the notch; and the length of the lateral lobes together with the origin of the sinus is explained below. Species agreeing in the main with the above particulars are Eucalyptus Globulus (fig. 339), E. rostrata, E. cordata, E. leucoxylon (fig. 340) and E. stellulata. A slight modification of the above is seen in E. coccifera having small, obcordate cotyledons with a cuneate base. A greatly exaggerated form is met with in $\mathrm{E}$. occidentalis (fig. 342) where the lateral lobes are ascending or suberect so as to give the cotyledons a furcate appearance strongly resembling those of Pentapetes puniceus amongst the Sterculiaceæ, with similar venation. The cotyledons of E. ficifolia are transversely oblong-reniform, with a moderately deep notch at the base, a very shallow apical sinus, the three nerves copiously branched, and long ascending petioles. On the whole they may be compared to those of a 
Geranium. The long petioles show a transition to a still more remarkable type occurring in E. marginata (fig. 343), in which the hypocotyl is subterranean and extremely short, while this deficiency is compensated for by the length of the petioles. The lamina is obcordate, cuneate and trinerved, resembling a Brassica. A striking departure from the common type occurs in E. calophylla (fig. 344) having reniform-orbicular, incipiently emarginate, foliaceous cotyledons of great size. The three nerves are copiously branched, the lateral ones again having three main divisions.

They all agree in having the primary leaves opposite and entire, but these differ slightly in form. Those of E. Globulus are linear-lanceolate; of E. rostrata, E. cordata and E. leucoxylon, lanceolate; of E. stellulata, oval ; of E. coccifera, E. marginata, and E. ficifolia, ovate; of E. occidentalis, oblong ; and of E. calophylla, cordate, covered on both surfaces with crystalline glands. The primary leaves of many individual specimens of $\mathrm{E}$. ficifolia are more or less distinctly alternate.

Amongst the species with aerial cotyledons are some which must be considered exceptions to the above-mentioned types. Rhodomyrtus tomentosa has oblong-ovate, obtuse, shortly petiolate, penninerved cotyledons which are much longer than the first two pairs of roundly ovate leaves. A most remarkable case occurs in a species of Lecythis, seeds of which were sent to Kew from Trinidad under the name of L. Ollaria (fig. 349). The cotyledons are palmately five-nerved and seven- to nine-lobed with finger-like, bluntly pointed segments. The first five or more leaves are lanceolate, finely serrated and much smaller (especially the first two) than the foliaceous persistent cotyledons.

In a third type the cotyledons where present are subterranean and shortly petiolate as in Eugenia bracteata (fig. 346). The embryo of Lecythis Zabucajo (fig. 348) consists of a solid piece while still in the seed, to the interior of which it strictly conforms. It is narrowly ellipsoid or fusiform, and is evidently homologous with the hypocotyl which has become thickened and fleshy in this remarkable way in order to constitute a storehouse of reserve-material. By remaining in the 
thick and woody testa both during and after germination it would be protected from the depredations of animals. Cotyledons are absent or very minute. This being the case it follows that the seedling must behave differently from those having cotyledons which are also generally if not always petiolate when they are subterranean or remain in the testa in germination, as in Eugenia bracteata and others mentioned above. The petioles in these cases allow the whole of the embryo to escape from the testa, with exception of the fleshy laminæ of the cotyledons. On the contrary the fleshy hypocotyl of Lecythis Zabucajo is held fast while the plumule splits the testa and pushes its way out at one end of the seed and the radicle at the other. The allied Bertholletia excelsa (fig. 350) behaves in the same way, as well as Barringtonia speciosa.

That there is good ground for considering this fleshy undivided embryo as homologous with the hypocotyl may be inferred from species belonging to other genera. For instance in Couroupita the radicle (so called) is long, clavate and curved round the outside of the cotyledons; in Couratari it is very large and cylindrical; in Planchonia it is very long, clavate and spirally convolute, while the cotyledons are short; but in Careya, Barringtonia, Lecythis and Bertholletia the embryo is quite undivided, with a bud at one end and the radicle proper at the other.

It is usual for some of the primary leaves to be reduced to colourless or brown scales when the cotyledons are subterranean. The first two pairs of Eugenia bracteata are in this condition. A great number of the primary leaves of Bertholletia excelsa are very small and completely cover the lower part of the stem owing to the non-development of the internodes. They gradually change from sheathing organs to perfect leaves, of gradually increasing length. The first eight are colourless, the next five are oblong, followed by one or more lanceolate ones, while the fifteenth and sixteenth are oblong-obovate, but very moderate in size. Only three or four of the first leaves of Lecythis Zabucajo are scale-like. In all three species the colourless leaves would act as a protection to the plumule while pushing its way through the soil, 
or whatever else might have accumulated above the seeds in a state of nature. The second four leaves of Lecythis are roundly cordate followed by four that are ovate, and then by others which are lanceolate. The ultimate form is oblonglanceolate, serrate, and the leaves are alternate, distichous, and arranged on the half plan.

\section{Callistemon rigidus, $R$. $B r$. (fig. 337).}

Primary root fibrous, tapering downwards, normal.

Hypocotyl erect, terete, glabrous, reddish, 4-7.5 mm. long.

Cotyledons elliptic or rather rhomboid, obtuse, petiolate, glabrous, with what appear to be alternate, ascending, very obscure nerves in the fresh state, entire, rather thick, light green above, paler beneath,

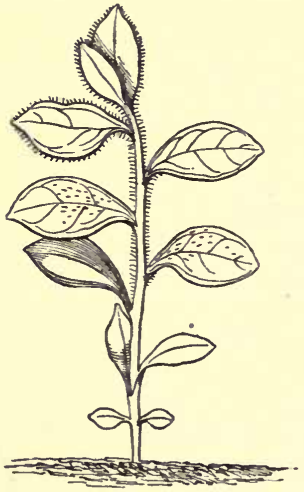

Fis. 337.-Callistemon rigidus. Nat. size. tapering into the petiole; lamina 1.5$3.5 \mathrm{~mm}$. long, $1 \cdot 25-2.5 \mathrm{~mm}$. wide; petiole flattened above, convex beneath, $1 \cdot 25-2 \cdot 5 \mathrm{~mm}$. long.

Stem erect, terete, somewhat flexuose, reddish at a very early stage, hairy or subvillous; 1 st internode $1 \cdot 25-2 \cdot 5$ mm. long ; 2nd not developed or rarely slightly; 3rd 9-15 mm. long; 4th $4.5-6.5 \mathrm{~mm}$.

Leaves simple, entire, cauline, alternate (first two opposite or almost so), exstipulate, very shortly petiolate in the seedling, but as the plant reaches the adult state the petiole becomes shorter and shorter until the leaves become sessile, merely tapering to the base, trinerved from base to apex, and in the seedling stage showing alternate, ascending nerves that connect the median with the marginal or submarginal ones, pubescent, or silky with adpressed or slightly spreading whitish hairs, dotted with pellucid glands; petioles in the seedling plant short, flattened beneath, convex above.

Nos. 1 and 2. Opposite or nearly so, rhomboid-elliptic, obtuse, obscurely trinerved in the lower half.

Nos. 3 to 12. Elliptic, acute or subacute, more or less distinctly trinerved, light green above, paler beneath and shining.

Ultimate leaves linear, acute, or ending in a spine, trinerved, with the marginal ones sunk in the thickened marginal tissue, 
suddenly tapered at the apex into the spine, narrowed to the base where by a slight twist the leaf is turned through an angle of $90^{\circ}$, and becomes more or less vertical, that is, with its edges perpendicular to the surface of the earth, silky on both surfaces with adpressed hairs.

Callistemon speciosus, $D C$.

Hypocotyl as in C. rigidus.

Cotyledons rhomboid, obtuse, deep green, and clothed with minute scales; lamina glabrous, $4.5 \mathrm{~mm}$. long, $4 \mathrm{~mm}$. wide; petiole $1.5 \mathrm{~mm}$. long.

Stem woody, erect; early internodes very short or hardly developed.

Leaves simple, entire, cauline, alternate, exstipulate, shortly petiolate, glabrous in the young stage and minutely scaly, deep green, opaque, obscurely alternately penninerved, coriaceous, perforated with translucent glands; petioles very short, flattened above.

Nos. 1 and 2. Opposite, ovate, obtuse.

Ultimate leaves lanceolate, acute, ascending, placed vertically, trinerved, glabrous, coriaceous, pale green, somewhat reticulated ; petiole very short, twisted, together with base of leaf, through an angle of $90^{\circ}$.

Callistemon Cunninghamii, ? F. Muell.

Primary root as in other species.

Hypocotyl short, erect, terete, glabrous, 3-4 $\mathrm{mm}$. long, light green or colourless.

Cotyledons ovate, obtuse, shallowly trilobed, glabrous, green, one-nerved; petioles rather long, shallowly channelled on the upper face.

Stem erect, terete, herbaceous; 1 st internode 1-1.5 mm. long; 2nd, 3rd, 4th, rather longer.

First leaves simple, entire, cauline (first two opposite), others alternate, ovate-oblong, obtuse, entire, petiolate, exstipulate, glabrous, green, trinerved; petioles short, flat, shallowly channelled above.

\section{Melaleuca hypericifolia, Sm.}

Hypocotyl erect, terete, glabrous, red, 5-10 mm. long.

Cotyledons ovate or rotund, or minutely emarginate, entire, small, petiolate, glabrous, dark green, indistinctly one-nerved. 
Stem erect, terete, herbaceous, ultimately woody, glabrous, tinged with red; 1 st internode $\cdot 75-1 \cdot 25 \mathrm{~mm}$. long; $2 \mathrm{nd}$, 3rd, etc. varying about the same length.

Leaves simple, entire, cauline, opposite, decussate, oblong, obtuse, tapering to the base, sessile, glabrous, light green, onenerved.

\section{Eucalyptus Globulus, Labill. (fig. 338).}

Fruit a capsule, three- to four-celled, many-seeded, sunk in the truncated receptacle dehiscing along the middle of the valves.

Seed horizontal, flattened, compressed and angled laterally or dorsally into very various shapes; testa deep brown or black; hilum ventral, paler in colour than the rest of the seed.

Endosperm absent.

Embryo straight or nearly so, fleshy, colourless, occupying the whole interior of the seed, and conforming to it in general outline; cotyledons broader than long, deflexed

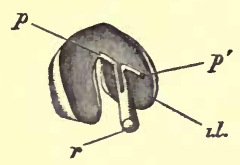

FIG, 338,-Eucalyptus Globulus. Cotyledon and radicle, $\times 8: i l$, inner lobe; $p$, petiole and its attachment; $p$, petiole from which the other cotyledon has been separated; $r$, radicle. and convolute over the radicle, which the lobes equal in length; half of one cotyledon lies over half of the other, and consequently only one half of each cotyledon lies against the testa ; radicle long, stout, fleshy, truncate at the end where it lies against the testa, otherwise wholly enclosed by the longitudinally coiled cotyledons, parallel with the axis and consequently some distance from the hilum.

\section{Seedling (fig. 339).}

Hypocotyl erect, terete, about $3.5 \mathrm{~cm}$. long.

Cotyledons deeply bifid, trinerved, the middle nerve ending in the sinus; lobes obovate-oblong, diverging; lamina $5 \mathrm{~mm}$. long, 9 mm. wide.

Stem woody, erect, terete at the base, and quadrangular upwards, warted on the angles and faces, covered with a glaucous-white bloom, then becoming pale green and ultimately brown; 1st internode $1.2 \mathrm{~cm}$. long; 2nd $1.1 \mathrm{~cm}$.; 3 rd $1.45 \mathrm{~cm}$.; 4 th $1 \mathrm{~cm}$.; 5 th $1.35 \mathrm{~cm}$.; 6th $1.1 \mathrm{~cm}$.; 7 th $1.35 \mathrm{~cm}$; 8 th $9 \mathrm{~mm}$.

Leaves simple, entire, cauline, opposite, decussate, and sessile in the young plant, alternate and petiolate in the adult, exstipulate, linear-lanceolate, glabrous, perforated with glands, covered with a glancous bloom, becoming pale green, ultimately dying off brown. 
First and second pairs linear-lanceolate, acute, tapering to both ends.

Third and fourth pairs lanceolate-oblong, subacute.

Fifth to eighth pairs (inclusive) oblong, acute.

Lower leaves on branches rotund-oblong, or rounded, then oblong-obtuse, afterwards oblongacute,- - all subcordate at the base.

Eucalyptus rostrata, Schlecht.

Hypocotyl erect, terete, glabrous, red, $5-8 \mathrm{~mm}$. long.

Cotyledons small, transversely oblong, obtuse, entire, sometimes almost cordate at the base, glabrous, green, indistinctly one-nerved, with short and rather flat petioles.

Stem erect, square, herbaceous, ultimately woody, stained with red; 1st internode 2-4 mm. ; 2nd, 3rd and 4th 6-10 mm.

First leaves as in E. Globulus, but oblong-lanceolate, obtuse, light green above, deep red beneath.

\section{Eucalyptus cordata, Labill.}

Hypocotyl erect, quadrangular, glabrous, red, $3-4 \cdot 2 \mathrm{~cm}$. long.

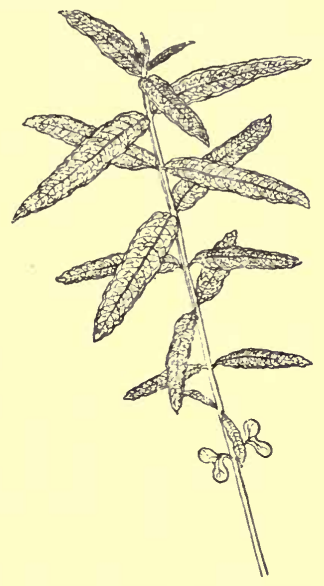

Fro. 339.-Eucalyptus, Globulus. Half nat. size.

Cotyledons very similiar to last species, shallowly emarginate, trinerved.

Stem terete, covered with tubercular or fleshy protuberances, otherwise as in E. rostrata; 1st to 4 th internodes $1.5-2.8 \mathrm{~cm}$. long.

First leaves as in E. rostrata, but sometimes entire, or slightly crenate, sessile, or in the case of the first pairs subsessile and acute.

\section{Eucalyptus leucoxylon, $F$. Muell. (fig. 340).}

Hypocotyl terete, glabrous, gradually tapering into the radicle, 6-9 mm. long.

Cotyledons as in E. rostrata, but truncate at the end, or sometimes possessing a small apical tooth, 1-25-2 $\mathrm{mm}$. long, 3-4.25 $\mathrm{mm}$. wide; petiole tapered downwards, slightly grooved above, 1.75$2.5 \mathrm{~mm}$. long. 
Stem square, glabrous, pale green or reddish, ultimately woody ; 1st internode $4.5 \mathrm{~mm}$. long; 2nd $5.5 \mathrm{~mm}$.; 3rd $4.5 \mathrm{~mm}$.

Leaves as in E. Globulus but oblong-lanceolate and petiolate; petioles tapering towards the base, channelled or grooved above.

First pair narrowly oblong, obtuse, small,

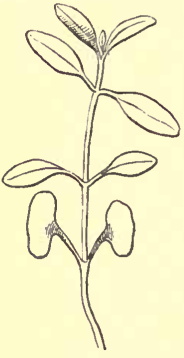

Frg. 340.

Eucalyptus leucoxylon, $\times 2$.

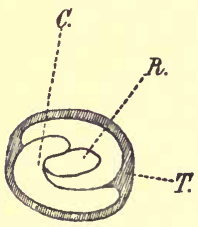

FIG. 341.-Eucalyptus stellulata, $\times 15$.

Transverse section of seed. $C$, cotyledons; $R$, radicle; $T$, testa. tapered to the base.

Second and fourth pairs oblong-lanceolate, obtuse, tapering at both ends, but mostly at the base.

\section{Eucalyptus stellulata, Sieb. (fig. 341).}

Fruit a many-seeded capsule, dehiscing loculicidally at the apex.

Seed small, from $\cdot 75-1 \mathrm{~mm}$. long, variously angled and shaped, exalbuminous; testa brownish, smooth; hilum inconspicuous.

Embryo straight, filling the interior of the seed, colourless; cotyledons transversely oblong, convolute and folded round the radicle ; radicle long, stout, truncate at the apex, occupying the centre of the seed and enveloped by the cotyledons.

\section{Eucalyptus coccifera, Hook. $f$.}

Hypocotyl terete, woody, glabrous, dark purple near the base, $1 \cdot 5-2 \mathrm{~cm}$. long, '5-1 mm. thick.

Cotyledons shortly stalked, $\cdot 5-\cdot 75 \mathrm{~cm}$. long, $.5 \mathrm{~cm}$. wide, obcordate, cuneate at base, retuse at apex, obscurely nerved, glabrous, not very thick, dark green above, dark purple beneath, rather persistent.

Stem firm, terete, scabrous, dark purple; internodes varying from 1-3 cm. in length, $1 \mathrm{~mm}$. thick.

Leaves as in E. Globulus, but ovate, deep green above, purplish beneath at least in the seedling stage.

Nos. 1 and 2. Including the short scabrous petiole, 1-1.5 cm. long, $\cdot 5 \mathrm{~cm}$. wide, ovate-lanceolate, entire, with sunk midrib and obscurely penninerved, glabrous, thin, dark green above, dark purple beneath in the early stages.

Nos. 3 and 4. The same, but more oblong, rounded at both ends. Nos. 5 and 6 . The same, but larger. 
Eucalyptus occidentalis, Endl. (fig. 342).

Hypocotyl erect, terete, glabrous, $1 \cdot 5-2 \cdot 2 \mathrm{~cm}$.long, stained with red.

Cotyledons deeply bifid, petiolate, glabrous, dark green, indistinctly nerved; lobes oblong, narrow, obtuse.

Stem erect, terete, glabrous, herbaceous, ultimately woody; 1st internode 4-5 mm. long.

First leaves linear-oblong, obtuse, petiolate, glabrous, light green, distinctly pinnatinerved.

\section{Eucalyptus ficifolia, F. Muell.}

Hypocotyl erect, terete, covered with short bristly hairs $2 \cdot 5-3 \mathrm{~cm}$. long, reddish.

Cotyledons reniform, obtuse, entire or slightly emarginate, cordate at the base, coriaceous, petiolate, glabrous except on the petioles which are covered

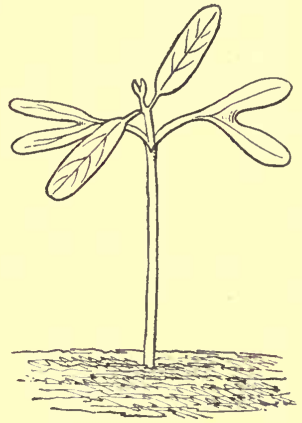

FIG. 342 .

Eucalyptus occidentalis, $\times 2$. with short bristly hairs, dark green, reddish beneath, palminerved.

Stem as in last species, but covered with bristly hairs; 1st internode $2-3.5 \mathrm{~cm}$. long; 2nd 1-2 $\mathrm{cm}$.

First leaves as in E. coccifera, but covered with numerous bristly hairs, tinged with red below, pinnatinerved.

The leaves in many specimens are alternate, not opposite, the internodes between the pairs of leaves at first being very short, but increasing in length after the second pair.

Eucalyptus marginata, Sm. (fig. 343).

Hypocotyl short, subterranean.

Cotyledons subrotund or transversely oblong, obtuse, emarginate, asymmetrical, petiolate, coriaceous, glabrous, dark green, reddish beneath, distinctly trinerved; petioles long, plano-convex, stained with red.

Stem as in E. ficifolia.

First leaves sessile, coriaceous, ovate-lanceolate, subacute, glabrous, light green, distinctly pinnatinerved.

Eucalyptus calophylla, $R$. Br. (fig. 344).

Hypocotyl erect, terete, reddish, densely covered with blunt, warty, glandular processes, about $1 \cdot 3-1 \cdot 5 \mathrm{~cm}$. above the soil. 
Cotyledons large, foliaceous, reniform-orbicular, petiolate, blunt, entire except at the base or incipiently emarginate, glabrous, deep opaque green and punctate above, much paler beneath and more conspicuously punctate, strongly trinerved from the base with the lateral nerves trifurcate a little above the base, and ascending while the midrib proceeds nearly straight to the apex with a few alternate, ascending branches; lamina $2.3 \mathrm{~cm}$. long, $3 \mathrm{~cm}$. wide; petiole subterete, flattened on the upper side above the base and

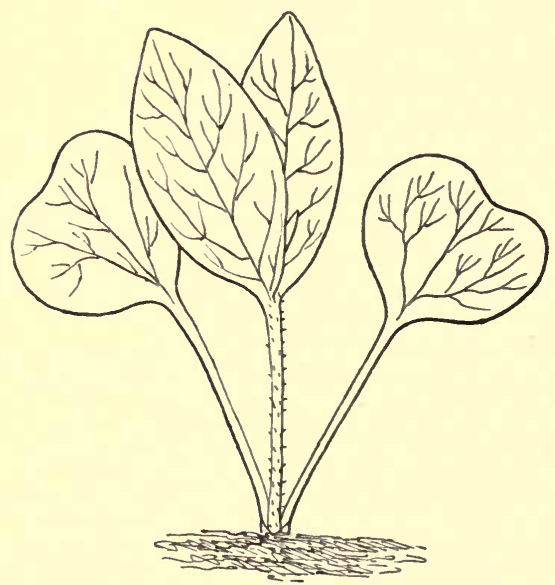

FIG. 343.-Eucalyptus marginata. Nat. size.

shallowly grooved upwards, much thickened and perfoliate at the base, densely covered with small glandular processes, about $1 \cdot 6 \mathrm{~cm}$. long.

Stem erect, terete, ultimately woody, green in the young state, densely covered with irregular crystalline, glandular processes; 1st internode $2.25 \mathrm{~cm}$. long; 2nd 5-6 mm.

Leaves opposite in the young plant, covered on both surfaces and at the margin, but especially on the petioles and midrib beneath, with various sized crystalline, glandular processes, rather closely and ascendingly penninerved and reticulate; petioles dilated and slightly flattened on the npper side at the base, otherwise nearly terete and tapering upwards. 
First pair broadly cordate, obtuse, tipped with a glandular mucro.

Second pair cordate-ovate, obtuse, tipped with a glandular mucro, alternate.

Tristania conferta, $R$. Br. (fig. 345). fibres.

Primary root tapering downwards, sending off numerous lateral

Hypocotyl erect, quadrangular, glabrous, red, 1-1.3 cm. long.

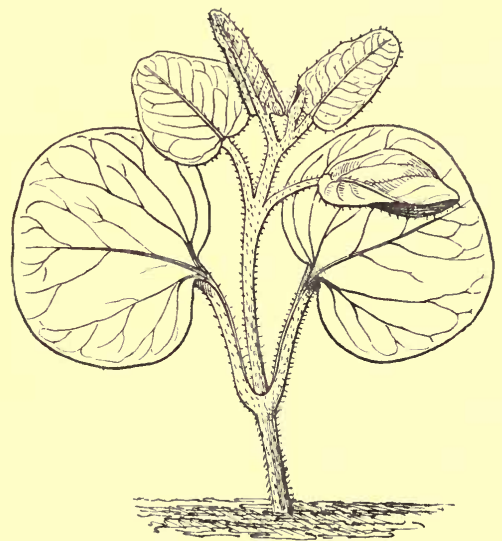

FIG. 344.-Eucalyptus calophylla. Nat. size

Cotyledons small, rhomboid, ovate, obtuse, entire somewhat fleshy, green, glabrous, petiolate, trinerved; petiole rather long and flat, glabrous.

Stem erect, quadrangular, slightly hairy, green; 1st internode $1 \cdot 2-1.5 \mathrm{~cm}$. long; 2nd internode 3-4 $\mathrm{mm}$.

First leaves entire, opposite, decussate, lanceolate, oval, obtuse, slightly ciliate, minutely hairy, green, pinnatinerved ; petioles short, slightly furrowed above.

\section{Psidium sp.}

Hypocotyl erect, terete or obtusely quadrangular, glabrous, pale green, about $1.8 \mathrm{~cm}$. above the soil.

Cotyledons aerial, ovate, acute, cuneate at the base, glabrous, 
shortly petiolate, coriaceous, thin, light green on both surfaces; lamina $1.3 \mathrm{~cm}$. long, $8 \mathrm{~mm}$. wide; petiole about $1 \mathrm{~mm}$. long.

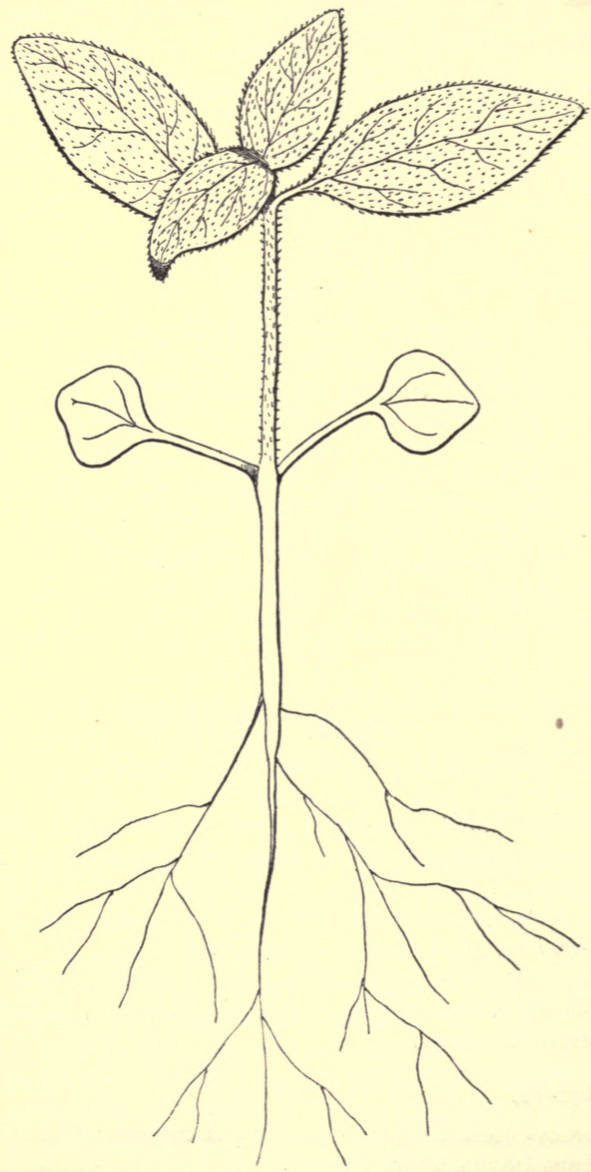

Fig. 345,-Tristania conferta, $\times 2$. 
Stem woody, erect, acutely quadrangular or almost four-winged, glabrous, pale reddish; 1 st internode $1.4 \mathrm{~cm}$. long; 2nd $1.9 \mathrm{~cm}$.; 3rd $7 \cdot 5 \mathrm{~mm}$.

Leaves entire, opposite, glabrous, deep green above, paler beneath, shining on both surfaces; petioles very short, glabrous, channelled above.

First to third pairs small, elliptic, obtuse, minutely cuspidate, or apiculate.

\section{Rhodomyrtus tomentosa, Wight.}

Hypocotyl erect, terete, glabrous, 5-10 mm. long, light green.

Cotyledons linear-oblong, obtuse, entire, shortly petiolate, glabrous, shiny green, pinnatinerved like the leaves.

Stem erect, somewhat quadrangular, herbaceous, ultimately woody; 1st internode $3-4 \mathrm{~mm}$. long; 2nd shorter.

First leaves simple, entire, cauline, opposite, ovate, obtuse, glabrous, shiny green, coriaceous with pellucid glands, exstipulate, pinnatinerved; petioles short, shallowly furrowed above.

Engenia bracteata, Räusch (fig. 346).

Hypocotyl subterranean.

Cotyledons subterrannean and remaining in the seed.

Stem woody, erect, terete, densely pubescent, pale green, ultimately brown; 1st internode $1 \mathrm{~cm}$. long; 2nd $1.15 \mathrm{~cm}$; 3rd $1.5 \mathrm{~cm} . ; 4$ th $8 \mathrm{~mm}$.

Leaves as in last species, obscurely penninerved, deep green above, pale below, shining on both surfaces, perforated with glands; petioles very short, channelled above, pubescent.

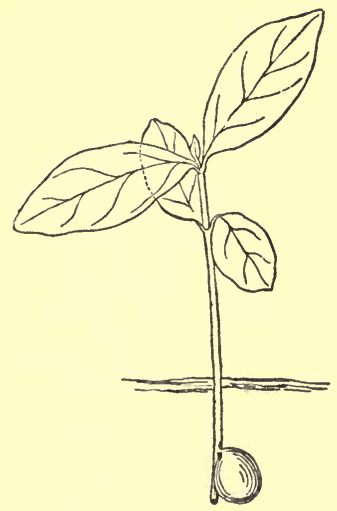

FIG. 346.-Eugenia bracteata. Four-fifths nat. size.

First and second pairs reduced to small scales, green, ultimately brown.

Third pair oval, obtuse, foliaceous.

Fourth pair elliptic, obtuse, much larger. 
Couroupita guianensis, Aubl. (fig. 347).

Pistil syncarpous, superior ; ovary of five to seven carpels, manyovuled; ovules campylotropous.

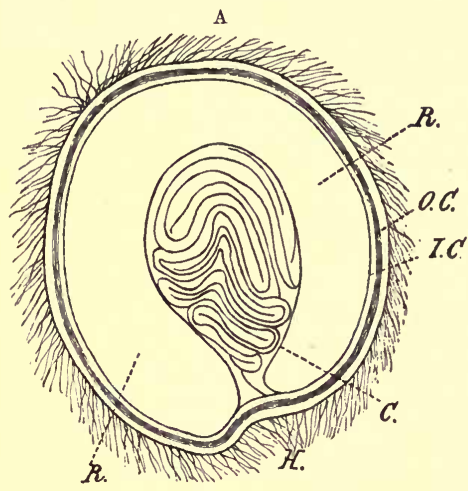

B

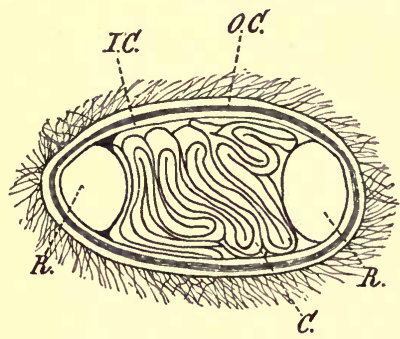

Fig. 347.-Couroupita guianensis, $\times 4$.

A, longitudinal section of seed. $B$, transverse section of seed. $H$, hilum; $R$, radicle; $C$, cotyledons; $O C$, testa; $I C$, tegmen.
Fruit subglobose, coriaceous or almost woody, many-seeded, indehiscent.

Seed large, villous, transversely oblong, considerably flattened; testa crustaceous by a thickening and hardening of the inner layer of the outer coat, villous ; hilum rather conspicuous.

Endosperm absent.

Embryo curved or rounded on itself, or involute, rather compressed, filling the whole of the seed, and pinkish. white; cotyledons large, oblong, contorted and plicate with numerous intricate folds; radicle very long, curved all round the seed and enclosing the cotyledons in the centre, clavate, obtuse.

Lecythis Zabucajo, Aubl. (fig. 348).

Primary root very long, stout, woody, giving off a few lateral fibres, and leaving the seed at the opposite end to the plumule.

Hypocotyl remaining in the seed, subterranean, large, fleshy, colourless, forming an oblong mass conforming to the shape of the cavity of the seed, and tapering to each end.

Cotyledons probably absent. 
Stem erect, terete, soon becoming woody, tapering gradually upwards, glabrous, light green.

Leaves always simple, alternate, cauline, exstipulate, sessile in the seedling, but ultimately shortly stalked, distichous, serrated, glabrous, light green, penninerved and reticulated.

A

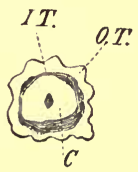

B

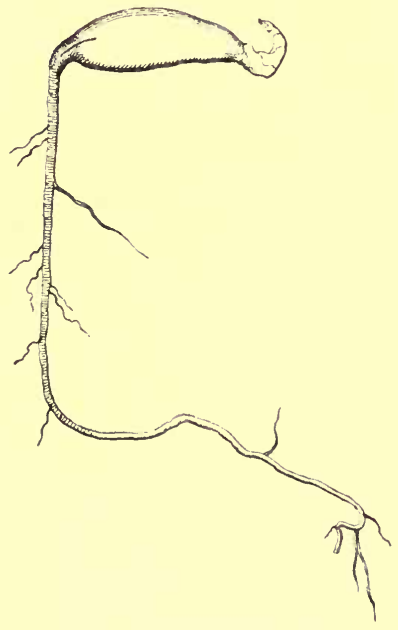

C

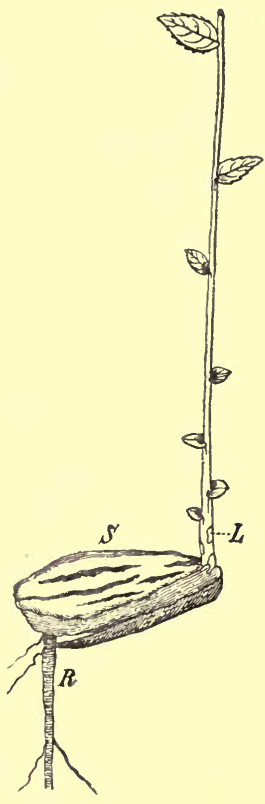

FIG. 348.-Lecythis Zabucajo. A, transverse section of seed: OT, testa; $I T$, tegmen; $C$, fleshy hypocotyl. $\mathrm{B}$, germinating embryo removed from seed. C, seedling: $S$, seed; $R$, radicle; $L$, scale-like leaf. Half nat. size.

Nos. 1-3 or 4. Small, scale-like, clasping the stem at its base.

Nos. 4-7. Broadly cordate, obtuse, clasping and decurrent on the stem, forming a slender line for some distance, or, on the upper portion of the seedling, running down as far as the next internode.

Nos. 8-11. Ovate, acute or acuminate, slightly toothed; No. 11 slightly stalked. 
Nos. 12-14. Lanceolate, acuminate, distantly serrulate, shortly petiolate.

Lecythis Ollaria, $L$. ? (fig. 349).

The seedling figured below (fig. 349) was grown under the above name, but I do not feel clear about it. Possibly it is a species of

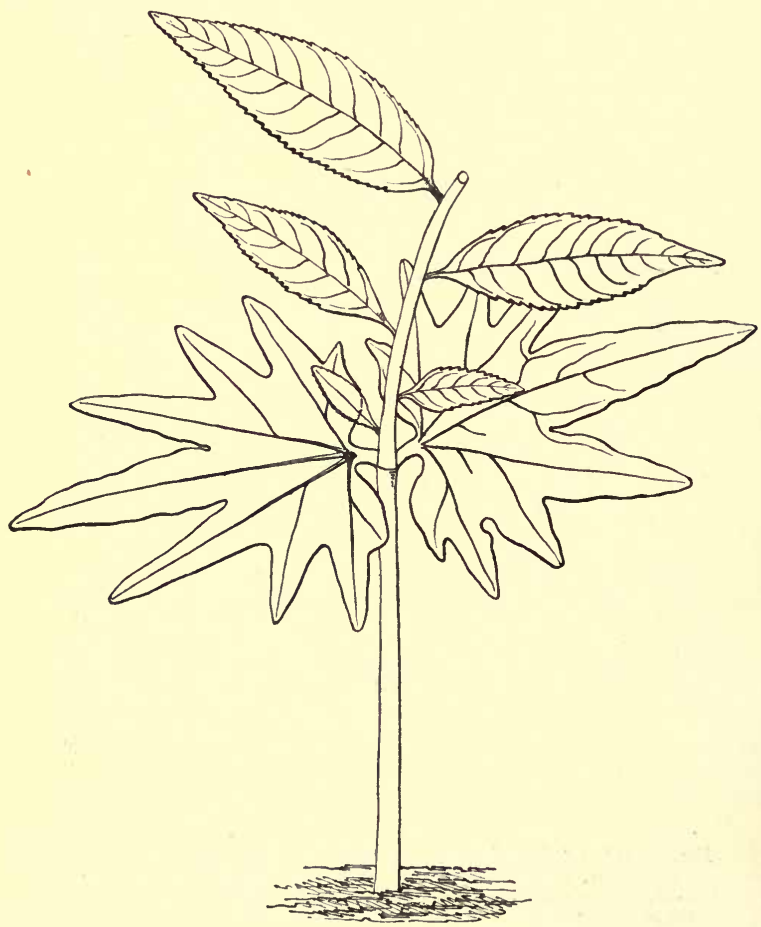

Fig. 349.-Lecythis Ollaria. Nat size.

Couratari. I figure it, however, on account of the remarkable cotyledons, which resemble those of Tilia.

Hypocotyl erect, terete, finely pubescent, 5-9 $\mathrm{cm}$. or more above the soil. 
Cotyledons very large, foliaceous, aerial, palmately seven- to eleven-nerved and-lobed, reticulated, glabrous, membranous, shining, shortly petiolate, 5-6 $\mathrm{cm}$. long including the petiole, $4 \cdot 5-5 \cdot 2 \mathrm{~cm}$. wide; middle segment lanceolate, obtuse, by far the longest, the

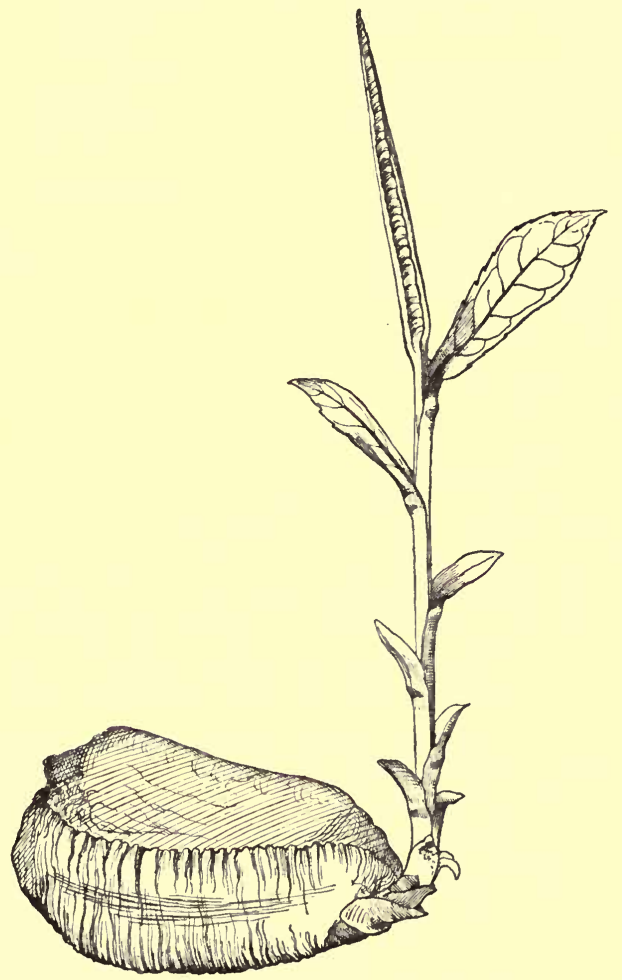

Fig. 350.-Bertholletia excelsa. Nat. size.

others gradually becoming shorter towards the base; petiole $2 \cdot 5-$ $3 \mathrm{~mm}$. long.

Stem erect or arching, terete, pubescent, more or less flexuose, ultimately woody; 1st internode $4 \mathrm{~mm}$. long; $2 \mathrm{nd} 7 \mathrm{~mm}$.; the others gradually becoming a little longer. 
Leaves simple, cauline, alternate, exstipulate, shortly petiolate, serrate, alternately incurvinerved, glabrous, bronze-coloured in a young state, ultimately bright green and shining, distichous and arranged on the half plan.

No. 1. Very small, lanceolate, obtuse, 7-9 mm. long including the petiole.

No. 2. Lanceolate, three times as large as No. 1.

Nos. 3-8. Lanceolate, acuminate, obtuse, and gradually larger,

Bertholletia excelsa, H. B. K. (fig. 350).

Radicle emerging towards the opposite end of the seed to that whence the plumule emerges.

Hypocotyl, as in Lecythis, very thick and fleshy, conforming to and filling the interior of the seed, subterranean.

Cotyledons absent.

Stem erect, terete, glabrous, stout, colourless beneath the soil and deep brown above it, ultimately woody; first eight to ten internodes very short and covered by scale-like leaves, mostly beneath the soil ; 11-15th gradually elongating from 6-14 $\mathrm{mm}$. long.

Leaves simple, cauline, alternate, or the lower ones appearing opposite owing to the suppression or shortening of the internodes, exstipulate, petiolate, or the lower sessile and clasping the stem and scale-like, alternately incurvinerved and reticulate, glabrous, shining on both surfaces, at least when young, and in that condition more or less stained with brownish-red; petioles wanting in a great number of the primary leaves, or short and sheath-like.

Nos. 1-8 (in specimen examined). Small, colourless, subterranean, scale-like.

Nos. 9-13. Green, oblong, acute, aerial, carinate owing to the stout midrib, entire, ascending or spreading.

No. 14. Lanceolate-oblong, subacuminate, entire or slightly serrulate, much larger than the previous ones.

Nos. 15 and 16. Oblong-obovate, acuminate, serrulate, narrowed at the base into a short sheath-like petiole, clasping the stem on one side. 


\section{MELASTOMACE $A$.}

Benth. et Hook. Gen. Pl. i. 725 .

Fruit and Seed.-The ovary is free or more or less adnate to the receptacular cup; when it matures into the fruit the free portion, if any, is nearly always enclosed in the cup. It varies with two to many carpels cohering to form as many cells. The members of the suborder Memecyleæ constitute an exception, inasmuch as the septa often disappear making the ovary one-celled, with the ovules arranged verticillately on a free central columella. In the suborder Melastomeæ the ovules are very numerous and inserted on placentas that project far into the interior of the ovary ; while in the suborder Astronieæ the numerous ovules are ascending and inserted on prominent basal or parietal placentas. In all cases they are anatropous. They are very few and definite in the tribe Miconieæ of the Melastomeæ and in the suborder Memecyleæ.

The fruit is baccate or capsular, dehiscing by valves or bursting irregularly. The seeds are varied in outline from cuneate, cochleate, or pyramidal to filiform and are very small, except in the cases mentioned where the ovules are few when they are large, globose or hemispherical. The testa is membranous, leathery, crustaceous and smooth or rugose, in Huberia and Acanthella it is winged. The raphe is sometimes enlarged and spongy. The seed is exalbuminous, and whether large or small the embryo occupies the whole of the interior, to which it conforms. In the suborder Memecyleæ the embryo is large with plano-convex or subfoliaceous cotyledons.

Seedlings.-The seedlings observed all belong to the suborder Melastomeæ having numerous small seeds, consequently the cotyledons even after germination are very small, or even minute in Rhexia Mariana (fig. 352). The lamina is only about 1-5 mm. long, by 1-2.5 mm. wide, shortly petiolate and rhomboid in outline. The first three or four pairs of leaves are broadly ovate, trinerved and gradually increase in size from the first pair which is very small or even minute. Several succeeding pairs are inclined to be elliptic and are 
serrate. Rhomboid cotyledons also occur in other genera and species, including Osbeckia rubicunda where they show a distinct midrib but no other venation. The latter species is notable for the length of the first internode. The first pair of leaves is roundly ovate, subcordate at the base and trinerved, while two or more succeeding pairs are inclined to be elliptic. Osbeckia capitata (fig. 351) has broadly ovate, one-nerved cotyledons; and the two forms given are likely to be the prevailing ones throughout a large number of the species with numerous small seeds. The first three pairs of leaves are ovate, while succeeding ones are inclined to be cordate at the base, and from the third pair onward they are five-nerved. Strong nerves proceeding from the base to the apex of the leaf are very prevalent and characteristic of the Order; but in Medinilla magnifica and M. amabilis, strong nerves are given off at various points along the midrib, and possibly in other species, where the venation is pinnate.

\section{Osbeckia capitata, Benth. (fig. 351).}

Primary root long, slender, tapering very gradually downwards, flexuose, and provided at an early stage with very short lateral rootlets.

Hypocotyl erect, terete, pubescent with very minute incurved hairs, almost colourless, and becoming pale red at an early stage, about $1 \mathrm{~mm}$. long when the first leaves have appeared, and elongating little or none at all after this.

Cotyledons ovate, obtuse, entire, minutely pubescent, at least at the edges, petiolate, showing an indistinct midrib, but no other venation, deep green above and red beneath; lamina $1.5 \mathrm{~mm}$. long, $1.25 \mathrm{~mm}$. wide; petiole flattened above, convex on the back, rather broad, $\cdot 75 \mathrm{~mm}$. long.

They do not increase much beyond these dimensions, but drop away after a time.

Stem erect, quadrangular; angles obtuse and densely covered with closely and upwardly adpressed, bulbous-rooted hairs, the intermediate faces smooth or more or less densely and irregularly covered with similar hairs, red, and ultimately shrubby; 1st inter-

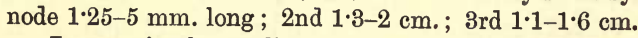

Leaves simple, cauline, entire, opposite, exstipulate, petiolate, covered more or less densely on both surfaces with bulbous-rooted 
adpressed hairs directed towards the apex, deep green above, pale beneath or often stained with red; petioles very short, channelled above, densely hairy, slightly connate at the base, or forming a ring round the stem, with one to three or more stronger, erect bristles on the ring.

First pair of leaves small, ovate, obtuse, entire, trinerved, with comparatively longer petioles than succeeding ones.
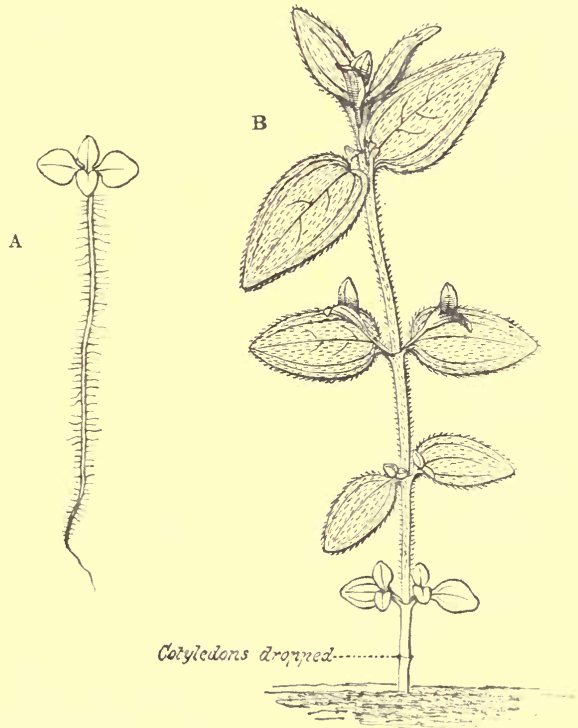

FIG. 351.-Osbeckia capitata. A, young seedling, $\times 4$. B, older seedling. Nat. size

Second pair ovate, obtuse, strongly trinerved.

Third pair ovate, obtuse, strongly trinerved with sometimes two other slender nerves.

Fourth to sixth pairs similar, but gradually wider and subcordate at the base.

Rhexia Mariana, L. (fig. 352).

Primary root very long, slender, flexuose, colourless, furnished with numerous lateral rootlets. 


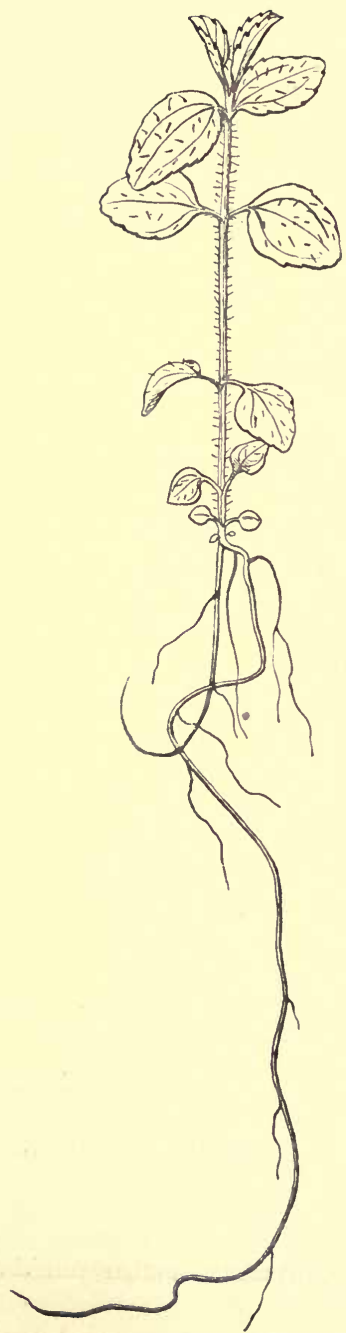

Hypocotyl short and indistinguishable from the root.

Cotyledons minute, rhomboid, obtuse, glabrous, shortly petiolate, bronze red; lamina $1.5 \mathrm{~mm}$. long, $1.25 \mathrm{~mm}$. wide; petiole grooved above, $1 \mathrm{~mm}$. long.

Stem herbaceous, erect, subterete, grooved on two sides from between the bases of the petioles downwards to the axils of the two lower leaves, coarsely hairy, or glandular-hairy when young, red; 1 st internode 1.5 $\mathrm{mm}$. long; 2nd $4 \mathrm{~mm}$.; 3rd $1.4 \mathrm{~cm}$; 4 th $2.05 \mathrm{~cm}$.

Leaves simple, cauline, opposite, decussate, petiolate, exstipulate, coarsely and thinly glandular-hairy on both surfaces, trinerved, with the lateral nerves describing an ellipse, bronze green above, deep red and shining beneath; petioles channelled above, rounded on the back, red, very thinly glandular-hairy.

First pair very small, broadly ovate, obtuse, entire, indistinctly trinerved.

Second pair larger, similar.

Third pair broadly ovate, obtuse, minutely emarginate, and minutely apiculate in the notch when quite young, distantly serrulate.

Fourth to sixth pairs ovateelliptic, obtuse, minutely emarginate and apiculate in the notch when young, serrulate. 


\section{LYTHRARIE E.}

Benth. et Hook. Gen. Pl. i. 773 .

Fruit and Seed.-The two- to six-celled ovary composed of as many carpels is mostly superior or free, rarely girt at the base by one or more glands, and still more rarely wholly immersed in the receptacle as in Punica and Axinandra. One-celled ovaries may arise by the destruction of the septa, or by one out of two carpels becoming suppressed. The ovules are numerous, multiseriate, anatropous, inserted on axile or basal, rarely parietal placentas. They are solitary in the cells of Axinandra, reduced to two in the one-celled ovary of Strephonema, and inserted on a free basal placenta in the one-celled ovary of Antherylium.

The fruit is capsular, two- to six-celled with axile placentas, or one-celled by the destruction of the septa when the placentas become free and central. Baccate fruits occur in Punica and Sonneratia which are in many respects anomalous for the Order. The first named has the walls of the fruit of a thick and leathery nature, while the seeds are surrounded by a deep layer of watery pulp. The interior is many-celled with the cells arranged in two tiers, one above the other. In other and more typical cases the seeds are smaller, and terete, angled or winged, exalbuminous or with a small quantity of endosperm. The testa varies in different species both in thickness and texture, and in some cases it is pilose or hispid.

The embryo is generally straight, with oblong or orbicular, flat, auricled cotyledons, varying in conformity with the shape of the seed. An exceptional case occurs in Dodecas which has small hispid seeds resembling sawdust, containing a slender, elongated embryo with linear cotyledons, and a terete radicle. The cotyledons of Punica are spirally convolute in the seed, and auricled at the base. A good type is represented by Cuphea silenoides (fig. 353). The cotyledons are suborbicular, deeply auricled at the base and distinctly emarginate, the emargination being due to a pronounced thickening at the slightly indented chalaza. The auricles are produced in order 
to occupy the space on each side of the radicle, which terminates abruptly in three rounded lobes. The reason for this peculiar form of the radicle is not rery evident. The seed in transverse section is thinly elliptic.

Seedlings.-At least two well-marked types of cotyledons occur as well as a few striking exceptional instances. One type is represented by Cuphea silenoides (fig. 354). The cotyledons are roundly-triangular, emarginate, truncate at the base and faintly five-nerved. A remarkable point about them is that they are auricled at the base while still in the seed as abore noticed, and for some time after germination; but as growth proceeds and they become fully dereloped the auricles become lost or obliterated by the more rapid growth of the lamina in the neighbourhood of their attachment to the petiole than in the auricles themselves. Similar examples are met with in species of Salvia belonging to the Labiatæ, but the obliteration of auricles already well-dereloped in the seed is by no means of frequent occurrence. They usually increase in size after germination. The primary causes of the auricles, and the emargination, are referred to above. The abrupt and sublobate condition of the hypocotyl in the seed shows itself after germination in the form of an annular thickening. C. Roezlii agrees generally with the type given, but the cotyledons are much smaller and subcuneate at the base when full grown; and the latter characteristic is no doubt due to growth subsequent to germination. This is carried to a still greater extent in Cuphea coccinea where the cotyledons are broadly obcordate with a cuneate base and trinerved. The first pair of leaves in all three cases is ovate and entire, and subsequent ones vary between oblong-elliptic or lanceolate, or remain unaltered except in size.

The second type is met with in Lythrum flexuosum and other species which have oblong-oval, obtuse cotyledons with a cuneate base. In L. flexuosum they are small, often slightly constricted near the apex and appearing obsoletely trinerved. Venation seems restricted to a faint midrib. The primary leaves at least are opposite, oblong-ovate, and decurrent on the stem, making it quadrangular or narrowly four-winged.

An exceptional case to the above types is met with in 
Punica Granatum (fig. 355) which has transversely oblong, deeply emarginate, five-nerved cotyledons, rounded at the sides. The outer pair of nerves follows the outline of the cotyledons, parallel to the margin. Their great width is due to their being convolute in the seed, which is unusually large for the Order. The leaves are opposite, lanceolate, shortly petiolate and decurrent upon the stem, making it narrowly four-winged as in Lythrum. The thick testa of the seed splits open during germination owing to the rapid growth and expansion of the cotyledons.

\section{Cuphea silenoides, Nees (fig. 353).}

Fruit a capsule, oblong, straight or oblique, one-celled by rupture of the septum, with the free columnar placenta bearing numerous seeds on one side only, while the side representing the placenta of the smaller and empty cell is naked; dehiscing longitudinally along one side.

Seed shortly and broadly oborate, retuse, generally shallowly emarginate, much compressed, glabrous, dull slaty-blue marked with black dots; hilum and micropyle basal; chalaza apical, thickened for a short way internally, causing the cotyledons to be emarginate; raphe forming a visible ridge along one flattened face; testa thick, coriaceous; tegmen thin, membranous, whitish.

Endosperm absent.

Embryo straight, conforming closely to the interior of the seed which it fills, colourless; cotyledons orbicular,
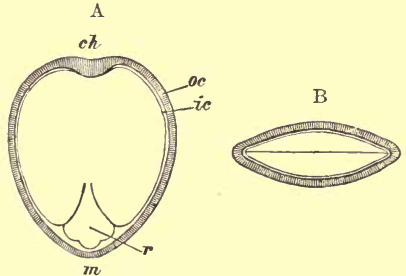

FIG. 353.-Cuphea silenoides, $\times 10 \mathrm{~A}$, longitudinal section of seed : ch, chalaza; $o c$, testa; and $i c$, tegmen ; $r$, radicle; $m$, micropyle. B, Transverse section of seed. emarginate, rather deeply auricled at the base, plano-convex or nearly flat; auricles evidently produced to fill up the space in the seed, and give room for the radicle and plumule; radicle protruding slightly beyond the cotyledons, trilobate with the middle point turbinate and generally longer than the obtuse lateral points.

Seedling (fig. 354).

Primary root tapering, flexuose, much branched. 
Hypocotyl erect, terete, glandular-hairy towards the upper end with red hairs, and densely covered with a minute, colourless, papil-

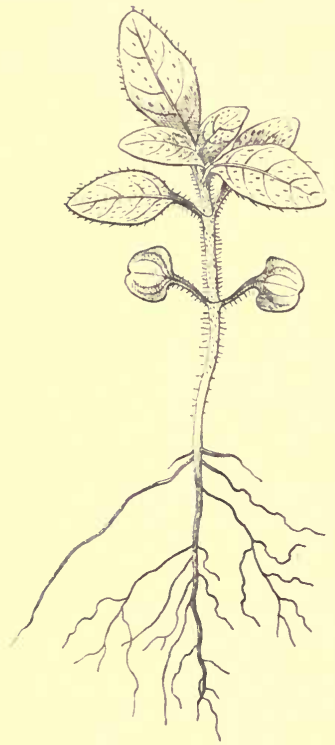

Fig. 354.-Cuphea silenoides. Nat. size. lose pubescence, $1 \cdot 6-2 \cdot 8 \mathrm{~cm}$. long.

Cotyledons rotund-triangular, obtuse, emarginate, more or less truncate at the base, petiolate, minutely puberulous at the margin and slightly glandular-hairy on the midrib beneath, light green; lamina $4 \cdot 5-5 \cdot 5$ $\mathrm{mm}$. long, 5.5-7 $\mathrm{mm}$. wide; petiole widening slightly upwards, convex on the back, channelled above, glandular-hairy on the back, densely and minutely pubescent, 4-7 $\mathrm{mm}$. long.

Stem herbaceous, annual, erect, terete, densely glandular-hairy with red hairs, and minutely pubescent with short, recurved, colourless hairs ; 1st internode 7-13 mm. long, second shorter.

Leaves simple, entire, cauline, opposite, exstipulate, petiolate, alternately and ascendingly incurvinerved, covered on both surfaces with red glandular hairs, which afterwards become colourless, and minutely pubescent on both surfaces as well as the margin with colourless hairs directed towards the apex of the leaf; petiole short, channelled above, convex on the back, hairy like the leaf.

First pair ovate or oblong, obtuse.

Second and third pairs oblong or elliptic-oblong, obtuse.

\section{Cuphea Roezlii, Carr.}

Primary root normal.

Hypocotyl slender, erect, terete, glabrous.

Cotyledons as in last species, but slightly cuneate at the base and glabrous; lamina $3.75 \mathrm{~mm}$. long, $4 \mathrm{~mm}$. wide.

Stem shrubby, otherwise as in last species, pale green; 1st internode scarcely developed or short.

Leaves as in last species, but finely scabrous on both surfaces with minute bristly hairs; petioles scabrous, channelled and green 
above, paler on the back and rounded, glandluar-hairy on the margins of the channels, and slightly so all round at the base.

First pair ovate, acute, small.

Ultimate leaves ovate, acuminate, acute, or the upper lanceolate, all tapering to the base, rather opaque green, paler beneath.

Cuphea coccinea, $D C$.

Hypocotyl similar to that of $\mathrm{C}$. silenoides, 3-5 $\mathrm{em}$. long, light green, colourless, or tinged with red.

Cotyledons broadly obcordate, emarginate, petiolate, glabrous except on the petioles, indistinctly trinerved.

Stem erect, herbaceous, hairy; 1st internode about $1 \mathrm{~mm}$. in diameter.

First leaves as in C. silenoides, hairy, light green, very shortly petiolate.

\section{Lythrum flexuosum, Lag.}

Primary root very long, slender, flexuose, fibrous.

Hypocotyl terete, glabrous, red, $4-12 \mathrm{~mm}$. long.

Cotyledons oblong-oval, obtuse, cuneate at the base, petiolate, often slightly constricted near the apes and hence appearing obsoletely tridentate, glabrous, showing a midrib on the lower two thirds of its length only, 5-8 $\mathrm{mm}$. long including the petiole, 3$4.5 \mathrm{~mm}$. wide.

Stem herbaceous, erect (in the seedling stage at least), quadrangular or somewhat four-winged, glabrous, reddish; 1st internode $1-4.5 \mathrm{~mm}$. long.

Leaves simple, cauline, opposite in the seedling, exstipulate, sessile, glabrous, with a distinct midrib, and a few lateral, ascending indistinct nerves.

First and second pairs oblong-ovate, obtuse, entire, sessile, with their bases decurrent on the stem forming the wings.

\section{Punica Granatum, $L$.}

Fruit very large, globose, baccate, glabrous, somewhat roughened on the exterior, many-celled, many-seeded, indehiscent, crowned with the persistent tube and five- to seven-lobed lamina of the calyx on which the numerous stamens are persistent ; exocarp subcrustaceous, yellowish ; style persistent.

Seeds very large, variously angled by mutual pressure, and tapered more or less to a cuneate base, glabrous ; outer layer of testa resolved into a deep mass of watery, reddish pulp; inner layer coriaceous or subcrustaceous when fresh, ultimately hard; hilum and mieropyle contiguous, basal ; chalaza apical. 
Endosperm absent.

Embryo very large, straight, spirally convolute, colourless, occupying the whole interior of the seed ; cotyledons broad, spirally convolute, unequally auricled, varying in the manner of folding in different seeds, one half of each cotyledon being turned inwards, the other half round the exterior of the coil and next to the testa, unequal-sided, but when spread out flat broadly oblong, obtuse, entire, with the exception of the basal auricles, or somewhat emarginate; larger auricle external to the coil ; smaller one rolled up internally ; radicle about half the length of the cotyledons, or a little more, fusiform and thinnest at the upper end which is covered with the cotyledons, tapered to a very obtuse point, and extending about $1-1.5 \mathrm{~mm}$. beyond the cotyledons, and lying in the basal and pointed end of the seed.

Larger half of the cotyledon $4 \cdot 5-5 \cdot 5 \mathrm{~mm}$. long; smaller one $3 \cdot 25-4 \cdot 5 \mathrm{~mm}$. long; together $3-4 \cdot 5 \mathrm{~mm}$. wide. Radicle $3-3 \cdot 5 \mathrm{~mm}$. long.

Germination.-Immediately, or soon after the radicle makes its appearance, the testa is split longitudinally into two valves by the

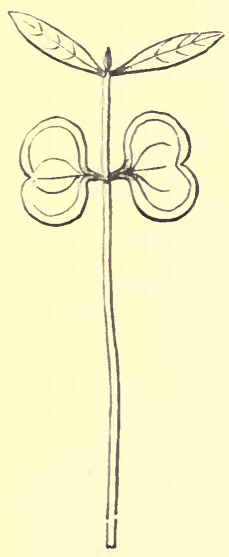

Fig. 355.

Punica Granatum. Nat. size. energy of the swelling cotyledons. Root-hairs are already present from the base of the hypocotyl downwards. When not very deeply buried, the testa is carried up by the elongating hypocotyl.

\section{Seedling (fig. 355).}

Hypocotyl long, erect, subquadrangular, glabrous, $2 \cdot 5-3 \mathrm{~cm}$. long, light green or colourless.

Cotyledons transversely oblong, emarginate, glabrous, with short flattened petioles, dark green, 1-1.3 cm. long including the short petioles, 1.4-1.55 $\mathrm{cm}$. wide, with a prominent midrib and two lateral nerves running parallel to the sides, meeting the midrib at the apex, also two faint nerves between these and the midrib.

Stem herbaceous, ultimately becoming woody, erect, square, with winged edges, glabrous, pale green; 1st internode 5-15 $\mathrm{mm}$. long.

Leaves linear-lanceolate, cuneate at the base, shortly petiolate, glabrous, light green; pinnatinerved. 


\section{ONAGRARIEA.}

Benth, et Hook. Gen. Pl. i. 785 .

Fruit and Seed.-The inferior ovary is four-celled in the more typical forms, but the number of cells varies from one to six, the ovary being one-celled when the septa are incomplete. The ovules are generally very numerous, anatropous, ascending or pendulous, and arranged in a single or double series, rarely in many series, upon the axile placentas. In Diplandra, Circæa, Trapa, Gaura, Heterogaura and Gongylocarpus the ovules are solitary and pendulous or ascending, in each cell, while the one-celled ovary of Stenosiphon, a monotypic genus from Texas, contains four pendulous ovules. The fruit is capsular, less often baccate as in Fuchsia, or nut-like as in Trapa. Capsular fruits are very frequently elongated and cylindrical, or quadrangular, dehiscing septicidally, or loculicidally by four longitudinal valves.

The seeds are numerous or few according to the number of ovules, but vary in number, and somewhat in size, even within the limits of a genus, as, for instance, in Enothera; they are for the most part comparatively small, those of Trapa being exceptionally large. The testa is thin, membranous or coriaceous, and smooth or papillose, with the papillæ hard when the seeds are mature. The seeds of Epilobium are comose at the apex as frequently occurs in the Asclepiadeæ, or at one or both extremities of the seeds of the Apocynaceæ and Salicineæ. Endosperm is wanting or is reduced to a thin stratum as in some species of Enothera and Eucharidium. The embryo is generally obovoid, and conforms to the interior of the seed. The cotyledons are plano-convex, compressed, sometimes slender, rarely curved and very rarely convolute; and the radicle is short and straight, rarely curved as in Trapa.

The fruit of the last-named genus is very exceptional, being nut-like, turbinate, and terminated by two or four spines, onecelled, one-seeded and indehiscent. The testa is spongy, and very much thickened in the upper part. The embryo is very 
remarkable in having one very large cotyledon, and one minute scale-like one.

A good type of the Order is represented by Clarkia sp. (fig. 356) which has amygdaloid cotyledons slightly emarginate and cordate at the base. The emargination is due to a slight thickening at the chalaza, and the basal auricles are produced to occupy the space on each side of the base of the radicle. The seeds of Enothera Lindleyana are similar, but show greatly elongated papillæ at the chalaza. In $\mathrm{E}$. biennis (fig. 364 ) the embryo is generally amygdaloid and entire. Instances occur where the cotyledons are slightly convolute with the edge of the one folded within that of the other. The testa shows a remarkable thickening in places, while elsewhere it is comparatively thin. The embryo of Eucharidium grandiflorum is like those of Clarkia sp. and Enothera Lindleyana, except that the base of the cotyledons is more deeply auricled. There is a strongly developed crest at the apex of the seed, passing round the chalaza, and extending nearly to the hilum, and it is fringed at its margin with papillæ throughout.

Seedlings.-The cotyledons of the various seedlings of this Order show great variation, both in size and outline, and in being entire or variously crenate, dentate, serrate or constricted at the margin, even within the limits of a single genus, so that it is often impossible to classify species of allied genera under any one group. Two very distinct kinds, however, may be noted, namely those which are small or generally so and entire, and secondly, those which attain a comparatively large size by intercalary growth whether entire or variously cut. To the first group belongs Epilobium angustifolium which has small ovate, entire, obtuse, shortly petiolate cotyledons, showing no other venation than the midrib. Here also may be grouped a number of species of Enothera; but for the sake of comparison with other species it is convenient to describe them under that genus.

Cotyledons that exhibit intercalary growth, and especially if they attain any size, partake of two natures, and that often in a marked manner. The upper part is the true cotyledon, while the lower part, which is generally much the larger, is of the nature of a true leaf, and varies in shape according to that 
of the latter as exhibited in the primary leaves with the margin similarly entire or toothed, and smooth or hairy. Most often also there is a distinct constriction between the true cotyledonary portion and the foliar one; and the former retains the apical notch or emargination it may have possessed while still in the seed.

One of the simplest forms coming under observation and showing a marginal constriction where intercalary growth commences, is that of Lopezia coronata with ovate cotyledons, the basal and foliar portion of which widens so as to produce a tooth on each side. Fuchsia corymbifolia is somewhat similar, but the cotyledons are emarginate. A very different form is met with in Clarkia pulchella (fig. 361) which has ovate, minutely emarginate, but otherwise entire cotyledons. The foliar portion is indicated only by being minutely ciliate at the margin like the first true leaves, and by the petiole; the cotyledons proper in the early stages being sessile, as in all the types mentioned below. The cotyledons of Clarkia sp. (figs. 357,358 ) after germination are sessile, suborbicu lar, emarginate, and vary to obcordate with a tooth in the notch, gradually becoming petiolate and then oblong, constricted in the middle, then panduriform, and ultimately rhomboidovate and serrate below the constriction. The upper portion retains its original form almost to the last, and constitutes but a very small portion of the cotyledon when fully developed. By unequal growth of the two sides of the stem the cotyledons in many individual seedlings become alternate. A similar development obtains amongst many of the species of Enothera and other genera. C. integripetala (fig. 362) differs chiefly in the upper surface of the cotyledons being minutely and papillosely pubescent all over, and in the two portions being separated by a transverse brown line. The pubescence is present in C. rhomboidea (fig. 360), but the minute, marginal cilia are carried entirely round the cotyledons which are oblong-ovate and entire in the foliar portion, thus corresponding to the primary leaves as in all other cases where intercalary growth prevails. The cotyledons of Eucharidium concinnum differ from those of the last named in being. broadly ovate, obsoletely crenate below the constriction, and 
ciliolate there only. Those of $\mathrm{E}$. grandiflorum differ from those of its congener in the upper surface being glabrous except at the very base. It will thus be seen that the species of Clarkia and Eucharidium differ from one another either in the shape of the cotyledons, the marginal toothing, or the distribution of the cilia or pubescence.

The seedlings of Enothera exhibit a great amount of variation in different species; but they may be arranged in groups, possessing well-recognised bonds of affinity. Those observed may be grouped under six types. The first is represented by E. fruticosa. The plants are perennial with yellow flowers, small, pale brown, smooth seeds, and diminutive slow-growing seedlings, with broadly or roundly ovate, or rotund-elliptic, entire cotyledons that scarcely differ from one another, and exhibit no distinct foliar innovation or intercalary growth. Other species agreeing with $\mathrm{E}$. fruticosa are $\mathrm{E}$. pumila, $\mathrm{E}$. glauca, $\mathrm{E}$. serotina, $\mathrm{E}$. linearis and $\mathrm{E}$. rosea. The cotyledons of the latter are more truncate at the base of the lamina in some stages than the rest.

The second type is represented by $\mathrm{E}$. taraxacifolia (fig. 363). Both the seeds and seedlings are large, the plant perennial, and the cotyledons oblong, emarginate, cuneate at the base with long petioles, glandular-pubescent all over, and mostly entire. In this latter respect they are rery exceptional, inasmuch as the primary leaves are obsoletely dentate. Sometimes a small tooth is discernible on each side giving an indication perhaps of the foliar nature of the lower portion.

The third group consists of biennials with comparatively large variously compressed and angled seeds, and an irregularly thickened subcrustaceous testa as mentioned under 'Seeds' (p. 554). The seedlings are robust, and the cotyledons are broadly orate, obtuse, and indicate foliaceous, intercalary growth in the lower portion by the renation, the ciliated margin, and more or less by a shallow constriction above the middle or a small tooth on each side. The constriction and the teeth are rather obscure howerer in many cases. This type is exemplified by (E. biennis (fig. 365). An exception to the general form of the cotyledons while yet in the seed was mentioned above, and in the seedling state individuals occur 
with unequal cotyledons due to contortion or folding in the seed. E. Lamarckiana agrees with this type, but the cotyledons are generally quite entire.

The fourth type consists of annuals represented by (E. stricta (fig. 366). The seeds are of medium size with a membranous reticulate testa, and the seedlings are vigorous, exhibiting a distinct foliar development in the lower portion of the cotyledons by the venation, the finely ciliate margin, and by a distinct tooth above the middle on each side. The cotyledons at different stages of growth vary from oblong to ovate, broadly ovate, spathulate, and finally oblong-obovate or subrhomboid.

The fifth type consists of annuals with purple flowers, large rugose or papillosely punctate seed, margined or winged at the chalaza, and sometimes around the raphe. The seedlings are large, vigorous and rapid in growth, while the large cotyledons show a marked foliar, intercalary growth such as occurs in Clarkia sp. and C. integripetala above mentioned. This type of Enothera is well exemplified by $\mathrm{E}$. Lindleyana. The cotyledons exhibit the same phases of growth as Clarkia sp. (figs. $357-8$ ), and ultimately become broadly ovate, emarginate with a tooth in the notch, constricted about the middle with two or three teeth on each side below that and finely ciliate. (E. amœna agrees pretty closely with this type, but the cotyledons are finely pubescent all over. E. tenella quadrivulnera has somewhat variable cotyledons. The commoner forms are obovate-cuneate and frequently alternate in the ultimate stage as in Clarkia sp. (figs. 357-8). Another form has obovate-oblong cotyledons with the other characters of the type given. EE. Romanzowii has obovate cotyledons, considerably tapered to the base in the ultimate stage, and often alternate. The upper or true portion of the cotyledons is much the broader in this species as well as in $\mathrm{E}$. tenella quadrivulnera, a condition contrary to the general rule in the group. (E. purpurea and E. cheiranthifolia agree with the other species of this group in all main particulars, and particularly in the lower portion of the cotyledons being of a foliaceous nature.

The sixth group corresponds to the subgenus Sphærostigma, as the fifth did to that of Godetia. E. macrantha (fig. $369)$ shows the foliar evolution of the cotyledons in this group. 
The true portion remains small and nearly orbicular and glabrous from first to last, while the leafy portion is linear, obscurely dentate, ciliate and gradually increases in length so as to resemble the true leaves, except in being somewhat narrower. E. contorta differs somewhat in the foliar portion being very narrow, distinctly crenate-dentate with opposite teeth, in all respects, however, resembling the primary leaves. E. bistorta (figs. 367, 368) strongly resembles $\mathbb{E}$. macrantha, but more stages of development are shown. EE. hirta bears some resemblance to $\mathrm{E}$. contorta, but the foliar portions of the cotyledons like the true leaves are very hairy, while the upper or true portion is smooth.

Clarkia sp. (fig. 356).

Fruit a capsule, linear, quadrangular, attenuated at the apex, dehiscing to the middle by four longitudinal valves, four-celled, many-seeded.

Seed narrowly obovoid, small, flattened on that side to which the raphe is attached; testa thick, coriaceous, papillose all over,
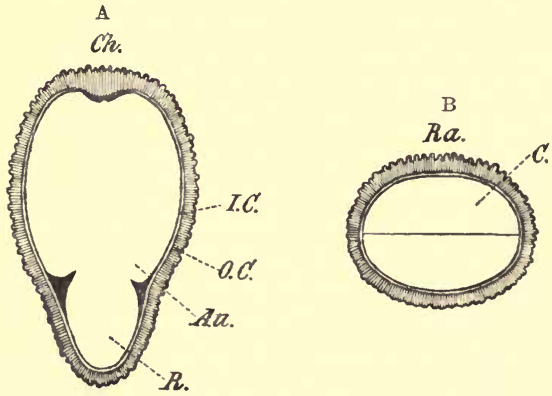

FIG. 356.-Clarkia sp., $\times 24$. A, longitudinal section of seed: Ch, chalaza ; $I C$, tegmen; $O C$, testa ; $A u$, auricle; $R$, radicle. $\mathrm{B}$, transverse section of seed: $R a$, position of raphe; $C$, cotyledon.

dark brown; raphe running along a flattened surface; chalaza apical, somewhat thickened externally and internally to the seed; hilum and micropyle basal, contiguous.

Endosperm absent.

Embryo straight, large for the seed which it completely fills, colourless; cotyledons broadly oblong, minutely emarginate with a 
tooth in the notch, auricled or cordate at the base, plano-convex, and conforming to the interior of the seed, lying in the broader way of the slightly compressed seed, with their backs to the raphe; radicle much shorter than the cotyledons, turbinate, obtuse, lying in the basal and pointed end of the seed, much longer than the auricles of the cotyledons.

Seedling (figs. 357, 358).

Primary root long, tapering downwards, and giving off short lateral rootlets, colourless, annual.

B

A

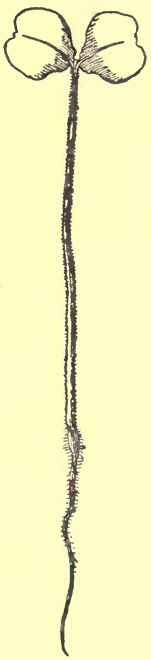

C

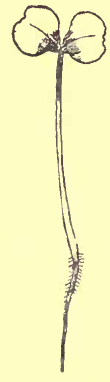

FIG. 357.-Clarkia sp., $\times 2$.

Hypocotyl erect, terete, densely and minutely pubescent, deep red, $2 \cdot 5-3 \cdot 5 \mathrm{~cm}$. long.

Cotyledons rhomboid-ovate, emarginate, with a tooth in the notch, distantly toothed at the sides, and constricted some distance below the apex, with narrow rounded notches, and a distinct midrib but no other discernible venation in the fresh state, petiolate, glabrous excepting the petiole, deep green above, glaucous beneath; lamina $8-14 \mathrm{~mm}$. long, $6 \cdot 5-10 \mathrm{~mm}$. wide; petiole subterete, 
shallowly grooved above, minutely pubescent, pale green or reddish especially on the midrib.

Stem erect, terete, minutely pubescent, pale green, annual ; 1st internode 9-12 mm. long.

Leaves simple, cauline, lower opposite, upper alternate, exstipu-

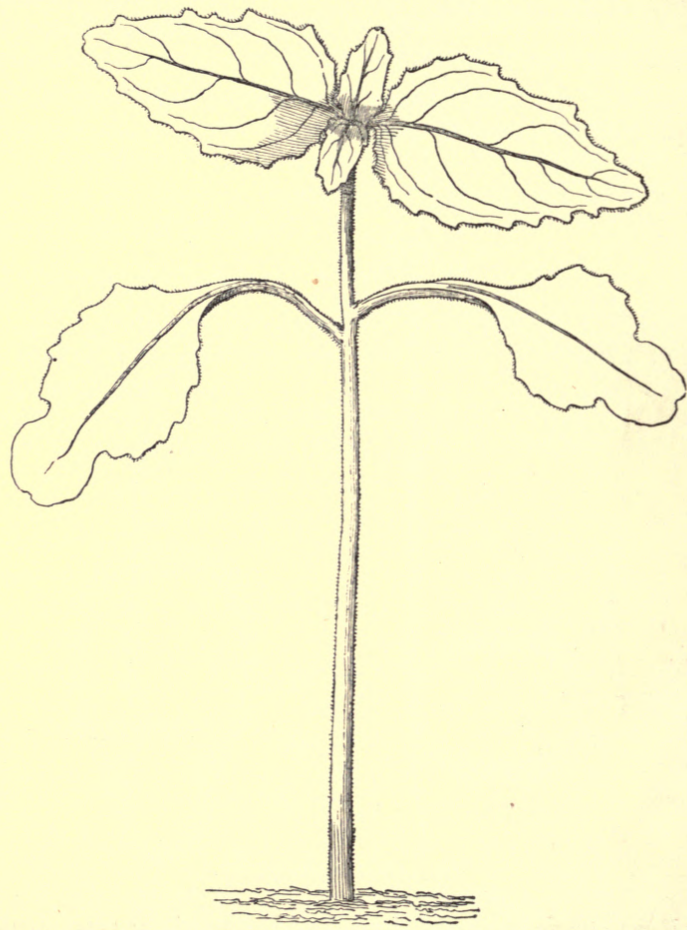

Frg. 358.-Clarkia sp., $\times 2$.

late, petiolate; glabrous or very nearly so excepting the petioles, alternately incurvinerved, deep green above with a deep red or crimson midrib, paler beneath or glaucous; petiole semiterete, rather deeply channelled above, minutely pubescent, slightly connate at the base, or forming a ring round the stem where the leaves are opposite. 
First pair of leaves ovate, obtuse, alternately incurvinerved, distantly and shallowly serrate-dentate, often minutely tricuspidate or tridentate at the apex.

Second pair narrower, oblong-ovate, otherwise similar to the first.

DEVELOPMENT OF THE COTYLEDONS.

The cotyledons immediately after germination are oblongorbicular, minutely emarginate, with a small tooth in the notch, slightly auricled at the base, sessile, with a scarcely discernible midrib.

They then enlarge, become orbicular or broadly obovate, subcuneate at the base, and shortly petiolate. Fig. 357, A, shows a specimen three days after germination.

A change now occurs at the base of the cotyledons, which is at first narrower and soon becomes conspicuous by the presence of a small tooth on each side, as is shown in Fig. 357, B, which represents a seedling five days after germination.

The new portion elongates, bearing two to four teeth on each side, and the whole cotyledon becomes oblong, with a broad emarginate upper half consisting of the true cotyledon, and a basal narrower half which is truly foliolar with the characteristic white and reddish midrib of the true leaves, and the marginal teeth; petiole now 1.5-2 mm. long. (Ten days after germination.) (Fig. 357, C.)

The cotyledons now become broadly orate, cuneate at the base, petiolate, and all or most of them more or less distinctly alternate; the lower part or innovation has four to six small obtuse teeth on each side, and is broadly subelliptic in outline, minutely ciliate at the margin. The upper part or true cotyledon is comparatively small, suborbicular, emarginate, with a tooth in the notch. (Eighteen days after germination.)

Clarkia rhomboidea, Douglas (figs. 359, 360).

Seeds 1.25-1.5 mm. long, and as wide near the apex.

DEVELOPMENT OF COTYLEDONS.

The cotyledons are at first orbicular, entire or faintly emarginate with a prominent apical tooth, sessile, and like the hypocotyl purplish, glabrous, but soon become minutely papillosely pubescent.

Nine days after germination (fig. 359) they are oborate or subpanduriform, emarginate with a small tooth in the notch, constricted below the middle, denoting the line between the upper part or true cotyledon which is minutely pubescent, and the lower part or innovation which is much more conspicuously pubescent with a 
pale pink or purplish midrib ending in a broader purple blotch on the base of the true cotyledon. Hypocotyl densely pubescent.

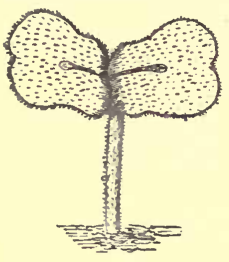

FIG. 359.

Clarkia rhomboidea, $\times 3$.

The lower foliar portion soon becomes broader and longer than the upper coty. ledonary part which is also only very slightly pubescent.

Thirty-five days after germination (fig. $360)$ the cotyledons are oblong, distinctly petiolate, constricted near the apex at the union of the foliaceous and cotyledonary part, emarginate with a minute tooth in the notch, cuneate at the base, with a distinct midrib throughout, and a few rather indistinct alternate nerves on each side, minutely pubescent all over the upper surface but more sparingly on the under surface, which

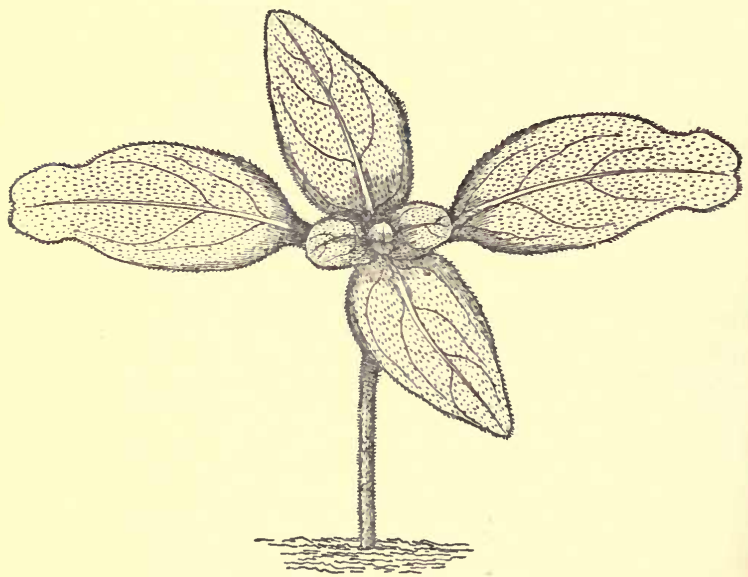

Fig. 360.-Clarkia rhomboidea, $\times 2$.

is reddish-purple; petiole semiterete, channelled above, densely pubescent.

First pair of leaves opposite, ovate, obtuse, cuneate at the base, alternately incurvinerved, entire, shortly petiolate, densely pubescent all over; petiole convex on the back or semiterete, channelled above, densely pubescent.

Second pair similar. 
Clarkia pulchella, Pursh (fig. 361).

Primary root as in C. sp., p. 559.

Hypocotyl erect, terete, or thicker under the cotyledons, and tapering downwards, glabrous, $1-1.5 \mathrm{~cm}$. long.

Cotyledons two rarely three, ovate, obtuse, foliaceous, glabrous, opaque green with a strong midrib, pale beneath; lamina $14 \mathrm{~mm}$. long, $8 \mathrm{~mm}$. wide; petiole channelled above, semiterete, minutely pubescent on the midrib beneath and at the margins above, about $4 \mathrm{~mm}$. long.

Stem as in C. sp.; 1st internode $2.5 \mathrm{~mm}$. long.

Leares cauline, opposite, decussate, glabrous or minutely pubescent, especially on the nerves, subfleshy, opaque green, witl a stout midrib; petioles semiterete, minutely pubescent, slightly channelled above.

First pair oral-elliptic, obtuse, with two very small lateral nerves visible near the base.

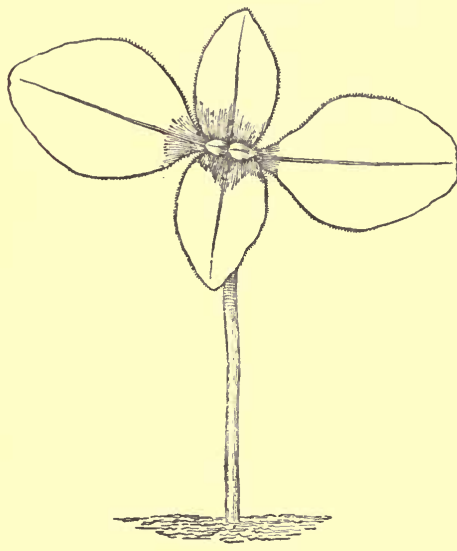

Fig. 361.-Clarkia pulchella, $\times 2$.

Second pair oval, obtuse, with two or four distinct lateral nerves near the base, ultimately as they approach the full size narrowly elliptic.

Third to sixth pairs, ditto.

When there are three cotyledons, the leaves are in whorls of three, and there are axillary buds in the axils of both cotyledons and leaves.

\section{DEVELOPMENT OF THE COTYLEDONS.}

Immediately after germination the cotyledons are oblong-oval, entire with a slightly prominent colourless tooth at the apex of the midrib, sessile and very shortly auricled at the base.

Eleven days after germination they are broadly ovate, emarginate with a tooth in the notch, almost rounded at the base and very shortly petiolate. The innovation is distinguishable from the true 
cotyledon only by being minutely ciliate at the margin and by possessing a distinct sunken midrib like the true leaves.

Finally they become elliptic, emarginate with a minute tooth in the notch, tapering most to the base and petiolate, minntely ciliate on the margin and petiole, without any toothing (fig. 361).

Clarkia integripetala, ? Hort. (fig. 362).

Seeds 1·25-1·75 mm. long, $\cdot 75-1 \mathrm{~mm}$. wide.

Cotyledons immediately after germination shortly oblong, obtuse, emarginate with a minute tooth in the notch, shallowly auricled at the base, sessile, glabrous.

Hypocotyl with a few minute glands.

Primary root furnished with root-hairs.

The day after germination the cotyledons have become transversely oral, and a shallow semicircular depression, and a grey midrib hare appeared at the base of each.

Next day a tooth on each side near the cuneate base denotes the point where the true cotyledon ends, and the foliar portion begins, and four days after germination they are obovate and very shortly petiolate; upper part oblate, emarginate, with the apical tooth now almost obsolete: lower part rotund-subcuneate with one to two small teeth on each side, shorter and narrower than the upper part, minutely and papillosely pubescent.

Eight days after germination they are as a whole oblong, distinctly petiolate; upper part oblate, emarginate with the tooth in the notch almost obsolete; lower part broadly oblong with three to four minute teeth on each side, and a distinct reddish or silvery midrib, minutely pubescent and ciliolate, suddenly narrowed into the petiole. Hypocotyl long, minutely pubescent.

Seventeen days after germination (fig. 362) the lower part is broadly ovate with three to fire teeth on each side and one to two pairs of very faint somewhat curved nerves running towards the marginal teeth, and a silvery midrib terminated above by a transverse brown line, papillosely pubescent all over; upper part oblate or oval, emarginate, with a tooth in the notch, minutely and much less conspicuously pubescent than the lower part; petioles semiterete, channelled above, shortly pubescent all over. Hypocotyl pubescent.

First two leares opposite, equal, obtusely serrate, orate, obtuse, oppositely and alternately incurvinerved, pubescent all over, petiolate.

Enothera fruticosa, $L$.

Seeds 1.25-1.5 mm. long, $\cdot 33-5$ (rarely $\cdot 75$ ) mm. wide. 
Primary root tapering downwards and furnished with lateral fibres, ultimately superseded by strong adventitious roots from below and above the cotyledonary node.

Hypocotyl very short and soon becoming indistinguishable from the root.

Cotyledons variable in outline, with two or three alternate, flexuose, incurved nerves on each side of the midrib discernible only by transmitted light, glabrous, deep green above, paler beneath; lamina $4-5.5 \mathrm{~mm}$. long, and about as broad except when ovate; petiole semiterete, shallowly channelled above, glabrous, slightly connate at the very base, $2 \cdot 5-6 \mathrm{~mm}$. long.

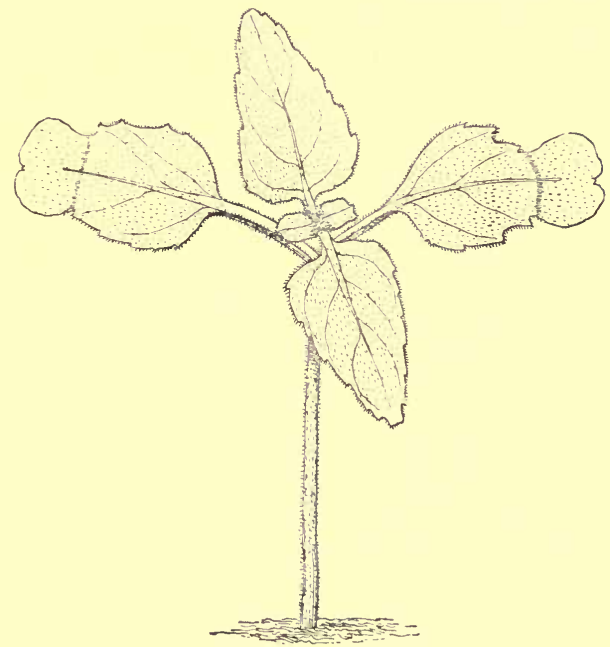

FIG. 362.-Clarkia integripetala, $\times 2$.

Stem herbaceous, and developing when about to flower, firm and suffruticose ; primary internodes undeveloped.

Leaves simple, almost entire, or obsoletely dentate with the teeth often hardly evident, radical and cauline, alternate, exstipulate, petiolate, alternately incurvinerved, obscurely reticulate, glabrous or with a few scattered hairs on the margins of the leaves and petioles in a young state; deep green above, paler beneath, thin but subcoriaceous and shining on both surfaces; petioles semiterete, 
channelled above, dilated and semiamplexicaul at the base of the radical ones, thinly ciliate at the margin with incurved hairs.

Nos. 1 to 4. Elliptic, or broadly oval, obtuse, the first or second sometimes apiculate, more or less cuneate at the base.

Nos. 5 and 6. Gradually

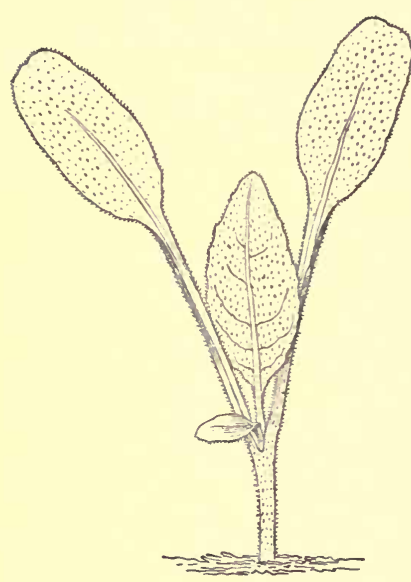

FIG. 363.-Enothera taraxacifolia, $\times 2$. more oblong, obtuse, tapering to the base.

Cotyledons immediately after germination rotundovate, entire, sessile or subsessile.

Eight days after germination they are rotund-ovate, or very broad, and deltoid, obtuse, rounded and entire at the apex, slightly cordate or almost truncate at the base, with a distinct channelled petiole about 1-1.5 mm. long.

The ultimate form of the cotyledons of this species is evidently subject to variation, but they never attain any great size as in the annual species. They vary from rotund to broadly elliptic, or ovate or deltoid, obtuse, more or less suddenly cuneate at the base, petiolate, and sometimes angled at the sides-in the larger ones, which is the only evidence or trace of an innovation in this species. Like the leaves they are glabrous.

Enothera rosea, Ait., resembles the foregoing very closely.

Enothera taraxacifolia, $S w$. (fig. 363).

Seeds 2.5-3 mm. long, 1·25-1.5 mm. wide.

\section{DEVELOPMENT OF COTYLEDONS.}

The cotyledons immediately after germination are oblong, obtuse, entire, sessile, glandular-pubescent on the upper surface.

Eight days after germination they are oblong and obtuse, very shallowly emarginate, with long petioles, glandular-pubescent all over, tapering to the base; petiole semiterete, channelled above, densely and shortly glandular-pubescent. 
Sixteen days after germination (fig. 363) the cotyledons are much larger, with longer petioles, and rarely show a minute tooth towards the base, otherwise the same.

Hypocotyl glandular-pubescent.

First leaf alternate, lanceolate, obtuse, petiolate, alternately incurvinerved in the upper half, and suboppositely incurvinerved in the lower, obtusely and obsoletely dentate at the margin, glandularpubescent.

\section{Enothera biennis, L. (fig. 364).}

Fruit a capsule, oblong or cylindrical, four-celled, many-seeded, dehiscing by four valves longitudinally and loculicidally, separating also from the axis, rigid or becoming woody when dry.

Seeds extremely variable in outline, oblong, obovoid, variously compressed and angled, often short, deep brown; testa variously thickened on one or two sides, but especially at all the projecting angles, corky, brown or almost black; tegmen thin, membranous, whitish; hilum and micropyle contiguous, basal ; raphe passing along one of the thickened sides; thickening corresponding to the chalaza, not quite apical, but a little on one side.

Endosperm absent.

Embryo straight, comparatively large and filling the interior of the seed, colourless; cotyledons normally oblong, obtuse, minutely auricled at the base, sessile, plano-convex, lying in the broader way of the seed when the latter is in any way compressed, with their backs to the raphe or their edges to it, variable; radicle shorter than the cotyledons, or about one third the length of the whole embryo, turbinate, obtuse, and projecting beyond the auricles of the cotyledons, lying in the generally pointed base of the seed.

Nоте.-Another very prevalent form of embryo has one of its cotyledons, or sometimes both, involute.

\section{Seedling (fig. 365).}

Primary root tapering, flexuose, furnished with flexuose fibres.

Hypocotyl partly subterranean, terete, glabrous, reddish, 2-4 mm. long (when germinated in the open ground).

Cotyledons ovate, obtuse, shortly petiolate, glabrous, with a prominent midrib, and ascending incurved anastomosing lateral nerves (the latter seen only when the cotyledons are colourless and decaying), deep green or stained red in cold weather, $3 \cdot 25-6 \mathrm{~mm}$. long exclusive of petiole, $2-4 \mathrm{~mm}$. wide; petiole channelled above, perfoliate at the base, $\cdot 75-1 \cdot 5 \mathrm{~mm}$. long.

Stem herbaceous and developed when about to flower, biennial. 
Leaves simple, entire, radical and cauline, alternate, exstipulate, petiolate, glabrous in seedling, hairy on both sides in the adult, alternately and ascendingly or subincurvedly penninerved, with a

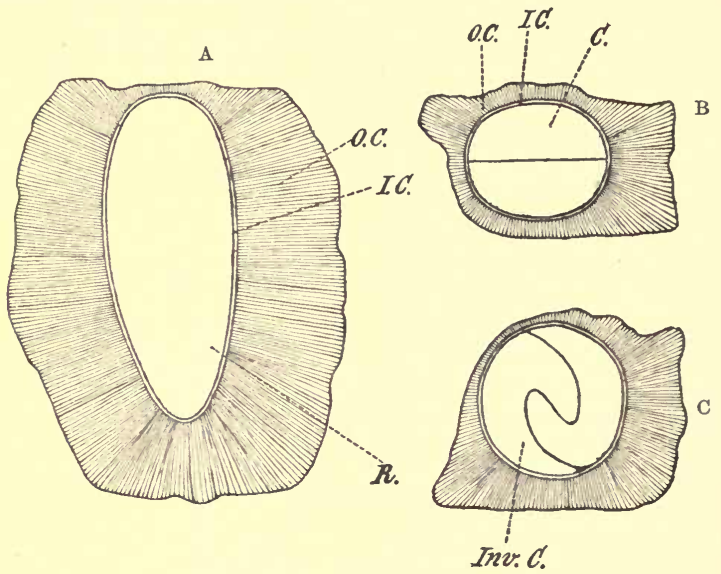

Fra. 361.-Enothera biennis, $\times 28$. A, longitudinal section of seed: $O C$, testa ; $I C$, tegmen; $R$, radicle. $\mathrm{B}$, transverse section of seed: $O C$, testa; $I C$, tegmen; $C$, cotyledon. $\mathrm{C}$, transverse section of another common form of embryo and seed: Inv. C, involute cotyledon.

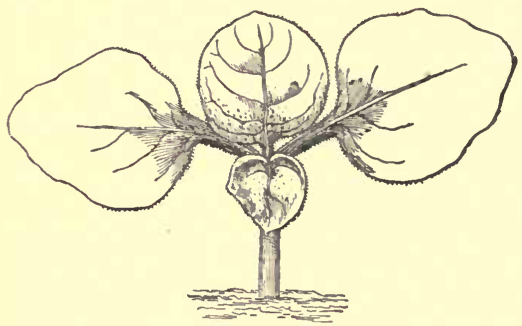

Fig. 365.-Enothera biennis, $\times 2$.

prominent midrib ; petioles flattened above or subchannelled on the cauline leaves, somewhat dilated at the base.

Nos. 1 and 2. Ovate, obtuse or subacute, shortly petiolate.

Ultimate radical leaves oblong, acute, tapered for some considerable distance at the base into the petiole; cauline shortly tapered 
at the base, oblong, acute, with a short petiole, all having the nerves ascending and incurved towards the tip where they unite with those next above them after having become exceedingly fine.

DEVELOPMENT OF THE COTYLEDONS.

(a) Immediately after germination the cotyledons are broadly ovate or oval-ovate, obtuse, entire, with a slightly prominent colourless tooth at the apex of the midrib, flat and subsessile.

$\left(a^{\prime}\right)$ Another form about equally common at this stage has the cotyledons involute, with one edge inside and the other outsiderarely with both edges inside the other cotyledon.

(b) Nine days after germination they become broadly ovate, obtuse, and entire with an innovation at the base not separated from the true cotyledon by a constriction as in several other species, but by a minute tooth on each side, and distinguished by being ciliate with incurved hairs, while the upper part is glabrous. Petiole $1 \cdot 25-$ $1.5 \mathrm{~mm}$. long, and ciliate or pubescent.

$\left(b^{\prime}\right)$ The unequal ones still maintain their inequality. Larger one deltoid or rotund, very obtuse, shallowly cordate at the base, with the innovation ciliated with incurved hairs, while the upper part is glabrous, marked with a minute or obsolete tooth on each side. Smaller cotyledon narrower and less rounded.

(c) Sixteen days after germination the equal cotyledons are still ovate, obtuse, equal at the base, petiolate with the innovation thinly ciliate at the margin.

$\left(c^{\prime}\right)$ The unequal cotyledons are broadly ovate or deltoid, obtuse, entire, generally very unequal at the base, but the two are often dissimilar in that respect, ciliated with incurved hairs on the lower larger part corresponding to the innovation (fig. 365).

\section{Enothera Lamarckiana, $D C$.}

Secds 1.5-2 mm. long, 1-1.5 mm. wide.

\section{DEVELOPMENT OF COTYLEDONS.}

The cotyledons immediately after germination are oblong or broadly ovate-oblong, obtuse, entire, sessile and glabrous. Hypocotyl short and glabrous. Primary root simple, with root-hairs.

Ten days after germination the cotyledons are ovate, obtuse, entire, shortly petiolate, ciliate in the lower part with incurved short hairs. Petioles pubescent. Hypocotyl pubescent.

Twenty-three days after germination they are broadly ovate, obtuse, entire, rather suddenly narrowed above the middle, with rather long petioles; upper part glabrous, without a discernible midrib; lower part pubescent at the margins with incurved hairs, and 
a distinct midrib; petiole semiterete, channelled above, pubescent with incurved hairs. Hypocotyl short, now rather stout, glabrous.

First and second leaf very broadly ovate, sometimes broadly oblong, obtuse, entire, alternately incurvinerved, thinly pubescent all over and at the margin with incurved hairs, petiolate.

Enothera stricta, Ledeb. (fig. 366).

Seeds $\cdot 5-1 \mathrm{~mm}$. wide or thick, $1 \cdot 25-1 \cdot 5 \mathrm{~mm}$. long.

\section{DEVELOPMENT OF COTYLEDONS.}

The cotyledons immediately after germination are oblong, obtuse, slightly auricled at the base, otherwise entire, sessile, thinly glandular-pubescent on the upper surface and ciliate. Hypocotyl thinly and minutely glandular-pubescent, short. Primary root simple, furnished with root-hairs.

Five days after germination they have become oblong-ovate, obtuse, shortly petiolate, thinly glandular-hairy.

Eight days after germination they are more distinctly petiolate, cuneate at the base, and sometimes with a minute but distinct tooth below the middle on each side, denoting the line of demarcation between the upper part or true cotyledon and the lower leaf-like part, thinly glandular-hairy and ciliate.

Twenty-nine days after germination they become spathulateobovate or oblong-obovate, obtuse, with a tooth at the union of the foliar with the cotyledonary part on each side, glabrous except the petioles; upper part without a distinctly visible midrib; lower part tapering much to the base; petiole semiterete, flattened above, or shallowly channelled towards the apex, minutely and thinly puberulous, connate at the base. Hypocotyl stout, thinly pubescent. First five leaves at least radical, alternate, lanceolate, obtuse, tapering into the petiole, obsoletely and distantly toothed at the margins, alternately incurvinerved, with a conspicuous whitish or colourless midrib, glabrous except the petioles which are semiterete, flattened above or shallowly channelled, dilated at the base.

\section{Enothera Lindleyana, Douglas.}

Fruit a narrowly oblong capsule.

Seed small, varying in shape and size, obovoid or oblong-obovoid, proportionately broad, or on the other hand narrow, sometimes angled ; testa thin, dark-coloured, marked with black spots and pale on the ventral aspect, with two decurrent lines of papillæ from the chalaza at the apical end of the seed where the papillæ are longest and form an appendage or crest ; micropyle at the narrow and basal end of the seed; raphe ventral. 
Endosperm forming a very thin layer surrounding the embryo, thickened somewhat at the chalaza.

Embryo straight, large, nearly occupying the whole interior of the seed, and conforming to it in shape, more or less obovoid, fleshy, colourless; cotyledons plano-convex in the broader way of the seed, but sometimes reversed, broadly obovate, oblong or more elongated

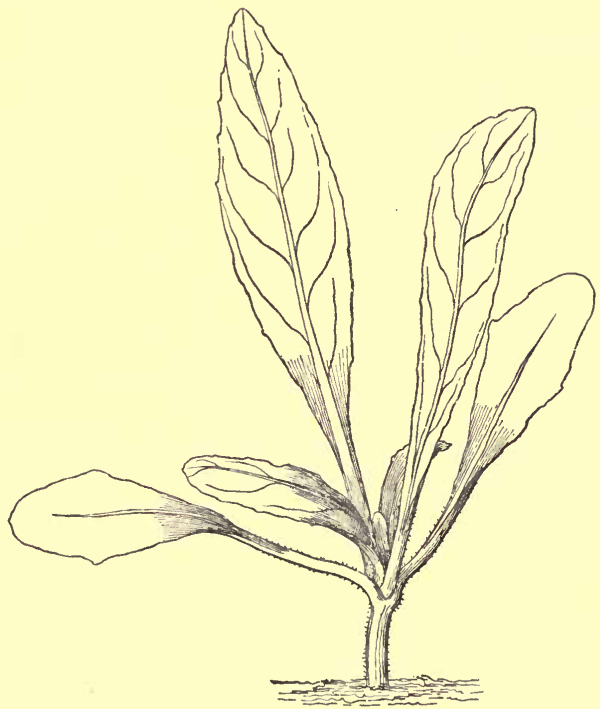

FIG. 366.-Enothera stricta, $\times 2$.

and proportionately narrower, slightly notched at the apex by the thickening of the endosperm at the chalaza, more deeply notched at the base where the radicle and plumule lie ; radicle short, straight, turbinate, obtuse, close to the hilum.

\section{DEVELOPMENT OF COTYLEDONS.}

Immediately after germination the cotyledons are oblong-oval, entire with a slightly prominent, colourless tooth at the apex of the midrib, or minutely emarginate with a sunk tooth, sessile or subsessile. Sometimes one cotyledon is entire, the other emarginate. 
Six days after germination they are orbicular, slightly narrowed at the base, with a small tooth on each side above the subtruncate innovation, shortly petiolate, emarginate with a small tooth in the notch.

In ten days from germination they become ovate-oblong, or simply oblong; the lower half below the constriction has two or three small teeth on each side and is suddenly narrowed, almost truncate at the base with a pale-coloured midrib; the upper half representing the true cotyledon remains slightly elongate-orbicular with a minute tooth in the notch, and no discernible midrib in the fresh state. Petiole 1.5-2 mm.

Finally they become ovate, cuneate at the base, the innoration forming now slightly the larger part, with generally three acute or slightly incurred teeth on each side, and a ciliate margin and petiole; the upper half or true cotyledon is elongate-orbicular or rhomboidorbicular, emarginate, with a tooth in the notch.

\section{Seedling.}

Primary root normal.

Hypocotyl erect, tapering downwards, glabrous, reddish, 9-12 mm. long.

Cotyledons ovate, obtuse, minutely emarginate and mucronate in the notch, constricted above the middle, causing the lamina to be somewhat trilobed, petiolate, alternately and ascendingly penninerved, with the lateral nerves of the upper lobe incurved and uniting at the mucro, and a strong branch entering each of the gland-tipped lateral lobes, minutely ciliate at the margin, otherwise glabrous except on the petiole; lamina 7-10 $\mathrm{mm}$. long, 5-6.25 mm. wide; petiole semiterete, channelled above, minutely hairy at the margin and beneath the midrib. Apex and small teeth of lateral lobes each tipped with a glandular, colourless mucro, having a few large, more or less discoloured openings into the interior.

Stem annual, erect, terete, minutely pubescent, reddish; 1st internode 4-8 mm. long; 2nd similar.

Leaves simple, cauline, opposite in the lower part, alternate upwards, exstipulate, petiolate, alternately and ascendingly incurvinerved, finely pubescent on both surfaces, bright green above, paler beneath; petioles semiterete, channelled above, finely pubescent.

First and second pairs ovate, obtuse, obtusely or obsoletely dentate.

Ultimate leaves ovate or oval, obtuse, more or less tapering or cuneate at the base, obtusely dentate. 
Enothera tenella, Cav., var. quadrivulnera.

Seeds 1.5-1.75 mm. long, 1.25-1.5 mm. wide.

\section{DEVELOPMENT OF COTYLEDONS.}

The cotyledons are at first very similar to those of $\mathbb{E}$. Lindleyana, but gradually become more cuneate at the base.

Eighteen days after germination they are obovate, emarginate with a minute tooth in the notch, and a more or less evident midrib extending to the apex, petiolate, cuneate at the base, with the upper part or true cotyledon suborbicular, and much larger than the lower foliaceous portion which is characterised by being cuneate, narrower, with two small teeth on each side, and minutely ciliate at the margin; petiole slender, semiterete, channelled above, densely pubescent.

First pair of leaves opposite, oblong or finally ovate, obtuse, mucronate, with a few small teeth on each side.

Ultimately there are two slightly different forms.

(a) The commoner form is obovate-cuneate, emarginate with a tooth in the notch, finely ciliate below the constriction, and having two to three small teeth there, more often slightly alternate than strictly opposite.

(b) The other form is obovate-oblong, considerably broader in the lower part than in the commoner form, otherwise exactly similar.

See Enothera Romanzowii, which is said to be a variety of E. tenella.

\section{Enothera Romanzowii, Ledeb.}

The stages of growth correspond closely to those of $\mathrm{E}$. tenella, as does also the ultimate form of the cotyledons, the cuneate innovation tapering much more gradually into the petiole.

\section{Enothera purpurea, Curt.}

Hypocotyl erect, terete, minutely pubescent, $2 \cdot 5-3 \mathrm{~cm}$. long, light green, tinged with red.

Cotyledons oblong-obovate, constricted above the middle, emarginate, obtuse, petiolate, with a few hairs on the petiole and base of the leaf, otherwise glabrous, light green, distinctly one-nerved.

Stem herbaceous, erect, terete, minutely pubescent; 1 st internode 2-2.5 cm. long; 2nd shorter.

First leaves cauline, opposite, ovate or oblong, acute, denticulate, shortly petiolate, hoary, light green, pinnatinerved. 
Enothera bistorta, Nutt. (figs. 367, 368).

Seeds 1-1.25 mm. long, $\cdot 33-\cdot 5 \mathrm{~mm}$. wide.

\section{DEVELOPMENT OF COTYLEDONS.}

Immediately after germination the cotyledons are oblong, obtuse, eutire, sessile with a few long, scattered, glandular hairs, especially at the base. Hypocotyl with a few glandular hairs at its apex. Cotyledons often unequal, owing to their greater or less development in the seed, and one folding over the other.

Six days after germination the base has become elongated, petiole-like, and glandular-pubescent, suddenly narrowed to a short petiole or subsessile; the upper half remains rotund and glabrous except at the base and possibly a few short hairs underneath.

Eight days after germination (fig.

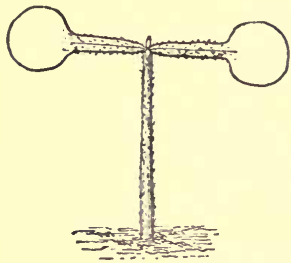

Fig. 367.-Enothera bistorta. $367)$ they have elongated considerably, the upper true cotyledonary part enlarging, but otherwise remaining unaltered, while the foliar basal and narrow part has become linear, entire or sometimes with a minute tooth on either side, glandular-pubescent, suddenly narrowed at the very base.

The lower portion elongates greatly, and the ultimate stage of the cotyledons (fig. 368) is linear, tapering at the base into a petiole; upper part or true cotyledon rotund or oval, entire, glabrous, very short, without an evident midrib; lower part linear, terminating abruptly in the upper part, tapering gradually to the base, with one or two minute and distant teeth on each side, thinly hairy, greyish-green with an evident midrib sunk on the upper surface, and prominent beneath ; petiole semiterete, flattened above, very thinly hairy, or at length nearly glabrous.

First eight leaves radical, alternate, linear, obtuse, tapering at the base into the petiole, thinly silky with adpressed pubescence, minutely and distantly toothed at the margin, greyish-green, more or less distinctly marked near the margin with black dots, with a very distinct, colourless nidrib, flattened above and prominent beneath; petioles semiterete, flattened above, thinly hairy at the margins, colourless. (Thirty-four days after germination.)

Enothera macrantha, A. Gray (fig. 369).

Primary root tapering downwards and furnished with lateral fibres, annual. 
Hypocotyl undeveloped.

Cotyledons immediately after germination oval, obtuse, with a slightly prominent, apical tooth, entire, very shortly petiolate, soon becoming spathulate, with an oval, entire tip representing the true cotyledon and a linear-cuneate innovation at the base, generally with a minute or obsolete tooth on each side, distinctly but shortly petiolate, glandular-pubescent, ultimately (nineteen days after germination) (fig. 369) they become narrowly spathulate or linear, with an oval tip, sometimes narrower than the innovation, which

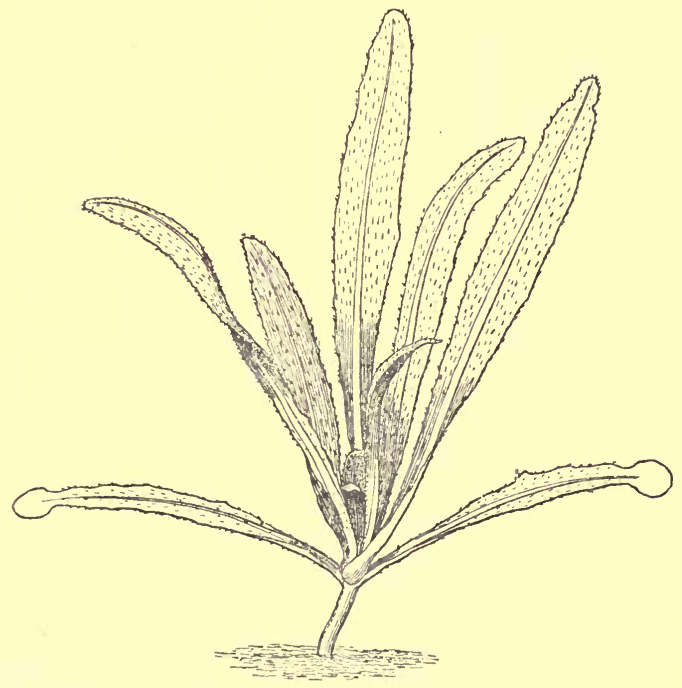

FIG. 368.-Enothera bistorta, $\times 3$.

has one to four or more obsolete teeth on each side, and gradually tapers into a long petiole-like base, with a short true petiole; the lamina is glabrous at the apex and thinly hairy elsewhere, with a distinct midrib and obscurely reticulate in a fresh state, tapering down into the petiole, dull green slightly spotted with black, 5-10 $\mathrm{mm}$. long, 1.5-2 mm. wide; petiole flattened above, convex on the back, suddenly dilated at the base and forming a little cup round the plumule, somewhat pubescent. 
Stem herbaceous, annual, developed when about to flower, with many of the primary internodes undeveloped.

Leaves simple, radical and cauline, alternate, exstipulate, first few petiolate, then sessile as far as the radical ones go, with difficulty discernible, alternate, ascending nerves on each side of a

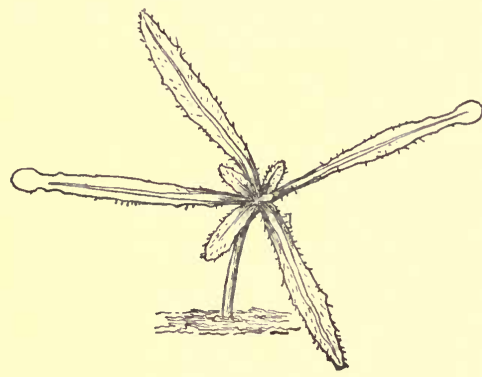

Fig. 369.

Enothera macrantha, $\times 3$. distinct midrib, somewhat hoary with a whitish pubescence above, more thinly pubescent beneath, dull green on both surfaces, slightly dotted with black; petioles of the first two leaves semiterete, flattened or convex above, dilated and subconnate at the base, thinly pubescent ; of the third to sixth very short, and the other leaves sessile.

Nos. 1 and 2. Linear-lanceolate, petiolate, minutely and distantly denticulate.

Nos. 3-11. Linear-oblong, obtuse, minutely and distantly denticulate, shortly petiolate, or gradually becoming subsessile, with a very distinct whitish midrib, downy.

\section{Enothera contorta, Hook.}

Hypocotyl erect, terete, glabrous, 1-10 mm. long, light green or colourless.

Cotyledons at first rotund-oval, obtuse, with short petioles, but soon the petiole-like lower part develops considerably, and they assume the character of the true leaves, glabrous, indistinctly onenerved.

Stem erect, terete, herbaceous, minutely pubescent; 1 st internode 2-3 mm. long.

Leaves simple, cauline, opposite, decussate, linear, obtuse, extremely narrow, with numerous obtuse teeth, glabrous, indistinctly one-nerved.

Eucharidium grandiflorum, Fisch. et Meyer.

Fruit a capsule, linear-oblong, four-celled, many-seeded, dehiscing loculicidally by four valves which break away from the placental 
axis, covered especially in the young state with pale-coloured or white papillæ.

Seed obovoid, slightly compressed, flattened on one side and produced into a wing at each edge, and a broader wing or crest round the apical end, with the lateral wings nltimately incurved, producing a deep groove or concavity, and the crest crenate or toothed at the margin; testa subcrustaceous, deep brown, tuberculated; hilum and micropyle basal, inferior, contiguous; chalaza apical; crest and wings readily separable from the rest of the seed.

Endosperm forming a thin white film lining the interior of the seed.

Embryo comparatively large, straight, colourless, filling the entire cavity of the seed to which it conforms in general outline; cotyledons oblong, slightly emarginate from a thickening of the chalaza, auricled at the base, plano-convex, occupying the greater part of the length of the seed, and lying in its broader plane with their backs to the placenta ; radicle turbinate, obtuse, several times shorter than the cotyledons, but protruded a little way beyond the auricles, and filling up the basal and narrow end of the seed.

\section{Eucharidium concinnum, Fisch. et Meyer.}

Seeds 1·5-2.25 mm. long, $\cdot 75-1 \mathrm{~mm}$. wide.

\section{DEVELOPMENT OF COTYLEDONS.}

Cotyledons immediately after germination shortly and broadly oblong, obtuse, emarginate, with a small purple tootl in the notch, shallowly auricled at the base, sessile, minutely dotted all over the upper surface with glands. Hypocotyl minutely glandular. Primary root simple, furnished with root-hairs.

Seven days after germination they are oblong-obovate, emarginate, constricted below the middle, with the upper part or true cotyledon transversely oblong, and the lower similar, but smaller and shortly ciliate at the margin, very shortly petiolate.

Sixteen days after germination they have become broadly ovate, blunt, emarginate with the apical tooth very small and inconspicuous, shortly petiolate ; upper part or true cotyledon transversely oblong, much shorter and narrower than the lower or foliaceous part, minutely and inconspicuously pulcscent; lower part with three to four crenatures on each side and more conspicuously pubescent all over the upper surface than the upper part. Midrib distinct to the apex.

Twenty-five days after germination the upper part or true 
cotyledon has become proportionately much shorter and narrower than the lower part, and is inconspicuously and minutely pubescent; lower part very broad with three to five shallow crenatures on each side, pubescent all over the upper surface ; under surface purple, or by transmitted light almost green and slightly suffused with purple; midrib distinct to the apex. Hypocotyl densely pubescent. Petioles elongated, semiterete, channelled above, densely pubescent. First two leaves opposite, oblong-ovate, obtuse, with a distinct midrib but indistinct, incurved lateral nerves, minutely glandular-pubescent all over the upper surface.

Lopezia coronata, Andr.

Primary root tapering downwards, with fibrous lateral rootlets.

Hypocotyl erect, subquadrangular, glabrous or with two rows of hairs, one on each side, reddish, $1 \cdot 5-2 \cdot 5 \mathrm{~cm}$. long.

Cotyledons ovate-oblong, obtuse, rather unequal, obsoletely or shallowly trilobed, petiolate, glabrous, green, one-nerved as far as the middle, after that with no apparent venation; petioles reddish, shorter than the cotyledons, deeply furrowed on the upper face.

Stem erect, square, herbaceous; 1 st and 2 nd internodes about $1 \mathrm{~mm}$. long.

First leaves simple, cauline, opposite, petiolate, exstipulate, ovateoblong, acute, serrate, glabrous, green, pinnatinerved; petioles short, furrowed on the upper face.

\section{LOASE E.}

Benth. et Hook. Gen. Pl. i. 801.

Fruit and Seed.-The ovary is inferior, rarely half-superior, one- very rarely two- or three- celled, with parietal placentas, and few or numerous or indefinite anatropous ovules suspended from the apex of the cell or from parietal placentas, and arranged in one or many series. The fruit is capsular, often ribbed with the ribs straight or spirally twisted, dehiscing at the apex with three to five valves or longitudinally with three to ten openings or slits and few- or many-seeded. The seeds are generally minute, oblong or variously angled, in Mentzelia angled, flattened, or even winged; the testa is membranous or thickened and subcrustaceous, or sometimes loose and reticu- 
late. Endosperm is absent or present in variable quantity and fleshy or very rarely horny. The embryo is straight or hooked as in Mentzelia, and linear, oblong, or terete with plano-convex foliaceous or hemispherical cotyledons, and a short or elongated radicle. Then endosperm is wanting the cotyledons are fleshy. The orule is solitary in Petalonyx, Gronovia and Cevallia, and when it has changed to a mature seed it conforms to the single cavity of the ovary. In a few species of Loasa the seeds are large, globose or oblong, with a horny albumen and minute embryo.

Seedlings.-The cotyledons, like the seeds, differ considerably. Those observed vary between roundly or broadly ovate and oral, and are generally emarginate.

Loasa prostrata, Gill. (fig. 370).

Hypocotyl 4-6 cm. long, erect, terete, covered with numerous hairs, some of which are much longer than the rest, and stinging, almost colourless.

Cotyledons broadly and ovately oblong, obtuse, entire, shortly petiolate, membranous, hairy with many stinging hairs, light green, five-nerved.

Stem erect, terete, herbaceons, hairy; 1 st internode 5-6 $\mathrm{mm}$. long.

Loasa lateritia, Gill. et Hook. (fig. 371).

Primary root tapering downwards, long, slender and rather sparingly furnished with lateral rootlets.

Hypocotyl erect, terete, pale green, almost colourless, hispidly pubescent, 5-7

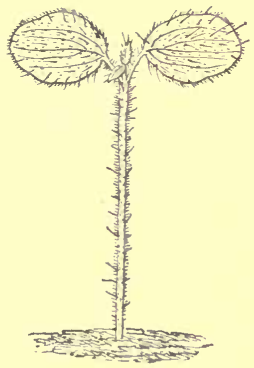

Fig. 370.-Loasa prostrata. Half nat. size. $\mathrm{mm}$. long.

Cotyledons small, rotund, emarginate, petiolate, thinly hispidly pubescent, pale green above, paler beneath, with a midrib discernible only by transmitted light; lamina $2-2.5 \mathrm{~mm}$. long and wide; petiole flattened or slightly grooved above, convex below, $\cdot 5-1 \cdot 5 \mathrm{~mm}$. long.

Stem herbaceous, ultimately twining ; primary internodes undeveloped.

Leaves simple, radical and cauline, opposite (or at least the lower ones), exstipulate, petiolate, hispidly pubescent and coarsely hairy 
with long, hyaline, bulbous-rooted stinging hairs, alternately and ascendingly penninerved, ultimately pinnatifid or bipinnatifid, with the ultimate segments similarly veined, and the nerves running directly into the teeth ; petioles semiterete, channelled above, glandular-pubescent and setose with stinging hairs, dilated and amplexicaul at the base.

First pair broadly ovate, obtuse, slightly dentate or entire, with a distinct midrib and one or two lateral ascending nerves on each side.

Second pair much larger, triangular, obtuse, crenate, with more numerous nerves, and glandular, mucronate teeth.

Third pair lyrately pinnatifid or pinnatisect with three segments;

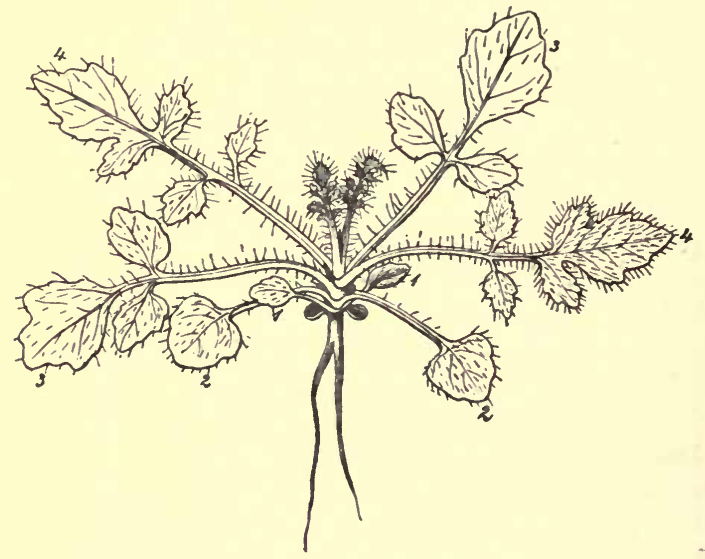

Fra. 371.-Loasa lateritia. Nat. size.

lateral segments unequally ovate, obtuse, crenate-dentate ; terminal segment much larger, rhomboid-obtuse, crenate-dentate and often subtrifid; teeth mucronate.

Fourth pair lyrately pinnatisect, with three or more, generally five, segments ; lateral segments ovate, obtuse, obtusely and mucronately dentate, more or less petiolate; terminal segment larger, lobed or pinnatifid and mucronately dentate.

In L. papaverifolia, $H$. B. et $K$., the hypocotyl is erect, terete, finely pubescent, and $1 \cdot 5-2 \cdot 5 \mathrm{~cm}$. long.

The cotyledons are broadly ovate, obtuse, slightly emarginate, petiolate, and finely pubescent. 
Loasa vulcanica, $A$ ndr.

Hypocotyl finely glandular-pubescent, variable in length according as the seeds are germinated in heat or out of doors.

Cotyledons ovate-rotund, glandular-pubescent on both surfaces, and 4-5 mm. long, 4-6 mm. wide, with a slender petiole channelled above, $1 \cdot 75-7 \mathrm{~mm}$. long.

Stem annual, erect, terete, densely covered with patent, glandular hairs of different lengths ; 1st internode 1-4 mm. long.

Leaves caulime and very similar to those of $\mathrm{L}$. lateritia.

First pair ovate, obtuse, distantly serrate-dentate.

\section{TURNERACEE.}

Benth. et Hook. Gen. Pl. i. 806 .

Fruit and Seed.-This small Order has a superior onecelled ovary and three parietal placentas on which the numerous ascending anatropous ovules are arranged in a double series. The fruit is capsular, many-seeded, and dehisces loculicidally throughout its length by three valves. The seeds are oblongcylindrical, sometimes with a prominent raphe and chalaza, reticulate or covered with small depressed areas and slightly curved. They are furnished with a membranous aril along the same side as the raphe. The endosperm is copious and fleshy. The embryo is straight, axile, and narrow, with plano-convex cotyledons and an elongated radicle.

Seedlings.-The only seedling of this Order coming under my notice is Turnera elegans (fig. 372). The cotyledons are ovate, petiolate, with a distinct midrib and two faint lateral nerves. The first two leaves are opposite, oblong-lanceolate, incise-serrate, while succeeding ones are alternate. A peculiar feature of the venation is that the primary reins run into the sinuses, not the teeth of the leaves. In some species of Turnera and Wormskioldia the ultimate leares are pinnatifid.

Turnera elegans, Otto (fig. 372).

Hypocotyl erect, terete, pubescent or hairy with upcurved and incurved hairs, pale green, $1-1.5 \mathrm{~cm}$. above soil. 
Cotyledons ovate, obtuse, petiolate, glabrous except the petioles with a distinct midrib and two slender, rather indistinct lateral nerves, light green ; lamina $6 \cdot 5-8 \mathrm{~mm}$. long, 4-5 $\mathrm{mm}$. wide; petiole slightly grooved above, hairy, $3 \mathrm{~mm}$. long.

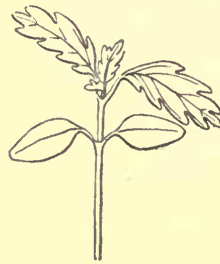

FIG. 372 .

Turnera elegans.

Nat. size.

Stem erect, terete, hairy with patent and ascending incurved hairs, pale green; 1st internode 3-8 $\mathrm{mm}$. long.

Leaves simple, cauline, alternate (1st and 2nd opposite), exstipulate, petiolate, thinly hairy on both sides, alternately penninerved with the nerves running into the sinus of the serratures, light green; petioles shallowly grooved above, hairy, pale green, with usually two tooth-like glands on the margins above the middle.

Nos. 1 and 2. Opposite, oblong-lanceolate, incise-serrate, with obtuse or subacute serratures.

Nos. 3 and 4. Alternate, lanceolate-oblong, incise-serrate, with obtuse serratures.

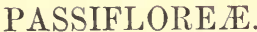

Benth. et Hook. Gen. Pl. i. 807.

Fruit and Seed.-The ovary is synearpous, quite free from the receptacle, and one-celled with three to five parietal placentas denoting as many carpels. The ovules are numerous, rarely few, pendulous, anatropous with a superior micropyle, and ventral raphe, and arranged in one to numerous series on the placentas. The funicle sometimes attains considerable length, and usually becomes widened or dilated at the apex forming a cup-shaped aril. The fruit is baccate or capsular, indehiscent or dehiscing loculicidally, and usually containing a large number of seeds. The latter are ovate or oval, much compressed, rarely oblong, or much thickened, covered with a fleshy or pulpy aril. The testa is leathery or often greatly thickened, crustaceous, black and pitted or indented so deeply in some cases that it forms small pointed processes projecting into the endosperm. The latter is fleshy and scanty or copious. The embryo is of large size, embedded in the endo- 
sperm, straight with broad foliaceous cotyledons, and an elongated radicle.

Basananthe is exceptional in having only three ovules in the ovary. In some species of Carica the ovary is five-celled by the development of spurious septa. A curious case occurs in Ceratiosicyos where the stipitate capsule is elongated, terete, membranous and greatly resembling a siliqua. Passiflora, Tacsonia and several other genera have also a stipitate ovary and fruit resembling that of the Capparideæ, where the capsule is also siliquiform in a number of genera.

A good type of the Order is furnished by Passiflora macrocarpa (fig. 373) which has a greatly thickened testa slightly indented and pushing blunt points into the endosperm. There is a groove in the edges of the seed and the raphe passes along it on one edge.

The cotyledons are broadly oblong-oval, slightly inclined to be cordate at the base. Taesonia ignea (fig. 376) differs chiefly in the relatively smaller size of the embryo, the absence of a groove on the edges of the seed, and in the testa being rather deeply depressed in places but hardly indented. The cotyledons are trinerved. The seeds of Tacsonia tubiflora are obovate, rather thickened, not grooved at the edges, but deeply indented internally, and running into the endosperm. In other respects it agrees with the two former species.

Seedlings.-The prevailing types of cotyledons belonging to different genera and species of the Passifloreæ vary from oblong to oral, and are foliaceous, entire, or slightly emarginate, three- or faintly five-nerved, reticulate and shortly petiolate. A fairly representative type of the Order is that of Passiflora cærulea (fig. 375). The first eight leaves are entire and vary from broadly ovate to the eighth which is lanceolate. From the ninth to the eleventh inclusive they are palmately tri-nerved and -partite. The ultimate leaves are five- to seven-lobed with linear lobes. In Passiflora Leschenaultii the third, in Tacsonia ignea the second, and in T. Tan Volxemii the first leaf is already trilobed. P. macrocarpa (fig. 374) has broadly or roundly oblong much reticulated cotyledons. All the leaves are entire and oblong-ovate from first to last. The cotyledons of P. Leschenaultii are inclined 
to be oblong-ovate. The first leaf is transversely oval ; the second roundly ovate; the next three shortly trifid and threeor faintly five-nerved.

A slight modification from the above types is met with in P. maliformis which has broadly oblong, emarginate coty. ledons. Its first three leaves are lanceolate and acuminate with a shallowly cordate base. In P. edulis the cotyledons are oval, and the first three leaves oblong-elliptic, and obtusely acuminate.

The oval cotyledons of T. Van Volxemii (fig. 378) are trinerved, but the lateral nerves give off each a strong branch. The first leaf is oblong, shortly trifid, and is followed by five others which are trinerved and tri-lobed or -partite, with narrowly oblong, or lanceolate, finely serrulate lobes. The cotyledons of Carica cundinamarcensis (fig. 380), and those of C. Papaya maxima differ but slightly from the type in being broadly oblong, and cuneate at the base. The first two leaves of the former are oblong-cordate, shallowly and coarsely toothed; these are succeeded by six others which show a few large teeth as if they were inclined to become pinnatifid. The first leaf of C. Papaya maxima is small, lanceolate, and entire.

The most remarkable variation from the type occurs in Modecea trilobata (fig. 379). The cotyledons are unusually large, broadly ovate and obtuse, with a wide sinus or indentation near the apex on one side, trinerved and copiously reticulate. The first leaf is ovate, subcordate at the base, distantly and irregularly toothed, and strongly acuminate. The second and third ones are deeply trilobed with ovate or lanceolate, acuminate, entire lobes.

\section{Passiflora Leschenaultii, $D C$.}

Hypocotyl glabrous, about $1 \mathrm{~cm}$. long.

Cotyledons oblong-ovate, obtuse, subemarginate; limb $9 \mathrm{~mm}$. long, $6 \mathrm{~mm}$. wide ; petiole $3 \mathrm{~mm}$. long.

Stem flexuose, suffrutescent, striate or somewhat furrowed, pubescent, green; 1 st internode $3 \mathrm{~mm}$. long; 2 nd $3.5 \mathrm{~mm}$.; 3rd $4.5 \mathrm{~mm}$.; 4th $5.5 \mathrm{~mm}$.; 5 th $4.5 \mathrm{~mm}$.

Leaves.-No. 1. Transversely oval, cuspidate, three- to fivenerved, subciliate at the margins, and pubescent on the nerves on 
both surfaces, $1.75 \mathrm{~cm}$. long, $1 \cdot 1 \mathrm{~cm}$. wide; petiole slender, subterete, subchannelled on the upper side, pubescent, $1.5 \mathrm{~cm}$. long.

No. 2. Rotund-ovate, acute, trinerved; lamina $2 \mathrm{~cm}$. long, $1.75 \mathrm{~cm}$. wide.

No. 3. Rotund-ovate, subtrifid, palmately trinerved; lateral lobes small, triangular, cuspidate ; middle lobe large, triangular, acute.

Nos. 4 and 5. Similar but proportionately broader and more decidedly palmate.

\section{Passiflora macrocarpa, Mast. (fig. 373).}

Fruit oblong, obtuse at both ends, stipitate, glabrous, one-celled, many-seeded, baccate or fleshy when mature, large and thick, indehiscent.

Seeds obovate, much compressed, bidentate at the base, tridentate at the apex, margins irregularly crenate, with the testa produced all round into a double wing, convex in the middle, and pitted with round or angular depressions, arillate; chalaza basal, forming a turbinate, yellow thickening, hidden by the wings or

A

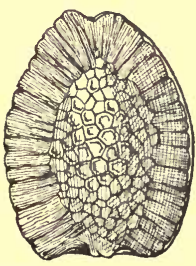

B

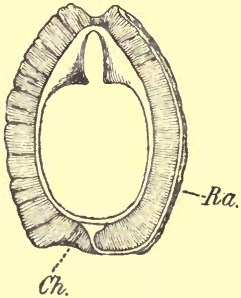

C

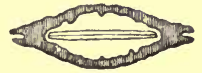

FIG. 373.-Passiflora macrocarpa. A, seed. B, longitudinal section of seed $C h$, chalaza; $R a$, raphe. $\mathrm{C}$, transverse section of seed. All $\times 3$.

produced edges of the testa, and in close contact with the endosperm ; raphe passing round from near the emargination of the base, and beneath or between the wings of the testa to the chalaza lying beneath the middle tooth at the basal end; micropyle superior; funicles stout, elongated, produced into a cup-shaped or subcylindrical aril, enclosing the seed but open at the upper end ; hilum a little to one side of the emarginate base.

Endosperm copious, fleshy, pitted by the indentations of the testa, and surrounding the embryo.

Embryo straight, large, colourless, nearly equalling the endosperm in length; cotyledons oblong-oval, obtuse, entire, slightly 
cordate at the base, alternately and ascendingly penninerved; radicle cylindrical, obtuse, slightly thinner at the base of the cotyledons, and much shorter.

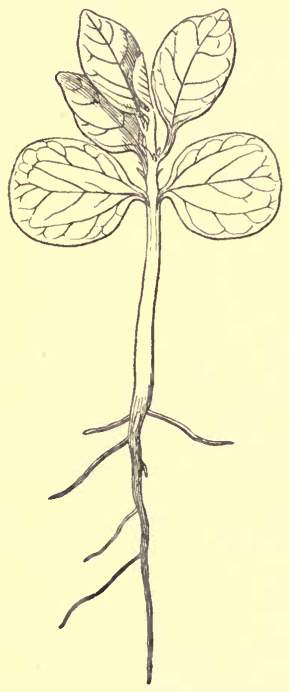

Fig. 374.

Passiflora macrocarpa. Nat. size.
Seedling (fig. 374).

Hypocotyl stout, erect, terete, but obtusely quadrangular beneath the cotyledons, glabrous, pale green, tapering upwards, $2 \cdot 3-2 \cdot 7 \mathrm{~cm}$. above the soil.

Cotyledons foliaceous, oblong-rotund, entire, very obtuse and rounded at the apex, shortly petiolate, three- or slightly five-nerved at the very base, reticulate, glabrous, shining on both surfaces, light green above, paler beneath; lamina $1.4-1.6 \mathrm{~cm}$. long, $1.3-1.35 \mathrm{~cm}$. wide; petiole flattened above, convex on the back, broadest at the base of the lamina, $2 \mathrm{~mm}$. long, with their edges decurrent on the hypocotyl.

Stem erect, slightly angled, pale green, glabrous, ultimately climbing by means of cirrhi from the axils of the petioles, acutely quadrangular or winged; 1st internode $2 \cdot 25-3.5 \mathrm{~mm}$. long; 2nd 2.5-4 mm.

Leaves simple, cauline, alternate, stipulate, petiolate, alternately incurvinerved, subreticulate, glabrous, light or bright shining green above, paler beneath; petioles short, flattened above or shallowly grooved on each side of a raised midrib, obtusely carinate beneath; stipules small, subulate, acute, entire or slightly serrate at the apex, pale green, glabrous, seated at the very base of the petiole or close to the stem.

Nos. 1 and 2. Ovate, obtuse, minutely apiculate, minutely and distantly serrulate.

No. 3. Subelliptic, otherwise similar to the first two.

\section{Passiflora cærulea, L. (fig. 375).}

Primary root long, tapering, abundantly furnished with adventitious rootlets.

Hypocotyl erect, suffrutescent, terete, longitudinally ribbed with elevated tuberculated lines, reddish, 3 to $4 \mathrm{~cm}$. long. 
Cotyledons foliaceous, petiolate, glabrous; lamina oblong-oval, obtuse, trinerved, $13.5 \mathrm{~mm}$. long, $8.5 \mathrm{~mm}$. wide; petiole channelled above, $7.5 \mathrm{~mm}$. long.

Stem erect, terete, ultimately climbing, suffrutescent, marked with lines of small tubercular bodies, glabrous, green, becoming stained with red; 1st internode $1.6 \mathrm{~cm}$. long; 2nd $9 \mathrm{~mm}$.; 3rd $9 \mathrm{~mm}$; 4 th $1 \mathrm{~cm}$. ; 5 th $1.5 \mathrm{~cm} . ; 6$ th $2.5 \mathrm{~cm}$.; 7 th $2.25 \mathrm{~cm}$; 8th $3.35 \mathrm{~cm} . ; 9$ th 5.85 cm.; 10 th $6.4 \mathrm{~cm}$.

Leaves simple, cauline, alternate, stipulate, petiolate, glabrous, dark green above, pale beneath, red or violet at the margin; petioles subterete, tapering upwards, pale green, suffused with red, often bearing capitate, stalked glands on the upper side which secrete a viscid, transparent liquid; sti-

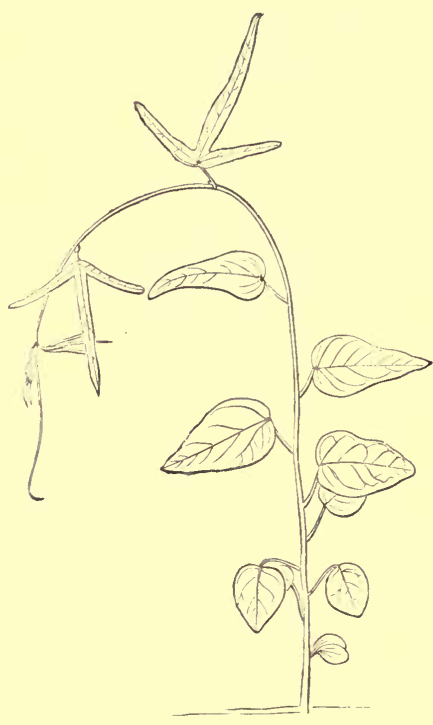

Frg. 375.-Passiflora carulea.

One-third nat. size. pules on the lower part of the stem, subulate, acute, attenuate, reddish, on the upper part of the stem, half cordate, acuminate, foliaceous, green, reticulate with a reddish margin.

Nos. 1 and 2. Small, broadly ovate, obtuse.

Nos. 3 to 5. Ovate, obtuse, mucronate.

Nos. 6 and 7. Ovate, attenuate, obtuse, mucronate, serrulate at the base.

No. 8. Lanceolate, attenuate, obtuse, mucronate or rather apiculate, serrulate at the very base, with ascending subincurved nerves as have all those below it.

Nos. 9-11. Palmately tri-partite and -nerved, or five-nerved at the base; lobes linear, attenuate, obtuse, apiculate, reticulate.

Cirrhous tendrils equivalent to branches are given off in the axils of the eleventh, twelfth and succeeding leaves. 
Tacsonia ignea, Hort. (fig. 376).

Fruit globose or oblong, baccate, stipitate, one-celled with three parietal placentas, many-seeded, indehiscent.

Seed obovate, much compressed laterally, tridentate at the apex, blunt or emarginate at the base, enclosed in a cup-shaped funicular aril ; testa thick, crustaceous, glabrous, black, deeply pitted on both

A

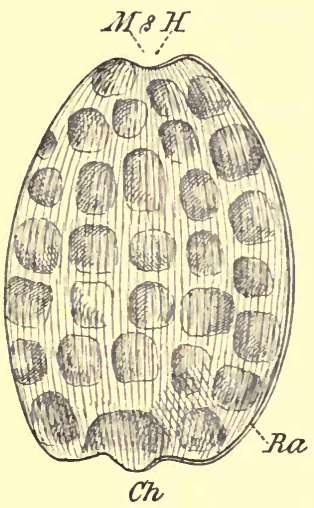

B

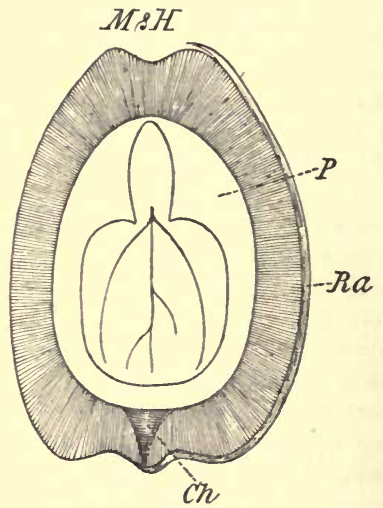

C

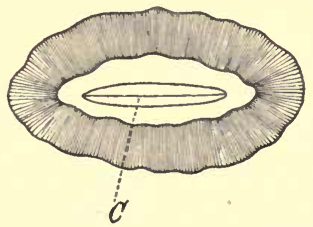

FIG. 376.-Tacsonia ignea, $\times 12$. A, seed. B, longitudinal section of seed. $\mathrm{C}$, transverse section of seed: $M \& H$, position of micropyle and hilum; $C h$, chalaza; $R a$, raphe; $P$, endosperm; $C$, cotyledons.

sides with the impressions so deep as to affect the aril; chalaza apical and passing through the testa, where it abuts against the endosperm in a dull yellow conical mass; raphe ventral passing along one edge of the seed from the hilum in the basal notch to the chalaza seated in the middle tooth at the apex of the seed. Seed $4 \cdot 25-4 \cdot 75 \mathrm{~mm}$. long; $2 \cdot 75-3 \mathrm{~mm}$. wide ; $1 \cdot 75-2 \mathrm{~mm}$. thick. 
Endosperm rather copious, fleshy, white, brittle, embedding the embryo.

Embryo straight, flat, nearly equal in length to the endosperm, colourless ; cotyledons broadly oblong-oval, entire, and rounded at both ends, closely applied face to face, embedded in the endosperm, and a little narrower than it, about twice as long as the radicle; radicle oblong-elliptical, suddenly pointed, embedded in the endosperm close to the micropyle.

Seedling (fig. 377).

Hypocotyl subwoody, erect, terete, glabrous, pale green, 1-1.5 em. long, $1 \mathrm{~mm}$. thick.

Cotyledons petiolate, rotundoval, obtuse, trinerved, pale green, glabrous; lamina $9 \mathrm{~mm}$. long, 6 mm. wide; petiole channelled above, $2.5 \mathrm{~mm}$. long.

Stem soft and succulent at first, erect, terete, glabrous or almost so, pale green; first three internodes each about $1 \mathrm{~cm}$. long.

Leaves simple, cauline, alternate, stipulate, petiolate.

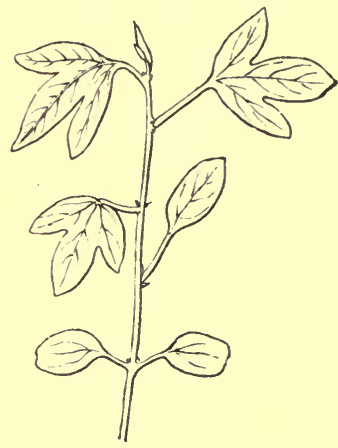

FIG. 377.-Tacsonia ignea. Nat. size.

No. 1. Oval, cuspidately acute, serrulate, with gland-tipped serratures, obscurely penninerved; petiole subterete, faintly channelled above, glabrous; stipules free, subulate, acute, small.

No. 2. Palmately tri-lobed and -nerved, finely serrulate at the margin; lateral lobes oblong, apiculate; terminal lobe oblong-oval, obtuse, apiculate.

Nos. 3 and 4. With longer, more pointed and apiculate, lateral lobes; terminal lobe oblong, longer and more acuminate than that of leaf No. 2.

\section{Tacsonia Van Volxemii, Hook. f. (fig. 378).}

Primary root suddenly tapering to a fine point and furnished with numerous strong lateral fibres.

Hypocotyl erect, subflexuose, terete, suffrutescent, glabrous, pale green suffused with red, $4 \cdot 7 \mathrm{~cm}$. long.

Cotyledons foliaceous, petiolate, glabrous, entire; lamina oval, obtuse, trinerved, deep green, shining, $11 \mathrm{~mm}$. long, $7 \mathrm{~mm}$. wide; petiole subchannelled above, $6 \mathrm{~mm}$. long.

Stem woody, erect at first and subflexuose, somewhat angular, 
glabrous, pale green; 1 st internode $7.5 \mathrm{~mm}$. long; $2 \mathrm{nd} 5.5 \mathrm{~mm}$. 3rd $9 \mathrm{~mm}$.; 4 th $1.5 \mathrm{~cm}$.; 5 th $1.3 \mathrm{~cm}$.

Leaves simple, cauline, alternate, stipulate, petiolate, glabrous lobed and glandular-serrulate ; petiole subterete, channelled above glandular towards the top, and glabrous, pale green or tinged with red on the upper side; stipules lanceolate or subulate, subacute glabrous, pale green, free.

No. 1. Oblong, trinerved, shortly trifid; lateral lobes ovate,

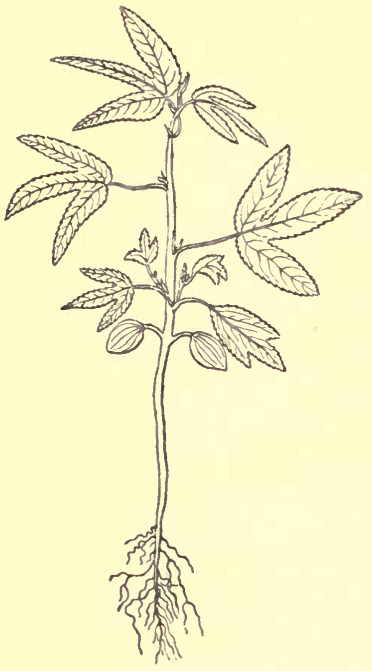

FIG. 378.-Tacsonia Van Volxemii. Half nat. size. mucronate; middle lobe ovate, elongate, mucronate.

No.2. Tri-partite and-nerved; lobes lanceolate, apiculate; middle one slightly longest.

No. 3. Tri-partite; lateral lobes oblong ; middle lobe lanceolate-elliptic.

Nos. 4-7. Tri-partite and -nerved; lobes linear-oblong, obtuse; middle one longest.

Modecca trilobata, Roxb. (fig. 379).

Hypocotyl erect, terete, glabrous, stout, pale green, shining, 4-6 $\mathrm{cm}$. above the soil.

Cotyledons very large, foliaceous, broadly ovate, obtuse, subcordate at the base, much cut away near the apex on one side, petiolate, glabrous, bright green and shining above, pale or subglaucous beneath and shining, with five ascending and incurved nerves arising in the top of the petiole; lamina $3.9 \mathrm{~cm}$. long, about $3 \cdot 2 \mathrm{~cm}$. wide in the middle, in average seedlings; petiole stout, channelled above, convex on the back, abont $1 \cdot 2 \mathrm{~cm}$. long.

Stem erect at first, ultimately twining, terete or slightly and obtusely angled, especially about the nodes, glabrous, pale green, shining; 1st internode $1.27 \mathrm{~cm}$. long; 2nd $8.5 \mathrm{~mm}$.

Leaves simple, more or less lobed, cauline, alternate, stipulate, petiolate, glabrous, shining green above, subglaucous and shining beneath, five-nerved from the base, more or less strongly and alternately nerved upwards, reticulate, biglandular at the base of 
the lamina; petiole subterete, narrowly and shallowly grooved on the upper side, pale green, shining, tapering upwards from a stoutish base; stipules small, subreniform, lacerated at the margin, glabrous, transparent or hyaline except at the very base, seated on a short pedestal. The glands are always on two small basal auricles, and together form a small arch over the top of the petiole.

No. 1. Ovate-cordate, strongly acuminate, irregularly and coarsely dentate below the middle, often trilobed, five-nerved from

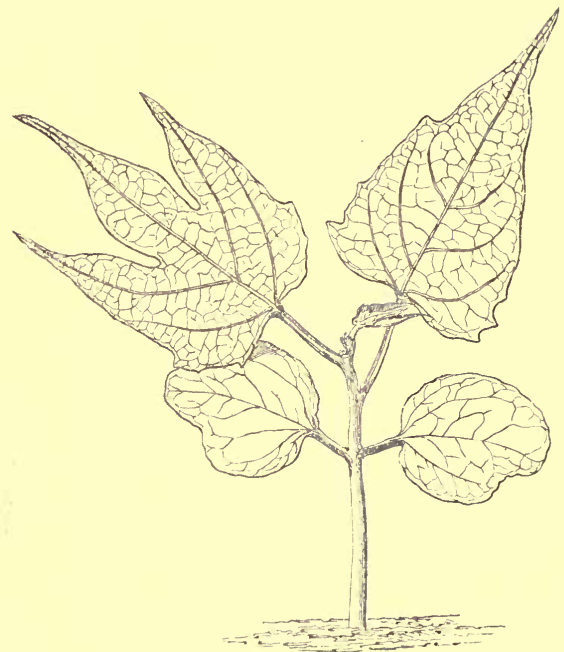

. Fig, 379.-Modecca trilobata. Half nat. size.

the base, and alternately nerved upwards, reticulate. The two basal nerves are always slender, while those next are always strong and like those above them incurved, giving off branches only to the teeth and to the higher nerves.

Nos. 2 and 3. Deeply trilobed, subcordate and five-nerved at the base; lowest pair of nerves slender; second pair strong, ascending towards the margin of the leaf and partly into the base of the lateral lobes, giving off lateral branches which form a series of submarginal arches continuous with the lowest pair of nerves, and continuing in the same manner to the apex of the strongly 
acuminate lateral lobes of the leaf. The third pair of nerves, originating below the middle of the leaf, are subopposite, strong, and run longitudinally to the very apex of the lateral lobes, giving off branches that curve and unite at their apex; midrib running to the apex of the middle lobe and similarly branching.

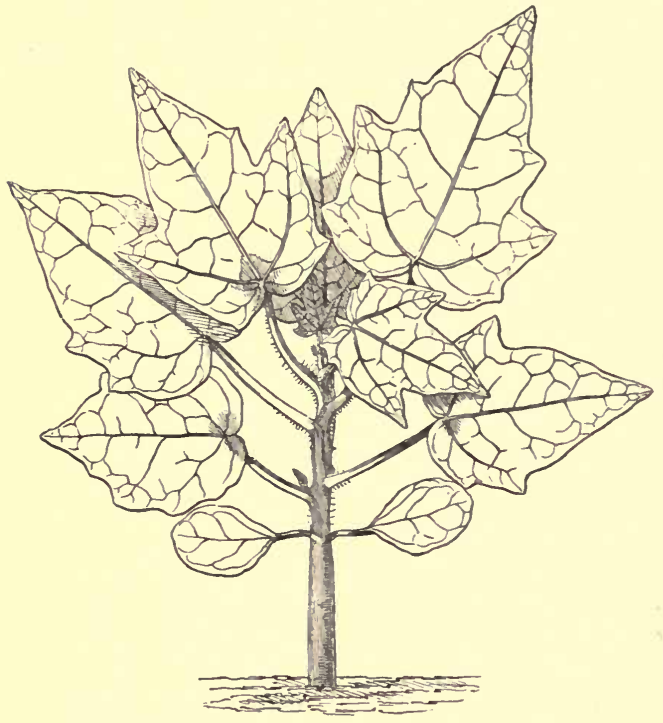

Fig. 380.-Carica cundinamarcensis. Half nat. size.

Carica cundinamarcensis, Lind. (fig. 380).

Hypocotyl stout, erect, terete, fleshy, tapering upwards, glabrous, pale green, becoming brown, $4 \cdot 0-4 \cdot 7 \mathrm{~cm}$. long, or sometimes more.

Cotyledons broadly oblong, obtuse, entire, subcuneate at the base, petiolate, trinerved at the base, alternately nerved upwards with the nerves uniting and forming an intramarginal wavy line, reticulate, at least when old, not very persistent, glabrous; lamina $2.5-2.8 \mathrm{~cm}$. long, 1.6-1.8 cm. wide; petiole rather slender, channelled above, $1 \cdot 0-1 \cdot 2 \mathrm{~cm}$. long.

Stem erect, stout, fleshy, flexuose in the young state, and more or less angled by the decurrent bases of the leaves, slightly hairy 
just beneath the petiole, brownish-green, ultimately shrubby, fleshy; 1st internode $8 \mathrm{~mm}$. long; 2nd $4 \mathrm{~mm}$; 3rd $6 \mathrm{~mm}$; 4th $3.5 \mathrm{~mm}$.

Leaves simple, cauline, alternate, stipulate, petiolate, three- to seven-nerved at the base, alternately nerved upwards, reticulate, hairy on the nerves beneath, and subglandular-ciliate, deep shining green above, glaucous or whitish beneath, with numerous small glands at the junction of lamina and petiole on the upper side, and a few small scattered ones on the midrib and principal nerves; petioles tapering upwards from a stout base, subterete, channelled on the upper side, glabrous except on the under side especially at the base; stipules small, tooth-like, tipped with a pale-coloured gland, seated on the somewhat decurrent base of the petiole.

No. 1. Oblong-cordate, obtuse, five-nerved at the base, with about two sinuate or repand obtuse teeth on each side.

No. 2. Similar, but angled or bilobulate on each side below the middle.

No. 3. Cordate-ovate, with one to two teeth on each side towards the base.

Nos. 4 and 5. Cordate, elongate, with two to three repand teeth on each side.

Nos. 6-8. Palmate, elongate, five-nerved at the base, three- or slightly five-lobed; basal lobes small, triangular, or tooth-like; middle lobes larger, triangular, subacute; terminal one much the largest, triangular-ovate, subacute, entire or slightly toothed.

\section{CUCURBITACEA.}

Benth. et Hook. Gen. Pl. i. 816.

Fruit and Seed.-The ovary, consisting for the most part of three carpels, is inferior, in a few cases free at the apex. It is three-, rarely one- or two-celled, or spuriously four- to five-celled. The species belonging to the tribe Elaterieæ are altogether abnormal; some have a one- or two-celled ovary, others are many-celled by the development of spurious septa between the seeds. Normally the placentas are parietal, fleshy, very often confluent in the axis of the ovary, and again reflexed towards the circumference. The ovules are pendulous, horizontal, or ascending and anatropous; and in ovaries consisting of one carpel they vary from one to two and 
are inserted at the base or suspended from the apex of the cavity. To be basal and erect is however unusual. In ovaries of three carpels and three cells, they are inserted on the sides of the placentas nearest the peripheral walls.

The fruit is in most cases baccate, and fleshy or cortucal, and botanically termed a pepo; very often it is one-celled by the destruction of the septa which become pulpy; hence the seeds are nearly always embedded in pulp. It is mostly indehiscent, rarely opening by valves or by an operculum, and many-seeded. In Elaterium and its allies the fruit separates from its peduncle, leaving an opening through which the pulp and seeds are ejected with some force by the elastic contraction of the walls. The seeds, like the ovules, vary in direction and are very often flattened as in the Passifloreæ. The testa is membranous, cartilaginous or crustaceous, granular, tuberculate, or smooth, sometimes covered with a watery epidermis, and toothed or lobed at the edges. The tegmen also varies in thickness and other characters. Endosperm is wanting; and the embryo therefore conforms to the cavity of the seed. The cotyledons are foliaceous and flattened, or plano-convex according to the thickness of the seed; and the radicle is comparatively short.

Besides the anomalous or unusual forms mentioned abore, Sechium edule is remarkable for its large, obovoid, fleshy, onecelled, one-seeded fruit. The seed is also large, subglobose, with a woody testa, and conforms to the interior of the indehiscent fruit. The embryo is very large and germinates in the fruit before the latter drops from the plant. The ovules and seeds of Hodgsonia heteroclita are connate in pairs, of which one is large and fertile, and the other small and empty.

A type of an obovoid and rather thickened seed is furnished by Bryonia dioica. It is surrounded by a slightly raised margin and is somewhat compressed laterally with a pale, crustaceous testa. The cotyledons are plano-convex, but otherwise characteristic of the Order. The average size of the seeds is $4.4 \mathrm{~mm}$. long by $3.08 \mathrm{~mm}$. wide and $2 \cdot 2 \mathrm{~mm}$. thick. The seeds of B. laciniosa (fig. 389) are somewhat larger, being $5 \mathrm{~mm}$. long by $3 \mathrm{~mm}$. wide. They are surrounded at the edges by a narrow ridge, and have a large mass of cortex projecting 
from each side and corresponding in position to the back of the cotyledons which are rather more flattened here than in the case of Bryonia dioica. The embryo as a whole is amygdaloid.

The seeds of Trichosanthes Anguina are very variable in shape, even in the same fruit, being oblong, oval, or suborbicular, much flattened laterally and irregularly jagged or crenate at the edges, presenting a gnawed appearance. The embryo conforms to the shape and size of the seed, and even when in the latter sometimes shows the effect of the indentations. This may be compared with the behaviour of the testa in Passiflora, where however the indentations affect the endosperm only. The fruit is very remarkable, being snakelike, more or less twisted, two to three feet long, green, striped with grey and scarlet when mature.

Seedlings.-Owing to the relatively uniform character of the seeds of this Order and the absence of endosperm, there is a very moderate amount of variation in the shape and appearance of the cotyledons. The seeds on the whole are relatively large, sometimes very large; and throughout the Order, so far as observed, the seedlings are correspondingly large and vigorous from the earliest stages of germination onwards. Generally speaking, the largest cotyledons come from the largest seeds ; but there are cases where the cotyledons of some species greatly exceed in size those of another species of the same genus, even although there is comparatively little difference in the size of the seeds. This arises in consequence of the growth after germination being more vigorous in some than in others. The shape of the seed would have some bearing upon the ultimate shape of the cotyledons, but modifications occur where these become much widened near the apex; and although the cotyledons as far as observed are always entire in the seed, they ultimately become more or less emarginate in some species by growth after germination. The simplest type appears to be that of Momordica involucrata, the seedlings of which have oblong-spathulate cotyledons, slightly connate at the base, of moderate size and sessile. The first two leaves are roundly cordate, opposite and five-nerved. Succeeding ones are three- to five-lobed and alternate. M. 
muricata (fig. 384) differs in having somewhat larger cotyledons and two pairs of opposite leaves, the first pair being obsoletely trilobed at the apex and seven- to nine-nerved. Trichosanthes palmata (fig. 382), T. Anguina, and Cucumis utilissimus have obovate-spathulate, three- to five-nerved cotyledons of much greater size than those of Momordica. The first named has the first leaf reniform and inserted close to the cotyledons owing to the non-elongation of the first internode. The primary leaves of Trichosanthes Anguina are cordate and also alternate, but all the internodes are elongated. A very remarkable instance of variability occurs in this species, for although the usual type is that just given, seedlings occur in which the two first leaves are opposite, and in rare cases there are three cotyledons followed by three leaves also in a whorl.

A second type is that in which the cotyledons are oblong or obovate-oblong, and narrowed at the base into short, more or less channelled petioles. They are also three- to five-nerved, although the intermediate pairs of nerves are not strictly basal.

Cucumis sativus (fig. 386) is an instance with entire cotyledons. The first leaf is cordate, incipiently lobed, and is inserted on the axis close to the cotyledons, a circumstance of very frequent occurrence, as for instance in Trichosanthes palmata mentioned above and Acanthosicyos horrida (fig. 383), Citrullus Colocynthis, Cephalandra palmata (fig. 388), Bryonia laciniosa (fig. 390) and Cionandra. In all the last five the cotyledons are large and more or less deeply emarginate. The primary leaves of most of them are very characteristic of the Order and show a greater or less amount of evolution. A good instance is that of Citrullus Colocynthis, the first leaf of which is rotund, truncate at the base, and obscurely crenate; the second is oblong-cordate, five-nerved and shallowly five-lobed, followed by others that are more deeply and sharply divided. The first leaf of Cephalandra palmata is cordate; the second and third palmately three- to fivenerred and -lobed. The first six leaves of Bryonia laciniosa are five-nerved and deeply tripartite, the divisions being narrow from the third leaf onwards. The most striking case 
occurring in this group, or indeed in the whole Order, is that of Acanthosicyos horrida which bears organs that are morphologically leaves but are functionally useless as such. The first leaf is small, linear, entire, concave and carinate. From the second to the fifth inclusive they are gradually smaller and subtended by a pair of spines, but otherwise similar to the first. This, the only species of the genus, is a native of the dry sandy deserts of Angola and Dammara Land; and the reduction in size or almost entire abortion of the leaves is the expression of the adaptation of the plant to its environment.

Besides the abure types a few others may be mentioned which differ so much from the leading ones and from one another as far as the cotyledons are concerned that they may be regarded at any rate for the present as exceptional. The cotyledons of Bryonia dioica (fig. 391) are suborbicular, entire, suddenly cuneate at the base, with slender, considerably elongated petioles. They are small compared with those of B. laciniosa, and altogether different in shape. The elongation of the petioles would appear to be necessary owing to the hypocotyl being almost suppressed or scarcely rising above ground. Thladiantha dubia (fig. 385 ) has a relatively short hypocotyl, suborbicular, broadly and shallowly emarginate cotyledons, with comparatively long petioles, all of which are rather thickly strewn with stiffish hairs.

An extraordinary instance of another kind oceurs in Megarrhiza californica, the hypocotyl of which is short, subterranean, and together with the upper portion of the root becomes developed into an enormously thickened and fleshy tuberous structure. The cotyledons are large, fleshy, plano-convex, and never leave the large, oblong, tumid seed although they are carried two or three inches above ground by the petioles. The latter appear further to be connate into a cylindrical tubular body tapering upwards, but they are really separable. The plumule proceeds from a slit between the petioles close to the base of the latter at the level of the ground or below it. The first three or four leaves are reduced to small scales. All this growth preliminary to the develupment of normally expanded leaves is produced at the expense 
of the fleshy cotyledons. This behaviour shows that the plant is adapted to germinate and rise through a considerable depth of superincumbent sand, or other material. The fleshy cotyledons and the large subterranean tuberous root would also show an adaptation to a dry elimate or soil.

\section{Trichosanthes Anguina, $L$.}

Root fibrous.

Hypocotyl herbaceous, 5-8 cm. long, 3-4 mm. thick, twisted, suberect, multiangular, slightly pubescent, pale green.

Cotyledons opposite, sometimes but rarely 1-3 and whorled (probably liable to still further modification), sessile, oblong-spathulate, obtuse, often emarginate, with entire, undulated and recurved margins, obscurely trinerved above, outer nerves showing veins running towards the margin if seen from below, thick, scabrous, rather persistent.

Stem ridged, suberect; 1st internode $3-4 \mathrm{~cm}$. long, $2 \mathrm{~mm}$. thick, slightly pubescent and scabrous ; 2nd 5-7 cm. long, $1.5 \mathrm{~mm}$. thick, with swollen buds in the axils of the first leaves and more hispid; in some the first two internodes are very short and stout, while the third elongates considerably.

Leaves usually alternate, but often opposite or even whorled, long-petioled, 7-12 cm. long, 4-7 cm. wide (the alternate ones being the largest, cordate-ovate, with deep base and acute or acuminate apex, sinuate-dentate, or doubly dentate, often irregularly lobed, scabrous on both surfaces as well as on the margin, palmatinerved and very distinctly veined, slightly convex, thin, yellowish-green above, less shining and lighter below.

The second pair, or the third alternate leaf, or the first one above the lower pair of the usual palmatilobed form, have a tendril in the axil of the petiole.

Trichosanthes cucumerina, $L$. (fig. 381).

Primary root long, tapering, much branched especially near the base.

Hypocotyl undeveloped, subterranean.

Cotyledons oblong-ovate, obtuse, plano-convex, fleshy, narrowed at the base to very short petioles, bursting the testa during germination, and partly or not at all expanded, strictly subterranean, conforming in outline to the shape of the seed.

Stem terete, hairy, climbing by means of tendrils; 1 st internode elongated. 
Leaves simple, palmately five-lobed, and three- to five-nerved, hairy or downy on both surfaces, alternate, exstipulate.

No. 1. Ovate, three- or incipiently five-lobed, five-nerved with

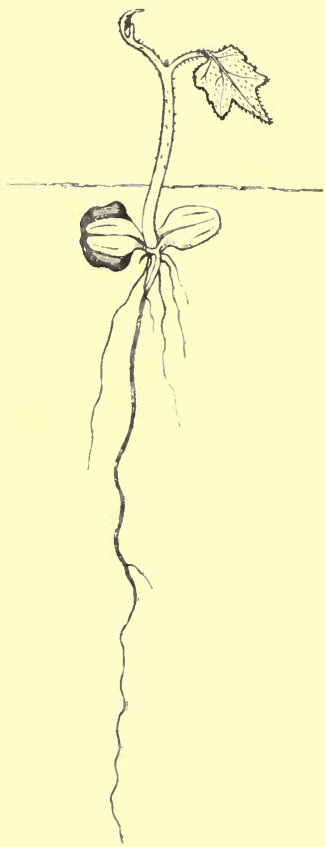

FIG. 381.-Trichosanthes cucumerina. Nat. size. the middle pair of nerves arising at some distance above the base.

Nos. 2-5, inclusive. Palmately five-lobed, trinerved with the nerves of the lower lobes arising as branches from above the base of the middle pair.

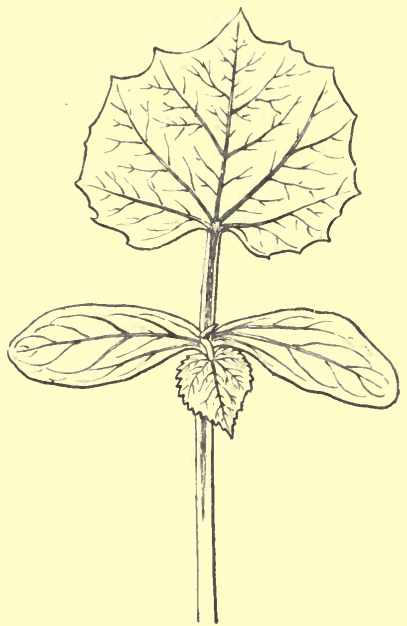

FIG. 382.-Trichosanthes palmata. Nat. size.

Trichosanthes palmata, Roxb. (fig. 382).

Hypocotyl succulent, 3-4 cm. long, 2-3 mm. thick, channelled above, round near the base, glabrous, whitish-green.

Cotyledons sessile or subsessile with connate, decurrent petioles, 25-3 cm. long, 1-1.25 cm. wide, elliptic, obtuse, scabrous, margin recurved, yellowish-green above, whitish below, rather persistent; nerves distinct and pinnate.

Stem suberect at first, nltimately climbing, quadrangular or 
ridged with dark green, edges hairy; the first few internodes very short, nearly as thick as the hypocotyl, the subsequent ones several

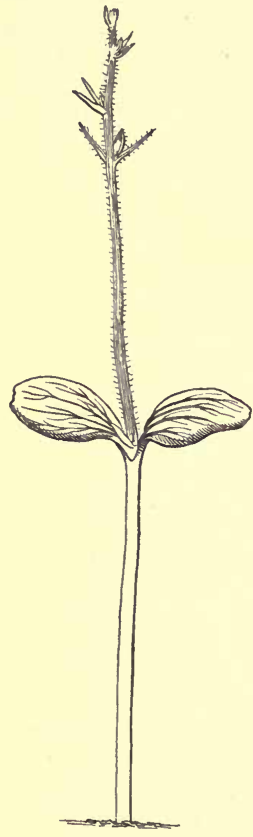

FIG. 383.

Acanthosicyos horrida. Half nat. size. centimetres long.

Leaves simple, cauline, alternate, petiolate, palmatinerved and reticulate, toothed, ultimately palmately three- to five-lobed, scabrous, deep green above, paler beneath; petiole semiterete, channelled above, tapering slightly upwards from a stout base.

No. 1. 4-6 cm. long and $3 \cdot 5-5 \mathrm{~cm}$. wide, with a stout, channelled petiole nearly half as long as the blade, broadly cordate, sinuate-dentate, often irregularly palmatilobed, each tooth and the acuminate apex ending in a mucro, palmatinerved and obscurely, although closely reticulated, scabrous, rather thick.

No. 2. Similar.

No. 3. With a tendril from the axil and more palmatilobed, also with a deeper notch at the base, and sunk nerves and veins.

Acanthosicyos horrida, Welw. (fig. 383).

Hypocotyl very variable in length, erect, succulent, pale green with two short lines of glandular hairs running down from the base of the cotyledons, otherwise glabrous.

Cotyledons ovate or obovate, obtuse, subemarginate, three- to five-nerved, convex above and covered with a short, dense, white, scabrous pubescence, pale, or subglaucous-green, paler beneath, glabrous, shining, five-nerved and subreticulate, $3 \cdot 15 \mathrm{~cm}$. long, $2 \cdot 2 \mathrm{~cm}$. wide.

Stem erect when young, succulent, terete, ridged and furrowed, thinly hairy with jointed hairs; ridges pale and furrows deep green; 1st internode undeveloped; 2nd $5 \cdot 1 \mathrm{~cm}$. long.

Leaves simple, cauline, alternate.

No. 1. Oblong, linear, acute, concave, carinate, entire, $8.25 \mathrm{~mm}$. long.

Nos. 2 and 3. Similar but smaller with a spine on each side at the very base in the position of stipules; spines ridged, furrowed and hairy like the stem. 
Nos. 4 and 5. Similar, but more reduced in size.

\section{Momordica muricata, Willd. (fig. 384).}

Hypocotyl suberect, herbaceous, 5-8 cm. long, 2-3 mm. thick, slightly twisted, glabrous, colourless.

Cotyledons sessile, about $1.5 \mathrm{~cm}$. long, $6-8$ $\mathrm{mm}$. wide, oblong, obtuse and recurved at the apex, entire, very obscurely nerved, generally concave, thick, flesliy, glabrous, dark green above, somewhat paler below, rather persistent.

Stem somewhat twisted, slightly pubescent; 1 st internode $3 \cdot 4 \mathrm{~cm}$. long, $2 \mathrm{~mm}$. thick ; 2nd and 3rd shorter and thinner.

Leaves.-First pair opposite, 6-9 cm. long, including the petiole, 4-5 cm. wide, longpetioled, rectangular, cordate at the base, the

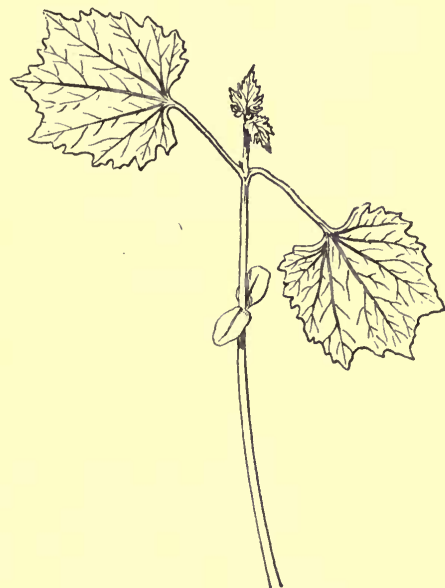

FIG. 384.-Momordica muricata. Half nat. size. apex and the two adjacent lobes acuminate, sinuate-dentate, palmately seven- to nine-nerved, and richly veined, nearly flat, not very scabrous, bright green above, slightly paler beneath, not very persistent.

Second pair palmately five-lobed and -nerved.

No. 3. and all the rest alternate, and assuming the ultimate sliape of the leaf.

Momordica involucrata, E. Meyer.

Hypocotyl succulent, $3 \mathrm{~cm}$. long, $2 \mathrm{~mm}$. thick, terete, glabrous, pale green.

Cotyledons sessile, about $1.2 \mathrm{~cm}$. long, $5 \mathrm{~mm}$. wide, $1 \mathrm{~mm}$ thick, spathulate, subconnate at base, rotund at apex, entire, obscurely nerved, glabrous, pale green on both sides.

Siem suberect at first, succulent, terete but compressed near the base, quadrangular just under the first two leaves, with a fow 
scattered hairs, light green; 1st internode $3-4 \mathrm{~cm}$. long, 1.5 mm. thick.

Leaves simple, cauline, alternate (first pair opposite), exstipulate, petiolate, palmati-nerved and -lobed, reticulate, pubescent, rather membranous, deep green above, paler beneath; petioles semiterete, tapering slightly upwards, channelled above.

First pair opposite with channelled, slightly pubescent petioles, $2 \mathrm{~cm}$. long and 1.25 mm. thick; lamina 4-5 cm. long, 3-4 cm. wide, broadly cordate with truncate apex, irregularly repanddentate, palmatinerved and reticulate with sunk nerves, pubescent and dark green above, slightly paler and pubescent on nerves only beneath, not very thick.

Nos. 3-5. Alternate, palmati-nerved and -lobed, cordate at base.

Thladiantha dubia, Bunge (fig. 385).

Hypocotyl erect, square, stout, minutely hairy, 1-2 cm. long, light green.

Cotyledons subrotund or orbicular, emarginate (entire at first), petiolate, covered with stiffish

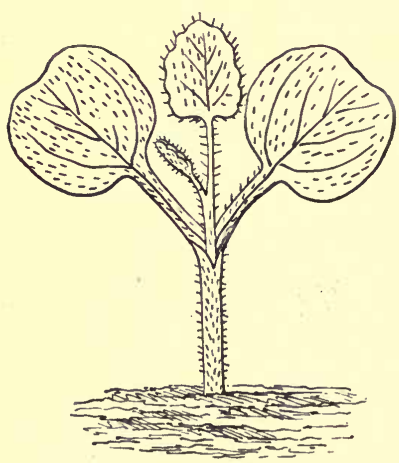

FIG. 385.-Thladiantha dubia, $\times 2$. hairs on the upper side, glabrous beneath, green, incurvinerved; petioles broad, deeply channelled on the upper side.

Stem erect, terete, hairy, herbaceous; 1st internode 3-4 mm. long.

First leaves simple, cauline, alternate, petiolate, extipulate, subrotund, obtusely crenate or bluntly serrate, cordate at the base, hairy, green, pinnatinerved. $386)$.

Cucumis sativus, L. (fig.

Hypocotyl quadrangular with obtuse angles and a median furrow along each face, succulent, pale green, pubescent or scabrous on the angles, erect, $5 \mathrm{~cm}$. long, lengthening as it develops to $9 \mathrm{~cm}$., $4 \mathrm{~mm}$. thick.

Cotyledons oblong, obtuse, narrowed at the base into short, broad, deeply-channelled petioles, with ascending nerves, pale green 
above and scabrous, paler beneath, shining and glabrous, $3 \mathrm{~cm}$. long, lengthening to $6.5 \mathrm{~cm}$., $1 \mathrm{~cm}$. wide, widening to $2 \mathrm{~cm}$.

Stem erect, deeply angled and furrowed, pale green, succulent, coarsely pubescent and scabrous, ultimately flexuose, or zigzag at the nodes, climbing; hairs usually deflexed; 1st internode undeveloped ; 2nd $4.5 \mathrm{~cm}$. long; $3 \mathrm{rd} 1.8 \mathrm{~cm}$.

Leaves simple, cauline, alternate, cirrhose or not, petiolate, coarsely pubescent or hairy on both sides and scabrous; petioles subterete and channelled above, frequently ridged and furrowed

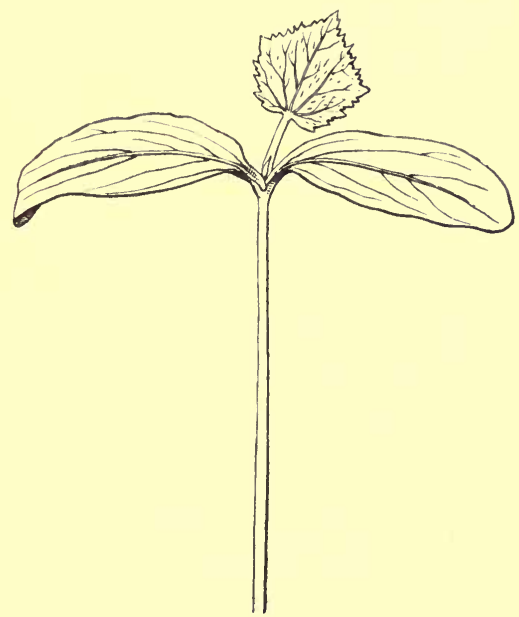

Frg. 386.-Cucumis sativus. Nat. size (very young).

especially at the sides. A tendril occurs in the axil of the second or third and succeeding leaves.

No. 1. Lamina broadly cordate, acute, palmately five-nerved, angled or shallowly lobed about the middle at the termination of the nerves, irregularly repand-dentate between the angles or lobes, entire towards the base on each side of the sinus, pale green above with sunk nerves, paler green beneath with prominent nerves and reticulations.

No. 2. More decidedly five-lobed, and toothed almost to the base.

No. 3. Similar. 
No. 4. Seven-nerved and -lobed; lobes more decidedly acuminate.

Citrullus Colocynthis, Schrad. (fig. 387).

Hypocotyl herbaceous, erect, terete, glabrous, pale green, $1 \cdot 7 \mathrm{~cm}$.

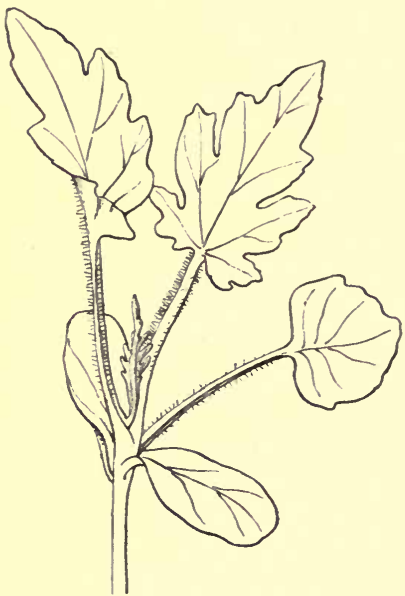

Fig. 387.-Citrullus Colocynthis. Nat size. long.

Cotyledons oblong, obtuse, subglandular on both surfaces, convex above, more or less concave beneath, tapering to a broad, short petiole, $2 \cdot 1 \mathrm{~cm}$. long, $1 \mathrm{~cm}$. wide.

Leaves cauline, simple, alternate, petiolate.

No. 1. Rotund, obtuse, truncate at the base, obsoletely crenate with many strong nerves, pubescent and scabrous on both surfaces, but chiefly at the margin and on the under side; petiole subterete, channelled above, scabrid with coarse short hairs.

No. 2. Oblong-ovate, subpalmately five-nerved and -lebed; lobes and serratures

obtuse, mucronate, otherwise like No. 1.

No. 3. Palmately oblong, five-nerved and -lobed; lobes distinct with obsolete and mucronate serratures; middle lobe largest, ovate.

Cephalandra palmata, Schrad. (fig. 388).

Hypocotyl succulent, about $2 \mathrm{~cm}$. long, 1.5-2 mm. thick, obtusely quadrangular, slightly pubescent, light green.

Cotyledons shortly stalked, about $2.5 \mathrm{~cm}$. long and nearly $1.5 \mathrm{~cm}$. wide, oblong-obovate, cuneate at the base, emarginate or bluntly mucronate at the apex, entire, with sunk midrib and two pairs of sunk nerves, rather thick, glabrous, light green above, pale beneath.

Stem with very short internodes $(1.5 \mathrm{~mm}$. long), succulent, angular, pubescent, light green, about $1 \mathrm{~mm}$. thick.

Leaves simple, cauline, alternate, exstipulate, petiolate, palmately nerved and lobed, scabrous, pubescent beneath, light green above, 
paler beneath; petioles tapering slightly upwards, semiterete, channelled on the upper side.

No. 1. With a channelled pubescent petiole $2-2 \cdot 5 \mathrm{~cm}$. long by $1.5 \mathrm{~mm}$. wide, and a cordate, acuminate, irregularly serrate-dentate lamina, scabrous above, pubescent beneath, light green, thin,

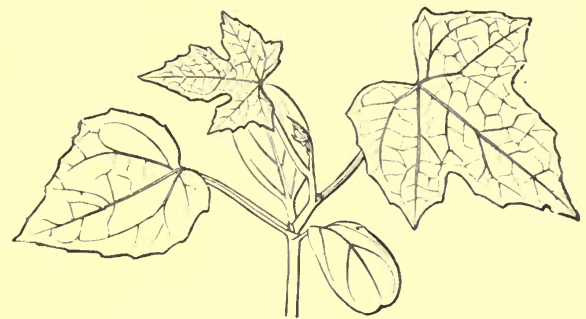

Fig. 388.-Cephalandra palmata. Three-quarters nat. size.

palmatinerved and reticulately veined, 3-4 cm. long and about $3 \mathrm{~cm}$. wide.

No. 2. Distinctly palmately trilobed.

Nos. 3 and 4. Palmately five-lobed like those of the Vine.

Bryonia laciniosa, $L$. (fig. 389).

Fruit baccate, giobose, indehiscent.

Seed obovoid, entirely surrounded at the edges with a shallow ridge, compressed at the sides where they are protected by a large semi-obovoid mass of corky-brown matter; micropyle and hilum basal; raphe and chalaza inconspicuous.

Endosperm absent.

Embryo straight, large, occupying the whole interior of the cavity to which it conforms ; cotyledons oblong-oval, obtuse, entire, thick or subfleshy, plano-convex, and closely occupying the cavity of the seed, pale yellow; radicle short, turbinate, obtuse, close to the lilum.

Seedling (fig. 390).

Hypocotyl erect, obtusely quadrangular, glabrous, shining, pale green mottled with darker green, and with green lines on the angles and sometimes between, $5 \cdot 6 \mathrm{~cm}$. above the soil.

Cotyledons foliaceous, obovate-oblong, obtuse, emarginate, trinerved in the basal half, and alternately penninerved in the upper, glabrous on both surfaces, green above, pale beneath, with short 
petioles; lamina $3.5 \mathrm{~cm}$. long, $2.1 \mathrm{~cm}$. wide ; petiole grooved above, $2 \mathrm{~mm}$. long.

Stem erect at first, herbaceous and zigzag, ultimately climbing, five-angled and furrowed, glabrous or slightly bristly, pale green with dark markings; 1st internode undeveloped ; 2nd and 3rd each $9.5 \mathrm{~mm}$. long.

Leaves simple, palmate, cauline, alternate, exstipulate, petiolate,

A

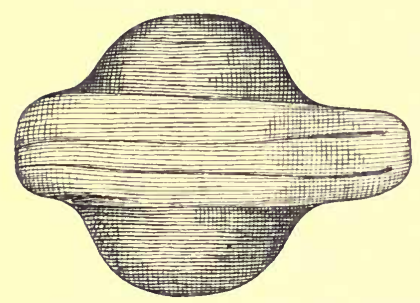

B

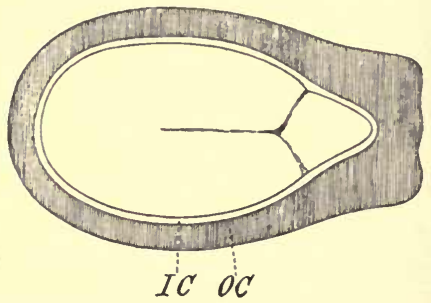

$\mathrm{C}$

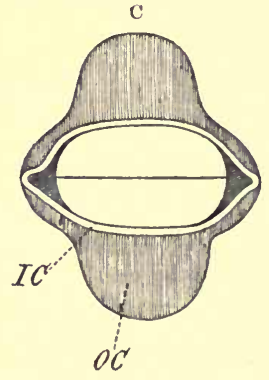

Fis. 389.-Bryonia laciniosa. A, seed, $\times 10$. B, longitudinal section of seed : $O C$, testa : $I C$, tegmen, $\times 10$. C, transverse section of seed, $\times 10$.

thinly hairy and scabrous above and deep green, paler beneath, scabrous on the principal nerves, otherwise glabrous ; petiole subterete, slightly bristly, channelled above, pale green with darker nerves, shining.

No. 1. Five-nerved, tripartite; middle segment lanceolateelliptic, acute, distantly dentate; lateral segments obliquely oblong or lanceolate, acute, slightly dentate especially on the oblique side, where a large tooth indicates further division.

No. 2. Similar, but more decidedly dentate.

Nos. 3 and 4. Palmately five-nerved, five-lobed; middle lobe 
lanceolate-ell ptic, acuminate, acute, serrate-dentate, revolute at the margin ; lateral lobes lanceolate, serrate-dentate especially on the posterior side; basal lobes small, developed by fission from the lateral or those lobes immediately above them, ovate, acute, dentate mostly on the posterior side, which is somewhat oblique.

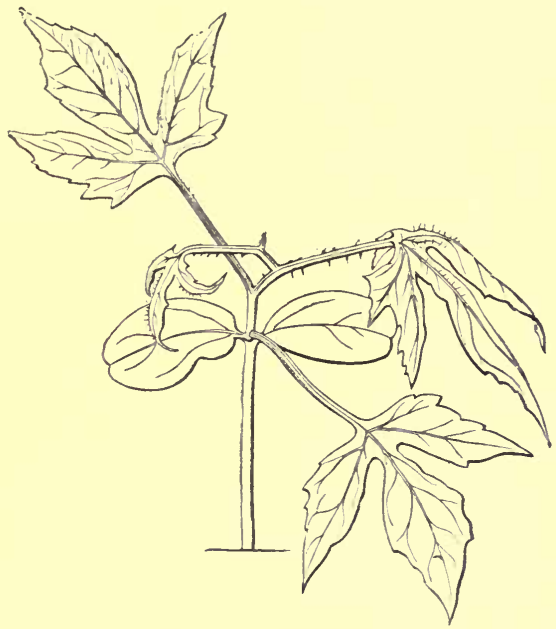

FIG. 390,-Bryonza laciniosa. Half nat. size.

Bryonia dioica, Jacq. (fig. 391).

Primary root succulent, oblique, colourless, with a few fibres.

Hypocotyl very short, succulent, ridged, about $\cdot 5 \mathrm{~cm}$. long, $1 \cdot 5$ mm. thick.

C'otyledons unequal, $1 \cdot 5-2 \mathrm{~cm}$. long, $\cdot 75-1 \mathrm{~cm}$. wide, with pubescent petiole as long as blade, $1-1.5 \mathrm{~mm}$. wide, orbicular or nearly so, suddenly cuneate at the base, rounded at the apex, entire, palmatinerved and coarsely reticulate, pubescent, thin, light green, not very persistent.

Stem suberect at first, ultimately climbing by means of tendrils, not quite $1 \mathrm{~mm}$. thick, angular, pubescent, pale green; 1 st internode about $1 \mathrm{~cm}$ long ; the others $1 \cdot 5-2 \mathrm{~cm}$.

Leaves simple, cauline, alternate, exstipulate, petiolate, ultimately palmately nerved and lobed, reticulate, pubescent, scabrous, deep 
green above, paler beneath; petiole rather slender, semiterete, channelled above, hairy.

No. 1. Long petioled, $2-3 \mathrm{~cm}$. long, $1-1.5 \mathrm{~cm}$. wide, cordate or subcordate, sinuate-dentate or lobed, with part of the blade often aborted, acuminate, palmatinerved, pubescent approaching to scabrous, dark green above, very slightly paler below.
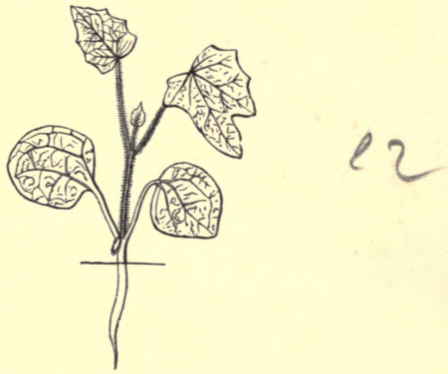

Fig. 391.-Bryonia dioica. Nat. size.

No. 2. Similar, but more ovate and uniformly sinuate-dentate and lobed.

No. 3 or 4 . As in the preceding species.

Tendrils do not appear as a rule before the sixth or seventh node.

END OF THE FIRST VOLUME 

UNIVERSITY OF CALIFORNIA LIBRARY

Los Angeles

This book is DUE on the last date stamped below.

NOV ${ }^{2} 3^{3}{ }^{1964} 3^{\text {RECD }}$

BLGMEDMARL2

MAR 211973

BIOMED LIB.

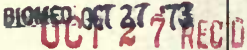


UC SOUTHERN REGIONAL LIBRARY FACIUTY A 0007316656

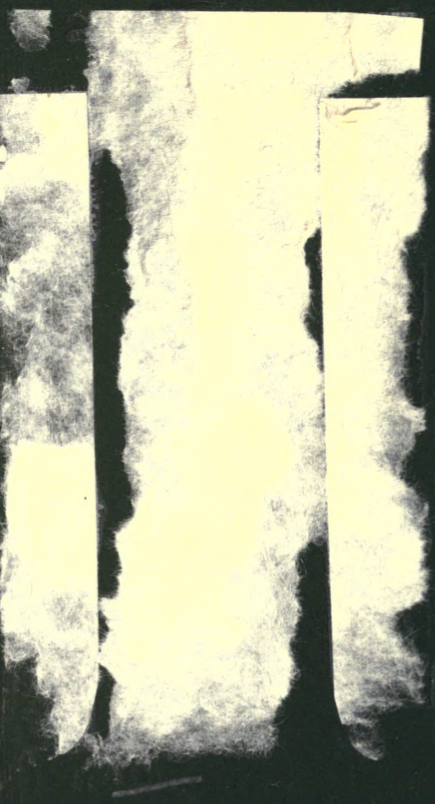


